UNIVERSIDADE DE SÃO PAULO

FACULDADE DE ECONOMIA, ADMINISTRAÇÃO E CONTABILIDADE DEPARTAMENTO DE ADMINISTRAÇÃO

\title{
O MERCADO IMOBILIÁRIO RESIDENCIAL DA REGIÃO METROPOLITANA DE SÃO PAULO: \\ Uma Aplicação de Modelos de Comercialização Hedônica de REGRESSÃo E CORRELAÇÃo CANÔNICA
}

\author{
Luiz Paulo Lopes Fávero \\ Orientador: Prof. Dr. Claudio Felisoni de Angelo \\ Tese de Doutorado apresentada ao \\ Departamento de Administração da \\ Faculdade de Economia, Administração e \\ Contabilidade da Universidade de São \\ Paulo como requisito parcial para a \\ obtenção do título de Doutor em \\ Administração.
}




\section{Reitor da Universidade de São Paulo Prof. Dr. Adolpho José Melfi}

Diretor da Faculdade de Economia, Administração e Contabilidade Profa $^{a}$. Dra ${ }^{a}$. Maria Tereza Leme Fleury

Chefe do Departamento de Administração Prof. Dr. Eduardo Pinheiro Gondim de Vasconcellos 
UNIVERSIDADE DE SÃO PAULO

FACULDADE DE ECONOMIA, ADMINISTRAÇÃO E CONTABILIDADE DEPARTAMENTO DE ADMINISTRAÇÃO

\title{
O MERCADO IMOBILIÁRIO RESIDENCIAL DA REGIÃO METROPOLITANA DE SÃO PAULO: \\ Uma Aplicação de Modelos de Comercialização Hedônica de REGRESSÃo E CORRELAÇÃo CANÔNICA
}

\author{
Luiz Paulo Lopes Fávero \\ Orientador: Prof. Dr. Claudio Felisoni de Angelo \\ Tese de Doutorado apresentada ao \\ Departamento de Administração da \\ Faculdade de Economia, Administração e \\ Contabilidade da Universidade de São \\ Paulo como requisito parcial para a \\ obtenção do título de Doutor em \\ Administração.
}




\section{FICHA CATALOGRÁFICA}

\section{Elaborada pela Seção de Processamento Técnico do SBD/FEA/USP}

\section{Fávero, Luiz Paulo Lopes}

O mercado imobiliário residencial da região metropolitana de São Paulo: uma aplicação de modelos de comercialização hedônica de regressão e correlação canônica / Luiz Paulo Lopes Fávero. -- São Paulo, 2005. $319 \mathrm{p}$.

Tese (Doutorado) - Universidade de São Paulo, 2005 Bibliografia.

1. Mercado imobiliário - São Paulo (cidade) 2. Preços hedônicos I. Universidade de São Paulo. Faculdade de Economia, Administração e Contabilidade II. Título. 
Comissão Julgadora 
a meus pais

a Patrícia

A Mariana e Roberto 


\section{AGRADECIMENTOS}

Ao professor Dr. Claudio Felisoni de Angelo, orientador, tutor, incentivador e amigo, por sua sabedoria, disposição e infatigável luta pela construção do saber, desenvolvida com a competência do profissional sério, digno e consciente, tornando-o merecedor de estar entre aqueles que são considerados "bem-aventurados por semearem o conhecimento".

Ao professor Dr. José Augusto Giesbrecht da Silveira, de admirável cultura e conhecimento, por sua calma e paciência características, pela leitura minuciosa que possibilitou críticas e sugestões essenciais e pelo tratamento sempre cordial.

Ao professor Dr. José Raimundo Novaes Chiappin, pelo incentivo, pelas palavras tão significativas, pelas valiosas sugestões e pela viagem de uma hora e meia que fizemos a Brasília, que me fez aprender mais do que a leitura de muitos livros.

Aos meus familiares e amigos, pelo incentivo, carinho e compreensão nos momentos difíceis.

Aos colegas Eduardo, Nuno, Marcelo Felippe, Rodrigo, Fernando, Edilene, Janaína, Claudia, Suely, Irene, Bruno, Juliana, Priscila, Cristiane, Elaine, Estér e Bruna, pela amizade, apoio e colaboração.

Ao PROVAR.

E, sobretudo, a Deus. 
Talvez Hamlet esteja certo. Podemos estar vivendo reclusos numa casca de noz, mas nos considerando reis do espaço infinito.

\section{Stephen Hawking}

O Universo numa Casca de Noz. 


\section{SUMÁRIO}

LISTAGEM DE GRÁFICOS iv

LISTAGEM DE GRÁFICOS - ANEXOS iv

LISTAGEM DE FIGURAS $\quad \mathbf{x}$

LISTAGEM DE FIGURAS - ANEXOS Xi

LISTAGEM DE QUADROS Xiii

LISTAGEM DE TABELAS XV XV

LISTAGEM DE TABELAS - ANEXOS X Xv

RESUMO

$\begin{array}{lll}\text { ABSTRACT } & \text { xxiii }\end{array}$

INTRODUÇÃO

CAPÍTULO I - O PROBLEMA DE PESQUISA

1.1 - DEFINIÇÃO DA SITUAÇÃO-PROBLEMA

$\begin{array}{ll}1.2 \text { - JUSTIFICATIVA DO TEMA } & 10\end{array}$

1.3 - OBJETIVOS DO ESTUDO

1.4 - QUESTÃO DE PESQUISA

1.5 - PRESSUPOSTOS DA PESQUISA 13

1.6 - MODELOS HEDÔNICOS - DEFINIÇÕES TEÓRICAS

CAPÍTULO II - FUNDAMENTAÇÃO TEÓRICA

2.1 - A TEORIA CLÁSSICA E A ABORDAGEM DOS ATRIBUTOS 17

2.2 - EQUILÍBRIO DE MERCADO 27

2.3 - REVISÃO DA LITERATURA 34

CAPÍTULO III - A REGIÃO METROPOLITANA E O MUNICÍPIO DE SÃO PAULO 57

3.1 - DEFINIÇÕES $\quad 57$

3.2 - EVOLUÇÃO HISTÓRICA E PROCESSO DE FORMAÇÃO DA REGIÃO METROPOLITANA

E DO MUNICÍPIO DE SÃO PAULO 60 
3.3 - O MERCADO IMOBILIÁRIO DE LANÇAMENTOS E COMERCIALIZAÇÕES RESIDENCIAIS

CAPÍTULO IV - PESQUISA

4.1 - MÉTODO DE PESQUISA

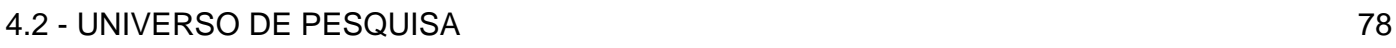

4.3 - DEFINIÇÃO DOS PERFIS SÓCIO-DEMOGRÁFICOS 79

4.3.1 - Análise Fatorial

4.3.2 - Definição das Variáveis Sócio-Demográficas

4.3.3 - Aplicação da Análise Fatorial

4.3.4 - Teste para Comparação de Médias de Duas Amostras Independentes

4.3.5 - Definição dos Grupos Sócio-Demográficos

4.4 - DIMENSIONAMENTO DA AMOSTRA 95

4.5 - MODELO TEÓRICO DE PESQUISA 98

4.6 - DEFINIÇÃO DAS VARIÁVEIS INDEPENDENTES 99

4.7 - COLETA DE DADOS DAS VARIÁVEIS INDEPENDENTES 108

4.8 - DEFINIÇÃO E COLETA DAS VARIÁVEIS DEPENDENTES 111

4.9 - REGRESSÃO MÚLTIPLA 113

4.10 - CORRELAÇÃO CANÔNICA 123

CAPÍTULO V - APRESENTAÇÃO DOS RESULTADOS

5.1 - PERFIL SÓCIO-DEMOGRÁFICO BAIXO 127

5.1.1 - Caracterização da Amostra

5.1.2 - O Primeiro Estágio de Rosen

5.1.3 - O Segundo Estágio de Rosen

5.1.4 - Resultados da Correlação Canônica

5.2 - PERFIL SÓCIO-DEMOGRÁFICO MÉDIO

5.2.1 - Caracterização da Amostra

5.2.2 - O Primeiro Estágio de Rosen

5.2.3 - O Segundo Estágio de Rosen

5.2.4 - Resultados da Correlação Canônica

5.3 - PERFIL SÓCIO-DEMOGRÁFICO ALTO

5.3.1 - Caracterização da Amostra

5.3.2 - O Primeiro Estágio de Rosen

5.3.3 - O Segundo Estágio de Rosen

5.3.4 - Resultados da Correlação Canônica

5.4 - COMPARAÇÃO ENTRE OS GRUPOS SÓCIO-DEMOGRÁFICOS

CONCLUSÕES, RECOMENDAÇÕES E POSSÍVEIS EXTENSÕES 
A) FIGURAS DO MUNICÍPIO E DA REGIÃO METROPOLITANA DE SÃO PAULO 193

B) ANÁLISE FATORIAL 222

C) INTERPRETAÇÃO DOS COEFICIENTES DE VARIÁVEIS DUMMY EM EQUAÇÕES SEMILOGARÍTMICAS DE REGRESSÃO 231

D) TESTE PARA VERIFICAÇÃO DE ENDOGENEIDADE EM VARIÁVEIS EXPLICATIVAS 234

E) O PROBLEMA DA IDENTIFICAÇÃO 236

F) O TESTE DE DURBIN-WATSON 239

G) TESTE DE GLEJSER PARA VERIFICAÇÃO DE HETEROCEDASTICIDADE 241

H) O TESTE CHOW 242

l) PERFIL SÓCIO-DEMOGRÁFICO BAIXO 243

I.1) Caracterização da Amostra 243

I.2) Resultados do Primeiro Estágio de Rosen 257

I.3) Resultados do Segundo Estágio de Rosen 258

I.4) Resultados da Correlação Canônica $\quad 261$

J) PERFIL SÓCIO-DEMOGRÁFICO MÉDIO $\quad 267$

J.1) Caracterização da Amostra 267

J.2) Resultados do Primeiro Estágio de Rosen 281

J.3) Resultados do Segundo Estágio de Rosen 282

J.4) Resultados da Correlação Canônica 285

K) PERFIL SÓCIO-DEMOGRÁFICO ALTO 291

K.1) Caracterização da Amostra $\quad 291$

K.2) Resultados do Primeiro Estágio de Rosen 305

K.3) Resultados do Segundo Estágio de Rosen 306

K.4) Resultados da Correlação Canônica 309

L) COMPARAÇÃO ENTRE OS PERFIS SÓCIO-DEMOGRÁFICOS 314

L.1) Regressão Múltipla $\quad 314$

$\begin{array}{ll}\text { L.2) Correlação Canônica } & 317\end{array}$ 


\section{LISTAGEM DE GRÁFICOS}

GRÁFICO 1.5.1: A EVOLUÇÃO TEMPORAL DO ÍNDICE DE VENDA SOBRE OFERTA PARA O PERÍODO DE JANEIRO A DEZEMBRO DE 2004

GRÁFICO 3.1.1: AS MAIORES AGLOMERAÇÕES URBANAS DO MUNDO, SEGUNDO A ONU 58

GRÁFICO 4.3.5.1: NÚMERO DE LOCALIDADES POR GRUPO SÓCIO-DEMOGRÁFICO

\section{LISTAGEM DE GRÁFICOS - ANEXOS}

GRÁFICO 1: FREQUÊNCIA DE PREÇOS NA AMOSTRA DE PERFIL SÓCIO-DEMOGRÁFICO BAIXO

GRÁFICO 2: FREQUÊNCIA DE ÁREA TOTAL NA AMOSTRA DE PERFIL SÓCIO-

DEMOGRÁFICO BAIXO

GRÁFICO 3: FREQUÊNCIA DE EXISTÊNCIA DE SALÃO DE FESTAS NA AMOSTRA DE PERFIL SÓCIO-DEMOGRÁFICO BAIXO

GRÁFICO 4: FREQUÊNCIA DE EXISTÊNCIA DE SALÃO DE JOGOS NA AMOSTRA DE PERFIL SÓCIO-DEMOGRÁFICO BAIXO

GRÁFICO 5: FREQUÊNCIA DE EXISTÊNCIA DE SALA DE GINÁSTICA NA AMOSTRA DE PERFIL SÓCIO-DEMOGRÁFICO BAIXO

GRÁFICO 6: FREQUÊNCIA DE EXISTÊNCIA DE PISCINA NA AMOSTRA DE PERFIL SÓCIO-DEMOGRÁFICO BAIXO

GRÁFICO 7: FREQUÊNCIA DE EXISTÊNCIA DE SAUNA NA AMOSTRA DE PERFIL SÓCIO-DEMOGRÁFICO BAIXO

GRÁFICO 8: FREQUÊNCIA DE EXISTÊNCIA DE CHURRASQUEIRA NA AMOSTRA DE PERFIL SÓCIO-DEMOGRÁFICO BAIXO

GRÁFICO 9: FREQUÊNCIA DE EXISTÊNCIA DE QUADRA NA AMOSTRA DE PERFIL SÓCIO-DEMOGRÁFICO BAIXO

GRÁFICO 10: FREQUÊNCIA DE EXISTÊNCIA DE GUARITA NA AMOSTRA DE PERFIL SÓCIO-DEMOGRÁFICO BAIXO

GRÁFICO 11: FREQUÊNCIA DE EXISTÊNCIA DE CFTV NA AMOSTRA DE PERFIL SÓCIO-DEMOGRÁFICO BAIXO 
GRÁFICO 12: FREQUÊNCIA DE EXISTÊNCIA DE VARANDA NA AMOSTRA DE PERFIL SÓCIO-DEMOGRÁFICO BAIXO

GRÁFICO 13: FREQUÊNCIA DE IMÓVEIS QUE SE ENCONTRAM NA METADE SUPERIOR DO EDIFÍCIO PARA A AMOSTRA DE PERFIL SÓCIO-DEMOGRÁFICO BAIXO

GRÁFICO 14: FREQUÊNCIA DE NÚMERO DE VAGAS NA GARAGEM PARA A AMOSTRA DE PERFIL SÓCIO-DEMOGRÁFICO BAIXO

GRÁFICO 15: FREQUÊNCIA DE NÚMERO DE DORMITÓRIOS PARA A AMOSTRA DE PERFIL SÓCIO-DEMOGRÁFICO BAIXO

GRÁFICO 16: FREQUÊNCIA DE NÚMERO DE BANHEIROS PARA A AMOSTRA DE PERFIL SÓCIO-DEMOGRÁFICO BAIXO

GRÁFICO 17: FREQUÊNCIA DE RENDA FAMILIAR NA AMOSTRA DE PERFIL SÓCIO-DEMOGRÁFICO BAIXO

GRÁFICO 18: FREQUÊNCIA DE MEMBROS NA FAMÍLIA NA AMOSTRA DE PERFIL SÓCIO-DEMOGRÁFICO BAIXO

GRÁFICO 19: FREQUÊNCIA DE DENSIDADE DEMOGRÁFICA NA AMOSTRA DE PERFIL SÓCIO-DEMOGRÁFICO BAIXO

GRÁFICO 20: FREQUÊNCIA DE POPULAÇÃO NA AMOSTRA DE PERFIL SÓCIO-DEMOGRÁFICO BAIXO

GRÁFICO 21: FREQUÊNCIA DE COLÉGIO PARTICULAR NA AMOSTRA DE PERFIL SÓCIO-DEMOGRÁFICO BAIXO

GRÁFICO 22: FREQUÊNCIA DE SHOPPING CENTER NA AMOSTRA DE PERFIL SÓCIO-DEMOGRÁFICO BAIXO

GRÁFICO 23: FREQUÊNCIA DE METRÔ NA AMOSTRA DE PERFIL SÓCIO-DEMOGRÁFICO BAIXO

GRÁFICO 24: FREQUÊNCIA DE HOSPITAL PARTICULAR NA AMOSTRA DE PERFIL SÓCIO-DEMOGRÁFICO BAIXO

GRÁFICO 25: FREQUÊNCIA DE PARQUES E ÁREAS VERDES NA AMOSTRA DE PERFIL SÓCIO-DEMOGRÁFICO BAIXO 
GRÁFICO 26: FREQUÊNCIA DE PONTOS DE INUNDAÇÃO NA AMOSTRA DE PERFIL SÓCIO-DEMOGRÁFICO BAIXO

GRÁFICO 27: FREQUÊNCIA DE ATERROS E LIXÕES NA AMOSTRA DE PERFIL SÓCIO-DEMOGRÁFICO BAIXO

GRÁFICO 28: FREQUÊNCIA DE PREÇOS NA AMOSTRA DE PERFIL SÓCIO-DEMOGRÁFICO MÉDIO

GRÁFICO 29: FREQUÊNCIA DE ÁREA TOTAL NA AMOSTRA DE PERFIL SÓCIO-

DEMOGRÁFICO MÉDIO

GRÁFICO 30: FREQUÊNCIA DE EXISTÊNCIA DE SALÃO DE FESTAS NA AMOSTRA DE PERFIL SÓCIO-DEMOGRÁFICO MÉDIO

GRÁFICO 31: FREQUÊNCIA DE EXISTÊNCIA DE SALÃO DE JOGOS NA AMOSTRA DE PERFIL SÓCIO-DEMOGRÁFICO MÉDIO

GRÁFICO 32: FREQUÊNCIA DE EXISTÊNCIA DE SALA DE GINÁSTICA NA AMOSTRA DE PERFIL SÓCIO-DEMOGRÁFICO MÉDIO

GRÁFICO 33: FREQUÊNCIA DE EXISTÊNCIA DE PISCINA NA AMOSTRA DE PERFIL SÓCIO-DEMOGRÁFICO MÉDIO

GRÁFICO 34: FREQUÊNCIA DE EXISTÊNCIA DE SAUNA NA AMOSTRA DE PERFIL SÓCIO-DEMOGRÁFICO MÉDIO

GRÁFICO 35: FREQUÊNCIA DE EXISTÊNCIA DE CHURRASQUEIRA NA AMOSTRA DE PERFIL SÓCIO-DEMOGRÁFICO MÉDIO

GRÁFICO 36: FREQUÊNCIA DE EXISTÊNCIA DE QUADRA NA AMOSTRA DE PERFIL SÓCIO-DEMOGRÁFICO MÉDIO

GRÁFICO 37: FREQUÊNCIA DE EXISTÊNCIA DE GUARITA NA AMOSTRA DE PERFIL SÓCIO-DEMOGRÁFICO MÉDIO

GRÁFICO 38: FREQUÊNCIA DE EXISTÊNCIA DE CFTV NA AMOSTRA DE PERFIL SÓCIO-DEMOGRÁFICO MÉDIO

GRÁFICO 39: FREQUÊNCIA DE EXISTÊNCIA DE VARANDA NA AMOSTRA DE PERFIL SÓCIO-DEMOGRÁFICO MÉDIO 
GRÁFICO 40: FREQUÊNCIA DE IMÓVEIS QUE SE ENCONTRAM NA METADE SUPERIOR DO EDIFÍCIO PARA A AMOSTRA DE PERFIL SÓCIO-DEMOGRÁFICO MÉDIO

GRÁFICO 41: FREQUÊNCIA DE NÚMERO DE VAGAS NA GARAGEM PARA A AMOSTRA DE PERFIL SÓCIO-DEMOGRÁFICO MÉDIO

GRÁFICO 42: FREQUÊNCIA DE NÚMERO DE DORMITÓRIOS PARA A AMOSTRA DE PERFIL SÓCIO-DEMOGRÁFICO MÉDIO

GRÁFICO 43: FREQUÊNCIA DE NÚMERO DE BANHEIROS PARA A AMOSTRA DE PERFIL SÓCIO-DEMOGRÁFICO MÉDIO

GRÁFICO 44: FREQUÊNCIA DE RENDA FAMILIAR NA AMOSTRA DE PERFIL SÓCIO-DEMOGRÁFICO MÉDIO

GRÁFICO 45: FREQUÊNCIA DE MEMBROS NA FAMÍLIA NA AMOSTRA DE PERFIL SÓCIO-DEMOGRÁFICO MÉDIO

GRÁFICO 46: FREQUÊNCIA DE DENSIDADE DEMOGRÁFICA NA AMOSTRA DE PERFIL SÓCIO-DEMOGRÁFICO MÉDIO

GRÁFICO 47: FREQUÊNCIA DE POPULAÇÃO NA AMOSTRA DE PERFIL SÓCIO-DEMOGRÁFICO MÉDIO

GRÁFICO 48: FREQUÊNCIA DE COLÉGIO PARTICULAR NA AMOSTRA DE PERFIL SÓCIO-DEMOGRÁFICO MÉDIO

GRÁFICO 49: FREQUÊNCIA DE SHOPPING CENTER NA AMOSTRA DE PERFIL SÓCIO-DEMOGRÁFICO MÉDIO

GRÁFICO 50: FREQUÊNCIA DE METRÔ NA AMOSTRA DE PERFIL SÓCIO-DEMOGRÁFICO MÉDIO

GRÁFICO 51: FREQUÊNCIA DE HOSPITAL PARTICULAR NA AMOSTRA DE PERFIL SÓCIO-DEMOGRÁFICO MÉDIO

GRÁFICO 52: FREQUÊNCIA DE PARQUES E ÁREAS VERDES NA AMOSTRA DE PERFIL SÓCIO-DEMOGRÁFICO MÉDIO

GRÁFICO 53: FREQUÊNCIA DE PONTOS DE INUNDAÇÃO NA AMOSTRA DE PERFIL SÓCIO-DEMOGRÁFICO MÉDIO 
GRÁFICO 54: FREQUÊNCIA DE ATERROS E LIXÕES NA AMOSTRA DE PERFIL SÓCIO-DEMOGRÁFICO MÉDIO

GRÁFICO 55: FREQUÊNCIA DE PREÇOS NA AMOSTRA DE PERFIL SÓCIO-DEMOGRÁFICO ALTO

GRÁFICO 56: FREQUÊNCIA DE ÁREA TOTAL NA AMOSTRA DE PERFIL SÓCIO-

DEMOGRÁFICO ALTO

GRÁFICO 57: FREQUÊNCIA DE EXISTÊNCIA DE SALÃO DE FESTAS NA AMOSTRA DE PERFIL SÓCIO-DEMOGRÁFICO ALTO

GRÁFICO 58: FREQUÊNCIA DE EXISTÊNCIA DE SALÃO DE JOGOS NA AMOSTRA DE PERFIL SÓCIO-DEMOGRÁFICO ALTO

GRÁFICO 59: FREQUÊNCIA DE EXISTÊNCIA DE SALA DE GINÁSTICA NA AMOSTRA DE PERFIL SÓCIO-DEMOGRÁFICO ALTO

GRÁFICO 60: FREQUÊNCIA DE EXISTÊNCIA DE PISCINA NA AMOSTRA DE PERFIL SÓCIO-DEMOGRÁFICO ALTO

GRÁFICO 61: FREQUÊNCIA DE EXISTÊNCIA DE SAUNA NA AMOSTRA DE PERFIL SÓCIO-DEMOGRÁFICO ALTO

GRÁFICO 62: FREQUÊNCIA DE EXISTÊNCIA DE CHURRASQUEIRA NA AMOSTRA DE PERFIL SÓCIO-DEMOGRÁFICO ALTO

GRÁFICO 63: FREQUÊNCIA DE EXISTÊNCIA DE QUADRA NA AMOSTRA DE PERFIL SÓCIO-DEMOGRÁFICO ALTO

GRÁFICO 64: FREQUÊNCIA DE EXISTÊNCIA DE GUARITA NA AMOSTRA DE PERFIL SÓCIO-DEMOGRÁFICO ALTO

GRÁFICO 65: FREQUÊNCIA DE EXISTÊNCIA DE CFTV NA AMOSTRA DE PERFIL SÓCIO-DEMOGRÁFICO ALTO

GRÁFICO 66: FREQUÊNCIA DE EXISTÊNCIA DE VARANDA NA AMOSTRA DE PERFIL SÓCIO-DEMOGRÁFICO ALTO

GRÁFICO 67: FREQUÊNCIA DE IMÓVEIS QUE SE ENCONTRAM NA METADE SUPERIOR DO EDIFÍCIO PARA A AMOSTRA DE PERFIL SÓCIO-DEMOGRÁFICO ALTO 
GRÁFICO 68: FREQUÊNCIA DE NÚMERO DE VAGAS NA GARAGEM PARA A AMOSTRA DE PERFIL SÓCIO-DEMOGRÁFICO ALTO

GRÁFICO 69: FREQUÊNCIA DE NÚMERO DE DORMITÓRIOS PARA A AMOSTRA DE PERFIL SÓCIO-DEMOGRÁFICO ALTO

GRÁFICO 70: FREQUÊNCIA DE NÚMERO DE BANHEIROS PARA A AMOSTRA DE PERFIL SÓCIO-DEMOGRÁFICO ALTO

GRÁFICO 71: FREQUÊNCIA DE RENDA FAMILIAR NA AMOSTRA DE PERFIL

SÓCIO-DEMOGRÁFICO ALTO

GRÁFICO 72: FREQUÊNCIA DE MEMBROS NA FAMÍLIA NA AMOSTRA DE PERFIL SÓCIO-DEMOGRÁFICO ALTO

GRÁFICO 73: FREQUÊNCIA DE DENSIDADE DEMOGRÁFICA NA AMOSTRA DE PERFIL SÓCIO-DEMOGRÁFICO ALTO

GRÁFICO 74: FREQUÊNCIA DE POPULAÇÃO NA AMOSTRA DE PERFIL SÓCIO-DEMOGRÁFICO ALTO

GRÁFICO 75: FREQUÊNCIA DE COLÉGIO PARTICULAR NA AMOSTRA DE PERFIL SÓCIO-DEMOGRÁFICO ALTO

GRÁFICO 76: FREQUÊNCIA DE SHOPPING CENTER NA AMOSTRA DE PERFIL SÓCIO-DEMOGRÁFICO ALTO

GRÁFICO 77: FREQUÊNCIA DE METRÔ NA AMOSTRA DE PERFIL SÓCIO-DEMOGRÁFICO ALTO

GRÁFICO 78: FREQUÊNCIA DE HOSPITAL PARTICULAR NA AMOSTRA DE PERFIL SÓCIO-DEMOGRÁFICO ALTO

GRÁFICO 79: FREQUÊNCIA DE PARQUES E ÁREAS VERDES NA AMOSTRA DE PERFIL SÓCIO-DEMOGRÁFICO ALTO

GRÁFICO 80: FREQUÊNCIA DE PONTOS DE INUNDAÇÃO NA AMOSTRA DE PERFIL SÓCIO-DEMOGRÁFICO ALTO

GRÁFICO 81: FREQUÊNCIA DE ATERROS E LIXÕES NA AMOSTRA DE PERFIL SÓCIO-DEMOGRÁFICO ALTO 


\section{LISTAGEM DE FIGURAS}

FIGURA 1.1.1: INTERFACE ENTRE A OFERTA E A DEMANDA POR ATRIBUTOS NO MERCADO IMOBILIÁRIO

FIGURA 2.1.1: ESCOLHA PARA DOIS BENS E DUAS CARACTERÍSTICAS 22

FIGURA 2.1.2: ESCOLHA PARA MAIS BENS DO QUE CARACTERÍSTICAS

(QUATRO BENS E DUAS CARACTERÍSTICAS) 23

FIGURA 2.1.3: FRONTEIRA EFICIENTE - DUAS CARACTERÍSTICAS E QUATRO BENS 24

FIGURA 2.1.4: FRONTEIRA EFICIENTE - DOIS ATRIBUTOS E QUATRO ATIVIDADES DE CONSUMO

FIGURA 2.2.1: CURVAS DE INDIFERENÇA PARA DECISÃO DE COMPRA

FIGURA 2.2.2: CURVAS DE INDIFERENÇA PARA DECISÃO DE COMPRA

FIGURA 2.3.1: CURVA DE INDIFERENÇA E O TRADEOFF ENTRE PREÇO E NÍVEL DE ATRIBUTO

FIGURA 2.3.2: O PROCESSO DECISÓRIO ENTRE BENS HEDÔNICOS E UTILITÁRIOS

FIGURA 2.3.3: CURVA DE INDIFERENÇA ENTRE CARACTERÍSTICAS HEDÔNICAS E UTILITÁRIAS

FIGURA 2.3.4: ESTRUTURA HIERÁRQUICA DE VALORES QUANDO DA AQUISIÇÃO

DE UM IMÓVEL RESIDENCIAL

FIGURA 2.3.5: LINHAS DE ESTUDO PARA MODELOS HEDÔNICOS, COM ENFOQUE PARA OS SEGMENTOS DE APLICAÇÃO

FIGURA 4.8.1: RELAÇÃO ENTRE OS VALORES DE PRESTAÇÃO E OS SISTEMAS

DE AMORTIZAÇÃO

FIGURA 4.9.1: A TRANSFORMAÇÃO DE BOX-COX

FIGURA 4.9.2: O PROBLEMA DA AUTOCORRELAÇÃO DOS RESÍDUOS 
FIGURA 6.1: PROCEDIMENTOS EFETUADOS PARA SE ATINGIREM OS RESPECTIVOS OBJETIVOS

\section{LISTAGEM DE FIGURAS - ANEXOS}

FIGURA 01: NÚCLEO URBANO DO MUNICÍPIO DE SÃO PAULO NO SÉCULO XVIII

FIGURA 02: EXPANSÃO DO MUNICÍPIO NO FINAL DO SÉCULO XIX

FIGURA 03: ESTRUTURA CENTRÍFUGA DO MUNICÍPIO DE SÃO PAULO

FIGURA 04: OS ARREDORES PAULISTANOS EM MEADOS DO SÉCULO XIX

FIGURA 05: A EVOLUÇÃO DA REDE FERROVIÁRIA REGIONAL - 1860 A 1890

FIGURA 06: A EVOLUÇÃO DA REDE FERROVIÁRIA REGIONAL - 1890 A 1950

FIGURA 07: A EVOLUÇÃO DA REDE FERROVIÁRIA REGIONAL - 1950 A 1980

FIGURA 08: DESMEMBRAMENTO DE MUNICÍPIOS METROPOLITANOS - 1940 A 2000

FIGURA 09: DIVISÃO POLÍTICO-ADMINISTRATIVA - 2000

COMPLEMENTO DAS FIGURAS 08 E 09

FIGURA 10: FAVELAS DA REGIÃO METROPOLITANA DE SÃO PAULO

FIGURA 13: RENDA E DESIGUALDADE NA REGIÃO METROPOLITANA DE SÃO PAULO

FIGURA 14: RENDA E DESIGUALDADE NA REGIÃO METROPOLITANA DE SÃO PAULO

FIGURA 15: RENDA E HABITAÇÃO NA REGIÃO METROPOLITANA DE SÃO PAULO 
FIGURA 16: TAXA DE CRESCIMENTO POPULACIONAL NA REGIÃO METROPOLITANA DE SÃO PAULO - 1950 A 2000

FIGURA 17: DENSIDADE DEMOGRÁFICA NA REGIÃO METROPOLITANA DE SÃO PAULO

- 1950 A 2000

FIGURA 18: DENSIDADE DEMOGRÁFICA NA REGIÃO METROPOLITANA DE SÃO PAULO

FIGURA 19: POPULAÇÃO RESIDENTE NA REGIÃO METROPOLITANA DE SÃO PAULO

- 1950 E 2000

FIGURA 20: ÁREA URBANIZADA DA REGIÃO METROPOLITANA DE SÃO PAULO -

1905 A 1997

FIGURA 21: EVOLUÇÃO DA ÁREA URBANIZADA - 1949 A 1992

215

FIGURA 22: ESTRATIFICAÇÃO SÓCIO-DEMOGRÁFICA DA REGIÃO METROPOLITANA DE SÃO PAULO - RESULTADO DA ANÁLISE FATORIAL

FIGURA 23: ESTRUTURA VIÁRIA E DE TRANSPORTES DA REGIÃO METROPOLITANA DE SÃO PAULO

FIGURA 24: LINHAS DO METRÔ NA REGIÃO METROPOLITANA DE SÃO PAULO

FIGURA 25: DETALHAMENTO DAS LINHAS DO METRÔ

FIGURA 26: PONTOS DE INUNDAÇÃO NA REGIÃO METROPOLITANA DE SÃO PAULO

FIGURA 28: ALTERAÇÕES NA EQUAÇÃO DE OFERTA E A DETERMINAÇÃO DA CURVA DE DEMANDA 


\section{LISTAGEM DE QUADROS}

QUADRO 4.3.2.1: VARIÁVEIS QUE SERÃO UTILIZADAS PARA A COMPOSIÇÃO DO PERFIL SÓCIO-DEMOGRÁFICO DA REGIÃO METROPOLITANA DE SÃO PAULO

QUADRO 4.3.2.2: JUSTIFICATIVA DAS VARIÁVEIS A SEREM UTILIZADAS PARA A COMPOSIÇÃO DO PERFIL SÓCIO-DEMOGRÁFICO DA REGIÃO METROPOLITANA DE SÃO PAULO

QUADRO 4.3.5.1: CLASSIFICAÇÃO SÓCIO-DEMOGRÁFICA EM FUNÇÃO DO ÍNDICE DO FATOR PRINCIPAL

QUADRO 4.3.5.2: CLASSIFICAÇÃO DAS FAIXAS DE RENDA EM FUNÇÃO DO ÍNDICE DO FATOR PRINCIPAL

QUADRO 4.6.1: CARACTERÍSTICAS CITADAS POR ESPECIALISTAS COMO SENDO IMPORTANTES PARA A COMPOSIÇÃO, SOB A ÓTICA DA OFERTA, DAS CONDIÇÕES COMERCIAIS DOS APARTAMENTOS EM LANÇAMENTO NA REGIÃO METROPOLITANA DE SÃO PAULO, E A RESPECTIVA CLASSIFICAÇÃO SEGUNDO ROSEN

QUADRO 4.6.2: CARACTERÍSTICAS CITADAS POR COMPRADORES COMO SENDO IMPORTANTES PARA A DECISÃO DE COMPRA (ÓTICA DA DEMANDA) DE APARTAMENTOS EM LANÇAMENTO NA REGIÃO METROPOLITANA DE SÃO PAULO, E A RESPECTIVA CLASSIFICAÇÃO SEGUNDO ROSEN

QUADRO 4.6.4: O VETOR Y 1 DE CARACTERÍSTICAS EXTRÍNSECAS QUE AFETAM EXCLUSIVAMENTE A DEMANDA

QUADRO 4.6.5: O VETOR Y 2 DE CARACTERÍSTICAS EXTRÍNSECAS QUE AFETAM EXCLUSIVAMENTE A OFERTA

QUADRO 4.6.6: O VETOR W DE CARACTERÍSTICAS EXTRÍNSECAS QUE AFETAM A DEMANDA E A OFERTA 
QUADRO 4.9.2: AS ETAPAS DA REGRESSÃO, COM OS RESPECTIVOS PROPÓSITOS E MÉTODOS

QUADRO 5.1.4.1: VARIÁVEIS DEPENDENTES E INDEPENDENTESA DA CORRELAÇÃO CANÔNICA PARA A EQUAÇÃO DE DEMANDA - PERFIL SÓCIO-DEMOGRÁFICO BAIXO

QUADRO 5.1.4.2: VARIÁVEIS DEPENDENTES E INDEPENDENTESA DA CORRELAÇÃO CANÔNICA PARA A EQUAÇÃO DE OFERTA - PERFIL SÓCIO-DEMOGRÁFICO BAIXO

QUADRO 5.2.4.1: VARIÁVEIS DEPENDENTES E INDEPENDENTESA DA CORRELAÇÃO CANÔNICA PARA A EQUAÇÃO DE DEMANDA - PERFIL SÓCIO-DEMOGRÁFICO MÉDIO

QUADRO 5.2.4.2: VARIÁVEIS DEPENDENTES E INDEPENDENTESA DA CORRELAÇÃO CANÔNICA PARA A EQUAÇÃO DE OFERTA - PERFIL SÓCIO-DEMOGRÁFICO MÉDIO

QUADRO 5.3.4.1: VARIÁVEIS DEPENDENTES E INDEPENDENTESA DA CORRELAÇÃO CANÔNICA PARA A EQUAÇÃO DE DEMANDA - PERFIL SÓCIO-DEMOGRÁFICO ALTO

QUADRO 5.3.4.2: VARIÁVEIS DEPENDENTES E INDEPENDENTESA DA CORRELAÇÃO CANÔNICA PARA A EQUAÇÃO DE OFERTA - PERFIL SÓCIO-DEMOGRÁFICO ALTO 


\section{LISTAGEM DE TABELAS}

TABELA 1.5.1: OS NÚMEROS DO MERCADO IMOBILIÁRIO RESIDENCIAL

TABELA 3.3.1: NÚMERO DE APARTAMENTOS RESIDENCIAIS EM LANÇAMENTO

COMERCIALIZADOS ENTRE OS MESES DE JANEIRO E DEZEMBRO DE 2004

TABELA 4.3.3.1: PESO DE CADA VARIÁVEL NA COMPOSIÇÃO DO PERFIL

SÓCIO-DEMOGRÁFICO

TABELA 4.3.4.1: ESTATÍSTICAS DO PERFIL SÓCIO-DEMOGRÁFICO PARA OS DISTRITOS DO MUNICÍPIO DE SÃO PAULO E PARA OS MUNICÍPIOS DA REGIÃO METROPOLITANA DE SÃO PAULO

TABELA 4.4.1: DESVIOS-PADRÃO DE CADA AMOSTRA-PILOTO, EM FUNÇÃO DE CADA GRUPO SÓCIO-DEMOGRÁFICO

TABELA 4.4.2: DETERMINAÇÃO DO TAMANHO DA SUB-AMOSTRA PARA CADA GRUPO SÓCIO-DEMOGRÁFICO

TABELA 4.4.3: PROPORÇÃO DE CADA SUB-AMOSTRA, EM FUNÇÃO DO GRUPO SÓCIO-DEMOGRÁFICO E DO MÊS DE COMERCIALIZAÇÃO

TABELA 5.4.1: EQUAÇÕES HEDÔNICAS DE DEMANDA E OFERTA PARA CADA PERFIL SÓCIO-DEMOGRÁFICO

\section{LISTAGEM DE TABELAS - ANEXOS}

TABELA 01: DADOS SÓCIO-DEMOGRÁFICOS ORIGINAIS DOS DISTRITOS DO MUNICÍPIO DE SÃO PAULO

TABELA 02: DADOS SÓCIO-DEMOGRÁFICOS ORIGINAIS DOS MUNICÍPIOS DA REGIÃO METROPOLITANA

TABELA 03: MATRIZ DE CORRELAÇÃO E SIGNIFICÂNCIA PARA OS DADOS SÓCIO-DEMOGRÁFICOS - ANÁLISE FATORIAL

TABELA 04: MATRIZ ANTIIMAGEM - ANÁLISE FATORIAL 
TABELA 07: TESTE T PARA COMPARAÇÃO DE MÉDIAS DAS DUAS AMOSTRAS INDEPENDENTES

TABELA 08: RELAÇÃO ENTRE OS COEFICIENTES DE VARIÁVEIS DUMMY EM EQUAÇÕES SEMILOGARÍTMICAS DE REGRESSÃO E OS RESPECTIVOS EFEITOS RELATIVOS

TABELA 9: VALORES DE R² AJUSTADOS RESULTANTES DO MÉTODO DE BOX-COX COM AS VARIAÇÕES DE $\theta$ E $\lambda$ PARA O PERFIL SÓCIO-DEMOGRÁFICO BAIXO

TABELA 10: RESULTADOS DA REGRESSÃO PARA A ESPECIFICAÇÃO LOGARÍTMICA

- MÉTODO ENTER - PERFIL SÓCIO-DEMOGRÁFICO BAIXO

TABELA 11: ESTIMAÇÃO DA EQUAÇÃO DE DEMANDA: SEGUNDO ESTÁGIO DE ROSEN - MÉTODO ENTER - PERFIL SÓCIO-DEMOGRÁFICO BAIXO

TABELA 12: ESTIMAÇÃO DA EQUAÇÃO DE OFERTA: SEGUNDO ESTÁGIO DE ROSEN - MÉTODO ENTER - PERFIL SÓCIO-DEMOGRÁFICO BAIXO

TABELA 13: EQUAÇÕES DE DEMANDA E OFERTA - MÉTODO STEPWISE - PERFIL SÓCIO-DEMOGRÁFICO BAIXO

TABELA 14: TESTES MULTIVARIADOS DE SIGNIFICÂNCIA PARA A EQUAÇÃO DE DEMANDA - PERFIL SÓCIO-DEMOGRÁFICO BAIXO

TABELA 15: TESTES MULTIVARIADOS DE SIGNIFICÂNCIA PARA A EQUAÇÃO DE OFERTA - PERFIL SÓCIO-DEMOGRÁFICO BAIXO

TABELA 16: CORRELAÇÕES CANÔNICAS E AUTOVALORES PARA A EQUAÇÃO DE DEMANDA - PERFIL SÓCIO-DEMOGRÁFICO BAIXO

TABELA 17: CORRELAÇÕES CANÔNICAS E AUTOVALORES PARA A EQUAÇÃO DE OFERTA - PERFIL SÓCIO-DEMOGRÁFICO BAIXO

TABELA 18: TESTE UNIVARIADO DE SIGNIFICÂNCIA PARA AS FUNÇÕES CANÔNICAS DA EQUAÇÃO DE DEMANDA - PERFIL SÓCIO-DEMOGRÁFICO BAIXO

TABELA 19: TESTE UNIVARIADO DE SIGNIFICÂNCIA PARA AS FUNÇÕES CANÔNICAS DA EQUAÇÃO DE OFERTA - PERFIL SÓCIO-DEMOGRÁFICO BAIXO

TABELA 20: PESOS CANÔNICOS PADRONIZADOS PARA A PRIMEIRA FUNÇÃO CANÔNICA - VARIÁVEIS DEPENDENTES - EQUAÇÃO DE DEMANDA - PERFIL SÓCIO-DEMOGRÁFICO BAIXO 
TABELA 21: PESOS CANÔNICOS PADRONIZADOS PARA A PRIMEIRA FUNÇÃO CANÔNICA - VARIÁVEIS DEPENDENTES - EQUAÇÃO DE OFERTA - PERFIL SÓCIO-DEMOGRÁFICO BAIXO

TABELA 22: PESOS CANÔNICOS PADRONIZADOS PARA A PRIMEIRA FUNÇÃO CANÔNICA - VARIÁVEIS INDEPENDENTES - EQUAÇÃO DE DEMANDA - PERFIL SÓCIO-DEMOGRÁFICO BAIXO

TABELA 23: PESOS CANÔNICOS PADRONIZADOS PARA A PRIMEIRA FUNÇÃO CANÔNICA - VARIÁVEIS INDEPENDENTES - EQUAÇÃO DE OFERTA - PERFIL SÓCIO-DEMOGRÁFICO BAIXO

TABELA 24: CORRELAÇÕES ENTRE AS VARIÁVEIS DEPENDENTES E AS VARIÁVEIS CANÔNICAS - EQUAÇÃO DE DEMANDA - PERFIL SÓCIO-DEMOGRÁFICO BAIXO

TABELA 25: CORRELAÇÕES ENTRE AS VARIÁVEIS DEPENDENTES E AS VARIÁVEIS CANÔNICAS - EQUAÇÃO DE OFERTA - PERFIL SÓCIO-DEMOGRÁFICO BAIXO

TABELA 26: CORRELAÇÕES ENTRE AS VARIÁVEIS INDEPENDENTES E AS VARIÁVEIS CANÔNICAS - EQUAÇÃO DE DEMANDA - PERFIL SÓCIO-DEMOGRÁFICO BAIXO

TABELA 27: CORRELAÇÕES ENTRE AS VARIÁVEIS INDEPENDENTES E AS VARIÁVEIS CANÔNICAS - EQUAÇÃO DE OFERTA - PERFIL SÓCIO-DEMOGRÁFICO BAIXO

TABELA 28: ÍNDICE DE REDUNDÂNCIA - PERFIL SÓCIO-DEMOGRÁFICO BAIXO

TABELA 29: VALORES DE R R AJUSTADOS RESULTANTES DO MÉTODO DE BOX-COX COM AS VARIAÇÕES DE $\theta$ E $\lambda$ PARA O PERFIL SÓCIO-DEMOGRÁFICO MÉDIO

TABELA 30: RESULTADOS DA REGRESSÃO PARA A ESPECIFICAÇÃO LOGARÍTMICA - MÉTODO ENTER - PERFIL SÓCIO-DEMOGRÁFICO MÉDIO

TABELA 31: ESTIMAÇÃO DA EQUAÇÃO DE DEMANDA: SEGUNDO ESTÁGIO DE ROSEN - MÉTODO ENTER - PERFIL SÓCIO-DEMOGRÁFICO MÉDIO

TABELA 32: ESTIMAÇÃO DA EQUAÇÃO DE OFERTA: SEGUNDO ESTÁGIO DE ROSEN - MÉTODO ENTER - PERFIL SÓCIO-DEMOGRÁFICO MÉDIO

TABELA 33: EQUAÇÕES DE DEMANDA E OFERTA - MÉTODO STEPWISE - PERFIL SÓCIO-DEMOGRÁFICO MÉDIO 
TABELA 34: TESTES MULTIVARIADOS DE SIGNIFICÂNCIA PARA A EQUAÇÃO DE DEMANDA - PERFIL SÓCIO-DEMOGRÁFICO MÉDIO

TABELA 35: TESTES MULTIVARIADOS DE SIGNIFICÂNCIA PARA A EQUAÇÃO DE OFERTA - PERFIL SÓCIO-DEMOGRÁFICO MÉDIO

TABELA 36: CORRELAÇÕES CANÔNICAS E AUTOVALORES PARA A EQUAÇÃO DE DEMANDA - PERFIL SÓCIO-DEMOGRÁFICO MÉDIO

TABELA 37: CORRELAÇÕES CANÔNICAS E AUTOVALORES PARA A EQUAÇÃO DE OFERTA - PERFIL SÓCIO-DEMOGRÁFICO MÉDIO

TABELA 38: TESTE UNIVARIADO DE SIGNIFICÂNCIA PARA AS FUNÇÕES CANÔNICAS DA EQUAÇÃO DE DEMANDA - PERFIL SÓCIO-DEMOGRÁFICO MÉDIO

TABELA 39: TESTE UNIVARIADO DE SIGNIFICÂNCIA PARA AS FUNÇÕES CANÔNICAS DA EQUAÇÃO DE OFERTA - PERFIL SÓCIO-DEMOGRÁFICO MÉDIO

TABELA 40: PESOS CANÔNICOS PADRONIZADOS PARA A PRIMEIRA FUNÇÃO CANÔNICA - VARIÁVEIS DEPENDENTES - EQUAÇÃO DE DEMANDA - PERFIL SÓCIO-DEMOGRÁFICO MÉDIO

TABELA 41: PESOS CANÔNICOS PADRONIZADOS PARA A PRIMEIRA FUNÇÃO CANÔNICA - VARIÁVEIS DEPENDENTES - EQUAÇÃO DE OFERTA - PERFIL SÓCIO-DEMOGRÁFICO MÉDIO

TABELA 42: PESOS CANÔNICOS PADRONIZADOS PARA A PRIMEIRA FUNÇÃO CANÔNICA - VARIÁVEIS INDEPENDENTES - EQUAÇÃO DE DEMANDA - PERFIL SÓCIO-DEMOGRÁFICO MÉDIO

TABELA 43: PESOS CANÔNICOS PADRONIZADOS PARA A PRIMEIRA FUNÇÃO CANÔNICA - VARIÁVEIS INDEPENDENTES - EQUAÇÃO DE OFERTA - PERFIL SÓCIO-DEMOGRÁFICO MÉDIO

TABELA 44: CORRELAÇÕES ENTRE AS VARIÁVEIS DEPENDENTES E AS VARIÁVEIS CANÔNICAS - EQUAÇÃO DE DEMANDA - PERFIL SÓCIO-DEMOGRÁFICO MÉDIO

TABELA 45: CORRELAÇÕES ENTRE AS VARIÁVEIS DEPENDENTES E AS VARIÁVEIS CANÔNICAS - EQUAÇÃO DE OFERTA - PERFIL SÓCIO-DEMOGRÁFICO MÉDIO

TABELA 46: CORRELAÇÕES ENTRE AS VARIÁVEIS INDEPENDENTES E AS VARIÁVEIS CANÔNICAS - EQUAÇÃO DE DEMANDA - PERFIL SÓCIO-DEMOGRÁFICO MÉDIO 
TABELA 47: CORRELAÇÕES ENTRE AS VARIÁVEIS INDEPENDENTES E AS VARIÁVEIS CANÔNICAS - EQUAÇÃO DE OFERTA - PERFIL SÓCIO-DEMOGRÁFICO MÉDIO

TABELA 48: ÍNDICE DE REDUNDÂNCIA - PERFIL SÓCIO-DEMOGRÁFICO MÉDIO

TABELA 49: VALORES DE R² AJUSTADOS RESULTANTES DO MÉTODO DE BOX-COX COM AS VARIAÇÕES DE $\theta$ E $\lambda$ PARA O PERFIL SÓCIO-DEMOGRÁFICO ALTO

TABELA 50: RESULTADOS DA REGRESSÃO PARA A ESPECIFICAÇÃO LOGARÍTMICA - MÉTODO ENTER - PERFIL SÓCIO-DEMOGRÁFICO ALTO

TABELA 51: ESTIMAÇÃO DA EQUAÇÃO DE DEMANDA: SEGUNDO ESTÁGIO DE ROSEN - MÉTODO ENTER - PERFIL SÓCIO-DEMOGRÁFICO ALTO

TABELA 52: ESTIMAÇÃO DA EQUAÇÃO DE OFERTA: SEGUNDO ESTÁGIO DE ROSEN - MÉTODO ENTER - PERFIL SÓCIO-DEMOGRÁFICO ALTO

TABELA 53: EQUAÇÕES DE DEMANDA E OFERTA - MÉTODO STEPWISE - PERFIL SÓCIO-DEMOGRÁFICO ALTO

TABELA 54: TESTES MULTIVARIADOS DE SIGNIFICÂNCIA PARA A EQUAÇÃO DE DEMANDA - PERFIL SÓCIO-DEMOGRÁFICO ALTO

TABELA 55: TESTES MULTIVARIADOS DE SIGNIFICÂNCIA PARA A EQUAÇÃO DE OFERTA - PERFIL SÓCIO-DEMOGRÁFICO ALTO

TABELA 56: CORRELAÇÕES CANÔNICAS E AUTOVALORES PARA A EQUAÇÃO DE DEMANDA - PERFIL SÓCIO-DEMOGRÁFICO ALTO

TABELA 57: CORRELAÇÕES CANÔNICAS E AUTOVALORES PARA A EQUAÇÃO DE OFERTA - PERFIL SÓCIO-DEMOGRÁFICO ALTO

TABELA 58: TESTE UNIVARIADO DE SIGNIFICÂNCIA PARA AS FUNÇÕES CANÔNICAS DA EQUAÇÃO DE DEMANDA - PERFIL SÓCIO-DEMOGRÁFICO ALTO

TABELA 59: TESTE UNIVARIADO DE SIGNIFICÂNCIA PARA AS FUNÇÕES CANÔNICAS DA EQUAÇÃO DE OFERTA - PERFIL SÓCIO-DEMOGRÁFICO ALTO

TABELA 60: PESOS CANÔNICOS PADRONIZADOS PARA A PRIMEIRA FUNÇÃO CANÔNICA - VARIÁVEIS DEPENDENTES - EQUAÇÃO DE DEMANDA - PERFIL SÓCIO-DEMOGRÁFICO ALTO 
TABELA 61: PESOS CANÔNICOS PADRONIZADOS PARA A PRIMEIRA FUNÇÃO CANÔNICA - VARIÁVEIS DEPENDENTES - EQUAÇÃO DE OFERTA - PERFIL SÓCIO-DEMOGRÁFICO ALTO

TABELA 62: PESOS CANÔNICOS PADRONIZADOS PARA A PRIMEIRA FUNÇÃO CANÔNICA - VARIÁVEIS INDEPENDENTES - EQUAÇÃO DE DEMANDA - PERFIL SÓCIO-DEMOGRÁFICO ALTO

TABELA 63: PESOS CANÔNICOS PADRONIZADOS PARA A PRIMEIRA FUNÇÃO CANÔNICA - VARIÁVEIS INDEPENDENTES - EQUAÇÃO DE OFERTA - PERFIL SÓCIO-DEMOGRÁFICO ALTO

TABELA 64: CORRELAÇÕES ENTRE AS VARIÁVEIS DEPENDENTES E AS VARIÁVEIS CANÔNICAS - EQUAÇÃO DE DEMANDA - PERFIL SÓCIO-DEMOGRÁFICO ALTO

TABELA 65: CORRELAÇÕES ENTRE AS VARIÁVEIS DEPENDENTES E AS VARIÁVEIS CANÔNICAS - EQUAÇÃO DE OFERTA - PERFIL SÓCIO-DEMOGRÁFICO ALTO

TABELA 66: CORRELAÇÕES ENTRE AS VARIÁVEIS INDEPENDENTES E AS VARIÁVEIS CANÔNICAS - EQUAÇÃO DE DEMANDA - PERFIL SÓCIO-DEMOGRÁFICO ALTO

TABELA 67: CORRELAÇÕES ENTRE AS VARIÁVEIS INDEPENDENTES E AS VARIÁVEIS CANÔNICAS - EQUAÇÃO DE OFERTA - PERFIL SÓCIO-DEMOGRÁFICO ALTO

TABELA 69: COEFICIENTES PADRONIZADOS DAS EQUAÇÕES DE DEMANDA DE CADA PERFIL SÓCIO-DEMOGRÁFICO

TABELA 70: COEFICIENTES PADRONIZADOS DAS EQUAÇÕES DE OFERTA DE CADA PERFIL SÓCIO-DEMOGRÁFICO

TABELA 72: CORRELAÇÕES ENTRE AS VARIÁVEIS DEPENDENTES E AS VARIÁVEIS CANÔNICAS DE CADA PERFIL SÓCIO-DEMOGRÁFICO - EQUAÇÃO DE DEMANDA

TABELA 73: CORRELAÇÕES ENTRE AS VARIÁVEIS DEPENDENTES E AS VARIÁVEIS CANÔNICAS DE CADA PERFIL SÓCIO-DEMOGRÁFICO - EQUAÇÃO DE OFERTA 
TABELA 74: CORRELAÇÕES ENTRE AS VARIÁVEIS INDEPENDENTES E AS VARIÁVEIS CANÔNICAS DE CADA PERFIL SÓCIO-DEMOGRÁFICO - EQUAÇÃO DE DEMANDA

TABELA 75: CORRELAÇÕES ENTRE AS VARIÁVEIS INDEPENDENTES E AS VARIÁVEIS CANÔNICAS DE CADA PERFIL SÓCIO-DEMOGRÁFICO - EQUAÇÃO DE OFERTA 


\section{RESUMO}

Este trabalho destina-se a realizar um estudo sobre o mercado imobiliário de lançamentos residenciais da Região Metropolitana de São Paulo, tendo como base a utilização de modelos de comercialização hedônica.

Para tanto, utiliza-se da Teoria dos Atributos proposta por Lancaster e dos modelos hedônicos e de equilíbrio de sub-mercados propostos por Rosen e Palmquist, a partir dos quais é possível analisar a importância relativa de "pacotes" de atributos, em função dos diferentes perfis sócio-demográficos determinados previamente por meio de análise fatorial elaborada com um grupo de 11 variáveis sócio-demográficas de cada Município da Região Metropolitana e de cada distrito do Município de São Paulo.

Por meio de um levantamento realizado com especialistas, com compradores de imóveis residenciais e por meio de anúncios específicos, definiram-se as variáveis hedônicas explicativas e dependentes a serem incluídas nos modelos de regressão múltipla de Box-Cox e de correlação canônica, sob a ótica da demanda e da oferta, para cada perfil sócio-demográfico definido.

O método proposto permite a determinação e a avaliação dos "pacotes" representativos de atributos para a composição das condições comerciais dos imóveis residenciais em lançamento na Região Metropolitana de São Paulo, propiciando a verificação da existência de eventuais descolamentos entre o comportamento da demanda e da oferta e possibilitando a comparação da importância relativa de cada variável entre os perfis sócio-demográficos.

Portanto, a aplicação do método proposto neste trabalho pode propiciar a implementação de iniciativas privadas e políticas públicas voltadas ao estabelecimento de novas estratégias de lançamento imobiliário, designadas para cada tipo específico de empreendimento e de acordo com as preferências dos consumidores e das características de cada localidade. 


\begin{abstract}
This work intends to research about the residential launchings of the real estate market in the Metropolitan Region of Sao Paulo, using hedonic models.

It's based on the approach to Theory of Attributes, proposed by Lancaster, and on the hedonic models and the sub-markets equilibrium approach proposed by Rosen and Palmquist, that make possible the analysis of the relative importance of the attributes "bundles" for each different social and demographic group previously defined by the factorial analysis statistical technique, that used 11 social and demographic variables related to each Municipality of the Metropolitan Region of Sao Paulo and each district of the City of Sao Paulo.
\end{abstract}

Using a survey realized with specialists, residential launchings buyers and through specific advertisements, many explicative and dependent hedonic variables were defined and are to be included in the models of Box-Cox multiple regression and canonical correlation, under the perspective of demand and supply, for each social and demographic defined group.

The proposed method allows the determination and the evaluation of the representative "bundles" of attributes to the composition of the residential launchings commercial conditions of the Metropolitan Region of Sao Paulo real estate market, making possible to verify the existence of eventual gaps between the demand and supply behaviors and allowing the comparison of the relative importance of each variable among the social and demographic groups.

Thus, the method application can facilitate private and public implementations, allowing the establishment of new strategies designated to each specific kind of real estate, according to the consumers' preferences and local characteristics. 


\section{INTRODUÇÃO}

As transformações urbanas que vêm ocorrendo na Região Metropolitana de São Paulo, principalmente nos últimos 20 anos, têm sido frequentemente observadas e documentadas. Os penosos deslocamentos diários daqueles que moram longe do trabalho ou da escola, os engarrafamentos nas ruas e garagens dos edifícios, a multiplicação de lugares com paisagem homogênea, os usos alternativos de galpões industriais, a proliferação das cabines de segurança que bloqueiam as passagens e controlam o acesso aos espaços residenciais, a verticalidade súbita de ruas e bairros antes horizontais, as rodovias que, pelo aumento abusivo do fluxo de veículos, ganham ares de avenidas e as avenidas que ganham equipamentos de controle de velocidade para não se transformarem em rodovias; enfim, todas estas características remetem a novas formas de ocupação e deslocamento social, espacial e temporal no território metropolitano, que tem cada vez mais assumido um comportamento dual, uma vez que, identificam-se, com clareza, aspectos modernos, funcionais e estruturados, e aspectos precários de ocupação urbana (MEYER; GROSTEIN; BIDERMAN, 2004, p. 10) ${ }^{1}$.

Enquanto, em 1980, a Região Metropolitana de São Paulo apresentava uma população de 12,6 milhões de habitantes, em 2000 este número passou para 17,9 milhões (INSTITUTO BRASILEIRO DE GEOGRAFIA E ESTATÍSTICA, 2004), e a existência de uma descontinuidade espacial ao longo da Metrópole, que evidencia a presença de um novo padrão urbano denominado de modernização precária, acentua os problemas relacionados à provisão de serviços de qualidade nas áreas da saúde, transporte, educação, moradia, entre outros.

O estabelecimento de uma Metrópole com suas características e dinâmicas físico-espaciais, segundo CASTELLS (1999, p. 500-507), é determinado por meio do entendimento de que a Metrópole é expressão e não reflexo do modo de produção da sociedade. E, portanto, segundo MEYER,

\footnotetext{
${ }^{1}$ As normas utilizadas neste trabalho para as citações e referências estão contidas em UNIVERSIDADE FEDERAL DO PARANÁ (2002).
} 
GROSTEIN e BIDERMAN (2004, p. 12), a Região Metropolitana de São Paulo pode ser vista como um poderoso agente das transformações que se organizam no âmbito de um novo padrão urbano e não como uma consequência lógica e passiva desse desenvolvimento. Assim sendo, poder-seia pensar que a determinação de novas características que sejam adequadas aos habitantes de cada localidade ou distrito surge frente a uma situação vigente dentro do próprio processo de mudança urbana, e não como consequência deste processo.

Ademais, o entendimento de que é o espaço que organiza o tempo nas sociedades, segundo defendem MEYER, GROSTEIN e BIDERMAN (2004, p. 13), estabelece que o papel das Metrópoles seja o de pontos dentro de uma hierarquia urbana construída segundo um panorama internacional, a partir dos quais se exercem as funções da economia globalizada. E, neste sentido, a Metrópole executa o seu papel efetivo de centro de gravitação, à medida que está apta a atender às demandas que emanam de funções nas quais a dimensão temporal exige um bom desempenho do território espacialmente organizado. E a organização das características de cada localidade do território gera impactos na vida urbana da sociedade, que depende da existência e da disponibilidade de tais recursos.

A atratividade de uma determinada Metrópole é medida em termos materiais e funcionais, sendo a avaliação relacionada à capacidade de determinada organização territorial metropolitana fornecer vantagens diferenciais em relação a outras. E a capacidade de uma grande Metrópole ser atrativa repousa na existência de atributos relacionados à qualificação de seus espaços e serviços públicos.

Nos últimos 15 anos, a área urbanizada da Região Metropolitana de São Paulo aumentou de $436 \mathrm{~km}^{2}$ para $2.139 \mathrm{~km}^{2}$, totalizando 39 Municípios (EMPRESA PAULISTA DE PLANEJAMENTO METROPOLITANO S.A., 2005). Dos 17,9 milhões de habitantes, apenas 4,25\% residem na zona rural e, por este motivo, a preocupação com a provisão de recursos e o entendimento de como eles podem ser utilizados e usufruídos, em função das características sócio-demográficas de cada localidade, devem cada vez mais estar presentes 
nas políticas de desenvolvimento urbano, em que a variedade e a disponibilidade de tais recursos podem ser definidas, abrangendo múltiplas variáveis intrínsecas e extrínsecas que podem ser representativas à população para a definição do local de moradia (BOWEN; MIKELBANK; PRESTEGAARD, 2001, p. 467).

Neste trabalho, o mercado imobiliário da Região Metropolitana de São Paulo é estudado e analisado, com enfoque nas características intrínsecas e extrínsecas pertencentes a cada residência, a fim de verificar quais atributos, ou "pacote" de atributos, mais interferem nas condições comerciais dos imóveis. E, para tanto, este estudo utiliza-se da Teoria dos Atributos proposta por LANCASTER (1966a e 1966b) e dos modelos hedônicos e de equilíbrio de sub-mercados propostos por ROSEN (1974, p. 34-55) e PALMQUIST (1984, p. 394-404), por meio dos quais é possível analisar a importância relativa de cada atributo, em função dos diferentes perfis sócio-demográficos determinados previamente para cada Município da Região Metropolitana e para cada distrito do Município de São Paulo, avaliando-se quais as variáveis que influenciam a oferta e a demanda.

Esta tese foi motivada pelo desejo de se aprofundar o entendimento dos processos pelos quais são lançados e comercializados os imóveis residenciais na Região Metropolitana de São Paulo, com enfoque para a influência dos atributos na composição dos preços e demais condições comerciais de imóveis residenciais em lançamento, sob a perspectiva da demanda e da oferta, respeitando as diferenças sócio-demográficas de cada localidade e seguindo a mesma linha de pesquisa adotada por FÁVERO (2003). No capítulo I, serão apresentados os aspectos relacionados ao problema de pesquisa, como a definição da situação-problema, a justificativa do tema, os objetivos do estudo, a questão e os pressupostos da pesquisa e as definições teóricas. O capítulo II será destinado à fundamentação teórica, com a abordagem dos modelos propostos por LANCASTER (1966a e 1966b) e ROSEN (1974, p. 34-55). Ainda nesse capítulo será apresentada a revisão da literatura. O capítulo III tratará da evolução histórica e do processo de formação da Região Metropolitana e do Município de São Paulo, assim como do mercado imobiliário local e das 
características sócio-demográficas existentes atualmente, que servirão de base, no capítulo seguinte, para a definição, por meio de análise fatorial, dos segmentos a serem estudados. No capítulo IV, serão abordados os tópicos relacionados à pesquisa propriamente dita, como método, universo de estudo, definição das variáveis sócio-demográficas a serem utilizadas na análise fatorial, aplicação de análise fatorial para a definição dos grupos sócioeconômicos distritais e municipais, definição dos grupos sócio-demográficos propriamente ditos, definição e caracterização da amostra, modelo teórico de pesquisa, definição e coleta de dados das variáveis independentes e dependentes e definição dos modelos de regressão múltipla e correlação canônica. No capítulo $V$, serão apresentados os resultados dos métodos propostos para os modelos de oferta e demanda, para cada um dos perfis sócio-demográficos, além da comparação entre eles. Por fim, serão discutidas as principais conclusões, recomendações e possíveis extensões. 


\section{CAPÍTULO I}

\section{O PROBLEMA DE PESQUISA}

\section{1 - Definição da Situação-Problema}

O desenvolvimento e o lançamento de empreendimentos residenciais, principalmente em Metrópoles como São Paulo, necessitam de análises cada vez mais profundas em relação ao potencial de mercado, escassez de poder aquisitivo da população, existência de inúmeros lançamentos com as mais diversas características e velocidade de vendas. A oferta de um determinado imóvel não depende somente da sua existência física, mas das condições associadas a preço, formas de financiamento e potencial de mercado. Da mesma forma, as condições para a existência de demanda relacionam-se a inúmeras características intrínsecas e extrínsecas pertinentes ao imóvel que, se consideradas representativas por parte dos consumidores, tornam-se atributos que influenciam na decisão de compra. Para que não haja um descolamento entre o que está sendo ofertado e o que se espera dos agentes que compõem a demanda, é importante que as variáveis relacionadas à oferta determinem um preço e condições de pagamento compatíveis com as características intrínsecas e extrínsecas analisadas e avaliadas pelos potenciais compradores, influenciando substancialmente a velocidade de venda do imóvel. Segundo ALENCAR (2001, p. 7), a velocidade de venda de um determinado imóvel de um empreendimento residencial é diretamente dependente da concepção do produto e de sua capacidade de oferecer satisfação ao consumidor em relação aos atributos de valor que detêm outros produtos lançados, visando ao mesmo grupo de clientes.

Ou seja, o planejamento do imóvel não pode ser entendido como uma tarefa que se desenha nos gabinetes do empreendedor, representado por imobiliárias, incorporadoras e construtoras, com o intuito de encontrar as soluções que possam atender aos seus desejos de rentabilidade e que são maturadas a partir do entendimento de como será o comportamento da demanda, na visão ideal do planejador. Esta postura se baseia na 
determinação dos resultados prováveis de empreendimentos, cujo planejamento está unicamente estruturado na visão que o empreendedor tem de como deveria se comportar o mercado, de onde deriva a definição do seu produto. Muitas vezes, a idealização do mercado se faz de uma forma ainda mais primária, mesmo que, pretensamente, mais acurada, quando o planejador procura, com o seu produto, repetir os padrões de sucesso que, por vezes, são aparentes, já que não levam em conta novas peculiaridades de cada localidade. Portanto, um imóvel terá tanto mais qualidade quanto seus atributos, relacionados com localização, vizinhança, acessibilidade, desenho, dimensões e qualidade intrínseca dos materiais e acabamentos, se aproximarem daquilo que deseja o comprador (LIMA JÚNIOR, 1993, p. 5).

Segundo MOREIRA (1997, p. 54), a descrição minuciosa do que deve ser entendido como propriedade imobiliária refere-se ao imóvel que fora adquirido por um comprador que reconheceu características de localização e tendências de evolução e involução, como estações ferroviárias ou de metrô, comércio, indústria, escolas, hospitais, estádios esportivos, entre outras. Em seguida, aspectos referentes ao logradouro em que se situa o imóvel, como características de vizinhança, infra-estrutura e serviços públicos de água, luz, gás, esgoto, telefonia, transporte e calçamento. Finalmente, características de benfeitorias pertencentes ao próprio imóvel, como área, número de vagas na garagem, número de elevadores, salões de festas, número de dormitórios e banheiros, entre outras.

Para que se possam desenvolver empreendimentos no mercado imobiliário, com expectativa de taxas de retomo capazes de compensar o padrão de riscos dos negócios, há necessidade de que o planejamento do produto e a definição do preço sejam feitos com rigor, pois a quebra de desempenho das variáveis utilizadas no curso da ação, relativamente à condição esperada, apresenta sensibilidade com respeito às variáveis dependentes tradicionalmente usadas como indicadores de utilidade, base para tomada de decisão (LIMA JÚNIOR, 1993, p. 6). Como os empreendimentos residenciais, foco deste trabalho, não são produzidos, na maioria das vezes, sob a ótica de algum modelo de produção massificada, o enfoque tradicional 
para a definição de preço especificado para produtos caracterizados como commodities não é praticado (LEEUW, 1993, p. 34).

De uma maneira geral, o mercado imobiliário é dominado por uma grande parte de agentes, como os incorporadores, empreendedores, entre outros, que concorrem entre si, utilizando meios de publicidade, inovações tecnológicas e oferta de atributos diferenciados (DANTAS, 1998, p. 10). Desta forma, para se analisarem os preços dos produtos, deve-se procurar tratar dos temas relacionados aos vetores de pressão nas relações de mercado, de forma que sua resultante caracterize o preço e as condições de cada transação.

No caso do produto imobiliário, graças ao ineditismo da compra em cada caso, pode-se considerar que ocorra um preço para cada transação de produtos semelhantes (LIMA JÚNIOR, 1993, p. 5). Em um empreendimento imobiliário, cada transação acaba sendo ajustada para as possibilidades do comprador, criando, para cada uma das suas unidades, uma determinada combinação de preço e utilidade. Poder-se-ia identificar a utilidade de um bem como sendo o estado ou nível de desempenho de um conjunto de atributos deste bem relativamente ao referencial que o consumidor mantém com respeito aos mesmos.

Os consumidores maximizam a sua satisfação a partir da escolha de uma cesta de atributos no mercado, em função daquilo que entendem como sendo de maior utilidade para si, sem ultrapassar a sua restrição orçamentária (PINDYCK; RUBINFELD, 1999, p. 83). Na figura 1.1.1, a seguir, pode-se observar que a linha divisória representa a interface entre o consumidor e a oferta de um determinado imóvel residencial em lançamento. Este imóvel apresenta um preço (PE) e uma utilidade (UE), representada por suas características relacionadas à oferta. Como os consumidores atribuem ao mesmo imóvel um determinado preço (PC) e condições de pagamento compatíveis com suas expectativas, além de uma determinada utilidade (UC) relacionada a atributos intrínsecos e extrínsecos, a aquisição pelo comprador do referido imóvel dar-se-á se houver um equilíbrio entre o preço estipulado na oferta e o preço compatível com os anseios do comprador e com sua restrição orçamentária. O imóvel terá tanto mais utilidade quanto seus atributos mais se 
aproximarem daquilo que deseja o consumidor, e a análise não é feita de forma absoluta, mas relativamente às demais ofertas que estão no mercado e que buscam atingir este mesmo consumidor que, observando as ofertas existentes, irá determinar um padrão de utilidade no patamar de preço que o atenda.

FIGURA 1.1.1: INTERFACE ENTRE A OFERTA E A DEMANDA POR ATRIBUTOS NO MERCADO IMOBILIÁRIO

linha divisória

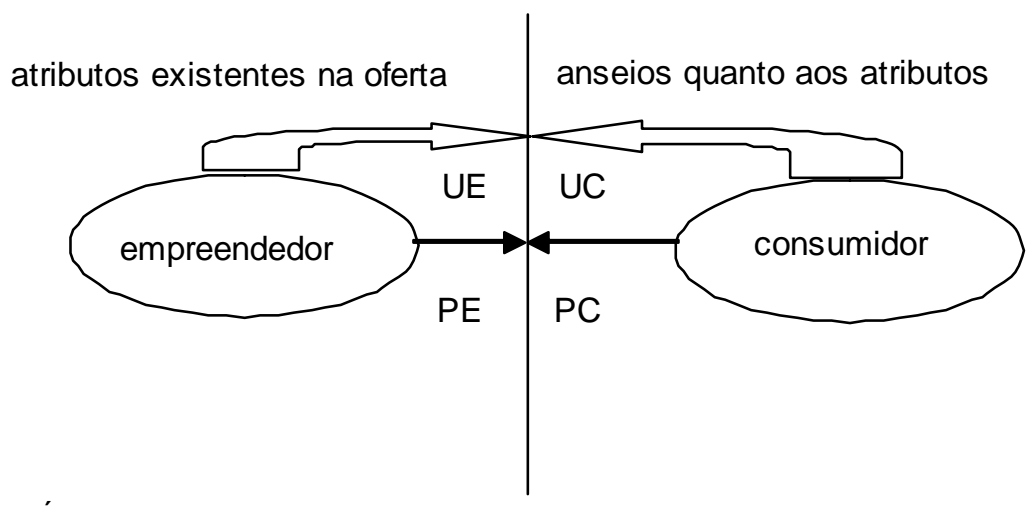

FONTE: LIMA JÚNIOR, 1993, p. 9.

Recentemente, a definição da estrutura de preços do mercado imobiliário tem sido estudada a partir de modelos que estimam o preço de uma determinada unidade residencial pelas características por ela apresentadas (LEEUW, 1993, p. 33), e não única e exclusivamente pelo custo da construção. Estes modelos podem apresentar o preço como variável dependente, como em FÁVERO (2003, p. 41), ou outras variáveis conjuntamente, como número de parcelas e condições de pagamento, de modo que a utilização de modelos de regressão apenas com o preço como variável dependente torna limitada a avaliação dos impactos de variáveis de oferta e demanda sobre as condições comerciais do imóvel, fazendo-se necessário também o uso de técnicas mais gerais de modelagem, como correlação canônica.

Em termos econômicos, uma das questões mais importantes refere-se à relação entre o volume disponível quando da produção e oferta de um determinado bem e a quantidade de fatores, ou características, utilizados para tal fim. Esta relação, que é denominada função de produção, pode trazer contribuições significativas para o campo do planejamento empresarial 
(ANGELO; SILVEIRA; TANABE, 1990). Segundo SARTORIS NETO (1996, p. 2), "se, talvez, em quase todo o século XIX, o conjunto de bens disponíveis à grande maioria dos consumidores não se alterou a não ser em momentos ocasionais e em situações específicas, hoje a comparação entre determinados bens cuja produção difere de uma década pode ser totalmente descabida, em função da enormidade de atributos percebidos. Veja-se, por exemplo, o caso dos automóveis e, de maneira ainda mais dramática, dos microcomputadores".

Neste trabalho, serão utilizados para análise imóveis lançados durante o ano de 2004, com enfoque para as características que interferem na oferta e na demanda. A aplicação prévia de uma análise fatorial auxiliará na definição dos perfis sócio-econômicos dos grupos distritais e municipais. Com os grupos e variáveis pré-estabelecidas, verificar-se-á, por meio do método de equilíbrio de mercado de ROSEN (1974, p. 34-55), com as devidas considerações propostas por PALMQUIST (1984, p. 394-404) sobre a segmentação em sub-mercados, quais os atributos de oferta, como densidade demográfica e população, e de demanda, como renda e número de membros na família, são mais representativos para a composição do preço final de imóveis lançados em cada segmento sócio-demográfico. Após esta verificação, avaliar-se-á se as variáveis consideradas representativas dos modelos de precificação hedônica, para cada perfil sócio-demográfico, também podem explicar, de maneira significativa, a composição das demais condições comerciais dos imóveis, como o número de parcelas do financiamento e o valor da primeira parcela, determinando, assim, os modelos de comercialização hedônica.

Em FÁVERO (2003), foram considerados apenas modelos hedônicos de oferta de imóveis residenciais lançados em localidades com diferentes perfis sócio-demográficos do Município de São Paulo, em que a variável dependente referia-se apenas ao preço de lançamento, sem a preocupação de ter ou não ocorrido a sua comercialização. Este trabalho, com o intuito de aprofundar esta linha de pesquisa, propõe uma estratificação sócio-demográfica alternativa, levando em consideração também os Municípios da Região Metropolitana de São Paulo, e utilizando, para a composição da amostra, imóveis lançados e 
comercializados, a fim de que seja possível a determinação de eventuais descolamentos existentes entre a perspectiva da demanda e da oferta.

\section{2 - Justificativa do Tema}

De acordo com ECO (1977, p. 35-40), quatro são os requisitos para se reconhecer a cientificidade de uma tese (CHEROBIM, 2002, p. 90-91). Desta forma, apresentam-se, a seguir, tais requisitos, com os respectivos comentários pertinentes a este trabalho.

1 - O estudo debruça-se sobre um objeto reconhecível e definido de tal modo que seja igualmente reconhecível pelos outros.

O mercado imobiliário e as empresas ofertantes de imóveis são reconhecidos no cenário econômico e empresarial da Região Metropolitana de São Paulo.

2 - O estudo deve dizer sobre este objeto coisas que já não tenham sido ditas, ou rever, com uma ótica diferente, coisas que já foram ditas.

Os modelos de precificação e comercialização por atributos já foram muito estudados para alguns segmentos, como o imobiliário, porém o tema ainda não está esgotado. Ademais, são diversas as técnicas a partir das quais estes modelos são definidos, e a combinação de algumas delas é evidenciada neste trabalho.

3 - O estudo deve ser útil aos outros.

Estudantes, pesquisadores, profissionais e potenciais consumidores de imóveis podem obter informações sobre os conceitos abordados neste trabalho.

4 - O estudo deve fornecer os elementos para a confirmação e para a rejeição das hipóteses que apresenta e, portanto, deve fornecer os elementos para a sua continuação pública.

O presente estudo pode ser efetuado em outras Regiões Metropolitanas do Brasil ou ser replicado em períodos futuros, tornando possível a elaboração de análises de evolução histórica de preços, formas de comercialização e exposição de atributos. Ademais, os métodos utilizados podem ser aplicados 
em outros setores da economia que oferecem bens e serviços que têm preços e condições de comercialização influenciados pela presença dos mais diversos tipos de atributos.

\section{3 - Objetivos do Estudo}

Este trabalho tem como um de seus objetivos identificar uma evolução histórica das principais linhas de pesquisa que se referem à utilização de modelos hedônicos, realizando uma análise dos autores e de suas influências.

Além disto, propõe-se a definir segmentos sócio-demográficos entre os 96 distritos municipais do Município de São Paulo e os 38 Municípios restantes que compõem a Região Metropolitana de São Paulo. Será, portanto, elaborada uma análise fatorial, por meio da utilização de variáveis relacionadas a aspectos sociais e demográficos de cada uma das 134 localidades mencionadas, a fim de que seja possível definir os grupos, que representarão os perfis sócio-demográficos existentes na Metrópole, a serem estudados isoladamente nas técnicas seguintes. Destaca-se que a utilização de modelos de atributos implica uma tendência natural de estratificação de mercado, uma vez que consegue captar as diferenças associadas a cada sub-amostra, o que está de acordo com o equilíbrio espacial descrito por ARYEETEY-ATTOH (1992, p. 184-185) e com a análise de condições de vizinhança elaborada por TIEBOUT (1956, p. 416-424)².

A valoração de atributos de oferta e demanda para a composição dos preços de imóveis residenciais em lançamento entre os meses de Janeiro e Dezembro de 2004, para cada perfil sócio-demográfico da Região Metropolitana de São Paulo estabelecido previamente, também é objetivo deste trabalho. Por meio da utilização da Teoria dos Atributos proposta por LANCASTER (1966a e 1966b) e da aplicação do método de equilíbrio de mercado proposto por ROSEN (1974, p. 34-55), com as devidas adequações desenvolvidas por PALMQUIST (1984, p. 394-404), definir-se-ão as variáveis mais representativas de oferta e demanda.

\footnotetext{
${ }^{2}$ Como também discutido em ELLICKSON (1971, p. 334-339).
} 
Além da definição das variáveis mais representativas de oferta e demanda para a composição dos preços de venda dos imóveis residenciais, este trabalho também tem como objetivo final definir quais as variáveis que são mais representativas para a composição de um conjunto de aspectos que compõem as condições comerciais do imóvel, não apenas se restringindo ao preço. Para esta abordagem, será utilizada a técnica de correlação canônica, para cada perfil sócio-demográfico.

\section{4 - Questão de Pesquisa}

A questão de pesquisa relaciona-se a:

1 - Identificar as principais linhas de pesquisa sobre o assunto, definindo seus autores e suas influências;

2 - Definir as variáveis representativas para a determinação dos grupos sócio-demográficos;

3 - Determinar os grupos sócio-demográficos para cada localidade da Região Metropolitana de São Paulo;

4 - Verificar se as variáveis de oferta e demanda, definidas por meio de pergunta aberta a especialistas e compradores, são significantes para a determinação dos preços e demais condições comerciais dos imóveis residenciais, para cada grupo sócio-demográfico;

5 - Verificar se cada uma das variáveis de demanda e oferta apresenta importância relativa diferenciada na composição dos preços e demais condições comerciais dos imóveis, quando da comparação entre os grupos sócio-demográficos;

6 - Verificar se cada uma das variáveis apresenta importância relativa diferenciada para a composição dos preços e demais condições comerciais dos imóveis, quando a comparação se der entre a equação de demanda e oferta dentro de um mesmo perfil sócio-demográfico.

Portanto, dando continuidade à linha de pesquisa adotada por FÁVERO (2003), a principal questão a ser respondida no estudo, após a identificação 
das influências históricas deste assunto e da determinação de sub-mercados pela segmentação sócio-demográfica, refere-se a quais atributos de demanda e oferta são mais representativos para a composição dos preços e demais condições comerciais de imóveis residenciais em lançamento, mais especificamente apartamentos ${ }^{3}$, em função do grupo sócio-demográfico em que se localizam.

\section{5 - Pressupostos da Pesquisa}

Os pressupostos adotados neste trabalho são:

1 - Os distritos do Município de São Paulo e os Municípios da Região Metropolitana de São Paulo que se encontram no mesmo grupo sócio-demográfico pertencem à mesma sub-amostra, ainda que existam diferenças entre eles;

2 - Um lançamento apresenta um determinado atributo extrínseco, se efetivamente estiver na localidade em que se situa o imóvel, independente do fato de ambos estarem ou não próximos;

3 - Considera-se que a opinião dos especialistas, quando da elaboração de um levantamento auto-administrado ${ }^{4}$, define, de maneira prévia, as variáveis hedônicas de oferta utilizadas no estudo;

4 - Considera-se que a opinião dos compradores define, de maneira prévia, as variáveis hedônicas de demanda utilizadas no estudo;

5 - Assume-se que no período de coleta de dados, entre os meses de Janeiro e Dezembro de 2004, não houve alterações significativas no mercado imobiliário de lançamentos residenciais, permitindo-se, portanto, a utilização de cross-section para o estudo. A seguir, na tabela 1.4.1, apresenta-se o comportamento do mercado imobiliário de São Paulo entre os referidos meses, no que diz respeito ao

\footnotetext{
${ }^{3}$ Dentro dos pressupostos do item 1.5 .

${ }^{4}$ Forma de pesquisa a ser discutida no item 4.1.
} 
número de apartamentos lançados, o número de apartamentos comercializados no mesmo período e o Índice de Venda sobre Oferta (VSO) $)^{5}$ que representa a relação entre comercialização e lançamento.

TABELA 1.5.1: OS NÚMEROS DO MERCADO IMOBILIÁRIO RESIDENCIAL

\begin{tabular}{|c|c|c|c|c|c|}
\hline MÊS & $\begin{array}{c}\mathrm{N}^{\circ} \text { DE } \\
\text { APARTAMENTOS } \\
\text { RESIDENCIAIS } \\
\text { COMERCIALIZADOS } \\
\end{array}$ & $\begin{array}{c}N^{\circ} \text { DE } \\
\text { APARTAMENTOS } \\
\text { RESIDENCIAIS } \\
\text { LANÇADOS } \\
\end{array}$ & $\begin{array}{c}N^{\circ} \text { DE } \\
\text { APARTAMENTOS } \\
\text { RESIDENCIAIS JÁ } \\
\text { DISPONIVEIS } \\
\end{array}$ & $\begin{array}{c}\mathrm{N}^{\circ} \text { DE } \\
\text { APARTAMENTOS } \\
\text { RESIDENCIAIS } \\
\text { EM OFERTA } \\
\end{array}$ & vso \\
\hline Jan / 04 & 1.591 & 588 & 21.351 & 21.939 & $7,3 \%$ \\
\hline Fev / 04 & 1.216 & 1.401 & 20.234 & 21.635 & $5,6 \%$ \\
\hline Mar / 04 & 2.065 & 1.867 & 20.093 & 21.960 & $9,4 \%$ \\
\hline Abr / 04 & 1.826 & 1.197 & 19.708 & 20.905 & $8,7 \%$ \\
\hline Mai / 04 & 1.211 & 1.434 & 18.782 & 20.216 & $6,0 \%$ \\
\hline Jun / 04 & 1.314 & 2.113 & 18.975 & 21.088 & $6,2 \%$ \\
\hline Jul / 04 & 1.028 & 1.174 & 19.723 & 20.897 & $4,9 \%$ \\
\hline Ago / 04 & 1.553 & 1.542 & 19.760 & 21.302 & $7,3 \%$ \\
\hline Set / 04 & 2.062 & 3.201 & 19.563 & 22.764 & $9,1 \%$ \\
\hline Out / 04 & 2.290 & 3.846 & 20.656 & 24.502 & $9,3 \%$ \\
\hline Nov / 04 & 1.812 & 2.198 & 22.056 & 24.254 & $7,5 \%$ \\
\hline Dez / 04 & 2.215 & 1.754 & 22.034 & 23.788 & $9,3 \%$ \\
\hline TOTAL & 20.183 & 22.315 & \multicolumn{2}{|c|}{ VSO MÉDIO } & $7,6 \%$ \\
\hline
\end{tabular}

Pode-se verificar a não existência de alterações significativas no mercado imobiliário de lançamentos residenciais no período em estudo, já que os valores de VSO permanecem em torno da média, com um desvio-padrão baixo (1,5\%), fato observado também por meio do gráfico 1.4 .1 a seguir.

\footnotetext{
${ }^{5}$ O Índice de Venda sobre Oferta começou a ser utilizado pelo Sindicato das Empresas de Compra, Venda, Locação e Administração de Imóveis Comerciais e Residenciais de São Paulo (Secovi-SP) no início de 2004, substituindo o Î́ndice de Velocidade de Vendas (IVV), utilizado por FÁVERO (2003, p. 8).
} 
GRÁFICO 1.5.1: A EVOLUÇÃO TEMPORAL DO ÍNDICE DE VENDA SOBRE OFERTA PARA O PERÍODO DE JANEIRO A DEZEMBRO DE 2004

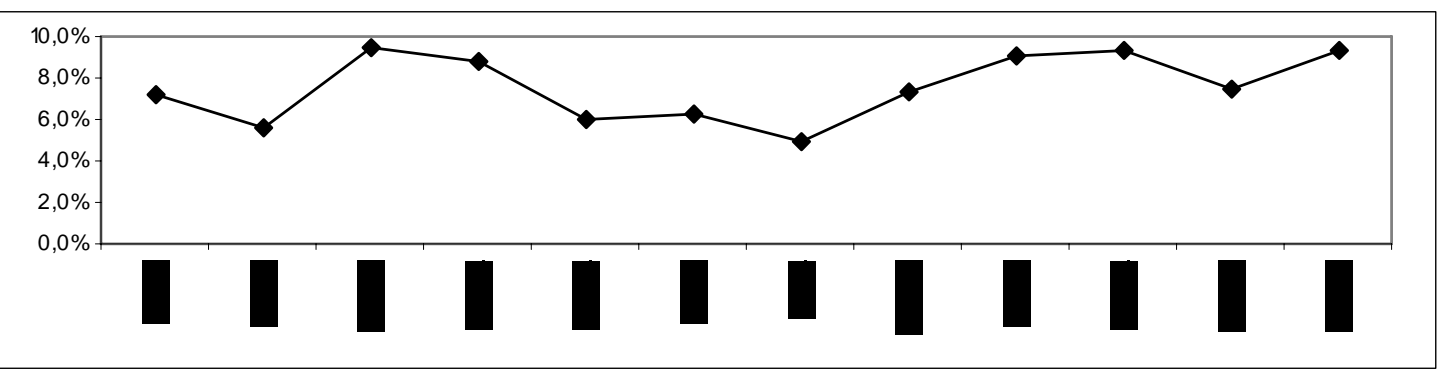

\section{6 - Modelos Hedônicos - Definições Teóricas}

Como os modelos de regressão e correlação canônica utilizados neste trabalho podem ser considerados hedônicos, já que apresentam, como variáveis independentes, características intrínsecas e extrínsecas para a determinação dos preços e das condições comerciais dos imóveis, faz-se necessário, para melhor entendimento dos termos relacionados a hedonismo, apresentar algumas entradas em dicionários atuais:

Hedônico, adj., que diz respeito ao hedonismo. Escola hedônica, a escola de Cirene, a primeira escola que propagou o hedonismo (CALDAS AULETE, 1980, p. 1827).

Hedônico, adj., relativo ao hedonismo; hedonístico. Relativo ao ou caracterizado pelo prazer. Etimologia: grego hedonikós, relativo ao prazer, voluptuoso (HOUAISS, 2001, p. 1510).

Hedonismo, s.m., sistema filosófico de moral, para o qual todo bem está no prazer. Do grego hedone (prazer) + ismo (CALDAS AULETE, 1980, p. 1827).

Hedonismo, s.m., Etimologia: cada uma das doutrinas que concordam na determinação do prazer como o bem supremo, finalidade e fundamento da vida moral, embora se afastem no momento de explicitar o conteúdo e as características da plena fruição, assim como os meios para obtê-la. Dedicação ao prazer dos sentidos, fundamento de todos os prazeres espirituais. Busca de prazeres moderados, únicos que não terminam por conduzir a sofrimentos 
indesejados. Procura do prazer individual, que somente se plenifica por meio de sua extensão para o maior número possível de pessoas. Modo de vida inspirado no ou evocativo do hedonismo, dedicação ao prazer como estilo de vida. Do grego hedon(o) + ismo (HOUAISS, 2001, p. 1510). 


\section{CAPÍTULO II}

\section{FUNDAMENTAÇÃO TEÓRICA}

\section{1 - A Teoria Clássica e a Abordagem dos Atributos}

A teoria clássica do consumidor considera ser a escolha de um determinado bem uma propriedade intrínseca do mesmo. Segundo HENDERSON e QUANDT (1988, p. 8), “a função de utilidade é definida com referência ao consumo num período de tempo especificado e o nível de satisfação que o consumidor obtém de uma dada combinação de bens depende da extensão do período em que ele é consumido. Normalmente, o consumidor obtém utilidade da variedade e da diversificação de bens que consome e, desta forma, a função utilidade não deve ser definida para um período tão curto que não seja possível satisfazer seu desejo de variedade".

LANCASTER (1966a, p. 132-157), citado por SARTORIS NETO (1996, p. 10), não desconsidera a tradicional abordagem da função de utilidade, porém propõe um tratamento mais amplo para a Teoria do Consumidor, na qual se permite subdividir um bem em suas características, passando a utilidade a ser obtida por meio das propriedades dos bens. Assim, a função utilidade passa a ter, como argumento, as características dos bens e não mais eles próprios. Portanto, assume-se que o consumo é uma atividade na qual os bens, singularmente ou em combinação, são "entradas" e a partir das quais a "saída" é um "pacote" de características. Nos dois trabalhos desenvolvidos por LANCASTER em 1966 (1966a e 1966b), o autor apresenta como o consumidor não escolhe um bem especificamente, mas um conjunto de atributos que têm correspondência a um determinado bem (PEREIRA, 2004, p. 32).

De acordo com PEREIRA (2004, p. 25), LANCASTER (1966a, p. 132157) desenvolveu uma abordagem que permite subdividir um bem em seus atributos e, se houver no mercado um produto com a combinação desses atributos, será este o bem adquirido pelo consumidor. A questão, portanto, envolve a descoberta de qual é a combinação de atributos desejados pelo consumidor para um dado produto e se há um conjunto de atributos que é 
comum a um conjunto de consumidores, o que permite realizar uma segmentação de mercado com base em atributos desejados (GRISI, 1986, p. 104).

Assume-se que o bem não propicia utilidade ao consumidor, mas possui características que o fazem. Da mesma forma, o bem possui, em geral, mais de uma característica e muitas delas podem estar presentes em mais de um bem. Ademais, bens em combinação podem apresentar características diferentes daquelas pertencentes aos bens em separado.

Assim, a abordagem oferece um caráter mais realista em relação aos bens e suas características (LANCASTER, 1966a, p. 132-157) e a construção de um modelo faz-se necessária.

O modelo formalizado por LANCASTER (1966a, p. 132-157) propõe que o consumo de um determinado bem seja expresso de modo a relacionar, de forma linear, o nível de atividade k, o número de bens consumidos y (atividade de consumo) e o j-ésimo bem consumido $x_{j}$, da seguinte forma:

$$
x_{j}=\sum_{k} a_{j k} y_{k}
$$

Desta forma, de acordo com LANCASTER (1966a, p. 135), o vetor de bens necessários para uma dada atividade de consumo é dado por:

$$
X=A \cdot y
$$

Conforme PEREIRA (2004, p. 35), como se assume que é possível objetivamente mensurar as qualidades dos bens consumidos, as equações são válidas para todos os consumidores em um dado mercado. De acordo com LANCASTER (1966a, p. 35), é possível assumir que $z_{i}$ é a quantidade da iésima característica adquirida em uma atividade de consumo. Assim:

$$
z_{i}=\sum_{k} b_{i k} y_{k}
$$


de onde vem que:

$$
z=B \cdot y
$$

Com a determinação dos vetores $X$, de bens consumidos, e $z$, das preferências dos consumidores, nota-se que a relação entre eles é medida pelo vetor $y$, que se refere à atividade de consumo (LANCASTER, 1966a, p. 136). De acordo com PEREIRA (2004, p. 36), "o fato da relação entre X e z ser mediada por y significa que não necessariamente há uma correspondência exata (um para um) entre as características desejadas pelos consumidores e o conjunto de bens disponíveis no mercado".

Porém, para simplificar o modelo e sua solução, LANCASTER (1966a, p. 136) sugere que a escolha do consumidor se dê da seguinte maneira: considerando que $z_{i}$ e $x_{j}$ são, respectivamente, a quantidade da característica $i$ e a quantidade do bem j, segue-se que em um sistema de $r$ características e $n$ bens, o "pacote" de características que uma série de bens $\left(x_{1}, \ldots, x_{n}\right)$ possui é dado, na forma matricial, por:

$$
Z=B \cdot X
$$

onde $z=\left[z_{i}\right]$ é o vetor de características, $x=\left[x_{i}\right]$ o vetor de bens, e $B=$ $\left[b_{i j}\right]$ a matriz $(r \times n)$ dos coeficientes que relacionam bens a características.

O consumidor obtém utilidade a partir das características encontradas nos bens que adquire e não nos bens em si. Assim, a função utilidade tem como argumento as características dos bens, representadas pelo vetor z, e não mais os bens em si, como na teoria tradicional (vetor $\mathrm{x}$ ), ou seja:

$$
U=U\left(z_{1}, \ldots, z_{n}\right)=U(z)
$$

Como o consumidor adquire as características que deseja ("pacote" de atributos) por meio da compra de um bem propriamente dito, sua restrição 
orçamentária depende do vetor de bens x e a solução do problema exige uma correspondência entre os dois vetores. Portanto, o modelo proposto compreende quatro partes que podem ser representadas como segue:

$U(z)$ maximizado

onde U é definido no espaço das características (espaço C),

$$
\text { p.x } \leq k
$$

onde a restrição orçamentária p.x é definida no espaço dos bens (espaço G),

$$
z=B \cdot x
$$

onde o sistema de equações, representado pelo vetor $z$, apresenta a transformação entre o espaço $\mathrm{G}$ e o espaço C,

$$
X, Z \geq 0
$$

que representa as restrições de não negatividade sobre x e z.

$\mathrm{Na}$ Teoria do Consumidor tradicional, a restrição orçamentária e a função utilidade são ambas definidas no espaço $G$ e, portanto, pode-se relacioná-las como em um diagrama de curvas de indiferença típico. Entretanto, segundo LANCASTER (1991, p. 17), duas alternativas são possíveis: a transformação da função utilidade para o espaço $G$, ou a transformação da restrição orçamentária para o espaço C. No primeiro caso, pode-se determinar que:

$$
U(z)=U(B \cdot x)=u(x)
$$


Portanto, tem-se uma função utilidade $u(x)$ que é definida diretamente em termos de bens, mas cujas propriedades dependem da estrutura da matriz B e conduzem a uma situação bem mais complexa do que aquela encontrada na análise tradicional. Também o segundo caso depende da estrutura da matriz B.

A matriz $B$, representada por $B=\left[b_{i j}\right]$, determina os coeficientes que relacionam bens a características. Desta forma, três casos possíveis podem surgir em relação ao número de bens e características.

Primeiro, quando o número de características for igual ao número de bens. Neste caso, tem-se uma relação de um para um entre os vetores de bens e características. Assim:

$$
z=B \cdot x, \text { ou } x=B^{-1} \cdot z
$$

Se B é uma matriz diagonal, existe então uma relação de um para um entre cada componente de $z$ e cada componente de $x$ e o modelo se torna idêntico ao tradicional. Se, no entanto, B não é uma matriz diagonal, os objetos de utilidade não são bens individuais, mas combinações de bens, e o modelo passa a apresentar diferenças significativas do modelo tradicional.

Segundo, se o número de características for maior do que o número de bens. As relações $z=$ B.x contêm mais equações que do que variáveis $x_{i}$, fazendo com que não seja possível, em geral, se encontrar um vetor de bens $x$ que dê origem a um vetor de características $z$, arbitrariamente especificado. Portanto, reduz-se o número de características a n, igualando-se ao número de bens. Neste caso, é em geral mais prático se analisar o comportamento do consumidor por meio da transformação da função utilidade para o espaço G.

O terceiro caso é analisado para se verificar um número de bens superior ao número de características. A equação $z=B \cdot x$ apresenta menos equações do que variáveis, de modo que, para cada ponto no espaço de características, o consumidor pode escolher entre os diferentes vetores de bens. Dado, por exemplo, um vetor de preços, a escolha é caracterizada por ser de eficiência pura, se para todo o vetor de características o consumidor 
escolher a combinação mais eficiente de bens para obter aquela coleção de características. A escolha eficiente para um vetor de característica $z^{*}$ representará a solução do seguinte programa linear:

$$
\begin{aligned}
& p . x \text { minimizado } \\
& z^{*}=B \cdot x \\
& x \geq 0
\end{aligned}
$$

Este último caso representa a situação que mais se adequa ao mercado de lançamentos imobiliários, objeto deste trabalho. Segundo LANCASTER (1966a, p. 133), as propriedades constantes em lançamentos de novos produtos e a oferta de novas qualidades definirão as reações dos consumidores a estes produtos.

A escolha completa de um consumidor sujeito a uma restrição orçamentária $p . x \leq k$ pode ser devida a dois fatores: à escolha eficiente, ou objetiva, que determina a fronteira de características e as coleções eficientes de bens, e à escolha privada, ou subjetiva, que determina qual o ponto da fronteira de características é o preferido pelo consumidor.

Um caso simples pode ser observado na figura 2.1.1, na qual a matriz B é composta de dois bens e duas características:

FIGURA 2.1.1: ESCOLHA PARA DOIS BENS E DUAS CARACTERÍSTICAS

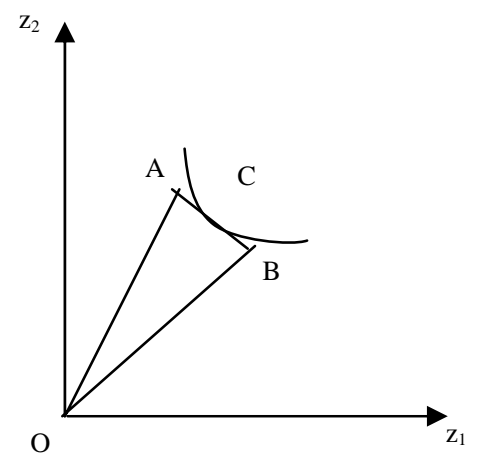

FONTE: SARTORIS NETO, 1996, p. 17. 
Na figura 2.1.1, "as características $z_{1}$ e $z_{2}$ são encontradas em dois bens $a$ e $b$, representados pelas linhas $O A$ e $O B$, respectivamente. $A$ linha $A B$ representa a fronteira de características para um dado nível de renda e preços dos bens a e $b$. O ponto de tangência entre a curva de indiferença e a fronteira (o ponto $\mathrm{C}$ da figura) determina a escolha do consumidor" (SARTORIS NETO, 1996, p. 16-18).

Já com relação à situação específica deste estudo, em que são analisados mais bens do que características, um gráfico genérico poderia ser elaborado, como se observa na figura 2.1.2.

FIGURA 2.1.2: ESCOLHA PARA MAIS BENS DO QUE CARACTERÍSTICAS (QUATRO BENS E DUAS CARACTERÍSTICAS)

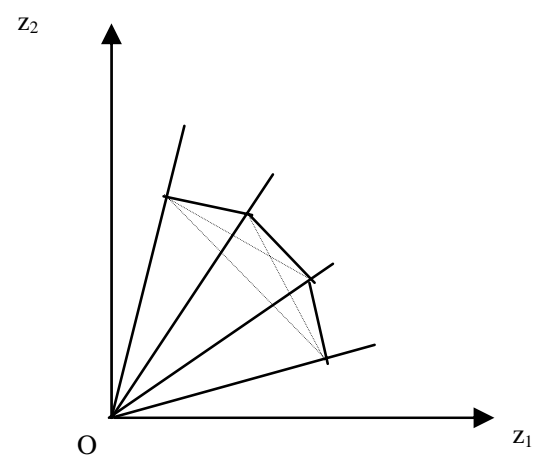

FONTE: SARTORIS NETO, 1996, p. 18.

De acordo com a figura 2.1.2, em que são considerados quatro bens e duas características, é possível estimar uma fronteira de eficiência, como a reta $A B C D$ da figura 2.1.3 a seguir, na qual a distância entre o ponto e a origem é o preço do bem. Assim, os segmentos $\mathrm{AO}, \mathrm{BO}, \mathrm{CO}$ e $\mathrm{DO}$ representam, respectivamente, os preços dos bens 1, 2, 3 e 4 . 
FIGURA 2.1.3: FRONTEIRA EFICIENTE - DUAS CARACTERÍSTICAS E QUATRO BENS

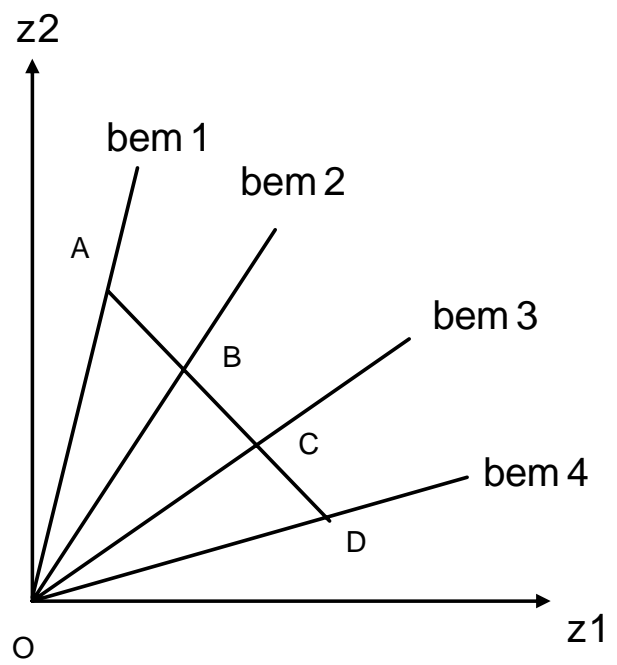

FONTE: PEREIRA, 2004, p. 39.

De acordo com PEREIRA (2004, p. 39), LANCASTER (1966a, p. 140) salienta que a fronteira expande-se ou contrai-se linearmente de acordo com a variação da renda, mas continua apresentando a mesma forma para todos os consumidores, uma vez que a escolha apresenta-se de maneira objetiva.

Para a construção da fronteira de eficiência para o caso de duas características e quatro bens, LANCASTER (1966a, p. 140) define as características da seguinte forma:

$$
\begin{aligned}
& z_{1}=b_{11} y_{1}+b_{12} y_{2}+b_{13} y_{3}+b_{14} y_{4} \\
& z_{2}=b_{21} y_{1}+b_{22} y_{2}+b_{23} y_{3}+b_{24} y_{4}
\end{aligned}
$$

Para a atividade de consumo 1 , as características são obtidas pela proporção $b_{11} / b_{21}$, sendo o mesmo processo aplicável às outras atividades de consumo (PEREIRA, 2004, p. 40). Dada a restrição orçamentária $\sum_{i} p_{i} x_{i} \leq k$ e havendo mais bens do que características, o resultado para cada bem $\mathrm{x}$ pode ser expresso da seguinte forma:

$$
x_{i}=a_{i 1} y_{1}+a_{i 2} y_{2}+a_{i 3} y_{3}+a_{i 4} y_{4}, i=1,2, \ldots, n
$$


Transformando a restrição orçamentária para o espaço C, de acordo com LANCASTER (1966a, p. 141), tem-se que:

$$
\left(\sum_{i} p_{i} a_{i 1}\right) y_{1}+\left(\sum_{i} p_{i} a_{i 2}\right) y_{2}+\left(\sum_{i} p_{i} a_{i 3}\right) y_{3}+\left(\sum_{i} p_{i} a_{i 4}\right) y_{4} \leq k
$$

onde cada termo $\sum_{i} p_{i} a_{i j}$ indica o preço de cada atividade de consumo (PEREIRA, 2004, p. 40).

A partir deste ponto, LANCASTER (1996a, p. 141-142), citado por PEREIRA (2004, p. 41-42), apresenta um exemplo. Dados $q_{1}, q_{2}, q_{3}, q_{4}$ e k, o máximo nível de cada atividade de consumo (pontos $E_{1}, E_{2}, E_{3}$ e $E_{4}$ ) pode ser apresentado na figura 2.1.4 a seguir.

FIGURA 2.1.4: FRONTEIRA EFICIENTE - DOIS ATRIBUTOS E QUATRO ATIVIDADES DE CONSUMO

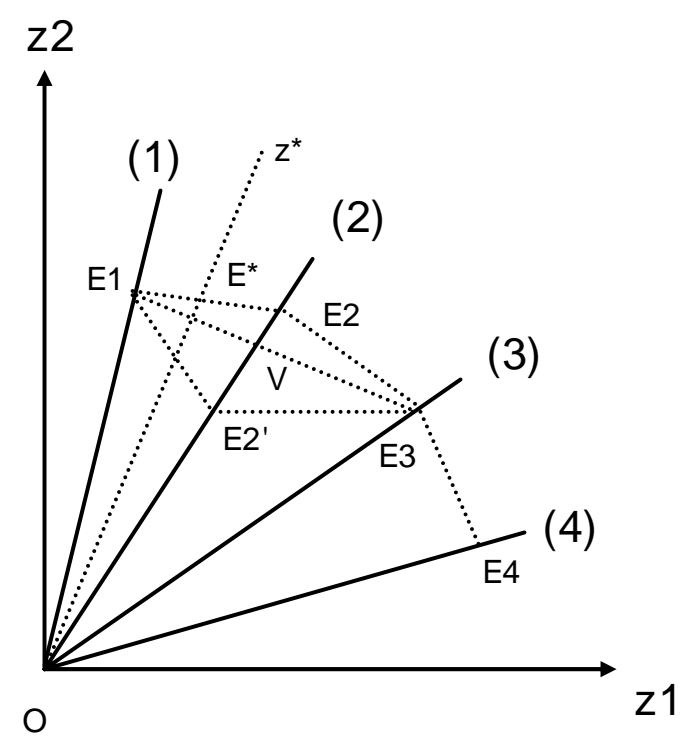

FONTE: PEREIRA, 2004, p. 41.

De acordo com a figura 2.1.4, as linhas que unem os pontos representam as combinações eficientes entre os objetos (1 e 2, 2 e 3 e 3 e 4), dada a restrição orçamentária. Supondo que o consumidor prefira uma dada 
combinação $Z^{\star}$, o ponto $E^{\star}$ estará na fronteira de eficiência e representará a combinação das características $\mathrm{z}_{1}$ e $\mathrm{z}_{2}$.

Segundo LANCASTER (1966a, p. 141-142), supondo que aconteça uma modificação nos preços relativos e a atividade de consumo do bem 2 torne-se mais cara, isto poderia significar uma mudança da fronteira de eficiência do ponto $E_{2}$ para o ponto $V$. Se esta mudança for pequena o bastante para não afetar o comportamento do consumidor, a fronteira continuará sendo $E_{2}$ e 0 consumidor não será afetado. Porém, se a alteração de preço for grande o bastante e significar uma mudança para além do ponto, indo, por exemplo, até o ponto $E_{2}$, , então a fronteira de eficiência será deslocada para $E_{1} E_{2}{ }^{\prime} E_{3} E_{4}$, com suposição de renda constante. O autor enfatiza que mudanças de preços podem gerar várias situações, uma vez que, se forem muito pequenas, talvez sejam ignoradas, porém, se forem grandes o bastante, podem até causar a mudança na atividade de consumo (PEREIRA, 2004, p. 41-42).

Portanto, LANCASTER (1966a, p. 132-157) propõe a idéia de que o consumidor não compra um bem, mas um conjunto de atributos. Os principais tópicos da abordagem de LANCASTER (1966a, p. 134) são resumidos por PEREIRA (2004, p. 34) e encontram-se a seguir.

- Um bem, por si mesmo, não oferece utilidade para um consumidor. São as características do bem que possuem utilidade.

- A princípio, um bem possui mais de uma característica. Ao apresentar várias características, é possível assumir que algumas são comuns a vários bens.

- A combinação de bens pode apresentar características diferentes daquelas pertencentes a cada bem em separado.

Assim, se houver no mercado um produto com a combinação desejada de atributos, será este o bem adquirido pelo consumidor. A questão, em termos práticos, é descobrir qual a combinação de atributos desejados pelo consumidor para um determinado bem e se há um conjunto de atributos que é comum a um conjunto de consumidores, o que permite realizar uma 
segmentação de mercado com base em atributos desejados (GRISI, 1986, p. 104).

\section{2 - Equilíbrio de Mercado 6}

Para a determinação de um equilíbrio de mercado, ROSEN (1974, p. 3455) supõe que os consumidores adquirem uma única unidade de um produto com valor particular de $z$. Logo, a função utilidade passa a ser $U\left(x, z_{1}, \ldots, z_{n}\right)$ que, por hipótese, é côncava e x representa a renda disponível para todos os outros bens consumidos. Logo, a expressão da renda é:

$$
y=x+p(z)^{7}
$$

onde $p(z)=\left(z_{1}, \ldots, z_{n}\right)$ é a função que relaciona o preço do bem adquirido a suas características. Por hipótese, $\mathrm{p}(\mathrm{z})$ é duplamente diferenciável.

A maximização da utilidade sujeita a uma restrição orçamentária não linear implica a escolha de $x$ e $\left(z_{1}, \ldots, z_{n}\right)$ satisfazendo à restrição, bem como às condições de primeira ordem:

$$
\left(\partial p / \partial z_{i}\right)=p_{i}=\left(U_{z i} / U_{x}\right), \mathrm{i}=1,2, \ldots, \mathrm{n}
$$

Para destacar a importância do contexto espacial, é definida uma função de acordo com:

$$
U\left(y-\theta, z_{1}, \ldots, z_{n}\right)=u
$$

E o valor total que o consumidor está disposto a pagar por diferentes valores de $\left(z_{1}, \ldots, z_{n}\right)$ a uma dada utilidade e renda é representado por $\theta(z ; u, y)$.

\footnotetext{
${ }^{6}$ Baseado nos trabalhos de ROSEN (1974, p. 34-55) e SARTORIS NETO (1996, p. 18-23).

${ }^{7}$ Preferiu-se manter a nomenclatura adotada por ROSEN (1974, p. 34-55), mesmo que, para isto, haja certa desobediência aos termos apresentados no item anterior, referente a LANCASTER (1966a e 1966b).
} 
Isto define um conjunto de superfícies de indiferença relacionando $z_{i}$ com unidades de $x$, e esta abordagem tem sido largamente utilizada em economia urbana. A diferencial de (19) resulta em:

$$
\theta_{z i}=\left(U_{z i} / U_{x}\right)>0
$$

Alternativamente, $\theta_{z i}$ é a taxa marginal de substituição entre $z_{i}$ e o valor a ser pago, ou o valor marginal implícito que o consumidor põe à disposição para $z_{i}$ a um dado nível de utilidade e renda. Isto indica o preço de demanda reservado pelo consumidor para uma unidade adicional de $z_{i}$, o qual decresce em $z_{i}$ à medida que maiores quantidades tornam-se disponíveis.

O montante que o consumidor está disposto a pagar por z a uma determinada utilidade e renda é $\theta(z ; u, y)$, onde $p(z)$ é o mínimo preço que ele deve pagar no mercado. Entretanto, a utilidade é maximizada quando:

$$
\begin{aligned}
& \theta\left(z^{\star} ; u^{\star}, y\right)=p\left(z^{\star}\right) \\
& \mathrm{e} \\
& \theta_{z i}\left(z^{\star} ; u^{\star}, y\right)=p_{i}\left(z^{\star}\right), \mathrm{i}=1,2, \ldots, \mathrm{n}
\end{aligned}
$$

onde $z^{*}$ e $u^{*}$ são quantidades ótimas. De outra forma, a localização ótima no plano $z$ ocorre quando as duas superfícies $p(z)$ e $\theta\left(z ; u^{\star}, y\right)$ são tangentes. A figura 2.2.1 mostra um conjunto de curvas de indiferença que é definido por $\theta\left(z_{1}, z^{*}{ }_{2}, \ldots z^{*} ; u, y\right)$. Dois diferentes compradores são mostrados na figura, representados por $\theta^{1}$ e $\theta^{2}$. 
FIGURA 2.2.1: CURVAS DE INDIFERENÇA PARA DECISÃO DE COMPRA

p, $\theta$

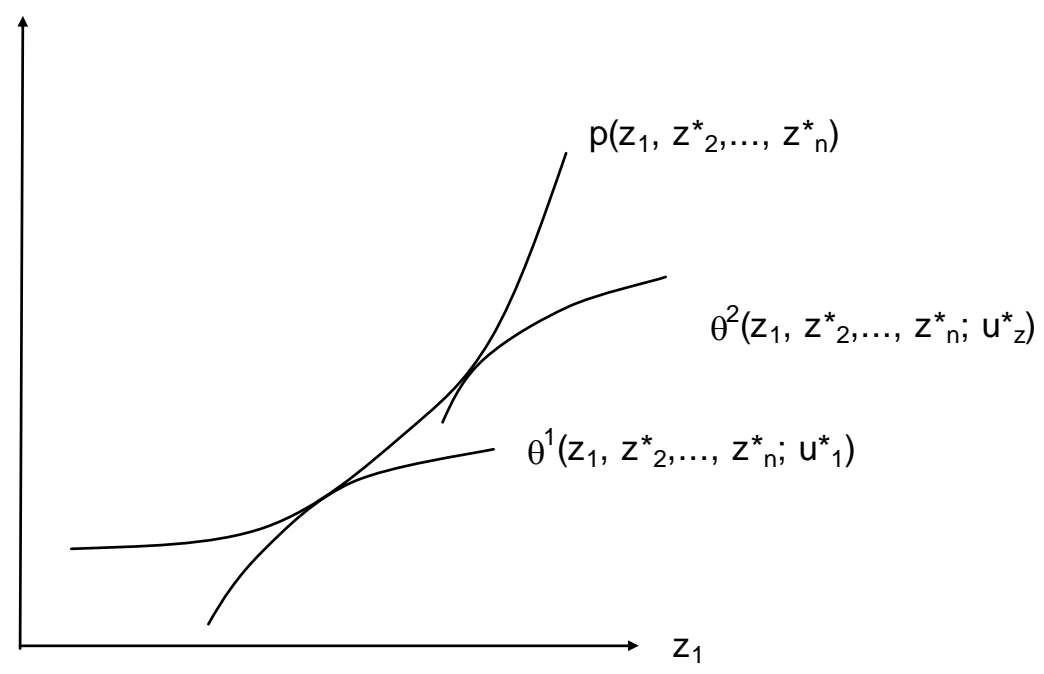

FONTE: ROSEN, 1974, p. 39.

Como afirma ROSEN (1974, p. 40), rendas adicionais sempre incrementam a utilidade máxima e, portanto, deve-se esperar que consumidores com rendas maiores adquiram maiores quantidades de características. Entretanto, em geral não há razão obrigatória para que as quantidades de todas as características devam sempre aumentar com a renda, já que alguns de seus componentes podem aumentar e outros diminuir. Portanto, o modelo tem, como consequência, uma natural segmentação de mercado, em que consumidores com disponibilidades de compra semelhantes adquirem produtos com características semelhantes. E este é o motivo principal da elaboração, no capítulo IV, da análise fatorial para a determinação da segmentação sócio-demográfica de cada localidade da Região Metropolitana de São Paulo.

Estas considerações representam um importante resultado dos modelos de equilíbrio espacial, podendo ser citado o trabalho de TIEBOUT (1956, p. 416), que analisou o mercado implícito de vizinhança, segmentando os consumidores por renda distrital e percepção de qualidade.

O modelo pode ser expandido para incluir muitas unidades com características $z$, passando a função utilidade a ser $U\left(x, z_{1}, \ldots, z_{n}, m\right)$, em que $m$ 
é o número de unidades de um bem ou de um conjunto de bens que contenha as características $z$ que são adquiridas pelo consumidor. Logo, a restrição passa a ser:

$$
y=x+m p(z)
$$

e as condições passam a ser:

$$
(\partial / \partial m)=-p(z) U_{x}+U_{m}=0
$$

e

$$
\left(\partial U / \partial_{z i}\right)=-m p_{i}(z) U_{x}+U_{z i}=0
$$

A função é ainda definida como o valor que o consumidor está disposto a pagar por z a uma dada utilidade, mas, agora, levando-se em conta o valor ótimo de $m$. De outra forma, $\theta\left(z_{1}, \ldots, z_{n}\right)$ é definido eliminando-se $m$, da seguinte forma:

$$
\begin{aligned}
& u=U\left(y-m \theta, z_{1}, \ldots, z_{n}, m\right) \\
& \left(U_{m} / U_{x}\right)=\theta
\end{aligned}
$$

Novamente, $\theta_{\mathrm{zi}}$ é proporcional a $\left(\mathrm{U}_{\mathrm{zi}} / \mathrm{U}_{\mathrm{x}}\right)$ e, portanto, a lógica da figura 2.2.1 permanece a mesma. É importante mostrar que não há qualquer consideração a respeito de monopsônio ${ }^{8}$ no modelo, já que os consumidores agem competitivamente, uma vez que, à medida que maiores quantidades são desejadas, as unidades podem ser adquiridas sem que o preço seja afetado. Logo, a função p(z) é a mesma para todos os potenciais compradores de cada segmento e independente de $\mathrm{m}$.

\footnotetext{
${ }^{8}$ Monopsônio é o mercado que possui um único comprador. Bem mais comuns do que o monopsônio puro são os mercados com apenas algumas empresas competindo entre si e atuando como compradoras.
} 
Em relação à decisão de produção, por hipótese as firmas se especializam em uma única maneira de combinação de características z, sendo cada firma uma coleção de estabelecimentos de produção que agem de forma independente. Os custos totais são definidos por $C(M, z ; \beta)$, onde $M(z)$ é o número de unidades produzidas por uma firma que oferece a especificação z, e $\beta$ reflete as variáveis subjacentes ao problema de minimização do custo, como aquelas relacionadas aos parâmetros da função de produção. Por hipótese, C apresenta-se com primeiras derivadas positivas e custo marginal crescente.

O lucro de cada estabelecimento de produção é dado por:

$$
\pi=M p(z)-C\left(M, z_{1}, \ldots, z_{n}\right)
$$

e, por meio da escolha de $\mathrm{M}$ e z ótimos, a receita unitária é dada pela função de preços implícitos para as características, $p(z)$.

Da mesma forma, cada firma encontra-se em um mercado competitivo e, portanto, não é monopolista, já que sua decisão isolada de produção não afeta o preço. Logo, $\mathrm{p}(\mathrm{z})$ independe de $\mathrm{M}$.

As condições para a escolha ótima de M e z são:

$$
p_{i}(z)=C_{z i}\left(M, z_{1}, \ldots, z_{n}\right) / M, \mathrm{i}=1,2, \ldots, \mathrm{n}
$$

e

$$
p(z)=C_{m}\left(M, z_{1}, \ldots, z_{n}\right)
$$

No ponto ótimo, a receita marginal se iguala ao custo marginal. Ou seja, as quantidades devem ser produzidas quando a receita marginal $p(z)$ se iguala ao custo marginal de produção, resultando em um "pacote" ótimo de características.

Analogamente ao tratamento oferecido à demanda, define-se uma função de oferta $\phi\left(z_{1}, \ldots, z_{n} ; \pi, \beta\right)$, indicando preços unitários que a firma está 
disposta a praticar em diferentes combinações de modelos para um nível de lucro constante, quando as quantidades para cada modelo são otimamente escolhidas. Um conjunto de superfícies de indiferença é definido por $\phi$, que é determinado eliminando-se $M$ da seguinte forma:

$$
\begin{aligned}
& \pi=M \phi-C\left(M, z_{1}, \ldots, z_{n}\right) \\
& \mathrm{e} \\
& C_{M}\left(M, z_{1}, \ldots, z_{n}\right)=\phi
\end{aligned}
$$

Como $\phi$ é o preço de oferta que o produtor está disposto a aceitar por um conjunto de características z ao nível de lucro $\pi$, enquanto $p(z)$ é o maior preço possível de se obter no mercado, o lucro é maximizado pela equivalente maximização do preço de oferta sujeito à restrição $p=\phi$. Logo, o lucro máximo e o modelo ótimo satisfazem:

$$
\begin{aligned}
& p_{i}\left(Z^{\star}\right)=\phi_{z i}\left(z^{\star}{ }_{1}, \ldots, z_{n}^{\star} ; \pi^{\star}, \beta\right), \mathrm{i}=1,2, \ldots, \mathrm{n} \\
& \mathrm{e} \\
& p\left(z^{\star}\right)=\phi\left(z^{\star}{ }_{1}, \ldots, z^{\star}{ }_{n} ; \pi^{\star}, \beta\right)
\end{aligned}
$$

O equilíbrio é caracterizado pela tangente entre a curva de indiferença de características que resultam no lucro e a superfície de preço implícito das características de mercado, mostrado na figura 2.2.2. A curva $\phi^{1}$ refere-se à produção de menores quantidades de $z_{1}$, enquanto a curva $\phi^{2}$ refere-se a uma firma com uma vantagem comparativa na produção de maiores quantidades de $\mathrm{z}_{1}$ 
FIGURA 2.2.2: CURVAS DE INDIFERENÇA PARA DECISÃO DE COMPRA

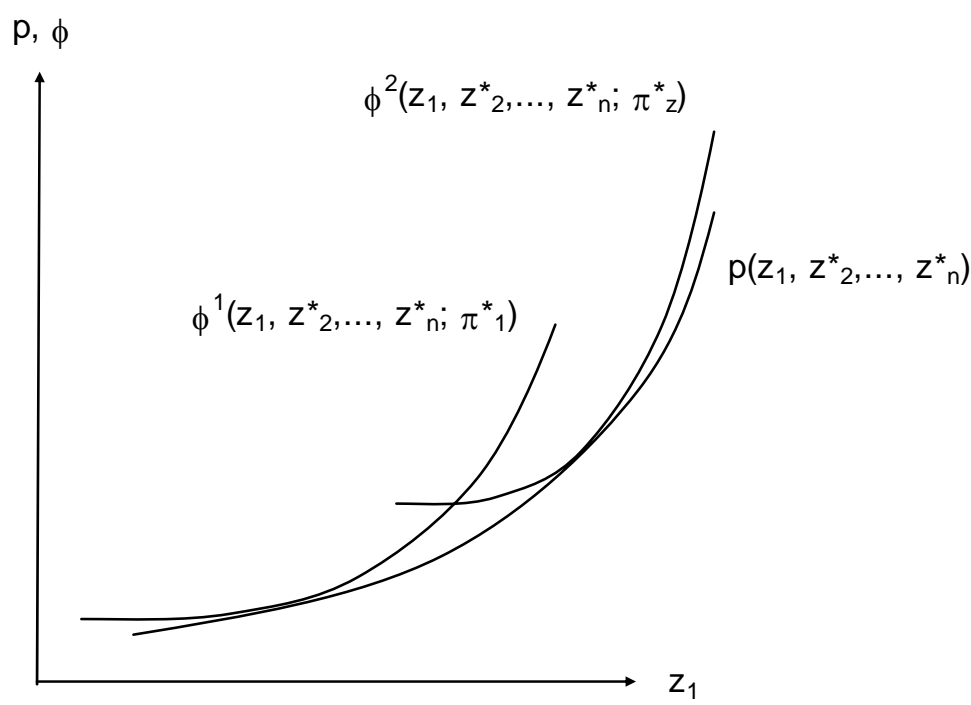

FONTE: ROSEN, 1974, p. 43.

O desenvolvimento teórico abordado até o presente momento serve de embasamento para a elaboração e aplicação dos modelos hedônicos de regressão e correlação canônica. Os conceitos relacionados a atributos e equilíbrio de mercado, sob a ótica da demanda e da produção, e o entendimento de como se comportam para a formação de preços e condições comerciais, oferecem embasamento para a aplicação de modelos hedônicos.

A quantidade demandada por produtos com características é $\mathrm{Q}^{\mathrm{D}}(\mathrm{z})$, sendo $Q^{S}(z)$ a respectiva quantidade ofertada. Pela análise efetuada anteriormente, o equilíbrio de mercado necessita de uma função $p(z)$, tal que $\mathrm{Q}^{\mathrm{D}}(\mathrm{z})=\mathrm{Q}^{\mathrm{S}}(\mathrm{z})$, para todo vetor de características $\mathrm{z}$. Mas, como se sabe, $\mathrm{Q}^{\mathrm{D}}(\mathrm{z}) \mathrm{e}$ $\mathrm{Q}^{\mathrm{S}}(\mathrm{z})$ dependem da função $\mathrm{p}(\mathrm{z})$. Deste modo, propõe-se o modelo que segue, ignorando-se os termos aleatórios:

Demanda: $\quad p_{i}(z)=F^{i}\left(z_{1}, z_{2}, \ldots, z_{n}, Y_{1}, W\right)$

$\mathrm{e}$

Oferta: $\quad p_{i}(z)=G^{i}\left(z_{1}, z_{2}, \ldots, z_{n}, Y_{2}, W\right)$ 
para $i=1,2, \ldots, n$ e onde $p_{i}$ é o preço de cada unidade, $z_{i}$ representa o vetor de variáveis intrínsecas do modelo, $Y_{1}$ é o vetor de variáveis extrínsecas que afetam exclusivamente a demanda, $Y_{2}$ é o vetor de variáveis extrínsecas que afetam exclusivamente a oferta e $\mathrm{W}$ representa $\mathrm{o}$ vetor de variáveis extrínsecas que afetam a demanda e a oferta.

No trabalho de ROSEN (1974, p. 34-55), o autor propõe um procedimento constituído de duas etapas, em que a primeira consiste em estimar $p(z)$ sem considerar $Y_{1}$ e $Y_{2}$, por meio da aplicação de uma regressão dos preços observados dos produtos diferenciados pelas características $z$. A função resultante passa então a ser $\hat{p}(z)$, permitindo-se o cálculo de um conjunto de preços marginais implícitos, que corresponde a $d \hat{p}(z) / d z_{i}=\hat{p}_{i}(z)$, para cada um dos compradores e vendedores. Na segunda etapa do método de Rosen, utilizam-se os preços marginais estimados $\hat{p}_{i}(z)$ como variáveis dependentes para a estimação das equações do modelo. Desta forma, a função $p(z)$, para este método, não pode ser linear, uma vez que, caso fosse, os valores $\hat{p}_{i}(z)$ seriam constantes para todos os valores de $\mathrm{z}_{\mathrm{i}}$, o que inviabilizaria qualquer possibilidade de utilização dos mesmos na segunda etapa. Logo, $\mathrm{p}(\mathrm{z})$, por hipótese, deve ser duplamente diferenciável (SARTORIS NETO, 1996, p. 23).

\section{3 - Revisão da Literatura}

Segundo BESANKO, DRANOVE, SHANLEY e SCHAEFER (2004, p. 417), os preços hedônicos utilizam dados do mercado provenientes de aquisições efetuadas por compradores para a determinação do valor dos atributos de um bem particular, e o termo hedônico, como discutido no item 1.6, é proveniente do termo hedonismo, já que o prazer ou a felicidade que um consumidor apresenta depende do nível de atributos que o bem adquirido possui. Por exemplo, os preços de automóveis refletem a quantidade, o tipo e a variedade de atributos presentes (nível de atributos), como, por exemplo, potência e características do interior. Pela análise de como os preços dos automóveis variam em função das diferentes combinações de atributos, pode- 
se determinar o preço de um outro automóvel que apresente estes atributos. Ainda segundo os referidos autores, os preços hedônicos têm sido utilizados para se identificar o valor das inovações em automóveis, computadores e imóveis residenciais, e requerem análises de regressão múltipla para se estimar o impacto dos atributos no preço de um bem. A variável dependente da regressão é o preço do bem e os preditores são as variáveis que medem a presença ou não de diferentes atributos. Se, por exemplo, estiver sendo estudado o mercado de automóveis, a análise de preços hedônicos pode identificar em quanto serão afetados os preços dos automóveis a partir do incremento de $1 \%$ de potência ou da inclusão de air bags. Ademais, os modelos de preços hedônicos podem representar uma ferramenta para a avaliação de tradeoffs envolvendo preço e inclusão, aprimoramento ou exclusão de atributos (nível de atributos). A análise, em última instância, pode auxiliar na determinação da inclinação da curva de indiferença proposta por BESANKO, DRANOVE, SHANLEY e SCHAEFER (2004, p. 366), que pode ser observada na figura 2.3.1 a seguir.

FIGURA 2.3.1: CURVA DE INDIFERENÇA E O TRADEOFF ENTRE PREÇO E NÍVEL DE ATRIBUTO

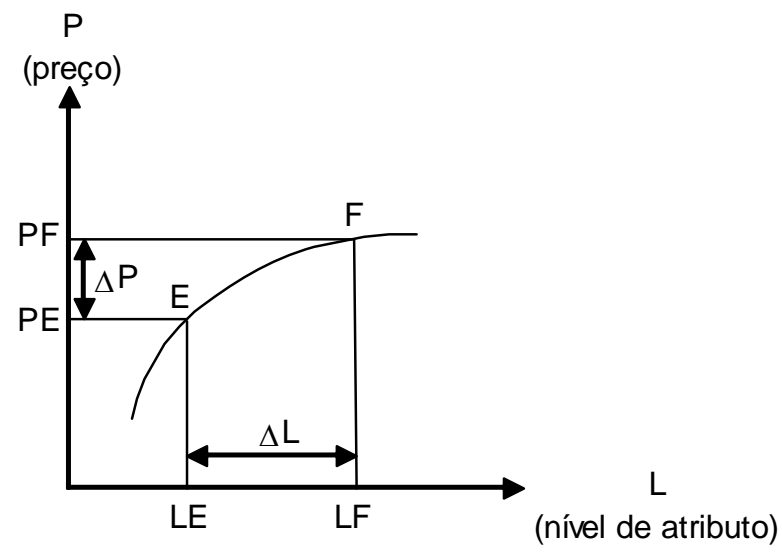

FONTE: BESANKO, DRANOVE, SHANLEY e SCHAEFER (2004, p. 366)

Faz-se necessário um comentário em relação à proposição dos autores acima citados. Segundo PINDYCK e RUBINFELD (1999, p. 74), as curvas de indiferença são convexas em relação à origem, pois à medida que maiores quantidades de um bem são consumidas, espera-se que o consumidor prefira pôr à disposição cada vez menos unidades de um segundo bem para obter 
unidades adicionais do primeiro. Assim, à medida que se percorre uma curva de indiferença e o consumo de um determinado bem aumenta, deve-se diminuir o desejo do consumidor de possuir unidades adicionais deste bem ${ }^{9}$. A curva proposta por BESANKO, DRANOVE, SHANLEY e SCHAEFER (2004, p. 366), por outro lado, relaciona o preço com o nível de atributos (quantidade de atributos) e, desta forma, pode ser considerada também uma curva de indiferença (ou curva de isosatisfação), em que o comportamento não é convexo em relação à origem, uma vez que, à medida que se percorre a referida curva e o consumo de um determinado atributo aumenta, deve-se diminuir o incremento do preço (inclinação da curva em cada nível de atributo) para a aquisição de níveis extras deste atributo.

Como pode ser analisado na figura 2.3.1, o incremento de preço ao longo de uma curva de indiferença corresponde exatamente a $\Delta \mathrm{P}$, causado pelo acréscimo $\Delta \mathrm{L}$ no nível de atributo do produto. A inclinação acentuada da curva para níveis baixos de atributo indica que há uma maior possibilidade de se aumentar o preço do bem pelo acréscimo do nível de atributo. Quando a inclinação da curva passa a ser menor, a possibilidade de aumento de preço torna-se menor para níveis extras de atributo. Salienta-se que maiores níveis de atributo estão relacionados à presença cada vez maior de quantidades, tipos diferenciados e variedade de atributos.

Uma outra abordagem é a realizada por DAHR e WERTENBROCH (2000, p. 60-71), na qual são avaliadas as condições de escolha de um determinado atributo hedônico e o processo decisório por meio do qual tal escolha foi efetuada. Segundo os autores, pode-se classificar os bens de duas maneiras, que se referem aos bens hedônicos e aos bens utilitários. Bens hedônicos, nesta perspectiva, são aqueles em que o consumo é caracterizado por experiências sensoriais de estética, prazer, fantasia, diversão ou luxo, propiciadas por meio da exposição de atributos representativos por parte de quem adquire o bem, que decide desembolsar uma quantia maior pelo mesmo. Por outro lado, os bens utilitários são aqueles em que o consumo se dá de forma funcional ou prática. Análoga a esta classificação é aquela proposta por

\footnotetext{
${ }^{9}$ No caso deste estudo, substitui-se o termo bem pelo termo atributo.
} 
BAZERMAN, TENBRUNSEL e WADE-BERZONI (1998, p. 255-241), que afirmam que as escolhas por características de bens ocorrem por preferências afetivas e por preferências racionais. Como colocam DAHR e WERTENBROCH (2000, p. 61), bens com alto valor hedônico estão sujeitos a escolhas afetivas, enquanto bens com alto valor utilitário estão sujeitos a escolhas racionais. Estas definições servem de auxílio para enquadrar muitas das características intrínsecas e extrínsecas de imóveis residenciais como sendo sujeitas a escolhas hedônicas, uma vez que uma simples presença pode, em muitos casos, tornar um determinado imóvel reconhecidamente mais caro. Assim sendo, um determinado comprador pode decidir pela aquisição de um imóvel em lançamento por conta da existência de atributos que sejam representativos do ponto de vista emotivo e do ponto de vista racional. A seguir, na figura 2.3.2, é apresentado um esquema do processo decisório por características de produtos hedônicos e utilitários.

FIGURA 2.3.2: O PROCESSO DECISÓRIO ENTRE BENS HEDÔNICOS E UTILITÁRIOS

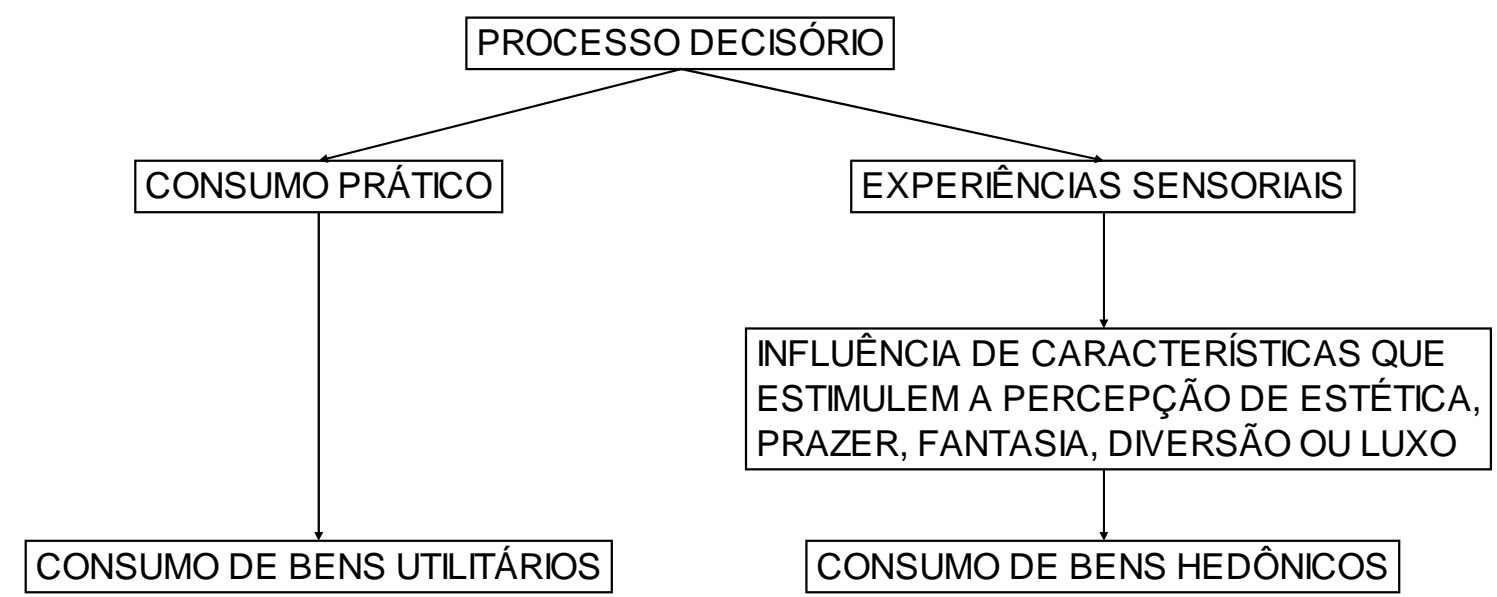

FONTE: DAHR e WERTENBROCH (2000, p. 62).

No mercado imobiliário, obviamente uma escolha não pode ser considerada puramente hedônica, uma vez que, segundo DAHR e WERTENBROCH (2000, p. 65), deve haver alguma característica utilitária que gere um motivo prático para a aquisição de um bem. E, assim, os autores 
propõem uma curva de indiferença entre características hedônicas e utilitárias de um determinado bem, ilustrada na figura 2.3.3 a seguir.

FIGURA 2.3.3: CURVA DE INDIFERENÇA ENTRE CARACTERÍSTICAS HEDÔNICAS E UTILITÁRIAS

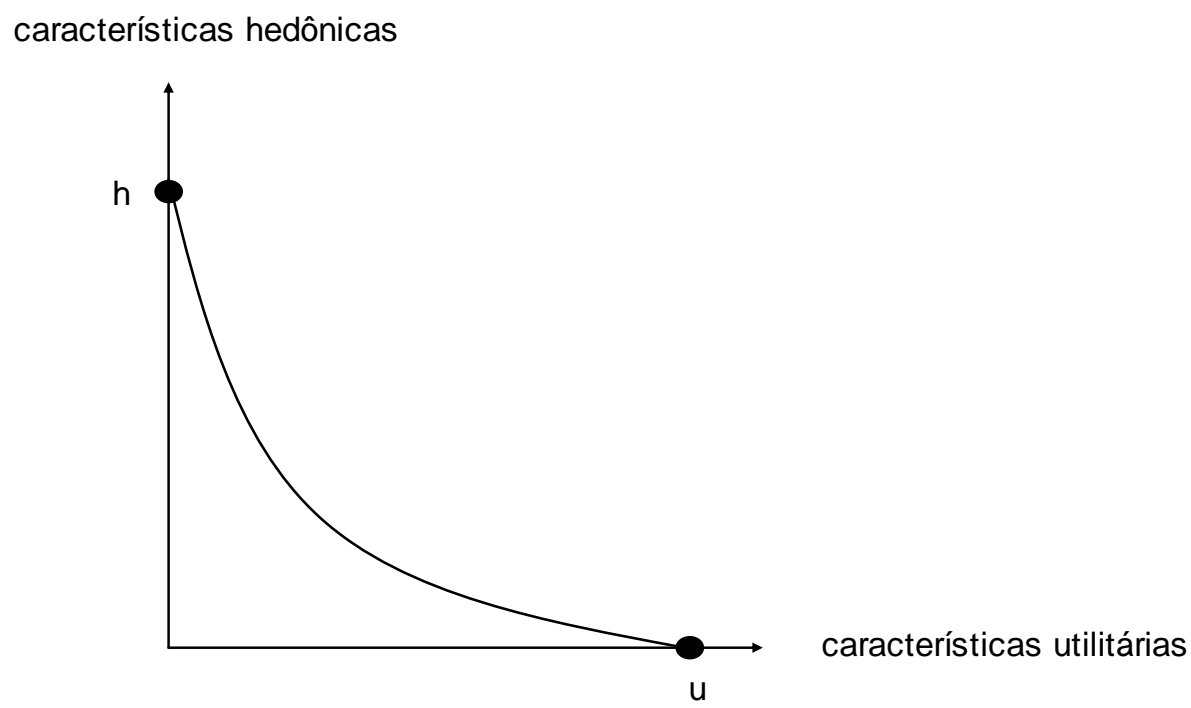

FONTE: DAHR e WERTENBROCH (2000, p. 65).

A figura 2.3.3 está de acordo com LANCASTER (1966a, p. 132-157), e representa uma curva ao longo da qual o consumidor adquire a mesma utilidade se puser à disposição, por exemplo, uma grande quantidade específica de características consideradas utilitárias para receber uma pequena quantidade de características consideradas hedônicas. Os pontos $h$ e $u$ referem-se à existência apenas de características hedônicas e utilitárias, respectivamente.

De acordo com DAHR e WERTENBROCH (2000, p. 60-71), KAUKO (2003, p. 250-270) inclusive propõe uma estrutura hierárquica de valores quando da decisão de compra de um determinado imóvel, que se encontra na figura 2.3.4 a seguir. 
FIGURA 2.3.4: ESTRUTURA HIERÁRQUICA DE VALORES QUANDO DA AQUISIÇÃO DE UM IMÓVEL RESIDENCIAL

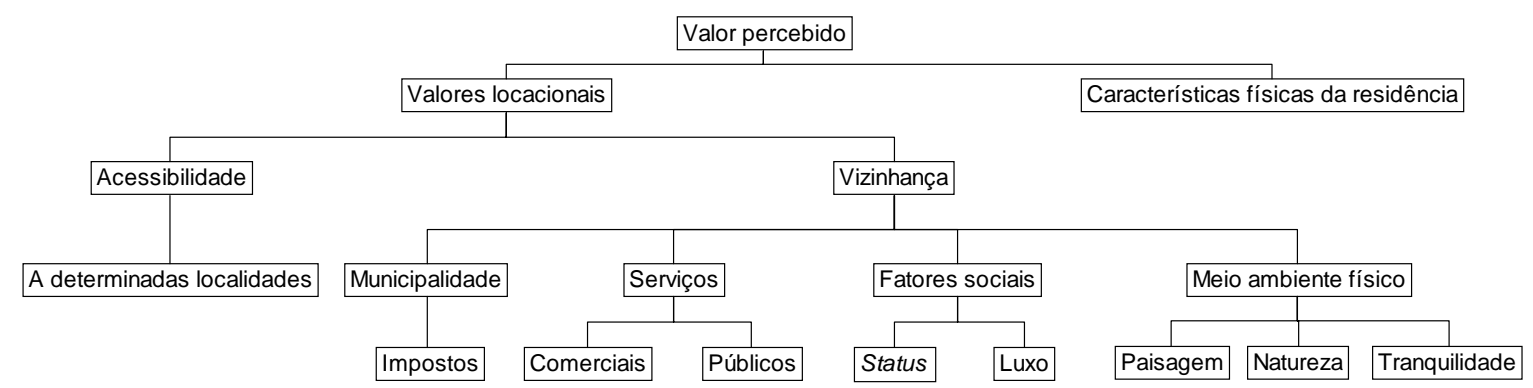

FONTE: KAUKO (2003, p. 259).

A estrutura de valores proposta por KAUKO (2003, p. 250-270) já tinha inicialmente sido proposta por HOESLI, GIACOTTO e FAVARGER (1997, p. 93-109) e apresenta pontos em comum com o modelo proposto por DAHR e WERTENBROCH (2000, p. 60-71) para escolhas sensoriais ou funcionais. Assim sendo, a escolha de um imóvel em lançamento pode ser devida a fatores relativos a status, luxo ou até mesmo tranquilidade do local, mas também pode ser feita em função de aspectos funcionais, como proximidade e acessibilidade a determinadas localidades ou características físicas da residência, e a decisão de compra pode sofrer influências de aspectos sensoriais e práticos. Este trade-off entre características hedônicas e utilitárias é também discutido, por exemplo, em TVERSKY e KAHNEMAN (1991, p. 1039-1061), porém esta abordagem não faz parte do escopo deste trabalho, uma vez que se pretende apenas avaliar a representatividade de características determinadas por especialistas e compradores que, quando forem consideradas representativas, serão classificadas como atributos hedônicos, sem que haja a preocupação com a classificação e hierarquização proposta pelos autores mencionados.

Os modelos hedônicos têm sido largamente utilizados para se avaliarem as características de mercados residenciais urbanos, já que se referem a valores implícitos destas características nas unidades residenciais. Tais modelos tipicamente utilizam as análises de regressões clássicas, nas quais os preços de vendas das unidades residenciais são regredidos em função da 
medição de seus atributos, estipulando-se 0 valor de mercado das características de um bem. A utilidade de uma unidade residencial é função de seus atributos e o preço de mercado para cada unidade residencial é conhecido. Uma função explícita, denominada função de preço hedônico, determina quais são os atributos, ou "pacote" de atributos, mais significantes da composição do preço, quando da avaliação de determinada unidade residencial (BOWEN; MIKELBANK; PRESTEGAARD, 2001, p. 467). Assim, os modelos de preços hedônicos têm sido utilizados para se estudar a demanda e a oferta, uma vez que se assume que os imóveis são vendidos como sendo um "pacote" de atributos inerentes e os respectivos preços são, portanto, determinados pela forma com que se apresentam os atributos (CHAU; NG; HUNG, 2001, p. 26). Uma equação hedônica auxilia na explicação da determinação de preços e demais condições comerciais de unidades residenciais em termos dos atributos apresentados por estas e cada unidade residencial oferece a sua própria "cesta" de atributos.

Alguns procedimentos recentes de pesquisa têm recomendado que se observem as características espaciais quando das aplicações residenciais de preços hedônicos. O entendimento a respeito destas considerações deve-se aos conceitos de heterogeneidade espacial e dependência espacial.

A heterogeneidade espacial refere-se, em termos de modelos hedônicos residenciais, à variação sistemática nas condições comerciais de venda que dependem da localização na região de estudo. Se a média e a variância das condições apresentarem-se constantes na região de estudo, dizse que são estacionárias. Se, entretanto, tenderem a variar em função da localização (a média, variância ou covariância diferem de localização para localização), diz-se que são espacialmente heterogêneas. A dependência espacial, por outro lado, refere-se à interdependência entre as observações em um mesmo espaço geográfico. Isto é, a condição comercial de uma determinada residência em uma localização deve ser similar à condição de outra situada próxima. Portanto, problemas de dependência espacial surgem quando existe uma tendência para o aparecimento de desvios em relação a valores médios, para residências situadas numa mesma vizinhança. A inclusão 
destes efeitos no modelo deve sempre ser tomada a fim de se efetuar uma representação real de cada sub-mercado que se analisa. Na realidade, modelos espaciais em mercados imobiliários apresentam-se como uma mescla entre a heterogeneidade espacial e a dependência espacial (BOWEN; MIKELBANK; PRESTEGAARD, 2001, p. 469). Estas considerações também foram elaboradas anteriormente por ABRAHAM, GOETZMANN e WACHTER (1994, p. 186-206).

A utilização de modelos hedônicos na determinação de valores das propriedades é bem documentada. Muitos autores efetuaram estudos sobre a utilização da abordagem de preços hedônicos, mas o primeiro a colocar o problema dentro de um contexto de mercado foi ROSEN (1974, p. 34-55), apresentando as equações de oferta e demanda em que os preços são funções das características. Segundo o autor, preços hedônicos são definidos como sendo os preços implícitos dos atributos e são revelados a partir de preços observados de produtos diferenciados e das respectivas características associadas a eles ${ }^{10}$. Econometricamente, preços implícitos são estimados a partir da análise de regressão, por meio da qual os preços dos produtos são regredidos em função das características (ANGELO; FÁVERO, 2003a). Estes modelos sugerem métodos que podem identificar índices de interesse para cada uma das características abordadas. Segundo ROSEN (1974, p. 34-55), a utilização de um método geral contextualizando o problema da diferenciação de produtos em termos de poucas características fundamentais, em vez de um grande número delas, leva a uma análise muito mais próxima da realidade, no que diz respeito ao equilíbrio espacial ${ }^{11}$. Uma contribuição anterior para o problema de avaliação da mudança de aspectos qualitativos para a definição do consumo de produtos diferenciados foi feita por HOUTHAKKER (1952, p. 155-164), cujos conceitos foram aprofundados por LANCASTER (1966a, p.

\footnotetext{
${ }^{10}$ Segundo MACKENZIE (1986, p. 174-195), a importância do atributo é fortemente influenciada pela atenção dirigida à característica específica de um produto.

11 Isto de fato se aplica no caso do mercado imobiliário. A inclusão de muitas características como variáveis independentes do modelo impossibilita o equilíbrio espacial para cada grupo sócio-demográfico.
} 
132-157) por meio da elaboração de considerações mais explícitas sobre a curva de utilidade composta por características.

Anteriormente a ROSEN, GRILICHES (1971, p. 3-15) afirma que os preços hedônicos referem-se à construção de índices de preços baseada em modelos econométricos, em que o preço de um determinado bem é explicado pelas características pertencentes ao mesmo e, portanto, o que representa utilidade ao consumidor não é o bem em si, mas sim os respectivos atributos. De uma forma análoga, a existência de uma explicação razoável das variações de preços de bens diferenciados por conta da inclusão ou exclusão de atributos é uma maneira de elaborar um modelo de preços hedônicos.

Nos modelos de preços hedônicos, as componentes do vetor de características $^{12}$ são objetivamente medidas, uma vez que a percepção dos consumidores sobre um montante de características é a mesma, embora avaliações subjetivas possam ocorrer em função de "pacotes" alternativos. É assumido nos modelos, segundo ROSEN (1974, p. 35), que um número suficientemente grande de produtos diferenciados estão disponíveis ${ }^{13}$ e, portanto, a escolha entre várias combinações do vetor de características é a mesma, isto é, existe um "espectro de produtos" dentro do qual as escolhas são efetuadas.

A construção de modelos hedônicos na determinação de valores de determinados bens diferenciados tem sido utilizada na avaliação de automóveis, computadores, vinhos, tarifas de energia elétrica, imóveis comerciais e residências (KRAVIS; LIPSEY, 1969, p. 233-246). Em um contexto histórico, o trabalho de WAUGH (1928, p. 185-196) foi o pioneiro neste tipo de análise, ao avaliar as variações de preços de vegetais no mercado de Boston em função de algumas características. Por outro lado, muitos autores dedicam o pioneirismo desta área de estudo a COURT (1939, p. 99-117), que analisa a indústria automobilística nos Estados Unidos, sendo o primeiro a utilizar o termo hedônico.

\footnotetext{
${ }^{12}$ Segundo LANCASTER (1966a, p.133) e ROSEN (1974, p. 35), o vetor z.

${ }^{13}$ De acordo com o que ocorre no mercado imobiliário, objeto deste trabalho.
} 
De forma teórica, LANCASTER (1966a, p. 132-157) propõe uma abordagem alternativa da Teoria do Consumidor, na qual os argumentos da função utilidade passam a ser as características dos bens, em vez dos bens em si. Nesta abordagem, o consumidor dispõe-se a pagar o preço do respectivo bem, a fim de adquiri-lo, visando à utilidade proveniente das características presentes naquele bem.

A estruturação dos conceitos relacionados à decisão de escolha de um bem e à utilidade por ele propiciada foi estruturada de maneira teórica, como já discutido, na abordagem da Teoria do Consumidor, proposta por LANCASTER (1966a e 1966b), em que a escolha por um determinado bem se dá não pelo bem em si, mas pelo "pacote" de características associadas a ele, e a função utilidade tem como argumentos estas próprias características, assumindo-se, portanto, que o consumo é uma atividade em que o bem ou uma combinação de bens são obtidos com o objetivo de se adquirir um conjunto de características presentes naquele bem ou no conjunto de bens (SARTORIS NETO, 1996, p. 10). Assim sendo, LANCASTER (1966a e 1966b) não substitui a Teoria do Consumidor tradicional, mas propõe uma ampliação, à medida que estrutura teoricamente estes conceitos, levando em consideração a presença das características dos bens, prática inclusive já efetuada anteriormente a LANCASTER (1966a e 1966b), como, por exemplo, por COURT (1939) e por GRILICHES (1961).

A partir de COURT (1939), GRILICHES (1961) e LANCASTER (1966a e 1966b), muitos outros autores efetuaram estudos sobre a utilização de modelos hedônicos, o que originou, basicamente, duas formas de abordagem. A primeira delas trata de modelos que aplicam uma única equação hedônica, seja de oferta ou demanda, para avaliação dos preços de determinados bens pelas características associadas a eles. Neste caso, podem-se citar os trabalhos pioneiros de MUELLBAUER (1974, p. 977-994), com a visão da demanda, e de OHTA (1975, p. 1-26), com a visão da oferta. Por outro lado, a segunda linha de trabalhos, originada em ROSEN (1974), tem por objetivo principal a definição de equações de oferta e demanda, com o intuito de ser possível a determinação do equilíbrio de mercado. Derivam desta linha os trabalhos de 
ANDERSON, PALMA e THISSE (1989, p. 21-35) sobre a oferta e a demanda por produtos diferenciados, de FEENSTRA (1995, p. 634-653) sobre a utilização de índices de preços hedônicos, e de BERRY, LEVINSOHN e PAKES (1995, p. 841-890) sobre os preços de automóveis em mercados em equilíbrio. O presente trabalho utiliza principalmente a segunda abordagem e, a seguir, são apresentados os principais estudos para cada uma das linhas mencionadas, bem como as respectivas contribuições.

Primeiramente, COURT (1939, p. 99-117), a fim de determinar uma equação hedônica que pudesse explicar o comportamento dos preços dos automóveis em função das características, propõe um procedimento simples, de equação única, permitindo a visualização do quanto cada característica influencia no preço final do veículo e tornando possível a criação de índices. Este método, também adotado por GRILICHES (1961, p. 137-196), define uma equação hedônica e corresponde ao primeiro estágio do procedimento proposto por ROSEN (1974, p. 34-55).

Em 1961, GRILICHES utiliza um contexto prático para efetuar uma comparação entre os preços de diferentes automóveis, por meio da aplicação das várias características existentes. Segundo AGUIRRE e MACEDO (1996, p. 1-16), GRILICHES, em sua compilação de diversos estudos sobre modelos hedônicos, elaborada em 1971, menciona muitos trabalhos, como os de HOFSTEN (1952), ADELMAN e GRILICHES (1961, p. 535-548), ALLEN (1963, p. 281-297), NICHOLSON (1967, p. 512-530) e GAVETT (1967, p. 16-20) sobre os índices de mudança qualitativa, de DEAN e DEPODWIN (1961, p. 271-279) sobre a aplicação de preços hedônicos em alguns aparatos elétricos, de MACK (1955, p. 5), FISHER, GRILICHES e KAYSEN (1962, p. 433-451), GRILICHES (1964, p. 301-404), CAGAN (1965, p. 217-236), TRIPLETT (1969, p. 408-417) e NAIK e TSAI (2001, p. 821-832) sobre os preços dos automóveis, de DHRYMES (1967, p. 501-518) sobre refrigeradores, de BAILEY, MUTH e NOURSE (1963, p. 933-942), BROWN (1964), MUSGRAVE (1969, p.771-786) e YOSHIHARA, FURUYA e SUZUKI (1970) sobre preços e índices relativos ao mercado imobiliário, e de KRAVIS e LIPSEY (1969, p. 233-246) sobre motores a diesel. 
GRILICHES (1971, p. 4) explica que a abordagem hedônica na construção de modelos leva em conta múltiplas variedades de diversas mercadorias que podem ser sintetizadas por um número relativamente pequeno de atributos. E esta caracterização ocorre também no trabalho de CHOW (1967, p.1117-1130) sobre o crescimento da demanda por serviços de computadores mainframe nos Estados Unidos no período compreendido entre os anos de 1955 e 1965.

Muitas outras áreas têm sido estudadas sob a ótica da modelagem hedônica, além do já mencionado segmento automobilístico, fazendo sentido uma menção especial para as relacionadas a computadores e vinhos, dada a considerável produção acadêmica e técnica. Em relação a esta última, merecem destaque os trabalhos de GOLAN e SHALIT (1993, p. 311-321) sobre a qualidade das uvas dos vinhos de Israel, de NERLOVE (1995, p. 1697-1716) sobre o monopólio governamental do mercado sueco, de COMBRIS, LECOCQ e VISSER (1997, p. 390-402) sobre os vinhos Bordeaux, de LANDON e SMITH (1998, p. 628-647) sobre a escolha das características empregadas em estudos relacionados a vinhos, de UNWIN (1999, p. 95-104) sobre formas de especificação de funções hedônicas para avaliação de vinhos, de CHARTERS, LOCKSHIN e UNWIN (1999, p. 183-195) sobre características em rótulos de garrafas, de ANGULO, GIL, GRACIA e SÁNCHEZ (2000, p. 481-493) sobre os preços dos vinhos tintos espanhóis, de COMBRIS, LECOCQ e VISSER (2000, p. 961-967) sobre os vinhos Burgundy, de OCZLOWSKI (2001, p. 374-382) sobre as características sensoriais, químicas, objetivas e climáticas que têm sido aplicadas em modelos hedônicos de vinhos, de SCHAMEL e ANDERSON (2003, p. 357-369) sobre a classificação de vinhos na Austrália e na Nova Zelândia, e de STEINER (2004, p. 287-307) sobre os vinhos australianos presentes no mercado varejista inglês.

Em relação ao segmento de computadores, segundo FOUTO (2004), pode-se citar o trabalho pioneiro de CHOW (1967, p. 1117-1130) e o trabalho sequencial de BERNDT, GRILICHES e RAPPAPORT (1995, p. 243-268), além dos trabalhos de GORDON (1990), SINCLAIR e CATRON (1990, p. 16-24), NELSON, TANGUAY e PATTERSON (1994, p. 23-31), IZQUIERDO e MATEA 
(2001) e PAKES (2002), que tratam apenas dos preços de computadores pessoais. Além dos estudos mencionados, podem ser citados também os trabalhos de OLINER (1990) sobre os computadores de grande porte, de RAO e LYNCH (1993, p. 95) sobre as estações de trabalho, de GANDAL (1995, p. 599-608) sobre a qualidade dos softwares, de LERNER (1995, p. 585-597) sobre os discos rígidos, de LUZIO e GREESTEIN (1995, p. 622-633) sobre a avaliação da indústria brasileira de microcomputadores, de STAVINS (1995, p. 571-584) sobre determinadas medidas de localização espacial no mercado dos computadores pessoais, de GOOLSBEE (2001) sobre as características extrínsecas e intrínsecas utilizadas em regressões para analisar a competitividade na venda de computadores no varejo de lojas físicas e virtuais, de KONIJN, MOCH e DALEN (2003) sobre os preços de computadores praticados em países como França, Alemanha, e Inglaterra, e de BASU, MAZUMDAR e RAJ (2003, p. 209-221) sobre os preços hedônicos em aparelhos de som e de discos compactos.

No mercado imobiliário, ainda de acordo com o procedimento de COURT e GRILICHES, pode-se afirmar que cada imóvel está inserido em um contexto de mercado e apresenta um preço associado ao vetor de características. Portanto, os produtos revelam implicitamente uma equação de preço em função de características $p(z)=p\left(z_{1}, \ldots, z_{n}\right)$, e a relação fornece $o$ preço mínimo para qualquer "pacote" de características presentes nos imóveis (GRILICHES, 1971, p. 15). O trabalho de $\operatorname{KING~(1976,~p.~1077-1087),~}$ considerado uma referência para a aplicação da linha de COURT, GRILICHES e LANCASTER e um dos poucos a se basear unicamente nesta abordagem, é o primeiro a utilizar o termo lancastriano e, do ponto de vista empírico, seu método não foi significativamente diferente daquele utilizado por COURT e GRILICHES (SARTORIS NETO, 1996, p. 34). Segundo KING (1976, p. 10771087), que utiliza modelos de preços hedônicos em Connecticut entre os anos de 1967 e 1970, uma equação apropriada para se determinar a forma geral dos preços de venda de imóveis obedece ao que segue: 


$$
P=\sum_{i=1}^{m} \alpha_{i} S C_{i}+\sum_{j=1}^{n} \beta_{i} L C_{j}+\gamma L
$$

onde $\mathrm{SC}_{\mathrm{i}}$ representa a i-ésima componente de características (número de imóveis, quantidade de insolação, entre outras) e $\alpha_{i}$ o respectivo preço unitário; $L C_{j}$ representa a j-ésima componente de localização (qualidade da vizinhança, proximidade de determinados locais, entre outras) e $\beta_{\mathrm{j}}$ o respectivo preço unitário; L é a quantidade de área adquirida e $\gamma$ o preço unitário por metro quadrado. O trabalho sofreu uma importante crítica efetuada por EREKSON e WITTE (1979, p. 640-648) que apresentaram, em seu estudo, importantes observações a respeito de eventuais falhas de especificação que podem surgir no segundo estágio de ROSEN, resultando em vieses quando da elaboração das regressões e, segundo os autores, que não foram consideradas nos modelos de KING. Este, por outro lado, justifica, em um outro artigo posterior ${ }^{14}$, que os vieses mencionados por EREKSON e WITTE (1979, p. 640-648) não se aplicam nos modelos utilizados, já que a cesta de características coletada foi proveniente de imóveis de diversos mercados ${ }^{15} \mathrm{e}$, consequentemente, são eliminadas quaisquer possibilidades de existência de correlação entre os preços dos imóveis e os termos dos erros em uma particular transação comercial.

Ainda de acordo com a abordagem de COURT, GRILICHES e LANCASTER, podem ser citados os trabalhos de ATKINSON e CROCKER (1971, p. 171-180), de HARRISON e RUBINFELD (1978, p. 81-102), de BENDER, GRONBERG e HWANG (1980, p. 638-643), de BRUCATO, MURDOCH e THAYER (1990, p. 265-279) e SMITH e HUANG (1995, p. 209227) sobre a poluição e a qualidade atmosférica, de BERRY (1976, p. 397-423) sobre a expansão dos guetos urbanos, de BALL e KIRWAN (1977, p. 11-32)

\footnotetext{
${ }^{14}$ Em KING (1979, p. 649-650).

${ }^{15}$ A utilização de mercados segmentados elimina uma eventual correlação existente entre os resíduos e os preços de venda dos imóveis. Esta consideração é utilizada neste trabalho e será mais bem detalhada posteriormente.
} 
sobre as condições de acesso a determinadas residências, de FREEMAN (1979, p. 191-217), LI e BROWN (1980, p. 125-141) e CAN (1990, p. 254-272) sobre as características geográficas e de vizinhança, de LINNEMAN (1980, p. 47-68) sobre a localização específica em que se encontram as residências, de BUTLER (1980, p. 439-453) e BACKLEY e FOLLAIN (1985, p. 179-205) sobre a construção de índices de preços residenciais, de FOLLAIN e MALPEZZI (1981, p. 381-398) sobre os aspectos relativos às localidades centrais e suburbanas, de HALL, BRESTON e TAYLOR (1982, p. 523-541) sobre a presença de ruídos rodoviários, de GOODMAN e KAWAI (1982, p. 214-237) sobre a influência de renda nas equações hedônicas de demanda, de BUTLER (1982, p.96-108) sobre o problema do viés de especificação em funções hedônicas, de FOLLAIN e JIMENEZ (1985b, p. 421-432) sobre a demanda por características habitacionais de cinco cidades em três países em desenvolvimento, de BAJIC (1985, p. 58-75) sobre a abordagem de características específicas no mercado imobiliário, de MALPEZZI e MAYO (1987, p. 687-721) sobre a aplicação de equações de demanda por residências em dezesseis cidades de oito países em desenvolvimento, de ANDERSON e CORDELL (1988, p. 153-164) sobre a influência de áreas verdes em locais residenciais, de MEGBOLUGBE (1989, p. 486-494) sobre as características do mercado imobiliário de Jos na Nigéria, de $\operatorname{KOHLHASE~(1991,~p.~1-26)~sobre~os~}$ impactos de lixo tóxico sobre as residências, de ARYEETEY-ATTOH (1992, p. 183-198) sobre as condições residenciais em função das faixas de renda para o Município do Rio de Janeiro, de CAN (1993, p. 453-474) sobre os preços de unidades residenciais que dependem das unidades adjacentes ${ }^{16}$, de FIGUEROA (1993, p. 779-805) sobre a influência de programas sociais para a valorização do mercado imobiliário na América Latina, de DIPASQUALE e WHEATON (1996) sobre a relação entre a economia urbana e o mercado imobiliário, de IRWIN e BOCKSTAEL (1998) sobre a evolução do uso da terra, de BRASINGTON (1999, p. 395-413) e de FIGLIO e LUCAS (2004, p. 591-604) sobre o impacto da qualidade do ensino de determinadas escolas para a valorização das residências que se situam nos mesmos bairros, de HAUGHEY

\footnotetext{
${ }^{16}$ Fenômeno conhecido como transbordamento, ou spillover effect.
} 
e BASOLO (2000, p. 283-289) sobre a proximidade de centros históricos, de CLARK e HERRIN (2000, p. 385-407) sobre a proximidade de escolas públicas, de UYENO, HAMILTON e BIGGS (1993, p. 3-18), de COLLINS e EVANS (1994, p. 175-197), de LEVESQUE (1994, p. 199-210), de ESPEY e LOPEZ (2000, p. 408-419) e de WILHELMSSON (2000, p. 799-815) sobre as influências de ruídos de diversas naturezas em diversas localidades, de SIMONS, GEIDEMAN e MIKELBANK (2001, p. 410-418) sobre a proximidade de oleodutos, de HOLMES e SLADE (2001, p. 567-588) sobre a construção de índices hedônicos no mercado de apartamentos da Região Metropolitana de Phoenix, de CHAU, MA e HO (2001, p.31-40) sobre a valorização de unidades imobiliárias situadas em pavimentos específicos em Hong Kong, de BIBLE e HSIEH (2001, p. 140-145) sobre segurança patrimonial, de LEISHMAN (2001, p. 131-152) sobre a segmentação no mercado imobiliário de Glasgow na Escócia, de HITE, CHERN, HITZHUSEN e RANDALL (2001, p. 185-194) sobre os impactos ambientais em localidades próximas a residências, e de STRAND e VAGNES (2001, p. 137-156) e de SIMONS e JAOUHARI (2004, p. 223-233) sobre o impacto da proximidade de rodovias e ferrovias em localidades residenciais.

Muitos outros trabalhos com aplicações de modelos hedônicos em edifícios de escritórios também podem ser citados, como os de CLAPP (1980, p. 387-399) sobre os imóveis comerciais em Los Angeles, de HOUGH e KRATZ (1983, p. 40-55) sobre as aparências arquitetônicas de prédios comerciais, de BRENNAN, CANNADAY e COLWELL (1984, p. 295-305) sobre os prédios de escritórios em Chicago, de GLASCOCK, JAHANIAN e SIRMANS (1990, p. 105-119) sobre a estabilidade dos preços de aluguéis comerciais, de CAVALLUZZO (1991, p. 508-512) sobre a demanda por benefícios nos locais de trabalho, de WHEATON e TORTO (1994, p. 121-139) sobre os índices de aluguéis comerciais de cinquenta Regiões Metropolitanas dos Estados Unidos, e de SILVER e HERAVI (2004, p. 24-49) sobre os modelos hedônicos aplicados no mercado imobiliário comercial com a utilização de variáveis dummy. 
O método proposto por ROSEN (1974, p. 34-55), por outro lado, objetiva a definição de equações de oferta e demanda, a fim de que possa ser definido o equilíbrio de mercado. Desta forma, são propostas duas equações, representando a demanda e a oferta, como discutido no item 2.2, e o referido trabalho consiste em dois estágios. O primeiro refere-se à estimação de $\mathrm{p}(\mathrm{z})$ sem a consideração de $Y_{1}$ e $Y_{2}$, ou seja, elabora-se a regressão dos preços observados dos produtos diferenciados pelas características z. O segundo estágio de Rosen refere-se a uma aplicação de métodos de equações simultâneas, em que cada uma delas terá a sua identificação em função da composição dos vetores $Y_{1}$ e $Y_{2}$ (SARTORIS NETO, 1996, p. 23).

Seguindo o método de Rosen para a determinação de equações de oferta e demanda, citam-se muitos autores que apresentaram contribuições significativas para o desenvolvimento de modelos hedônicos, sendo um dos pioneiros NELSON (1978, p. 357-369), que procura avaliar a demanda por qualidade do ar e a preocupação com a poluição, testando as especificações linear, exponencial e semilogarítmica para a análise de diversas variáveis independentes do vetor $z$, como índice de criminalidade, área do terreno e, principalmente, quantidade de particulado, medido em $\mu \mathrm{g} /\left(\mathrm{cm}^{3}\right.$.dia).

Em WITTE, SUMKA e EREKSON (1979, p. 1151-1173), há a utilização de diversas variáveis relacionadas a características de residências, como área construída e qualidade da construção. Para o primeiro estágio de WITTE, SUMKA e EREKSON, foi utilizada a seguinte especificação:

$$
R=\alpha+\sum_{i=1}^{5} \beta_{i} X_{i}+\sum_{i=1}^{5} \sum_{j=1}^{5} \delta_{i j} X_{i} X_{j}+\sum_{i=1}^{2} \gamma_{i} D_{i}+U_{i}
$$

onde $\mathrm{R}$ é $\mathrm{o}$ valor anual do aluguel, $\mathrm{X}_{1}$ a $\mathrm{X}_{5}$ referem-se a variáveis relativas à construção e à vizinhança (qualidade da habitação, área construída, dimensão do terreno, qualidade da vizinhança e acessibilidades), as variáveis $D_{1}$ e $D_{2}$ são dummies relativas à presença de aquecimento e mobília e $U$ é o termo aleatório. 
É necessário destacar que o método proposto por ROSEN (1974, p. 3455) sofreu várias críticas de diversos autores que se propuseram a estudar as formas de precificação hedônica. Uma versão modificada do método de ROSEN é a utilizada por PALMQUIST (1984, p. 394-404) que utiliza uma coleta de dados proveniente de diversas localidades para evitar problemas de identificação e endogeneidade ${ }^{17}$, que não foram considerados nos trabalhos de ROSEN (1974, p. 34-55), de NELSON (1978, p. 357-369) e de WITTE, SUMKA e EREKSON (1979, p. 1151-1173). No referido trabalho, PALMQUIST utilizou dados provenientes de diversos sub-mercados para eliminar o problema de identificação e, além disto, considerou a endogeneidade dos preços marginais resultantes de equações hedônicas não lineares para a estimação das equações de oferta e demanda. Segundo PARSONS (1986, p. 348), PALMQUIST modificou o primeiro estágio de ROSEN, uma vez que separou o método de coleta em sub-mercados, considerando-os segmentados, o que de fato resultou na eliminação do problema de endogeneidade. Segundo EPPLE (1987, p. 59-80), PALMQUIST estimou as equações de preços hedônicos pelo método dos mínimos quadrados ordinários, uma vez que utilizou variáveis instrumentais exógenas em cada uma das equações de demanda e oferta, como renda e características sócio-econômicas de cada sub-mercado, para a resolução dos problemas de identificação e endogeneidade.

Um outra crítica ao método de ROSEN é feita anteriormente por BROWN e ROSEN (1982, p. 765-768), que argumentam que o segundo estágio proposto por ROSEN (1974, p. 34-55) não é adequado, uma vez que não acrescenta nenhuma informação às já existentes quando da elaboração do primeiro estágio. De fato, a derivada em relação a $z_{i}^{18}$ utilizada por WITTE, SUMKA e EREKSON (1979, p. 1151-1173), que representa os preços marginais, tem uma relação exata com as características dadas pelo vetor $\mathrm{z}$ (SARTORIS NETO, 1996, p. 42), e pode ser representada por:

\footnotetext{
${ }^{17}$ Os problemas de identificação e endogeneidade serão abordados de maneira pormenorizada no item 4.9 deste trabalho.

${ }^{18}$ Substituiu-se a nomenclatura $X_{\mathrm{i}}$, utilizada por WITTE, SUMKA e EREKSON (1979, p. 1151-1173), por $\mathrm{z}_{\mathrm{i}}$, utilizada por ROSEN (1974, p. 34-55).
} 


$$
\frac{\partial p}{\partial z_{i}}=\delta_{i}+\sum_{i=1}^{n} \delta_{i j} z_{j}+2 . \delta_{i j} z_{i}
$$

Segundo BROWN e ROSEN (1982, p. 765-768), a coleta de variáveis provenientes de segmentos diferentes e mutuamente excludentes faz com que o preço de cada imóvel passe a ser dependente não somente das características do vetor $z$, mas também de outras características associadas às peculiaridades de cada segmento, o que elimina eventuais problemas de identificação, já que outras variáveis passam a fazer parte das equações de demanda e de oferta. Por outro lado, se não houver variação suficiente das características locais entre os segmentos, torna-se impossível a estimação das equações de demanda e oferta separadamente, já que passa a ser considerável a existência dos problemas de identificação. Ainda segundo os autores, esta dificuldade acabou não prejudicando a qualidade dos resultados obtidos por WITTE, SUMKA e EREKSON (1979, p. 1151-1173) que consideraram, para análise, quatro diferentes cidades e, embora não citassem o fato em seu trabalho, a consideração de sub-mercados diferentes acabou não gerando problemas de identificação quando da aplicação do segundo estágio. A utilização de sub-mercados será considerada nesta tese e será mais bem examinada no item 4.3. A importância desta consideração já havia sido exposta por PALM (1978, p. 210-221), em um trabalho sobre preços de residências em San Francisco, levando-se em conta aspectos relacionados à composição étnica e de jurisdição entre cada sub-mercado definido. Os trabalhos de MENDELSOHN (1985, p. 525-529), PARSONS (1986, p. 347-363) e KAHN e LANG (1988, p. 157-166) também abordam a importância da consideração de amostras de sub-mercados diferentes para a definição de equações de oferta e demanda em modelos de preços hedônicos.

BARTIK (1987b, p. 81-88) também critica o procedimento de ROSEN, já que afirma que o problema de estimação hedônica não se deve à interação entre oferta e demanda, mas à existência de endogeneidade presente nas 
variáveis consideradas nos modelos. O autor apresenta as equações do modelo da seguinte forma:

$$
\begin{aligned}
& \text { Demanda: } \frac{\partial p}{\partial z_{j}}=B_{0}+B_{1} z_{i}+B_{2} X_{i}+B_{3} D_{0 i}+e_{i j} \\
& \text { e } \\
& \text { Oferta: } \frac{\partial p}{\partial z_{j}}=A_{0}+A_{1} z_{i}+A_{2} S_{0 i}+u_{i j}
\end{aligned}
$$

onde $X$ representa o vetor que contém quaisquer características que não estejam presentes em $z, D_{0}$ é o vetor de características do consumidor que afeta os preços implícitos e $\mathrm{S}_{0}$ é o vetor de características do produtor e, portanto, uma decisão de um determinado consumidor não pode, segundo BARTIK (1987b, p. 81-88), afetar os produtores no modelo hedônico. O autor afirma, ainda, que o cuidado que deve ser tomado para se verificar a existência de problemas de endogeneidade pode evitar resultados viesados, e esta consideração não foi feita em ROSEN (1974, p. 34-55) e FREEMAN (1979, p. 191-217). Em um outro estudo, BARTIK (1987a, p. 178-180) aponta que muitos autores, entre eles MENDELSOHN (1984, p. 673-677), propuseram a inclusão de variáveis exógenas para a eliminação dos problemas de endogeneidade, fazendo-se necessária a coleta de dados provenientes de mais de um submercado.

ANAS e EUM (1984, p. 87-106) também questionam ROSEN (1974, p. 34-55), uma vez que afirmam que as decisões de oferta e demanda não estão sujeitas apenas a características atuais, mas também a questões associadas à evolução das taxas de juros, aos movimentos do mercado e aos fenômenos políticos temporais.

O modelo de ROSEN, portanto, assume algumas limitações, que se referem ao pressuposto de que haja um equilíbrio em todo o mercado e 
nenhuma inter-relação entre o preço de cada uma das variáveis explicativas que correspondem aos atributos (EKELAND; HECKMAN; NESHEIM, 2002, p. 304-309). Assim sendo, o preço implícito para um atributo adicional passa a ser igual para todas as áreas e tipos de propriedades e, apesar das limitações, a técnica tem sido amplamente utilizada nas análises do mercado imobiliário.

No que se refere à especificação do primeiro estágio, BITROS e PANAS (1988, p.167-186) utilizam o procedimento de transformação de BOX e COX (1964, p. 211-243) ${ }^{19}$, que busca a melhor especificação possível para p(z). Tal especificação também foi utilizada em MENDELSOHN (1984, p. 673-677).

Muitos autores discutem a respeito da melhor especificação da função hedônica a ser utilizada, bem como sobre os coeficientes dos atributos resultantes dos modelos. Entretanto, FOLLAIN e JIMENEZ (1985a, p. 77-107) afirmam que a decisão de escolha de uma determinada especificação pode gerar viés, e a melhor alternativa, segundo os autores, para se garantir um método mais robusto, é a utilização do procedimento de ROSEN em dois estágios.

Ainda com relação ao método de dois estágios proposto por ROSEN, pode-se citar o trabalho de BAJARI e BENKARD (2001), que estima equações hedônicas de oferta e demanda por meio da consideração de muitas características que não são observadas.

Desta forma, o presente trabalho basear-se-á nos modelos de dois estágios propostos por ROSEN (1974, p. 34-55), porém com as considerações sobre a utilização de sub-mercados segmentados e sobre os cuidados relativos aos problemas de identificação e endogeneidade de variáveis, propostas por muitos dos autores mencionados, como BROWN e ROSEN (1982, p. 765-768), PALMQUIST (1984, p. 394-404), MENDELSOHN (1984, p. 673-677), MENDELSOHN (1985, p. 525-529), PARSONS (1986, p. 347-363), BARTIK (1987a, p. 178-180) e BARTIK (1987b, p. 81-88).

De maneira geral, muitos estudos internacionais sobre modelagem hedônica estão documentados em SHEPPARD (1999). No Brasil, alguns trabalhos publicados também trazem contribuições a este campo de pesquisa,

\footnotetext{
${ }^{19}$ Tal procedimento será discutido no capítulo IV e será utilizado neste trabalho.
} 
como os de DANTAS e CORDEIRO (1988, p. 27-46) sobre alguns novos métodos de avaliação de imóveis, de BARBOSA e BIDURIN (1991, p. 105-120) sobre a seleção de modelos de regressão no mercado imobiliário, de GONZÁLEZ e FORMOSO (1994, p. 59-72) sobre os modelos hedônicos para a locação residencial em Porto Alegre, de AGUIRRE e MACEDO (1996, p. 1-16) sobre o mercado imobiliário residencial de Belo Horizonte, de AGUIRRE e FARIA (1997, p. 391-411) sobre a utilização de preços hedônicos para a avaliação social de projetos, de ANGELO e FÁVERO (2003a) sobre o mercado imobiliário residencial de São Paulo, de MORAIS e CRUZ (2003) sobre a demanda por residências e serviços urbanos no Brasil, de FÁVERO e ANGELO (2003) sobre os lançamentos de apartamentos e as estratégias de projetos em São Paulo, de ANGELO e FÁVERO (2003b) sobre os preços hedônicos de automóveis no Brasil, de ANGELO, FÁVERO e LUPPE (2004, p. 97-110) sobre o mercado imobiliário comercial de São Paulo, de PEREIRA (2004) sobre os consumidores de restaurantes em São Paulo, e de ANGELO e FÁVERO (2004) e ANGELO, FÁVERO e FOUTO (2005) sobre a remuneração e a gestão de carreiras de executivos do varejo brasileiro.

A seguir, na figura 2.3.5 é possível observar os principais trabalhos realizados em cada segmento de mercado, bem como aqueles que mais influenciaram o presente estudo, que se encontram em negrito e com asterisco. Assim, permite-se também analisar as principais linhas de estudo propostas por muitos dos autores citados anteriormente, bem como aquelas que mais se aproximam dos propósitos deste trabalho, definindo, de maneira histórica, suas influências. 
FIGURA 2.3.5: LINHAS DE ESTUDO PARA MODELOS HEDÔNICOS, COM ENFOQUE PARA OS SEGMENTOS DE APLICAÇÃO

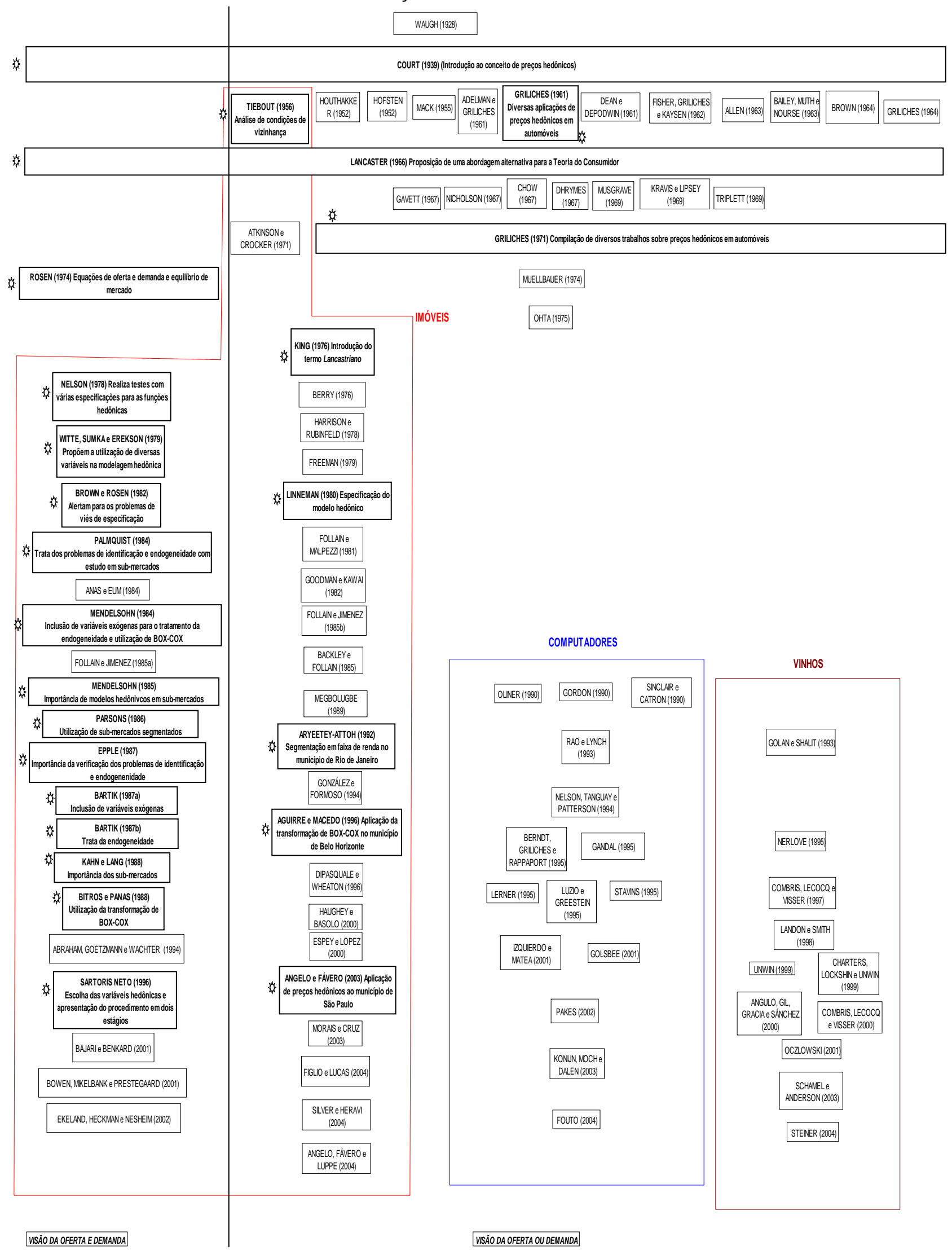




\section{CAPÍTULO III}

\section{A REGIÃO METROPOLITANA E O MUNICÍPIO DE SÃO PAULO}

\section{1 - Definições ${ }^{20}$}

A nova economia global e a sociedade informacional emergente têm uma nova forma espacial que se desenvolve em vários contextos geográficos e sociais, e é denominada Megacidade ${ }^{21}$. Segundo CASTELLS (1999, p. 492494), Megacidades são aglomerações enormes de seres humanos, com mais de dez milhões de pessoas no ano de 1992 e com projeção de ultrapassar os vinte milhões de habitantes em 2010. Por outro lado, seu tamanho não é sua qualidade definidora. São os nós da economia global, que são representados pelas funções superiores direcionais, produtivas e administrativas, pelo controle da mídia, pela política do poder e pela capacidade simbólica de criar e difundir mensagens. Segundo a Organização das Nações Unidas, as Megacidades são, em sua maioria, estranhas à matriz cultural européia / norte-americana e são representadas por Tóquio, São Paulo, Nova York, Cidade do México, Xangai, Bombaim, Los Angeles, Buenos Aires, Seul, Pequim, Rio de Janeiro, Calcutá e Osaka. Elas também funcionam como ímãs para o país inteiro ou para a área regional onde estão localizadas.

As Megacidades não podem ser vistas apenas em termos de tamanho, mas como uma função de seu poder gravitacional em direção às principais regiões do mundo. Elas articulam a economia global, ligam redes informacionais e concentram o poder mundial. Mas, por outro lado, são depositárias de todos os segmentos da população que lutam para sobreviver, bem como daqueles grupos que querem mostrar sua situação de abandono, para que não morram ignorados em áreas negligenciadas pelas redes de comunicação.

\footnotetext{
${ }^{20}$ Baseado no trabalho de MEYER, GROSTEIN e BIDERMAN (2004).

${ }^{21}$ O conceito de Megacidades foi popularizado por vários especialistas em urbanização que atuam no cenário internacional, segundo CASTELLS (1999, p. 520).
} 
A seguir, no gráfico 3.1.1, são apresentadas as Megacidades mundiais, bem como as respectivas populações em 1970 e 1992 e as projeções para 2010.

GRÁFICO 3.1.1: AS MAIORES AGLOMERAÇÕES URBANAS DO MUNDO, SEGUNDO A ONU

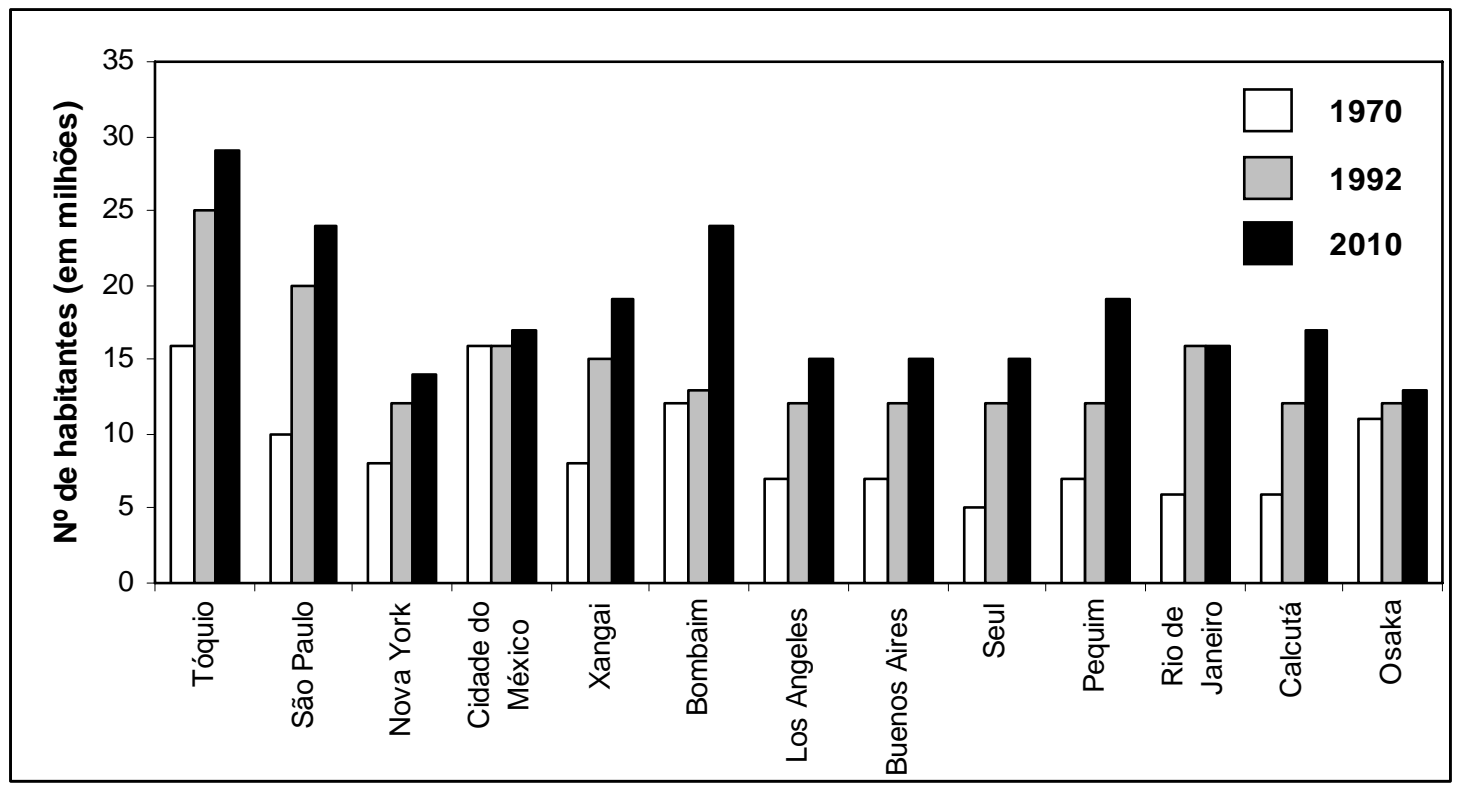

FONTE: CASTELLS, 1999, p. 494.

Como este trabalho especificamente não trata da Megacidade de São Paulo, que envolve até Municípios como Campinas e São José dos Campos, mas sim da Metrópole, faz-se necessária uma revisão das definições que envolvem este termo. Uma das definições de Metrópole, segundo MEYER, GROSTEIN e BIDERMAN (2004, p. 19), sustenta que, do ponto de vista estritamente funcional, é uma congregação de unidades administrativas autônomas que apresentam problemas urbanos comuns. E, de acordo com esta concepção, seu desenvolvimento está associado às diversas formas de organização urbana, em que o traço principal é a economia de escala ${ }^{22}$. A Metrópole é uma condição, e não um resultado, da industrialização e do desenvolvimento econômico, tornando-se uma forma de estruturação urbana

\footnotetext{
${ }^{22}$ Segundo BESANKO, DRANOVE, SHANLEY e SCHAEFER (2004, p. 73), um processo de produção de um bem específico ou um determinado serviço apresenta economia de escala quando uma produção maior faz com que o custo médio seja reduzido. Logo, o custo marginal deve ser menor do que o custo médio.
} 
que o desenvolvimento econômico contemporâneo tende a produzir em todo o mundo.

Historicamente a Metrópole moderna esteve associada a processos de industrialização e urbanização aceleradas. O espaço físico resultante da associação destes dois processos identificou-se, por sua vez, com três características básicas, relacionadas à congregação de populações muito grandes, à multifuncionalidade e à existência de economias diferenciadas tanto no âmbito nacional quanto no internacional. Assim sendo, o processo de metropolização é descrito como sendo o aprofundamento destas características. A materialização de novos padrões de modernização oferece atualmente uma nova face para a Metrópole. O território e o espaço onde está em andamento a transição de um modo de produção essencialmente mecânico para um modo de produção predominantemente tecnológico vêm sendo designados como Metrópole contemporânea. Na Metrópole moderna, o crescimento ilimitado produziu um organismo expandido, extenso, multifacetado e setorizado, no qual o traçado viário buscava reforçar a estrutura e fazer face à dispersão. Já na Metrópole contemporânea, a forma e a continuidade do tecido urbano deixam de ser metas para se tornarem condicionantes.

Analisada dentro destes parâmetros, a Metrópole deve possuir um conjunto de atributos que assegurem vantagens locacionais baseadas no seu bom funcionamento como máquina operacional e máquina social. Neste sentido, para que uma Metrópole atinja sua plena capacidade de atração, passa a ser importante o seu potencial de fornecer infra-estrutura urbana adequada e com qualidade, a fim de que possa ser possível demonstrar competência para enfrentar seus conflitos sociais. A Metrópole representa a expressão de um processo de articulação do território urbano, sendo esta a principal característica que a distingue das demais formas de organização territorial.

A Metrópole também pode ser descrita como o resultado de um processo de expansão física acompanhado de crescimento demográfico, de desenvolvimento econômico e de instalação de lógicas sociais específicas. No 
contexto dos países em desenvolvimento, a organização metropolitana apresenta peculiaridades quando comparada a outros processos de metropolização que ocorrem em países desenvolvidos. O traço mais marcante, a ser discutido no item 3.2, a seguir, concretiza-se nas características físicas e materiais do processo de expansão urbana e se traduz na formação das periferias metropolitanas.

No Brasil, o termo Região Metropolitana inclui apenas dez regiões, definidas pela classificação da Pesquisa Nacional de Amostragem de Domicílios, realizada pelo INSTITUTO BRASILEIRO DE GEOGRAFIA E ESTATíSTICA (2004): Belém, Belo Horizonte, Brasília, Curitiba, Fortaleza, Porto Alegre, Recife, Rio de Janeiro, Salvador e São Paulo.

\section{2 - Evolução Histórica e Processo de Formação da Região Metropolitana e do Município de São Paulo ${ }^{23}$}

Até o final do século XVIII, quase 250 anos após a sua fundação, o Município de São Paulo ainda se restringia ao seu sítio original (v. Anexos Figura 01). A área do núcleo urbano mais edificado não ultrapassava 40 hectares e era envolvida por um cinturão de chácaras e sítios habitados pelos senhores mais ricos, que se mantiveram ali até o século XIX, constituindo-se em reserva de expansão urbana.

Entre 1872 e 1875, sob o governo de João Teodoro Xavier, iniciaram-se as obras de remodelamento da cidade. $O$ acesso às Freguesias do Brás, Santa Efigênia e Luz foi melhorado e o Jardim Público e o Largo 7 de Abril (atual Praça da República) foram reformados com arborização das principais ruas, execução de benfeitorias de iluminação a gás das vias públicas e pavimentação com paralelepípedos em diversas vias do triângulo central.

Nessa época, a preocupação com a expansão urbana residia apenas em questões estéticas e de higiene. Em 1886, o Código de Posturas se constituía na primeira legislação urbanística da cidade, sem, entretanto, configurar diretrizes gerais de uso e ocupação do solo. Estabelecia largura mínima das

\footnotetext{
${ }^{23}$ Baseado nos trabalhos de SPOSATI (2002) e de MEYER, GROSTEIN e BIDERMAN (2004).
} 
vias de circulação, localização de algumas atividades como teatros, hospitais, indústrias e seus horários de funcionamento (v. Anexos - Figura 02).

No período compreendido entre 1889 e 1911, Antônio da Silva Prado, prefeito do Município de São Paulo, realizou inúmeras intervenções, tais como arborização de ruas e avenidas, remodelação do Jardim da Luz, abertura da Avenida Angélica e construção do Mercado Municipal e do Teatro Municipal, visando ao embelezamento da cidade.

Obedecendo à tendência de expansão urbana rumo aos terrenos mais altos, aos poucos atingia-se o espigão central, na época denominado Altos do Caagaçu. $\mathrm{Na}$ área, instalava-se o loteamento Chácara Bela Cintra, de propriedade de Joaquim Eugênio de Lima, sendo aberta a Avenida Paulista, em 1891. Um ano depois foi inaugurado o Parque Villon (atual Siqueira Campos ou Trianon), projeto do paisagista francês Paul Villon, inserido no loteamento e preservando parte da mata existente na época.

A estruturação metropolitana de São Paulo é o resultado de um processo histórico que envolveu a ocupação urbana e a topografia do planalto paulista. Na análise de MORSE (1970, p. 42), um conjunto de cinco grandes artérias de convergência determinaram o território metropolitano e definiram seu papel de ponto de entroncamento e articulação regional. As análises da evolução urbana de São Paulo atestam que sua expansão foi sempre determinada por estes eixos de comunicação, que correspondem ao perfil de expansão metropolitana. Para nordeste, a rota migrava para o Rio de Janeiro, ao longo do Rio Paraíba. Para o norte, seguia para Minas Gerais, passando por Atibaia e Bragança. Para noroeste, via Jundiaí, para Campinas. Para oestenoroeste, para Itu e Porto Feliz. E, por fim, para oeste, seguia para Sorocaba. Esta estrutura centrífuga (v. Anexos - Figuras 03 e 04) encontrou no Município de São Paulo, ao longo de todo século $X X$, um núcleo em que atuavam forças urbanas centrípetas. A relação entre estas duas forças permitiu que se estabelecesse uma interpretação da estruturação metropolitana em sua fase atual, uma vez que, já no início do século XX, o Município de São Paulo havia se constituído na forma de um núcleo urbano relativamente estruturado com arredores articulados. Segundo MEYER, GROSTEIN e BIDERMAN (2004, p. 
35), o Município de São Paulo é uma das cidades que melhor ilustram, no seu processo de desenvolvimento urbano, uma clara tendência das cidades e Metrópoles latino-americanas de crescerem de forma centrípeta, incorporando territórios e concentrando funções. Tais observações oferecem um ponto de partida para a compreensão de sua estruturação metropolitana, já que, no final do século XIX, a articulação do núcleo central da cidade com seu entorno imediato ocorreu pela conjugação de um sistema de novos loteamentos residenciais sustentado pelos bondes, que eram, naquele momento, o principal sistema de transporte urbano.

Em relação às localidades intramunicipais, as antigas regiões centrais, conservando o mesmo traçado estreito e sinuoso definido pelos jesuítas, passavam a interligar-se com a "cidade nova" - região além Anhangabaú - por meio dos trilhos de bonde da Light The São Paulo Tramway, Light \& Power, com a conclusão do Viaduto do Chá, em 1892. Criava-se um sistema de transporte coletivo, que passava a atender o centro e os bairros, tornando-se fator de indução na ocupação da Penha, Santana, Ipiranga, Pinheiros e Lapa, sendo implantados 188,7 km de linhas, no período de 1901 a 1912.

A análise da estruturação metropolitana, por meio deste sistema de transporte coletivo intramunicipal e dos grandes eixos de comunicação, é decisiva e justifica a afirmação de que São Paulo nasceu metropolitana. E a inauguração da São Paulo Railway, que ligava o Porto de Santos a Jundiaí, a partir de 1867, funcionou como elemento de consolidação do processo. A instalação desse primeiro corredor de exportação que ligava o Porto de Santos às regiões cafeeiras marcou o fim de um processo de disputa entre vários grupos econômicos e políticos, gerando uma fase de estabelecimento de uma rede ferroviária que conformaria a Metrópole.

Polarizado pelo Município de São Paulo, o sistema ferroviário organizou as forças centrífugas da expansão metropolitana e, simultaneamente, reforçou a hegemonia da capital enquanto pólo centralizador. O sistema era composto por cinco principais ferrovias, que eram denominadas de São Paulo Railway, Companhia Paulista, Estrada de Ferro Sorocabana, Companhia Mogiana e Estrada de Ferro Central do Brasil. O sistema foi montado em poucas décadas 
e favoreceu a urbanização dos bairros centrais da capital, enquanto expandia o território metropolitano. Com uma infra-estrutura de caráter principalmente econômico, o sistema ferroviário implantado na segunda metade do século XIX estava voltado, sobretudo, para o transporte de carga. Com o tempo, entretanto, começava também a ganhar características de serviço público, à medida que se tornou o mais importante meio de transporte de passageiros para os Municípios do entorno e mesmo para os distritos mais afastados da cidade.

Em 1912, com a iniciativa privada se propondo a desenvolver novos subúrbios, tinha início o projeto do loteamento do Jardim América, constituindose no primeiro empreendimento da América do Sul nos padrões das cidades repletas de jardins da Inglaterra. A influência da City de San Paulo Improvements and Free Hold Land Co. Ltd. é notória nos projetos de loteamentos residenciais, que levaram à transformação da malha urbana e no encaminhamento de sugestões para algumas alterações dos dispositivos legais, especialmente os relativos às diretrizes de loteamentos residenciais. Em 1921, instalava-se o Jardim Europa, em continuidade à ocupação da encosta sudoeste do espigão, em direção ao rio Pinheiros.

Nas áreas mais periféricas da cidade, como Brás, Belenzinho, Mooca, Canindé, Pari, faixa do Ipiranga e Vila Prudente, concentravam-se as populações mais pobres, constituídas de imigrantes e operários sem acesso a muitos serviços públicos e em péssimas condições de moradia. A população do Município, na época, atingia a marca de 700 mil habitantes, sendo mais de um terço formado por imigrantes estrangeiros (RODRIGUEZ, 1998, p. 10-20).

Em 1925 foi criada a Comissão para a elaboração do Plano Geral do Conjunto, que abrangia planos parciais de extensão, melhoramento e embelezamento do Município de São Paulo, com a participação de Prestes Maia e Ulhôa Cintra. Esta foi a origem do "Plano de Avenidas" de Prestes Maia, apresentado em 1930, que consolidava os trabalhos mais importantes da comissão e delineava uma reestruturação de toda a cidade (ZMITROWICZ, 1996, p. 28-35). O Plano, além de dar as primeiras diretrizes gerais de zoneamento da cidade, contemplava propostas para os aspectos viários, a 
localização de edifícios públicos e áreas verdes e a correção do índice de área verde por habitante, que na época era de $0,71 \mathrm{~m}^{2}$ / hab., com a proposição da implantação de grandes parques, como Cabeceiras do Ipiranga, Ibirapuera, Cantareira (reserva natural), Alto da Serra (reserva florestal), além de parques médios como Butantã e Aclimação, entre outros. Em 1929, a Lei Municipal 3.427, que se refere ao Código de Obras Arthur Saboya, demonstrou a intenção de se controlar a estética, higiene e segurança das edificações.

A concentração do desenvolvimento econômico-industrial de São Paulo praticamente determinou seu ritmo de crescimento populacional, que decorreu, basicamente, da migração interna. No período de 1940/1950 a população do Município de São Paulo crescia a uma taxa de 5,2\% ao ano, sendo a migração responsável por cerca de $73 \%$ deste crescimento. São Paulo contava em 1940 com 4.876 indústrias, que respondiam por $54 \%$ do Valor da Produção Industrial do Estado e, para atender ao processo de desenvolvimento, iniciava-se uma expansão rumo aos terrenos da periferia, com características naturais desfavoráveis à ocupação, tais como solos frágeis e suscetíveis à erosão e relevos mais inclinados. Concomitantemente, incrementava-se o processo de verticalização da região central. Já ao longo das primeiras décadas valeu a regra geral segundo a qual as características econômicas que regiam o processo de expansão da cidade se evidenciaram nas áreas periféricas, criando o território característico identificado como padrão periférico. Sua principal marca foi, no momento de sua expansão na década de 1950, a constituição da periferia, na qual a segregação residencial apresentou um papel decisivo, e este traço do processo de metropolização ganhou maior intensidade entre 1940 e 1960, correspondendo à instalação da indústria de base e do consumo de massa. FURTADO (1965) desenvolve uma teoria para explicar a concentração demográfica nas cidades brasileiras nesse período, com ênfase para São Paulo. De acordo com sua interpretação, ela foi precedentemente constituída de uma população que se transferia do campo para a cidade, ficando para um momento posterior o estabelecimento de uma massa de trabalhadores industriais (MEYER; GROSTEIN; BIDERMAN, 2004, p. 36). 
A consolidação do parque industrial paulista na década de 1950, atrelado ao Plano de Metas de Juscelino Kubitscheck, concentrou investimentos significativos no espaço físico do que viria a constituir a Grande São Paulo. A dinâmica territorial da Metrópole alterou-se significativamente pela conjugação da instalação de indústrias relacionadas com o setor automobilístico na região do $A B C$ Paulista, gerando uma mudança na escala de demanda habitacional para o assentamento de expressivos contingentes de trabalhadores atraídos pela oferta de empregos na Metrópole.

A descrição do processo histórico de estruturação do Município de São Paulo e da Metrópole está relacionada à compreensão do desenvolvimento dos três elementos articulados que os constituíram: a dispersão do padrão periférico; o deslocamento da função residencial para áreas desprovidas de atributos urbanos básicos; e a desarticulação do sistema de transporte público e dos fluxos responsáveis pela mobilidade intramunicipal e intrametropolitana. O primeiro, com características sócio-espaciais, aponta para uma dispersão da precariedade na malha urbana. O segundo, de caráter funcional, indica 0 deslocamento da função residencial para áreas de urbanização recente, contribuindo para um uso inadequado de infra-estruturas de saúde, habitação e transporte. Este último acaba por se relacionar com o terceiro elemento do processo histórico de estruturação já mencionado anteriormente e, em muitos casos, é responsável pela criação das denominadas novas centralidades do mercado imobiliário.

A partir dos anos 40, o território metropolitano, já parcialmente estruturado pelo feixe de vias e pelo sistema ferroviário, foi submetido a um novo elemento constituído por um sistema rodoviário de abrangência territorial. Esta transformação começou a ocorrer a partir do final dos anos 20, na gestão de Pires do Rio no Governo do Estado, quando se estabeleceram as premissas para a instalação de uma nova organização viária.

Pode-se, portanto, segundo MEYER, GROSTEIN e BIDERMAN (2004), determinar três fases de estruturação municipal e metropolitana, que correspondem ao articulado feixe de caminhos que rompeu o território com a aproximação dos distritos e núcleos urbanos, ao sistema ferroviário que criou 
as condições mecânicas de transporte coletivo intramunicipal e de produção agrícola metropolitano e intermunicipal, e à instalação da rede rodoviária. Observando de forma comparativa o conjunto das três fases, percebe-se que há uma distinção entre a primeira e as duas últimas, uma vez que, embora cada uma delas possa ser examinada de forma isolada, as fases ferroviária e rodoviária correspondem a uma conjuntura econômica e política semelhante e contínua, enquanto a primeira fase esteve mais associada a um intercâmbio de tipo colonial, pré-capitalista. O surto ferroviário iniciado na década de 1860 e o ciclo rodoviário implantado a partir dos anos 40 apresentam traços comuns e apontam para uma nova lógica econômica e produtiva (v. Anexos - Figuras 05 a 07).

Em 1956, a Prefeitura de São Paulo assinou um termo de contrato com a Sociedade de Pesquisas de Economia e Urbanismo, coordenada pelo Padre Louis Joseph Lebret, tendo por objetivo a realização de uma análise da estrutura fundamental da aglomeração paulistana, compreendendo, em particular, pesquisas sobre a expansão urbana e suas tendências, a população e seu crescimento, os equipamentos públicos e de vida coletiva, a estrutura e a vida social da aglomeração paulistana. O termo aglomeração paulistana foi adotado, a partir de 1957, para descrever a Metrópole, e já era, simultaneamente, a expressão do dinamismo, do avanço demográfico, da dimensão alcançada pela ocupação urbana e da relação que se estabelecia entre os diferentes Municípios. A Metrópole compreendia o Município de São Paulo e os Municípios adjacentes, como Osasco, Guarulhos, São Caetano do Sul, São Bernardo do Campo e Taboão da Serra. Entretanto, a Metrópole somente foi institucionalizada em 1967, inicialmente por iniciativa do Governo do Estado de São Paulo e em seguida pelo Governo Federal que criou, em 1973/75, as Regiões Metropolitanas Nacionais, entre elas a de São Paulo ${ }^{24}$.

Desta forma, os anos que se passaram entre o desenho municipal e metropolitano da aglomeração paulistana e o instituído por meio da criação da

\footnotetext{
${ }^{24}$ Decreto Estadual n. 47.863/67 e Lei Complementar Federal n. 14 de 8 de junho de 1973, que institui a Região Metropolitana de São Paulo, e a Lei n. 27 de 3 de novembro de 1975, que estipulou os serviços de interesse comum.
} 
Região Metropolitana de São Paulo revelam, por um lado, mudanças de escala, com a importante ampliação do território metropolitano e o grande crescimento populacional e, por outro, a ampliação das relações de complementaridade entre Municípios. Apesar do ritmo de expansão da área urbanizada não ser uniforme e nem tampouco unidirecional, a expansão radioconcêntrica do Município de São Paulo se reproduz em escala regional. Em determinados casos, consolidam-se vetores de expansão urbana que acompanham o dinamismo econômico dos Municípios industriais e, em outros, reforça-se e define-se o destino de Municípios que adquirem a função de dormitórios, ocupados pela população de baixa renda. Sob o impacto imposto pela nova dimensão, pelo ritmo adquirido pelo processo de urbanização e pela incapacidade de assimilação das novas populações migrantes, emergiu e consolidou-se, entre os anos 40 e 60, uma mancha urbana desarticulada e pouco densa.

O conjunto de Municípios que compõe a Metrópole tem alguma acessibilidade garantida ao núcleo, sendo que a qualidade do acesso é determinante pelo papel que desempenham no conjunto metropolitano. 0 sistema ferroviário, obsoleto e abandonado pelo poder público, permanece como elo entre o Município de São Paulo e as periferias pobres e distantes. No momento em que o poder público, no decorrer dos anos 70, comprou grandes áreas rurais no extremo leste do Município de São Paulo e em outros Municípios a oeste e ao norte da Região Metropolitana, para a produção pública de habitação social, os loteamentos populares irregulares e clandestinos eram uma realidade, assim como a precariedade presente nestas áreas.

Entre 1965 e 1974, a área urbanizada no Município de São Paulo cresceu $35,9 \%$ ao ano e $16,3 \%$ na região do ABC Paulista. Nas demais direções, a área urbanizada estendeu-se de forma descontínua e com menor intensidade, sendo, por exemplo, $14,0 \%$ ao ano para o extremo leste, no caminho de Mogi das Cruzes e Suzano, e 6,0\% ao ano para oeste, em direção a Carapicuíba, Cajamar, Barueri, Itapevi e Jandira (MARCONDES, 1999, p. 138-139). E, nesse movimento incontido, configurou-se um dos grandes 
problemas da urbanização contemporânea, relacionado à ocupação urbana precária e ilegal em áreas de proteção de mananciais metropolitanos, especialmente nos arredores das represas Guarapiranga e Billings. As estradas de Parelheiros, do M’Boi Mirim, do Bororé e do Alvarenga são vetores desta urbanização imprópria e descontrolada. Estas periferias apresentam como características comuns a distância ao Centro, a função de dormitórios e a presença de população de mais baixa renda da região.

Esses movimentos populacionais no interior da Região Metropolitana de São Paulo representam uma nova dinâmica de deslocamento a partir do Município de São Paulo e dos sub-centros regionais inicialmente polarizados por Osasco e pelo ABC Paulista, que concentravam um número significativo de empregos vinculados à indústria nas décadas de 1960 e 1970. No período subsequente, Guarulhos passa a desempenhar um papel semelhante e o crescimento da área urbanizada acompanha esse movimento, que constituiu uma nova etapa nas relações metropolitanas que respondem às transformações em curso de mudanças na estrutura produtiva da Metrópole e no papel relativo que estão adquirindo os diferentes Municípios metropolitanos.

Estes sub-centros, que diversificaram sua estrutura produtiva e de serviços, tornaram-se também pontos nodais do processo de expansão da Região Metropolitana, sendo que Osasco e o ABC Paulista foram responsáveis por $18,0 \%$ e 31,4\%, respectivamente, de toda a migração intrametropolitana já nos anos 70. Na sub-região oeste, Osasco interagiu com Barueri, Carapicuíba, Itapevi, Jandira e Santana de Parnaíba, tendo Osasco e Carapicuíba recebido a maior parte desse contingente. Na sub-região sudeste, os Municípios centrais do ABC Paulista, como Santo André, São Bernardo do Campo e São Caetano do Sul, interagiram com Diadema, Mauá, Ribeirão Pires e Rio Grande da Serra. A redistribuição da população no interior da Metrópole, juntamente com o crescimento da pobreza, repercutiu significativamente nas características da expansão da área urbanizada, especialmente pela reprodução do padrão periférico em Municípios metropolitanos.

Desde 1971, o processo de urbanização destruiu 31\% das áreas cobertas por matas, ocupou fundos de vale com avenidas e favelas, destruiu 
morros e avançou sobre encostas íngremes e áreas de proteção aos mananciais de abastecimento público. Entre 1965 e 1990, o processo de urbanização incorporou, de forma indisciplinada, para uso urbano, $1.021 \mathrm{~km}^{2}$ de área rural aos $745 \mathrm{~km}^{2}$ de urbanização metropolitana existente em 1965.

Pode-se afirmar que grande parte deste incremento de área urbanizada, que atualmente se encontra em $2.139 \mathrm{~km}^{2}$, ocorreu pela multiplicação de loteamentos populares e, portanto, a expansão urbana e a irregularidade, ou clandestinidade, no parcelamento do solo urbano, são fenômenos associados e têm como produto o rápido descolamento entre a oferta de habitação para população de baixa renda e o crescimento dos Municípios.

Outros processos também contribuíram para o espraiamento e desmembramento da área urbanizada metropolitana (v. Anexos - Figura 08) até a configuração atual (v. Anexos - Figura 09). Entre eles destacam-se a desconcentração de funções e atividades propiciadas pela criação de núcleos autônomos como os de Alphaville em Barueri e Tamboré em Santana de Parnaíba, a oferta de loteamentos e condomínios residenciais para moradores de renda média e alta em Cotia e Itapecerica da Serra, a consolidação de áreas para o lazer e o turismo em Embu e Mairiporã e a implementação do Aeroporto Internacional de Cumbica em Guarulhos.

Como tentativa preliminar de identificação e tratamento destes problemas, a Prefeitura do Município de São Paulo, em 1968, contratou um consórcio internacional para a elaboração do Plano Urbanístico Básico (PUB), constituído de diagnósticos exaustivos e de caracterização físico-territorial, sócio-econômica, dos déficits dos serviços públicos e das condições da estrutura administrativa. Os resultados apontavam para a profunda defasagem entre as necessidades da população e a capacidade de atendimento dos serviços oferecidos. Na Administração Figueiredo Ferraz iniciavam-se as obras do Metrô e instituía-se o primeiro Plano Diretor de Desenvolvimento Integrado (PDDI), referente à Lei Municipal 7.688/71, pautado nas recomendações do PUB e do Plano Metropolitano de Desenvolvimento Integrado (PMDI). As diretrizes do PMDI estão consolidadas na primeira legislação de zoneamento da cidade (7.805/72, 8.001/73 e subsequentes), em vigor até os dias de hoje. 
A partir da década de 70 intensificou-se o processo de concentração de renda e a lógica da construção da Região Metropolitana passa pelo deslocamento dos centros, associada à exclusão territorial dos mais pobres, com o incremento da presença de favelas e assentamentos. As favelas se caracterizam por ocupar áreas não compradas, públicas ou privadas, sobre as quais são edificadas habitações precárias. Segundo o censo de 1987 da Secretaria de Habitação e Desenvolvimento Urbano, atualizado em 1999, existem, apenas no Município de São Paulo, 1.855 favelas, distribuídas ao longo das regiões distritais, com maior concentração nas áreas periféricas da cidade (v. Anexos - Figura 10). Em 1973, 1\% da população morava em favelas e, em 1980, o número saltava para 4\%, chegando a $8 \%$ no início dos anos 90 . Paralelamente, ocorre o sucessivo deslocamento do centro nobre que, com o desgaste dos centros anteriores, propicia o surgimento do eixo Itaim - Berrini Marginal Pinheiros.

A precariedade tem sido atributo permanente das periferias metropolitanas. A partir dos anos 70, no momento em que o Estado passa a produzir habitação social adotando a tipologia dos grandes conjuntos, a situação se agrava, pois os projetos reproduziram as deficiências e carências urbanísticas típicas das regiões periféricas. Em cada uma das situações verificaram-se processos de ocupação das áreas de expansão urbana que resultaram em precariedades específicas dos ambientes construídos, legando um tecido urbano desestruturado e carente de atributos municipais. Por um lado, esta desestruturação está associada ao processo de produção dos espaços residenciais para a população de baixa renda e, por outro, à insuficiência crônica de investimentos públicos na escala requerida, sendo ainda reforçada pelo descaso para com a qualidade dos espaços construídos. Portanto, a oferta de atributos representativos à população deve levar em conta a precariedade já estabelecida, no sentido de avaliar o destino social destas áreas, a distribuição desequilibrada dos investimentos públicos e a ausência de uma política de desenvolvimento urbano que equacione a expansão do Município e da Metrópole. 
As décadas de 1980 e 1990 foram responsáveis apenas pelo aumento da concentração de renda na Região Metropolitana de São Paulo. Enquanto o Brasil reverteu, ainda que timidamente, o grau de concentração, a Região Metropolitana de São Paulo manteve a tendência verificada na década anterior. Quando se compara o que ocorreu com a distribuição de renda na região com o que ocorreu no Brasil, nota-se que a renda das parcelas mais ricas, que correspondem aos três últimos décimos, cresceu a taxas próximas às verificadas para o país, ou seja, cerca de $0,5 \%$ ao ano. No entanto, os quatro décimos mais pobres perderam renda durante esse período, o que representa um comportamento bem diferente do observado nas demais áreas urbanas brasileiras, para as quais a renda aumentou a taxas superiores a 1\% ao ano. Com este comportamento, embora o grau de desigualdade na Região Metropolitana de São Paulo tenha aumentado, ele continua abaixo daqueles levantados nas demais Metrópoles do Brasil. Por outro lado, a diferença de desigualdade entre a Região Metropolitana de São Paulo e as Regiões Metropolitanas do Nordeste diminuiu não porque o grau tenha caído nestas últimas, mas porque aumentou na primeira.

Segundo MEYER, GROSTEIN e BIDERMAN (2004, p. 148), uma forma de se distribuir a renda, considerando que as camadas mais pobres são proprietárias dos seus imóveis, seria diminuir o tempo de deslocamento, ou seja, melhorar a mobilidade. Os maiores índices de proprietários morando em seus imóveis ocorrem em geral na periferia, com valores muitas vezes acima dos 70\%. Uma diminuição no tempo de deslocamento nas regiões periféricas implicaria uma maior demanda de imóveis na periferia, resultando, em última instância, em um aumento no preço dos imóveis.

Na Região Metropolitana de São Paulo existe um círculo de alta renda em que todos os distritos estão entre os $20 \%$ mais ricos, denominado de círculo de riqueza. Este círculo está centrado no encontro da Avenida Marginal Pinheiros com a Avenida dos Bandeirantes. Porém há algumas exceções a esse padrão urbano, como ocorre no ABC Paulista, onde a renda tem crescido nos últimos anos de maneira considerável, e em Barueri, Santana de Parnaíba, Itapecerica da Serra, Mairiporã e Arujá, pela presença cada vez maior de 
condomínios fechados de alto padrão. Parte do comportamento em círculos já podia ser verificado em FÁVERO (2003), mas especificamente para o Município de São Paulo. Neste trabalho, por outro lado, a análise será elaborada para toda a Região Metropolitana de São Paulo.

A precariedade urbana existente nos círculos mais periféricos ostenta diversas faces. Hoje, depois de um processo de consolidação que vem ocorrendo há pelo menos quatro décadas, tem, como traços principais, a insuficiência de serviços básicos como os de educação, saúde e saneamento, a mobilidade limitada dos moradores de cada localidade, dependentes de transporte público de baixa qualidade, e a presença de altos índices de violência.

Dado o alto grau de desarticulação urbana, MEYER, GROSTEIN e BIDERMAN (2004, p. 51) propõem a existência de dois setores urbanos, o equipado e o precário, justificando o uso da expressão segregação urbana para definir a relação que a periferia mantém com o Município central e a Metrópole.

A Região Metropolitana de São Paulo, até a década de 70, era altamente concentrada em atividades industriais, porém, nos anos 80 e 90, sofreu uma considerável redução da concentração neste ramo de atividade. $O$ fato gerou uma preocupação tanto para os executores de política como para os pensadores do tema. O aumento da demanda de espaço, por parte dos produtores de serviços, acabou por encarecer o preço da terra e dos salários, ou seja, o custo do espaço urbano, o que fez com que houvesse um fenômeno de saída das indústrias, acelerado também pelas suas inerentes externalidades negativas, como poluição sonora e atmosférica. Desta forma, a transição funcional da Metrópole contemporânea apresenta uma série de consequências sobre as decisões de políticas públicas e de investimentos privados que apresentem uma consciência urbana e social.

O século XXI inicia-se com a Metrópole em crise, marcada pela exclusão social de grande parte dos seus 18 milhões de habitantes e pela intensa degradação do seu ambiente urbano. Com quase $60 \%$ de seus habitantes vivendo no Município de São Paulo, as dificuldades de acesso à moradia impelem quase $10 \%$ da população à adoção de soluções como favelas, 
$\operatorname{cortiços}^{25}$, invasões e assentamentos clandestinos, sendo o segundo pior desempenho entre todas as Regiões Metropolitanas do Brasil. Somente os parcelamentos clandestinos ocupam uma área de aproximadamente $500 \mathrm{Km}^{2}$ (ANCONA, 1993, p. 411). Além disto, a Região Metropolitana apresenta uma renda per capita média de $\mathrm{R} \$ 507,93$, com $14 \%$ das pessoas situando-se abaixo da linha da pobreza, ou seja, com renda per capita menor de meio salário mínimo (DANTAS, 2004).

Assim sendo, a escassez de recursos sociais tem se apresentado de maneira frequente e o desenvolvimento econômico se faz por meio da administração dos atributos existentes, para que possam ser atendidas as necessidades da população. Porém, percebe-se que grande parte dos projetos lançados apresenta um ponto de vista privado, ao invés de um ponto de vista social, e a atratividade de projetos com tais perspectivas depende, além das distorções entre os preços, da própria natureza dos bens. À medida que todos os atributos fornecem utilidade delineada para os consumidores, o valor da utilidade passa a ser identificado por meio dos preços de mercado (CONTADOR, 2000, p. 19-24). E, como as empresas atuantes neste mercado têm como objetivo o crescimento e o lucro, explica-se o porquê da escassez do lançamento de projetos com um ponto de vista social.

Ao longo das últimas décadas muito tem sido observado em relação ao crescimento urbano da Região Metropolitana de São Paulo, no que diz respeito ao volume de lançamentos imobiliários residenciais, com características próprias e diferenciadas. Da mesma forma, percebe-se também, como descrito anteriormente, um incremento de algumas características em relação a outras, até formar o que se pode chamar de configuração atual de atributos de cada localidade da Região Metropolitana de São Paulo. E, como já afirmado anteriormente, a relação entre a presença destes atributos, dos preços e das demais condições comerciais dos imóveis residenciais será examinada nos próximos capítulos.

\footnotetext{
${ }^{25}$ Habitação de caráter coletivo, ou seja, uma ou mais habitações no mesmo lote, com índice de ocupação excessivo, deficiências de instalações hidráulicas e sanitárias, cômodos alugados e congestionados com uso comum dos sanitários e cozinha (LANGENEST, 1962, p. 2).
} 


\section{3 - O Mercado Imobiliário de Lançamentos e Comercializações Residenciais}

Um mercado pode ser definido como sendo o grupo de compradores e vendedores que, por meio de suas reais ou potenciais interações, determina o preço de um produto ou de um conjunto de produtos disponíveis para aquisição (PINDYCK e RUBINFELD, 1999, p. 9).

Em relação ao mercado imobiliário de São Paulo, no ano de 2004, o volume de lançamentos ficou $16 \%$ abaixo do ano anterior e, do total de unidades lançadas, aproximadamente 12,4\% localizam-se em condomínios horizontais, o que justifica a utilização, para este trabalho, de apenas unidades residenciais em empreendimentos verticais (apartamentos), dada a representatividade no mercado. Do total de unidades lançadas, cerca de 58\% corresponderam a unidades de dois dormitórios, com valor médio aproximado de R\$ 100 mil. Quanto ao valor comercializado, o Valor Geral de Vendas somou uma quantia aproximada de R\$ 6 bilhões em 2004.

A quantidade de apartamentos residenciais em lançamento comercializados (e, portanto, com existência de demanda para a oferta estabelecida) e a velocidade média de comercialização, entre os meses de Janeiro e Dezembro de 2004, são fornecidos pelo Secovi-SP (Sindicato das Empresas de Compra, Venda, Locação e Administração de Imóveis Comerciais e Residenciais de São Paulo) e são apresentados na tabela 3.3.1 a seguir. 
TABELA 3.3.1: NÚMERO DE APARTAMENTOS RESIDENCIAIS EM LANÇAMENTO COMERCIALIZADOS ENTRE OS MESES DE JANEIRO E DEZEMBRO DE 2004

\begin{tabular}{ccc}
\hline MÊS & $\begin{array}{c}\text { No DE APARTAMENTOS } \\
\text { RESIDENCIAIS COMERCIALIZADOS }\end{array}$ & PRAZO MÉDIO DE VENDA (MESES) \\
\hline Jan / 04 & 1.591 & 14 \\
Fev / 04 & 1.216 & 11 \\
Mar / 04 & 2.065 & 7 \\
Abr / 04 & 1.826 & 11 \\
Mai / 04 & 1.211 & 15 \\
Jun / 04 & 1.314 & 14 \\
Jul / 04 & 1.028 & 16 \\
Ago / 04 & 1.553 & 15 \\
Set / 04 & 2.062 & 13 \\
Out / 04 & 2.290 & 8 \\
Nov / 04 & 1.812 & 9 \\
Dez / 04 & 2.215 & 8 \\
\hline TOTAL & 20.183 & MÉDIA PMV \\
\hline
\end{tabular}

FONTE: SECOVI-SP

A tabela 3.3.1 fornece a população a ser estudada neste trabalho. É importante relevar que, para cada mês, a quantidade de imóveis a ser estudada obedecerá à proporção apresentada na referida tabela. No item 4.4 serão definidas as dimensões de cada sub-amostra, em função de cada perfil sócio-demográfico, a ser definido por meio de uma aplicação prévia da técnica estatística de análise fatorial. 


\section{CAPÍTULO IV PESQUISA}

\section{1 - Método de Pesquisa}

O método aqui utilizado pode ser descrito em algumas etapas, que correspondem à definição de variáveis que conduzam a uma estratificação sócio-demográfica dos distritos do Município de São Paulo e dos Municípios da Região Metropolitana de São Paulo (v. Anexos - Figuras 11 e 12). Definidas as variáveis, a referida estratificação poderá ser elaborada a partir de uma análise fatorial, por meio da qual a criação de um índice sócio-demográfico definirá os perfis, que corresponderão a cada uma das sub-amostras a serem consideradas nos modelos hedônicos. Este procedimento está de acordo com o apresentado na revisão teórica sobre o assunto, no item 2.3 deste trabalho, em relação à importância da divisão do mercado em sub-mercados quando da aplicação de modelos hedônicos que levam em consideração as perspectivas da demanda e da oferta. Ressalta-se que será elaborado um teste de comparação de médias do perfil sócio-demográfico definido na análise fatorial entre o grupo composto pelos distritos do Município de São Paulo e o grupo composto pelos Municípios da Região Metropolitana de São Paulo (exceto a capital), com o intuito de verificar a necessidade de desmembramento de algum dos Municípios que compõem o segundo grupo. Este procedimento será mais bem detalhado no item 4.3.

Com a definição dos perfis sócio-demográficos, faz-se necessária a definição das variáveis consideradas hedônicas que serão aplicadas nos modelos de regressão e correlação canônica. A especificação de modelos hedônicos, quando aplicados em um contexto de estimação de preços e demais condições marginais de atributos em um mercado imobiliário residencial, necessita que as variáveis independentes utilizadas como atributos se relacionem de forma representativa com as condições comerciais de lançamento dos imóveis. Porém, estas variáveis não são completamente definidas, tendo em vista a complexidade e a infinidade de possibilidades, 
fazendo-se necessária uma avaliação prévia de quais seriam as mais adequadas para inclusão nos modelos, já que abrangem características diversas que podem ou não interferir nas condições comerciais dos imóveis. Esta avaliação prévia é elaborada a partir da realização de um levantamento auto-administrado com especialistas e com compradores recentes, a fim de ser possível a determinação das variáveis extrínsecas e intrínsecas mais significantes da composição dos preços e demais condições comerciais de venda dos imóveis residenciais em lançamento e tornar possível a elaboração dos modelos e da análise quantitativa com as variáveis selecionadas pelo método inicial qualitativo. Estas variáveis serão definidas com profissionais atuantes no mercado imobiliário (engenheiros, arquitetos e administradores que trabalham em empresas construtoras, incorporadoras e projetistas) e com compradores que adquiriram, em diversas localidades, apartamentos no último ano. A aplicação do levantamento auto-administrado tem por propósito a determinação, a priori, de algumas variáveis que compõem os preços e demais condições comerciais dos apartamentos em lançamento.

Com a definição das variáveis hedônicas, do dimensionamento de cada uma das sub-amostras com específicas caracterizações sócio-demográficas e da coleta dos dados, torna-se possível a elaboração dos modelos hedônicos de regressão e correlação canônica.

\section{2 - Universo de Pesquisa}

O universo, no qual o estudo está baseado, é constituído pelos apartamentos residenciais lançados na Região Metropolitana de São Paulo entre os meses de Janeiro e Dezembro de 2004. 


\section{3 - Definição dos Perfis Sócio-Demográficos}

\subsection{1 - Análise Fatorial}

Se for fato que uma função hedônica pode representar um instrumento útil para a segmentação de mercado, uma possível solução para sua determinação consiste na utilização prévia da técnica estatística multivariada de análise fatorial (PEREIRA, 2004, p. 63).

O primeiro autor a desenvolver esta técnica, apresentando-a em um artigo publicado em 1904, foi Charles Spearman, que estudou uma questão que se referia à descoberta de uma medida de inteligência geral para seres humanos que fosse mais confiável do que os outros vários testes existentes à época. Para tanto, Spearman desenvolveu a técnica de análise fatorial, na qual o processo empregado consistia em calcular todas as correlações entre diversas variáveis e isolar o fator principal, ou medida de inteligência geral (PEREIRA, 2004, p. 161).

Segundo ANGELO (1991, p. 136), a análise fatorial é uma técnica estatística para identificar um número reduzido de fatores que podem ser utilizados para representar um conjunto de variáveis inter-relacionadas. Podese dizer, portanto, que o objetivo do método é encontrar fatores não diretamente observados a partir do conjunto inicial de variáveis. Assim, a expressão de cada fator pode ser representada por:

$$
F_{j}=W_{j 1} X_{1}+W_{j 2} X_{2}+\ldots+W_{j n} X_{n}
$$

onde $F_{j}$ é o fator j obtido pela combinação linear das $n$ variáveis e $X_{i}$ é a variável original $\mathrm{i}$.

Segundo AAKER, KUMAR e DAY (1998, p. 582), a análise fatorial é utilizada para a combinação de variáveis que criam novos fatores e, conforme apontam HAIR, ANDERSON, TATHAM e BLACK (1998, p. 89), um fator representa uma combinação linear de variáveis originais. Segundo CURRY (1994, p. 204), a análise fatorial é uma técnica multivariada que examina a 
correlação entre variáveis, criando um ou mais fatores que representam a condensação das variáveis originais em uma ou mais colunas de um banco de dados. No âmbito da análise fatorial, o que se pretende é a identificação de possíveis associações entre variáveis observacionais, de modo que se defina a existência de um fator comum entre elas. Assim, pode-se dizer que a análise fatorial, ou análise de fator comum, tem como objetivo a identificação destes fatores, ou contructos, subjacentes às variáveis observacionais, o que contribui para facilitar a interpretação dos dados (RODRIGUES, 2002, p. 76).

Segundo JOHNSON e WICKERN (1992, p. 396), na análise do fator comum, as variáveis são agrupadas em função de suas correlações. Isto significa que variáveis que compõem um determinado fator devem ser altamente correlacionadas entre si e fracamente correlacionadas com as variáveis que entram na composição de um outro fator qualquer.

O modelo de análise fatorial estima os fatores e as variâncias, de modo que as covariâncias ou as correlações previstas estejam o mais próximo possível dos valores observados. Para tal, os métodos de estimação ou extração mais usados são o das componentes principais e o da máxima verossimilhança. Neste trabalho será usado o método das componentes principais.

A necessidade de aplicação de análise fatorial em avaliações de características sócio-demográficas urbanas está apresentada em MEYER, GROSTEIN e BIDERMAN (2004, p. 26) que afirmam que a "dinâmica que se instalou no território metropolitano contemporâneo está diluindo aceleradamente a forma urbana, tomada no seu sentido mais linear, isto é, de configuração urbana total e inextensa, para substituí-la por um imenso conjunto de espaços, denominados de maneira acertada de peças urbanas, que não revelam facilmente as conexões espaciais e funcionais que as colocam em relação. O mesmo ocorre para a importante questão da escala metropolitana, que já não poderá ser vista apenas como superfície contínua".

Após a definição das variáveis observacionais sócio-demográficas, será apresentado um roteiro básico que, segundo PESTANA E GAGEIRO (2000, p. 389 a 427), é fundamental para se avaliar a adequação da análise fatorial. 


\subsection{2 - Definição das Variáveis Sócio-Demográficas}

Utilizando um critério já estabelecido pela Prefeitura do Município de São Paulo, mas agora com a inclusão de novas variáveis, pode-se definir um indicador sócio-demográfico que representará a estratificação da Região Metropolitana de São Paulo em sub-amostras.

Para tanto, utilizaram-se onze variáveis representativas das condições de cada localidade (distrito do Município de São Paulo ou Município da Região Metropolitana), apresentadas, a seguir, no quadro 4.3.2.1.

QUADRO 4.3.2.1: VARIÁVEIS QUE SERÃO UTILIZADAS PARA A COMPOSIÇÃO DO PERFIL SÓCIODEMOGRÁFICO DA REGIÃO METROPOLITANA DE SÃO PAULO

\begin{tabular}{|c|c|c|}
\hline $\begin{array}{c}\text { VARIÁVEL SÓCIO- } \\
\text { DEMOGRÁFICA } \\
\text { OBSERVACIONAL }\end{array}$ & DESCRIÇÂO & FONTE \\
\hline Renda Média Familiar & $\begin{array}{l}\text { Renda média familiar em } \\
\text { valores em } \mathrm{R} \$\end{array}$ & $\begin{array}{l}\text { Prefeitura do Município de São Paulo - } \\
\text { PMSP, em } \\
\text { www.prodam.sp.gov.br/svma/atlas_amb } \\
\text { Fundação Sistema Estadual de Análise } \\
\text { de Dados - SEADE, em } \\
\text { www.seade.gov.br } \\
\text { Instituto Brasileiro de Geografia e } \\
\text { Estatística - IBGE, em www.ibge.gov.br }\end{array}$ \\
\hline $\begin{array}{l}\% \text { da População com até } 1 / 2 \\
\text { Salário Mínimo por Mês }\end{array}$ & $\begin{array}{l}\text { Porcentagem de chefes } \\
\text { (homens ou mulheres) } \\
\text { responsáveis pelo domicílio, } \\
\text { agrupados por classe de } \\
\text { rendimento expresso em até } 1 / 2 \\
\text { salário mínimo por mês. }\end{array}$ & $\begin{array}{l}\text { Fundação Sistema Estadual de Análise } \\
\text { de Dados - SEADE, em } \\
\text { www.seade.gov.br } \\
\text { Instituto Brasileiro de Geografia e } \\
\text { Estatística - IBGE, em www.ibge.gov.br }\end{array}$ \\
\hline
\end{tabular}




\begin{tabular}{|c|c|c|}
\hline $\begin{array}{l}\text { \% da População com até } 10 \\
\text { Salários Mínimos por Mês }\end{array}$ & $\begin{array}{l}\text { Porcentagem de chefes } \\
\text { (homens ou mulheres) } \\
\text { responsáveis pelo domicílio, } \\
\text { agrupados por classe de } \\
\text { rendimento expresso em mais } \\
\text { de } 10 \text { salários mínimos por } \\
\text { mês. }\end{array}$ & $\begin{array}{l}\text { Fundação Sistema Estadual de Análise } \\
\text { de Dados - SEADE, em } \\
\text { www.seade.gov.br } \\
\text { Instituto Brasileiro de Geografia e } \\
\text { Estatística - IBGE, em www.ibge.gov.br }\end{array}$ \\
\hline Escolaridade & $\begin{array}{l}\text { Média de anos de estudo da } \\
\text { população de } 4 \text { anos ou mais. }\end{array}$ & $\begin{array}{l}\text { Fundação Sistema Estadual de Análise } \\
\text { de Dados - SEADE, em } \\
\text { www.seade.gov.br }\end{array}$ \\
\hline Taxa de Mortalidade Infantil & $\begin{array}{l}\text { Relação entre os óbitos de } \\
\text { menores de um ano, residentes } \\
\text { numa unidade geográfica, num } \\
\text { determinado período de tempo } \\
\text { (geralmente um ano) e os } \\
\text { nascidos vivos na mesma } \\
\text { unidade, no período, segundo a } \\
\text { expressão: } \\
\text { TMI = óbitos de menores de } 1 \\
\text { ano ocorridos no período } \\
\text { dividido pelo número de } \\
\text { nascidos vivos no mesmo } \\
\text { período, multiplicado por } 1000 .\end{array}$ & $\begin{array}{l}\text { Fundação Sistema Estadual de Análise } \\
\text { de Dados - SEADE, em } \\
\text { www.seade.gov.br }\end{array}$ \\
\hline $\begin{array}{l}\text { Taxa de Crescimento } \\
\text { Populacional }\end{array}$ & $\begin{array}{l}\text { Expressa, em termos } \\
\text { percentuais, o crescimento } \\
\text { médio da população em um } \\
\text { determinado período de tempo, } \\
\text { geralmente ao ano. }\end{array}$ & $\begin{array}{l}\text { Fundação Sistema Estadual de Análise } \\
\text { de Dados - SEADE, em } \\
\text { www.seade.gov.br }\end{array}$ \\
\hline $\begin{array}{l}\text { Índice de Mortalidade por } \\
\text { Causas Externas }\end{array}$ & $\begin{array}{l}\text { Quociente entre os óbitos por } \\
\text { homicídio ocorridos em uma } \\
\text { determinada unidade geográfica } \\
\text { e período de tempo e a } \\
\text { população da mesma unidade } \\
\text { estimada ao meio do período, } \\
\text { segundo a fórmula: Taxa de } \\
\text { mortalidade por homicídios = } \\
\text { (Óbitos por homicídio / } \\
\text { População ao meio do período } \\
\text { X 100.000). Obs: As } \\
\text { informações de óbitos têm } \\
\text { como fonte os atestados de } \\
\text { óbitos recebidos pelos cartórios. }\end{array}$ & $\begin{array}{l}\text { Fundação Sistema Estadual de Análise } \\
\text { de Dados - SEADE, em } \\
\text { www.seade.gov.br }\end{array}$ \\
\hline
\end{tabular}




\begin{tabular}{|c|c|c|}
\hline Densidade Demográfica & $\begin{array}{l}\text { Número de habitantes } \\
\text { residentes de uma unidade } \\
\text { geográfica em determinado } \\
\text { momento, em relação à área } \\
\text { desta mesma unidade. A } \\
\text { densidade demográfica é um } \\
\text { índice utilizado para verificar a } \\
\text { intensidade de ocupação de um } \\
\text { território, dado em habitantes / } \\
\mathrm{km}^{2} \text {. }\end{array}$ & $\begin{array}{l}\text { Fundação Sistema Estadual de Análise } \\
\text { de Dados - SEADE, em } \\
\text { www.seade.gov.br }\end{array}$ \\
\hline População & $\begin{array}{l}\text { Os dados de população são } \\
\text { apresentados de acordo com a } \\
\text { divisão geográfica e } \\
\text { administrativa vigente. }\end{array}$ & $\begin{array}{l}\text { Fundação Sistema Estadual de Análise } \\
\text { de Dados - SEADE, em } \\
\text { www.seade.gov.br } \\
\text { Instituto Brasileiro de Geografia e } \\
\text { Estatística - IBGE, em www.ibge.gov.br }\end{array}$ \\
\hline $\begin{array}{l}\text { Número de Domicílios } \\
\text { Particulares }\end{array}$ & $\begin{array}{l}\text { Total de domicílios particulares } \\
\text { permanentes. O domicílio é } \\
\text { considerado particular quando o } \\
\text { relacionamento entre seus } \\
\text { ocupantes é ditado por laços de } \\
\text { parentesco, de dependência } \\
\text { doméstica ou por normas de } \\
\text { convivência. }\end{array}$ & $\begin{array}{l}\text { Fundação Sistema Estadual de Análise } \\
\text { de Dados - SEADE, em } \\
\text { www.seade.gov.br } \\
\text { Instituto Brasileiro de Geografia e } \\
\text { Estatística - IBGE, em www.ibge.gov.br }\end{array}$ \\
\hline Taxa de Urbanização & $\begin{array}{l}\text { Percentual da população } \\
\text { urbana em relação à população } \\
\text { total. É calculado, geralmente, a } \\
\text { partir de dados censitários. }\end{array}$ & $\begin{array}{l}\text { Fundação Sistema Estadual de Análise } \\
\text { de Dados - SEADE, em } \\
\text { www.seade.gov.br } \\
\text { Instituto Brasileiro de Geografia e } \\
\text { Estatística - IBGE, em www.ibge.gov.br }\end{array}$ \\
\hline
\end{tabular}

A seguir, no quadro 4.3.2.2, é apresentada, para cada uma destas variáveis, a justificativa de terem sido escolhidas para a composição do perfil sócio-demográfico da Região Metropolitana de São Paulo. 
QUADRO 4.3.2.2: JUSTIFICATIVA DAS VARIÁVEIS A SEREM UTILIZADAS PARA A COMPOSIÇÃO DO PERFIL SÓCIO-DEMOGRÁFICO DA REGIÃO METROPOLITANA DE SÃO PAULO

\begin{tabular}{|c|c|}
\hline $\begin{array}{l}\text { VARIÁVEL SÓCIO-DEMOGRÁFICA } \\
\text { OBSERVACIONAL }\end{array}$ & JUSTIFICATIVA \\
\hline Renda Média Familiar & $\begin{array}{l}\text { Indica a condição sócio-demográfica associada ao } \\
\text { consumo das famílias (v. Anexos - Figuras } 13 \text { e 14). }\end{array}$ \\
\hline $\begin{array}{l}\text { \% da População com até } 1 / 2 \text { Salário } \\
\text { Mínimo por Mês }\end{array}$ & $\begin{array}{l}\text { Indica o percentual da população que se situa em } \\
\text { patamares de pobreza (v. Anexos - Figura 15). }\end{array}$ \\
\hline $\begin{array}{l}\text { \% da População com até } 10 \text { Salários } \\
\text { Mínimos por Mês }\end{array}$ & $\begin{array}{l}\text { Indica o percentual da população que se situa em } \\
\text { patamares de riqueza (v. Anexos - Figura 15). }\end{array}$ \\
\hline Escolaridade & $\begin{array}{l}\text { Relaciona-se com os níveis de educação presentes em } \\
\text { cada localidade de estudo. }\end{array}$ \\
\hline Taxa de Mortalidade Infantil & $\begin{array}{l}\text { Indica fatores médico-sanitários relacionados às condições } \\
\text { de saúde e higiene. }\end{array}$ \\
\hline Taxa de Crescimento Populacional & $\begin{array}{l}\text { Representa o comportamento do crescimento (positivo ou } \\
\text { negativo) da população local, indicando eventuais } \\
\text { problemas sociais advindos do provimento de condições } \\
\text { adequadas (v. Anexos - Figura 16). }\end{array}$ \\
\hline $\begin{array}{l}\text { Índice de Mortalidade por Causas } \\
\text { Externas }\end{array}$ & Relaciona-se com fatores de criminalidade e violência. \\
\hline Densidade Demográfica & $\begin{array}{l}\text { Está associada com o espalhamento e a aglomeração } \\
\text { urbana (v. Anexos - Figuras } 17 \text { e 18). }\end{array}$ \\
\hline População & $\begin{array}{l}\text { Representa o número de habitantes de cada localidade (v. } \\
\text { Anexos - Figura 19). }\end{array}$ \\
\hline Número de Domicílios Particulares & $\begin{array}{l}\text { Indica as condições relacionadas à disponibilidade de } \\
\text { recursos para a habitação e moradia. }\end{array}$ \\
\hline Taxa de Urbanização & $\begin{array}{l}\text { Permite avaliar a presença de população rural na } \\
\text { localidade (v. Anexos - Figuras } 20 \text { e } 21 \text { ). }\end{array}$ \\
\hline
\end{tabular}

Poder-se-ia pensar na utilização da variável relacionada à área de cada localidade para a criação do perfil, o que não ocorreu, uma vez que ela não apresenta características sócio-demográficas. Ademais, a inclusão desta variável possivelmente faria com que os Municípios da Região Metropolitana de São Paulo fossem desmembrados em áreas menores, pois o teste de comparação de médias entre este grupo e o composto pelos distritos do Município de São Paulo mostraria diferenças significativas, o que não necessariamente é verdade e poderia possibilitar uma eventual descaracterização do perfil sócio-demográfico gerado por meio da análise fatorial. 
Nas tabelas 01 e 02, em anexo, são apresentados os dados originais de cada variável sócio-demográfica, para cada localidade.

\subsection{3 - Aplicação da Análise Fatorial ${ }^{26}$}

Há vários métodos, segundo ANGELO (1991, p. 136-137), para a obtenção de cada fator de uma combinação de variáveis. Empregou-se aqui a técnica de componentes principais, em que são obtidas combinações lineares das variáveis originais. A primeira componente refere-se à combinação que capta a maior parcela da variância da amostra e corresponderá, no presente trabalho, ao fator sócio-demográfico de cada localidade.

A seguir, apresenta-se um roteiro proposto por PESTANA E GAGEIRO (2000, p. 389 a 427) para se avaliar a adequação da análise fatorial.

Antes de iniciar-se a análise fatorial, deve-se explorar individualmente cada variável em termos de um eventual enviesamento da distribuição. Embora a normalidade não seja um pressuposto necessário de análise fatorial, as distribuições enviesadas podem distorcer os resultados, uma vez que alteram as estimativas das médias e dos desvios-padrão, modificando as estimativas das covariâncias e das correlações. Deve-se igualmente analisar o número de não-respostas, pois, quando são elevadas (correspondendo a pelo menos $20 \%$ dos dados) e não são aleatórias, podem distorcer os resultados da análise fatorial.

Por meio dos testes de Kolmogorov-Smirnov e Shapiro-Wilk, verifica-se, para todas as variáveis observacionais, a existência de normalidade, a um nível de significância de 0,1 . Ademais, a inexistência de dados faltantes para as variáveis observacionais faz com que não seja necessária a análise de nãorespostas.

Pelo fato de as variáveis observacionais sócio-demográficas apresentarem valores de diferentes grandezas, o que dificultaria a comparação

\footnotetext{
${ }^{26}$ Esse método foi aplicado por meio do software SPSS 12.0.
} 
entre as informações, foi realizado, primeiramente, um processo de padronização dos dados ${ }^{27}$.

Para ser possível a aplicação da análise fatorial, deve existir correlação entre as variáveis que, se for pequena, é pouco provável que as variáveis originais partilhem fatores comuns. Segundo GOUVÊA (2004), a aplicação da técnica multivariada de análise fatorial necessita que a matriz de correlação apresente um razoável número de correlações superiores a 0,30. Por meio da análise da matriz de correlações em anexo (v. Anexos - Tabela 03), é possível verificar que as variáveis, em sua maioria, apresentam correlações altas.

$\mathrm{O}$ segundo passo refere-se à aplicação do teste KMO (Kaiser-MeyerOlkin) e do teste de esfericidade de Bartlett. Utiliza-se este último com o intuito de avaliar a hipótese de que a matriz das correlações pode ser a matriz identidade, com determinante igual a 1 e, caso seu nível de significância seja inferior a 5\%, para uma significância definida de 5\%, deve-se rejeitar a hipótese da matriz das correlações entre as variáveis ser a matriz identidade, o que resultaria, portanto, na existência de correlação entre as variáveis. Caso tal fato não se verifique, deve-se reconsiderar a utilização de análise fatorial.

$\mathrm{O}$ teste $\mathrm{KMO}$, que varia entre 0 e 1, avalia a adequação da amostra quanto ao grau de correlação parcial entre as variáveis, que deve ser pequeno. $\mathrm{O}$ valor de $\mathrm{KMO}$ próximo de 0 indica que a análise fatorial pode não ser adequada, pois existe uma correlação fraca entre as variáveis. Os intervalos de análise dos valores de KMO podem ser observados no quadro a seguir.

QUADRO 4.3.3.1: VALORES DE KMO PARA A ANÁLISE FATORIAL

\begin{tabular}{|c|c|}
\hline KMO & ANÁLISE FATORIAL \\
\hline $1-0,9$ & Muito boa \\
\hline $0,8-0,9$ & Boa \\
\hline $0,7-0,8$ & Média \\
\hline $0,6-0,7$ & Razoável \\
\hline $0,5-0,6$ & Má \\
\hline$<0,5$ & Inaceitável \\
\hline
\end{tabular}

FONTE: PESTANA e GAJEIRO (2000, p. 397)

\footnotetext{
${ }^{27}$ A padronização de dados corresponde à aplicação da seguinte expressão: $\mathrm{Zi}=(\mathrm{Xi}-\mathrm{Média})$ / Desviopadrão, onde Zi é a informação padronizada.
} 
Este teste sugere que há a adequação da amostra quanto ao grau de correlação parcial entre as variáveis, uma vez que ofereceu um valor de 0,740. Por fim, o teste de esfericidade de Bartlett permite rejeitar a hipótese nula de que o modelo não é adequado em razão das associações verificadas, uma vez que o nível de significância é 0,000 (menor do que 5\%).

A matriz antiimagem é uma medida da adequação amostral de cada variável para uso da análise fatorial, em que pequenos valores na diagonal levam à consideração de uma eventual eliminação da respectiva variável. As medidas da adequação da amostra são os valores da diagonal principal da matriz e, quanto maiores, melhor será a análise fatorial. Os valores de fora da diagonal representam a simetria da matriz de correlações e deverão ser pequenos para a aplicação do modelo das componentes principais. Por meio da análise da matriz antiimagem em anexo ( $v$. Anexos - Tabela 04), é possível verificar serem elevados os valores na diagonal principal, o que mostra que as variáveis utilizadas são adequadas para o uso da análise fatorial.

A proporção de variância de cada variável explicada pelas componentes principais retidas é designada por comunalidade. As comunalidades iniciais são iguais a 1 e, após a extração, variam entre 0 e 1, sendo 0 quando os fatores comuns não explicam nenhuma variância da variável e 1 quando explicam a variância em sua totalidade. Os resultados das comunalidades (v. Anexos Tabela 05) mostram uma forte relação das variáveis com os fatores retidos e, portanto, permitem verificar que a variância total explicada após a criação dos fatores é $72,89 \%$.

Conforme afirmado anteriormente, o modelo de análise fatorial estima as cargas dos fatores e as variâncias, de modo a que as covariâncias ou as correlações previstas pelo modelo estejam o mais próximo possível dos valores observados, quer pelo método de extração das componentes principais, quer pelo método de estimação da máxima verosimilhança. A matriz de componentes inicial apresenta os coeficientes, ou cargas, que correlacionam as variáveis com os fatores antes da rotação e, caso não haja nenhuma carga elevada em nenhum dos fatores, torna-se necessário o uso de rotações. 
Os métodos de rotação podem ser ortogonais ou oblíquos. O primeiro produz fatores que não estão correlacionados entre si, e são chamados de fatores ortogonais, que são interpretados por meio de suas cargas. Na rotação oblíqua, os fatores estão correlacionados e, para a interpretação da solução, torna-se necessária a consideração simultânea da matriz de correlações e das cargas fatoriais. As rotações Varimax, Quartmax e Equamax são exemplos de rotações ortogonais, enquanto o Direct Oblimin e o Promax são exemplos de rotações oblíquas. O Varimax, por exemplo, minimiza o número de variáveis com elevadas cargas em um único fator e, como a intenção é a criação de um fator sócio-demográfico, este método de rotação foi escolhido para a análise fatorial neste trabalho.

Assim, os pesos de cada variável que compõe o perfil sócio-demográfico são apresentados na tabela 4.3.3.1 e o perfil de cada localidade é obtido pela somatória da multiplicação dos pesos dos indicadores pelos seus valores padronizados na respectiva localidade, gerando a classificação desejada.

TABELA 4.3.3.1: PESO DE CADA VARIÁVEL NA COMPOSIÇÃO DO PERFIL SÓCIO-DEMOGRÁFICO

\begin{tabular}{ll}
\hline \multicolumn{1}{c}{$\begin{array}{l}\text { VARIÁVEL QUE COMPÕE O PERFIL SÓCIO- } \\
\text { DEMOGRÁFICO DE CADA LOCALIDADE }\end{array}$} & PESO \\
\hline Renda Média Familiar & 0,893 \\
\hline $\begin{array}{l}\text { \% da População com até 1/2 Salário Mínimo por } \\
\text { Mês }\end{array}$ & $-0,657$ \\
\hline $\begin{array}{l}\text { \% da População com até 10 Salários Mínimos por } \\
\text { Mês }\end{array}$ & 0,907 \\
\hline Escolaridade & 0,858 \\
\hline Taxa de Mortalidade Infantil & $-0,629$ \\
\hline Taxa de Crescimento Populacional & $-0,465$ \\
\hline Índice de Mortalidade por Causas Externas & $-0,696$ \\
\hline Densidade Demográfica & $-0,124$ \\
\hline População & $-0,174$ \\
\hline Número de Domicílios Particulares & $-0,032$ \\
\hline Taxa de Urbanização & 0,328 \\
\hline
\end{tabular}


Desta forma, possibilita-se a criação do perfil sócio-demográfico, que agrega o maior número de informações mais fortemente correlacionadas. Assim, o perfil indica uma alta correlação positiva entre as variáveis de renda familiar, percentual da população com mais de 10 salários mínimos por mês e nível de escolaridade, e uma forte correlação negativa entre as variáveis relacionadas ao percentual da população com menos de $1 / 2$ salário mínimo por mês, à mortalidade infantil e à mortalidade por causas externas. Além disto, 0 perfil sócio-demográfico apresenta uma correlação negativa mais baixa entre as variáveis de crescimento populacional, densidade demográfica, população e números de domicílios particulares. Por fim, o perfil sócio-demográfico apresenta uma correlação positiva mais baixa para a variável relacionada à taxa de urbanização.

A criação do perfil sócio-demográfico acaba por refletir a importância que se deseja conferir a cada um dos aspectos considerados. Esclarece-se que a base teórica adotada para este método encontra respaldo em PERROUX (1964), com a Teoria dos Pólos de Desenvolvimento, e em CHRISTALLER (1966), com a Teoria das Localidades Centrais.

O fator, ou perfil, sócio-demográfico de cada uma das 134 localidades (96 distritos do Município de São Paulo e 38 Municípios da Região Metropolitana de São Paulo) pode ser encontrado em anexo (v. Anexos Tabela 06), em ordem crescente.

\subsection{4 - Teste para Comparação de Médias de Duas Amostras Independentes}

Após a análise fatorial, faz-se necessária a aplicação de um teste para comparação das médias da variável que representa o perfil, ou fator, sóciodemográfico do grupo composto pelos distritos do Município de São Paulo (96 localidades) e do grupo composto pelos demais Municípios da Região Metropolitana de São Paulo (38 localidades), com o intuito de se verificar a eventual necessidade de desmembramento de algum dos Municípios que compõem o segundo grupo em dois ou mais distritos. Segundo MEYER, 
GROSTEIN e BIDERMAN (2004, p. 35), a análise da organização sócioespacial da Metrópole necessita de aprofundamentos no que diz respeito à avaliação das especificidades e crescimento de cada localidade. E entende-se que o aprofundamento mencionado pelos autores pode ser descrito por uma investigação da necessidade de desmembramento das localidades com características sócio-demográficas eventualmente distintas.

Os testes para comparação de médias permitem avaliar hipóteses sobre médias de uma variável de nível quantitativo, permitindo a verificação da existência de diferenças entre as condições experimentais. Segundo NORUSIS (1998, p. 233-257) e PESTANA e GAJEIRO (2000, p. 159-165), no teste t para duas amostras independentes, compara-se a média de uma variável num grupo com a média da mesma variável no outro grupo. Assim, a comparação do perfil sócio-demográfico dos distritos do Município de São Paulo e dos Municípios da Região Metropolitana de São Paulo leva às seguintes hipóteses:

\footnotetext{
$\mathrm{H}_{0}: \mu_{\text {DistritosSP }}=\mu_{\text {MunicípiosRMSP }}$

$\mathrm{H}_{\mathrm{a}}: \mu_{\text {DistritosSP }} \neq \mu_{\text {MunicípiosRMSP }}$
}

sendo $\mu$ o perfil sócio-demográfico médio.

Como os dois grupos apresentam dimensão superior a 30, a distribuição $\mathrm{t}$ aproxima-se da distribuição normal (PESTANA; GAJEIRO, 2000, p. 160).

Portanto, a elaboração do teste t para duas amostras independentes, sendo uma representada pelos distritos do Município de São Paulo e a outra representada pelos Municípios da Região Metropolitana de São Paulo (exceto a capital), tem como objetivo avaliar se as médias dos perfis sóciodemográficos de cada um dos grupos, cujos valores são apresentados na tabela 4.3.4.1, são iguais ou não, ou seja, se a diferença entre elas é estatisticamente significativa. 
TABELA 4.3.4.1: ESTATÍSTICAS DO PERFIL SÓCIO-DEMOGRÁFICO PARA OS DISTRITOS DO MUNICÍPIO DE SÃO PAULO E PARA OS MUNICÍPIOS DA REGIÃO METROPOLITANA DE SÃO PAULO ${ }^{28}$

\begin{tabular}{lccc}
\hline \multicolumn{1}{c}{ REGIÃO } & DIMENSÃO & MÉDIA & DESVIO-PADRÃO \\
\hline Distritos do Município de SP & 96 & 0,077 & 0,111 \\
\hline Municípios da RMSP & 38 & $-0,196$ & 0,109 \\
\hline
\end{tabular}

O resultado do teste t pode ser analisado em anexo ( $v$. Anexos - Tabela 07). A observação do seu nível de significância não leva a uma recusa da hipótese nula de que as médias sejam iguais, a um nível de 98\%. Esta conclusão é confirmada pelos intervalos de confiança para as diferenças de perfis médios dos dois grupos, já que, para este nível de confiança, os intervalos incluem o zero.

Pode-se dizer que não é preciso, para este método e com as variáveis observacionais sócio-demográficas escolhidas, o desmembramento dos Municípios da Região Metropolitana de São Paulo em localidades menores. Como já discutido no item 4.3.2, a inclusão da variável relacionada à área da localidade poderia fazer com que houvesse uma diferença significativa entre a média de cada grupo, uma vez que os Municípios da Região Metropolitana de São Paulo são mais vastos do que os distritos do Município de São Paulo, mas não necessariamente melhoraria a estratificação desejada, uma vez que esta variável não diz respeito em nada com os critérios sócio-demográficos adotados.

\subsection{5 - Definição dos Grupos Sócio-Demográficos}

Seguindo uma classificação prévia, de acordo com a Prefeitura do Município de São Paulo, tem-se que a estratificação dos grupos sóciodemográficos obedece ao critério apresentado no quadro 4.3.5.1 a seguir.

\footnotetext{
${ }^{28}$ Esse teste foi elaborado por meio do software SPSS 12.0.
} 
QUADRO 4.3.5.1: CLASSIFICAÇÃO SÓCIO-DEMOGRÁFICA EM FUNÇÃO DO ÍNDICE DO FATOR PRINCIPAL

\begin{tabular}{|c|c|}
\hline LOCALIDADE & PERFIL SÓCIO-DEMOGRÁFICO \\
\hline GRUPO I & Perfil $<-1,01$ \\
\hline GRUPO II & $-1,00<$ Perfil $<-0,51$ \\
\hline GRUPO III & $-0,50<$ Perfil $<-0,01$ \\
\hline GRUPO IV & $0,00<$ Perfil $<0,99$ \\
\hline GRUPO V & Perfil $>1,00$ \\
\hline
\end{tabular}

Como já discutido em FÁVERO (2003, p. 46), adota-se que as localidades consideradas como sendo de perfil sócio-demográfico baixo são aquelas classificadas como sendo as pertencentes aos grupos I, II e III, uma vez que, para estes grupos, a heterogeneidade é menor, optando-se, portanto, pela aglomeração dos respectivos distritos do Município de São Paulo e Municípios da Região Metropolitana de São Paulo em uma única faixa. As localidades consideradas neste estudo como sendo de perfil sócio-demográfico médio são aquelas classificadas como grupo IV. Já as localidades classificadas como sendo pertencentes a um perfil sócio-demográfico alto referem-se ao grupo V. Esta classificação pode ser observada no quadro 4.3.5.2 a seguir.

QUADRO 4.3.5.2: CLASSIFICAÇÃO DAS FAIXAS DE RENDA EM FUNÇÃO DO ÍNDICE DO FATOR PRINCIPAL

\begin{tabular}{|c|c|}
\hline PERFIL SÓCIO-DEMOGRÁFICO & CLASSIFICAÇÃO \\
\hline BAIXO & Perfil $<-0,01$ \\
\hline MÉDIO & $0,00<$ Perfil $<0,99$ \\
\hline ALTO & Perfil $>1,00$ \\
\hline
\end{tabular}

De acordo com o critério apresentado no quadros 4.3.5.1 e 4.3.5.2, pode-se elaborar o mapa sócio-demográfico da Região Metropolitana de São Paulo (v. Anexos - Figura 22). A análise do mapa fornece informações que não se distanciam daquelas existentes em outras Metrópoles mundiais. Tal análise permite afirmar que as áreas centrais da Região Metropolitana de São Paulo, que coincidem com o centro do Município de São Paulo, apresentam indicadores socioeconômicos que sugerem a presença de um padrão de vida 
associado às classes mais ricas da população. Pertencem a este grupo também os Municípios de Santana de Parnaíba, São Bernardo do Campo e São Caetano do Sul. À medida que ocorre o distanciamento das áreas centrais, há a progressiva queda no padrão socioeconômico da população residente, atingindo os piores índices nos distritos limítrofes do Município de São Paulo, que acabam por formar extensas manchas de pobreza nas regiões leste e sul, conforme também apresentado por FÁVERO (2003, p. 47). O extremo norte da Região Metropolitana de São Paulo, representado pelo Município de Francisco Morato, também oferece condições sócio-demográficas inadequadas, de modo a propiciar o incremento da mancha de pobreza mencionada. Também fazem parte destas condições os Municípios de Ferraz de Vasconcelos e Itaquaquecetuba, que acabam por fazer divisa com o extremo leste do Município de São Paulo.

Por outro lado, quando o aumento do distanciamento da área central, para leste ou oeste, atinge os Municípios da Região Metropolitana, volta a aparecer uma condição sócio-demográfica associada a um perfil mais abastado, o que sugere a ausência ou fuga dos padrões de deterioração presentes nas regiões periféricas do Município central. A redução da densidade demográfica e a volta do aparecimento de condições propícias ao estabelecimento humano fazem com que Municípios como Mogi das Cruzes, Santo André, Ribeirão Pires, Guarulhos, São Lourenço da Serra, Cotia, Vargem Grande Paulista, Barueri, Caieiras e Pirapora do Bom Jesus apresentem perfis sócio-demográficos mais elevados. A própria presença de condomínios residenciais de médio e alto padrão em algumas destas localidades pode propiciar um incremento na média dos indicadores, elevando, por consequência, o próprio perfil sócio-demográfico.

Nas áreas limítrofes da Região Metropolitana de São Paulo, a oeste (mais especificamente a sudoeste), a leste e a nordeste, voltam a aparecer algumas condições sócio-demográficas adversas ao estabelecimento humano, e podem ser citados, como exemplo, os Municípios de Juquitiba, Biritiba Mirim, Salesópolis, Guararema e Santa Isabel. 
O objetivo deste trabalho não é avaliar os motivos pelos quais as localidades apresentam determinadas condições sócio-demográficas específicas, mas utilizar tais especificidades para a determinação de perfis semelhantes, tornando possível a estratificação em sub-amostras.

Procurou-se elaborar uma estratificação sócio-demográfica, uma vez que, como afirma SARTORIS NETO (1996, p. 45), uma divisão geográfica seria descabida, pois seria supor que a Zona Sul de São Paulo, por exemplo, onde estão localizadas as regiões dos Jardins, Santo Amaro e Parelheiros, teria, por si só, algum grau de homogeneidade. Assim, procurou-se a adequação aos já mencionados problemas de heterogeneidade e dependência espacial.

Ademais, quando da coleta de dados, deve-se reduzir problemas relacionados à presença de "ilhas" de riqueza inseridas em distritos de baixa renda, ou vice-versa. Desta forma, outliers em cada uma das faixas de renda devem ser excluídos, a fim de se manter uma maior homogeneidade e coerência entre os imóveis lançados e as respectivas características locais.

A seguir, no gráfico 4.3.5.1, pode-se analisar, para cada perfil sóciodemográfico, o número de distritos do Município de São Paulo e o número de Municípios da Região Metropolitana de São Paulo.

GRÁFICO 4.3.5.1: NÚMERO DE LOCALIDADES POR GRUPO SÓCIO-DEMOGRÁFICO

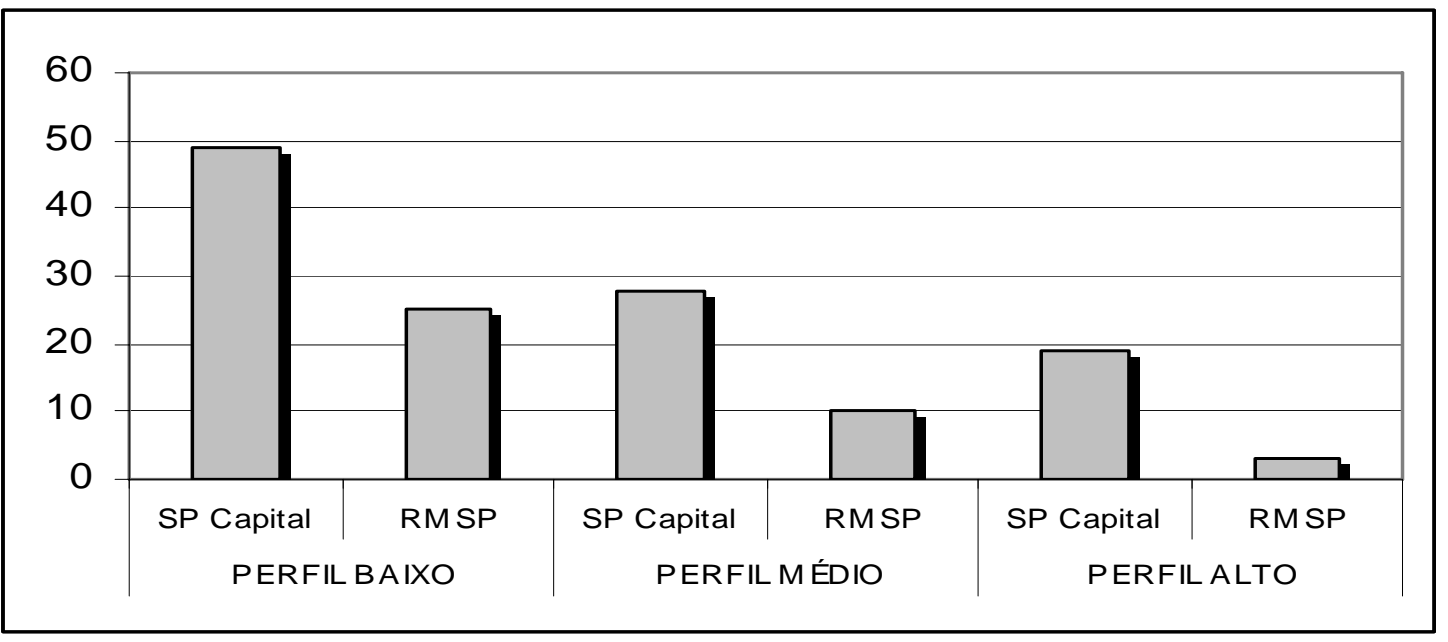




\section{4 - Dimensionamento da Amostra ${ }^{29}$}

Como uma pesquisa envolvendo todo o universo descrito no item 4.2 torna-se inviável do ponto de vista da coleta dos dados, opta-se pela utilização de amostras, para cada grupo de perfis sócio-demográficos (LEVY; LEMESHOW, 1999, p. 4). Assim, é desejada a determinação do tamanho de cada sub-amostra, de modo que a média amostral não se afaste da média populacional por mais de um valor de erro $\varepsilon$ com um nível de confiança $\gamma$.

A partir de BUSSAB e MORETTIN (2003, p. 280), há condições de se determinarem as dimensões amostrais para cada sub-população, em função de cada perfil sócio-demográfico ${ }^{30}$.

Como não se conhecem os desvios-padrão de cada sub-população, utilizaram-se amostras-piloto para estimá-los. Assim, tomaram-se 40 lançamentos residenciais para as localidades que compõem cada faixa de renda, e os desvios-padrão de cada amostra-piloto são apresentados na tabela 4.4.1 a seguir.

\footnotetext{
${ }^{29}$ Esse procedimento também foi utilizado em FÁVERO (2003, p. 33).

${ }^{30}$ A expressão que determina o tamanho de uma amostra para o estudo da média populacional, por meio de uma amostragem aleatória simples (BUSSAB; MORETTIN, 2003, p. 260-281), é:

$n=\frac{\sigma^{2} Z_{\gamma}^{2}}{\varepsilon^{2}}$

onde:

- n é o tamanho da amostra;

- $\sigma$ é o desvio-padrão da população;

- Z $\gamma$ é a abscissa da distribuição normal padrão, fixando um determinado nível de confiança $\gamma$;

- $\varepsilon$ é o erro amostral. Define-se $\varepsilon=5 \%$ e $\gamma=95 \%(\operatorname{logo} Z \gamma=1,96)$.
} 
TABELA 4.4.1: DESVIOS-PADRÃO DE CADA AMOSTRA-PILOTO, EM FUNÇÃO DE CADA GRUPO SÓCIO-DEMOGRÁFICO

PERFIL SÓCIO-DEMOGRÁFICO

DESVIO-PADRÃO DA AMOSTRA-PILOTO

$\begin{array}{lc}\text { BAIXO } & 0,63 \\ \text { MÉDIO } & 0,54 \\ \text { ALTO } & 0,52\end{array}$

A partir da tabela 4.4.1 e da definição do erro $\varepsilon$ do nível de confiança $\gamma$, podem ser calculados os tamanhos de cada sub-amostra. A tabela 4.4.2, a seguir, apresenta os resultados.

TABELA 4.4.2: DETERMINAÇÃO DO TAMANHO DA SUB-AMOSTRA PARA CADA GRUPO SÓCIODEMOGRÁFICO

PERFIL SÓCIO-DEMOGRÁFICO

TAMANHO DA SUB-AMOSTRA

\begin{tabular}{lc}
\hline BAIXO & 610 \\
MÉDIO & 449 \\
ALTO & 416 \\
\hline $\begin{array}{l}\text { NOTA: Todos as aproximações foram feitas para o número inteiro acima do valor calculado, a fim de } \\
\text { minimizar o erro quando do arredondamento. }\end{array}$
\end{tabular}

A fim de garantir uma homogeneização da coleta e uma melhor estruturação do banco de dados, optou-se por uma quantidade igual de imóveis em cada sub-amostra. Como as sub-amostras deste trabalho são obtidas por conveniência $^{31}$, a fim de se evitar a não utilização de dados representativos da população, serão utilizados todos os dados coletados para cada grupo sóciodemográfico, obviamente excluindo-se dados inconsistentes e não significativos da respectiva localidade. Logo, o número utilizado como tamanho

$\overline{{ }^{31} \text { Como será explicado no item 4.7. }}$ 
de cada sub-amostra será igual a 620, o que inclusive minimizará os erros amostrais.

Portanto, a fim de que seja mantida a proporção de unidades residenciais comercializadas entre os meses de Janeiro e Dezembro de $2004^{32}$, apresenta-se, a seguir, na tabela 4.4.3, o número de imóveis que deverão compor cada sub-amostra.

TABELA 4.4.3: PROPORÇÃO DE CADA SUB-AMOSTRA, EM FUNÇÃO DO GRUPO SÓCIODEMOGRÁFICO E DO MÊS DE COMERCIALIZAÇÃO

\begin{tabular}{cccc}
\hline MÊS & $\begin{array}{c}\mathbf{N}^{\circ} \text { DE APARTAMENTOS } \\
\text { RESIDENCIAIS } \\
\text { COMERCIALIZADOS }\end{array}$ & PROPORÇÃO NO ANO & $\begin{array}{c}\text { DIMENSÃO DE CADA SUB- } \\
\text { AMOSTRA }\end{array}$ \\
\hline Jan / 04 & 1.591 & $7,9 \%$ & 49 \\
Fev / 04 & 1.216 & $6,0 \%$ & 37 \\
Mar / 04 & 2.065 & $10,2 \%$ & 63 \\
Abr / 04 & 1.826 & $9,0 \%$ & 56 \\
Mai / 04 & 1.211 & $6,0 \%$ & 37 \\
Jun / 04 & 1.314 & $6,5 \%$ & 40 \\
Jul / 04 & 1.028 & $5,1 \%$ & 32 \\
Ago / 04 & 1.553 & $7,7 \%$ & 48 \\
Set / 04 & 2.062 & $10,2 \%$ & 63 \\
Out / 04 & 2.290 & $11,3 \%$ & 70 \\
Nov / 04 & 1.812 & $9,0 \%$ & 69 \\
\hline Dez / 04 & 2.215 & $11,0 \%$ & 620 \\
\hline & TOTAL PARA CADA SUB-AMOSTRA & 56 \\
\hline
\end{tabular}

${ }^{32}$ Conforme tabela 3.3.1. 


\section{5 - Modelo Teórico de Pesquisa}

Como apresentado no item 1.3, este estudo tem por objetivo efetuar a valoração de atributos de oferta e demanda para a composição das condições comerciais de imóveis residenciais em lançamento entre os meses de Janeiro e Dezembro de 2004, para cada perfil sócio-demográfico da Região Metropolitana de São Paulo estabelecido previamente. A figura 4.5.1, a seguir, propõe um melhor entendimento do que se deseja.

FIGURA 4.5.1: MODELO TEÓRICO DA PESQUISA

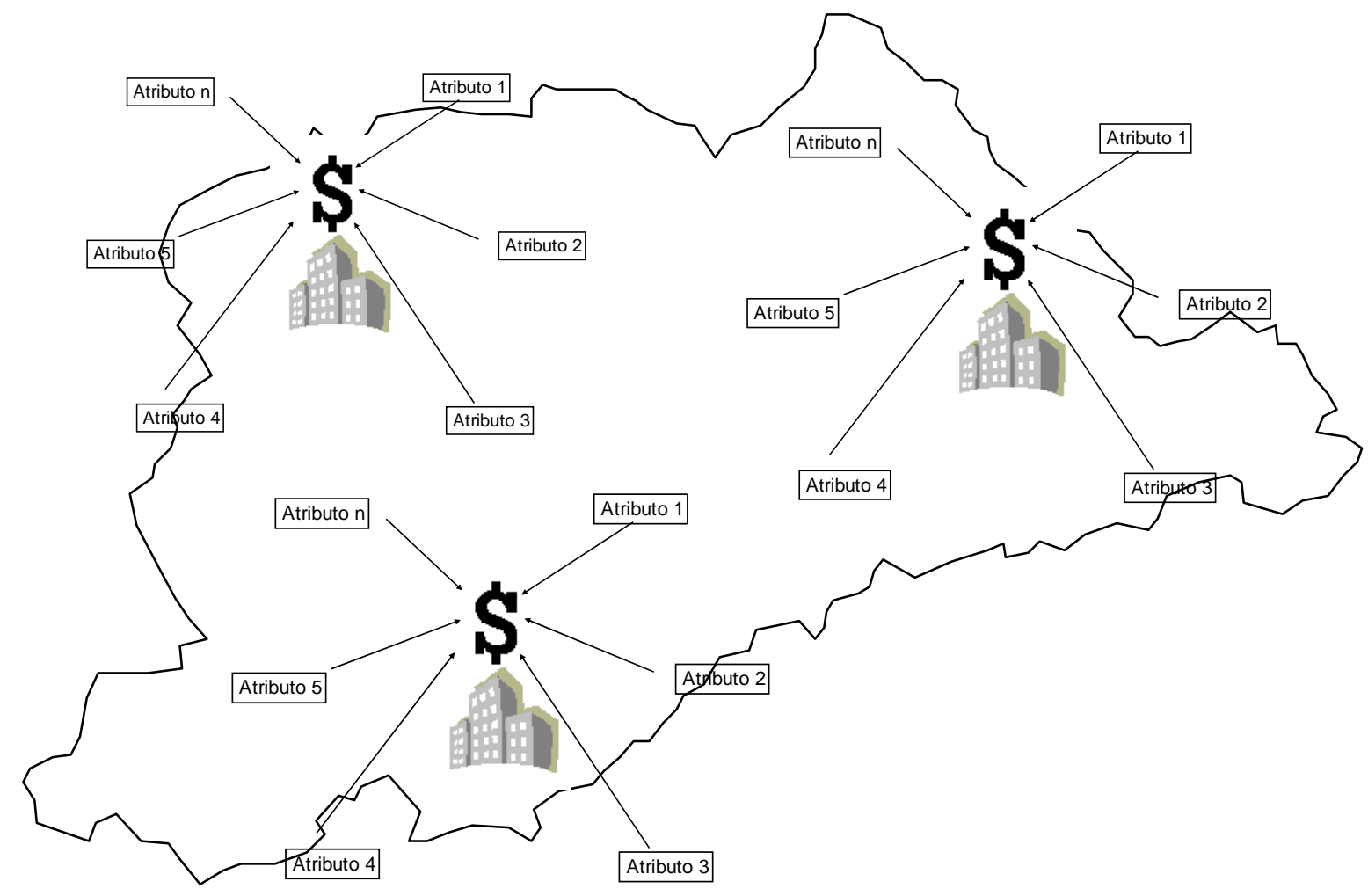

O modelo utilizado pode ser sub-dividido em dois, que correspondem, respectivamente, à definição dos preços, por meio de atributos intrínsecos e extrínsecos aos imóveis, e à definição de condições comerciais (preços e condições de pagamento) em função dos atributos mencionados. O primeiro modelo será elaborado por meio da técnica econométrica de regressão 
múltipla, seguindo os dois estágios de ROSEN (1974). O segundo, por meio da utilização da técnica multivariada de correlação canônica.

Anteriormente à apresentação dos modelos propriamente ditos, faz-se necessária a definição das variáveis explicativas (independentes) e variáveis dependentes a serem utilizadas neste trabalho.

\section{6 - Definição das Variáveis Independentes}

A fim de possibilitar a determinação das variáveis explicativas para a inclusão nos modelos hedônicos de regressão e correlação canônica, foi enviada por correio eletrônico, de acordo com o método já adotado por FÁVERO (2003, p 38), a seguinte pergunta aberta para 30 profissionais do mercado imobiliário:

"Quais características são mais representativas para a formação das condições comerciais dos imóveis (apartamentos) residenciais em lançamento na Região Metropolitana de São Paulo?"

O número de respostas obtido, também por e-mail, foi 19. Tal número, embora baixo, permite selecionar muitas variáveis intrínsecas e extrínsecas relacionadas à oferta, possibilitando a definição de algumas das variáveis independentes a serem utilizadas nos modelos.

Para que seja evitada a exclusão de alguma variável representativa, todas as variáveis mencionadas pelos especialistas serão incluídas nos modelos. Segundo as respostas, as características que podem explicar as condições comerciais dos apartamentos residenciais em lançamento na Região Metropolitana de São Paulo e que serão, portanto, inseridas nos modelos hedônicos, para que as verificações possam ser elaboradas sob a ótica da oferta, são apresentadas no quadro 4.6 .1 a seguir. 
QUADRO 4.6.1: CARACTERÍSTICAS CITADAS POR ESPECIALISTAS COMO SENDO IMPORTANTES PARA A COMPOSIÇÃO, SOB A ÓTICA DA OFERTA, DAS CONDIÇÕES COMERCIAIS DOS APARTAMENTOS EM LANÇAMENTO NA REGIÃO METROPOLITANA DE SÃO PAULO, E A RESPECTIVA CLASSIFICAÇÃO SEGUNDO ROSEN

\begin{tabular}{|c|c|c|}
\hline CARACTERÍSTICA & VARIÁVEL & $\begin{array}{l}\text { CLASSIFICAÇÃO } \\
\text { SEGUNDO ROSEN }\end{array}$ \\
\hline $\begin{array}{l}\text { PROXIMIDADE DE COLÉGIO } \\
\text { PARTICULAR }\end{array}$ & EXTRÍNSECA & $\mathrm{W}$ ou $\mathrm{Y}_{2}$ \\
\hline PROXIMIDADE DE SHOPPING CENTER & EXTRÍNSECA & $\mathrm{W}$ ou $\mathrm{Y}_{2}$ \\
\hline $\begin{array}{c}\text { PROXIMIDADE DE ESTAÇÃO DE } \\
\text { METRÔ }\end{array}$ & EXTRÍNSECA & $\mathrm{W}$ ou $\mathrm{Y}_{2}$ \\
\hline $\begin{array}{l}\text { PROXIMIDADE DE HOSPITAL } \\
\text { PARTICULAR }\end{array}$ & EXTRÍNSECA & $\mathrm{W}$ ou $\mathrm{Y}_{2}$ \\
\hline $\begin{array}{c}\text { PROXIMIDADE DE PARQUE E ÁREAS } \\
\text { VERDES }\end{array}$ & EXTRÍNSECA & $\mathrm{W}$ ou $\mathrm{Y}_{2}$ \\
\hline $\begin{array}{l}\text { PONTOS DE INUNDAÇÃO NA } \\
\text { LOCALIDADE }\end{array}$ & EXTRÍNSECA & W ou $Y_{2}$ \\
\hline $\begin{array}{l}\text { EXISTÊNCIA DE ATERROS OU LIXÕES } \\
\text { NA LOCALIDADE }\end{array}$ & EXTRÍNSECA & $\mathrm{W}$ ou $\mathrm{Y}_{2}$ \\
\hline $\begin{array}{l}\text { DENSIDADE DEMOGRÁFICA DA } \\
\text { LOCALIDADE }\end{array}$ & EXTRÍNSECA & W ou $Y_{2}$ \\
\hline POPULAÇÃO DA LOCALIDADE & EXTRÍNSECA & $\mathrm{W}$ ou $\mathrm{Y}_{2}$ \\
\hline ÁREA TOTAL DO IMÓVEL & INTRÍNSECA & z \\
\hline $\begin{array}{c}\text { EXISTÊNCIA DE SALÃO DE FESTAS NO } \\
\text { CONDOMÍNIO }\end{array}$ & INTRÍNSECA & z \\
\hline $\begin{array}{c}\text { EXISTÊNCIA DE SALÃO DE JOGOS NO } \\
\text { CONDOMÍNIO }\end{array}$ & INTRÍNSECA & z \\
\hline $\begin{array}{l}\text { EXISTÊNCIA DE SALA DE GINÁSTICA } \\
\text { NO CONDOMÍNIO }\end{array}$ & INTRÍNSECA & z \\
\hline $\begin{array}{l}\text { EXISTÊNCIA DE PISCINA NO } \\
\text { CONDOMÍNIO }\end{array}$ & INTRÍNSECA & z \\
\hline $\begin{array}{l}\text { EXISTÊNCIA DE SAUNA NO } \\
\text { CONDOMÍNIO }\end{array}$ & INTRÍNSECA & z \\
\hline $\begin{array}{c}\text { EXISTÊNCIA DE CHURRASQUEIRA NO } \\
\text { CONDOMÍNIO }\end{array}$ & INTRÍNSECA & z \\
\hline $\begin{array}{l}\text { EXISTÊNCIA DE QUADRA NO } \\
\text { CONDOMÍNIO }\end{array}$ & INTRÍNSECA & z \\
\hline $\begin{array}{c}\text { EXISTÊNCIA DE VARANDA NO } \\
\text { APARTAMENTO }\end{array}$ & INTRÍNSECA & z \\
\hline $\begin{array}{c}\text { ALTURA RELATIVA DO APARTAMENTO } \\
\text { NO EDIFÍCIO }\end{array}$ & INTRÍNSECA & z \\
\hline $\begin{array}{l}\text { QUANTIDADE DE VAGAS DE GARAGEM } \\
\text { POR APARTAMENTO }\end{array}$ & INTRÍNSECA & z \\
\hline
\end{tabular}




\begin{tabular}{|c|c|c|}
\hline $\begin{array}{c}\text { QUANTIDADE DE DORMITÓRIOS NO } \\
\text { APARTAMENTO }\end{array}$ & INTRÍNSECA & $\mathrm{z}$ \\
\hline $\begin{array}{c}\text { QUANTIDADE DE BANHEIROS NO } \\
\text { APARTAMENTO }\end{array}$ & INTRÍNSECA & $\mathrm{z}$ \\
\hline
\end{tabular}

Conforme apresentado no item 2.2, z representa o vetor de variáveis intrínsecas do modelo, $\mathrm{Y}_{1}$ é o vetor de variáveis extrínsecas que afetam exclusivamente a demanda, $Y_{2}$ é o vetor de variáveis extrínsecas que afetam exclusivamente a oferta e $\mathrm{W}$ representa o vetor de variáveis extrínsecas que afetam a demanda e a oferta. Como ainda não se sabe com clareza se as variáveis extrínsecas mencionadas afetam exclusivamente a oferta ou a oferta e a demanda, optou-se por deixar, momentaneamente, tais variáveis classificadas com $\mathrm{W}$ ou $\mathrm{Y}_{2}$.

Além do questionamento efetuado junto aos profissionais do mercado imobiliário, foi feita uma pergunta similar a alguns compradores de apartamentos, que efetivamente adquiriram um imóvel durante o ano de 2004. A partir de uma lista com 30 contatos, apenas 9 pessoas responderam à questão (sendo 3 para cada perfil sócio-demográfico). Salienta-se que esta forma de abordagem tem como intuito apenas selecionar as variáveis explicativas que serão utilizadas nos modelos de regressão e correlação canônica, sob a ótica da demanda. Ademais, a citação de uma variável específica por apenas um dos respondentes de um determinado perfil sóciodemográfico não a excluirá da lista de possíveis variáveis independentes, uma vez que a respectiva significância estatística obtida nas técnicas multivariadas é que vai determinar a sua inclusão definitiva nos modelos. A referida pergunta encontra-se a seguir.

"Quais características o levaram a adquirir um imóvel residencial (apartamento) na Região Metropolitana de São Paulo no ano de 2004?"

Utilizando o mesmo critério adotado para os especialistas, todas as variáveis mencionadas pelos compradores serão incluídas nos modelos. Segundo as respostas, as características que podem explicar as condições comerciais de apartamentos residenciais em lançamento na Região 
Metropolitana de São Paulo e que serão, portanto, inseridas nos modelos hedônicos, para que as verificações possam ser elaboradas sob a ótica da demanda, são apresentadas no quadro 4.6.2 a seguir.

QUADRO 4.6.2: CARACTERÍSTICAS CITADAS POR COMPRADORES COMO SENDO IMPORTANTES PARA A DECISÃO DE COMPRA (ÓTICA DA DEMANDA) DE APARTAMENTOS EM LANÇAMENTO NA REGIÃO METROPOLITANA DE SÃO PAULO, E A RESPECTIVA CLASSIFICAÇÃO SEGUNDO ROSEN

\begin{tabular}{|c|c|c|}
\hline CARACTERÍSTICA & VARIÁVEL & $\begin{array}{l}\text { CLASSIFICAÇÃO } \\
\text { SEGUNDO ROSEN }\end{array}$ \\
\hline $\begin{array}{l}\text { PROXIMIDADE DE COLÉGIO } \\
\text { PARTICULAR }\end{array}$ & EXTRÍNSECA & W ou $Y_{1}$ \\
\hline PROXIMIDADE DE SHOPPING CENTER & EXTRÍNSECA & W ou $Y_{1}$ \\
\hline $\begin{array}{c}\text { PROXIMIDADE DE ESTAÇÃO DE } \\
\text { METRÔ }\end{array}$ & EXTRÍNSECA & W ou $Y_{1}$ \\
\hline $\begin{array}{c}\text { PROXIMIDADE DE HOSPITAL } \\
\text { PARTICULAR }\end{array}$ & EXTRÍNSECA & W ou $Y_{1}$ \\
\hline $\begin{array}{c}\text { PROXIMIDADE DE PARQUE E ÁREAS } \\
\text { VERDES }\end{array}$ & EXTRÍNSECA & W ou $Y_{1}$ \\
\hline $\begin{array}{l}\text { PONTOS DE INUNDAÇÃO NA } \\
\text { LOCALIDADE }\end{array}$ & EXTRÍNSECA & W ou $Y_{1}$ \\
\hline $\begin{array}{c}\text { EXISTÊNCIA DE ATERROS OU LIXÕES } \\
\text { NA LOCALIDADE }\end{array}$ & EXTRÍNSECA & W ou $Y_{1}$ \\
\hline RENDA FAMILIAR & EXTRÍNSECA & $\mathrm{W}$ ou $\mathrm{Y}_{1}$ \\
\hline NÚMERO DE MEMBROS DA FAMÍLIA & EXTRÍNSECA & $W$ ou $Y_{1}$ \\
\hline ÁREA TOTAL DO IMÓVEL & INTRÍNSECA & z \\
\hline $\begin{array}{c}\text { EXISTÊNCIA DE SALÃO DE FESTAS NO } \\
\text { CONDOMÍNIO }\end{array}$ & INTRÍNSECA & z \\
\hline $\begin{array}{c}\text { EXISTÊNCIA DE SALÃO DE JOGOS NO } \\
\text { CONDOMÍNIO }\end{array}$ & INTRÍNSECA & z \\
\hline $\begin{array}{c}\text { EXISTÊNCIA DE SALA DE GINÁSTICA } \\
\text { NO CONDOMÍNIO }\end{array}$ & INTRÍNSECA & z \\
\hline $\begin{array}{l}\text { EXISTÊNCIA DE PISCINA NO } \\
\text { CONDOMÍNIO }\end{array}$ & INTRÍNSECA & z \\
\hline $\begin{array}{c}\text { EXISTÊNCIA DE CHURRASQUEIRA NO } \\
\text { CONDOMÍNIO }\end{array}$ & INTRÍNSECA & z \\
\hline $\begin{array}{l}\text { EXISTÊNCIA DE QUADRA NO } \\
\text { CONDOMÍNIO }\end{array}$ & INTRÍNSECA & z \\
\hline $\begin{array}{l}\text { EXISTÊNCIA DE GUARITA NO } \\
\text { CONDOMÍNIO }\end{array}$ & INTRÍNSECA & z \\
\hline
\end{tabular}




\begin{tabular}{|c|c|c|}
\hline $\begin{array}{c}\text { EXISTÊNCIA DE CÂMERAS E CIRCUITO } \\
\text { FECHADO DE TV NO CONDOMÍNIO }\end{array}$ & INTRÍNSECA & z \\
\hline $\begin{array}{c}\text { EXISTÊNCIA DE VARANDA NO } \\
\text { APARTAMENTO }\end{array}$ & INTRÍNSECA & z \\
\hline $\begin{array}{c}\text { QUANTIDADE DE VAGAS DE GARAGEM } \\
\text { POR APARTAMENTO }\end{array}$ & INTRÍNSECA & $\mathrm{z}$ \\
\hline $\begin{array}{c}\text { QUANTIDADE DE DORMITÓRIOS NO } \\
\text { APARTAMENTO }\end{array}$ & INTRÍNSECA & $\mathrm{z}$ \\
\hline $\begin{array}{c}\text { QUANTIDADE DE BANHEIROS NO } \\
\text { APARTAMENTO }\end{array}$ & INTRIINSECA & \\
\hline
\end{tabular}

Por meio dos quadros 4.6.1 e 4.6.2 há condições de se classificarem as variáveis segundo ROSEN. Logo, as variáveis intrínsecas a serem inseridas nos modelos (vetor z) são todas as variáveis mencionadas pelos especialistas e pelos compradores, segundo os critérios adotados por ROSEN (1974, p. 3455), e podem ser observadas no quadro 4.6 .3 a seguir. 
QUADRO 4.6.3: O VETOR z DE CARACTERÍSTICAS INSTRÍNSECAS

\begin{tabular}{|c|c|}
\hline ITEM & CARACTERÍSTICA \\
\hline 01 & ÁREA TOTAL DO IMÓVEL \\
\hline 02 & EXISTÊNCIA DE SALÃO DE FESTAS NO CONDOMÍNIO \\
\hline 03 & EXISTÊNCIA DE SALÃO DE JOGOS NO CONDOMÍNIO \\
\hline 04 & $\begin{array}{l}\text { EXISTÊNCIA DE SALA DE GINÁSTICA NO } \\
\text { CONDOMÍNIO }\end{array}$ \\
\hline 05 & EXISTÊNCIA DE PISCINA NO CONDOMÍNIO \\
\hline 06 & EXISTÊNCIA DE SAUNA NO CONDOMÍNIO \\
\hline 07 & EXISTÊNCIA DE CHURRASQUEIRA NO CONDOMÍNIO \\
\hline 08 & EXISTÊNCIA DE QUADRA NO CONDOMÍNIO \\
\hline 09 & EXISTÊNCIA DE GUARITA NO CONDOMÍNIO \\
\hline 10 & $\begin{array}{c}\text { EXISTÊNCIA DE CÂMERAS E CIRCUITO FECHADO DE } \\
\text { TV NO CONDOMÍNIO }\end{array}$ \\
\hline 11 & EXISTÊNCIA DE VARANDA NO APARTAMENTO \\
\hline 12 & ALTURA RELATIVA DO APARTAMENTO NO EDIFÍCIO \\
\hline 13 & $\begin{array}{l}\text { QUANTIDADE DE VAGAS DE GARAGEM POR } \\
\text { APARTAMENTO }\end{array}$ \\
\hline 14 & QUANTIDADE DE DORMITÓRIOS NO APARTAMENTO \\
\hline 15 & QUANTIDADE DE BANHEIROS NO APARTAMENTO \\
\hline
\end{tabular}

Ainda por meio dos quadros 4.6.1 e 4.6.2 é possível definir os vetores $\mathrm{Y}_{1}$ e $Y_{2}$, apresentados nos quadros 4.6 .4 e 4.6.5, respectivamente. O vetor $Y_{1}$ é composto pelas variáveis extrínsecas que afetam exclusivamente a demanda e, portanto, são as variáveis extrínsecas que não se encontram no quadro 4.6.1. O vetor $Y_{2}$, por sua vez, é representado pelas variáveis que se encontram apenas no referido quadro. 
QUADRO 4.6.4: O VETOR $\mathrm{Y}_{1}$ DE CARACTERÍSTICAS EXTRÍNSECAS QUE AFETAM EXCLUSIVAMENTE A DEMANDA

\begin{tabular}{|c|c|}
\hline ITEM & CARACTERÍSTICA \\
\hline 01 & RENDA FAMILIAR \\
\hline 02 & NÚMERO DE MEMBROS DA FAMÍLIA \\
\hline
\end{tabular}

$O$ vetor $Y_{2}$ é apresentado a seguir.

QUADRO 4.6.5: O VETOR $Y_{2}$ DE CARACTERÍSTICAS EXTRÍNSECAS QUE AFETAM EXCLUSIVAMENTE A OFERTA

\begin{tabular}{|c|c|}
\hline ITEM & CARACTERÍSTICA \\
\hline 01 & DENSIDADE DEMOGRÁFICA DA LOCALIDADE \\
\hline 02 & POPULAÇÃO DA LOCALIDADE \\
\hline
\end{tabular}

Por fim, as demais variáveis extrínsecas que são mencionadas pelos especialistas e pelos compradores (e, portanto, estão incluídas nos quadros 4.6.1 e 4.6.2) compõem o vetor $W$, já que afetam a demanda e a oferta. Tais variáveis são apresentadas no quadro 4.6.6 a seguir. 
QUADRO 4.6.6: O VETOR W DE CARACTERÍSTICAS EXTRÍNSECAS QUE AFETAM A DEMANDA E A OFERTA

\begin{tabular}{|c|c|}
\hline ITEM & CARACTERÍSTICA \\
\hline 01 & PROXIMIDADE DE COLÉGIO PARTICULAR \\
\hline 02 & PROXIMIDADE DE SHOPPING CENTER \\
\hline 03 & PROXIMIDADE DE ESTAÇÃO DE METRÔ \\
\hline 04 & PROXIMIDADE DE HOSPITAL PARTICULAR \\
\hline 05 & PROXIMIDADE DE PARQUE E ÁREAS VERDES \\
\hline 06 & PONTOS DE INUNDAÇÃO NA LOCALIDADE \\
\hline 07 & EXISTÊNCIA DE ATERROS OU LIXÕES NA \\
\hline
\end{tabular}

Com as variáveis apresentadas, faz-se necessária a definição do modo como elas serão inseridas nos modelos. O quadro 4.6.7, a seguir, apresenta a definição das variáveis hedônicas explicativas dos modelos. 
QUADRO 4.6.7: DEFINIÇÃO DAS VARIÁVEIS HEDÔNICAS EXPLICATIVAS

\begin{tabular}{|c|c|}
\hline VARIÁVEL & DEFINIÇÃO DA VARIÁVEL \\
\hline COLP & Colégio Particular $=1 ;$ Não $=0$ \\
\hline SHOP & Shopping Center = 1; Não = 0 \\
\hline METR & Estação de Metrô = 1; Não = 0 \\
\hline HOSP & Hospital Particular $=1 ;$ Não $=0$ \\
\hline PARQ & Parques e Áreas Verdes = 1; Não = 0 \\
\hline INUN & Pontos de Inundação = 1; Não = 0 \\
\hline ATER & Aterros ou Lixões = 1; Não = 0 \\
\hline DENS & Densidade Demográfica da Localidade \\
\hline POP & População da Localidade \\
\hline RND & Renda Familiar \\
\hline MEMB & Número de Membros da Família \\
\hline AREA & Área Total do Imóvel \\
\hline SFES & Salão de Festas no Condomínio = 1; Não = 0 \\
\hline SJOG & Salão de Jogos no Condomínio = 1; Não = 0 \\
\hline SGIN & Sala de Ginástica no Condomínio = 1; Não = 0 \\
\hline PISC & Piscina no Condomínio = 1; Não = 0 \\
\hline SAUN & Sauna no Condomínio = 1; Não = 0 \\
\hline CHUR & Churrasqueira no Condomínio = 1; Não = 0 \\
\hline QUAD & Quadra no Condomínio = 1; Não = 0 \\
\hline GUAR & Guarita no Condomínio = 1; Não = 0 \\
\hline CFTV & Câmeras e CFTV no Condomínio = 1; Não = 0 \\
\hline VARD & Varanda no Apartamento $=1 ;$ Não $=0$ \\
\hline ALTR & $\begin{array}{l}\text { Altura Relativa do Apartamento no Edifício: } \\
\text { Metade Superior do Edifício = } 1 \text {; Não = } 0\end{array}$ \\
\hline VAGA1 e VAGA2 & $\begin{array}{c}\text { Vagas na Garagem: } \\
\text { Se VAGA1 = } 0 \text { e VAGA2 = 0: } 01 \text { vaga } \\
\text { Se VAGA1 = } 1 \text { e VAGA2 = 0: } 02 \text { vagas } \\
\text { Se VAGA1 }=0 \text { e VAGA2 }=1: 03 \text { vagas }\end{array}$ \\
\hline DORM1, DORM2, DORM3 e DORM4 & $\begin{aligned} & \text { Dormitórios no Apartamento: } \\
& \text { Se DORM1 }=0, \text { DORM2 }=0, \text { DORM3 }=0 \text { e DORM4 }=0: 01 \text { dormitório } \\
& \text { Se DORM1 }=1, \text { DORM2 }=0, \text { DORM3 }=0 \text { e DORM4 }=0: 02 \text { dormitórios } \\
& \text { Se DORM1 }=0, \text { DORM2 }=1, \text { DORM3 }=0 \text { e DORM4 }=0: 03 \text { dormitórios } \\
& \text { Se DORM1 }=0, \text { DORM2 }=0, \text { DORM3 }=1 \text { e DORM4 }=0: 04 \text { dormitórios } \\
& \text { Se DORM1 }=0, \text { DORM2 }=0, \text { DORM3 }=0 \text { e DORM4 }=1: 05 \text { dormitórios }\end{aligned}$ \\
\hline
\end{tabular}




\begin{tabular}{|c|c|}
\hline Banheiros no Apartamento: \\
& Se BANH1 $=0, \mathrm{BANH} 2=0, \mathrm{BANH} 3=0$ e BANH4 $=0: 01$ banheiro \\
& Se BANH1 $=1, \mathrm{BANH} 2=0, \mathrm{BANH} 3=0$ e BANH4 $=0: 02$ banheiros \\
BANH1, BANH2, BANH3 e BANH4 & Se BANH1 $=0, \mathrm{BANH} 2=1, \mathrm{BANH} 3=0$ e BANH4 $=0: 03$ banheiros \\
& Se BANH1 $=0, \mathrm{BANH} 2=0, \mathrm{BANH} 3=1$ e BANH4 $=0: 04$ banheiros \\
& Se BANH1 $=0, \mathrm{BANH} 2=0, \mathrm{BANH} 3=0$ e BANH4 $=1: 05$ banheiros \\
\hline
\end{tabular}

Segundo VASCONCELLOS e ALVES (2000, p. 92) e ROGERS (2000, p. 208-213), a utilização de uma única variável que abrange números inteiros representando quantidades, quando da construção do banco de dados, para cada variável que apresenta poucas possibilidades de ocorrência (como número de dormitórios, banheiros e vagas na garagem) assume que as diferenças entre cada possibilidade provocam diferenças de mesma magnitude nas condições comerciais dos imóveis, o que justifica a utilização de uma variável dummy ${ }^{33}$ para cada possibilidade. A forma de coleta dos dados de cada variável independente será descrita no item 4.7 a seguir.

\section{7 - Coleta de Dados das Variáveis Independentes}

A seguir, apresenta-se, no quadro 4.7.1, a forma de coleta de dados para cada variável extrínseca apresentada nos quadros 4.6.4, 4.6.5 e 4.6.6.

QUADRO 4.7.1: FORMA DE COLETA PARA CADA VARIÁVEL EXPLICATIVA EXTRÍNSECA

\begin{tabular}{|c|c|}
\hline VARIÁVEL & FORMA DE COLETA \\
& sites: \\
COLP & http://atlasambiental.prefeitura.sp.gov.br/ \\
& Acesso em 30 jan.2005 \\
& http://www.seade.gov.br/produtos/imp/ \\
& Acesso em 30 jan 2005 \\
\hline SHOP & sites: \\
& http://atlasambiental.prefeitura.sp.gov.br/ \\
\hline
\end{tabular}

\footnotetext{
${ }^{33}$ Segundo VANCONCELLOS e ALVES (2000, p. 89), o artifício das variáveis dummy, ou binárias, permite incluir o efeito de variáveis qualitativas, categóricas ou mesmo variáveis mensuráveis, quando o importante for a distribuição em classes.
} 


\begin{tabular}{|c|c|}
\hline & $\begin{array}{c}\text { Acesso em } 30 \text { jan.2005 } \\
\text { http://www.seade.gov.br/produtos/imp/ } \\
\text { Acesso em } 30 \text { jan } 2005\end{array}$ \\
\hline METR & $\begin{array}{c}\text { site: } \\
\text { http://www.metro.sp.gov.br } \\
\text { Acesso em 06 fev.2005 } \\
\text { (v. Anexos - Figuras 23 a 25) }\end{array}$ \\
\hline HOSP & $\begin{array}{c}\text { sites: } \\
\text { http://atlasambiental.prefeitura.sp.gov.br/ } \\
\text { Acesso em } 12 \text { fev.2005 } \\
\text { http://www.seade.gov.br/produtos/imp/ } \\
\text { Acesso em } 12 \text { fev } 2005\end{array}$ \\
\hline PARQ & $\begin{array}{c}\text { sites: } \\
\text { http://atlasambiental.prefeitura.sp.gov.br/ } \\
\text { Acesso em } 13 \text { fev } 2005 \\
\text { http://www.seade.gov.br/produtos/imp/ } \\
\text { Acesso em } 13 \text { fev } 2005\end{array}$ \\
\hline INUN & $\begin{array}{c}\text { MEYER, GROSTEIN e BIDERMAN (2004, p. 104) } \\
\text { (v. Anexos - Figura 26) }\end{array}$ \\
\hline ATER & $\begin{array}{c}\text { MEYER, GROSTEIN e BIDERMAN (2004, p. 105) } \\
\text { (V. Anexos - Figura 27) }\end{array}$ \\
\hline RND & $\begin{array}{c}\text { sites: } \\
\text { http://atlasambiental.prefeitura.sp.gov.br/ } \\
\text { Acesso em } 30 \text { jan } 2005 \\
\text { http://www.seade.gov.br/produtos/imp/ } \\
\text { Acesso em } 30 \text { jan } 2005 \\
\text { http://www.ibge.gov.br } \\
\text { Acesso em } 30 \text { jan } 2005\end{array}$ \\
\hline MEMB & $\begin{array}{c}\text { sites: } \\
\text { http://www.seade.gov.br/produtos/imp/ } \\
\text { Acesso em } 30 \text { jan } 2005 \\
\text { http://www.ibge.gov.br } \\
\text { Acesso em } 30 \text { jan } 2005\end{array}$ \\
\hline DENS & $\begin{array}{c}\text { sites: } \\
\text { http://atlasambiental.prefeitura.sp.gov.br/ } \\
\text { Acesso em } 30 \text { jan } 2005\end{array}$ \\
\hline
\end{tabular}




\begin{tabular}{|c|c|}
\hline & http://www.seade.gov.br/produtos/imp/ \\
& Acesso em 30 jan 2005 \\
\hline POP & sites: \\
& http://atlasambiental.prefeitura.sp.gov.br/ \\
& Acesso em 30 jan 2005 \\
& http://www.seade.gov.br/produtos/imp/ \\
& Acesso em 30 jan 2005 \\
& http://www.ibge.gov.br \\
& Acesso em 30 jan 2005 \\
\hline
\end{tabular}

Os dados referentes às variáveis explicativas intrínsecas foram coletados, por meio de sorteio aleatório, a partir de anúncios de lançamentos imobiliários residenciais publicados nos cadernos de imóveis dos jornais "Folha de São Paulo" e "O Estado de São Paulo", e dos sites de oferta imobiliária http://www.imovelweb.com.br e http://www.planetaimovel.com.br, com coleta realizada entre os meses de Janeiro e Dezembro de 2004. O levantamento teve o cuidado de não incluir apenas imóveis lançados sem a respectiva comercialização, já que podem não apresentar características relevantes sob a ótica da demanda. Assim sendo, verificou-se a comercialização dos imóveis ofertados nos meios mencionados, com o intuito de incluir no banco de dados características que sejam eventualmente ${ }^{34}$ relevantes não somente à oferta, mas também à demanda, respeitando-se, dentro de cada mês, a proporcionalidade do total das sub-amostras, para cada perfil sóciodemográfico definido. Logo, a amostragem deste trabalho pode ser considerada como sendo de conveniência.

Em seguida, no item 4.8, serão discutidas as variáveis dependentes dos modelos hedônicos.

\footnotetext{
${ }^{34}$ Utilizou-se o termo eventualmente, uma vez que a relevância propriamente dita de cada variável independente será verificada por meio dos modelos de regressão e correlação canônica, sob a ótica da oferta e da demanda, para cada grupo sócio-demográfico.
} 


\section{8 - Definição e Coleta das Variáveis Dependentes}

Nos modelos hedônicos de regressão múltipla, a variável dependente é representada pelo preço de comercialização do imóvel, que foi coletado por meio dos já mencionados veículos de mídia impressa (cadernos de imóveis dos jornais "Folha de São Paulo" e "O Estado de São Paulo") e dos sites de oferta imobiliária http://www.imovelweb.com.br e http://www.planetaimovel.com.br.

Analogamente ao método de coleta realizado para as variáveis independentes, o levantamento realizado para as variáveis dependentes verificou a comercialização dos imóveis inseridos na amostra, com o intuito de respeitar a inclusão de variáveis eventualmente relevantes à oferta e à demanda.

As demais condições comerciais, que se relacionam com as formas de financiamento imobiliário e com os valores relativos à primeira parcela, também foram coletadas da mesma forma que os preços dos imóveis. Segundo VIEIRA SOBRINHO (2000, p. 220-260), os sistemas de financiamento mais utilizados no Brasil são o Sistema Francês (Tabela Price) ${ }^{35}$, o Sistema de Amortização Constante (SAC) e o Sistema de Amortização Misto (SAM). Enquanto o primeiro é largamente utilizado em todos os setores financeiros e de capitais, os dois últimos são mais utilizados pelo Sistema Financeiro de Habitação para as operações de financiamento para aquisição de casa própria.

O Sistema Francês consiste em um plano de amortização de uma dívida em prestações periódicas iguais e sucessivas, em que o valor de cada uma, ou pagamento, é composto por duas parcelas distintas: uma de juros e outra de capital (chamada de amortização). O Sistema de Amortização Constante, por outro lado, consiste em um plano de amortização de uma dívida em prestações periódicas sucessivas e decrescentes em progressão aritmética. Já o Sistema de Amortização Misto, criado pelo BNH em maio de 1979, constitui-se numa mescla entre os dois sistemas anteriormente mencionados, em que o plano de

\footnotetext{
${ }^{35}$ A denominação Tabela Price deve-se ao nome do matemático, filósofo e teólogo inglês Richard Price, que viveu no século XVIII e que incorporou a teoria dos juros compostos às amortizações de empréstimos e financiamentos. A denominação Sistema Francês deve-se ao fato de o mesmo ter se desenvolvido efetivamente na França, no século XIX.
} 
pagamentos é composto por prestações resultantes da média aritmética dos valores determinados pelos planos Francês e SAC, correspondentes aos respectivos prazos.

Como o objetivo deste trabalho não é analisar as formas de financiamento imobiliário, mas verificar, por meio de uma correlação canônica, quais variáveis explicativas são mais representativas para a composição de um conjunto de aspectos que compõem as condições comerciais do imóvel, definese que o número de parcelas e o valor referente à primeira delas também farão parte da composição do vetor de variáveis dependentes a serem utilizadas na referida técnica multivariada. Este critério é confirmado pelos especialistas que afirmam serem o número de parcelas do financiamento imobiliário e o valor da primeira, em muitos casos, mais determinantes para a formação das condições comerciais do que a própria forma de financiamento, já que, quando do lançamento de um determinado empreendimento residencial, são estas as informações divulgadas por incorporadoras, imobiliárias e construtoras. A seguir, na figura 4.8.1, apresenta-se uma relação entre os valores de cada prestação e o sistema de amortização, destacando-se a importância do valor inicial (diferente para cada plano) na condução do financiamento.

FIGURA 4.8.1: RELAÇÃO ENTRE OS VALORES DE PRESTAÇÃO E OS SISTEMAS DE AMORTIZAÇÃO

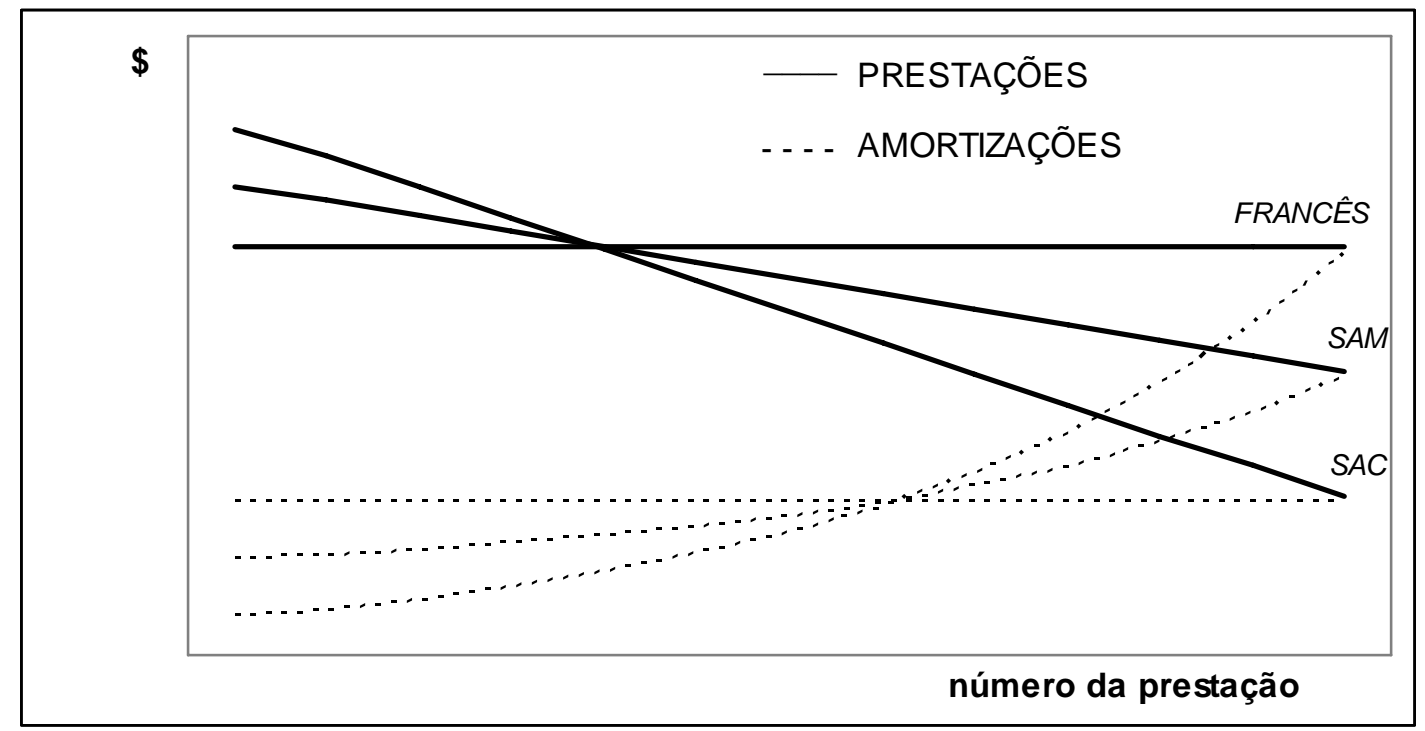

FONTE: VIEIRA SOBRINHO (2000, p. 254). 
Com as variáveis definidas, elaborar-se-á a apresentação dos modelos que serão aqui estudados.

\section{9 - Regressão ${ }^{36}$ Múltipla}

Segundo HAIR, ANDERSON, TATHAM e BLACK (1998, p. 148), a análise de regressão múltipla é uma técnica estatística que pode ser utilizada para se analisar a relação entre uma única variável dependente e muitas variáveis independentes e, de acordo com WOOLDRIDGE (2003, p. 68), propicia o estudo das influências simultâneas das diversas variáveis explicativas sobre a variável dependente, propiciando a avaliação das relações de causalidade.

O objetivo da regressão múltipla é o uso de variáveis independentes para a predição de uma variável dependente selecionada, sendo cada variável independente avaliada e mensurada. Os pesos representam a contribuição relativa de cada variável independente e facilitam a interpretação da influência de cada uma delas, embora uma eventual correlação existente possa prejudicar a interpretação (HAIR; ANDERSON; TATHAM; BLACK, 1998, p. 148-149).

Torna-se, portanto, necessária a apresentação dos modelos a serem utilizados. Seguindo a análise de LINNEMAN (1980, p. 47-68) sobre as características das residências, pode-se definir que o valor de uma residência é função de suas características, bem como daquelas associadas aos atributos relacionados à mesma. Assim:

$$
V_{i}=V\left(C_{i}, A_{i}\right)
$$

\footnotetext{
${ }^{36}$ O termo regressão é uma referência à aplicação pioneira realizada por Francis Galton e Karl Pearson na estimação de uma reta representativa da relação entre altura dos filhos e altura dos pais. Os dois autores estavam interessados em provar a validade de uma suposta "lei da regressão universal”, que estabelecia que as características de uma pessoa eram transmitidas de pai para filho de forma amortecida (VASCONCELLOS; ALVES, 2000, p. 21).
} 
onde $V_{i}$ é o preço associado a cada unidade residencial, $C$ representa o vetor das características intrínsecas associadas à residência e $A$, o vetor das características extrínsecas (ARYEETEY-ATTOH, 1992, p. 185) ${ }^{37}$.

Em relação à melhor forma funcional a ser elaborada em modelos hedônicos, FOUTO (2004, p. 28-29) apresenta as mais usadas em trabalhos que utilizam a formulação em suas diversas aplicações. A síntese de sua exposição pode ser observada no quadro 4.9 .1 a seguir.

QUADRO 4.9.1: FORMAS FUNCIONAIS MAIS UTILIZADAS

\begin{tabular}{|c|c|}
\hline CLASSIFICAÇÃO & FORMA FUNCIONAL \\
\hline Linear & $p=\beta_{0}+\Sigma \beta_{n} z_{n}$ \\
\hline Exponencial & $\ln p=\ln \beta_{0}+\Sigma \beta_{n} z_{n}$ \\
\hline Potência ou Logarítmica & $\ln p=\ln \beta_{0}+\Sigma \beta_{n} \ln z_{n}$ \\
\hline Semilogarítmica & $\ln p=\beta_{0}+\Sigma \beta_{n} z_{n}$ \\
\hline Recíproca & $p=\beta_{0}+\Sigma \beta_{n}\left(1 / z_{n}\right)$ \\
\hline Quadrática & $p=\beta_{0}+\sum \beta_{n} z_{n}+\sum \beta_{n+1} z_{n}^{2}$ \\
\hline Logística & $\ln (p / 1-p)=\beta_{0}+\sum \beta_{n} z_{n}$ \\
\hline Interação & $p=\beta_{0}+\Sigma \beta_{n} z_{n}+\sum \beta_{n+1} z_{n} k$ \\
\hline
\end{tabular}

FONTE: FOUTO (2004, p. 29).

$\mathrm{Na}$ forma linear, observa-se que o coeficiente da regressão $\beta_{\mathrm{n}}$ indica o efeito marginal da variação do preço em relação à variação da n-ésima característica $\mathrm{z}_{\mathrm{n}}$ do produto. No modelo exponencial, os coeficientes da regressão podem ser interpretados como taxas de crescimento. Já na formulação de potência, também denominada de logarítmica ${ }^{38}$, os coeficientes dos regressores podem ser interpretados como elasticidades parciais, indicando o efeito percentual de aumento de $\mathrm{p}$ em um determinado nível, se a n-ésima característica $z_{n}$ apresentar uma variação de um ponto percentual, fato

\footnotetext{
${ }^{37}$ A soma dos vetores C e A é o vetor de características z de LANCASTER. Já para ROSEN (1974, p. 3455), apenas o vetor $C$ representa o vetor $z$, sendo $A$ o vetor que representa os vetores $Y_{1}, Y_{2}$ e W.

38 FOUTO (2004, p. 28-29) denomina a formulação de potência de $\log -\log$ e a formulação semilogarítmica de logarítmica. Apenas para manter a coerência de nomenclatura neste trabalho, serão mantidas as denominações semilogarítmica e logarítmica (potência).
} 
que não ocorre na especificação semilogarítmica, uma vez que, segundo HALVORSEN e PALMQUIST (1980, p. 474-475), em equações semilogarítmicas de regressão, isto só é válido se a variável independente não for uma dummy. Quando a variável for dummy, seu coeficiente multiplicado por 100 não representa o efeito percentual desta variável sobre aquela que está sendo explicada (variável dependente). A formulação matemática proposta pelos referidos autores está detalhada em anexo (v. Anexos - Item C).

Segundo AGUIRRE e MACEDO (1996, p. 3-4), a teoria econométrica não define um melhor critério em relação à definição da forma funcional da expressão que relaciona o preço e os atributos intrínsecos e extrínsecos de um dado imóvel. Contudo, a partir do trabalho de LINNEMAN (1980, p. 47-68), muitos estudos sobre preços em mercados de moradias urbanas abordam 0 assunto como uma questão empírica a ser decidida a favor do melhor ajuste dos dados, por meio da transformação de variáveis proposta por BOX e COX (1964, p. 211-252). Esta transformação de variáveis será utilizada no presente trabalho e permite ampliar o conjunto de formas funcionais passíveis de representar a relação entre as variáveis explicativas e a variável dependente, tornando possível a inclusão tanto das formas mais frequentemente utilizadas nos estudos existentes, como a linear, a semilogarítmica e a logarítmica, como também de outras formas não-lineares. Alguns trabalhos podem ser citados em relação a qual modelo foi utilizado, na definição de preços de imóveis residenciais em diversas cidades do mundo, como, por exemplo, os semilogarítmicos de QUIGLEY (1982, p. 177-201) e de ARYEETEY-ATTOH (1992, p. 183-198) e o logarítmico de LEEUW (1993, p. 33-42).

De acordo com AGUIRRE e MACEDO (1996, p. 4-5), os modelos de preços hedônicos relacionam os preços de imóveis ao conjunto de características demandadas pelos compradores da seguinte forma:

$$
p=\alpha_{0}+\sum_{1}^{n} \beta_{i} z_{i}+u
$$


onde $\mathrm{p}$ é o preço do imóvel, $\beta$ é o vetor de coeficientes de regressão, z é o vetor de características da unidade residencial e u é o vetor de choques estocásticos.

$\mathrm{Na}$ perspectiva da determinação da forma funcional do modelo apresentado em (44), sugere-se a aplicação da transformação de Box-Cox que implica a extensão das formas tradicionalmente usadas (casos particulares da transformação de Box-Cox) a um contínuo de formas não-lineares alternativas.

Pela transformação de Box-Cox, substitui-se p por $\left(p_{i}^{\theta}-1\right) / \theta$. Assim sendo, a equação (44) pode ser expressa da seguinte forma:

$$
\frac{p^{\theta}-1}{\theta}=\alpha_{0}+\sum_{1}^{n} \beta_{i}\left(\frac{z_{i}^{\lambda}-1}{\lambda}\right)+u
$$

onde $p, \beta, z$ e u têm o mesmo significado que na equação (44), e $\theta$ e $\lambda$ são os parâmetros das transformações de Box-Cox. A transformação permite verificar que a especificação linear corresponde a parâmetros $\theta=1$ e $\lambda=1$, a especificação semilogarítmica, a parâmetros $\theta=0$ e $\lambda=1$, e a especificação logarítmica, a valores $\theta=0$ e $\lambda=0$. A expressão $\left(p_{i}^{\theta}-1\right) / \theta$ parece ser indeterminada quando $\theta=0$, porém, elaborando-se a sua expansão em séries de Taylor, segundo SIMON e BLUME (1994, p. 872), encontra-se:

$$
\frac{p_{i}^{\theta}-1}{\theta}=\log p_{i}+\frac{\theta}{2 !}\left(\log p_{i}\right)^{2}+\frac{\theta^{2}}{3 !}\left(\log p_{i}\right)^{3}+\ldots
$$

onde, para $\theta=0$, tem-se que:

$$
\frac{p_{i}^{\theta}-1}{\theta}=\log p_{i}
$$

A seguir, na figura 4.9.1, são apresentadas as soluções que relacionam $p$ com a expressão $\left(p_{i}^{\theta}-1\right) / \theta$, em função da variação de $\theta$. Deve-se ressaltar 
que, quando $\theta$ é muito próximo de 0 (no exemplo apresentado na figura 4.9.1 utilizou-se $\theta=0,00001)$, a curva $\left(p_{i}{ }^{\theta}-1\right) / \theta$ sobrepõe-se à curva $\log (p)$, conforme já demonstrado pela expansão de Taylor.

FIGURA 4.9.1: A TRANSFORMAÇÃO DE BOX-COX

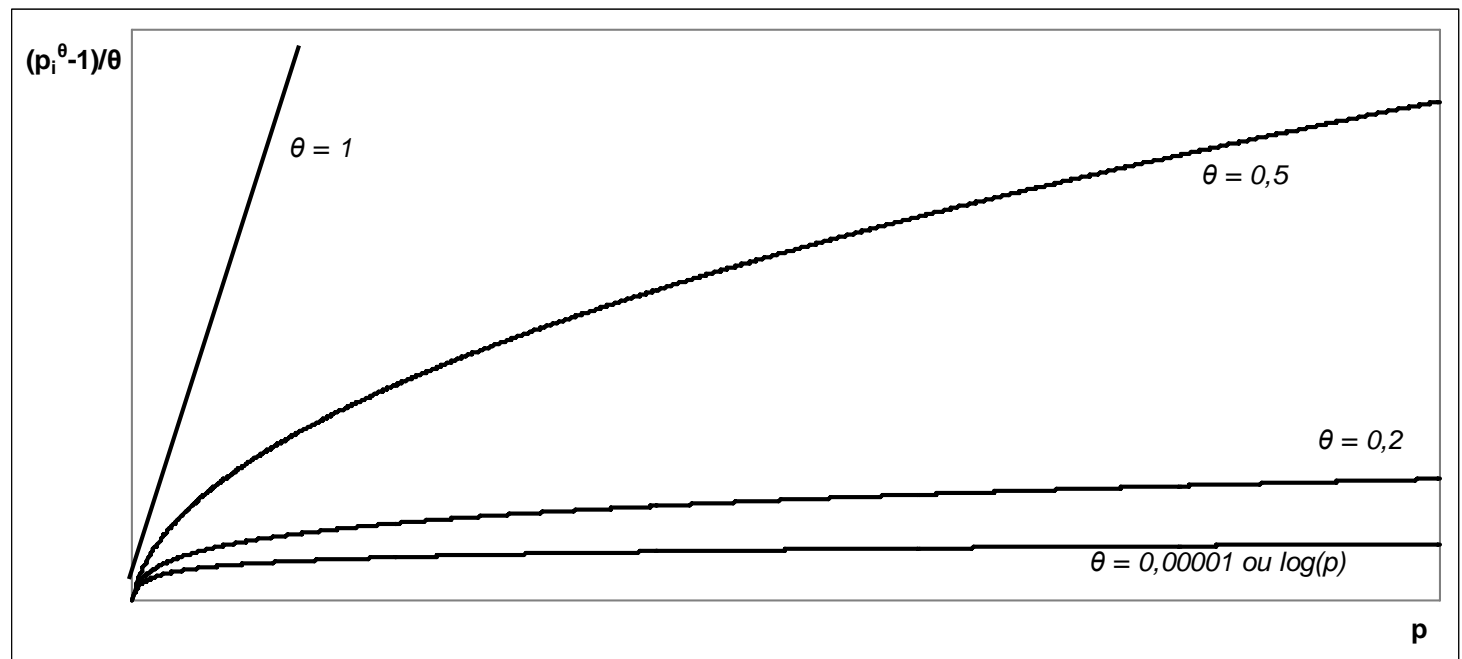

Quaisquer outros valores de $\theta$ e $\lambda$ podem maximizar o coeficiente de ajuste da regressão, oferecendo uma especificação não-linear adequada. Neste trabalho, serão utilizados, para efeito de escolha da melhor especificação no primeiro estágio de Rosen, os modelos semilogarítmico $(\theta=0$ e $\lambda=1$ ), logarítmico ( $\theta=0$ e $\lambda=0$ ) e os resultantes de transformações de Box-Cox para valores de $\theta$ e $\lambda$ variando de 0 a 1 , com intervalos de 0,1 . Além disto, também serão testadas as especificações quadrática e cúbica para a variável explicativa não binária (área total do imóvel).

Como discutido no item 2.2, o primeiro estágio consiste na estimação da função $\mathrm{p}(\mathrm{z})$, considerando-se apenas as características $\mathrm{z}$ intrínsecas aos imóveis. A função resultante passa então a ser $\hat{p}(z)$, permitindo-se o cálculo de um conjunto de preços marginais implícitos, que corresponde a $d \hat{p}(z) / d z_{i}=\hat{p}_{i}(z)$, para cada um dos compradores e vendedores de cada grupo sócio-demográfico. No segundo estágio do método de Rosen, utilizam-se os preços marginais estimados $\hat{p}_{i}(z)$ como variáveis dependentes para a estimação das equações do modelo. Deste modo, a função $p(z)$, para o 
primeiro estágio do método, não pode ser linear, uma vez que, caso fosse, os valores $\hat{p}_{i}(z)$ seriam constantes para todos os valores de $z_{i}$, o que inviabilizaria qualquer possibilidade de utilização dos mesmos na segunda etapa. Logo, p(z), por hipótese, deve ser duplamente diferenciável, como já discutido no item 2.2, e a variável $z_{i}$, que será utilizada para a elaboração da diferenciação de $p(z)$, será a área total do imóvel, já que é a única variável do vetor z que não é dummy.

Desta forma, o primeiro estágio de Rosen corresponde à seguinte expressão:

$$
p=f(z, A R E A)
$$

que representa a equação definida pelo método de Box-Cox descrito anteriormente e possibilita a determinação das expressões de demanda e oferta do segundo estágio.

Já para o segundo estágio de Rosen, que define as equações de oferta e demanda com a inclusão de variáveis extrínsecas que as afetam, será utilizado o modelo definido como sendo a melhor especificação dentre aquelas estudadas no primeiro estágio. Logo, as equações do segundo estágio de Rosen são apresentadas a seguir.

$$
\begin{aligned}
& \text { Demanda: } \quad(\partial p / \partial A R E A)=f\left(z, A R E A, Y_{1}, W\right) \\
& \text { Oferta: } \quad(\partial p / \partial A R E A)=f\left(z, A R E A, Y_{2}, W\right)
\end{aligned}
$$

Como o segundo estágio representa uma estimação de modelos de equações simultâneas, as equações de oferta e demanda serão estimadas, se necessário, pelo método de mínimos quadrados de dois estágios, uma vez que algumas das variáveis independentes podem ser endógenas, ou seja, correlacionadas com o termo do erro por conta da existência de uma outra 
variável omitida ou por conta da simultaneidade com a variável dependente. Serão primeiramente elaborados os testes de endogeneidade propostos por HAUSMAN (1978, p. 1251-1271) para a verificação da necessidade de aplicação do método dos mínimos quadrados de dois estágios e, caso não seja necessário, será aplicado o método tradicional dos mínimos quadrados ordinários. Segundo WOOLDRIDGE (2003, P. 506), os testes de endogeneidade são aplicados por meio da comparação do método dos mínimos quadrados ordinários e do método dos mínimos quadrados de dois estágios e, se as diferenças forem estatisticamente significantes, há pelo menos uma variável endógena, fazendo sentido a aplicação do método dos mínimos quadrados de dois estágios. De acordo com o mesmo autor, os estimadores provenientes do método dos mínimos quadrados de dois estágios são menos eficientes do que aqueles resultantes do método dos mínimos quadrados ordinários quando as variáveis explicativas forem exógenas, porém oferecem resultados não viesados quando há a existência de variáveis explicativas endógenas. Segundo GUJARATI (2000, p. 676) e WOOLDRIDGE (2003, p. 506), a verificação se dá por meio de modelos intermediários de regressão, nos quais são regredidas as variáveis suspeitas de endogeneidade com as outras variáveis explicativas e com os resíduos resultantes. Em anexo (v. Anexos - Item D), é apresentada a formalização do modelo de verificação de endogeneidade proposta por WOOLDRIDGE (2003, p. 506).

Com a verificação de existência de endogeneidade em variáveis explicativas, faz-se necessária a verificação do problema de identificação, comum às modelagens de equações de oferta e demanda. Segundo GUJARATI (2000, p. 663-680), o problema consiste na possibilidade de identificação, por meio da verificação da existência de variáveis endógenas em modelos de oferta e demanda, dos valores numéricos dos parâmetros de uma equação. Se isto for possível, diz-se que a equação em particular está identificada. Caso contrário, a equação pode ser considerada não identificada. A verificação dos problemas de identificação e de existência de endogeneidade é abordada, mais especificamente em modelos hedônicos, por BROWN e ROSEN (1982, p. 765-768), PALMQUIST (1984, p. 394-404), MENDELSOHN 
(1984, p. 673-677), MENDELSOHN (1985, p. 525-529), PARSONS (1986, p. 347-363), BARTIK (1987a, p. 178-180), BARTIK (1987b, p. 81-88), EPPLE (1987, p. 59-80), KAHN e LANG (1988, p. 157-166), EKELAND, HECKMAN e NESHEIM (2002, p. 304-309) e KOUNDOURI e PASHARDES (2003, p. 45-56). Em anexo ( $v$. Anexos - Item E), é apresentada a formalização do problema de identificação em sistemas de duas equações, com as condições de ordem e posto pertinentes à situação.

Muitos outros cuidados devem ser tomados quando da aplicação da técnica de regressão múltipla, como aqueles relacionados à verificação da existência de autocorrelação entre os resíduos, à presença de heterocedasticidade e à multicolinearidade das variáveis independentes.

Segundo VASCONCELLOS e ALVES (2000, p. 113), o problema de autocorrelação entre os resíduos deve-se ao fato de o resíduo incorporar os efeitos de uma variável que foi excluída do modelo, e pode ser testada por meio do teste de Durbin-Watson. Além disto, uma especificação incorreta da forma funcional do modelo pode ser responsável pela geração de resíduos autocorrelacionados. Em anexo ( $v$. Anexos - Item F), apresenta-se a formulação do teste e, a seguir, na figura 4.9.2, ilustra-se o problema da autocorrelação dos resíduos.

FIGURA 4.9.2: O PROBLEMA DA AUTOCORRELAÇÃO DOS RESÍDUOS
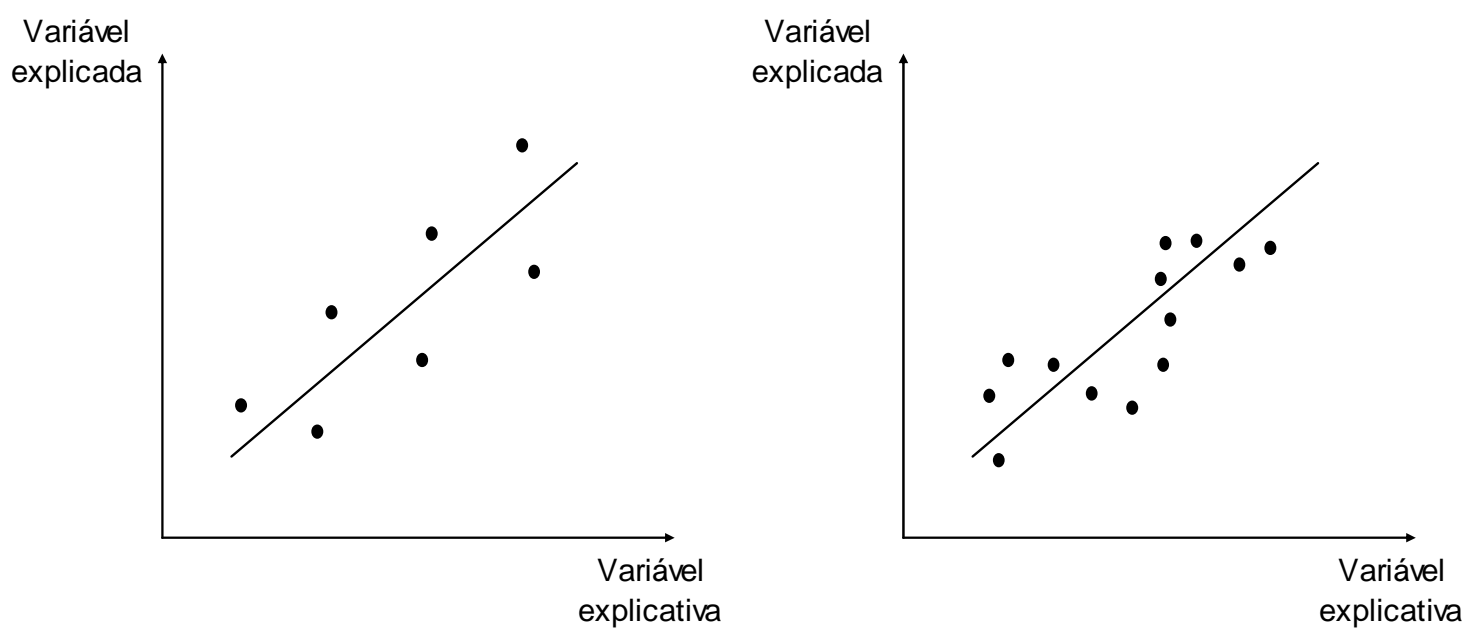

FONTE: VASCONCELLOS e ALVES (2000, p. 31). 
A presença de heterocedasticidade também será testada, por meio do teste de Glejser ${ }^{39}$, uma vez que falhas na especificação do modelo podem gerar um resíduo heterocedástico, ou seja, à medida que ocorre um incremento de uma variável explicativa, há um aumento na dispersão de pontos. Isto implica que a variância do termo aleatório será tanto maior quanto maiores forem os valores da variável explicativa, ou vice-versa. Em anexo (v. Anexos Item G), apresenta-se a formulação do teste de Glejser e, a seguir, na figura 4.9.3, ilustra-se o problema da heterocedasticidade.

FIGURA 4.9.3: O PROBLEMA DA HETEROCEDASTICIDADE
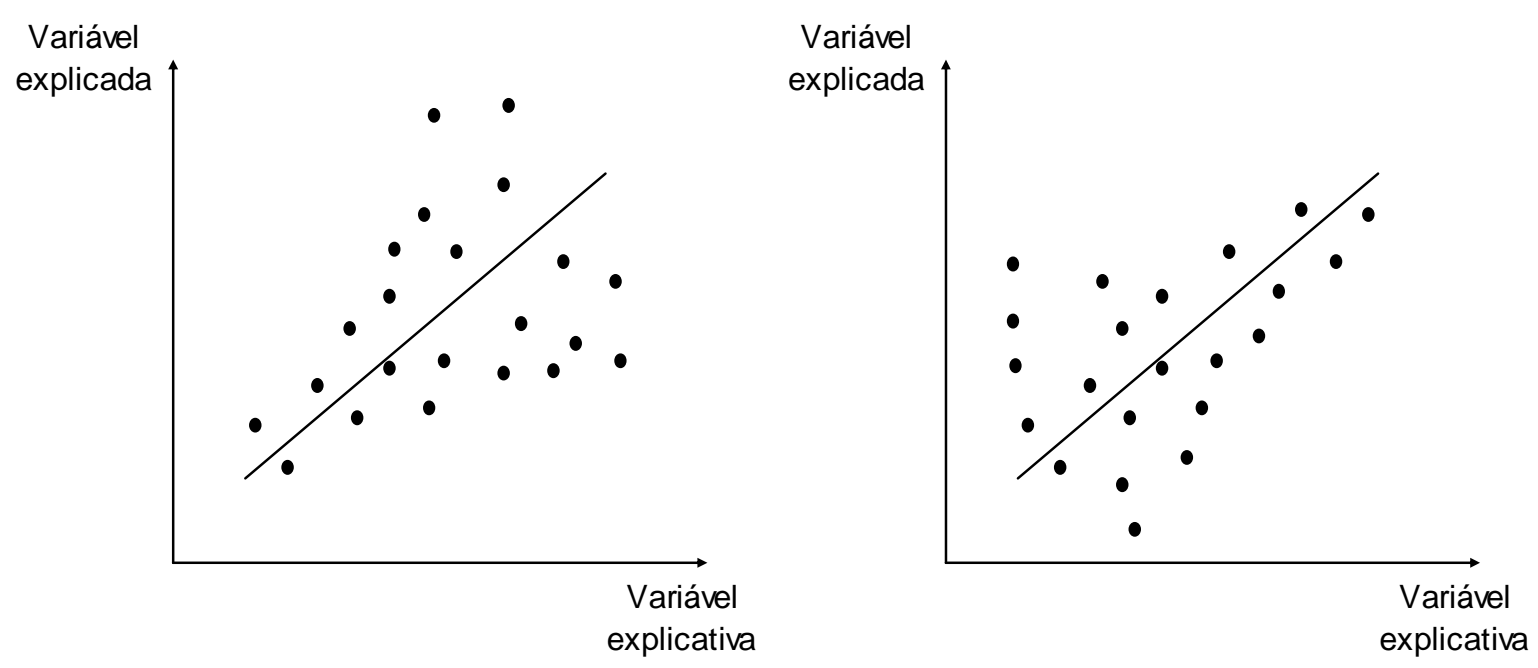

FONTE: VASCONCELLOS e ALVES (2000, p. 119).

Uma vez que muitas das variáveis explicativas a serem consideradas neste estudo podem apresentar comportamentos semelhantes, ou seja, entre algumas delas pode existir uma correlação maior do que se espera teoricamente, como decorrência ou da seleção de uma amostra coletada por conveniência ou do número insuficiente de observações, a existência de multicolinearidade também deve ser verificada, por meio da análise dos coeficientes de correlação simples entre cada par de variáveis $^{40}$ (VASCONCELLOS; ALVES, 2000, p. 140).

\footnotetext{
${ }^{39}$ Em (VASCONCELLOS; ALVES, 2000, p. 123).

${ }^{40}$ A facilidade desse método é contrabalançada pela sua inadequação no caso da existência de uma interrelação entre mais de duas variáveis (VASCONCELLOS; ALVES, 2000, p. 142).
} 
Com a elaboração das verificações mencionadas e da determinação da representatividade de cada variável explicativa, torna-se necessária a comparação, para cada grupo sócio-demográfico, da importância relativa de cada uma delas. Além disto, torna-se possível comparar a igualdade dos parâmetros de cada variável entre os grupos sócio-demográficos definidos, por meio da aplicação do teste Chow (CHOW, 1960, p. 591-605), utilizado por LEISHMAN (2001, p. 131-152) para o mercado imobiliário. O teste consiste na avaliação dos parâmetros de duas equações de regressão, com o intuito de testar a hipótese nula de que os parâmetros dos atributos de dois mercados diferentes são iguais. Como este trabalho trata de três grupos sóciodemográficos, serão aplicados três testes Chow (dois a dois) para as equações de oferta e três para as equações de demanda. Uma explicação pormenorizada deste teste pode ser encontrada em anexo (v. Anexos - Item $\mathrm{H}$ ).

Assim, apresentam-se, no quadro 4.9.2, a seguir, as etapas que serão abordadas quando da elaboração dos modelos de regressão, bem como os respectivos métodos e o propósito de cada uma delas. 
QUADRO 4.9.2: AS ETAPAS DA REGRESSÃO, COM OS RESPECTIVOS PROPÓSITOS E MÉTODOS

\begin{tabular}{|c|c|c|}
\hline ETAPA & PROPÓSITO & MÉTODO \\
\hline $\begin{array}{l}\text { Determinação dos modelos de } \\
\text { oferta e demanda. }\end{array}$ & $\begin{array}{l}\text { Avaliar qual é a melhor forma funcional } \\
\text { para cada grupo sócio-demográfico. }\end{array}$ & $\begin{array}{l}\text { - Método de Rosen em } \\
\text { dois estágios. } \\
\text { - Método de Box-Cox. }\end{array}$ \\
\hline $\begin{array}{l}\text { Verificação da presença de } \\
\text { variáveis endógenas nas } \\
\text { equações de oferta e demanda. }\end{array}$ & $\begin{array}{l}\text { Verificar se há a necessidade de } \\
\text { aplicação do método dos mínimos } \\
\text { quadrados de dois estágios. }\end{array}$ & $\begin{array}{l}\text { - Teste de } \\
\text { endogeneidade. }\end{array}$ \\
\hline $\begin{array}{l}\text { Verificação de problemas de } \\
\text { identificação em equações de } \\
\text { oferta e demanda. }\end{array}$ & $\begin{array}{l}\text { Avaliar se há alguma equação (oferta ou } \\
\text { demanda) que apresenta problemas em } \\
\text { relação à determinação dos valores } \\
\text { numéricos dos seus parâmetros. }\end{array}$ & $\begin{array}{l}\text { - Condições de ordem. } \\
\text { - Condições de posto. }\end{array}$ \\
\hline $\begin{array}{l}\text { Verificação da existência de } \\
\text { autocorrelação entre os } \\
\text { resíduos. }\end{array}$ & $\begin{array}{l}\text { Verificar se os resíduos incorporam os } \\
\text { efeitos de uma variável que foi excluída } \\
\text { do modelo, ou se o referido modelo } \\
\text { apresenta uma especificação incorreta } \\
\text { da forma funcional. }\end{array}$ & $\begin{array}{l}\text { - Teste de Durbin- } \\
\text { Watson. }\end{array}$ \\
\hline $\begin{array}{l}\text { Verificação de problemas de } \\
\text { heterocedasticidade. }\end{array}$ & $\begin{array}{l}\text { Avaliar se há falhas na especificação do } \\
\text { modelo que possam gerar um resíduo } \\
\text { heterocedástico, ou seja, correlacionado } \\
\text { com alguma variável explicativa. }\end{array}$ & - Teste de Glejser. \\
\hline $\begin{array}{l}\text { Verificação de problemas de } \\
\text { multicolinearidade. }\end{array}$ & $\begin{array}{l}\text { Avaliar se entre algumas das variáveis } \\
\text { explicativas há uma alta correlação. }\end{array}$ & $\begin{array}{l}\text { - Análise de correlação } \\
\text { simples. }\end{array}$ \\
\hline $\begin{array}{l}\text { Comparação da igualdade dos } \\
\text { parâmetros de cada variável } \\
\text { entre os grupos sócio- } \\
\text { demográficos. }\end{array}$ & $\begin{array}{l}\text { Verificar se as diferenças entre as } \\
\text { equações de demanda e entre as } \\
\text { equações de oferta são significativas } \\
\text { para cada um dos grupos sócio- } \\
\text { demográficos. }\end{array}$ & - Teste Chow. \\
\hline
\end{tabular}

\subsection{0 - Correlação Canônica}

Segundo HAIR, ANDERSON, TATHAM e BLACK (1998, p. 445), o conceito de correlação canônica foi primeiramente proposto por HOTELLING (1936, p. 321-377), e é uma técnica estatística que permite a avaliação da relação entre variáveis independentes múltiplas (métricas ou não métricas) e variáveis dependentes também múltiplas (métricas ou não métricas). Portanto, a correlação canônica é considerada uma técnica geral a partir da qual muitas 
outras técnicas são baseadas. E sendo considerada uma extensão da técnica de regressão, o objetivo da correlação canônica é quantificar a força da relação existente entre dois vetores de variáveis, representados pelas dependentes e pelas independentes. Como discutem ALPERT e PETERSON (1972, p. 187192) e DOUTRIAUX e CRENER (1982, p. 99-111), a correlação canônica identifica a estrutura ótima de cada vetor de variáveis que maximiza a relação entre as variáveis dependentes e as variáveis independentes, desenvolvendo uma combinação linear para cada conjunto de variáveis de modo a maximizar a correlação entre os dois conjuntos.

Nesta parte do trabalho, é aplicada a técnica de correlação canônica para avaliar as eventuais inter-relações entre as variáveis intrínsecas e extrínsecas representativas dos modelos de regressão e as variáveis que compõem as condições comerciais dos imóveis, sob a ótica da demanda e da oferta, para cada grupo sócio-demográfico.

Como o intuito é apenas verificar as inter-relações entre as variáveis explicativas e as variáveis comerciais de venda dos imóveis, para cada perfil sócio-demográfico, aplicar-se-á apenas a relação linear entre elas, uma vez que a correlação canônica representa, linearmente, a relação entre conjuntos e, portanto, qualquer relação não-linear não será captada pela correlação canônica (HAIR; ANDERSON; TATHAM; BLACK, 1998, p. 448). De acordo com LAWSON e BROSSART (2004, p. 476), a linearidade é importante, uma vez que a análise é elaborada pelas matrizes de correlação ou variânciacovariância, que refletem e maximizam somente as relações lineares entre dois grupos de variáveis.

Segundo EPLEY (2001, p. 228), que utiliza a presente técnica para o mercado imobiliário nos Estados Unidos, a forma geral de um modelo de correlação canônica é:

$$
\left(c_{1} \ldots c_{n}\right)=f\left(p_{1} \ldots p_{n}\right)
$$

onde $c_{i}$ são as variáveis dependentes (criterion) e $\mathrm{p}_{\mathrm{i}}$, as variáveis independentes (predictor). A seguir, são apresentados os modelos gerais por 
meio dos quais será efetuada a correlação canônica deste trabalho, que se baseia no estudo efetuado por MOORE (1987, p. 684-703) para o mercado imobiliário.

$$
\begin{aligned}
& \text { Demanda: }(\partial p / \partial A R E A)+C+V=z+Y_{1}+W \\
& \text { e } \\
& \text { Oferta: } \quad(\partial p / \partial A R E A)+C+V=z+Y_{2}+W
\end{aligned}
$$

onde ( $\partial \mathrm{p} / \partial \mathrm{AREA})$ é o preço por metro quadrado do imóvel, $\mathrm{C}$ representa o vetor que compõe o número de parcelas do financiamento imobiliário e $\mathrm{V}, \mathrm{o}$ valor da primeira parcela do financiamento. Os vetores que se apresentam do lado direito das equações $\left(z, Y_{1}, Y_{2}\right.$ e $W$ ) têm a mesma nomenclatura que vem sendo aqui adotada.

Como condição do método, é recomendável que se tenha, pelo menos, 10 observações por variável, uma vez que amostras pequenas podem apresentar o problema de não representar bem as correlações, obscurecendo algumas relações significativas. Como há 3 variáveis dependentes e, no máximo $^{41}$, 31 variáveis independentes (22 do vetor $z, 7$ do vetor $W$ e 2 para $Y_{1}$ ou $\mathrm{Y}_{2}$ ), acredita-se que o fato de haver 620 dados para cada sub-amostra está de acordo com as recomendações vigentes para a aplicação da correlação canônica.

Ademais, a correlação canônica pode ser aplicada sem que, necessariamente, as variáveis métricas apresentem normalidade. Obviamente a normalidade é desejada, uma vez que padroniza a distribuição das variáveis a serem correlacionadas, mas até mesmo variáveis sem normalidade podem ser utilizadas na correlação canônica, sem que ocorra prejuízo do método (HAIR; ANDERSON; TATHAM; BLACK, 1998, p. 448). Como não estão

\footnotetext{
${ }^{41} \mathrm{O}$ fato de haver, no máximo, 31 variáveis independentes acontece porque muitas delas podem não entrar nos modelos de correlação canônica por não terem se mostrado estatisticamente significantes quando da aplicação da técnica de regressão para cada um dos perfis sócio-demográficos.
} 
disponíveis testes para a verificação de normalidade multivaridada, cada variável será testada isoladamente por meio do teste $\mathrm{K}-\mathrm{S}^{42}$.

A seguir, no capítulo $V$, são apresentados os resultados dos métodos propostos.

42 O teste Kolmogorov-Smirnov de aderência à normalidade serve para analisar o ajustamento à normalidade da distribuição de uma variável de nível ordinal ou superior, por meio da comparação das freqüências relativas acumuladas observadas com as freqüências relativas acumuladas esperadas, em que a hipótese nula afirma que a variável a ser testada tem distribuição normal (PESTANA; GAKEIRO, 2000, p. 183). 


\section{CAPÍTULO V}

\section{APRESENTAÇÃO DOS RESULTADOS}

Neste capítulo, os resultados dos métodos adotados serão apresentados e discutidos, para cada um dos grupos sócio-demográficos definidos. Ao final, serão elaboradas comparações, com enfoque para as principais diferenças entre cada um deles e, portanto, verificar-se-á se as variáveis de oferta e demanda, definidas por meio de pergunta aberta a especialistas e compradores, são significantes para a composição dos preços e demais condições comerciais dos imóveis residenciais, para cada grupo sóciodemográfico, bem como se apresentam importância relativa diferenciada na referida composição, quando da comparação entre os diferentes grupos.

\section{1 - Perfil Sócio-Demográfico Baixo}

\subsection{1 - Caracterização da Amostra}

A coleta de dados para a composição da amostra deste grupo sóciodemográfico forneceu características específicas, que podem ser observadas por meio dos gráficos 1 a 27 em anexo (v. Anexos - Item I.1). A partir do gráfico 1, nota-se que a média de preço dos imóveis está em torno de $\mathrm{R} \$ 88.000,00$, o que está em acordo com dados divulgados periodicamente pelo Secovi-SP (Sindicato das Empresas de Compra, Venda, Locação e Administração de Imóveis Comerciais e Residenciais de São Paulo), que tem publicado que o preço médio de imóveis residenciais de até dois dormitórios não tem ultrapassado o valor de $\mathrm{R} \$ 154.000,00^{43}$. O gráfico 2 oferece as frequências em relação à área total de cada um dos imóveis que compõem a amostra, e a área total média encontra-se em torno de $85 \mathrm{~m}^{2}$, o que faz com que se tenha

\footnotetext{
${ }^{43}$ É importante ressaltar que os valores divulgados pelo Secovi-SP são médios e estão de acordo com esse perfil sócio-demográfico, já que os imóveis pertencentes a esse grupo não apresentaram, em sua maioria, mais do que dois dormitórios.
} 
um preço unitário de aproximadamente $\mathrm{R} \$ 1.035,00 / \mathrm{m}^{2}$ para o perfil sóciodemográfico baixo.

Em relação às demais variáveis que compõem o vetor z (dummies), nota-se, por meio da amostra de 620 unidades residenciais, que a maioria dos imóveis oferece salão de jogos (600) e churrasqueira (590), tem apenas uma vaga na garagem (466), apresenta dois dormitórios (415) e um banheiro (448). Porém, as demais variáveis intrínsecas estudadas neste trabalho não estão presentes na maioria dos imóveis localizados em regiões pertencentes ao perfil sócio-demográfico baixo. No item 5.1.2, a seguir, será avaliada a representatividade de cada umas das variáveis que compõem o vetor $z$ para a composição dos preços dos imóveis.

As variáveis que compõem os vetores $W, Y_{1}$ e $Y_{2}$ também são apresentadas por meio dos gráficos mencionados e, a partir delas, tem-se, para a amostra coletada, que a renda média familiar para o perfil sóciodemográfico baixo é de $\mathrm{R} \$ 1.528,00$, o número médio de membros da família nestas localidades é igual a 3,0, a densidade populacional média é de 11.225,00 hab / km², a população média é de 164.600 habitantes e, dos 620 imóveis pesquisados, 249 possuem colégio particular na proximidade, 329 possuem Shopping Center na região, 124 estão próximos de alguma estação de metrô, 329 possuem hospital particular na proximidade, 166 estão próximos de parques e áreas verdes, 460 estão próximos de pontos de inundação e 41 possuem aterros ou lixões nas imediações.

\subsection{2 - O Primeiro Estágio de Rosen}

Como discutido nos itens 2.2 e 4.9, o primeiro estágio de Rosen consiste na estimação de uma função $p(z)$, considerando-se apenas as características z intrínsecas aos imóveis, e a função resultante passa então a ser $\hat{p}(z)$, permitindo-se o cálculo de um conjunto de preços marginais implícitos, que corresponde à variável dependente do segundo estágio de Rosen, $d \hat{p}(z) / d z_{i}=\hat{p}_{i}(z)$. Portanto, como já discutido, a função $\mathrm{p}(\mathrm{z})$ para o primeiro estágio não pode ser linear e a sua derivada parcial pode ser elaborada em 
relação à área total do imóvel, já que representa uma variável métrica não binária. Desta forma, o primeiro estágio de Rosen corresponde à aplicação do método de Box-Cox, com $\theta$ variando de 0 a 0,9 (em intervalos de 0,1 ) e $\lambda$ variando de 0 a 1 (em intervalos de 0,1 ) e assumindo também valores iguais a 2 (especificação quadrática) e 3 (especificação cúbica).

Em anexo (v. Anexos - Item I.2), a tabela 9 apresenta os resultados das regressões realizadas para todas as combinações de $\theta$ e $\lambda$ descritas, de onde se pode concluir que a melhor especificação, para o perfil sócio-demográfico baixo, é a logarítmica $(\theta=\lambda=0)$, já que apresenta o maior coeficiente de ajuste $\mathrm{R}^{2}$ e está de acordo com as considerações apresentadas por BOX e COX (1982, p. 209-210) sobre modelos logarítmicos de regressão.

Faz-se, assim, necessária a aplicação da regressão logarítmica para o primeiro estágio de Rosen. Os resultados desta regressão encontram-se em anexo (V. Anexos - Item I.2), na tabela 10. Por meio da análise da tabela, podese perceber que as variáveis intrínsecas mais representativas para a composição dos preços dos imóveis residenciais deste grupo sóciodemográfico são aquelas referentes à existência de guarita, à área total do imóvel, à existência de churrasqueira, ao incremento da quantidade de dormitórios (de um para dois e de dois para três), ao aumento do número de vagas na garagem (de uma para duas), à existência de salão de festas no condomínio, ao incremento da quantidade de banheiros (de um para dois e de dois para três), à existência de varanda no apartamento e à presença de piscina, salão de jogos e quadra poliesportiva. A variável relacionada ao fato de o apartamento estar situado na metade superior do edifício apresenta sinal negativo, o que demonstra, para este perfil, que pavimentos mais elevados não necessariamente significam imóveis mais valorizados. As demais variáveis intrínsecas estudadas foram excluídas do modelo, por não serem estatisticamente significativas ou por não apresentarem variações na amostra.

Por meio dos testes apresentados no quadro 4.9.2, esta regressão intermediária não indicou, para os resíduos, problemas de autocorrelação e heterocedasticidade e, para as variáveis explicativas, problemas de multicolinearidade. 
Para que seja possível a aplicação do segundo estágio de Rosen, faz-se necessária a elaboração do cálculo da derivada parcial $d \hat{p}(z) / d z_{i}=\hat{p}_{i}(z)$. Assim sendo, como o modelo apresenta uma especificação logarítmica, temse, de acordo com o quadro 4.9.1, que:

$$
\ln p=\ln \beta_{0}+\sum \beta_{n} \ln z_{n}
$$

e desenvolvendo-se, chega-se a:

$$
\ln p=\ln \beta_{0}+\beta_{1} \ln z_{1}+\beta_{2} \ln z_{2}+\ldots+\beta_{n} \ln z_{n}
$$

$$
\ln p=\ln \beta_{0}+\ln z_{1}^{\beta_{1}} z_{2}^{\beta_{2}} \ldots z_{n}^{\beta_{n}}
$$

Desta forma, pode-se isolar a variável referente ao preço:

$$
\begin{aligned}
& p=e^{\ln \beta_{0}} z_{1}^{\beta_{1}} z_{2}^{\beta_{2}} \ldots z_{n}^{\beta_{n}} \\
& p=\beta_{0} z_{1}^{\beta_{1}} z_{2}^{\beta_{2}} \ldots z_{n}^{\beta_{n}}
\end{aligned}
$$

de onde se pode derivar $\mathrm{p}$ em relação a $\mathrm{z}_{\mathrm{i}}$, para a elaboração do segundo estágio de Rosen:

$$
\frac{\partial p}{\partial z_{i}}=\beta_{i} \beta_{0} z_{1}^{\beta_{1}} z_{2}^{\beta_{2}} \ldots z_{i}^{\beta_{i-1}} \ldots z_{n}^{\beta_{n}}
$$

Multiplicando-se e dividindo-se por $z_{\mathrm{i}}$, tem-se que:

$$
\frac{\partial p}{\partial z_{i}}=\frac{1}{z_{i}} \beta_{i} \beta_{0} z_{1}^{\beta_{1}} z_{2}^{\beta_{2}} \ldots z_{i}^{\beta_{i}} \ldots z_{n}^{\beta_{n}}
$$


e substituindo-se na equação (58):

$$
\frac{\partial p}{\partial z_{i}}=\frac{\beta_{i} p}{z_{i}}
$$

Portanto, a variável dependente (preço marginal implícito) do segundo estágio de Rosen, para o grupo sócio-demográfico baixo, será dada por:

$$
p / m^{2}=\frac{0,129 \cdot p}{A R E A}
$$

O procedimento está de acordo SARTORIS NETO (1996, p. 61), torna possível a aplicação do segundo estágio de Rosen e será elaborado também para os grupos sócio-demográficos médio e alto.

\subsection{3 - O Segundo Estágio de Rosen}

No segundo estágio de Rosen, é utilizado, como variável dependente, o preço por metro quadrado definido na expressão (62), para as equações de demanda e oferta. Assim, como o primeiro estágio definiu que os modelos a serem aplicados no segundo estágio são logarítmicos, as equações de demanda e oferta obedecem, respectivamente, ao que segue:

$(\not p /$ DAREA $)=f(z, \log (A R E A), \log (R N D), \log (M E M B), W)$
e
$(\partial p / \partial A R E A)=f(z, \log (A R E A), \log (D E N S), \log (P O P), W)$
e, como as únicas variáveis dos modelos que não são dummies referemse à área total do imóvel e às variáveis que compõem os vetores $Y_{1}$ (renda 
familiar da localidade e número médio de membros da família) e $Y_{2}$ (população e densidade demográfica da localidade), apenas nelas aplicar-se-ão os respectivos logaritmos naturais.

Apresentam-se, em anexo, (v. Anexos - Item I.3), os resultados obtidos a partir da aplicação dos modelos descritos de demanda e oferta para o perfil sócio-demográfico baixo.

Por meio da tabela 11, que se refere à estimação da equação de demanda, é possível observar que o sinal da variável LNAREA é negativo, conforme se esperava, por se tratar de uma equação de demanda. Além da representatividade desta variável para a composição do preço unitário do imóvel a um nível de significância de 95\%, percebe-se também a importância das variáveis que se relacionam com o incremento do número de dormitórios (DORM1 e DORM2), de banheiros (BANH1 e BANH2) e de vagas na garagem (VAGA1). A representatividade de variáveis como CHUR, SFES, SJOG, PISC e QUAD demonstra a importância de áreas de lazer e festas, já que se mostraram significativas, sob a ótica da demanda, para a composição dos preços dos imóveis. A existência de guarita na entrada do edifício (GUAR) também se mostrou relevante, fazendo com que seja possível verificar a importância de aspectos relativos à segurança em localidades onde nem todos os edifícios apresentam tal característica. Ainda em relação às características intrínsecas aos imóveis, aqueles que possuem varanda (VARD) são mais bem avaliados pelos potenciais compradores, uma vez que tal característica apresentou-se representativa e com sinal positivo.

As características extrínsecas, embora menos representativas do que as já mencionadas, também merecem atenção, com destaque para as variáveis COLP e METR. A primeira pode significar um aumento nos níveis médios de educação na localidade (aumentando o padrão de consumo da região e, consequentemente, o valor percebido dos imóveis), podendo fazer com que muitos compradores decidam adquirir um imóvel nas proximidades de colégios particulares. Além disto, a decisão de compra pode se dar por aspectos que se relacionam com a proximidade e facilidade de condução dos filhos até a escola e até por aspectos relativos a segurança ou pela oferta existente de outras 
benfeitorias no entorno destes estabelecimentos, como padarias e drogarias, que acabam por formar um centro comercial. Já a representatividade da variável relativa à proximidade de estações de metrô demonstra a importância da utilização deste tipo de transporte público por parte da população residente nas localidades que compõem o perfil sócio-demográfico baixo, o que pode, inclusive, servir de subsídio, por parte do poder público, quando da elaboração de planos de expansão de novas linhas e de linhas existentes.

A variável que se refere à renda média da localidade (LNRND) também se mostrou relevante, demonstrando a importância desta característica quando da formação da demanda por área total em localidades de perfil sóciodemográfico baixo.

Por fim, a variável INUN apresenta sinal negativo, como já era de se esperar, e apareceu de forma significativa na equação de demanda, demonstrando a preocupação por que passa esta população, sujeita a fenômenos climáticos que dão origem a fortes inundações principalmente em locais de baixa renda, que apresentam alto grau de impermeabilização do solo urbano sem que haja concentração considerável de áreas verdes.

As demais variáveis do modelo não se mostraram relevantes ou não foram explicitadas, por apresentarem problemas de multicolinearidade com uma ou mais variáveis explicativas.

A estimação da equação de oferta, apresentada na tabela 12, mostrou que, em relação ao esperado, há uma inversão do sinal (que continua negativo) da variável referente à área total do imóvel. Como foram utilizados apenas imóveis lançados e comercializados, a substituição do vetor $Y_{1}$ pelo vetor $Y_{2}$, para a determinação da função de oferta, não fez com que houvesse uma inversão do sinal desta variável.

As variáveis DORM1, DORM2, BANH1, BANH2, SFES, SJOG, PISC, CHUR, GUAR e VARD também são relevantes para a composição do preço unitário de oferta. Já em relação às variáveis extrínsecas que são representativas, merece destaque a característica COLP, que se mostrou significante e com sinal positivo, além da variável ATER, que apresentou sinal negativo, como já era de se esperar. 
Os coeficientes da densidade demográfica (LNDENS) e da população (LNPOP) são positivos e significantes na equação de oferta, o que mostra que estas variáveis refletem a dificuldade cada vez maior de se encontrarem espaços disponíveis para a construção de novos empreendimentos residenciais, valorizando o preço por metro quadrado de regiões mais populosas e povoadas.

Com a aplicação do método Enter para as equações de oferta e demanda, faz-se necessária a aplicação do método Stepwise, já que algumas das variáveis mostraram-se não relevantes a um nível de confiança de 95\% e precisam ser excluídas dos modelos. Enquanto o método Enter inclui todas as variáveis nos resultados da regressão, o método Stepwise, por um processo interativo, apresenta somente aquelas relevantes ao nível de confiança desejado. Portanto, aplicou-se primeiramente o método Enter com o intuito de se verificar apenas a consistência dos sinais dos coeficientes das variáveis presentes nos modelos de demanda e oferta, porém a análise da importância relativa de cada uma delas, bem como das diferenças entre as referidas equações, e a elaboração dos testes mencionados no quadro 4.9.2 serão efetuados por meio dos resultados obtidos a partir do método Stepwise, e serão discutidos a seguir.

A tabela 13 (v. Anexos - Item I.3) apresenta os resultados das estimações das equações de oferta e demanda para o perfil sócio-demográfico baixo pelo método Stepwise. Por meio da tabela, é possível observar que, tanto para a equação de demanda quanto para a de oferta, a variável correspondente à área total do imóvel é a que apresenta a maior importância relativa para a composição dos preços unitários, sendo ainda mais relevante para a primeira equação. Ademais, a variável relativa à segurança do condomínio, que se refere à presença de guarita, é a segunda característica mais representativa nas duas equações, porém oferece uma importância relativa maior na equação de oferta, o que mostra a utilização de argumentos de venda, por parte de incorporadoras e imobiliárias, quando da existência do atributo. Outro ponto de destaque refere-se ao incremento do número de dormitórios que, enquanto para a demanda a representatividade maior se dá 
quando há o aumento de um para dois, sob a ótica da oferta, a maior representatividade ocorre quando há um aumento de dois pra três dormitórios e, portanto, talvez haja um descolamento entre as perspectivas de demanda para este público e o que efetivamente está sendo ofertado. As demais variáveis que compõem o vetor z não apresentaram diferenças significativas entre as equações de demanda e oferta, a exceção das variáveis QUAD e VAGA1, que se mostraram representativas sob a ótica da demanda, porém não aparecem na equação de oferta, o que mostra a importância dada por potenciais consumidores em relação à existência de quadra poliesportiva no condomínio e ao incremento do número de vagas na garagem (de uma para duas), sem que houvesse a respectiva importância dada pelos agentes que compõem a oferta.

Em relação às variáveis extrínsecas, a única presente nas duas equações é a variável COLP, ficando todas as demais somente em uma delas. $\mathrm{Na}$ equação de demanda, são relevantes as características relativas à proximidade de estações de metrô e à renda da localidade, com sinal positivo, além da existência de pontos de inundação na região, com sinal negativo. Por outro lado, na equação de oferta, são representativas as variáveis referentes à densidade demográfica, à população da localidade e à existência de aterros ou lixões nas imediações do empreendimento em lançamento, sendo esta última com sinal negativo. Novamente surgem descolamentos entre a percepção da demanda e a da oferta, o que propicia eventuais medidas corretivas em relação a políticas e estratégias de lançamento imobiliário em localidades situadas nas regiões definidas como sendo de perfil sócio-demográfico baixo. É importante ressaltar que as variáveis mais representativas para a composição da equação de oferta também apareceram na modelagem proposta por FÁVERO (2003, p. 54) apenas para o Município de São Paulo, porém, nesse caso, sem a utilização das transformações de Box-Cox e com um número relativamente menor de características.

Em relação aos testes propostos no quadro 4.9.2, primeiramente aplicou-se o de endogeneidade, de onde se concluiu que todas as variáveis explicativas são exógenas, uma vez que não apresentaram correlação 
significativa com os termos do erro a um nível de confiança de 95\%. Desta forma, confirma-se a possibilidade de aplicação do método dos mínimos quadrados ordinários já utilizado. As equações apresentadas para este perfil sócio-demográfico também não apresentaram problemas de identificação, já que, como discutido em anexo ( $v$. Anexos - Item E), as condições de ordem e de posto estão satisfeitas, uma vez que há ao menos uma variável em cada equação que não está presente na outra equação (condição de ordem), pois QUAD, VAGA1, METR, INUN e LNRND somente aparecem na equação de demanda, e ATER, LNDENS e LNPOP somente aparecem na equação de oferta. Além disto, estas variáveis apresentam coeficientes diferentes de zero, o que faz com que também seja obedecida a condição de posto.

Por fim, os testes de Durbin-Watson e de Glejser mostraram que não há problemas de autocorrelação ou heterocedasticidade dos resíduos resultantes dos modelos de demanda e oferta. A análise de correlação simples também não identificou problemas de multicolinearidade entre as variáveis explicativas das equações resultantes.

\subsection{4 - Resultados da Correlação Canônica}

Para o perfil sócio-demográfico baixo, as variáveis utilizadas na equação de demanda para a aplicação da correlação canônica encontram-se no quadro 5.1.4.1 a seguir. 
QUADRO 5.1.4.1: VARIÁVEIS DEPENDENTES E INDEPENDENTESA DA CORRELAÇÃO CANÔNICA PARA A EQUAÇÃO DE DEMANDA - PERFIL SÓCIO-DEMOGRÁFICO BAIXO

\begin{tabular}{|c|c|}
\hline VARIÁVEIS DEPENDENTES & VARIÁVEIS INDEPENDENTES \\
\hline \multirow{5}{*}{$\partial \mathrm{p} / \partial \mathrm{AREA}=\mathrm{DPDAREA}$} & LNAREA \\
\hline & SFES \\
\hline & SJOG \\
\hline & PISC \\
\hline & CHUR \\
\hline \multirow{6}{*}{$\mathrm{C}$} & QUAD \\
\hline & GUAR \\
\hline & VARD \\
\hline & VAGA1 \\
\hline & DORM1 \\
\hline & DORM2 \\
\hline \multirow{6}{*}{$\mathrm{V}$} & BANH1 \\
\hline & BANH2 \\
\hline & COLP \\
\hline & METR \\
\hline & INUN \\
\hline & LNRND \\
\hline
\end{tabular}

Primeiramente, o teste K-S não rejeitou a hipótese nula de existência de normalidade das variáveis métricas a serem utilizadas nas correlações canônicas.

Sabe-se que o número máximo de variáveis estatísticas (funções) que podem ser extraídas dos conjuntos de variáveis é igual ao número de variáveis no menor conjunto de dados, dependentes ou independentes (HAIR; ANDERSON; TATHAM; BLACK, 2005, p. 366). Logo, o número de funções canônicas é 3 (número de variáveis dependentes) e a operação por meio da qual a correlação canônica é efetuada, para a demanda, encontra-se a seguir $^{44}$.

\footnotetext{
${ }^{44}$ Esse método foi aplicado por meio do software SPSS 12.0.
} 
MANOVA DPDAREA C V with LNAREA SFES SJOG PISC CHUR QUAD GUAR VARD VAGA1 DORM1 DORM2 BANH1 BANH2 COLP METR INUN LNRND

/print=error (SSCP COV COR) signif

(hypoth eigen dimenr)

/discrim=raw stan estim cor alpha(1.0)

/residuals=casewise plot

/design.

O quadro 5.1.4.2, a seguir, apresenta as variáveis utilizadas na equação de oferta para o perfil sócio-demográfico baixo.

QUADRO 5.1.4.2: VARIÁVEIS DEPENDENTES E INDEPENDENTESA DA CORRELAÇÃO CANÔNICA PARA A EQUAÇÃO DE OFERTA - PERFIL SÓCIO-DEMOGRÁFICO BAIXO

\begin{tabular}{|c|c|}
\hline VARIÁVEIS DEPENDENTES & VARIÁVEIS INDEPENDENTES \\
\hline \multirow{5}{*}{$\partial p / \partial A R E A=$ DPDAREA } & LNAREA \\
\hline & SFES \\
\hline & SJOG \\
\hline & PISC \\
\hline & CHUR \\
\hline \multirow{5}{*}{ C } & GUAR \\
\hline & VARD \\
\hline & DORM1 \\
\hline & DORM2 \\
\hline & BANH1 \\
\hline \multirow{5}{*}{ V } & BANH2 \\
\hline & COLP \\
\hline & ATER \\
\hline & LNDENS \\
\hline & LNPOP \\
\hline
\end{tabular}

A operação por meio da qual a correlação canônica é efetuada, para a oferta, é: 
MANOVA DPDAREA $C \vee$ with LNAREA SFES SJOG PISC CHUR GUAR VARD DORM1 DORM2 BANH1 BANH2 COLP ATER LNDENS LNPOP

/print=error (SSCP COV COR) signif

(hypoth eigen dimenr)

/discrim=raw stan estim cor alpha(1.0)

/residuals=casewise plot

/design.

O método de Wilk's (estatística multivariada) testa a significância coletiva do conjunto das funções canônicas, avaliando se as funções canônicas são significantes coletivamente. Pelas tabelas 14 e 15 em anexo (v. Anexos Item I.4), verifica-se que pode ser rejeitada a hipótese nula de que as funções canônicas não são significantes coletivamente para as equações de demanda e oferta.

Nas tabelas 16 e 17 são apresentadas as raízes canônicas de cada função canônica, para as equações de demanda e oferta, além de se verificar se cada uma delas pode ser considerada relevante. Como as raízes canônicas são os quadrados de cada uma das correlações canônicas, para a equação de demanda apresentaram resultados respectivamente iguais a 0,985, 0,978 e 0,876, o que mostra a significância de cada uma das correlações. O mesmo acontece para a equação de oferta, que oferece resultados iguais a 0,987, 0,974 e 0,876. Pelo próprio teste univariado, apresentado nas tabelas 18 e 19, pode-se concluir que as funções são significantes.

Como a primeira função canônica responde pelo máximo do percentual da variância no conjunto de todas as variáveis, a análise será somente elaborada para esta função ${ }^{45}$.

Em relação às variáveis dependentes, os pesos canônicos para a primeira função canônica representam os coeficientes padronizados, de forma análoga aos coeficientes padronizados obtidos por meio de uma regressão. As tabelas 20 e 21 apresentam os pesos canônicos das variáveis dependentes

\footnotetext{
${ }^{45}$ A primeira função canônica é gerada de modo a ser obtida a máxima correlação possível entre os dois conjuntos de variáveis. Como pares sucessivos de variáveis estatísticas canônicas são baseados em variância residual, cada par de variáveis estatísticas é ortogonal e independente de todas as outras variáveis estatísticas obtidas a partir do mesmo conjunto de dados.
} 
para a primeira função canônica, de onde se observa que a hierarquia, tanto para a equação de demanda quanto para a de oferta, segue a sequência DPAREA, C e V, ou seja, preço unitário, número de parcelas do financiamento e valor da primeira parcela. Porém, quando a comparação é feita entre as equações de demanda e oferta, percebe-se um peso relativo maior das variáveis relacionadas ao preço unitário do imóvel e ao valor da primeira parcela para a equação de oferta e da variável relacionada à quantidade de parcelas para a equação de demanda.

Já em termos de variáveis independentes, pela análise da primeira função canônica, tem-se, por meio das tabelas 22 e 23, que a variável relacionada à área total do imóvel (LNAREA) apresenta a maior hierarquia, sendo seguida pelas variáveis que compõem os vetores $z, Y$ (1 e 2) e W.

As tabelas 24 e 25 apresentam as correlações entre as variáveis dependentes e as variáveis canônicas e, por meio da análise dos mesmos, é possível verificar, para a equação de demanda, que o que foi compartilhado pelas variáveis na primeira função canônica é igual a $\left[(0,959)^{2}+(-0,577)^{2}+\right.$ $\left.(0,464)^{2}\right] / 3=0,489$. De forma similar, para a equação de oferta, o que foi compartilhado pelas variáveis na primeira função canônica é igual a 0,480. Ainda por meio da análise das tabelas 24 e 25, acredita-se que as três variáveis escolhidas são boas dependentes para o conjunto de variáveis independentes, uma vez que as correlações na primeira função canônica são elevadas.

Analogamente, em referência às independentes, as tabelas 26 e 27 mostram as correlações entre estas variáveis e aquelas relativas às canônicas. Por meio das tabelas, é possível verificar que o que foi compartilhado pelas variáveis na primeira função canônica é igual a 0,251 para a equação de demanda e 0,259 para a equação de oferta. Com base na tabela 26, o ranking das cargas canônicas ${ }^{46}$, que é uma estimativa do que resultaria se fosse feita

\footnotetext{
${ }^{46}$ Segundo HAIR, ANDERSON, TATHAM e BLACK (2005, p. 369), as cargas canônicas, também conhecidas como correlações canônicas estruturais, medem a correlação linear simples entre uma variável observada original no conjunto dependente ou independente e a variável estatística canônica do conjunto, podendo ser interpretada como uma carga fatorial na avaliação da contribuição relativa de cada variável observada em cada função canônica.
} 
uma regressão pelo método stepwise para cada variável dependente, para a primeira função canônica, seria LNAREA, VAGA1, GUAR, VARD, DORM1, CHUR, SJOG, SFES e BANH1. Acredita-se que as demais variáveis não são boas independentes (não explicam de forma relevante as variáveis dependentes escolhidas), uma vez que as correlações, na primeira função canônica, são menores do que $0,300^{47}$. Em relação à equação de oferta, de acordo com a tabela 27, o ranking seria composto pelas variáveis LNAREA, GUAR, VARD, DORM1, CHUR, SJOG, PISC, DORM2, SFES e BANH1. Assim sendo, demonstra-se novamente um descolamento entre o que é considerado relevante por parte da demanda e o que está sendo considerado como representativo sob a ótica da oferta.

Por fim, são relacionadas as raízes canônicas e a variância compartilhada (proporção da variância do conjunto explicada pelo próprio conjunto canônico) com o índice de redundância (proporção da variância de cada conjunto explicada pelo conjunto canônico oposto). Para se calcular o índice de redundância, necessita-se ter a média da variância compartilhada no próprio conjunto e a correlação canônica ao quadrado ${ }^{48}$, ambas já calculadas anteriormente. A tabela 28 apresenta o índice de redundância para as equações de demanda e oferta. O índice de redundância, a média da variância compartilhada no próprio conjunto e a correlação canônica ao quadrado relacionam-se na forma de um produto, no qual as últimas duas multiplicadas resultam no primeiro. O índice de redundância também pode ser considerado uma estimativa do $\mathrm{R}^{2}$ que seria resultante de uma regressão, caso fosse regredida isoladamente cada variável dependente em função das variáveis independentes, sendo uma estimativa da média de cada $\mathrm{R}^{2}$ encontrado. Devese destacar que os índices de redundância são calculados tanto para variáveis estatísticas dependentes quanto para as independentes, apesar de haver uma preocupação maior com a variância extraída do conjunto de variáveis dependentes, a qual fornece uma medida mais realista da habilidade preditiva

\footnotetext{
${ }^{47}$ Segundo GOUVÊA (2004), a magnitude da correlação canônica deve ser superior a 0,300 quando da estimação e seleção das funções canônicas.

${ }^{48}$ A correlação canônica ao quadrado é comumente chamada de $\mathrm{R}^{2}$ canônico.
} 
de relações canônicas (HAIR; ANDERSON; TATHAM; BLACK, 2005, p. 368369). Como podem ser observados por meio da tabela 28 , os índices de redundância para a variável estatística dependente são mais substanciais (0,482 para a demanda e 0,474 para a oferta). A variável estatística independente, contudo, tem índices de redundância menores $(0,247$ para a demanda e 0,256 para a oferta), provenientes das variâncias compartilhadas relativamente baixas na variável estatística independente e não das correlações ao quadrado.

Pode-se concluir que as variáveis independentes que foram significantes nos modelos de correlação canônica formam um vetor que explica, de modo adequado, as variáveis dependentes e, portanto, estas variáveis, relacionadas ao preço unitário do imóvel, à quantidade de parcelas do financiamento e ao valor da primeira parcela, necessitam estar, quando do lançamento de um novo empreendimento residencial em localidades de perfil sócio-demográfico baixo, adequadas ao vetor de variáveis explicativas, representadas por características presentes nos respectivos imóveis. 


\section{2 - Perfil Sócio-Demográfico Médio}

\subsection{1 - Caracterização da Amostra}

A coleta de dados para a composição da amostra deste grupo sóciodemográfico forneceu algumas características que podem ser observadas por meio dos gráficos 28 a 54 em anexo (v. Anexos - Item J.1). A partir do gráfico 28 , nota-se que a média de preço dos imóveis está em torno de $\mathrm{R} \$ 261.000,00$, o que está em acordo com dados divulgados periodicamente pelo Secovi-SP (Sindicato das Empresas de Compra, Venda, Locação e Administração de Imóveis Comerciais e Residenciais de São Paulo), que tem publicado que o preço médio de imóveis residenciais de até três dormitórios não tem ultrapassado o valor de $\mathrm{R} \$ 332.000,00^{49}$. O gráfico 29 oferece as frequências em relação à área total de cada um dos imóveis que compõem a amostra, e a área total média encontra-se em torno de $102 \mathrm{~m}^{2}$, o que faz com que se tenha um preço unitário de aproximadamente $\mathrm{R} \$ 2.558,00 / \mathrm{m}^{2}$ para o perfil sóciodemográfico médio, ou seja, mais do que o dobro do calculado para o perfil baixo.

Em relação às demais variáveis que compõem o vetor $z$, nota-se, por meio da amostra de 620 unidades residenciais, que a maioria (ou até mesmo a totalidade para alguns casos) dos imóveis oferece salão de festas (620), salão de jogos (576), piscina (609), churrasqueira (510), quadra poliesportiva (380), guarita (620), varanda (609), tem duas vagas na garagem (580), apresenta dois ou três dormitórios (430 e 160, respectivamente) e dois banheiros (499). Percebe-se um aumento na presença de características intrínsecas existentes nos imóveis localizados em regiões de perfil sócio-demográfico médio em relação aos situados em locais de perfil baixo, o que, em parte, justifica a estratificação adotada neste trabalho. No item 5.2.2, a seguir, será avaliada a

\footnotetext{
${ }^{49}$ Os valores divulgados pelo Secovi-SP são médios e estão de acordo com esse perfil sócio-demográfico, já que os imóveis pertencentes a esse grupo não apresentaram, em sua maioria, mais do que três dormitórios.
} 
representatividade de cada umas das variáveis que compõem o vetor z para a composição dos preços dos imóveis.

As variáveis que compõem os vetores $W, Y_{1}$ e $Y_{2}$ também são apresentadas por meio dos gráficos mencionados e, a partir delas, tem-se, para a amostra coletada, que a renda média familiar para o perfil sóciodemográfico médio é de $\mathrm{R} \$ 2.021,00$, o número médio de membros da família nestas localidades é igual a 3,0, a densidade populacional média é de 8.870,00 hab / km², a população média é de 230.400 habitantes e, dos 620 imóveis pesquisados, 579 possuem colégio particular na proximidade, 579 possuem Shopping Center na região, 82 estão próximos de alguma estação de metrô, 579 possuem hospital particular na proximidade, 412 estão próximos de parques e áreas verdes, 620 estão próximos de pontos de inundação e 88 possuem aterros ou lixões nas imediações.

\subsection{2 - O Primeiro Estágio de Rosen}

Analogamente ao procedimento elaborado para o perfil sóciodemográfico baixo, a tabela 29 em anexo (v. Anexos - Item J.2) apresenta os resultados das regressões realizadas para todas as combinações de $\theta$ e $\lambda$ descritas, de onde se pode concluir que a melhor especificação, para o perfil sócio-demográfico médio, é a logarítmica $(\theta=\lambda=0)$, já que também apresenta o maior coeficiente de ajuste $\mathrm{R}^{2}$. Os resultados da regressão encontram-se em anexo (V. Anexos - Item J.2), na tabela 30 e, por meio de sua análise, nota-se que as variáveis intrínsecas mais representativas para a composição dos preços dos imóveis residenciais deste grupo sócio-demográfico são aquelas relacionadas à área total do imóvel, ao incremento da quantidade de dormitórios (de dois para três e de três para quatro), ao aumento do número de vagas na garagem (de duas para três), à existência de salão de jogos, piscina, quadra e sauna, ao incremento da quantidade de banheiros (de dois para três), à presença de varanda no apartamento, à existência de circuito fechado de TV no condomínio e à posição relativa do apartamento no edifício (metade superior). As demais variáveis intrínsecas estudadas foram excluídas do 
modelo por não serem estatisticamente significativas ou por não apresentarem variações na amostra.

Nos testes explicitados no quadro 4.9.2, a regressão intermediária não apresentou, para os resíduos, problemas de autocorrelação e heterocedasticidade e, para as variáveis explicativas, problemas de multicolinearidade.

Por meio do mesmo método de cálculo apresentado para o perfil sóciodemográfico baixo, tem-se que a variável dependente (preço marginal implícito) do segundo estágio de Rosen, para o grupo sócio-demográfico médio, será dada por:

$$
p / m^{2}=\frac{0,550 \cdot p}{A R E A}
$$

e, portanto, faz-se necessária a elaboração do segundo estágio de Rosen para o grupo sócio-demográfico médio.

\subsection{3 - O Segundo Estágio de Rosen}

Analogamente ao procedimento realizado para o perfil sóciodemográfico baixo, é possível observar, por meio das tabelas 31 e 32 em anexo (v. Anexos - Item J.3), os resultados obtidos a partir da aplicação dos modelos de demanda e oferta para o perfil sócio-demográfico médio. Por meio da tabela 31, que se refere à estimação da equação de demanda, é possível observar que o sinal da variável LNAREA é negativo, conforme se esperava. Além da representatividade desta variável para a composição do preço unitário do imóvel a um nível de significância de 95\%, percebe-se também a importância das variáveis que se relacionam com o incremento do número de dormitórios (DORM2 e DORM3), de banheiros (BANH2) e de vagas na garagem (VAGA2). A representatividade de variáveis como SAUN, PISC, SJOG e QUAD demonstra a importância de áreas de lazer e esportes, já que se mostraram significativas, sob a ótica da demanda, para a composição dos 
preços dos imóveis. A existência de circuito fechado de TV (CFTV) também se mostrou relevante, fazendo com que seja possível verificar a importância de aspectos relativos à segurança em localidades nas quais nem todos os edifícios apresentam tal característica. Ainda em relação às características intrínsecas aos imóveis, aqueles que possuem varanda (VARD) são mais bem avaliados pelos potenciais compradores, uma vez que tal característica apresentou-se representativa e com sinal positivo.

As características extrínsecas, também representativas (ao contrário do ocorrido no perfil sócio-demográfico baixo, no qual apresentavam importância relativa menor em comparação com as intrínsecas) para a formação dos preços unitários de comercialização dos imóveis sob a ótica da demanda, apresentam sinal positivo, e referem-se às variáveis SHOP, COLP, HOSP, PARQ e METR. A importância de variáveis relativas à proximidade de parques e Shopping Centers não foi relevante para o perfil sócio-demográfico baixo, para a formação da equação de demanda, o que sugere uma maior representatividade para a tomada de decisão de compra de um imóvel residencial por parte das pessoas que desejam morar em localidades pertencentes ao grupo sócio-demográfico médio, e é importante notar que as comparações entre os grupos estudados serão mais bem pormenorizadas no item 5.4 do presente capítulo.

A variável ATER apresenta sinal negativo, como já era de se esperar, e apareceu de forma significativa na equação de demanda, demonstrando a preocupação por que passa esta população em relação à proximidade de aterros e lixões, já que estas áreas representam maiores riscos de contaminação e prejuízos à saúde. Por fim, a variável que se refere ao número médio de membros da família (LNMEMB) também se mostrou relevante, demonstrando a importância da característica quando da formação da demanda por área total em localidades de perfil sócio-demográfico médio.

As demais variáveis do modelo não se mostraram relevantes ou não foram explicitadas, por apresentarem problemas de multicolinearidade com uma ou mais variáveis explicativas. 
Para a equação de oferta, explicitada na tabela 32, a variável relacionada à área também apresentou sinal negativo, pelo mesmo motivo apresentado para o perfil sócio-demográfico baixo. As variáveis DORM2, DORM3, BANH2, VAGA2, VARD, CFTV, SAUN, PISC, SJOG e QUAD também são relevantes para a composição do preço unitário de oferta, a um nível de significância de 95\%. Já em relação às variáveis extrínsecas, aquelas que se mostraram representativas e com sinal positivo são SHOP, METR, HOSP, COLP e PARQ, que inclusive têm marcado presença relevante em anúncios e folders de comercialização elaborados por imobiliárias e incorporadoras destas regiões. A variável ATER apresenta sinal negativo, como já era de se esperar, e apareceu de forma significativa na equação de oferta, assim como já tinha ocorrido na equação de demanda.

Por fim, o coeficiente da densidade demográfica (LNDENS) é negativo e significante na equação de oferta, o que mostra a representatividade de locais menos povoados para a composição dos preços de venda dos imóveis. Porém, como o sinal da variável relativa à população do local (LNPOP) é positivo, verifica-se um aumento relativo nos preços de comercialização de imóveis situados em regiões com populações relativamente elevadas, mas sem aglomerações fortes, e a situação é cada vez mais encontrada nos Municípios da Região Metropolitana de São Paulo, que possuem vastas áreas e populações também consideráveis, demonstrando a valorização imobiliária das localidades de perfil sócio-demográfico médio.

De forma análoga ao realizado para o perfil sócio-demográfico baixo, apresentam-se os resultados das estimações das equações de oferta e demanda para o perfil sócio-demográfico médio pelo método Stepwise, na tabela 33 em anexo (v. Anexos - Item J.3).

Por meio da tabela, é possível observar que, tanto para a equação de demanda quanto para a de oferta, a variável correspondente à área total do imóvel é a que apresenta a maior importância relativa para a composição dos preços unitários, sendo ainda mais relevante para a segunda equação. Em relação às características que compõem o vetor z (SJOG, PISC, SAUN, QUAD, CFTV, VARD, VAGA2, DORM2, DORM3 e BANH2), todas aparecem em 
ambas as equações, porém de forma mais representativa na equação de oferta, merecendo destaque as variáveis DORM2, DORM3, BANH2 e VAGA2. Ademais, as variáveis que compõem o vetor W (COLP, SHOP, METR, HOSP, PARQ e ATER) também aparecem nas duas equações, porém com maior importância relativa também na equação de oferta, ficando a exceção por conta da variável relativa à existência de colégio particular na região, que é mais representativa na equação de demanda. Fica, assim, explicitado que os agentes que compõem a oferta têm valorizado mais do que proporcionalmente a presença de determinados atributos em relação ao modo como os mesmos são interpretados sob a ótica da demanda, para o perfil sócio-demográfico médio.

Ainda em relação às variáveis extrínsecas, na equação de demanda não foi significativa a variável referente à renda familiar da região, ficando o vetor $Y_{1}$ representado apenas pela variável que se refere ao número de membros da família. Já o vetor $Y_{2}$ está representado na equação de oferta, de forma significativa, pelas suas duas variáveis (densidade demográfica, com sinal negativo, e população, com sinal positivo).

Da mesma forma que para o perfil sócio-demográfico baixo, deve-se dizer que as variáveis mais representativas para a composição da equação de oferta também apareceram na modelagem proposta por FÁVERO (2003, p. 54).

Em relação aos testes propostos no quadro 4.9.2, primeiramente aplicou-se o de endogeneidade, de onde se concluiu que todas as variáveis explicativas são exógenas, uma vez que não apresentaram correlação significativa com os termos do erro a um nível de confiança de 95\%. Confirmase, portanto, a possibilidade de aplicação do método dos mínimos quadrados ordinários já utilizado. As equações apresentadas para este perfil sóciodemográfico também não apresentaram problemas de identificação, já que as condições de ordem e de posto estão satisfeitas, uma vez que há ao menos uma variável em cada equação que não está presente na outra equação (condição de ordem), pois LNMEMB somente aparece na equação de 
demanda, e LNDENS e LNPOP somente aparecem na equação de oferta, com coeficientes diferentes de zero (condição de posto).

Por fim, os testes de Durbin-Watson e de Glejser mostraram que não há problemas de autocorrelação ou heterocedasticidade dos resíduos resultantes dos modelos de demanda e oferta, e a análise de correlação simples também não identificou problemas de multicolinearidade entre as variáveis explicativas das equações resultantes.

\subsection{4 - Resultados da Correlação Canônica}

Neste perfil sócio-demográfico, as variáveis utilizadas na equação de demanda para a aplicação da correlação canônica encontram-se no quadro 5.2.4.1 a seguir.

QUADRO 5.2.4.1: VARIÁVEIS DEPENDENTES E INDEPENDENTESA DA CORRELAÇÃO CANÔNICA PARA A EQUAÇÃO DE DEMANDA - PERFIL SÓCIO-DEMOGRÁFICO MÉDIO

\begin{tabular}{|c|c|}
\hline VARIÁVEIS DEPENDENTES & VARIÁVEIS INDEPENDENTES \\
\hline \multirow{6}{*}{$\partial \mathrm{p} / \partial \mathrm{AREA}=\mathrm{DPDAREA}$} & LNAREA \\
\hline & SJOG \\
\hline & PISC \\
\hline & SAUN \\
\hline & QUAD \\
\hline & CFTV \\
\hline \multirow{6}{*}{$\mathrm{C}$} & VARD \\
\hline & VAGA2 \\
\hline & DORM2 \\
\hline & DORM3 \\
\hline & BANH2 \\
\hline & COLP \\
\hline \multirow{6}{*}{ V } & $\mathrm{SHOP}$ \\
\hline & METR \\
\hline & HOSP \\
\hline & PARQ \\
\hline & ATER \\
\hline & LNMEMB \\
\hline
\end{tabular}


Da mesma forma que no procedimento elaborado para o perfil sóciodemográfico baixo, a operação por meio da qual a correlação canônica é efetuada, para a demanda, encontra-se a seguir.

MANOVA DPDAREA C $V$ with LNAREA SJOG PISC SAUN QUAD CFTV VARD VAGA2 DORM2 DORM3 BANH2 COLP SHOP METR HOSP PARQ ATER LNMEMB /print=error (SSCP COV COR) signif (hypoth eigen dimenr) /discrim=raw stan estim cor alpha(1.0) /residuals=casewise plot /design.

Já para a equação de oferta, o quadro 5.2.4.2, a seguir, apresenta as variáveis utilizadas para o perfil sócio-demográfico médio.

QUADRO 5.2.4.2: VARIÁVEIS DEPENDENTES E INDEPENDENTESA DA CORRELAÇÃO CANÔNICA PARA A EQUAÇÃO DE OFERTA - PERFIL SÓCIO-DEMOGRÁFICO MÉDIO

\begin{tabular}{|c|c|}
\hline VARIÁVEIS DEPENDENTES & VARIÁVEIS INDEPENDENTES \\
\hline \multirow{6}{*}{$\partial \mathrm{p} / \partial \mathrm{AREA}=\mathrm{DPDAREA}$} & LNAREA \\
\hline & SJOG \\
\hline & PISC \\
\hline & SAUN \\
\hline & QUAD \\
\hline & CFTV \\
\hline \multirow{6}{*}{$\mathrm{C}$} & VARD \\
\hline & VAGA2 \\
\hline & DORM2 \\
\hline & DORM3 \\
\hline & BANH2 \\
\hline & COLP \\
\hline \multirow{7}{*}{ V } & $\mathrm{SHOP}$ \\
\hline & METR \\
\hline & HOSP \\
\hline & PARQ \\
\hline & ATER \\
\hline & LNDENS \\
\hline & LNPOP \\
\hline
\end{tabular}


A operação por meio da qual a correlação canônica é efetuada, para a oferta, é:

MANOVA DPDAREA C $V$ with LNAREA SJOG PISC SAUN QUAD CFTV VARD VAGA2 DORM2 DORM3 BANH2 COLP SHOP METR HOSP PARQ ATER LNDENS LNPOP /print=error (SSCP COV COR) signif (hypoth eigen dimenr) /discrim=raw stan estim cor alpha(1.0) /residuals=casewise plot /design.

Os testes multivariados de significância coletiva do conjunto das funções canônicas mostram, por meio das tabelas 34 e 35 em anexo (v. Anexos - Item J.4), que pode ser rejeitada a hipótese nula de que as funções canônicas não são significantes coletivamente para as equações de demanda e oferta.

As tabelas 36 e 37 apresentam as raízes canônicas de cada função canônica, para as equações de demanda e oferta, e verificam se cada uma delas pode ser considerada relevante. As raízes canônicas da equação de demanda apresentaram resultados respectivamente iguais a 0,839, 0,673 e 0,494, o que mostra a significância da primeira função canônica. O mesmo acontece para a equação de oferta, que oferece resultados iguais a 0,840, 0,670 e 0,510. O teste univariado, apresentado nas tabelas 38 e 39, também mostra que as funções são significantes.

Assim como para o perfil sócio-demográfico baixo, a análise será somente elaborada para a primeira função canônica. As tabelas 40 e 41 apresentam os pesos canônicos das variáveis dependentes para a primeira função canônica, de onde se observa que a hierarquia, tanto para a equação de demanda quanto para a de oferta, segue a sequência $V$, DPAREA e $C$, ou seja, valor da primeira parcela, preço unitário e número de parcelas do financiamento. Porém, quando a comparação é feita entre as equações de demanda e oferta, percebe-se um peso relativo maior da variável relacionada ao valor da primeira parcela para a equação de oferta e das variáveis 
relacionadas ao preço unitário e à quantidade de parcelas para a equação de demanda. As diferenças entre estes resultados e os obtidos para o perfil sóciodemográfico baixo serão discutidos no item 5.4 .

Em relação às variáveis independentes, pela análise da primeira função canônica, tem-se, por meio das tabelas 42 e 43, que a variável relacionada à área total do imóvel (LNAREA) apresenta a maior hierarquia, sendo seguida pelas variáveis que compõem os vetores z, Y (1 e 2) e W.

As tabelas 44 e 45 apresentam as correlações entre as variáveis dependentes e as variáveis canônicas e, por meio da análise das mesmas, é possível verificar, para a equação de demanda, que o que foi compartilhado pelas variáveis na primeira função canônica é igual a $\left[(0,439)^{2}+(-0,880)^{2}+(-\right.$ $\left.0,883)^{2}\right] / 3=0,582$. De forma análoga, para a equação de oferta, o que foi compartilhado pelas variáveis na primeira função canônica é igual a 0,586. Ainda por meio da análise das tabelas 44 e 45, acredita-se que as três variáveis escolhidas são boas dependentes para o conjunto de variáveis independentes para o perfil sócio-demográfico médio, uma vez que as correlações na primeira função canônica são elevadas.

Analogamente, em referência às variáveis independentes, as tabelas 46 e 47 mostram as correlações entre as variáveis independentes e as variáveis estatísticas canônicas. A partir dos mesmos, verifica-se que o que foi compartilhado pelas variáveis na primeira função canônica é igual a 0,152 para a equação de demanda e 0,145 para a equação de oferta. Com base na tabela 46, o ranking, para a primeira função canônica, seria composto pelas variáveis LNAREA, DORM2, CFTV, SJOG, SAUN, QUAD, BANH2, DORM3 e VAGA2. Acredita-se, assim, que as demais variáveis não explicam de forma relevante as variáveis dependentes escolhidas, já que as correlações, na primeira função canônica, são menores do que 0,300. Em relação à equação de oferta, de acordo com a tabela 47, o ranking seria composto pelas variáveis LNAREA, DORM2, CFTV, SJOG, SAUN, QUAD, DORM3, BANH2 e VAGA2. Assim sendo, não há descolamentos significativos entre o que é considerado relevante por parte da demanda e o que está sendo considerado como representativo sob a ótica da oferta. 
Por fim, são relacionadas as raízes canônicas e a variância compartilhada com o índice de redundância. Como podem ser observados por meio da tabela 48, os índices de redundância para a variável estatística dependente são mais substanciais $(0,488$ para a demanda e 0,492 para a oferta). A variável estatística independente, contudo, tem índices de redundância menores (0,128 para a demanda e 0,122 para a oferta), já que são resultantes das variâncias compartilhadas relativamente baixas na variável estatística independente e não das correlações ao quadrado.

De forma análoga ao perfil sócio-demográfico baixo, pode-se também concluir que o vetor de variáveis dependentes é relevante e explicado de forma adequada pelas variáveis independentes que se mostraram significantes quando da aplicação dos modelos de correlação canônica. 


\section{3 - Perfil Sócio-Demográfico Alto}

\subsection{1 - Caracterização da Amostra}

A coleta de dados para a composição da amostra deste grupo sóciodemográfico forneceu algumas características que podem ser observadas por meio dos gráficos 55 a 81 em anexo (v. Anexos - Item K.1). Por meio do gráfico 55 , nota-se que a média de preço dos imóveis está em torno de $\mathrm{R} \$ 740.000,00$, o que está em acordo com dados divulgados periodicamente pelo Secovi-SP (Sindicato das Empresas de Compra, Venda, Locação e Administração de Imóveis Comerciais e Residenciais de São Paulo), que tem publicado que o preço médio de imóveis residenciais de até cinco dormitórios não tem ultrapassado o valor de $\mathrm{R} \$ 980.000,00^{50}$. O gráfico 56 oferece as frequências em relação à área total de cada um dos imóveis que compõem a amostra, e a área total média encontra-se em torno de $249 \mathrm{~m}^{2}$, o que faz com que se tenha um preço unitário de aproximadamente $\mathrm{R} \$ 2.971,00 / \mathrm{m}^{2}$ para o perfil sóciodemográfico alto, ou seja, quase o triplo do calculado para o perfil baixo.

Em relação às demais variáveis que compõem o vetor $z$, nota-se, por meio da amostra de 620 unidades residenciais, que a maioria (ou até mesmo a totalidade para alguns casos) dos imóveis oferece salão de festas (620), salão de jogos (620), piscina (615), sauna (620), churrasqueira (620), quadra poliesportiva (620), guarita (620), circuito fechado de TV (620), varanda (620), tem três vagas na garagem (330), apresenta três, quatro ou cinco dormitórios (345, 176 e 66, respectivamente) e três, quatro ou cinco banheiros (165, 430 e 25, respectivamente). Percebe-se um aumento na presença de características intrínsecas existentes nos imóveis localizados em regiões de perfil sóciodemográfico alto em relação aos situados em locais de perfil baixo e médio, o que também justifica, para este caso, a estratificação aqui adotada. No item

\footnotetext{
${ }^{50}$ Assim como já comentado para os perfis sócio-demográficos baixo e médio, os valores divulgados pelo Secovi-SP são médios e estão de acordo com esse perfil sócio-demográfico, já que os imóveis pertencentes a esse grupo não apresentaram, quando da coleta da amostra, mais do que cinco dormitórios.
} 
5.3.2, a seguir, será avaliada a representatividade de cada umas das variáveis que compõem o vetor z para a composição dos preços dos imóveis.

Analogamente ao realizado para os perfis sócio-demográficos baixo e médio, as variáveis que compõem os vetores $W, Y_{1}$ e $Y_{2}$ também são apresentadas por meio dos gráficos mencionados e, a partir delas, tem-se, para a amostra coletada, que a renda média familiar para o perfil sóciodemográfico alto é de $\mathrm{R} \$ 3.402,00$, o número médio de membros da família nestas localidades é igual a 3,0, a densidade populacional média é de 8.158,00 hab / km², a população média é de 204.300 habitantes e, dos 620 imóveis pesquisados, 620 possuem colégio particular na proximidade, 538 possuem Shopping Center na região, 372 estão próximos de alguma estação de metrô, 620 possuem hospital particular na proximidade, 454 estão próximos de parques e áreas verdes, 620 estão próximos de pontos de inundação e nenhum deles possui aterros ou lixões nas imediações.

\subsection{2 - O Primeiro Estágio de Rosen}

Analogamente ao procedimento elaborado para os perfis sóciodemográficos baixo e médio, a tabela 49 em anexo (v. Anexos - Item K.2) apresenta os resultados das regressões realizadas para todas as combinações de $\theta$ e $\lambda$ descritas, de onde se pode concluir que a melhor especificação, para o perfil sócio-demográfico alto, é também a logarítmica $(\theta=\lambda=0)$, já que apresenta o maior coeficiente de ajuste $R^{2}$. Os resultados da regressão encontram-se em anexo ( $\mathrm{V}$. Anexos - Item K.2), na tabela 50 e, por meio da sua análise, verifica-se que as variáveis intrínsecas mais representativas para a composição dos preços dos imóveis residenciais deste grupo sóciodemográfico são aquelas relacionadas à área total do imóvel, ao incremento da quantidade de banheiros (de dois para três, de três para quatro e de quatro para cinco), ao incremento da quantidade de dormitórios (de três para quatro e de quatro para cinco), à existência de sala de ginástica no condomínio, ao aumento do número de vagas na garagem (de duas para três) e à posição relativa do imóvel no edifício (metade superior). As demais variáveis intrínsecas 
estudadas foram excluídas do modelo por não serem estatisticamente significativas ou por não apresentarem variações na amostra.

Por meio dos testes apresentados no quadro 4.9.2, esta regressão intermediária não apresentou, para os resíduos, problemas de autocorrelação e heterocedasticidade e, para as variáveis explicativas, problemas de multicolinearidade.

Com a utilização do mesmo método de cálculo apresentado para os perfis sócio-demográficos baixo e médio, tem-se que a variável dependente (preço marginal implícito) do segundo estágio de Rosen, para o grupo sóciodemográfico alto, será dada por:

$$
p / m^{2}=\frac{0,406 \cdot p}{A R E A}
$$

e, portanto, faz-se necessária a elaboração do segundo estágio de Rosen para o grupo sócio-demográfico alto.

\subsection{3 - O Segundo Estágio de Rosen}

Analogamente ao procedimento realizado para os perfis sóciodemográficos baixo e médio, é possível observar, por meio das tabelas 51 e 52 em anexo (v. Anexos - Item K.3), os resultados obtidos a partir da aplicação dos modelos de demanda e oferta para o perfil sócio-demográfico alto. A tabela 51 refere-se à estimação da equação de demanda, de onde é possível observar que o sinal da variável LNAREA é negativo, conforme era esperado. Nota-se também a importância das variáveis que se relacionam com 0 incremento do número de dormitórios (DORM3 e DORM4), de banheiros $(B A N H 2$, BANH3 e BANH4) e de vagas na garagem (VAGA2). A representatividade da variável SGIN demonstra a importância desta característica, sob a ótica da demanda, para a composição dos preços dos imóveis. Ainda em relação às características intrínsecas aos imóveis, aqueles que se situam na metade superior do edifício (variável ALTR) são mais bem 
avaliados pelos potenciais compradores, uma vez que tal característica apresentou-se representativa e com sinal positivo.

As características extrínsecas que se mostraram representativas e com sinal positivo referem-se à presença de parques (PARQ) e Shopping Centers (SHOP) nas localidades onde se encontram os imóveis. A variável que se refere ao número médio de membros da família (LNMEMB) também se mostrou relevante. As demais variáveis do modelo não se mostraram significativas ou não foram explicitadas, por apresentarem problemas de multicolinearidade com uma ou mais variáveis explicativas.

Para a equação de oferta, apresentada na tabela 52, a variável relacionada à área também apresentou sinal negativo, como já ocorrido para os perfis sócio-demográficos baixo e médio. As variáveis DORM3, DORM4, BANH2, BANH3, BANH4, VAGA2, SGIN e ALTR também se mostraram relevantes para a composição do preço unitário de oferta, a um nível de significância de 95\%. Já em relação às variáveis extrínsecas, mostrou-se representativa e com sinal positivo a variável PARQ. Por fim, a característica associada à população da localidade (LNPOP) mostrou-se relevante e com sinal negativo, demonstrando que imóveis lançados em regiões mais populosas não têm apresentado incremento de seus preços unitários por parte dos agentes que compõem a oferta.

Analogamente ao procedimento realizado para os perfis sóciodemográficos baixo e médio, apresentam-se os resultados das estimações das equações de oferta e demanda para o perfil sócio-demográfico alto pelo método Stepwise, na tabela 53 em anexo (v. Anexos - Item K.3).

A tabela permite observar, assim como para os perfis anteriormente analisados, que a variável correspondente à área total do imóvel é a que apresenta a maior importância relativa para a composição dos preços unitários de demanda e oferta, sendo ainda mais relevante para esta última. As características do vetor z também aparecem em ambas as equações, ficando a cargo das variáveis relativas ao incremento do número de banheiros e de dormitórios (principalmente BANH4 e DORM4), além da presença de sala de ginástica, a maior representatividade para a composição dos preços unitários. 
Estas variáveis são ainda mais significativas na equação de oferta, o que demonstra novamente um eventual descolamento entre as perspectivas de demanda para este público e o que efetivamente está sendo considerado quando da elaboração dos preços de oferta.

Em relação às variáveis extrínsecas, a única presente nas duas equações é a variável PARQ, ficando todas as demais somente em uma delas. $\mathrm{Na}$ equação de demanda, são relevantes as características relativas à proximidade de Shopping Centers e ao número de membros da família. Por outro lado, na equação de oferta, é representativa a variável referente à população da localidade. O fato de a variável SHOP somente aparecer na equação de demanda também pode propiciar eventuais investigações por parte de incorporadoras e imobiliárias que atuam neste segmento e ofertam imóveis em lançamento situados nas regiões definidas como sendo de perfil sóciodemográfico alto. Destaca-se que as variáveis mais representativas para a composição da equação de oferta também apareceram na modelagem proposta por FÁVERO (2003, p. 54).

A aplicação do teste de endogeneidade permitiu concluir que todas as variáveis explicativas são exógenas, uma vez que não apresentaram correlação significativa com os termos do erro a um nível de confiança de 95\%. Desta forma, confirma-se a possibilidade de aplicação do método dos mínimos quadrados ordinários. As equações apresentadas para este perfil sóciodemográfico também não apresentaram problemas de identificação, uma vez que as condições de ordem e de posto estão satisfeitas, pois há ao menos uma variável em cada equação que não está presente na outra equação (condição de ordem), visto que SHOP e LNMEMB somente aparecem na equação de demanda e LNPOP somente aparece na equação de oferta. Além disto, estas variáveis apresentam coeficientes diferentes de zero, o que faz com que também seja obedecida a condição de posto.

Por fim, os testes de Durbin-Watson e de Glejser mostraram que não há problemas de autocorrelação ou heterocedasticidade dos resíduos resultantes dos modelos de demanda e oferta, e a análise de correlação simples também 
não identificou problemas de multicolinearidade entre as variáveis explicativas das equações estudadas.

\subsection{4 - Resultados da Correlação Canônica}

Neste perfil sócio-demográfico, as variáveis utilizadas na equação de demanda para a aplicação da correlação canônica encontram-se no quadro 5.3.4.1 a seguir.

QUADRO 5.3.4.1: VARIÁVEIS DEPENDENTES E INDEPENDENTESA DA CORRELAÇÃO CANÔNICA PARA A EQUAÇÃO DE DEMANDA - PERFIL SÓCIO-DEMOGRÁFICO ALTO

\begin{tabular}{|c|c|}
\hline VARIÁVEIS DEPENDENTES & VARIÁVEIS INDEPENDENTES \\
\hline \multirow{4}{*}{$\partial \mathrm{p} / \partial \mathrm{AREA}=\mathrm{DPDAREA}$} & LNAREA \\
\hline & SGIN \\
\hline & ALTR \\
\hline & VAGA2 \\
\hline \multirow{4}{*}{$\mathrm{C}$} & DORM3 \\
\hline & DORM4 \\
\hline & BANH2 \\
\hline & BANH3 \\
\hline \multirow{4}{*}{ V } & BANH4 \\
\hline & SHOP \\
\hline & PARQ \\
\hline & LNMEMB \\
\hline
\end{tabular}

Assim como o realizado para os perfis anteriores, a operação por meio da qual a correlação canônica é efetuada, para a demanda, encontra-se a seguir.

MANOVA DPDAREA C V with LNAREA SGIN ALTR VAGA2 DORM3 DORM4 BANH2 BANH3 BANH4 SHOP PARQ LNMEMB

/print=error (SSCP COV COR) signif

(hypoth eigen dimenr)

/discrim=raw stan estim cor alpha(1.0)

/residuals=casewise plot

/design. 
Já para a equação de oferta, o quadro 5.3.4.2, a seguir, apresenta as variáveis utilizadas para o perfil sócio-demográfico alto.

QUADRO 5.3.4.2: VARIÁVEIS DEPENDENTES E INDEPENDENTESA DA CORRELAÇÃO CANÔNICA PARA A EQUAÇÃO DE OFERTA - PERFIL SÓCIO-DEMOGRÁFICO ALTO

\begin{tabular}{|c|c|}
\hline VARIÁVEIS DEPENDENTES & VARIÁVEIS INDEPENDENTES \\
\hline \multirow{3}{*}{$\partial \mathrm{p} / \partial \mathrm{AREA}=$ DPDAREA } & LNAREA \\
\cline { 2 - 2 } & SGIN \\
\cline { 2 - 2 } & ALTR \\
\cline { 2 - 2 } & VAGA2 \\
\hline \multirow{3}{*}{$\mathrm{c}$} & DORM3 \\
\cline { 2 - 2 } & DORM4 \\
\cline { 2 - 2 } & BANH2 \\
\cline { 2 - 2 } & BANH3 \\
\hline \multirow{2}{*}{$\mathrm{V}$} & BANH4 \\
\cline { 2 - 2 } & PARQ \\
\cline { 2 - 2 } & LNPOP \\
\hline
\end{tabular}

A operação que efetua a correlação canônica para a oferta é:

MANOVA DPDAREA C V with LNAREA SGIN ALTR VAGA2 DORM3 DORM4 BANH2 BANH3 BANH4 PARQ LNPOP

/print=error (SSCP COV COR) signif

(hypoth eigen dimenr)

/discrim=raw stan estim cor alpha(1.0)

/residuals=casewise plot

/design.

Os testes multivariados de significância coletiva do conjunto das funções canônicas mostram, por meio das tabelas 54 e 55 em anexo (v. Anexos - Item K.4) que a hipótese nula de que as funções canônicas não são significantes coletivamente para as equações de demanda e oferta pode ser rejeitada.

As raízes canônicas de cada função canônica são apresentadas nas tabelas 56 e 57 e, para a equação de demanda, apresentaram resultados respectivamente iguais a 0,607, 0,086 e 0,032, o que mostra a significância da 
primeira função canônica. O mesmo acontece para a equação de oferta, que oferece resultados iguais a 0,613, 0,086 e 0,032. O teste univariado, apresentado nas tabelas 58 e 59, também mostra que as primeiras funções canônicas são significantes. Porém, como elaborado para os demais perfis sócio-demográficos, a análise será somente elaborada para a primeira função canônica.

As tabelas 60 e 61 apresentam os pesos canônicos das variáveis dependentes para a primeira função canônica, de onde se observa que a hierarquia segue a sequência DPAREA, V e C, sem diferenças significativas entre a equação de demanda e a equação de oferta.

Em relação às variáveis independentes, pela análise da primeira função canônica, tem-se, por meio das tabelas 62 e 63, que a variável relacionada à área total do imóvel (LNAREA) apresenta a maior hierarquia, sendo seguida pelas variáveis que compõem os vetores z, Y (1 e 2) e W. As diferenças entre estes resultados e os obtidos para os perfis sócio-demográficos baixo e médio serão discutidos no item 5.4 .

As correlações entre as variáveis dependentes e as variáveis canônicas são apresentadas nas tabelas 64 e 65 e, por meio da análise das mesmas, é possível verificar, para a equação de demanda, que o que foi compartilhado pelas variáveis na primeira função canônica é igual a $\left[(-0,982)^{2}+(0,053)^{2}+(-\right.$ $\left.0,011)^{2}\right] / 3=0,322$. Para a equação de oferta, este valor também é igual a 0,322 . Ainda por meio da análise das tabelas 64 e 65 , nota-se que somente a variável relacionada ao preço unitário do imóvel é uma boa dependente para o conjunto de variáveis independentes, para o perfil sócio-demográfico alto, uma vez que apenas a sua correlação na primeira função canônica é elevada.

Para as variáveis independentes, as tabelas 66 e 67 mostram as correlações entre as variáveis independentes e as variáveis estatísticas canônicas. A partir dos mesmos, verifica-se que o que foi compartilhado pelas variáveis na primeira função canônica é igual a 0,184 para a equação de demanda e 0,202 para a equação de oferta. Com base na tabela 66, o ranking, para a primeira função canônica, seria composto pelas variáveis LNAREA, VAGA2, ALTR, BANH4 e DORM4. Acredita-se, portanto, que as demais 
variáveis não explicam de forma relevante as variáveis dependentes escolhidas, já que as correlações, na primeira função canônica, são menores do que 0,300. Em relação à equação de oferta, de acordo com a tabela 67, o ranking seria composto pelas variáveis LNAREA, VAGA2, ALTR, BANH4 e DORM4. Não há, portanto, diferenças significativas entre o que é considerado relevante por parte da demanda e o que está sendo considerado como representativo por parte da oferta.

Por fim, são relacionadas as raízes canônicas e a variância compartilhada com o índice de redundância. Como podem ser observados por meio da tabela 68 , os índices de redundância para a variável estatística dependente são um pouco mais substanciais $(0,195$ para a demanda e 0,197 para a oferta). A variável estatística independente, contudo, tem índices de redundância menores (0,112 para a demanda e 0,124 para a oferta), resultantes das variâncias compartilhadas um pouco baixas na variável estatística independente. De maneira geral, os índices de redundância para o perfil sócio-demográfico alto mostraram-se menores do que os calculados para os outros perfis, já que duas das três variáveis escolhidas como dependentes não são relevantes e nem tampouco explicadas de forma adequada pelas variáveis independentes utilizadas. 


\section{4 - Comparação entre os Grupos Sócio-Demográficos}

Quando a comparação entre os três perfis sócio-demográficos é elaborada, notam-se diferenças que podem justificar a importância da segmentação adotada para a aplicação dos modelos hedônicos.

Em relação às equações de demanda, conforme pode ser observado na tabela 69 em anexo (v. Anexos - Item L.1), nota-se que os perfis sóciodemográficos baixo e médio são os que apresentam as maiores quantidades de variáveis representativas, com um número total de 17 e 18, respectivamente, ficando o perfil sócio-demográfico alto com 12 variáveis representativas. Isto talvez ocorra pelo fato de terem sido utilizadas as mesmas variáveis em cada perfil sócio-demográfico, para a estimação das funções de demanda, e não necessariamente variáveis talvez mais representativas para o último perfil.

Em relação a cada variável específica, percebe-se um incremento da importância relativa da área do imóvel quando se aumenta o perfil sóciodemográfico, o que demonstra uma maior procura por imóveis com áreas maiores por parte dos compradores que buscam adquirir apartamentos nas localidades deste perfil. Além disto, enquanto as variáveis SFES, CHUR e GUAR são representativas apenas para o perfil baixo, as variáveis SGIN e ALTR aparecem somente no perfil alto, o que demonstra a importância da aplicação da análise fatorial para a divisão do mercado em sub-amostras. No último perfil, todas as unidades coletadas da sub-amostra ofereceram salão de festas, churrasqueira e guarita, enquanto no perfil baixo, nenhuma unidade apresentou sala de ginástica no empreendimento. As variáveis SJOG, PISC e QUAD são representativas apenas para os perfis sócio-demográficos baixo e médio, havendo um aumento das respectivas importâncias relativas, à medida que se passa do primeiro para o segundo perfil, e não se mostraram significativas para o incremento dos preços unitários dos imóveis, para o perfil alto, pelo fato de quase a totalidade das unidades residenciais terem oferecido tais características. Da mesma forma, a variável VARD também valoriza os 
imóveis localizados em regiões pertencentes aos perfis baixo e médio, sendo mais representativa para este último.

Entre os três perfis sócio-demográficos analisados, nota-se que o perfil médio é o que oferece a maior representatividade das variáveis relacionadas às áreas de lazer do empreendimento, ficando o fato bem ilustrado pela variável SAUN, que inclusive só é significativa para este perfil. O mesmo acontece para a variável CFTV, que demonstra a preocupação com a segurança e a valorização, sob a perspectiva da demanda, dos imóveis que possuem esta característica.

Em relação às variáveis pertencentes a cada unidade residencial, notase o incremento da importância relativa da quantidade de dormitórios e banheiros à medida que se passa do perfil sócio-demográfico baixo para o médio, e do médio para o alto. O mesmo acontece para a quantidade de vagas na garagem, sendo o aumento de duas para três vagas mais representativo para a valorização de imóveis situados em locais de perfil médio.

Por fim, ainda por meio da análise da tabela 69 em anexo, nota-se a importância das variáveis relacionadas à proximidade de colégios particulares e estações de metrô para os perfis sócio-demográficos baixo e médio, de hospitais particulares apenas para o perfil médio e de Shopping Centers e parques com áreas verdes para os perfis médio e alto. Ressalta-se que as variáveis extrínsecas relativas às características da localidade aparecem de forma mais representativa e com maior frequência para o perfil sóciodemográfico médio. Além disto, a renda é representativa para a aquisição de imóveis em locais de perfil baixo, enquanto o número de membros da família passa a ser para os outros dois perfis.

As equações de oferta também podem ser encontradas em anexo ( $v$. Anexos - Item L.1), na tabela 70, na qual se observam praticamente as mesmas considerações realizadas para as equações de demanda. Porém, alguns descolamentos acontecem, já que, sob a perspectiva da oferta, 15 variáveis são representativas para o perfil sócio-demográfico baixo, 19 para o perfil médio e 11 para o perfil alto. Para o primeiro perfil, as variáveis QUAD, VAGA1 e METR são representativas para a equação de demanda e não 
aparecem na equação de oferta. Além disto, a variável INUN é significativa para a composição da demanda, com sinal negativo, porém é a variável ATER que é levada em conta, também com sinal negativo, quando da composição da oferta. Já para o perfil alto, a principal diferença entre o que é representativo para a demanda e para a oferta relaciona-se à variável SHOP, que está presente na composição da equação de demanda e não na equação de oferta.

Ademais, as variáveis que compõem o vetor $\mathrm{Y}_{2}$, de características extrínsecas que afetam exclusivamente a oferta, apresentam importâncias relativas diferenciadas entre os perfis sócio-demográficos. Enquanto, para o perfil baixo, a densidade demográfica e a população são pouco representativas e com sinal positivo sob a ótica da oferta, para o perfil médio apresentam-se de forma mais representativa, sendo a primeira com sinal negativo. Já para o perfil alto, apenas a variável relativa à população local mostra-se representativa, porém também com sinal negativo. Isto demonstra a utilização de estratégias diferenciadas para a elaboração de lançamentos imobiliários residenciais efetuados por incorporadoras, imobiliárias e construtoras, já que indicadores maiores de densidade demográfica e população acabam fazendo com que sejam mais valorizados os imóveis situados em locais de perfil baixo. Por outro lado, aqueles imóveis lançados em regiões de perfil médio são mais valorizados se a população local for maior, porém com densidade demográfica menor, ou seja, em áreas mais vastas. Por último, os imóveis que se situam no perfil alto e que mais se valorizam, sob a perspectiva da oferta, são aqueles localizados em regiões menos populosas.

A seguir, na tabela 5.4.1, são apresentadas as equações hedônicas de demanda e oferta para cada perfil sócio-demográfico. 
TABELA 5.4.1: EQUAÇÕES HEDÔNICAS DE DEMANDA E OFERTA PARA CADA PERFIL SÓCIODEMOGRÁFICO ${ }^{51}$

\begin{tabular}{|c|c|c|}
\hline PERFIL & EQUAÇÃO & MODELO HEDÔNICO \\
\hline \multirow{2}{*}{ BAIXO } & DEMANDA & 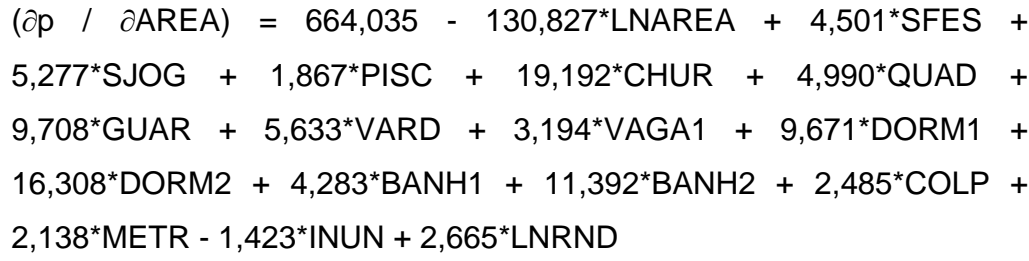 \\
\hline & OFERTA & 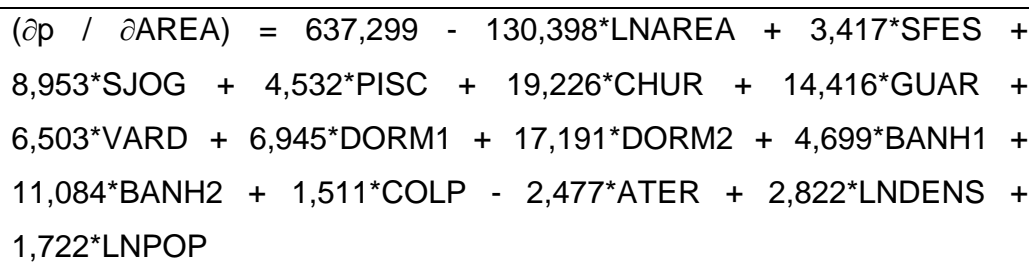 \\
\hline \multirow[b]{2}{*}{ MÉDIO } & DEMANDA & 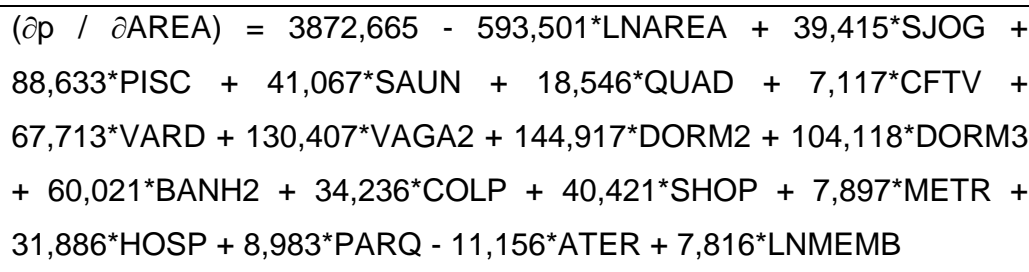 \\
\hline & OFERTA & 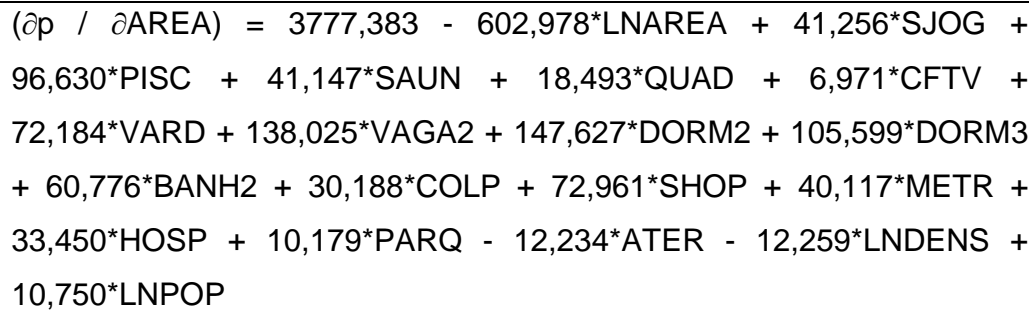 \\
\hline \multirow{2}{*}{ ALTO } & DEMANDA & $\begin{array}{l}(\partial p / \quad \partial A R E A)=3946,468-544,041 * \text { LNAREA }+79,049 * \text { SGIN }+ \\
48,350 * A L T R+53,053 * \text { VAGA2 + 61,241*DORM3 + 219,410*DORM4 + } \\
\text { 31,633*BANH2 + 123,170*BANH3 + 558,115*BANH4 + 10,350*SHOP + } \\
\text { 13,038*PARQ + 7,377*LNMEMB }\end{array}$ \\
\hline & OFERTA & $\begin{array}{l}(\partial p / \partial A R E A)=4079,385-547,625 * \text { LNAREA }+81,412 * \text { SGIN + } \\
45,455^{\star} \text { ALTR }+46,558 * \text { VAGA2 + 61,700*DORM3 + 221,361*DORM4 + } \\
\text { 33,640*BANH2 + 118,925*BANH3 + 559,863*BANH4 + 13,438*PARQ - } \\
\text { 8,595*LNPOP }\end{array}$ \\
\hline
\end{tabular}

NOTA: Os resultados são provenientes do software SPSS 12.0.

\footnotetext{
${ }^{51}$ Os coeficientes apresentados não estão padronizados.
} 
Por meio da aplicação do teste Chow, permite-se verificar que os parâmetros dos atributos das equações de demanda e oferta diferem, quando da comparação entre cada perfil sócio-demográfico, o que reforça a importância da estratificação em sub-mercados demográficos para a aplicação de modelos hedônicos. A análise da tabela 71, em anexo ( $v$. Anexos - Item L.1), permite rejeitar a hipótese nula de que os parâmetros dos atributos dos perfis sócio-demográficos são iguais, já que as estatísticas F calculadas excedem os valores críticos de F a um nível de significância de 1\%.

Os resultados obtidos por meio da técnica multivariada de correlação canônica também oferecem diferenças significativas quando da comparação entre os perfis sócio-demográficos, e não se distanciam daqueles já apresentados, quando da análise elaborada para a técnica de regressão múltipla. As comparações entre as cargas canônicas (correlações canônicas) do grupo de variáveis dependentes e independentes, para cada perfil sócio demográfico, podem ser observadas por meio das tabelas 72, 73, 74 e 75 em anexo (v. Anexos - Item L.2). Nota-se uma manutenção da quantidade de variáveis independentes representativas em relação aos resultados apresentados, quando da elaboração da técnica de regressão múltipla, para cada equação de cada perfil sócio-demográfico, o que demonstra que as variáveis independentes explicam de maneira adequada não somente o preço unitário dos imóveis, mas também as demais variáveis dependentes utilizadas na técnica de correlação canônica. Para salientar o fato, elaboraram-se, apenas em caráter de verificação, todas as regressões anteriormente apresentadas, utilizando-se, como variáveis dependentes, a quantidade de parcelas do financiamento e o valor da primeira parcela. Nestes casos, todas as variáveis independentes utilizadas, para cada perfil, mostraram-se, da mesma forma, relevantes para a composição de cada variável dependente utilizada isoladamente, o que faz como que seja possível classificar os modelos apresentados neste trabalho não apenas de precificação hedônica, mas, de uma forma mais ampla, de comercialização hedônica. 


\section{CONCLUSÕES, RECOMENDAÇÕES E POSSÍVEIS EXTENSÕES}

Este trabalho apresenta os principais conceitos relacionados à formulação de problemas que envolvem a modelagem hedônica de comercialização e escolha de imóveis residenciais em lançamento, em função de determinados "pacotes" de atributos que venham a ser representativos para a formação de preços e demais condições comerciais em cada sub-mercado determinado. Ainda em um ambiente teórico, são apresentadas as principais linhas de pesquisa que tratam do assunto, com ênfase para os trabalhos que mais influenciaram o presente estudo. Deve-se ressaltar a importância da consideração de sub-mercados segmentados para a coleta de dados que, embora não tenha sido considerada por ROSEN (1974, p. 34-55), representa uma forma de eliminação de problemas de identificação em equações de demanda e oferta e de endogeneidade de determinadas variáveis presentes nestas equações, já que se aumenta a representatividade de algumas variáveis para a formação dos preços e demais condições comerciais dos imóveis em cada perfil sócio-demográfico.

Acredita-se que foram atendidos os objetivos apresentados no item $1.3 \mathrm{e}$ respondida a questão de pesquisa proposta no item 1.4 deste trabalho, uma vez que se identificaram as principais linhas de pesquisa que tratam do assunto, além de terem sido determinadas as variáveis mais representativas para a composição dos grupos sócio-demográficos e definidos os próprios perfis dentro da Região Metropolitana de São Paulo. Além disto, também foram definidas as variáveis mais significativas, sob a perspectiva da demanda e da oferta, para determinação dos preços e demais condições comerciais dos imóveis em cada um dos sub-mercados sócio-demográficos e, por fim, apresentaram-se as principais diferenças entre cada uma das variáveis, tanto no que diz respeito aos descolamentos observados entre as equações de demanda e oferta dentro de um mesmo perfil, quanto em relação à importância relativa diferenciada, quando da comparação elaborada entre os grupos sóciodemográficos. 
A seguir, na figura 6.1, são apresentados, de forma esquemática, os procedimentos efetuados neste estudo, por meio dos quais foi possível atender aos objetivos propostos.

FIGURA 6.1: PROCEDIMENTOS EFETUADOS PARA SE ATINGIREM OS RESPECTIVOS OBJETIVOS

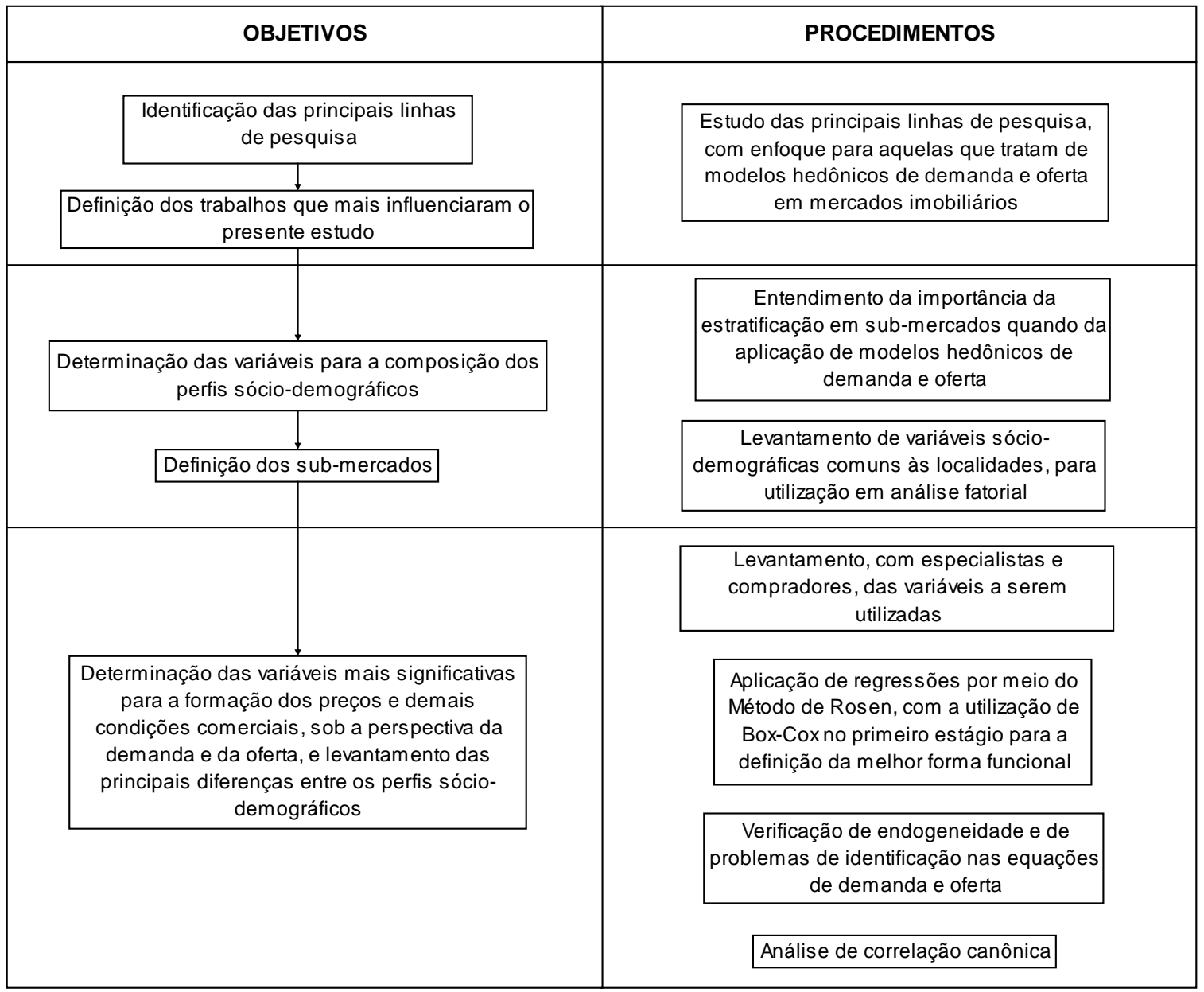

Poder-se-ia pensar na inclusão de novas variáveis independentes nos modelos de regressão e correlação canônica, para a composição dos preços e demais condições comerciais dos imóveis, como aquelas relacionadas à infraestrutura urbana (saneamento, pavimentação, redes de gás ou coleta de lixo) ou até mesmo as marcas da construtora e da incorporadora. Além disto, algumas outras variáveis também podem, em estudos futuros, fazer parte do vetor de variáveis dependentes nos modelos de correlação canônica, como aquelas referentes aos valores intermediários do parcelamento ou o fato de 
haver necessidade ou não de comprovação de renda quando da aquisição do financiamento.

Ademais, a inclusão de variáveis relativas a mudanças temporais e a taxas de crescimento de determinados indicadores sócio-demográficos e do mercado imobiliário pode ser elaborada nos modelos hedônicos, o que talvez propicie a criação de índices hedônicos de evolução em cada um dos submercados analisados, tanto para as equações de demanda, quanto para as de oferta, permitindo a avaliação da importância relativa de cada um dos atributos estudados, bem como do surgimento ou do desaparecimento de um ou mais deles ao longo do tempo.

O próprio método utilizado, que compreende etapas que vão desde o processo de coleta das variáveis, passando pela determinação dos perfis sócio-demográficos, pela utilização de modelos de regressão Box-Cox, pela elaboração de equações de demanda e oferta em dois estágios com a verificação de problemas de identificação e endogeneidade e pela ampliação dos modelos de preços hedônicos para uma ótica de comercialização hedônica, por meio da utilização de correlação canônica, pode ser estendido a outros Municípios ou Regiões Metropolitanas do Brasil, respeitando-se as peculiaridades sócio-demográficas de cada localidade. A utilização para mercados imobiliários comerciais ou residenciais com enfoque para a locação também podem ser objeto desta forma de abordagem.

O estudo da avaliação dos atributos e dos respectivos impactos para a formação de determinadas condições comerciais pode permitir, aos agentes atuantes no mercado imobiliário, uma maior compreensão das dinâmicas e dos processos por meio dos quais os produtos são lançados e comercializados em cada localidade, em função de cada perfil sócio-demográfico. As análises de comercialização hedônica apresentam implicações estratégicas e políticas, no que diz respeito à definição de projetos, ao suprimento de recursos e serviços e até mesmo à definição de cargas tributárias diferenciadas em função de cada localidade. Já que os valores e benefícios de um determinado imóvel dependem dos componentes do "pacote" de atributos, deve-se, nas fases de projeto, prospecção, planejamento e determinação regional, levar em conta as 
prioridades associadas a cada local, consistentes com as preferências daqueles que poderão vir a ser os pretendentes para a compra (FOLLAIN; JIMENEZ, 1985b, p. 422). Com isto, pode-se inclusive determinar os níveis mínimos de recursos e tecnologias dispensados para cada tipo de construção, em função de seus atributos intrínsecos e extrínsecos.

Atualmente, a Região Metropolitana de São Paulo não apresenta uma adequação em relação ao total cumprimento de suas funções urbanas, já que os níveis de esgotamento dos espaços metropolitanos passam a comprometer o seu desempenho cotidiano. Assim, as organizações privadas que têm, no mercado imobiliário, sua principal forma de atuação, necessitam, cada vez mais, da compreensão em torno do comportamento de cada um dos submercados existentes, para que sejam minimizados os eventuais descolamentos entre o que está sendo ofertado e o que desejam os compradores potenciais.

Segundo MEYER, GROSTEIN e BIDERMAN (2004, p. 14-51), do ponto de vista das atribuições e responsabilidades dos diferentes níveis do poder público, a Região Metropolitana de São Paulo deverá realizar, em um futuro breve, um programa de ações pautado pela necessidade de promover as políticas públicas e as ações que correspondam ao atendimento das significativas demandas sociais acumuladas, decorrentes do padrão de urbanização, criando condições para um desenvolvimento urbano efetivo e capaz de minimizar os problemas que acompanham a modernização precária, e fazendo com que haja uma reestruturação metropolitana que crie novos atributos espaciais e funcionais em todas as dimensões e escalas referentes aos sistemas intra-urbano, municipal, metropolitano e até regional. A concentração de investimentos públicos e a consequente valorização do solo urbano, na ausência de políticas públicas que atuassem de forma eficiente nos processos de retenção especulativa de terra no interior do município-sede ou na formulação e implantação de uma política habitacional na escala metropolitana, contribuíram para acentuar os processos de exclusão e segregação espacial que têm conduzido a expansão da mancha urbana. E, neste aspecto, verifica-se, na relação entre o poder público e a iniciativa privada, a desobediência às normas previstas de estabelecimento de novos 
empreendimentos que sejam adequados a cada parcela da população, gerando uma dissociação entre a oferta de habitação e as reais condições de aquisição de imóveis. A chamada "metropolização da pobreza" é hoje o dado determinante na elaboração de políticas urbanas em todo o mundo. No Brasil, e mais drasticamente na Região Metropolitana de São Paulo, a precariedade da oferta de infra-estrutura urbana tem causado sérios danos físicos e materiais à população menos abastada (IOKOI, 1995, p.10), e a elaboração de uma política urbana voltada para as periferias é essencial, já que assume um caráter de estratégia ampla e de adequação da oferta de atributos representativos e acessíveis.

O assunto é realmente vasto e deve ser visto como um alicerce ao poder público e à iniciativa privada para a formulação e a implantação de ações estratégicas de administração municipal e metropolitana. Neste sentido, o estudo da comercialização hedônica, sob a ótica da demanda e da oferta, pode propiciar o constante aprimoramento e a utilização das técnicas de modelagem estatística para a determinação da importância relativa de cada uma das características existentes, além de oferecer subsídios ao estabelecimento de iniciativas privadas e políticas públicas com o intuito de tornar possível a avaliação do que está sendo distribuído e o que está sendo valorizado e perseguido pelos consumidores, possibilitando, assim, a determinação de uma composição ideal do "pacote" de atributos. 


\section{REFERÊNCIAS}

AAKER, D.; KUMAR, V.; DAY, G. Marketing research. 6. ed. New York: John Wiley \& Sons Inc., 1998.

ABRAHAM, J. M.; GOETZMANN, W. N.; WACHTER, S. M. Homogenous groupings of metropolitan housing markets. Journal of Housing Economics, v. 3, n. 3, p. 186206, 1994.

ADELMAN, I.; GRILICHES, Z. On an index of quality change. Journal of the American Statistical Association, v. 56, p. 535-548, 1961.

AGUIRRE, A.; FARIA, D. M. C. P. A utilização de preços hedônicos na avaliação social de projetos. Revista Brasileira de Economia, v. 51, n. 3, p. 391-411, 1997.

AGUIRRE, A.; MACEDO, P. B. R. Estimativas de preços hedônicos para o mercado imobiliário de Belo Horizonte. In: XVIII ENCONTRO BRASILEIRO DE ECONOMETRIA, 1996, Águas de Lindóia. Anais do Congresso. Águas de Lindóia: Sociedade Brasileira de Econometria, 1996.

ALENCAR, C. T. Um modelo para formulação de estratégia empresarial no mercado residencial. São Paulo: EPUSP-PCC, 2001. 10 p. Boletim Técnico.

ALLEN, R. G. D. Price index numbers. Review of the International Statistical Institute, v. 31, p. 281-297, 1963.

ALPERT, M. I.; PETERSON, R. A. On the interpretation of canonical analysis. Journal of Marketing Research, v. 9, p. 187-192, maio 1972.

ANAS, A.; EUM, S. J. Hedonic analysis of a housing market in disequilibrium. Journal of Urban Economics, v. 15, p. 87-106, 1984.

ANCONA, A. L. O Plano Diretor e a questão ambiental. Revista A Questão Ambiental Urbana, p. 411-425, 1993.

ANDERSON, L. M.; CORDELL, H. K. Influence of trees on residential property values in Athens, Georgia (U.S.A.): a survey based on actual sales prices. Landscape and Urban Planning, v. 15, p. 153-164, 1988.

ANDERSON, S. P.; PALMA, A.; THISSE, J. F. Demand for differentiated products, discrete choice models and the characteristics approach. Review of Economic Studies, v. 56, p. 21-35, 1989.

ANGELO, C. F. A estrutura do mercado de transportes, a conduta e o desempenho das empresas ferroviárias brasileiras. São Paulo, 1991. 143 f. Tese (Livre-Docência em Administração) - Faculdade de Economia, Administração e Contabilidade, Universidade de São Paulo. 
ANGELO, C F.; FÁVERO, L. P. L. A model of hedonic prices to the evaluation of residential launchings in the city of Sao Paulo. Série de Working Papers da Faculdade de Economia, Administração e Contabilidade da USP, São Paulo, n. 03/002, 2003a.

Modelo de preços hedônicos para a avaliação de veículos novos. In: VI SEMINÁRIO EM ADMINISTRAÇÃO FEA-USP, 2003, São Paulo. Relação de trabalhos. São Paulo: VI SEMEAD, 2003b. 1 CD-ROM.

Remuneração e carreira no varejo brasileiro: uma abordagem sob a ótica dos preços hedônicos. Série de Working Papers da Faculdade de Economia, Administração e Contabilidade da USP, São Paulo, n. 04/012, 2004.

ANGELO, C. F.; FÁVERO, L. P. L.; FOUTO, N. M. M. D. A human resource management hedonic approach in Brazilian retailing. In: 12th RECENT ADVANCES IN RETAILING AND SERVICES SCIENCE CONFERENCE, 2005, Orlando. Anais do Congresso. Orlando: EIRASS, 2005. 1 CD-ROM.

ANGELO, C. F.; FÁVERO, L. P. L.; LUPPE, M. R. Modelos de preços hedônicos para a avaliação de imóveis comerciais no Município de São Paulo. Revista de Economia e Administração, v. 3, n. 2, p. 97-110, 2004.

ANGELO, C. F.; SILVEIRA, J. A. G.; TANABE, M. Função de produção: aplicações gerenciais em três indústrias brasileiras. Revista de Administração da Universidade de São Paulo, São Paulo, v. 25, n. 3, julho / setembro 1990.

ANGULO, A. M.; GIL, J. M.; GRACIA, A.; SÁNCHEZ, M. Hedonic prices for Spanish red quality wine. British Food Journal, v. 102, p. 481-493, 2000.

ARYEETEY-ATTOH, S. An analysis of household valuations and preference structures in Rio de Janeiro, Brazil. American Journal of Agricultural Economics, Oregon, p. 183-198, agosto 1992.

ATKINSON, R. J.; CROCKER, T. D. Air pollution and residential property value. Urban Studies, v. 8, p. 171-180, 1971.

BACKLEY, D. M.; FOLLAIN, J. An evaluation of hedonic price indexes for thirty-four large SMSAs. AREUEA Journal, v. 14, p. 179-205, 1986.

BAILEY, M. J.; MUTH, R. F.; NOURSE, H. O. A regression method for real estate price index construction. Journal of the American Statistical Association, v. 58, p. 933-942, 1963.

BAJARI, P.; BENKARD, C. L. Demand estimation with heterogeneous consumers and unobserved product characteristics: a hedonic approach. Research Papers, Graduate School of Business, Stanford University, n. 1691, junho 2001. 
BAJIC, V. Housing market segmentation and demand for housing attributes. AREUEA Journal, v. 13, p. 58-75, 1985.

BALL, M. J.; KIRWAN, R. M. Accessibility and supply constraints in the urban housing market. Urban Studies, v. 14, p. 11-32, 1977.

BARBOSA, E. P.; BIDURIN, C. P. Seleção de modelos de regressão para predição via validação cruzada: uma aplicação na avaliação de imóveis. Revista Brasileira de Estatística, n. 52, p. 105-120, 1991.

BARTIK, T. J. Estimating hedonic demand parameters with single market data: the problems caused by unobserved tastes. The Review of Economics and Statistics, v. 69, n. 1, p. 178-180, fevereiro 1987a.

The estimation of demand parameters in hedonic price models. Journal of Political Economy, v. 95, n. 1, p. 81-88, fevereiro 1987b.

BASU, A.; MAZUMDAR, T.; RAJ, S. P. Indirect network externality effects on product attributes. Marketing Science, v. 22, n. 2, p. 209-221, 2003.

BAZERMAN, M. H.; TENBRUNSEL, A. E.; WADE-BERZONI, K. Negotiating with yourself and losing: understanding and managing conflicting internal preferences. Academy of Management Review, v. 23, p. 255-241, 1998.

BENDER, B. T.; GRONBERG, J.; HWANG, H. S. Choice of functional form and the demand for air quality. Review of Economics and Statistics, v. 62, p. 638-643, 1980.

BERNDT, E. R.; GRILICHES, Z; RAPPAPORT, N. J. Econometric estimates of price indexes for personal computers in the 1990's. Journal of Econometrics, v. 68, p. 243268, 1995.

BERRY, B. J. L. Ghetto expansion and single-family housing prices: Chicago, 19681972. Journal of Urban Economics, v. 3, p. 397-423, 1976.

BERRY, S.; LEVINSOHN, J.; PAKES, A. Automobile prices in market equilibrium. Econometrica, v. 63, n. 4, p. 841-890, 1995.

BESANKO, D; DRANOVE, D.; SHANLEY, M; SCHAEFER; S. Economics of strategy, 3. ed. Wiley, 2004.

BIBLE, D. S.; HSIEH, C. Gated communities residential property values. The Appraisal Journal, p. 140-145, abril 2001.

BITROS, G. C.; PANAS, E. E. Measuring product prices under conditions of quality change: the case of passenger cars in Greece. The Journal of Industrial Economics, v. 37, n. 2, p. 167-186, 1988. 
BOWEN, W.; MIKELBANK, B. A.; PRESTEGAARD, D. Theoretical and empirical considerations regarding space in hedonic housing price model applications. Growth and Change, v. 32, n. 4, p. 466-490, outono 2001.

BOX, G. E. P.; COX, D. R. An analysis of transformations. Journal of the Royal Statistical Society, v. 26, n. 2, p. 211-252, 1964.

An analysis of transformations revisited. Journal of the American Statistical Association, v. 77, p. 209-210, março 1982.

BRASINGTON, D. M. Which measures of school quality does the housing market value? Spatial evidence vs. non-spatial evidence. Journal of Real Estate Research, v. 18, p. 395-413, 1999.

BRENNAM, T.; CANNADAY, R.; COLDWELL, P. Office rent in the Chicago CBD. AREUEA Journal, v. 12 , p. 295-305, 1984.

BROWN, J. N.; ROSEN, S. On the estimation of structural hedonic price models. Econometrica, v. 50, n. 3, p. 765-768, maio 1982.

BROWN, S. L. Price variation in new houses, 1959-1961. Staff Working Paper in Economics and Statistics, Washington DC, n. 6, 1964.

BRUCATO, P. F.; MURDOCH, J. C.; THAYER, M. A. Urban air quality improvements: a comparison of aggregate health and welfare benefits to hedonic price differential. Journal of Environmental Management, v. 30, p. 265-279, 1990.

BUSSAB, W. O.; MORETTIN, P. A. Estatística básica. 5. ed. São Paulo: Saraiva, 2003.

BUTLER, R. V. Cross-sectional variation in the hedonic relationship for urban housing markets. Journal of Regional Science, v. 20, p. 439-453, 1980.

The specification of hedonic indexes for urban housing. Land Economics, v. 58, p. 96-108, 1982.

CAGAN, P. Measuring quality changes and the purchasing power of money: an exploratory study of automobiles. National Banking Review, v. 3, p. 217-236, 1965.

CAN, A. The measurement of neighborhood dynamics in urban house prices. Economic Geography, v. 66, p. 254-272, 1990.

Specification and estimation of hedonic housing price models. Science and Urban Economics, v. 22, p. 453-474, 1993.

CASTELLS, M. A sociedade em rede. 7. ed. São Paulo: Paz e Terra, 1999. 
CAVALLUZZO, L. C. Nonpecuniary rewards in the workplace: demand estimates using quasi-market data. Review of Economics and Statistics, v. 78, p. 508-512, 1991.

CHARTERS, S.; LOCKSHIN, L.; UNWIN, T. Consumer responses to wine bottle back labels. Journal of Wine Research, v. 10, p. 183-195, 1999.

CHAU, K. W.; NG, F. F.; HUNG, E. C. T. Developer's good will as significant influence on apartment unit prices. The Appraisal Journal, p. 26-30, janeiro 2001.

CHAU, K. W.; MA V. S. M.; HO, D. C. W. The pricing of 'luckiness' in the apartment market. Journal of Real Estate Literature, v. 9, n. 1, p. 31-40, 2001.

CHEROBIM, A. P. M. S. O processo de decisão de investimentos em logística: estudo com operadores logísticos que atuam no Brasil. São Paulo, 2002. 204 f. Tese (Doutorado em Administração) - Faculdade de Economia, Administração e Contabilidade, Universidade de São Paulo.

CHOW, G. C. Technological change and the demand for computers. American Economic Review, v. 57, p. 1117-1130, 1967.

Tests of equality between sets of coefficients in two linear regressions. Econometrica, v. 28, n. 3, p. 591-605, 1960.

CHRISTALLER, W. Central places in Southern Germany. New Jersey: Prentice Hall, 1966.

CLAPP, J. The intrametropolitan location of office activities. Journal of Regional Science, v. 20, p.387-399, 1980.

CLARK, D. E.; HERRIN, W. E. The impact of public school attributes on home sale prices in California. Growth and Change, v. 31, p. 385-407, verão 2000.

COLLINS, A. EVANS, A. Aircraft noise and residential property values: an artificial neural network approach. Journal of Transport Economics and Policy, p. 175-97, maio 1994.

COMBRIS, P.; LECOCQ, S.; VISSER, M. Estimation of hedonic price equation for Bordeaux wine: does quality matter? The Economic Journal, v. 107, p. 390-402, 1997.

Estimation of a hedonic equation for Burgundy wine. Applied Economics, v. 32, p. 961-967, 2000.

CONTADOR, C. R. Projetos sociais: avaliação e prática. 4. ed. São Paulo: Atlas, 2000.

COOPER, D. R.; SCHNDLER, P. S. Métodos de pesquisa em administração. 7. ed. São Paulo: Bookman, 2003. 
COURT, A.T. Hedonic price indexes with automotive examples. The Dinamics of Automobile Demand, Nova York, The General Motors Corporation, p. 99-117, 1939.

CURRY, D. J. The new marketing research systems: how to use strategic database information for better marketing decisions. New York: John Wiley \& Sons Inc., 1994.

DAHR, R.; WERTENBROCH, K. Consumer choice between hedonic and utilitarian goods. Journal of Marketing Research, v. 37, p. 60-71, fevereiro 2000.

DANTAS, F. Em 10 anos, indigentes quase dobraram. O Estado de S. Paulo, 26 setembro 2004. Dossiê Estado, p. H3.

DANTAS, R. A. Engenharia de avaliações: uma introdução à metodologia científica. São Paulo: Pini, 1998.

DANTAS, R. A.; CORDEIRO, G. M. Uma nova metodologia para a avaliação de imóveis utilizando modelos lineares generalizados. Revista Brasileira de Estatística, v. 49, p. 27-46, 1988.

DEAN, C. R..; DEPODWIN, H. J. Product variation and price indexes: a case study of electrical apparatus. Proceedings of the Business and Economic Statistics Section, p. 271-279, 1961.

DHRYMES, P. J. On the measurement of price and quality changes in some consumer capital goods. American Economic Review, v. 57, p. 501-518, 1967.

DIPASQUALE, D.; WHEATON, W. Urban economics and real estate markets. Nova Jersey: Prentice-Hall, 1996.

DOUGLAS, E. J. Managerial economics: analysis and strategy. 4. ed. New Jersey: Prentice-Hall, 1992.

DOUTRIAUX, J.; CRENER, M. A. Which statistical technique should I use? A survey and marketing case study. Managerial and Decision Economics, v. 3, n. 2, p. 99-111, junho 1982.

ECO, H. Como se faz uma tese em ciências humanas. Lisboa: Editorial Presença, 1977.

EKELAND, I.; HECKMAN, J.; NESHEIM, L. Identifying hedonic models. American Economic Review, v. 92, n. 2, p. 304-309, 2002

ELLICKSON, B. Jurisdictional fragmentation and residential choice. American Economic Review, v. 61, n. 2, p. 334-339, 1971.

EMPLASA. Empresa Paulista de Planejamento Metropolitano S.A. Disponível em: < http://www.emplasa.com.br > Acesso em: 28 jan. 2005. 
EPLEY, D. R. U. S. real estate agent income and commercial / investment activities. The Journal of Real Estate Research, v. 21, n. 3, p. 221-244, 2001.

EPPLE, D. Hedonic prices and implicit markets: estimating demand and supply functions for differentiated products. The Journal of Political Economy, v. 95, n. 1, p. 59-80, fevereiro 1987.

EREKSON, H.; WITTE, A. D. The demand for housing: comment. Southern Economic Journal, v. 46, n. 2, p. 640-648, outubro 1979.

ESPEY, M.; LOPEZ, H. The impact of airport noise and proximity on residential property values. Growth and Change, v. 31, p. 408-419, verão 2000.

FÁVERO, L. P. L. Modelos de preços hedônicos aplicados a imóveis residenciais em lançamento no Município de São Paulo. São Paulo, 2003. 103 f. Dissertação (Mestrado em Administração) - Faculdade de Economia, Administração e Contabilidade, Universidade de São Paulo.

FÁVERO, L. P. L.; ANGELO, C. F. Modelo de preços hedônicos para a avaliação de apartamentos em lançamento e a definição de estratégias de projetos e gerenciamento de empreendimentos para o Município de São Paulo. In: VI SIMPÓSIO DE ADMINISTRAÇÃO DA PRODUÇÃO, LOGÍSTICA E OPERAÇÕES INTERNACIONAIS FGV-SP, 2003, São Paulo. Anais do Congresso. São Paulo: VI SIMPOI, 2003. 1 CD-ROM.

FEENSTRA, R. C. Exact hedonic price indexes. The Review of Economic and Statistics, v. 77, n.. 4, p.634-653, 1995.

FIGLIO, D.; LUCAS, M. What's in a grade? School report cards and housing prices. American Economic Review, v. 94, p. 591-604, junho 2004.

FIGUEROA, B. E. Estimaciones hedónicas del valor de mercado de los programas de vivienda social en la América Latina. El Trimestre Econômico, v. 60, n. 240, p. 779805, 1993.

FISHER, F. M.; GRILICHES, Z.; KAYSEN, C. The costs of automobile model changes since 1949. Journal of Political Economy, v. 79, p. 433-451, 1962.

FOLLAIN, J.; JIMENEZ, E. Estimating the demand for housing characteristics: a survey and critique. Regional Science and Urban Economics, n. 15, p. 77-107, 1985a.

The demand for housing characteristics in developing countries. Urban Studies, n. 22, p. 421-432, 1985 b.

FOLLAIN, J.; MALPEZZI, S. Flight to the suburbs: insights gained from an analysis of central city versus suburban price differentials. Journal of Urban Economics, p. 381398, 1981. 
FOUTO, N. M. M. D. Determinação de uma função de preços hedônicos para computadores pessoais no Brasil. São Paulo, 2004. 150 f. Dissertação (Mestrado em Administração) - Faculdade de Economia, Administração e Contabilidade, Universidade de São Paulo.

FREEMAN, A. The hedonic price approach to measuring demand for neighborhood characteristics. The Economics of Neighborhood, p. 191-217, 1979.

FURTADO, C. Desenvolvimento e subdesenvolvimento. Rio de Janeiro: Fondo de Cultura, 1965.

GANDAL, N. Competing compatibility standards and network externalities in the PC software market. The Review of Economic and Statistics, v. 77, n. 4, p. 599-608, 1995.

GAVET, T. W. Quality and a pure price index. Monthly Labor Review, v. 90, p. 1620, 1967.

GLASCOCK, J.; JAHANIAN, S.; SIRMANS, C. An analysis of office market rents: some empirical evidence. AREUEA Journal, v. 18, p. 105-119, 1990.

GOLAN, A.; SHALIT, H. Wine quality differentials in hedonic grape pricing. Journal of Agricultural Economics, v. 44, p. 311-321, 1993.

GONZÁlEZ, M. A. S.; FORMOSO, C. T. Especificação de modelos de preços hedônicos para locação residencial em Porto Alegre. Cadernos IPPUR / UFRJ, v. 8, n. 1, p. 59-72, 1994.

GOODMAN, A.; KAWAI, M. Permanent income, hedonic prices, and demand for housing: new evidence. Journal of Urban Economics, n. 12, p. 214-237, 1982.

GOOLSBEE, A. Competition in the computer industry; online versus retail. Working Paper - National Bureau of Economic Research, Cambridge MA, n. 8351, julho 2001.

GORDON, R. J. The measurement of durable goods. Chicago: University of Chicago Press, 1990.

GOUVÊA, M. A. EAD-5963 Análise fatorial. São Paulo. 2004. 47 transparências: color.

GRILICHES, Z. Hedonic price indexes for automobiles: an econometric analysis of quality change. The Price Statistics of the Federal Government, General Series, $n$. 73, p. 137-196, 1961.

Notes on the measurement of price and quality changes. Studies in Income and Wealth, v. 28, p. 301-404, 1964. 
1971.

Price indexes quality change. Cambridge: Harvard University Press,

GRISI, C. C. H. Contribuições ao estudo das técnicas de segmentação de mercado: uma análise de dados sobre apostadores da Loteria Federal. São Paulo, 1986. 275 f. Dissertação (Mestrado em Economia) - Faculdade de Economia, Administração e Contabilidade, Universidade de São Paulo.

GROOTAERT, C.; DUBOIS, J. The demand for housing in the Ivory Coast. Staff Working Paper - World Bank, Washington DC, n. 25, 1985.

GUJARATI, D. N. Econometria básica. 3. ed. São Paulo: Makron Books, 2000.

HAIR, J. F.; ANDERSON, R. E.; TATHAM, R. L.; BLACK, W. C. Análise multivariada de dados. 5. ed. Porto Alegre: Bookman, 2005.

Multivariate data analysis. 5. ed. New Jersey: Prentice Hall, 1998.

HALL, F. L.; BRESTON, B. E.; TAYLOR, S. M. The effect of road traffic noise on house prices. Journal of Sound and Vibration, v. 80, p. 523-541, 1982.

HALVORSEN, R.; PALMQUIST, R. B. The interpretation of dummy variables in semilogarithmic equations. The American Economic Review, v. 70, n. 3, p. 474-475, 1980.

HARRISON, D.; RUBINFELD, D. L. Hedonic housing prices and the demand for clean air. Journal of Environmental Economics and Management, v. 5, p. 81-102, 1978.

HAUGHEY, P.; BASOLO, V. The effect of dual local national register historic district designations on single-family housing prices in New Orleans. The Appraisal Journal, p. 283-289, julho 2000.

HAUSMAN, J. A. Specification tests in econometrics. Econometrica, v. 46, p. 12511271, 1978.

HEDÔNICO. In: DICIONÁRIO Caldas Aulete. Rio de Janeiro: Editora Delta, 1980. p. 1827.

2001. p. 1510.

In: DICIONÁRIO Houaiss da Língua Portuguesa. São Paulo: Objetiva,

HEDONISMO. In: DICIONÁRIO Caldas Aulete. Rio de Janeiro: Editora Delta, 1980. p. 1827.

2001. p. 1510.

In: DICIONÁRIO Houaiss da Língua Portuguesa. São Paulo: Objetiva, 
HENDERSON, J. M.; QUANDT, R. E. Teoria microeconômica: uma abordagem matemática. 2. ed. São Paulo: Livraria Pioneira Editora, 1988, p. 5-49.

HITE, D.; CHERN, W.; HITZHUSEN, F.; RANDALL, A. Property-value impacts of an environmental disamenity: the case of landfills. Journal of Real Estate Finance and Economics, v. 22, n. 2, p. 185-194, 2001.

HOESLI, M.; GIACOTTO, C.; FAVARGER, P. Three new real estate price indices for Geneva, Switzerland. Journal of Real Estate Finance and Economics, v. 15, n. 1, p. 93-109, 1997.

HOFSTEN, E. Price indexes and quality changes. Stockholm: Bokforlaget Forum AB, 1952.

HOLMES, A.; SLADE, B. A. Do tax-deferred exchanges impact purchase price? Evidence from the Phoenix apartment market. Real Estate Economics, v. 29, n. 4, p. 567-588, 2001.

HOTELLING, H. Relations between two sets of variates. Biometrika, v. 28, p. 321377, 1936.

HOUGH, D; KRATZ, C. Can 'good' architecture meet the market test? Journal of Urban Economics, v. 14, p. 40-55, 1983.

HOUTHAKKER, H. S. Compensated changes in quantities and qualities consumed. Review of Economic Studies, v. 19, n. 3, p. 155-164, 1952.

IBGE. Instituto Brasileiro de Geografia e Estatística. Disponível em: < http://www.ibge.gov.br > Acesso em: 12 dez. 2004.

IOKOI, Z. M. G. (Coord.). Bibliografia comentada: industrialização, urbanização e migrações - São Paulo - séculos XIX e XX. Série iniciação, n. 2. São Paulo: FFLCHUSP, 1995.

IRWIN, E. G.; BOCKSTAEL, N. E. Interacting agents, spatial externalities and the endogenous evolution of land use pattern. Working Paper, Department of Agricultural and Resource Economics, University of Maryland, n. 98-24, 1998.

IZQUIERDO, M.; MATEA, M. L. Hedonic prices for personal computers in Spain during the 90s. Servicio de Estudios Económicos de Banco de España, n. 74, 2001.

JOHNSON, R.; WICKERN, D. Applied multivariate statistical analysis. 3. ed. New Jersey: Prentice Hall, 1992.

KAHN, S.; LANG, K. Efficient estimation of structural hedonic systems. International Economic Review, v. 29, n. 1, p. 157-166, fevereiro 1988. 
KAUKO, T. Residential property value and locational externalities: on the complementary and substitutability of approaches. Journal of Property Investment and Finance, v. 21, n. 3, p. 250-270, 2003.

KING, A. T. The demand for housing: a Lancastrian approach. Southern Economic Journal, v. 42, n. 3, p. 1077-1087, outubro 1976.

The demand for housing: reply. Southern Economic Journal, v. 46, n. 2, p. 649-650, outubro 1979.

KOHLHASE, J. The impact of toxic waste sites on housing values. Journal of Urban Economics, v. 30, p. 1-26, 1991.

KONIJN, P.; MOCH, D.; DALEN, J. Comparison of hedonic functions for PC's across EU countries. Preliminary note of the European hedonic center project, 2003.

KOUNDOURI, P.; PASHARDES, P. Hedonic price analysis and selectivity bias: water salinity and demand for land. Environmental and Resource Economics, v. 26, n. 1, p. 45-56, setembro 2003.

KRAVIS, I. B.; LIPSEY, R. E. International price comparisons. International Economic Review, v. 10, p. 233-246, 1969.

LANCASTER, K. A new approach to consumer's theory. Journal of Political Economy, n. 74, p. 132-157, 1966a.

Change and innovation in the technology of consumption. American Economic Review, n. 56, p. 14-23, 1966 b.

Company, 1991, p. 11-21.

Modern consumer theory. New York: Edward Elgar Publishing

LANDON, S., SMITH, C. E. Quality expectations, reputations and price. Southern Economic Journal, v. 64, p. 628-647, 1998.

LANGENEST, B. Os cortiços de São Paulo. Revista Anhembi, n. 139, 1962.

LAWSON, D. M.; BROSSART, D. F. The association between current intergenerational family relationships and sibling structure. Journal of Counseling and Development, v. 82, n. 4, p. 472-482, 2004.

LEEUW, F. A price index for new multifamily housing. Bureau of Economic Research, p. 33-42, fevereiro 1993.

LEISHMAN, C. House building and product differentiation: an hedonic price approach. Journal of Housing and the Built Environment, v. 16, n. 2, p. 131-152, 2001. 
LERNER, J. Pricing and financial resources: an analysis of the disk drive industry, 1980-88. The Review of Economic and Statistics, v. 77, n. 4, p. 585-597, 1995.

LEVESQUE, T. J. Modeling the effects of airport noise on residential housing markets: a case study of Winnipeg International Airport. Journal of Transport Economics and Policy, p. 199-210, 1994.

LEVY, P. S.; LEMESHOW, S. Sampling of populations: methods and applications. 3. ed. New York: John Wiley \& Sons Inc., 1999.

LI, M. M.; BROWN, H. J. Micro-neighborhood externalities and hedonic housing prices. Land Economics, v. 56, p. 125-141, 1980.

LIMA JÚNIOR, J. R. Planejamento do produto no mercado habitacional. São Paulo: EPUSP-PCC, 1993. 26 p. Boletim Técnico.

LINNEMAN, P. Some empirical results on the nature of hedonic price function for the urban housing market. Journal of Urban Economics, n. 8, p. 47-68, 1980.

LUZIO, E.; GREENSTEIN, S. Measuring the performance of a protected infant industry: the case of Brazilian microcomputers. The Review of Economic and Statistics, v. 77, n. 4, p. 622-633, 1995.

MACK, L. J. Automobile prices in the consumer price index. Monthly Labor Review, v. 72, p. 5, 1955.

MACKENZIE, S. The role of attention in mediating the effect of advertising on attribute importance. Journal of Consumer Research, n. 13, p. 174-195, setembro 1986.

MALPEZZI, S.; MAYO, S. K. The demand for housing in developing countries: empirical estimates from household data. Economic Development and Cultural Change, v. 35, n. 4, p. 687-721, 1987.

MARCONDES, M. J. Cidade e natureza: proteção aos mananciais e exclusão social. São Paulo: Studio Nobel / Editora da Universidade de São Paulo / FAPESP, 1999.

MEGBOLUGBE, I. F. A hedonic index model: the housing market of Jos, Nigeria. Urban Studies, v. 26, p. 486-494, 1989.

MENDELSOHN, R. Estimating the structural equations of implicit markets and household production functions. The Review of Economics and Statistics, v. 66, n. 4, p. 673-677, novembro 1984.

Identifying structural equations with single market data. The Review

of Economics and Statistics, v. 67, n. 3, p. 525-529, agosto 1985. 
MEYER, R. M. P.; GROSTEIN, M. D.; BIDERMAN, C. São Paulo Metrópole. São Paulo: Editora da Universidade de São Paulo / Imprensa Oficial do Estado de São Paulo, 2004.

MOORE, J. S. An investigation of the major influences of residential liquidity: a multivariate approach. AREUEA Journal, v. 15, n. 1, p. 684-703, 1987.

MORAIS, M. P.; CRUZ, B. O. Demand for housing and urban services in Brazil: a hedonic approach. Textos para Discussão do Instituto de Pesquisa Econômica Aplicada, Brasília, n. 946, 2003.

MOREIRA, A. L. Princípio de engenharia de avaliações. 4. ed. São Paulo: Pini, 1997.

MORSE, R. Formação histórica de São Paulo. São Paulo: Difel, 1970.

MUELLBAUER, J. Household production theory, quality, and the hedonic technique. The American Economic Review, v. 64, n. 6, p. 977-994, 1974.

MUSGRAVE, J. C. The measurement of price changes in construction. Journal of the American Statistical Association, v. 64, p. 771-786, 1969.

NAIK, P. A.; TSAI, C. L. Single-index model selections. Biometrika, n. 88, v. 3, p. 821-832, 2001.

NELSON, J. P. Residential choice, hedonic prices and the demand for urban air quality. Journal of Urban Economics, n. 3, v. 5, p. 357-369, julho 1978.

NELSON, R. A.; TANGUAY, T. L.; PATTERSON, C. D. A quality-adjusted price index for personal computers. Journal of Business and Economic Statistics, v. 12, p. 23-31, 1994.

NERLOVE, M. Hedonic price functions and the measurement preference: the case of Swedish wine consumers. European Economic Review, v. 36, p. 1697-1716, 1995.

NICHOLSON, J. L. The measurement of quality changes. Economic Journal, v. 77, p. 512-530, 1967.

NORUSIS, M. J. SPSS 8.0 guide to data analysis. New Jersey: Prentice Hall, 1998.

OCZLOWSKI, E. Hedonic price functions and measurement error. The Economic Record, v. 77, p. 374-382, 2001.

OLINER, S. D. Constant quality price change, depreciation and retirement of mainframe computers. Working Paper Series, Federal Reserve System, Economic Activity Section, n. 110, outubro 1990. 
OTHA, M. Production technologies for the US boiler and turbo generator industries and hedonic prices indexes for their products: a cost-function approach. The Journal of Political Economy, v. 83, n. 1, p. 1-26, 1975.

PAKES, A. A reconsideration of hedonic price indexes with an application to PC's. Working Paper NBER, Cambridge MA, n. 8715, janeiro 2002.

PALM, R. Spatial segmentation of the urban housing market. Economic Geography, v. 54, n. 3, p. 210-221, julho 1978.

PALMQUIST, R. B. Estimating the demand for the characteristics of housing. The Review of Economics and Statistics, v. 66, n. 3, p. 394-404, agosto 1984.

PARSONS, G. R. An almost ideal demand system for housing attributes. Southern Economic Journal, v. 53, n. 2, p. 347-363, outubro 1986.

PEREIRA, C. B. O marketing do lugarzinho: uma aplicação exploratória da técnica de índice de preços hedônicos a jovens consumidores de restaurantes na cidade de São Paulo, 2004. 165 f. Tese (Doutorado em Administração) - Faculdade de Economia, Administração e Contabilidade, Universidade de São Paulo.

PERROUX, F. L'Economie du XX ème siècle. 2. ed. Paris : Presses Universitaires de France, 1964.

PESTANA, M. H.; GAGEIRO, J. N. Análise de dados para ciências sociais: a complementaridade do SPSS. 2. ed. Lisboa: Edições Silabo, 2000.

PINDYCK, R. S.; RUBINFELD, D. L. Microeconomia. 4. ed. São Paulo: Makron Books, 1999.

PREFEITURA MUNICIPAL DE SÃO PAULO. Secretaria de Planejamento Urbano. Disponível em: < http://www.prodam.sp.gov.br/svma/atlas_amb/ > Acesso em: 17 ago. 2002.

QUIGLEY, J. Non-linear budget constraints and consumer demands: an application to public programs for residential housing. Journal of Urban Economics, p. 177-201, 1982.

RAO, H. R.; LYNCH, B. D. Hedonic prices analysis of workstations attributes. Communications of the Association for Computer Machinery, v. 36, n. 12, p. 95, dezembro 1993.

RODRIGUES, M. C. P. Potencial de desenvolvimento dos Municípios Fluminenses: uma metodologia alternativa ao IQM, com base na análise fatorial exploratória e na análise de clusters. Caderno de Pesquisas em Administração, v. 9, n. 1, p. 75-89, 2002. 
RODRIGUEZ, S. K. Geologia urbana da Região Metropolitana de São Paulo. São Paulo, 1998, 184 f. Tese de Doutorado - Instituto de Geociências, Universidade de São Paulo.

ROGERS, W. Errors in hedonic modeling regressions: compound indicator variables and omitted variables. The Appraisal Journal, p. 208-213, abril 2000.

ROSEN, S. Hedonic prices and implicit markets: production differentiation in pure competition. Journal of Political Economy, v. 82, n. 1, p. 34-55, 1974.

SARTORIS NETO, A. Estimação de modelos de preços hedônicos: um estudo para residências na cidade de São Paulo. São Paulo, 1996. 74 f. Dissertação (Mestrado em Economia) - Faculdade de Economia, Administração e Contabilidade, Universidade de São Paulo.

SCHAMEL, G.; ANDERSON, K. Wine quality and varietal, regional and winery reputations: hedonic prices for Australia and New Zealand. Economic Record, v. 79, p.357-369, 2003.

SEADE. Fundação Sistema Estadual de Análise de Dados. Disponível em: < http://www.seade.gov.br > Acesso em: 29 jan. 2005.

SECOVI-SP. Sindicato das Empresas de Compra, Venda, Locação e Administração de Imóveis Comerciais e Residenciais de São Paulo. Disponível em: < http://www.secovi.com.br > Acesso em: 28 jan. 2005.

SHEPPARD, S. Hedonic analysis of housing markets. In: CHESHIRE, P.; MILLS, E. S. Handbook of regional and urban economics, v. 3 (Applied urban economics), Amsterdam: Elsevier / North-Holland, 1999.

SILVER, M.; HERAVI, S. Hedonic price indexes and the matched models approach. The Manchester School, v. 72, p. 24-49, 2004.

SIMON, C. P.; BLUME, L. Mathematics for Economists. New York: W. W. Norton, 1994.

SIMONS, R. A.; JAOUHARI, A. E. The effect of freight railroad tracks and train activity on residential property values. The Appraisal Journal, v. 72, n. 3, p. 223-233, 2004.

SIMONS, R. A.; WINSON-GEIDEMAN, K.; MIKELBANK, B. A. The effects of an oil pipeline rupture on single-family house prices. The Appraisal Journal, p. 410-418, outubro 2001.

SINCLAIR, J.; CATRON, B. An experimental price index for the computer industry. Monthly Labor Review, p.16-24, outubro 1990. 
SMITH V. K.; HUANG, J. C. Can markets value air quality? A meta-analysis of hedonic property values. Journal of Political Economy, v. 103, p. 209-227, 1995.

SPOSATI, A. São Paulo: do pátio do colégio à Metrópole global. Disponível em: <http://www.prodam.sp.gov.br/svma/atlas_amb/> Acesso em: 17 ago. 2002.

STAVINS, J. Model entry and exit in a differentiated-product industry: the personal computer market. The Review of Economic and Statistics, v. 77, n. 4, p. 571-584, 1995.

STEINER, B. Australian wines in the British wine market: a hedonic price analysis. Agrobusiness, v. 20, p. 287-307, 2004.

STRAND, J.; VAGNES, M. The relationship between property values and railroad proximity: a study based on hedonic prices and real estate brokers' appraisals. Transportation, v. 28, p. 137-156, 2001.

TIEBOUT, C. M. A pure theory of local expenditure. Journal of Political Economy, v. 64, p. 416-424, 1956.

TRIPLETT, J. E. Automobiles and hedonic quality measurement. Journal of Political Economy, v. 77, p. 408-417, 1969.

TVERSKY, A.; KAHNEMAN, D. Loss aversion in riskless choice: a referencedependent model. Quarterly Journal of Economics, v. 106, n. 4, p. 1039-1061, 1991.

UNIVERSIDADE FEDERAL DO PARANÁ. Biblioteca Central. Normas para apresentação de trabalhos. Curitiba: Ed.da UFPR, 2002.

UNWIN, T. Hedonic price indexes and the qualities of wines. The Journal of Wine Research, v. 10, p. 95-104, 1999.

UYENO, D.; HAMILTON, S. W.; BIGGS, A. Density of residential land use and the impact of airport noise. Journal of Transport and Economics and Policy, v. 27, p. 318, 1993.

VASCONCELlOS, M. A. S.; ALVES, D. (Coord.). Manual de econometria. São Paulo: Atlas, 2000.

VIEIRA SOBRINHO, J. D. Matemática financeira. 7. ed. São Paulo: Atlas, 2000.

WAUGH, F. W. Quality factors influencing vegetable prices. Journal of Farm Economics, v. 10, p. 185-196, 1928.

WHEATON, W.; TORTO, R. Office rent indices and their behavior over time. Journal of Urban Economics, n. 35, p. 121-139, 1994. 
WILHELMSSON, M. The impact of traffic noise on the values of single-family houses. Journal of Environmental Planning and Management, v. 43, n. 6, p. 799-815, 2000.

WITTE, A. D.; SUMKA, H. J.; EREKSON, H. An estimate of a structural hedonic price model of the housing market: an application of Rosen's theory of implicit markets. Econometrica, n. 47, p. 1151-1173, 1979.

WOOLDRIDGE, J. M. Introductory econometrics. 2. ed. Mason: Thomson South Western, 2003.

YOSHIHARA, K.; FURUYA, K.; SUZUKI, T. The problem of accounting for productivity change in the construction index. SEAS Discussion Paper, Kyoto, n. 5, 1970.

ZMITROWICZ, W. Francisco Prestes Maia: o sonho e a realidade do Plano de Avenidas. Revista Cidade, p. 28-35, 1996. 


\section{ANEXOS}

A) FIGURAS DO MUNICÍPIO E DA REGIÃO METROPOLITANA DE SÃO PAULO

FIGURA 01: NÚCLEO URBANO DO MUNICÍPIO DE SÃO PAULO NO SÉCULO XVIII

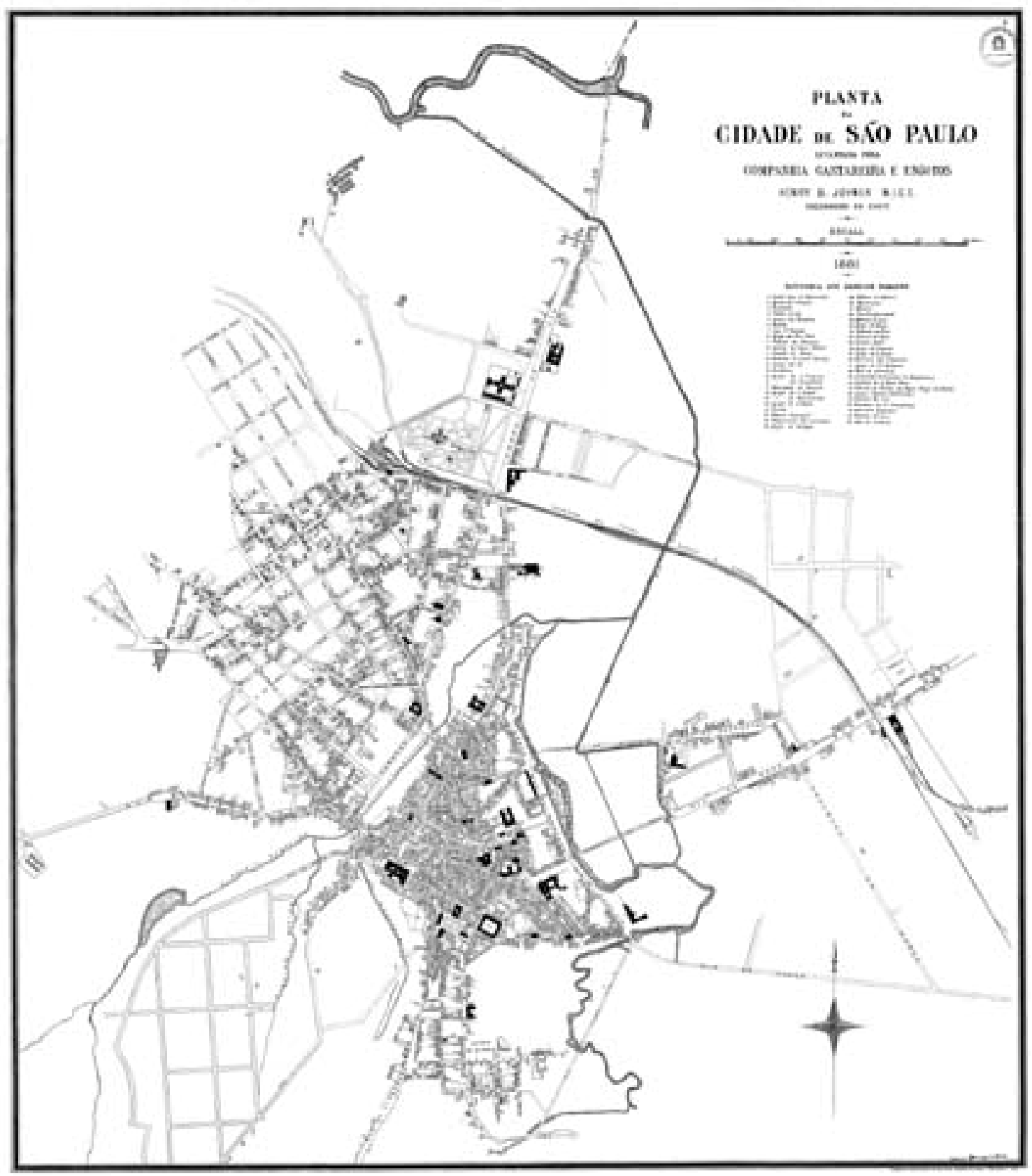

(FONTE: SITE www.prodam.sp.gov.br/svma/atlas_amb) 
FIGURA 02: EXPANSÃO DO MUNICÍPIO NO FINAL DO SÉCULO XIX

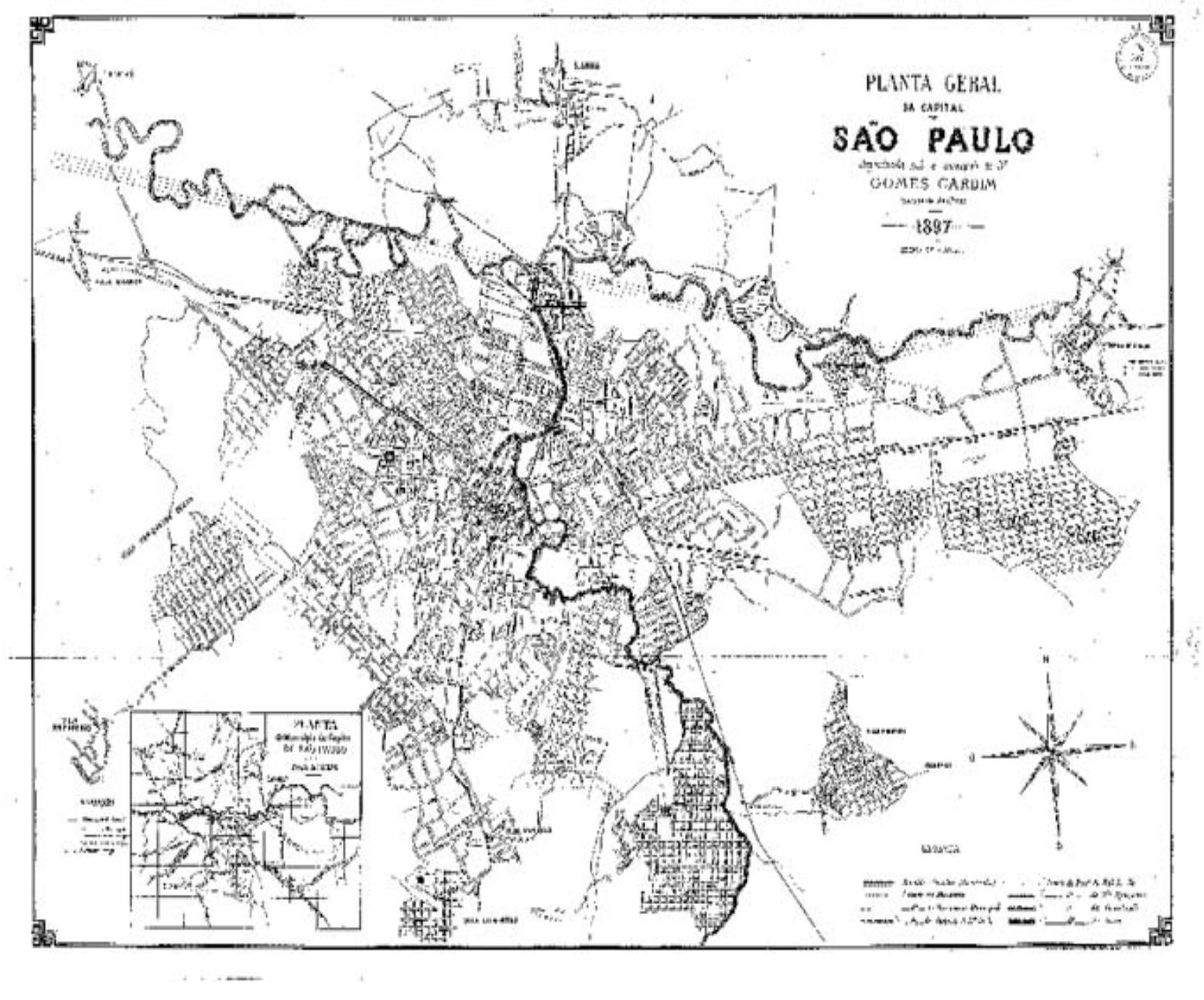

(FONTE: SITE www.prodam.sp.gov.br/svma/atlas_amb) 


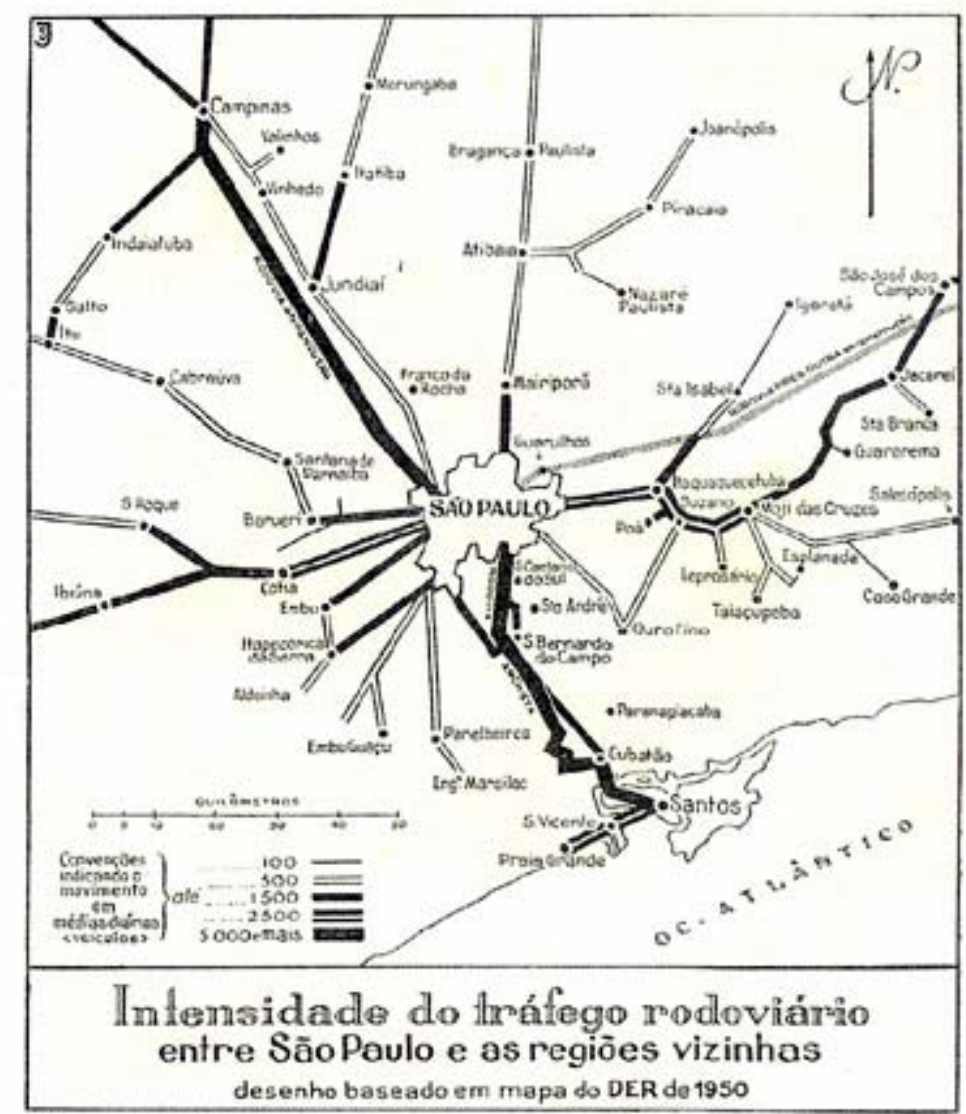

Fonte: Azevedo, 1958 .

(FONTE: MEYER, BIDERMAN e GROSTEIN, 2004, p. 34) 
FIGURA 04: OS ARREDORES PAULISTANOS EM MEADOS DO SÉCULO XIX

2. Bolaffi, 1979, utilizou o termo "padrễo periférico de crescimento" e Bonduki, 1983 o termo "padrāo perférico de urbanizaçăo".

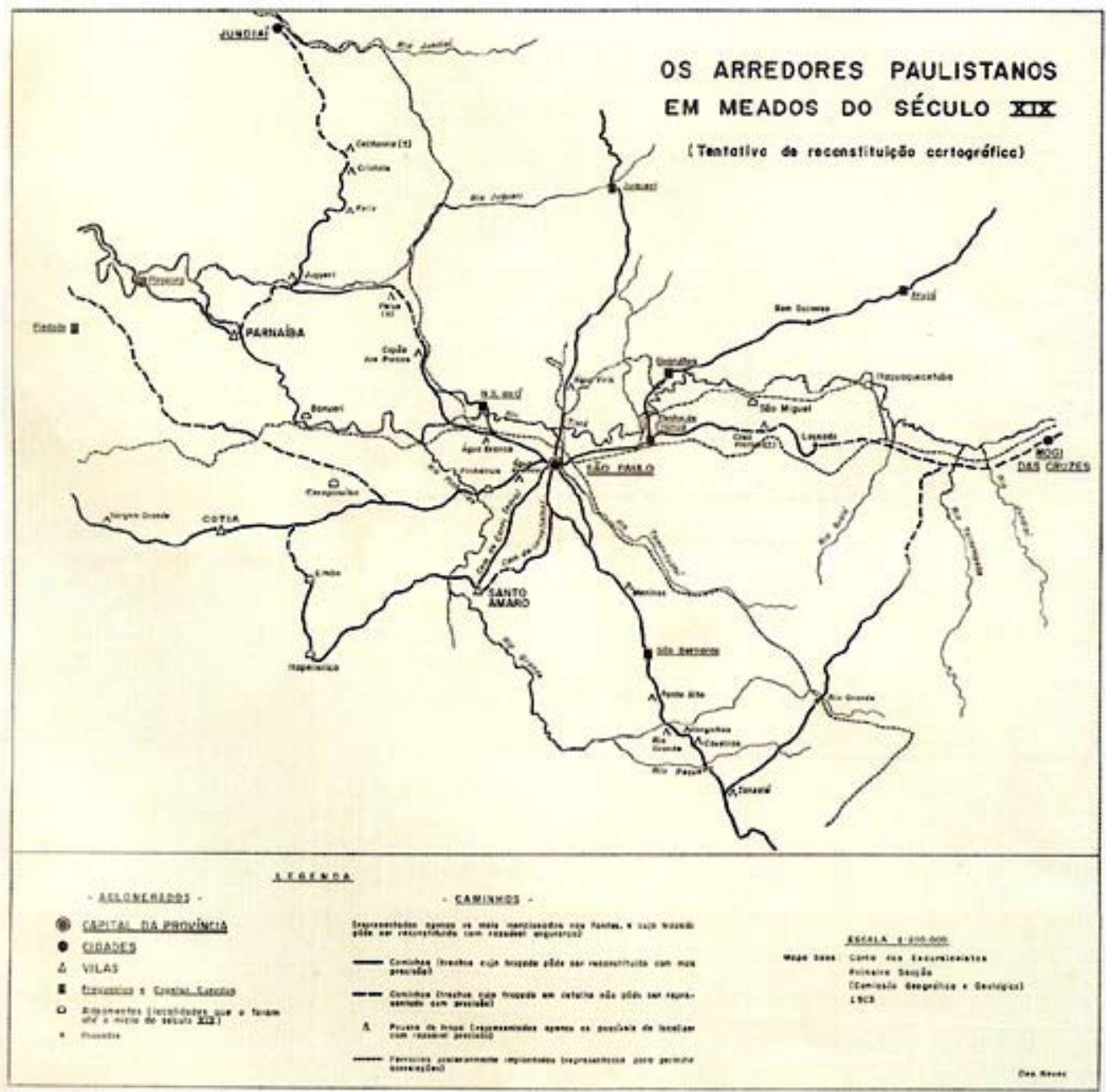

Fonte: Langenbuch, 1971

(FONTE: MEYER, BIDERMAN e GROSTEIN, 2004, p. 36) 
FIGURA 05: A EVOLUÇÃO DA REDE FERROVIÁRIA REGIONAL - 1860 A 1890
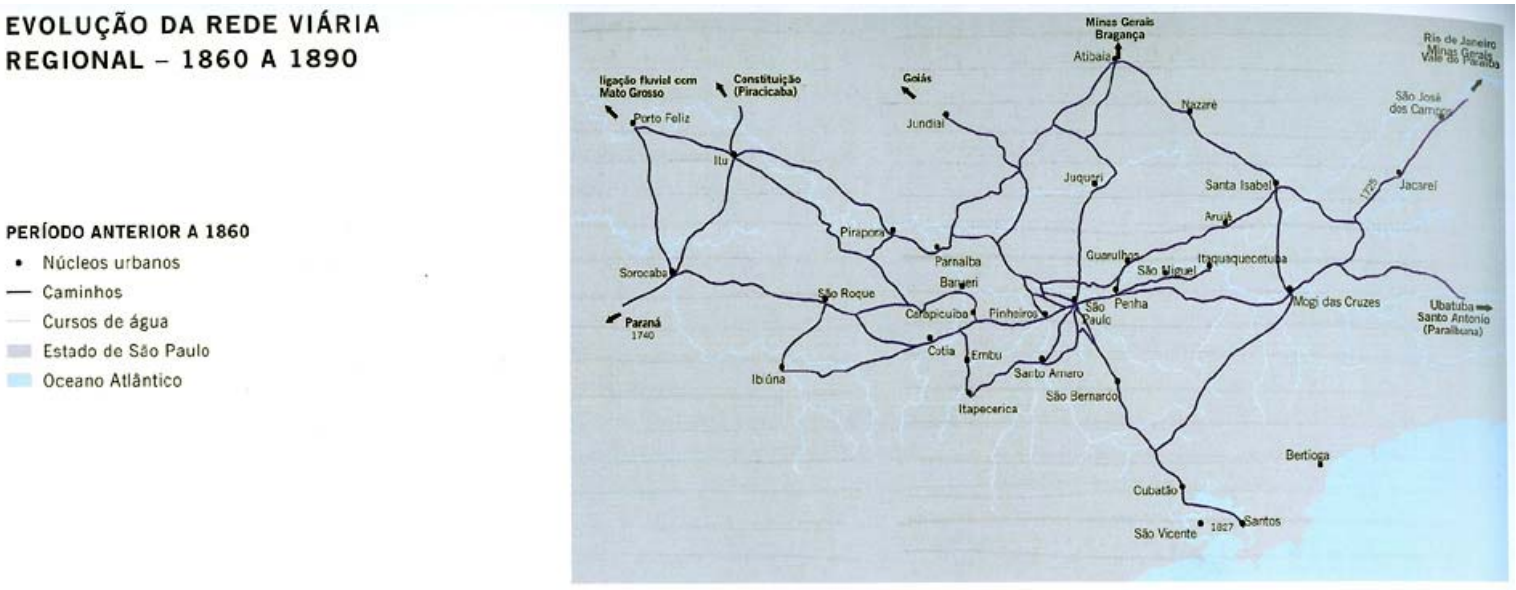

PERÍODO DE 1860 A 1890

- Núcleos urbanos

- Estaçós ferroviárias

Ferrovias

.... Caminhos novos e restaurados

- Caminhos

Cursos de água

- Area urbanizada 1905

- Estado de São Paulo

Eve Oceano Ailăntico

(FONTE: MEYER, BIDERMAN e GROSTEIN, 2004, p. 38) 
FIGURA 06: A EVOLUÇÃO DA REDE FERROVIÁRIA REGIONAL - 1890 A 1950

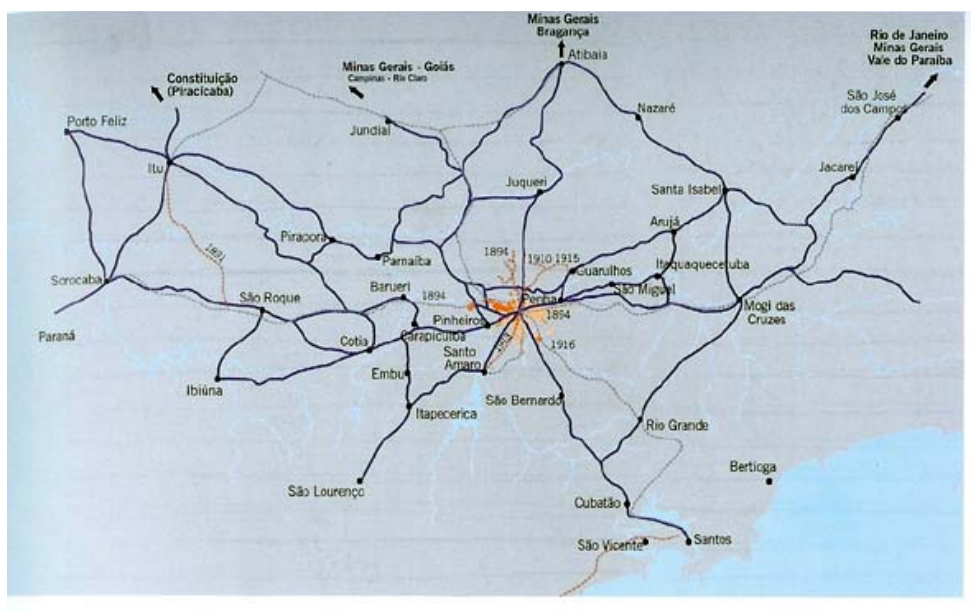

EVOLUÇÃO DA REDE VIÁRIA

REGIONAL - 1890 A 1950

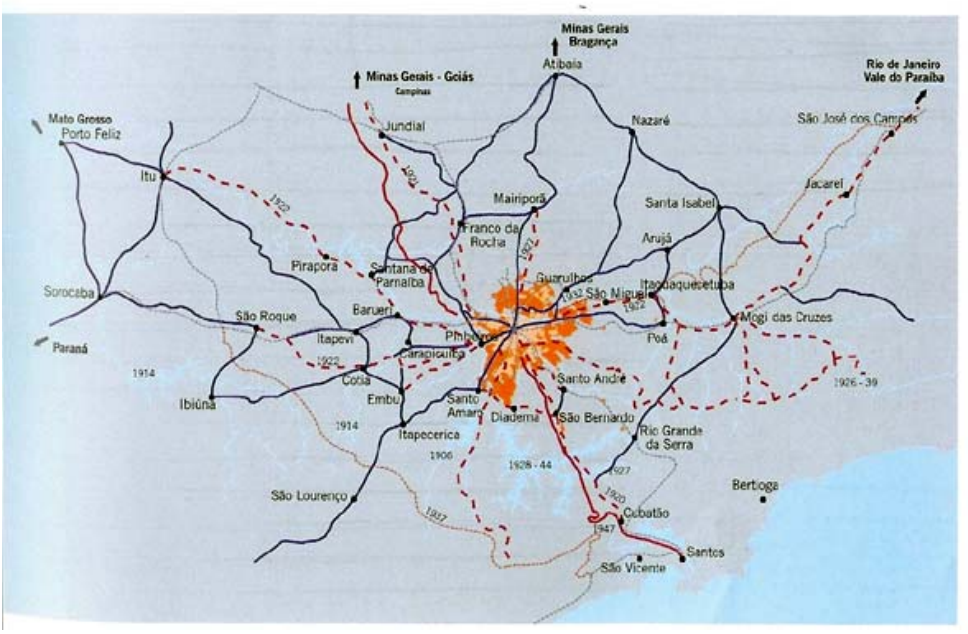

PERÍODO DE 1890 A 1920

- Núcleos urbanos

-w- Ferrovias novas 1890 a 1920

-2.- Ferrovias existentes 1890

- Caminhos existentes 1890

Cursos de água

Represas e Oceano Atlantico

En Area urbanizada 1905

Arrea urbanizada 1914

Estado de São Paulo

(FONTE: MEYER, BIDERMAN e GROSTEIN, 2004, p. 39)

PERÍODO DE 1920 A 1950

- Núcleos urbanos

Ferrovias novas 1920 a 1950

-... Ferrovias existentes 1920

- Rodovias

- Caminhos existentes 1920

-..- Estradas carroçáveis

Cursos de água

Represas e Oceano Atlântico

En Area urbanizada 1924

- Area urbanizada 1949

Estado de Săo Paulo

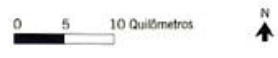


FIGURA 07: A EVOLUÇÃO DA REDE FERROVIÁRIA REGIONAL - 1950 A 1980

EVOLUÇÃO DA REDE VIARIA

REGIONAL - 1950 A 1980

PERÍODO DE 1950 A 1980

- Núcleos urbanos

+m- Ferrovia nova 1950-1980

-.-. Ferrovia existente 1950

- Rodovias

- Caminhos

-..- Vias novas 1950-1980

Cursos de água

Represas e Oceano Atlăntico

Area urbanizada 1949

- Area urbanizada 1980

Estado de São Paulo

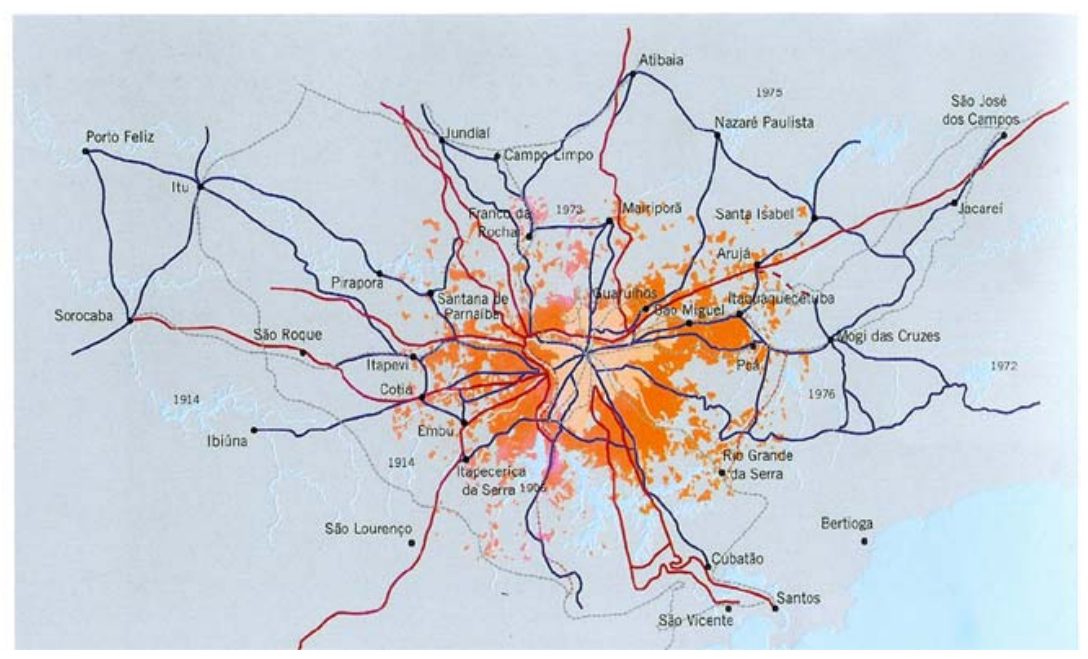

(FONTE: MEYER, BIDERMAN e GROSTEIN, 2004, p. 40) 
FIGURA 08: DESMEMBRAMENTO DE MUNICÍPIOS METROPOLITANOS - 1940 A 2000

\section{DESMEMBRAMENTOS DE MUNICÍPIOS \\ METROPOLITANOS \\ 1940 A 2000}

desmembramentos ocorridos na
década de 1940
desmembramentos ocorridos na
década de 1950
desmembramentos ocorridos na
década de 1960
desmembramentos ocorridos entre

1970 e 1991

$1940 \cdot 1950$

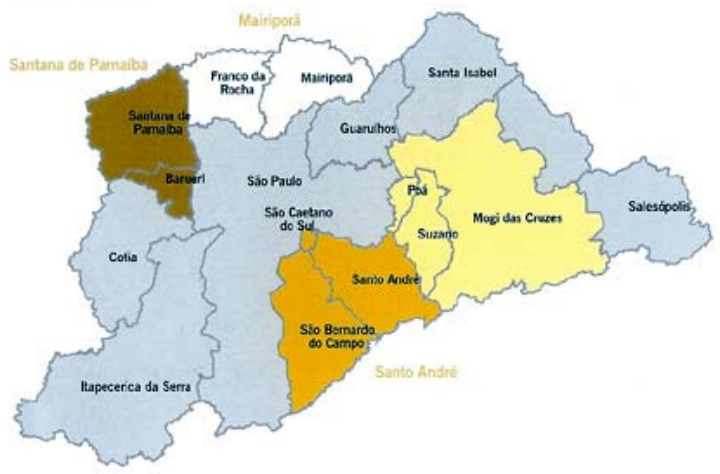

1960-1970

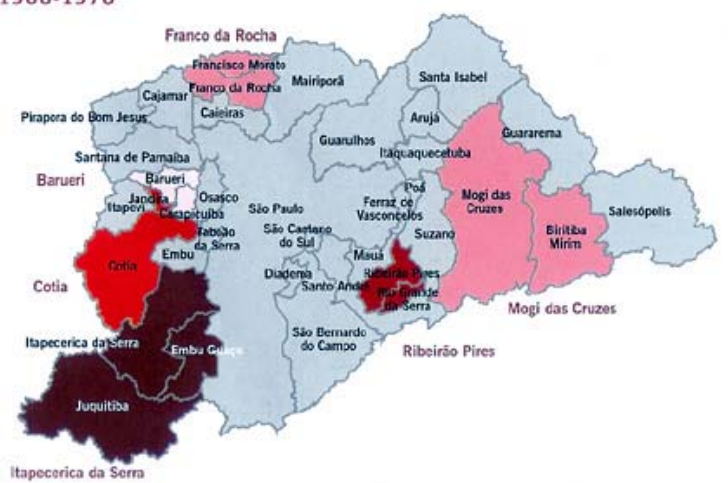

Municipios da Regiåo Metropolitana de São Paulo

1950-1960

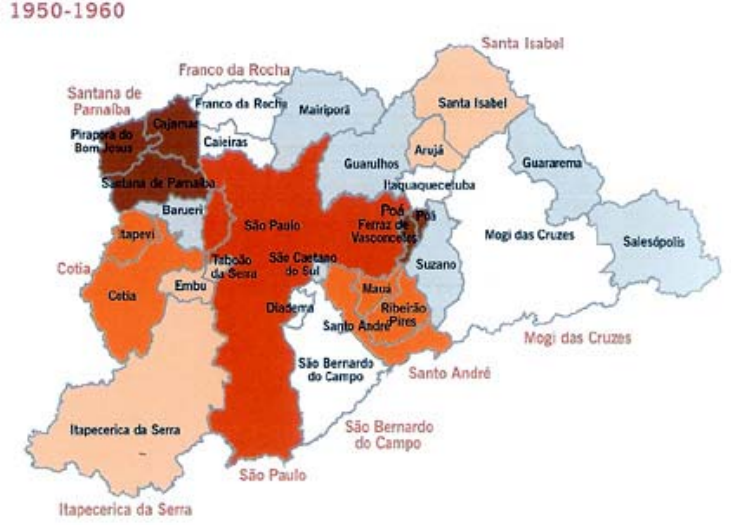

1970-2000

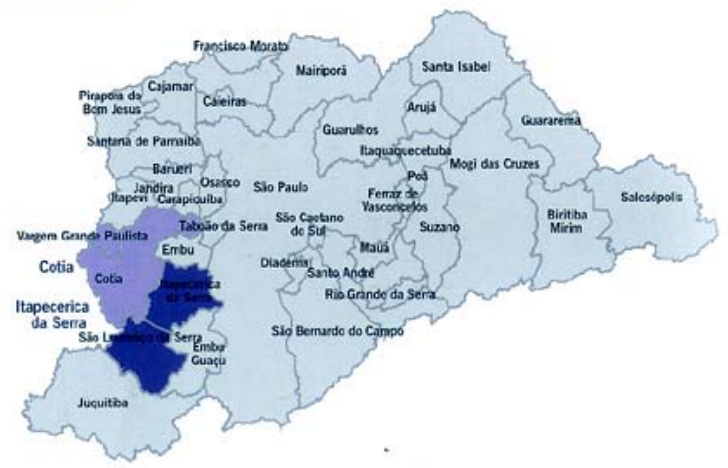

(FONTE: MEYER, BIDERMAN e GROSTEIN, 2004, p. 46) 


\section{DIVISÃO POLÍTICO-ADMINISTRATIVA - 2000}

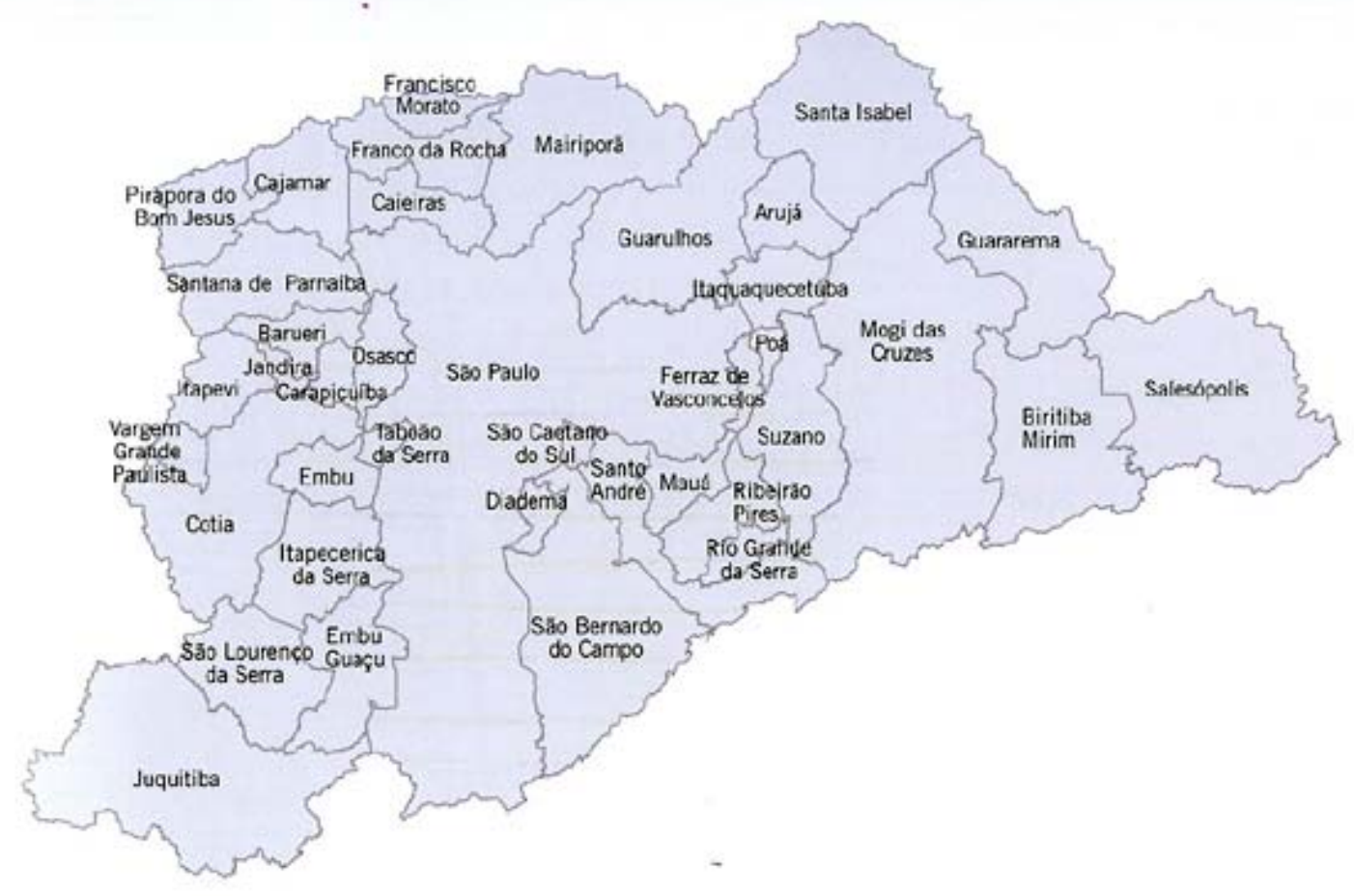

(FONTE: MEYER, BIDERMAN e GROSTEIN, 2004, p. 47) 


\begin{tabular}{|c|c|}
\hline Antes de 1940 & $\begin{array}{l}\text { Sso Paulo (1558) } \\
\text { Mogi das Cruzes (161 1) } \\
\text { Santana do Parnaiba (1625) } \\
\text { Santa Isabel (1832) } \\
\text { Cotia (1856) } \\
\text { Salesopolis (1857) } \\
\text { Itapecerica da Serra (1877) } \\
\text { Guarulhos (1880) } \\
\text { Mairiporă (1889) } \\
\text { Santo Andre (1889) } \\
\text { Guararema (1898) }\end{array}$ \\
\hline $\begin{array}{l}1940 \\
\text { Mairipora }\end{array}$ & $\begin{array}{l}\text { Mairiporā } \\
\text { Franco da Rocha (1944) }\end{array}$ \\
\hline Mogi das Cruzes & $\begin{array}{l}\text { Mogi das Cruzes } \\
\text { Suzano (1948) } \\
\text { Poat }(1948)\end{array}$ \\
\hline Santana de Parnaíba & $\begin{array}{l}\text { Santana de Parnaiba } \\
\text { Barueri }\{1948 \text { ) }\end{array}$ \\
\hline Santo Andiê & $\begin{array}{l}\text { Santo André } \\
\text { São Bernardo do Campo (1944) } \\
\text { Săo Caetano do Sul (1948) }\end{array}$ \\
\hline $\begin{array}{l}1950 \\
\text { Cotia }\end{array}$ & $\begin{array}{l}\text { Cotia } \\
\text { Itapevi (1959) }\end{array}$ \\
\hline Itapecerica da Serra & $\begin{array}{l}\text { Itapecerica da Serra } \\
\text { Taboão da Serra (1959) } \\
\text { Embu (1959) }\end{array}$ \\
\hline Franco da Rocha & $\begin{array}{l}\text { Franco da Focha } \\
\text { Caieiras (1959) }\end{array}$ \\
\hline Mogi das Cruzes & $\begin{array}{l}\text { Mogi das Cruzes } \\
\text { Itaquaquecetuba (1953) }\end{array}$ \\
\hline Poá & $\begin{array}{l}\text { Pas } \\
\text { Ferraz de Vasconcelos } 01953 \text { ) }\end{array}$ \\
\hline Santo André & $\begin{array}{l}\text { Santo André } \\
\text { Mauá (1953) } \\
\text { Ribeirao Pires (1953) }\end{array}$ \\
\hline Sāo Bernardo do Campo & $\begin{array}{l}\text { Sáa Bernardo do Campo } \\
\text { Diadema (1959) }\end{array}$ \\
\hline Santa Isabel & $\begin{array}{l}\text { Santa Isabel } \\
\text { Aruja (1959) }\end{array}$ \\
\hline Santana de Parnaiba & $\begin{array}{l}\text { Santana de Parnaiba } \\
\text { Pirapora do Bom Jesus (1959) } \\
\text { Cajamar (1959) }\end{array}$ \\
\hline São Paulo & $\begin{array}{l}\text { Săo Paulo } \\
\text { Osasco (1959] }\end{array}$ \\
\hline $\begin{array}{l}1960 \\
\text { Cotia }\end{array}$ & $\begin{array}{l}\text { Cotia } \\
\text { Jandira (1964) }\end{array}$ \\
\hline Barueri & $\begin{array}{l}\text { Barueri } \\
\text { Carapicuiba (1964) }\end{array}$ \\
\hline Itapecerica da Serra & $\begin{array}{l}\text { Itapecerica da Serra } \\
\text { Embu-Guaçu (196.4) } \\
\text { Juquitiba }(1964)\end{array}$ \\
\hline Franco da Rocha & $\begin{array}{l}\text { Franco da Rocha } \\
\text { Francisco Morato (1964) }\end{array}$ \\
\hline Rabeiräo Pires & $\begin{array}{l}\text { Ribeiräo Pires } \\
\text { Rio Grande da Serra (1964) }\end{array}$ \\
\hline Mogi das Cruzes & $\begin{array}{l}\text { Mogi das Cruzes } \\
\text { Biritiba Minim (1964) }\end{array}$ \\
\hline $\begin{array}{l}1970 \\
\text { Itapecerica da Serra }\end{array}$ & $\begin{array}{l}\text { Itapecerica da Serra } \\
\text { Sao Lourenço da Serra (1991) }\end{array}$ \\
\hline Cotia & $\begin{array}{l}\text { Cotia } \\
\text { Vargem Grande Paulista }(1981\}\end{array}$ \\
\hline
\end{tabular}

(FONTE: MEYER, BIDERMAN e GROSTEIN, 2004, p. 47) 
FIGURA 10: FAVELAS DA REGIÃO METROPOLITANA DE SÃO PAULO
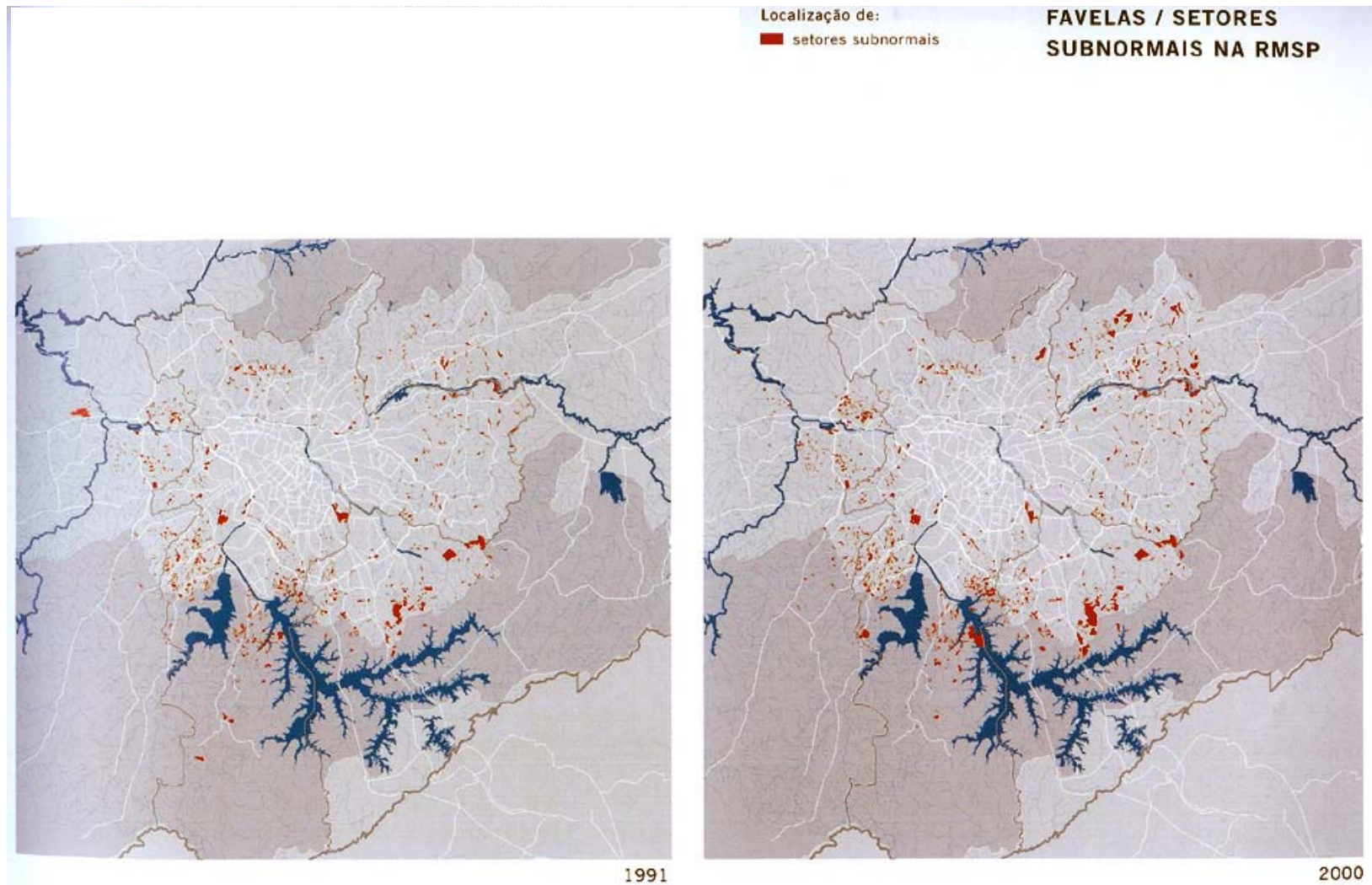

(FONTE: MEYER, BIDERMAN e GROSTEIN, 2004, p. 63) 
FIGURA 11: DISTRITOS DO MUNICÍPIO DE SÃO PAULO

\section{DISTRITOS DO MUNICÍPIO DE SÃO PAULO}

62

3
83

41

$\begin{array}{lll}11 & 13 & 51\end{array}$

$\begin{array}{llllllll}64 & & 38 & & & & & \\ & & 84 & 94 & 43\end{array}$

$\begin{array}{lllllll}73 & 29 & 50 & 21 & 71 & 91\end{array}$

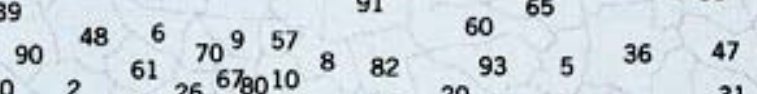

$\begin{array}{lllllllllll}40 & 2 & & 26^{6} 88010 & & 20 & 5 & 31\end{array}$

$\begin{array}{llllllllll}55 & 34 & 92 & 33 & 95 & 74 & & 25\end{array}$
$\begin{array}{llll}85 & 15 & 79 & 27\end{array}$

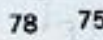
$77^{32}$

$17 \quad 8$

37

19

$\begin{array}{llll}45 & 81 & 16 & 22\end{array}$

42

59

23

30

56

52

(FONTE: MEYER, BIDERMAN e GROSTEIN, 2004, p. 277)
ÁREA CENTRAL E CENTRO EXPANDIDO

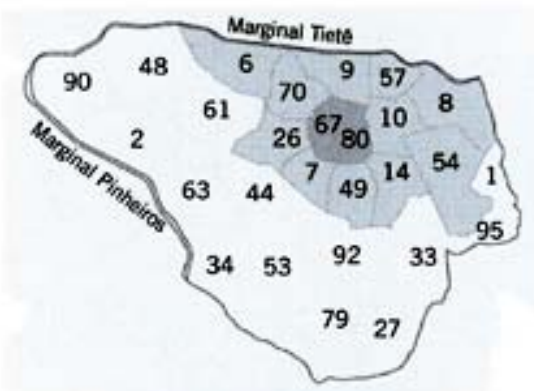

Limite do centro expandido

Centro

Distritos centrais

Demais distritos do centro expandido 


\begin{tabular}{|c|c|c|c|c|c|}
\hline & DISTRITO & SIGLA & & DISTRITO & SIGLA \\
\hline 1 & Água Rasa & ARA & 49 & Liberdade & LIB \\
\hline 2 & Alto de Pinheiros & API & 50 & Limão & LIM \\
\hline 3 & Anhanguera & ANH & 51 & Mandaqui & MAN \\
\hline 4 & Aricanduva & ARI & 52 & Marsilac & MAR \\
\hline 5 & Artur Alvim & AAL & 53 & Moema & MOE \\
\hline 6 & Barra Funda & $B F U$ & 54 & Mooca & MOO \\
\hline 7 & Bela Vista & BVI & 55 & Morumbi & MOR \\
\hline 8 & Belém & BEL & 56 & Parelheiros & PLH \\
\hline 9 & Bom Retiro & BRE & 57 & Pari & PRI \\
\hline 10 & Brás & BRS & 58 & Parque do Carmo & $\mathrm{PQC}$ \\
\hline 11 & Brasilândia & BRL & 59 & Pedreira & PDR \\
\hline 12 & Butantā & BUT & 60 & Penha & PEN \\
\hline 13 & Cachoeirinha & CAC & 61 & Perdizes & PDR \\
\hline 14 & Cambuci & CMB & 62 & Perus & PRS \\
\hline 15 & Campo Belo & CBE & 63 & Pinheiros & PIN \\
\hline 16 & Campo Grande & CGR & 64 & Pirituba & PIR \\
\hline 17 & Campo Limpo & CLM & 65 & Ponte Rasa & PRA \\
\hline 18 & Cangaiba & CNG & 66 & Raposo Tavares & RTA \\
\hline 19 & Capăo Redondo & CRE & 67 & República & REP \\
\hline 20 & Carrăo & CAR & 68 & Rio Pequeno & RPE \\
\hline 21 & Casa Verde & CVE & 69 & Sacomå & SAC \\
\hline 22 & Cidade Ademar & CAD & 70 & Santa Cecilia & SCE \\
\hline 23 & Cidade Dutra & CDU & 71 & Santana & STN \\
\hline 24 & Cidade Lider & CLD & 72 & Santo Amaro & SAM \\
\hline 25 & Cidade Tiradentes & CTI & 73 & Săo Domingos & SDO \\
\hline 26 & Consolaçẵo & $\mathrm{CON}$ & 74 & São Lucas & SLU \\
\hline 27 & Cursino & CUR & 75 & Sz̃o Mateus & SMT \\
\hline 28 & Ermelino Matarazzo & ERM & 76 & São Miguel & SMI \\
\hline 29 & Freguesia do 0 & FRE & 77 & Săo Rafael & SRA \\
\hline 30 & Grajaú & GRA & 78 & Sapopemba & SAP \\
\hline 31 & Guaianases & GUA & 79 & Saúde & SAU \\
\hline 32 & Iguatemi & IGU & 80 & Sé & SEE \\
\hline 33 & Ipiranga & IPI & 81 & Socorro & SOC \\
\hline 34 & Itaim Bibi & IBI & 82 & Tatuapé & TAT \\
\hline 35 & Itaim Paulista & IPA & 83 & Tremembé & TRE \\
\hline 36 & Itaquera & ITQ & 84 & Tucuruvi & TUC \\
\hline 37 & Jabaquara & JAB & 85 & Vila Andrade & VAN \\
\hline 38 & Jaçană & JAC & 86 & Vila Curuçá & VCR \\
\hline 39 & Jaguara & $J A G$ & 87 & Vila Formosa & VFO \\
\hline 40 & Jaguaré & JRE & 88 & Vila Guilherme & VGL \\
\hline 41 & Jaraguá & JAR & 88 & Vila Jacuí & VJA \\
\hline 42 & Jardim Ãngela & JDA & 90 & Vila Leopoldina & VLE \\
\hline 43 & Jardim Helena & JDH & 91 & Vila Maria & VMR \\
\hline 44 & Jardim Paulista & JDP & 92 & Vila Mariana & VMN \\
\hline 45 & Jardim Sāo Luis & JDS & 93 & Vila Matilde & VMT \\
\hline 46 & José Bonifácio & JBO & 94 & Vila Medeiros & VMD \\
\hline 47 & Lajeado & LAJ & 95 & Vila Prudente & VPR \\
\hline 48 & Lapa & LAP & 96 & Vila Sônnia & vso \\
\hline
\end{tabular}

(FONTE: MEYER, BIDERMAN e GROSTEIN, 2004, p. 277) 
FIGURA 12: MUNICÍPIOS E SUB-REGIÕES DA REGIÃO METROPOLITANA DE SÃO PAULO

\section{MUNICIPIOS DA REGIÃO METROPOLITANA DE SÃO PAULO}

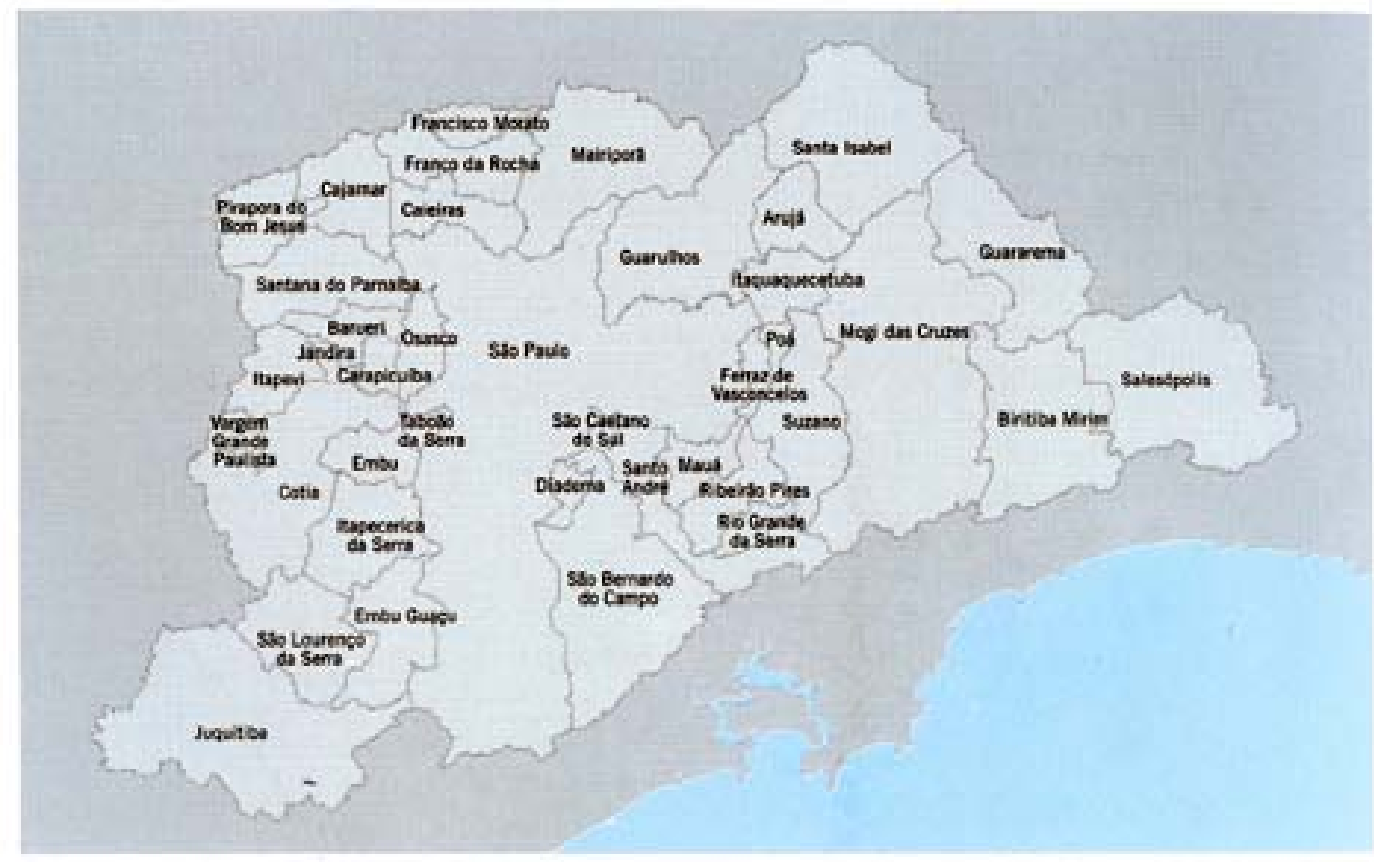

\section{SUB-REGIŌES DA REGIÃO METROPOLITANA DE SÃO PAULO}

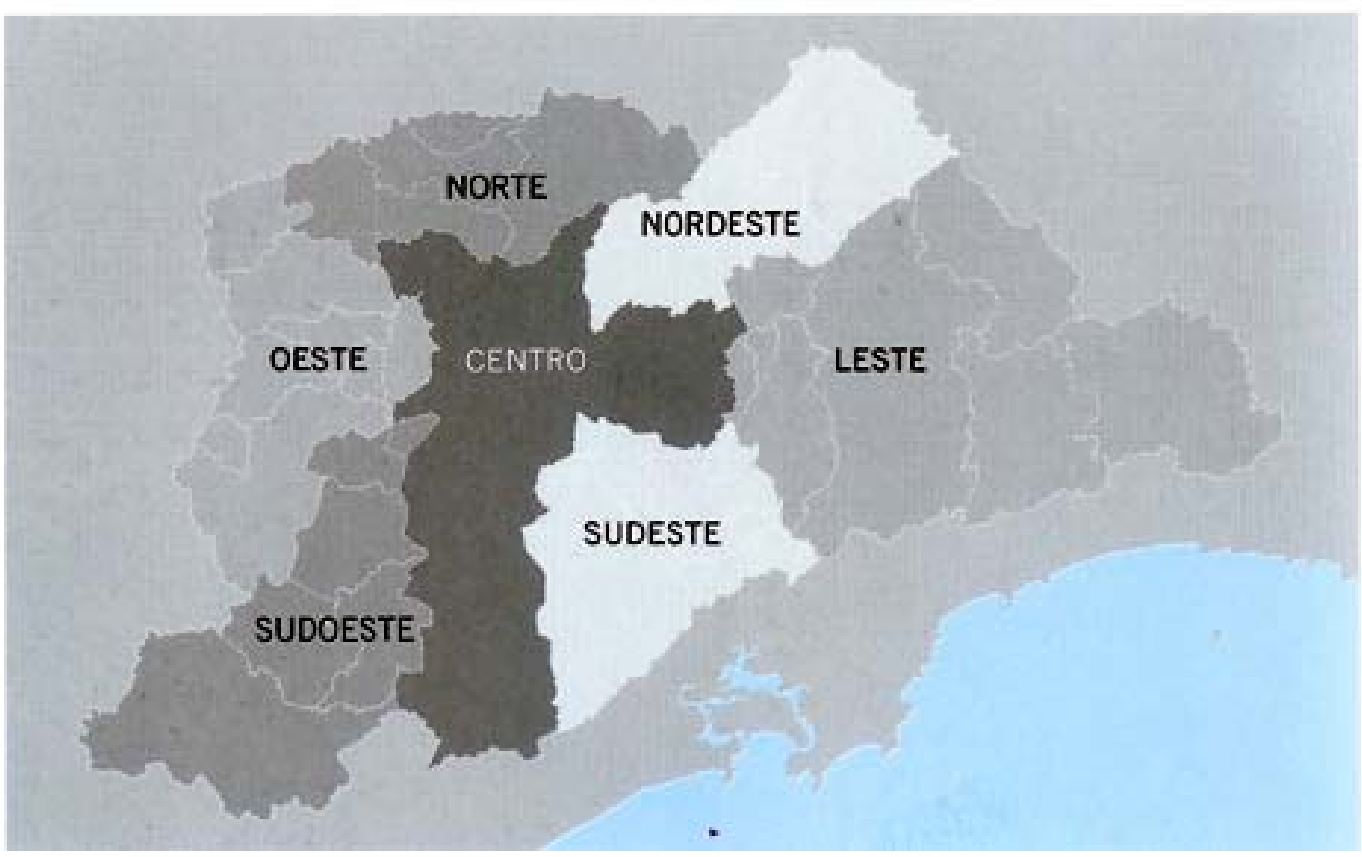

(FONTE: MEYER, BIDERMAN e GROSTEIN, 2004, p. 276) 
FIGURA 13: RENDA E DESIGUALDADE NA REGIÃO METROPOLITANA DE SÃO PAULO - 1980 A 1991

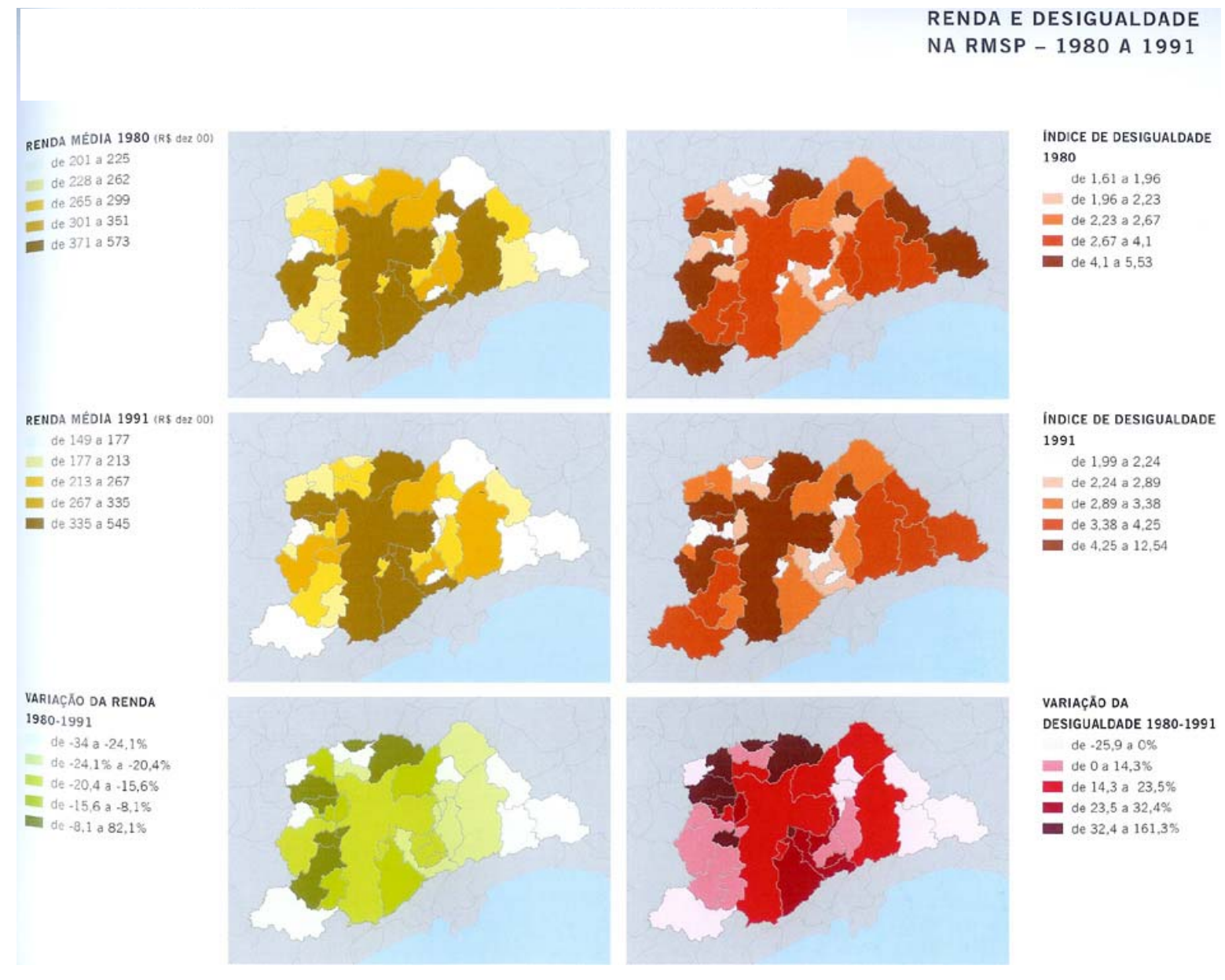

(FONTE: MEYER, BIDERMAN e GROSTEIN, 2004, p. 143) 
FIGURA 14: RENDA E DESIGUALDADE NA REGIÃO METROPOLITANA DE SÃO PAULO -1991 A 2000

\section{RENDA E DESIGUALDADE}

NA RMSP - 1991 A 2000

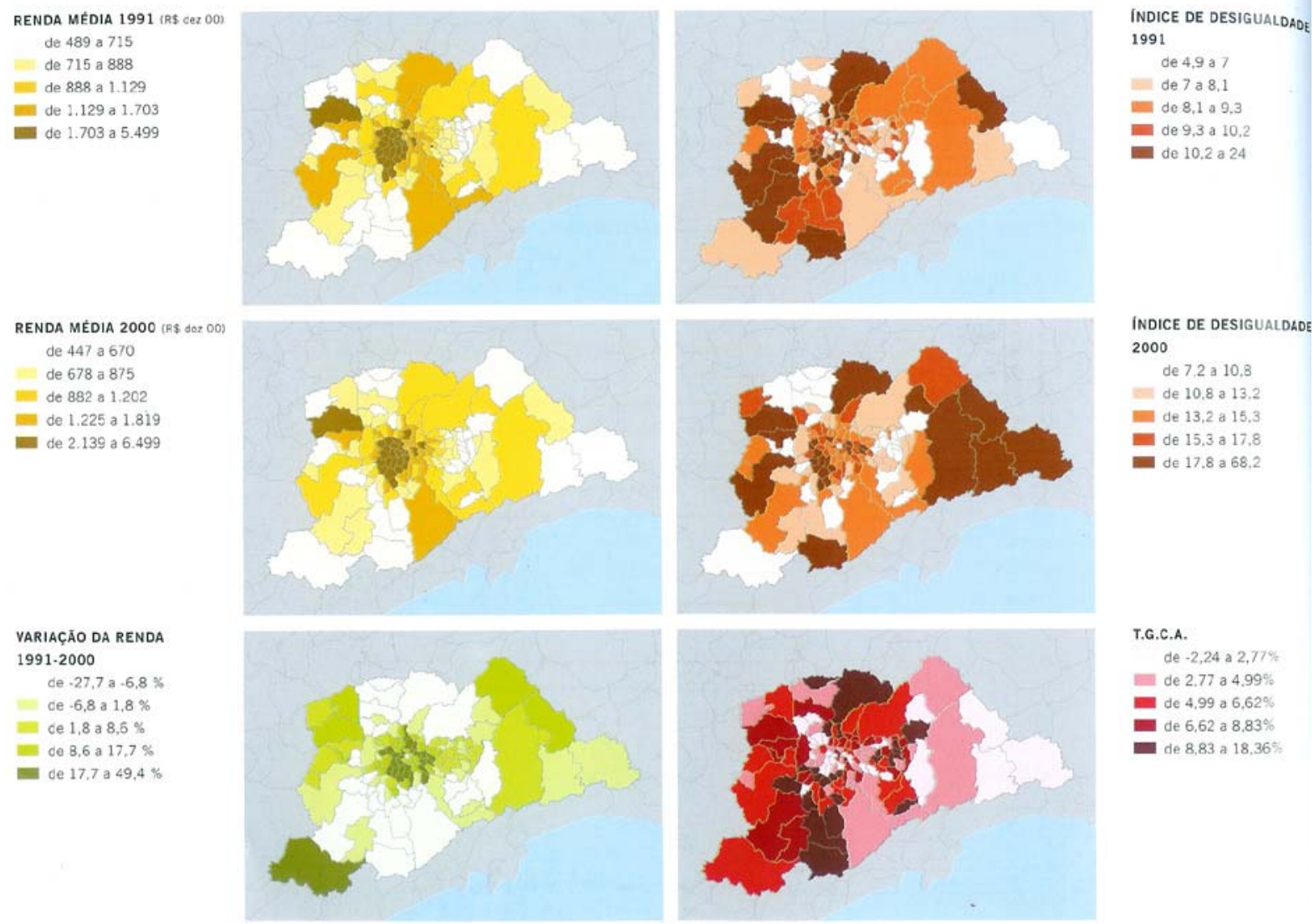

(FONTE: MEYER, BIDERMAN e GROSTEIN, 2004, p. 146) 
FIGURA 15: RENDA E HABITAÇÃO NA REGIÃO METROPOLITANA DE SÃO PAULO - 1991 A 2000

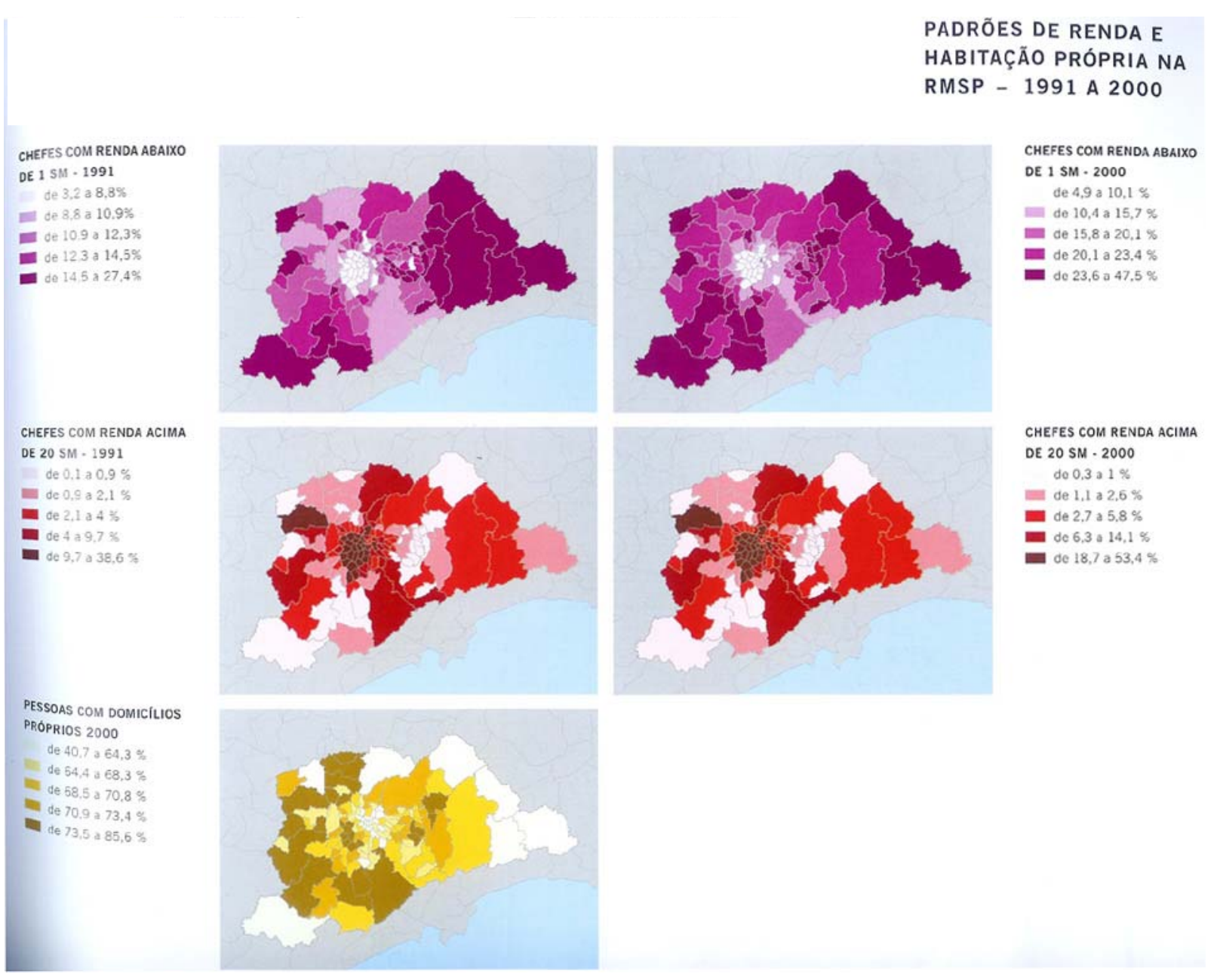

(FONTE: MEYER, BIDERMAN e GROSTEIN, 2004, p. 149) 
FIGURA 16: TAXA DE CRESCIMENTO POPULACIONAL NA REGIÃO METROPOLITANA DE SÃO PAULO - 1950 A 2000

$\begin{array}{lc}\text { EVOLUÇÃO DA TAXA DE } & \text { Taxa de crescimento populacional: } \\ \text { CRESCIMENTO } & \text { crescimento negativo } \\ \text { POPULACIONAL NA RMSP } & \text { ate } 1 \% \\ \text { 1950 A } 2000 & \text { de } 1 \text { a } 2 \% \\ & \text { de } 2 \text { a } 5 \% \\ & \text { mais de } 5 \%\end{array}$
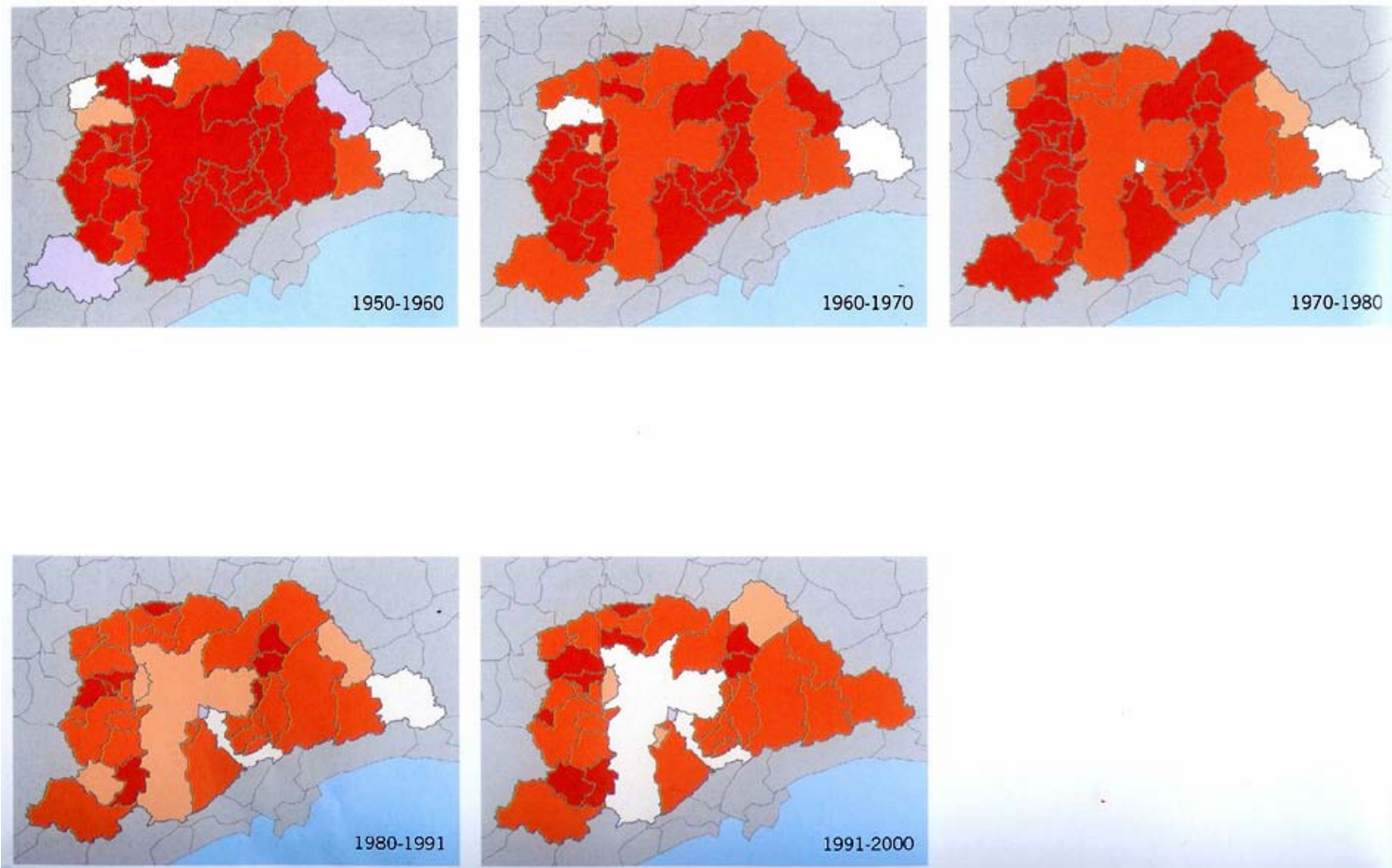

(FONTE: MEYER, BIDERMAN e GROSTEIN, 2004, p. 60) 
FIGURA 17: DENSIDADE DEMOGRÁFICA NA REGIÃO METROPOLITANA DE SÃO PAULO

-1950 A 2000

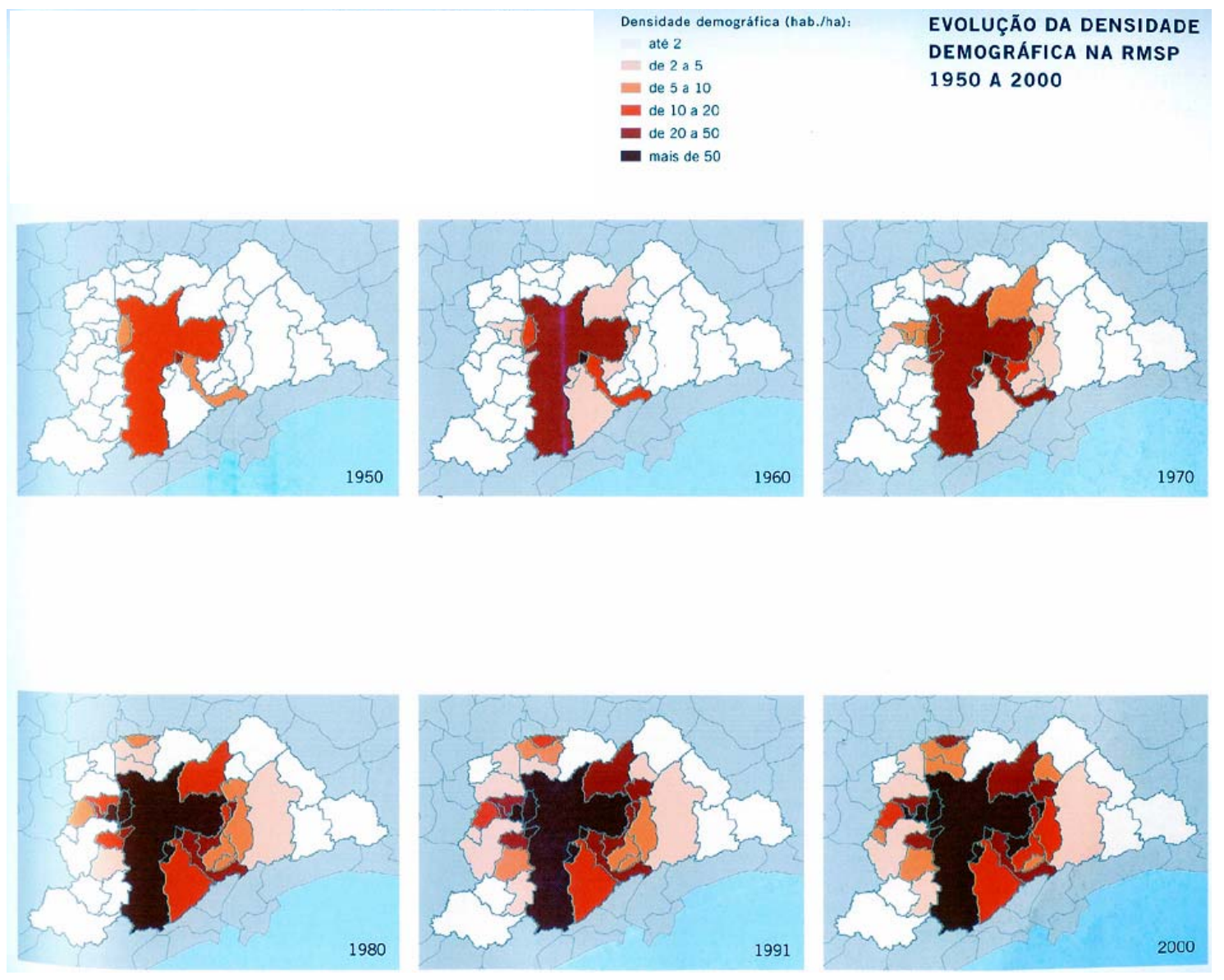

(FONTE: MEYER, BIDERMAN e GROSTEIN, 2004, p. 61) 
FIGURA 18: DENSIDADE DEMOGRÁFICA NA REGIÃO METROPOLITANA DE SÃO PAULO

Densidade demográfica na area
urbanizada (hab./km²)
de 50 a 455
de 459 a 1.181
de 1.720 a 3.376
de 3.453 a 7.633
de 7.653 a 20.940

= de 3.453 a 7.633

m de 7.653 a 20.940

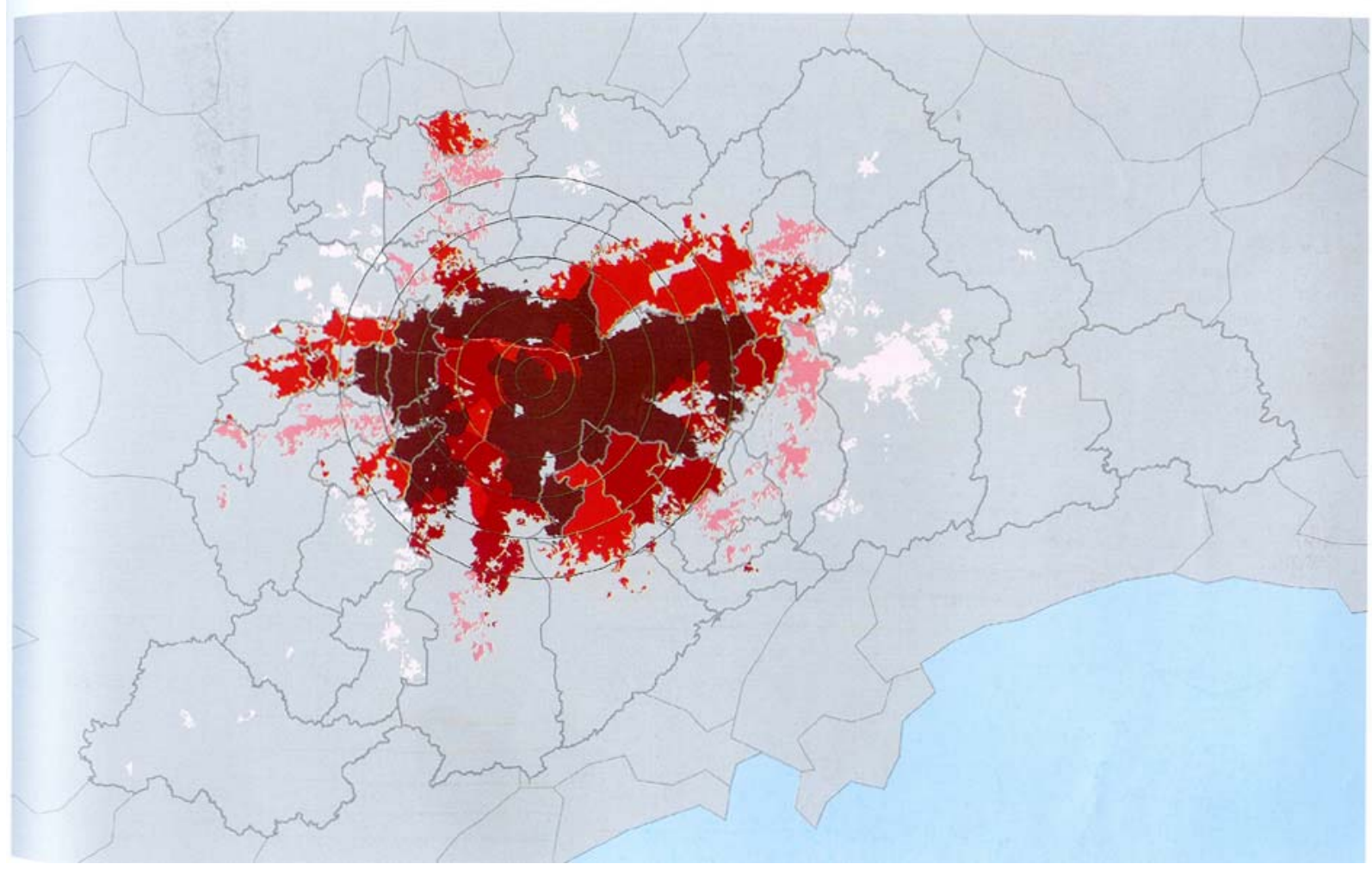

(FONTE: MEYER, BIDERMAN e GROSTEIN, 2004, p. 147) 
FIGURA 19: POPULAÇÃO RESIDENTE NA REGIÃO METROPOLITANA DE SÃO PAULO - 1950 E 2000

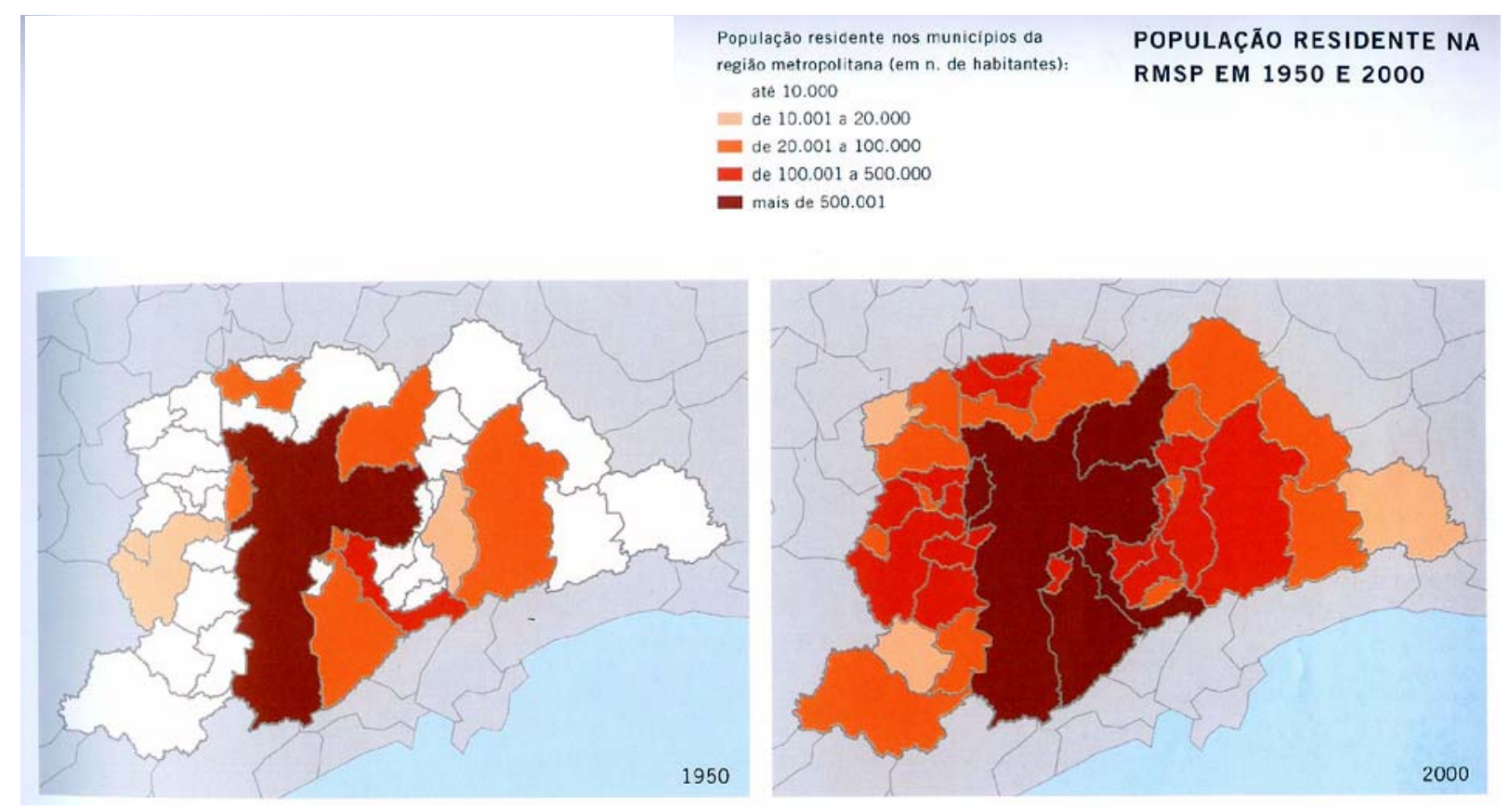

(FONTE: MEYER, BIDERMAN e GROSTEIN, 2004, p. 59) 
FIGURA 20: ÁREA URBANIZADA DA REGIÃO METROPOLITANA DE SÃO PAULO - 1905 A 1997

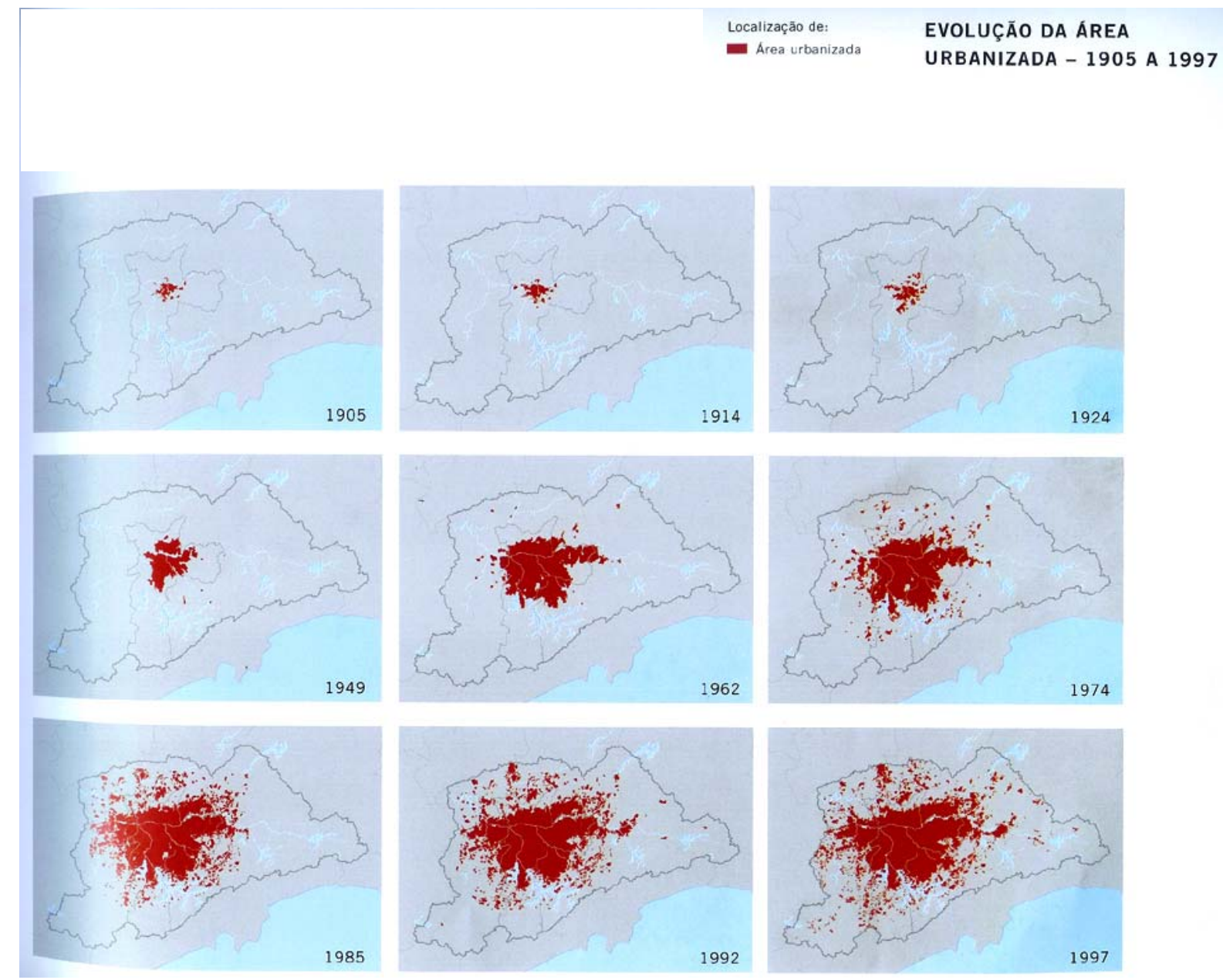

(FONTE: MEYER, BIDERMAN e GROSTEIN, 2004, p. 43) 
FIGURA 21: EVOLUÇÃO DA ÁREA URBANIZADA - 1949 A 1992

$\begin{array}{lc}\text { EVOLUÇÃO DA ÁREA } & \text { Área urbanizada: } \\ \text { URBANIZADA - 1949 A } 1992 & 1949 \\ & =1962 \\ & =1974 \\ & =1980 \\ & =1985 \\ & =1992\end{array}$

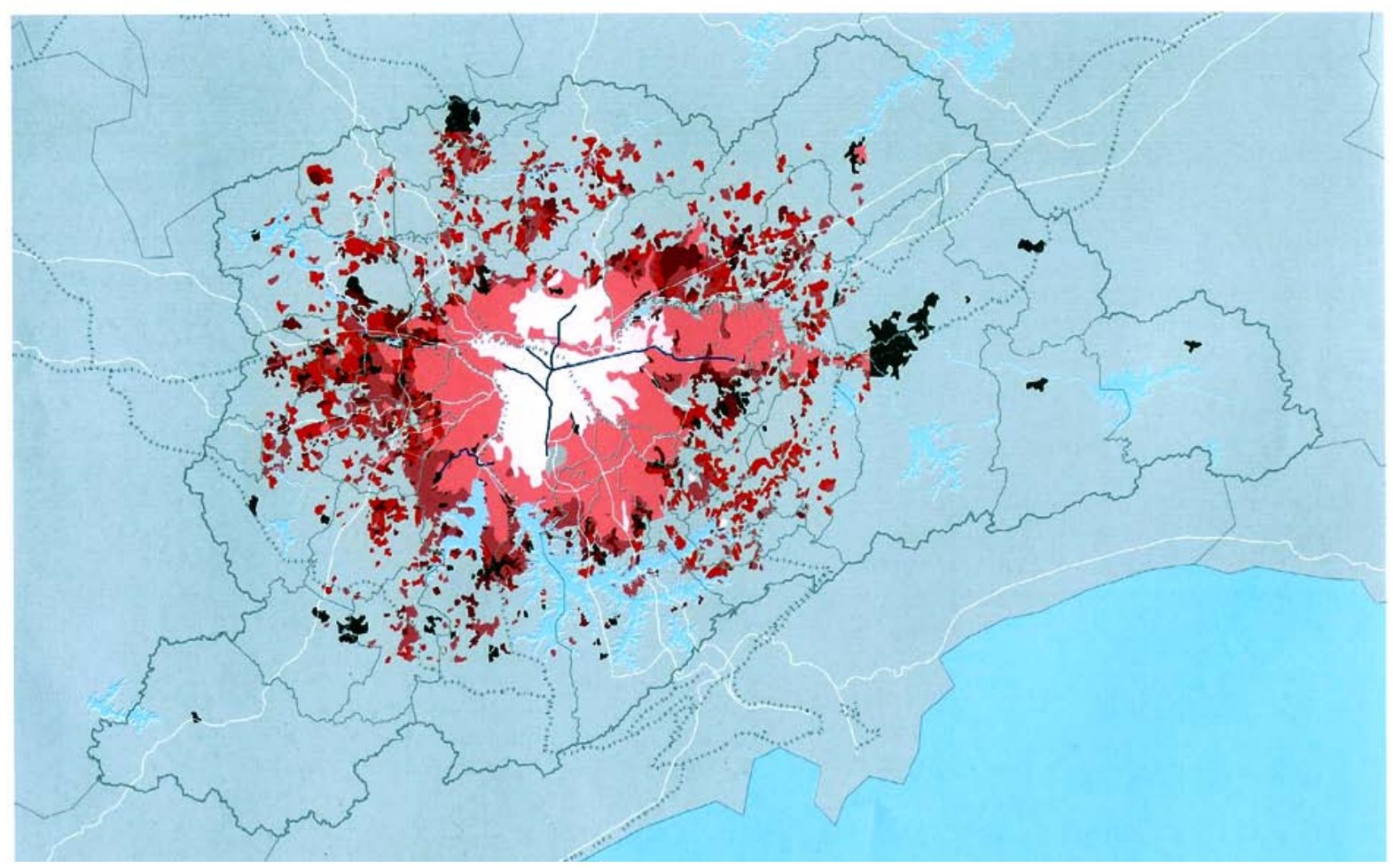

(FONTE: MEYER, BIDERMAN e GROSTEIN, 2004, p. 44) 
FIGURA 22: ESTRATIFICAÇÃO SÓCIO-DEMOGRÁFICA DA REGIÃO METROPOLITANA DE SÃO PAULO - RESULTADO DA ANÁLISE FATORIAL

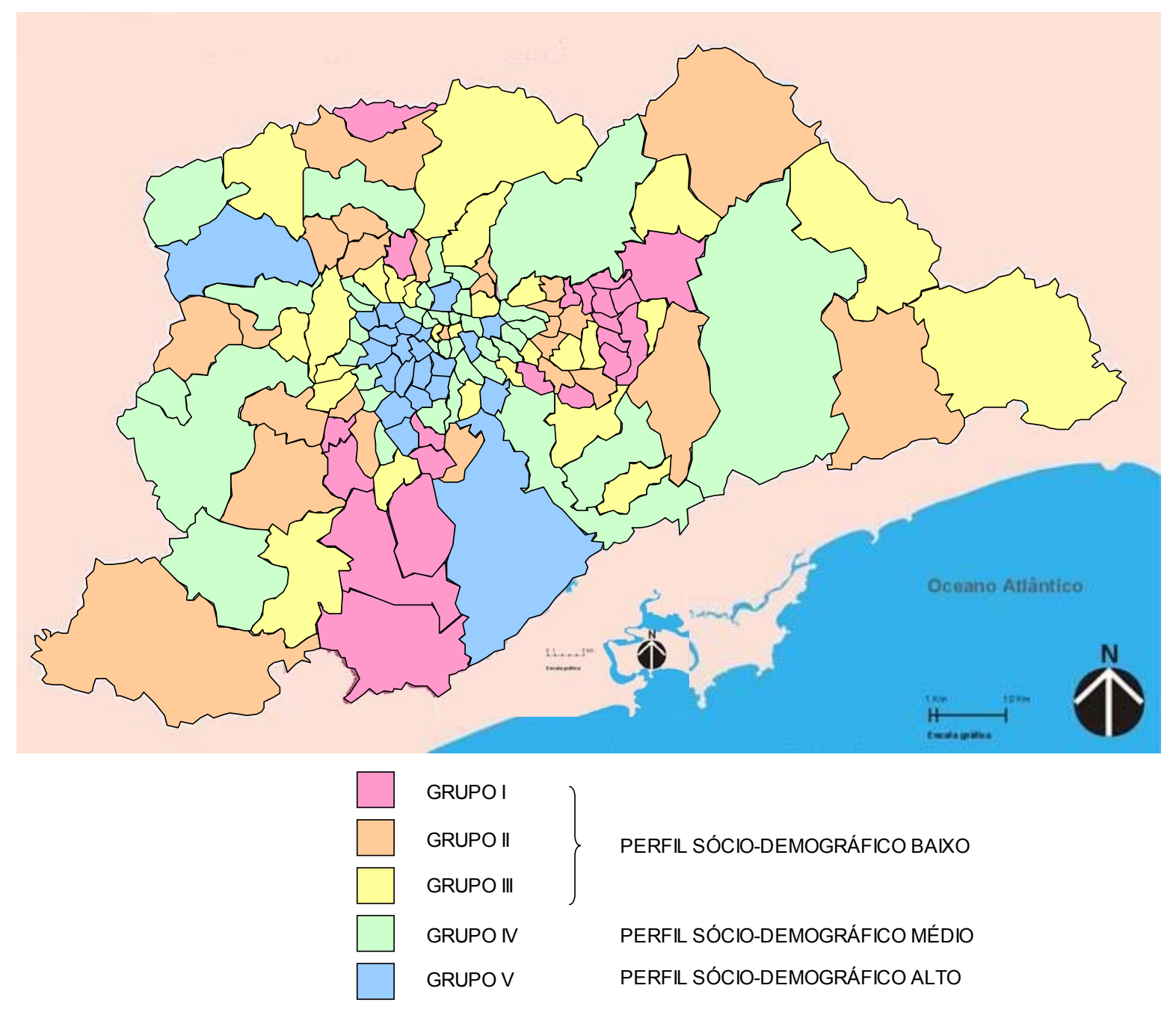


FIGURA 23: ESTRUTURA VIÁRIA E DE TRANSPORTES DA REGIÃO METROPOLITANA DE SÃO PAULO

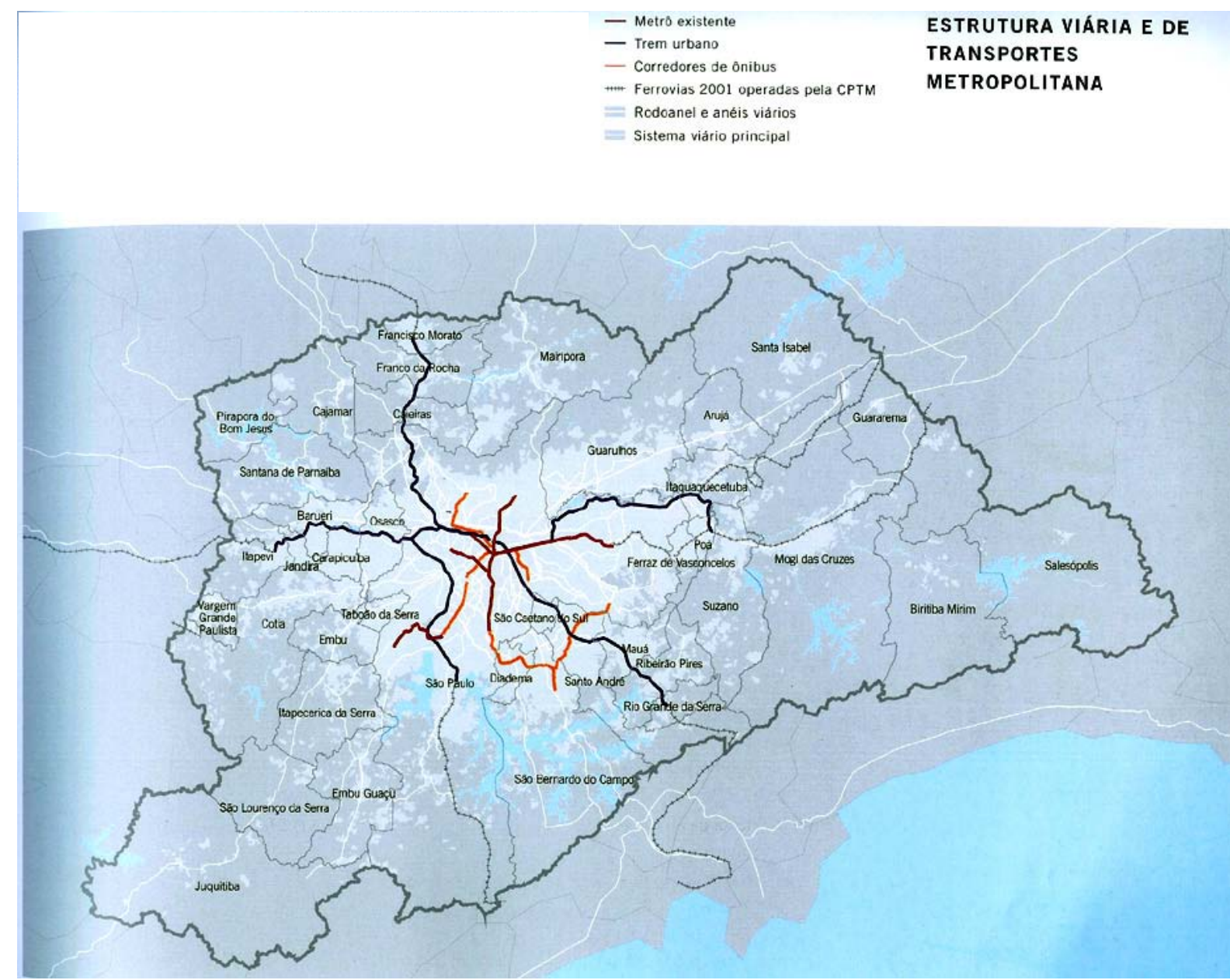

(FONTE: MEYER, BIDERMAN e GROSTEIN, 2004, p. 75) 
FIGURA 24: LINHAS DO METRÔ NA REGIÃO METROPOLITANA DE SÃO PAULO

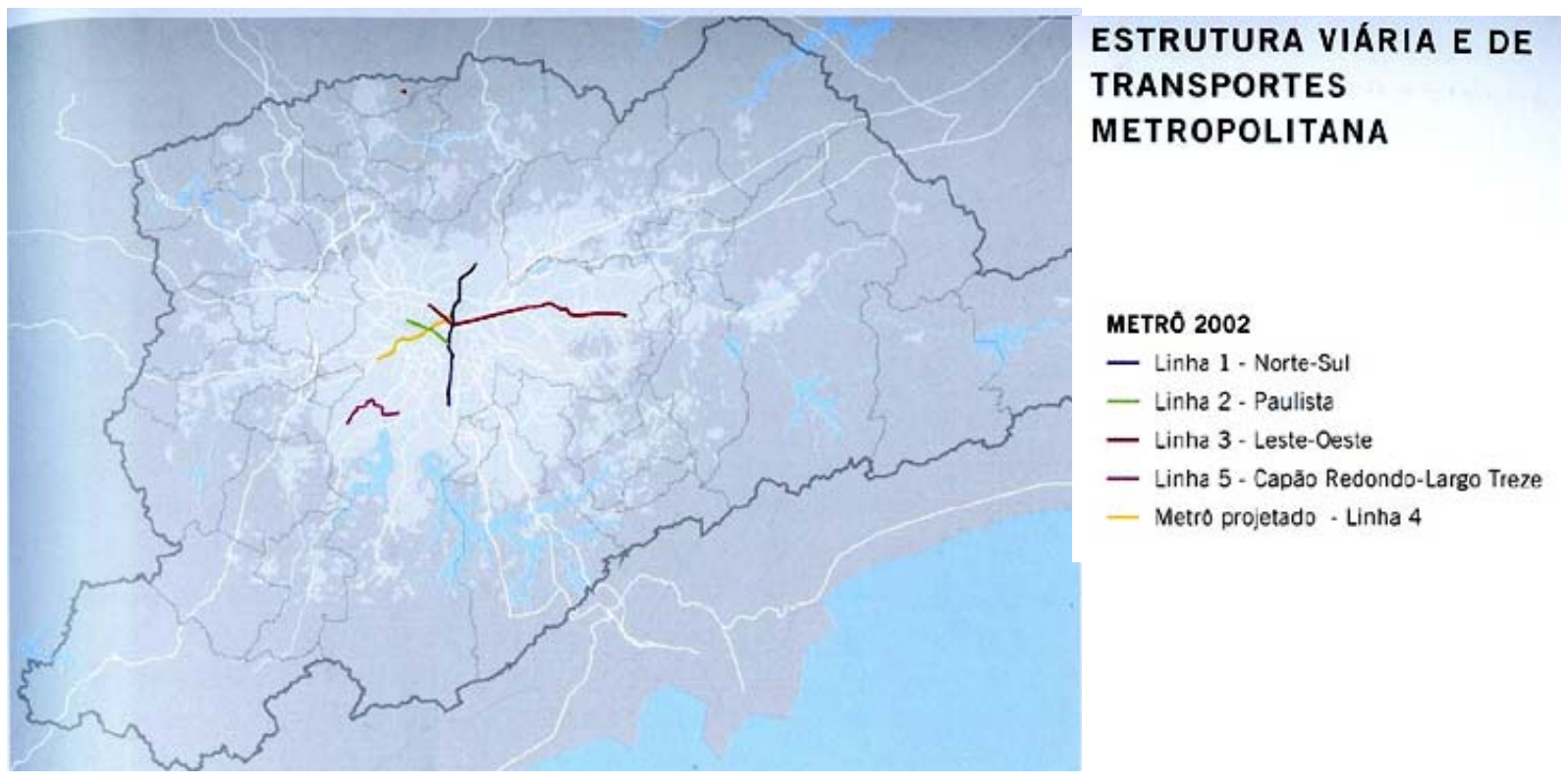

(FONTE: MEYER, BIDERMAN e GROSTEIN, 2004, p. 77) 
FIGURA 25: DETALHAMENTO DAS LINHAS DO METRÔ

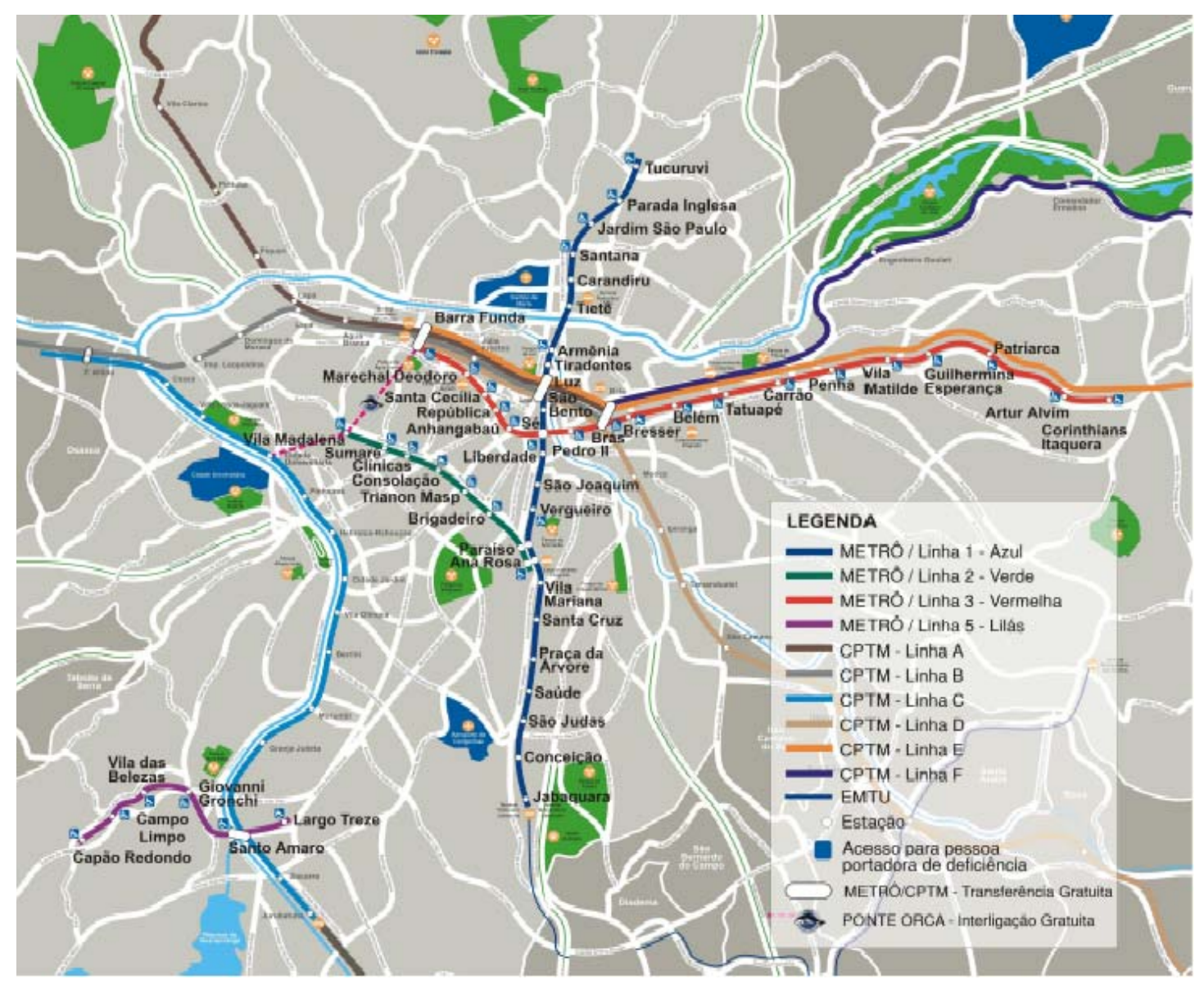

(FONTE: SITE http://www.metro.sp.gov.br) 
FIGURA 26: PONTOS DE INUNDAÇÃO NA REGIÃO METROPOLITANA DE SÃO PAULO

$\begin{array}{ll}\text { PRINCIPAIS PONTOS DE } & \text { - Limite da Bacia Hidrográfica do Alto } \\ \text { INUNDAÇÃO NA RMSP } & \text { Tieté } \\ & \text { - Principais avenidas de fundo de vale } \\ & \text { - Principais pontos de inundaçåo }\end{array}$

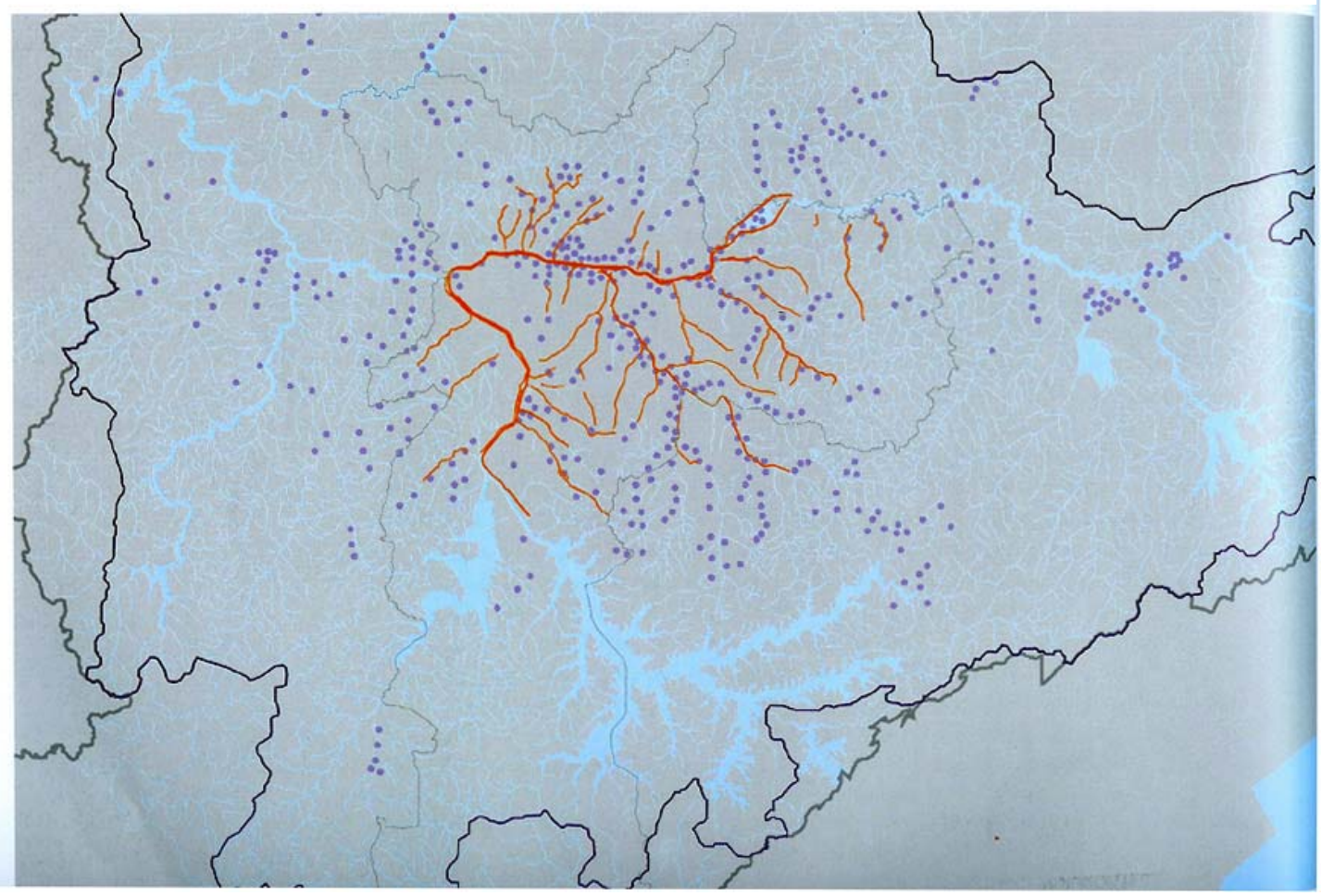

(FONTE: MEYER, BIDERMAN e GROSTEIN, 2004, p. 104) 
FIGURA 27: ATERROS E LIXÕES DA REGIÃO METROPOLITANA DE SÃO PAULO

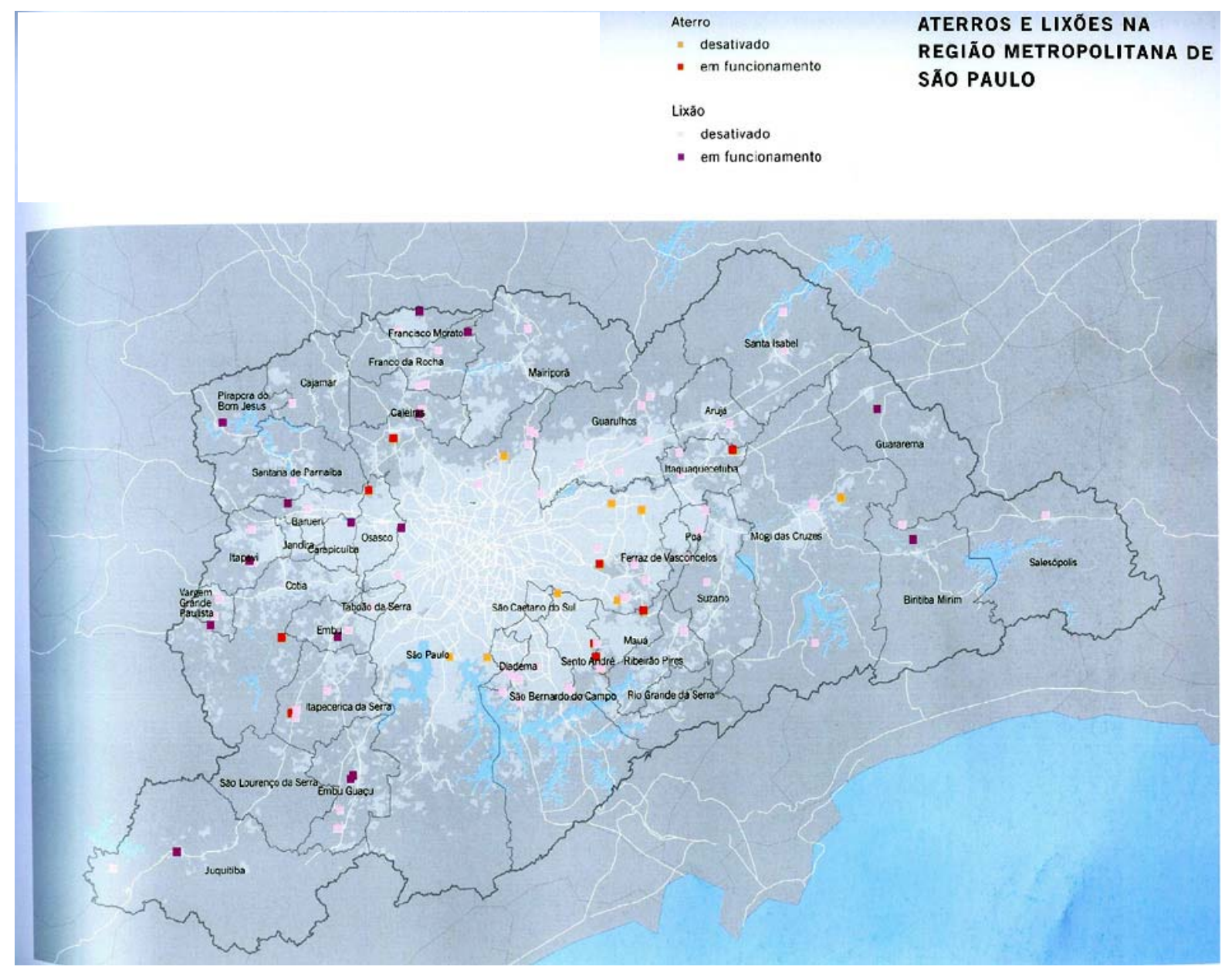

(FONTE: MEYER, BIDERMAN e GROSTEIN, 2004, p. 105) 


\section{B) ANÁLISE FATORIAL}

TABELA 01: DADOS SÓCIO-DEMOGRÁFICOS ORIGINAIS DOS DISTRITOS DO MUNICÍPIO DE SÃO

PAULO

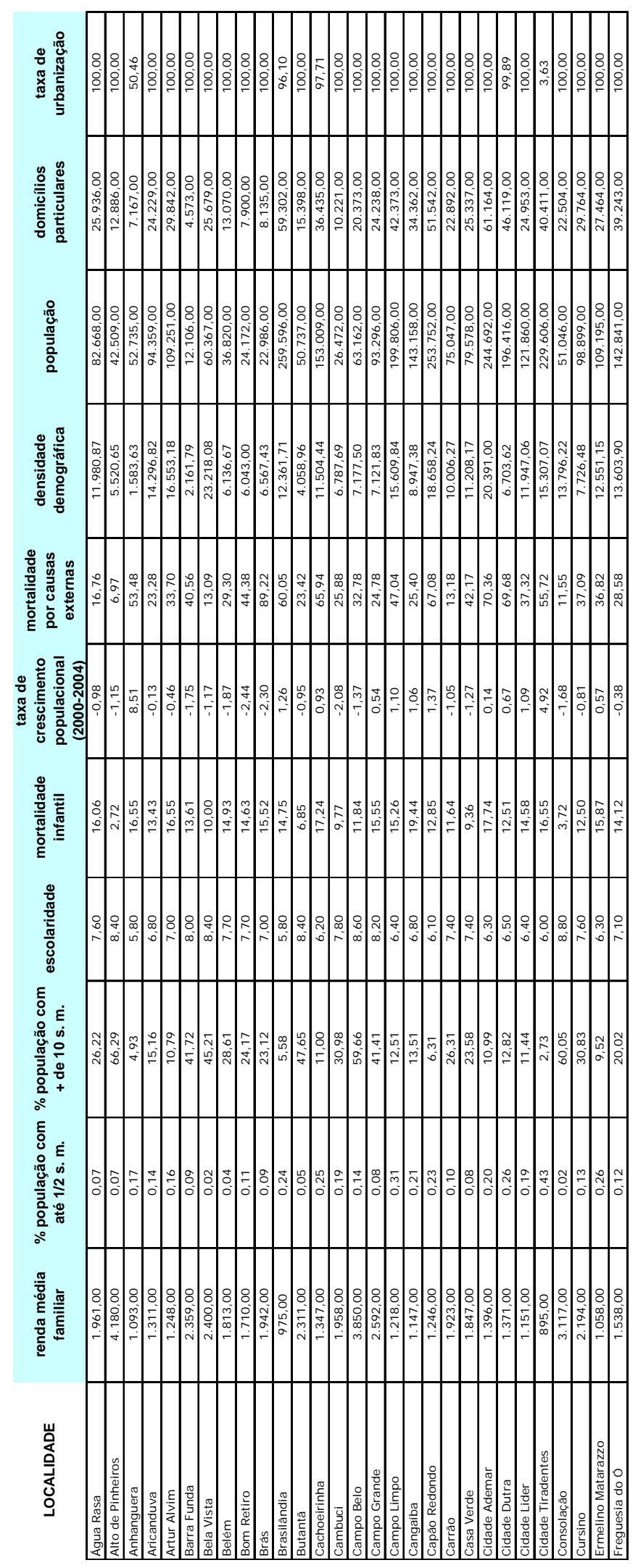




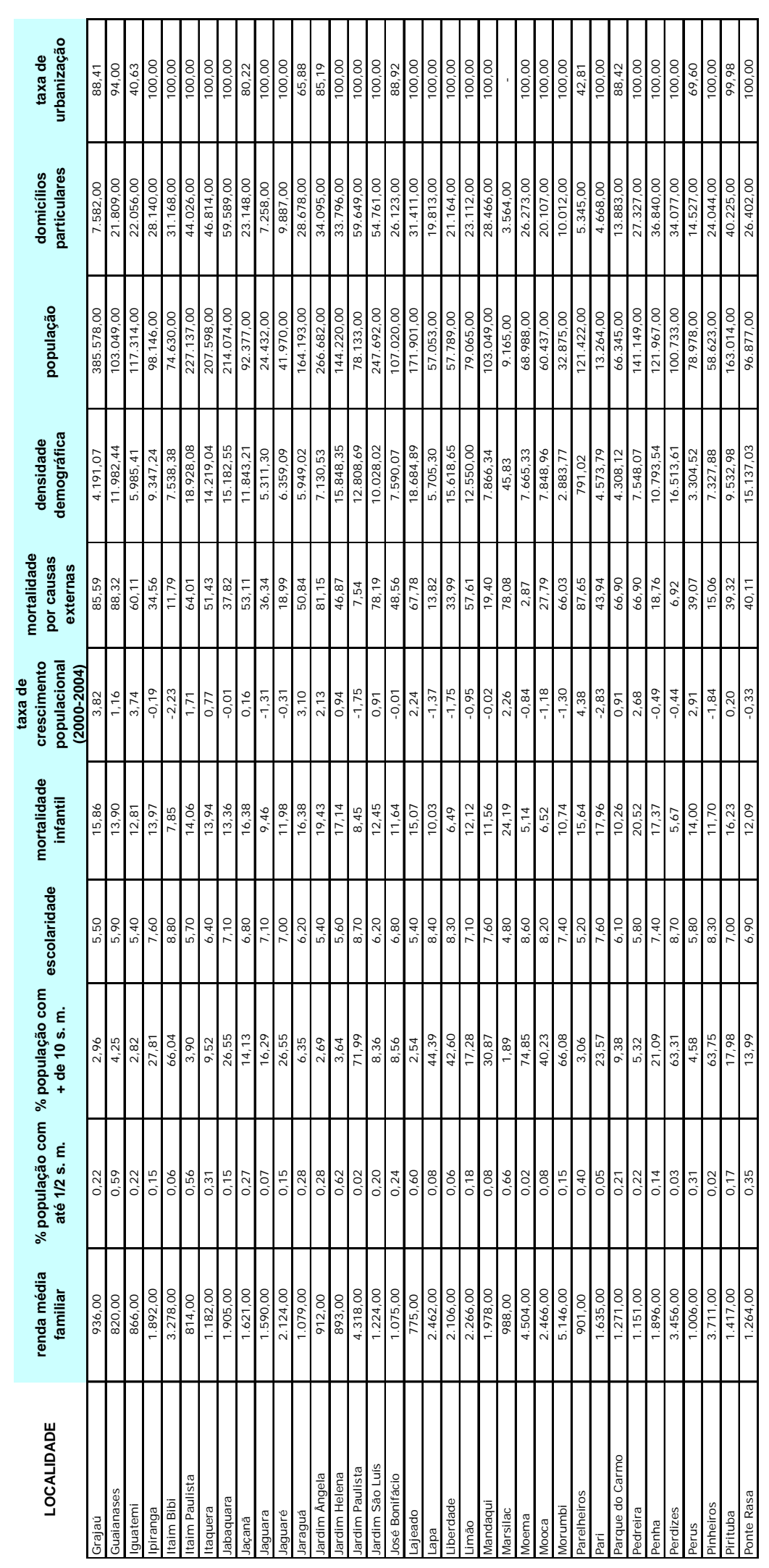




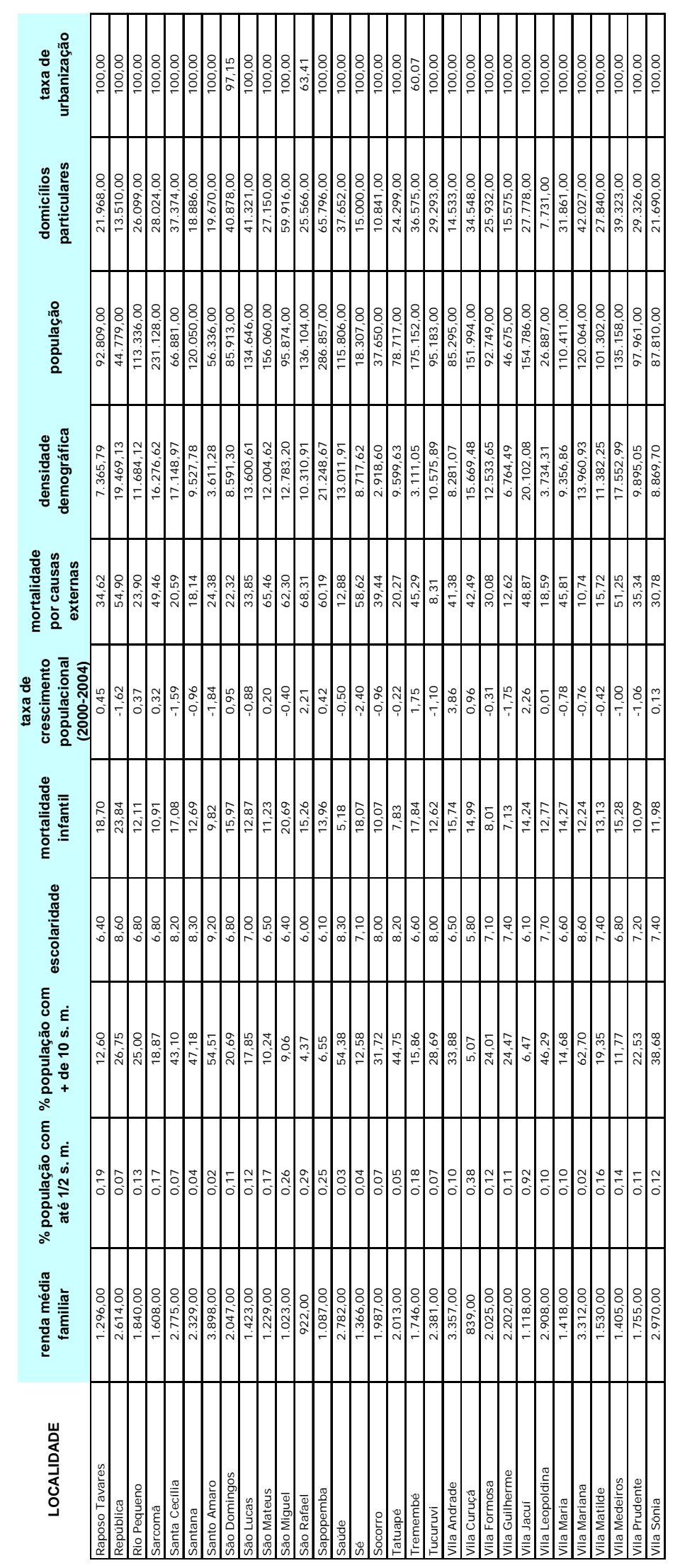


TABELA 02: DADOS SÓCIO-DEMOGRÁFICOS ORIGINAIS DOS MUNICÍPIOS DA REGIÃO METROPOLITANA

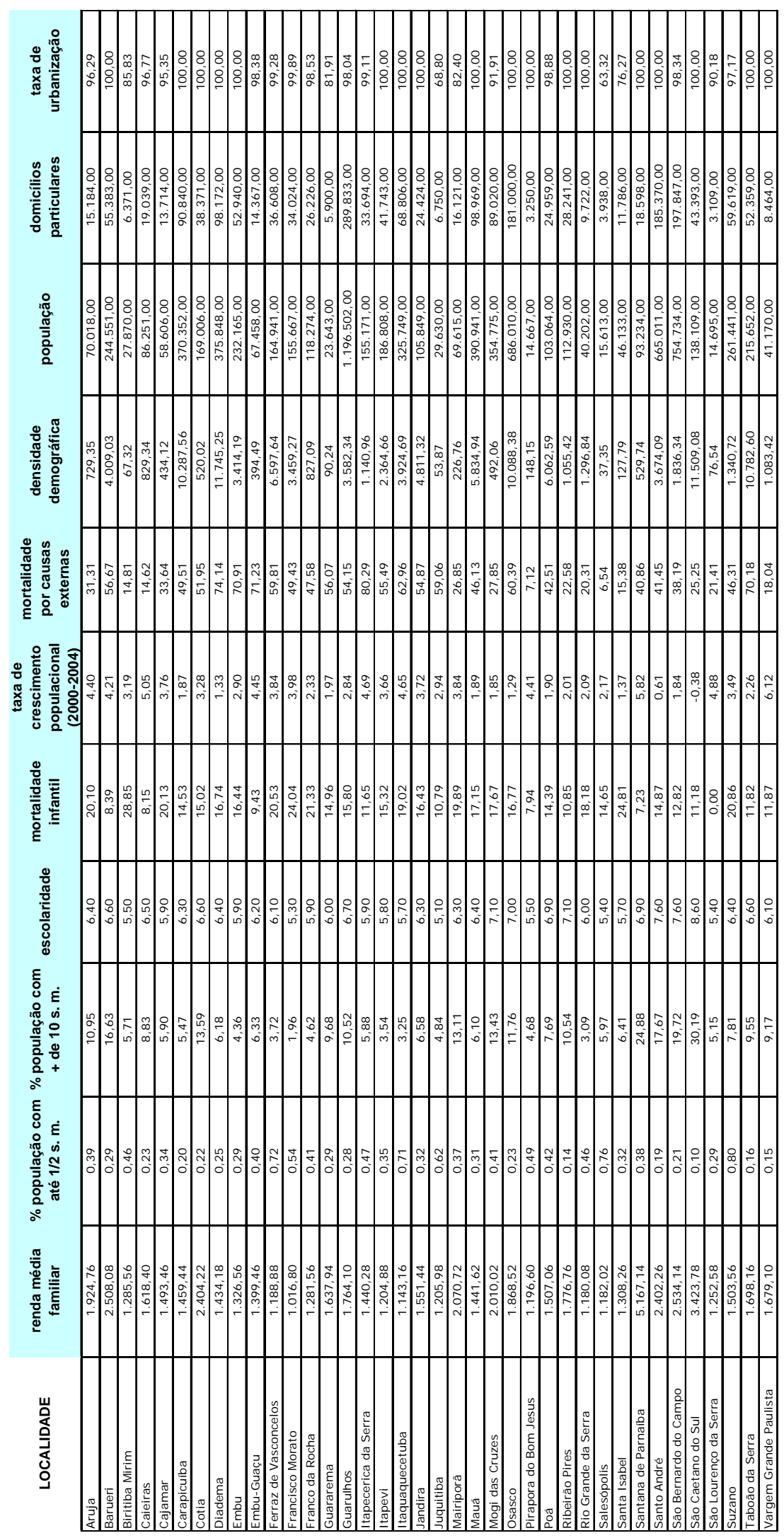


TABELA 03: MATRIZ DE CORRELAÇÃO E SIGNIFICÂNCIA PARA OS DADOS SÓCIODEMOGRÁFICOS - ANÁLISE FATORIAL

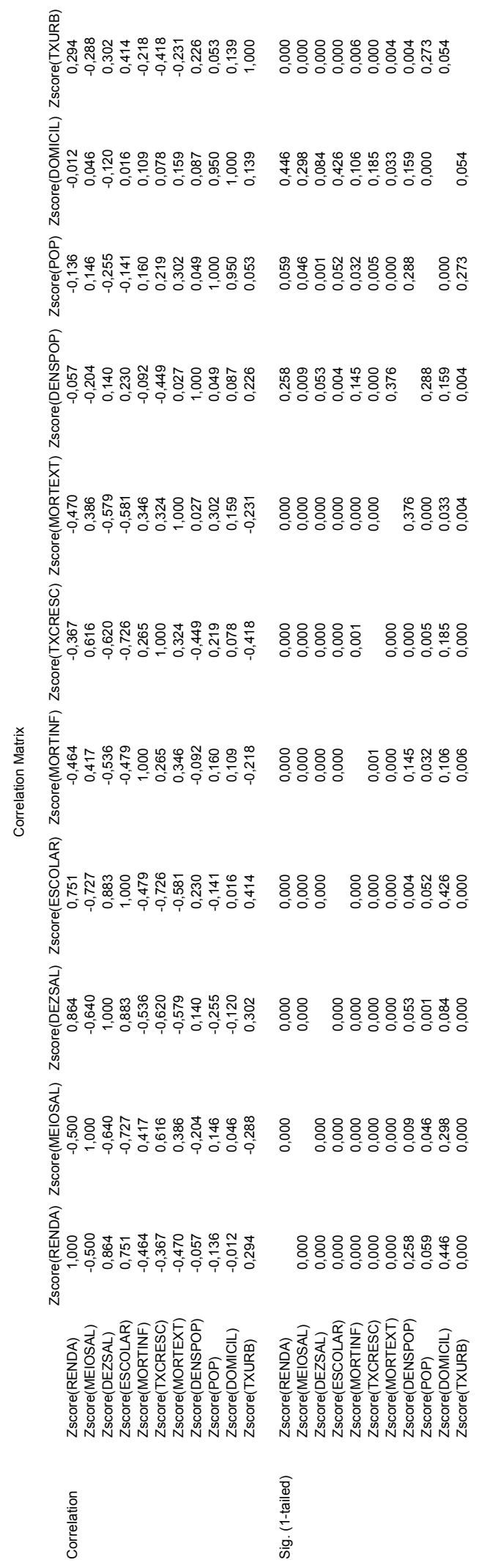


TABELA 04: MATRIZ ANTIIMAGEM - ANÁLISE FATORIAL

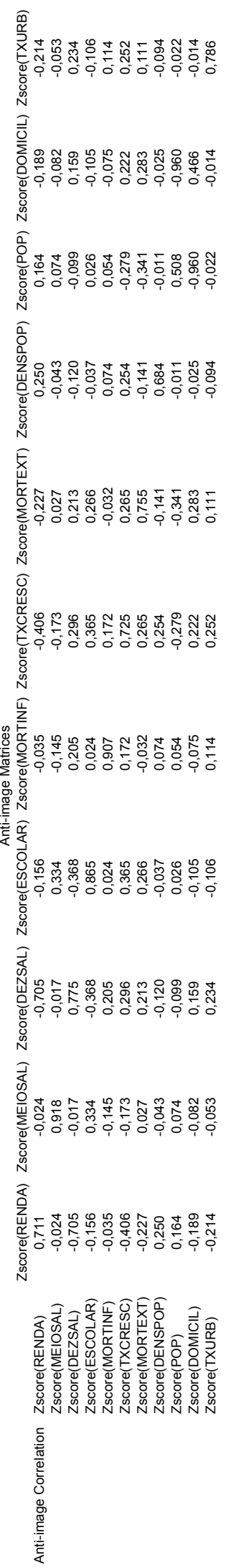


TABELA 05: RESULTADOS DAS COMUNALIDADES - ANÁLISE FATORIAL

Communalities

\begin{tabular}{|l|r|r|}
\hline & \multicolumn{1}{|c|}{ Initial } & Extraction \\
\hline RENDA & 1,000 &, 799 \\
MEIOSAL & 1,000 &, 615 \\
DEZSAL & 1,000 &, 890 \\
ESCOLAR & 1,000 &, 903 \\
MORTINF & 1,000 &, 407 \\
TXCRESC & 1,000 &, 794 \\
MORTEXT & 1,000 &, 523 \\
DENSPOP & 1,000 &, 764 \\
POP & 1,000 &, 972 \\
DOMICIL & 1,000 &, 966 \\
TXURB & 1,000 &, 383 \\
\hline
\end{tabular}

Extraction Method: Principal Component Analysis. 
TABELA 06: PERFIL SÓCIO-DEMOGRÁFICO PARA CADA UMA DAS 134 LOCALIDADES

\begin{tabular}{|c|c|c|c|}
\hline $\begin{array}{l}\text { LOCALIDADE } \\
\end{array}$ & PERFIL SÓCIO-DEMOGRPAFICO & \begin{tabular}{|l} 
LOCALIDADE \\
\end{tabular} & PERFIL SÓCIO-DEMOGRPAFICO \\
\hline Lajeado & $-1,80$ & Osasco & $-0,17$ \\
\hline Marsilac & $-1,76$ & São Lucas & $-0,17$ \\
\hline Itaim Paulista & $-1,60$ & Aruja & $-0,15$ \\
\hline Guaianases & $-1,60$ & Tremembé & $-0,13$ \\
\hline Vila Jacuí & $-1,55$ & Limão & $-0,11$ \\
\hline Jardim Helena & $-1,50$ & Freguesia do Ó & $-0,08$ \\
\hline Cidade Tiradentes & $-1,41$ & Mairiporã & $-0,03$ \\
\hline Jardim Ângela & $-1,41$ & Pirapora do Bom Jesus & 0,01 \\
\hline Parelheiros & $-1,28$ & Jabaquara & 0,03 \\
\hline Francisco Morato & $-1,28$ & Pari & 0,11 \\
\hline Ferraz de Vasconcelos & $-1,24$ & Penha & 0,17 \\
\hline Cidade Ademar & $-1,22$ & Vila Matilde & 0,18 \\
\hline Sapopemba & $-1,22$ & Bom Retiro & 0,20 \\
\hline Vila Curuçá & $-1,17$ & Rio Pequeno & 0,21 \\
\hline São Rafael & $-1,16$ & São Domingos & 0,24 \\
\hline São Miguel & $-1,15$ & Cotia & 0,24 \\
\hline Itaquaquecetuba & $-1,13$ & Vila Prudente & 0,27 \\
\hline Grajaú & $-1,13$ & Casa Verde & 0,27 \\
\hline Pedreira & $-1,10$ & Guarulhos & 0,27 \\
\hline Capão Redondo & $-1,09$ & Mogi das Cruzes & 0,29 \\
\hline Brasilândia & $-1,01$ & Jaguara & 0,29 \\
\hline Iguatemi & $-0,94$ & Vargem Grande Paulista & 0,29 \\
\hline Cachoeirinha & $-0,92$ & Ipiranga & 0,31 \\
\hline Diadema & $-0,87$ & São Lourenço da Serra & 0,32 \\
\hline Biritiba Mirim & $-0,85$ & Água Rasa & 0,35 \\
\hline Campo Limpo & $-0,82$ & Vila Formosa & 0,38 \\
\hline Juquitiba & $-0,81$ & Barueri & 0,39 \\
\hline Itaquera & $-0,80$ & Belém & 0,48 \\
\hline Jardim São Luís & $-0,80$ & Caieiras & 0,49 \\
\hline Franco da Rocha & $-0,76$ & Ribeirão Pires & 0,54 \\
\hline Embu & $-0,75$ & Cursino & 0,56 \\
\hline Ermelino Matarazzo & $-0,74$ & Carrão & 0,56 \\
\hline Vila Medeiros & $-0,73$ & Jaguaré & 0,57 \\
\hline Jaraguá & $-0,72$ & Vila Andrade & 0,61 \\
\hline Suzano & $-0,72$ & Santa Cecília & 0,68 \\
\hline São Mateus & $-0,65$ & Cambuci & 0,69 \\
\hline Itapecerica da Serra & $-0,65$ & Mandaqui & 0,73 \\
\hline \begin{tabular}{|l} 
Itapevi \\
\end{tabular} & $-0,64$ & Santo André & 0,74 \\
\hline Anhanguera & $-0,62$ & Bela Vista & 0,76 \\
\hline Artur Alvim & $-0,62$ & Liberdade & 0,80 \\
\hline Jaçanã & $-0,59$ & Socorro & 0,84 \\
\hline Perus & $-0,58$ & Tucuruvi & 0,87 \\
\hline Santa Isabel & $-0,56$ & Vila Guilherme & 0,91 \\
\hline Ponte Rasa & $-0,55$ & Vila Sônia & 0,92 \\
\hline Cidade Lider & $-0,55$ & Barra Funda & 0,94 \\
\hline \begin{tabular}{|l|} 
Jandira \\
\end{tabular} & $-0,53$ & Campo Grande & 1,00 \\
\hline Sé & $-0,51$ & São Bernardo do Campo & 1,01 \\
\hline Salesópolis & $-0,49$ & Santana & 1,10 \\
\hline Rio Grande da Serra & $-0,48$ & Tatuapé & 1,12 \\
\hline Cidade Dutra & $-0,48$ & São Caetano do Sul & 1,22 \\
\hline Carapicuíba & $-0,47$ & Mooca & 1,22 \\
\hline Parque do Carmo & $-0,47$ & Vila Leopoldina & 1,33 \\
\hline Raposo Tavares & $-0,46$ & Lapa & 1,39 \\
\hline Cajamar & $-0,44$ & Butantã & 1,49 \\
\hline Taboão da Serra & $-0,44$ & Saúde & 1,60 \\
\hline José Bonifácio & $-0,41$ & Vila Mariana & 1,65 \\
\hline Mauá & $-0,41$ & Santana de Parnaíba & 1,65 \\
\hline Cangaíba & $-0,40$ & Campo Belo & 1,73 \\
\hline Embu-Guaçu & $-0,38$ & Morumbi & 1,87 \\
\hline Brás & $-0,36$ & Consolação & 1,89 \\
\hline Guararema & $-0,35$ & Perdizes & 1,91 \\
\hline Poá & $-0,34$ & Pinheiros & 1,93 \\
\hline Sacomã & $-0,34$ & Itaim Bibi & 2,08 \\
\hline Vila Maria & $-0,30$ & Santo Amaro & 2,17 \\
\hline Aricanduva & $-0,26$ & Jardim Paulista & 2,36 \\
\hline República & $-0,24$ & Alto de Pinheiros & 2,60 \\
\hline Pirituba & $-0,22$ & Moema & 2,78 \\
\hline
\end{tabular}


TABELA 07: TESTE t PARA COMPARAÇÃO DE MÉDIAS DAS DUAS AMOSTRAS INDEPENDENTES

Independent Samples Test

\begin{tabular}{|c|c|c|c|c|c|c|c|c|c|c|}
\hline & \multicolumn{2}{|c|}{$\begin{array}{l}\text { Levene's Test for } \\
\text { Equality of Variances }\end{array}$} & \multicolumn{7}{|c|}{ t-test for Equality of Means } \\
\hline & & \multirow[b]{2}{*}{$\mathrm{F}$} & \multirow[b]{2}{*}{ Sig. } & \multirow[b]{2}{*}{$t$} & \multirow[b]{2}{*}{ df } & \multirow[b]{2}{*}{$\begin{array}{c}\text { Sig. } \\
\text { (2-tailed) }\end{array}$} & \multirow[b]{2}{*}{$\begin{array}{c}\text { Mean } \\
\text { Difference }\end{array}$} & \multirow[b]{2}{*}{$\begin{array}{l}\text { Std. Error } \\
\text { Difference }\end{array}$} & \multicolumn{2}{|c|}{$\begin{array}{l}98 \% \text { Confidence } \\
\text { Interval of the } \\
\text { Difference }\end{array}$} \\
\hline & & & & & & & & & Lower & Upper \\
\hline $\begin{array}{c}\text { REGR factor score } \\
1 \text { for analyis } 1\end{array}$ & $\begin{array}{l}\text { Equal variances } \\
\text { assumed } \\
\text { Equal variances } \\
\text { not assumed }\end{array}$ & 11,828 & 0,001 & $\begin{array}{l}1,434 \\
1,751\end{array}$ & $\begin{array}{c}132 \\
108,817\end{array}$ & $\begin{array}{l}0,154 \\
0,083\end{array}$ & $\begin{array}{l}0,273789 \\
0,273789\end{array}$ & $\begin{array}{c}0,1909 \\
0,156331\end{array}$ & $\begin{array}{c}-0,1757669 \\
-9,50 E-02\end{array}$ & $\begin{array}{l}0,723346 \\
0,642904\end{array}$ \\
\hline
\end{tabular}




\section{C) INTERPRETAÇÃO DOS COEFICIENTES DE VARIÁVEIS DUMMY EM EQUAÇÕES SEMILOGARÍTMICAS DE REGRESSÃO}

Segundo HALVORSEN e PALMQUIST (1980, p. 474-475), há um erro muito frequente em relação à interpretação dos coeficientes de variáveis dummy em equações semilogarítmicas de regressão. Muitos autores assumem, nesta situação, que o coeficiente de uma variável dummy, multiplicado por 100, é igual ao efeito percentual desta variável sobre a variável dependente. Entretanto, os autores mostram que esta interpretação, correta apenas quando as variáveis explicativas não forem dummies, gera erros substanciais que podem ser verificados por meio das considerações em torno do modelo a seguir:

$$
\ln Y=a+\sum_{i} b_{i} X_{i}+\sum_{j} c_{j} D_{j}
$$

onde $X_{i}$ representa as variáveis contínuas e $D_{j}$ representa as variáveis dummy. O coeficiente de uma variável contínua pode ser expresso como:

$$
b_{i}=\frac{\partial \ln Y}{\partial X_{i}}=\frac{1}{Y} \cdot \frac{\partial Y}{\partial X_{i}}
$$

Portanto, o coeficiente de uma variável contínua, multiplicado por 100 , é igual ao efeito percentual em $\mathrm{Y}$ gerado por meio de uma pequena mudança na referida variável explicativa.

Por outro lado, quando uma variável dummy é inserida na equação, a derivada parcial da dependente sobre a explicativa (dummy) não existe. Assim, o coeficiente da variável dummy mede o efeito da descontinuidade em Y. A correta interpretação do coeficiente de uma variável dummy pode ser mostrada por meio da transformação da equação (A.1). Para simplificar o modelo, considerou-se a presença de uma única variável dummy:

$$
Y=(1+g)^{D} \cdot \exp \left(a+\sum_{i} b_{i} X_{i}\right)
$$


onde $\mathrm{g}$ representa o efeito relativo em $\mathrm{Y}$ por causa da presença de uma variável dummy. Logo,

$$
g=\frac{\left(Y_{1}-Y_{0}\right)}{Y_{0}}
$$

onde $Y_{1}$ e $Y_{0}$ são os valores da variável dependente quando a variável dummy assume valores iguais a 1 e 0 , respectivamente.

Desta forma, o coeficiente da variável dummy na equação (A.1) pode ser calculado da seguinte forma:

$$
\exp \left(\sum_{j} c_{j} D_{j}\right)=(1+g)^{D_{j}}
$$

e como se tem apenas uma variável dummy:

$$
\exp (c)=(1+g)
$$

Assim, o efeito relativo em Y é:

$$
g=\exp (c)-1
$$

e, portanto, o efeito percentual é:

$$
100 . g=100 \cdot[\exp (c)-1]
$$

o que demonstra efetivamente que $c \neq g$. Por meio da expansão, em série de Taylor, de c, tem-se que:

$$
c=\ln (1+g)=g-\frac{1}{2} g^{2}+\frac{1}{3} g^{3}-\ldots
$$


Desta maneira, para valores pequenos de g, c é aproximadamente igual a g. Quando $g$ é positivo, c é menor do que $g$, mas quando $g$ é negativo, $c$ é algebricamente menor do que g, porém maior em valor absoluto.

$\mathrm{Na}$ tabela 8 a seguir, são apresentadas as relações entre os coeficientes da variável dummy e os respectivos efeitos relativos:

TABELA 8: RELAÇÃO ENTRE OS COEFICIENTES DE VARIÁVEIS DUMMY EM EQUAÇÕES SEMILOGARITMICAS DE REGRESSÃO E OS RESPECTIVOS EFEITOS RELATIVOS

\begin{tabular}{cc}
\hline Coeficiente da variável dummy $(\mathrm{c})$ & Efeito relativo $(\mathrm{g})$ \\
\hline 1,50 & 3,48 \\
1,25 & 2,49 \\
1,00 & 1,72 \\
0,75 & 1,12 \\
0,50 & 0,65 \\
0,25 & 0,28 \\
0,00 & 0,00 \\
$-0,25$ & $-0,22$ \\
$-0,50$ & $-0,39$ \\
$-0,75$ & $-0,53$ \\
$-1,00$ & $-0,63$ \\
$-1,25$ & $-0,71$ \\
$-1,50$ & $-0,78$ \\
\hline
\end{tabular}

FONTE: HALVORSEN e PALMQUIST (1980, p. 474-475). 


\section{D) TESTE PARA VERIFICAÇÃO DE ENDOGENEIDADE EM VARIÁVEIS EXPLICATIVAS}

Para ilustrar de verificação de endogeneidade, WOOLDRIDGE (2003, p. 506) propõe um modelo com uma única variável suspeita de endogeneidade, y:

$$
y_{1}=\beta_{0}+\beta_{1} \cdot y_{2}+\beta_{2} \cdot z_{1}+\beta_{3} \cdot z_{2}+\mu_{1}
$$

onde $z_{1}$ e $z_{2}$ são exógenas. Sabe-se também que há duas outras variáveis exógenas no modelo, $z_{3}$ e $z_{4}$, que não aparecem na equação apresentada.

Se $y_{2}$ não apresenta correlação com $\mu_{1}$, pode-se estimar o modelo por meio do método dos mínimos quadrados ordinários. HAUSMAN (1978, 1251-1271), portanto, sugere uma comparação direta entre as estimativas provenientes do método dos mínimos quadrados ordinários e do método dos mínimos quadrados de dois estágios, com o intuito de verificar se as diferenças são estatisticamente significantes. Assim, se os dois métodos apresentarem diferenças significativas, conclui-se que $\mathrm{y}_{2}$ deve ser endógena, mantendo as variáveis $z_{j}$ exógenas.

Para determinar se as diferenças são estatisticamente significantes, utiliza-se uma regressão em que a variável dependente passa a ser $\mathrm{y}_{2}$, da seguinte forma:

$$
y_{2}=\pi_{0}+\pi_{1} \cdot z_{1}+\pi_{2} \cdot z_{2}+\pi_{3} \cdot z_{3}+\pi_{4} \cdot z_{4}+v_{2}
$$

Como cada $z_{\mathrm{j}}$ não apresenta correlação com $\mu_{1}, \mathrm{y}_{2}$ não será correlacionada com $\mu_{1}$ se, e somente se, $v_{2}$ não for correlacionada com $\mu_{1}$. Assim sendo, propõe-se a seguinte verificação:

$$
\mu_{1}=\delta_{1} \cdot v_{2}+e_{1}
$$

onde $e_{1}$ apresenta média zero e não é correlacionado com $v_{2}$. Portanto, $\mu_{1}$ e $v_{2}$ não serão correlacionados se, e somente se, $\delta_{1}=0$. Segundo WOOLDRIDGE (2003, p. 506), a maneira mais fácil de verificar este fato é incluir o termo $v_{2}$ na regressão proposta na equação (A.10) e elaborar um teste t. Porém, v $v_{2}$ não é observado, uma vez que é o termo do erro da regressão expressa na equação (A.11). Assim sendo, o 
termo $v_{2}$ a ser utilizado será $\hat{v}_{2}$, obtido por meio da equação (A.11) a partir do método dos mínimos quadrados ordinários.

Assim, pode-se estimar:

$$
\mathrm{y}_{1}=\beta_{0}+\beta_{1} \cdot \mathrm{y}_{2}+\beta_{2} \cdot \mathrm{z}_{1}+\beta_{3} \cdot \mathrm{z}_{2}+\delta_{1} \hat{v}_{2}+e_{1}
$$

por meio do método dos mínimos quadrados ordinários, testando a hipótese $\mathrm{H}_{0}$ : $\delta_{1}=0$ por meio do teste t. Se $\mathrm{H}_{0}$ for rejeitada a um determinado nível de significância, então se pode concluir que $y_{2}$ é endógena, uma vez que $v_{2}$ será correlacionada com $\mu_{1}$. 


\section{E) O PROBLEMA DA IDENTIFICAÇÃO}

Segundo WOOLDRIDGE (2003, p. 532-534) e GUJARATI (2000, p. 663-680), o conceito do problema de identificação pode ser expresso por meio da apresentação de um sistema de equações de oferta e demanda em equilíbrio $\left(q_{s}=q_{d}=q\right)$, de acordo como segue:

$$
\begin{aligned}
& q=\alpha_{1} \cdot p+\beta_{1} \cdot z_{1}+\mu_{1} \\
& \mathrm{e} \\
& q=\alpha_{2} \cdot p+\mu_{2}
\end{aligned}
$$

Por meio do sistema apresentado, é possível verificar que a equação de demanda (A.15) está identificada, porém a equação de oferta não, uma vez que se pode utilizar $z_{1}$ como uma variável instrumental para o preço na equação (A.15). Porém, como $z_{1}$ aparece na equação de oferta (A.14), não se tem uma variável instrumental para o preço nesta equação. Em uma equação com uma determinada variável endógena, uma variável instrumental é uma variável que não aparece na referida equação, além de não ser correlacionada com o termo do erro e ser parcialmente correlacionada com a variável endógena.

Desta forma, a equação de demanda é identificada uma vez que se tem uma variável observada $z_{1}$, que altera a equação de oferta sem afetar a equação de demanda. Assim, qualquer variação em $z_{1}$ pode tornar possível a determinação da curva de demanda, como mostrado na figura 28 a seguir. 
FIGURA 28: ALTERAÇÕES NA EQUAÇÃO DE OFERTA E A DETERMINAÇÃO DA CURVA DE DEMANDA

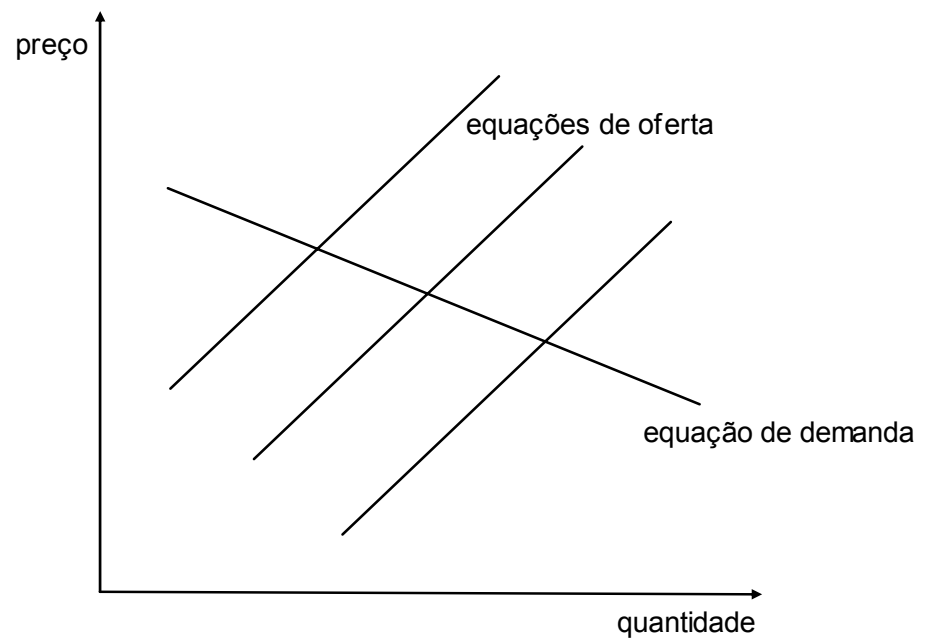

FONTE: WOOLDRIDGE, 2003, p. 533.

Por meio da figura 28, pode-se verificar que a equação de demanda está identificada uma vez que cada curva de oferta pode ser obtida por meio da variação dos valores da variável exógena $z_{1}$. Por outro lado, a equação de oferta não pode ser identificada, já que não há variáveis observadas exógenas presentes na equação de demanda.

Estendendo a discussão do problema de identificação para um modelo geral de duas equações, tem-se que:

$$
y_{1}=\beta_{10}+\alpha_{1} \cdot y_{2}+\beta_{1} \cdot z_{1}+\mu_{1}
$$

e

$$
y_{2}=\beta_{20}+\alpha_{2} \cdot y_{1}+\beta_{2} \cdot z_{2}+\mu_{2}
$$

onde $y_{1}$ e $y_{2}$ representam as variáveis endógenas e $\mu_{1}$ e $\mu_{2}$ os termos dos erros. Os interceptos são representados por $\beta_{10}$ e $\beta_{20}$, respectivamente. $A$ variável $z_{1}$ representa o vetor de $k_{1}$ variáveis exógenas presentes na primeira equação: $z_{1}=\left(z_{11}\right.$, $\left.z_{12}, \ldots, z_{1 k}\right)$. Analogamente, $z_{2}$ representa o vetor de $k_{2}$ variáveis exógenas presentes na segunda equação: $z_{2}=\left(z_{21}, z_{22}, \ldots, z_{2 k}\right)$. Assim sendo: 
$z_{1} \beta_{1}=\beta_{11} \cdot z_{11}+\beta_{12 \cdot} \cdot z_{12}+\ldots+\beta_{1 k 1} \cdot z_{1 k 1}$

e

$z_{2} \beta_{2}=\beta_{21} \cdot z_{21}+\beta_{22} \cdot z_{22}+\ldots+\beta_{2 k 2 \cdot} \cdot z_{2 k 2}$

$O$ fato de $z_{1}$ e $z_{2}$ genericamente conterem diferentes variáveis exógenas significa que se assume que certas variáveis exógenas não aparecem na primeira equação e que outras não aparecem na segunda.

Portanto, para se verificar se as equações presentes em determinados modelos podem ser identificadas, deve-se recorrer às condições de ordem e de posto. Segundo GUJARATI (2000, p. 671-676) a condição de ordem (condição necessária) é verificada por meio da análise da quantidade de variáveis exógenas nas equações de oferta e demanda. Desta maneira, em um modelo de $M$ equações (no caso, duas equações, sendo uma de oferta e uma de demanda), para que cada equação seja identificada, deve haver pelo menos $M$ - 1 (no caso deste trabalho, $M-1=1$ ) variáveis exógenas que apareçam na outra equação e que não estejam presentes na equação a ser avaliada. Se isto acontecer para cada uma das equações, pode-se afirmar que estas não apresentarão problemas de identificação.

WOOLDRIDGE (2003, p. 534) afirma que a condição de posto, por outro lado, é uma condição necessária e suficiente, já que requer que pelo menos uma das variáveis exógenas não presentes em uma determinada equação apresente um coeficiente diferente de zero na outra equação. 


\section{F) O TESTE DE DURBIN-WATSON}

Segundo VASCONCELLOS e ALVES (2000, p. 113-114), o teste de DurbinWatson é um dos mais utilizados para a verificação de autocorrelação dos resíduos, a partir do qual é verificado se $\rho$ é igual a zero na equação a seguir:

$$
\varepsilon_{t}=\rho \cdot \varepsilon_{t-1}+\mu_{t}
$$

onde $\varepsilon$ tem distribuição normal com média 0 , variância constante e não autocorrelacionado.

Assim, se $\rho=0$, tem-se que $\mu_{t}=\varepsilon_{t}$ e nenhum problema existiria. Entretanto, como não se conhece a distribuição de probabilidade de seu estimador $\hat{\rho}$, criou-se a seguinte estatística com o intuito de verificar o problema em questão:

$$
d=\frac{\sum_{t=2}^{n}\left(e_{t}-e_{t-1}\right)^{2}}{\sum_{t=1}^{n} e_{t}^{2}}
$$

onde e corresponde aos valores dos resíduos estimados pelo modelo e n é o número de observações.

É possível, por meio do desenvolvimento a seguir, mostrar a relação existente entre d e o valor $\hat{\rho}$. Para tanto, escreve-se d da seguinte forma:

$$
d=\frac{\sum_{t=2}^{n}\left(e_{t}^{2}-2 \cdot e_{t} e_{t-1}+e_{t-1}^{2}\right)}{\sum_{t=1}^{n} e_{t}^{2}}
$$

e

$$
d=\frac{\sum_{t=2}^{n} e_{t}^{2}-2 \cdot \sum_{t=2}^{n} e_{t} e_{t-1}+\sum_{t=2}^{n} e_{t-1}^{2}}{\sum_{t=1}^{n} e_{t}^{2}}
$$


Se n, em (A.23), for suficientemente grande, tem-se que:

$\sum_{t=1}^{n} e_{t}^{2} \cong \sum_{t=2}^{n} e_{t-1}^{2} \cong \sum_{t=2}^{n} e_{t}^{2}$

de onde vem que:

$d \cong \frac{2 \cdot \sum_{t=2}^{n} e_{t-1}^{2}}{\sum_{t=2}^{n} e_{t-1}^{2}}-\frac{2 \cdot \sum_{t=2}^{n} e_{t} e_{t-1}}{\sum_{t=2}^{n} e_{t-1}^{2}}$

$d \cong 2 .\left(1-\frac{\sum_{t=2}^{n} e_{t} e_{t-1}}{\sum_{t=2}^{n} e_{t-1}^{2}}\right)$

e, para a equação de regressão (A.20), tem-se que:

$$
\hat{\rho}=\frac{\sum_{t=2}^{n} e_{t} e_{t-1}}{\sum_{t=2}^{n} e_{t-1}^{2}}
$$

e, desta forma:

$d \cong 2 .(1-\hat{\rho})$

e, portanto, para que não haja autocorrelação dos resíduos, a estatística d apresentada em (A.21) deve ser próxima de 2. 


\section{G) TESTE DE GLEJSER PARA VERIFICAÇÃO DE HETEROCEDASTICIDADE}

Segundo VASCONCELLOS e ALVES (2000, p. 123-124), o teste de Glejser oferece indicações sob padrão da heterocedasticidade. Com os resíduos obtidos por meio da elaboração da regressão original, estimam-se, a partir deste teste, as seguintes regressões:

$$
\begin{aligned}
& \left|e_{i}\right|=a_{0}+a_{1} \cdot X_{i} \\
& \left|e_{i}\right|=a_{0}+a_{1} \cdot X_{i}^{2} \\
& \left|e_{i}\right|=a_{0}+a_{1} \cdot \frac{1}{X_{i}} \\
& \left|e_{i}\right|=a_{0}+a_{1} \cdot \sqrt{X_{i}}
\end{aligned}
$$

ou, em termos gerais:

$$
\left|e_{i}\right|=a_{0}+a_{1} \cdot X_{i}^{h}
$$

sendo $X$ a variável explicativa com a qual se supõe que $e_{i}$ esteja relacionado, e h qualquer potência selecionada.

Desta maneira, se $a_{1}=0$ para todas as regressões estimadas, não se rejeita a hipótese nula de que não há heterocedasticidade. 


\section{H) O TESTE CHOW}

O teste Chow considera o seguinte modelo:

$y=\alpha+\beta \cdot X 1+\gamma \cdot X 2+\mu$

onde se pode estimar o modelo por meio de dois grupos separadamente:

$y=\alpha_{1}+\beta_{1} \cdot X_{1}+\gamma_{1} X_{2}+\mu \quad$ para o grupo 1

$y=\alpha_{2}+\beta_{2} \cdot X_{1}+\gamma_{2} \cdot X_{2}+\mu \quad$ para o grupo 2

e por meio dos quais se pode estimar uma regressão única, chamada de equação mesclada:

$$
y=\alpha+\beta \cdot X_{1}+\gamma \cdot X_{2}+\mu
$$

Verificar-se-á, assim, se $\alpha_{1}=\alpha_{2}, \beta_{1}=\beta_{2}$, e $\gamma_{1}=\gamma_{2}$. A expressão do teste Chow é apresentada a seguir:

$$
\frac{\frac{S Q R c-(S Q R 1+S Q R 2)}{k}}{\frac{S Q R 1+S Q R 2}{N 1+N 2-2 . k}}
$$

onde SQR1 e SQR2 representam a soma dos resíduos ao quadrado para cada uma das regressões modeladas separadamente, SQRc representa a soma dos resíduos ao quadrado da equação de regressão combinada (entre as equações 1 e 2), k é o número de parâmetros e N1 e N2 representam o número de observações em cada um dos grupos. A estatística resultante do teste que deve ser verificada é $F$, com graus de liberdade (k, N1+N2-2.k). Se a estatística F exceder o valor crítico de F em um determinado nível de confiança, rejeitar-se-á a hipótese nula de que os coeficientes das duas regressões sejam iguais. 


\section{I) PERFIL SÓCIO-DEMOGRÁFICO BAIXO}

\section{I.1) Caracterização da Amostra}

GRÁFICO 1: FREQUÊNCIA DE PREÇOS NA AMOSTRA DE PERFIL SÓCIO-DEMOGRÁFICO BAIXO

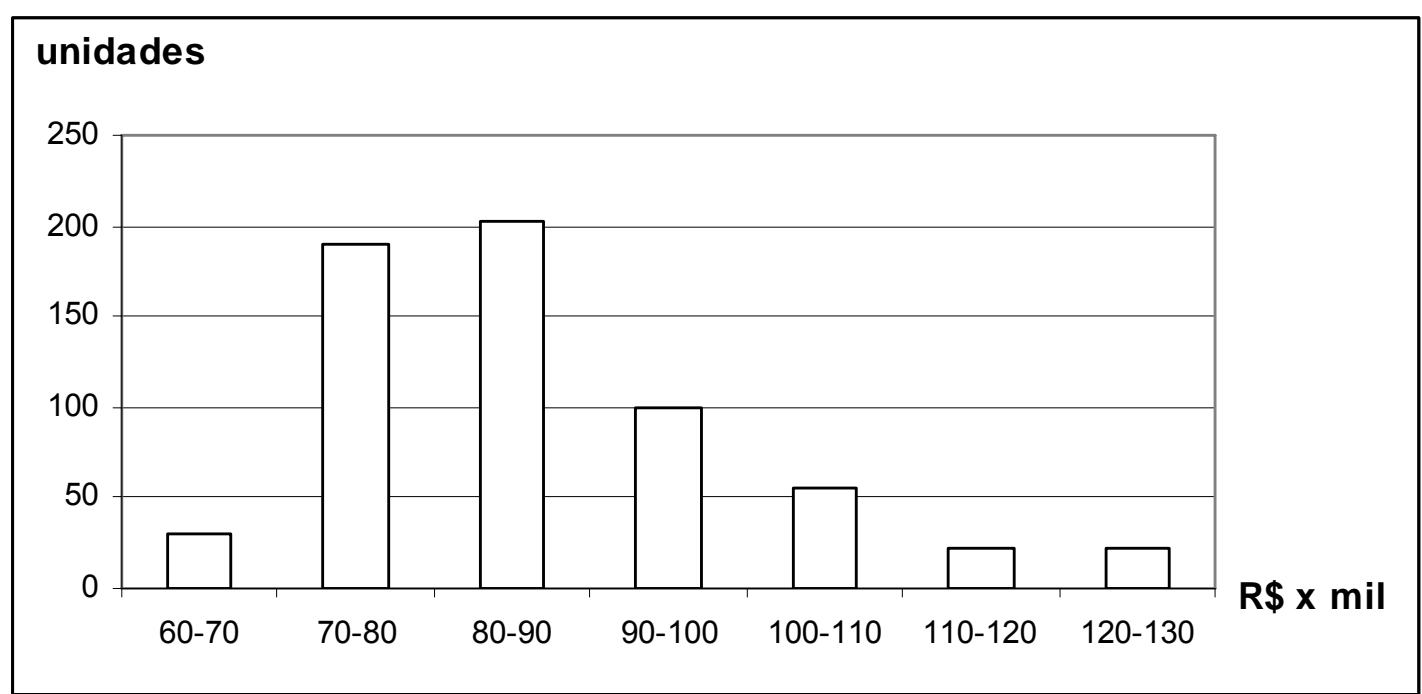

GRÁFICO 2: FREQUÊNCIA DE ÁREA TOTAL NA AMOSTRA DE PERFIL SÓCIO-DEMOGRÁFICO BAIXO

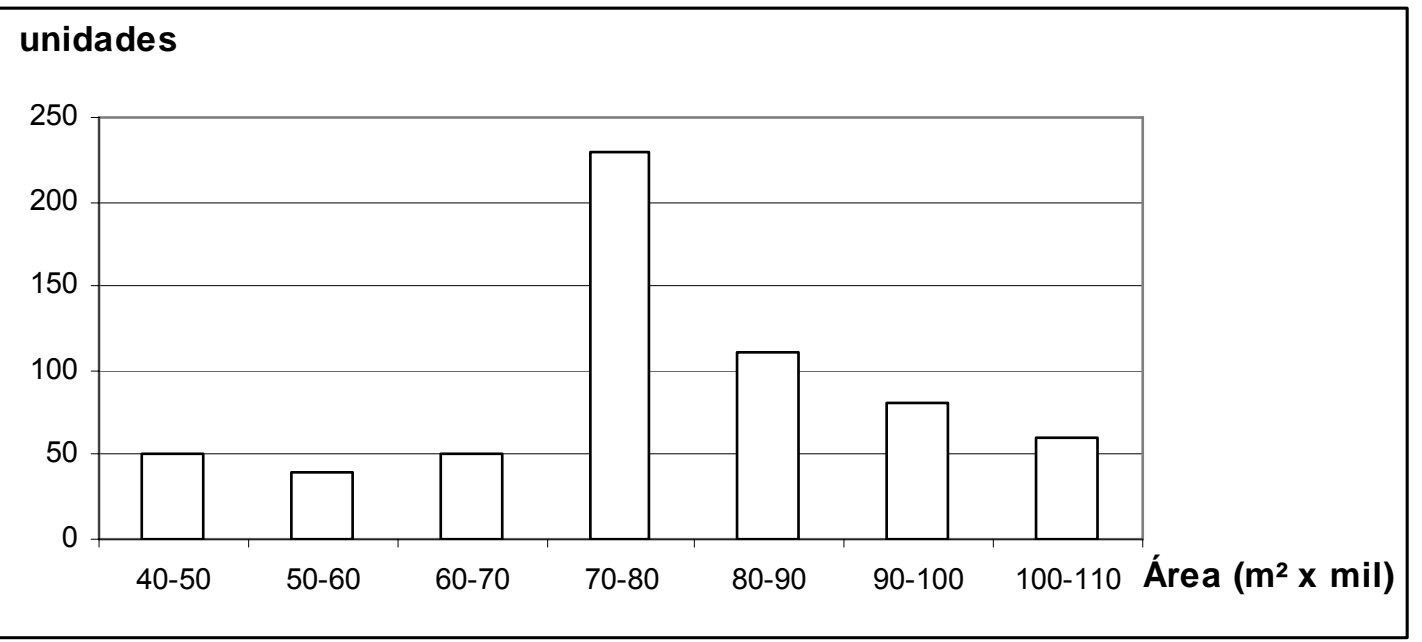


GRÁFICO 3: FREQUÊNCIA DE EXISTÊNCIA DE SALÃO DE FESTAS NA AMOSTRA DE PERFIL SÓCIO-DEMOGRÁFICO BAIXO

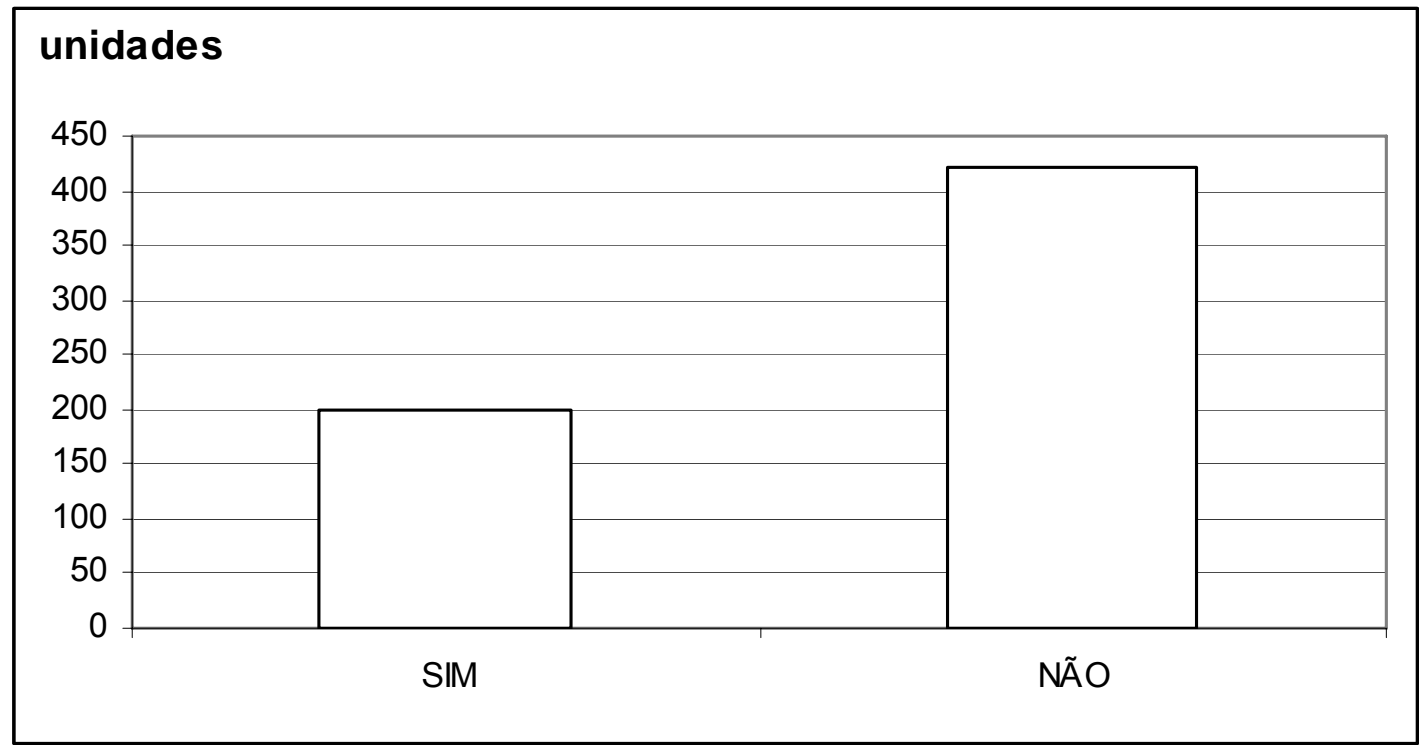

GRÁFICO 4: FREQUÊNCIA DE EXISTÊNCIA DE SALÃO DE JOGOS NA AMOSTRA DE PERFIL SÓCIO-DEMOGRÁFICO BAIXO

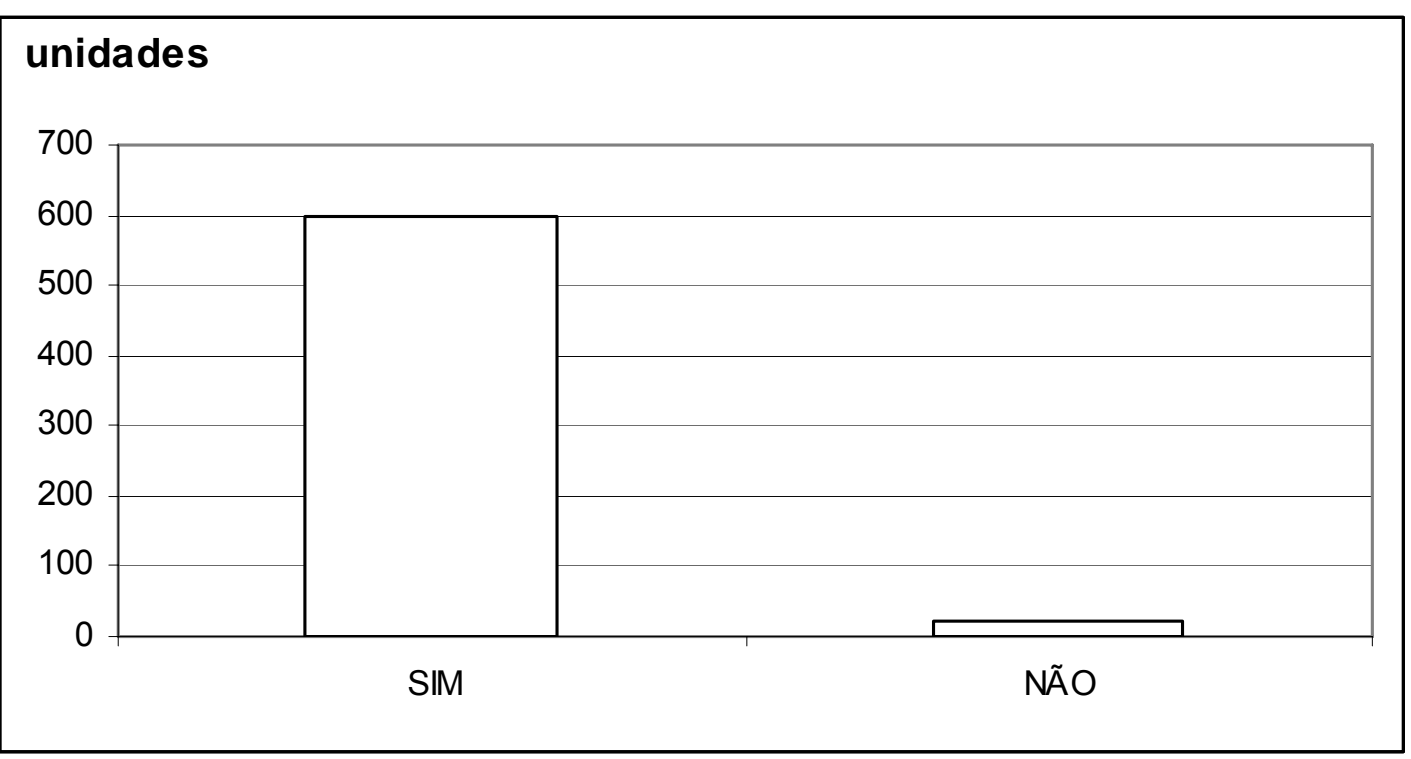


GRÁFICO 5: FREQUÊNCIA DE EXISTÊNCIA DE SALA DE GINÁSTICA NA AMOSTRA DE PERFIL SÓCIO-DEMOGRÁFICO BAIXO

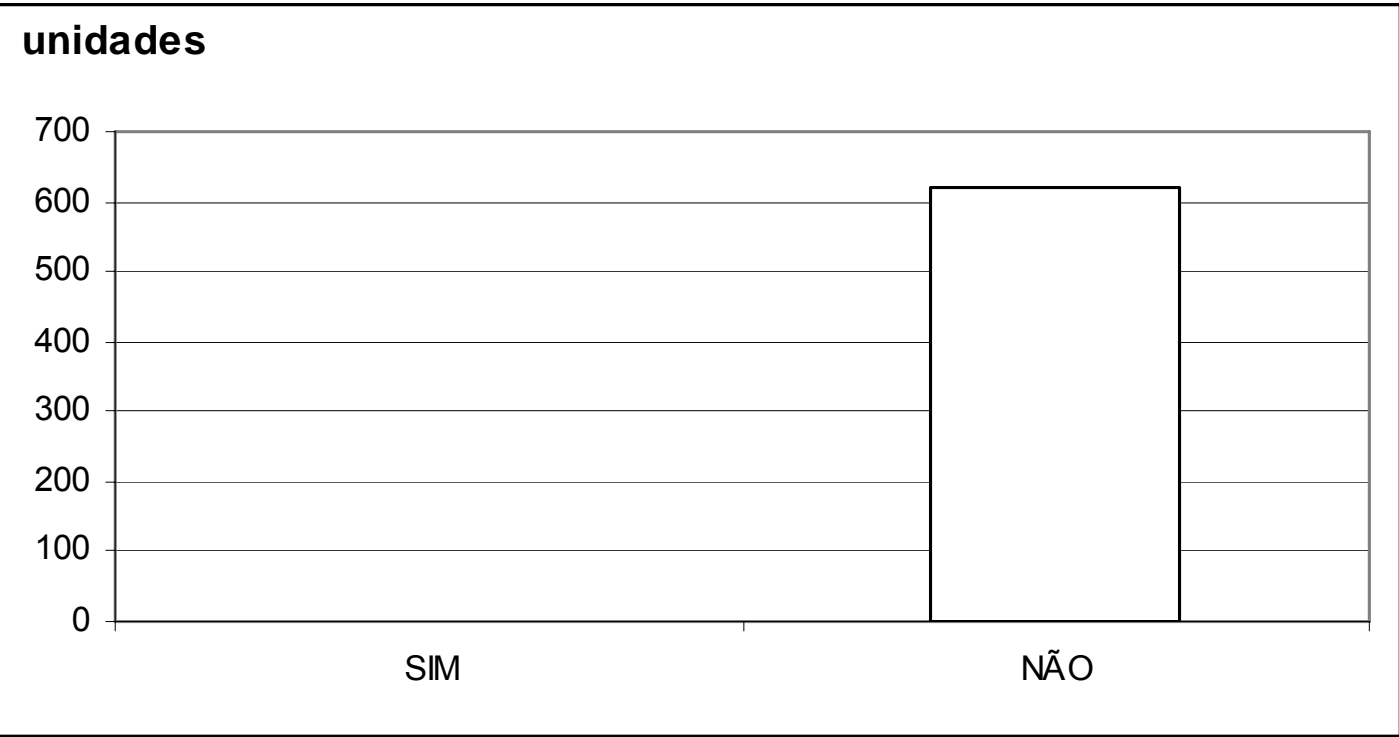

GRÁFICO 6: FREQUÊNCIA DE EXISTÊNCIA DE PISCINA NA AMOSTRA DE PERFIL SÓCIODEMOGRÁFICO BAIXO

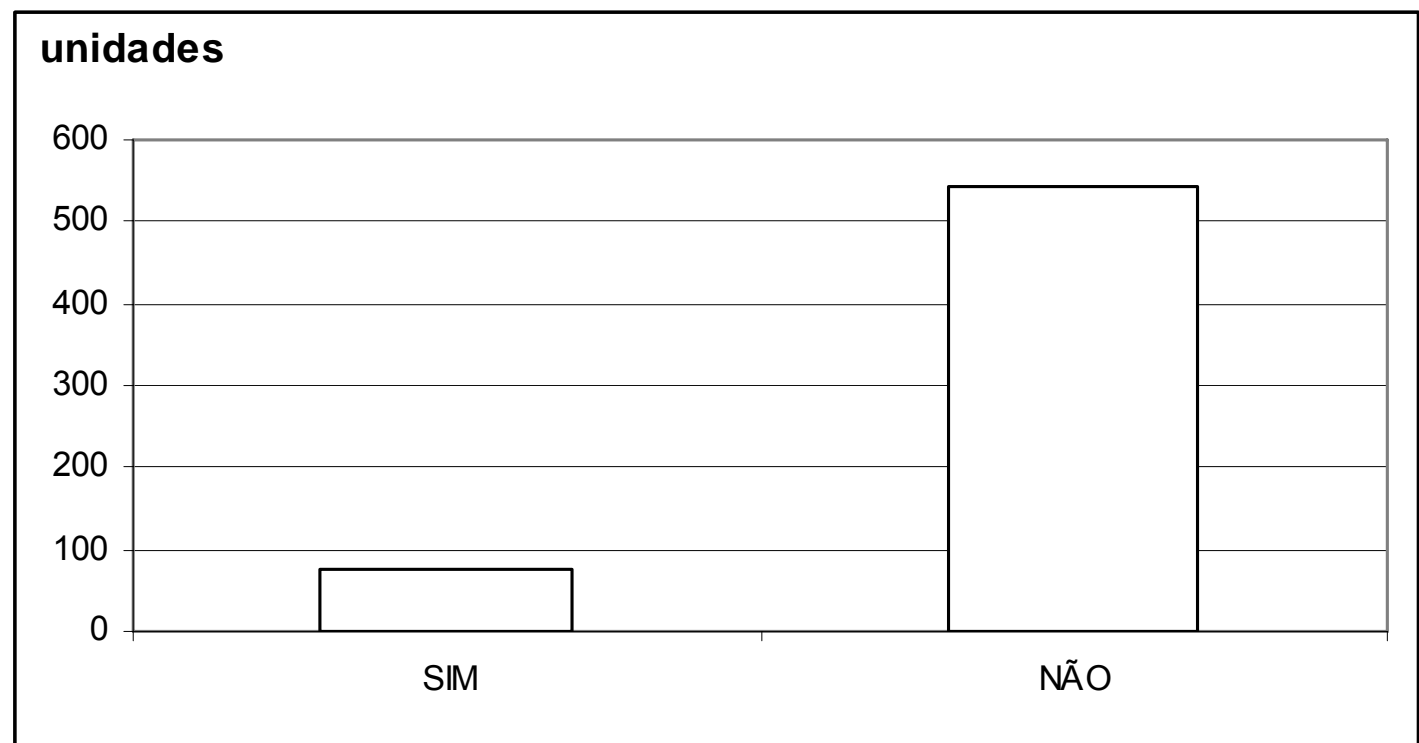


GRÁFICO 7: FREQUÊNCIA DE EXISTÊNCIA DE SAUNA NA AMOSTRA DE PERFIL SÓCIODEMOGRÁFICO BAIXO

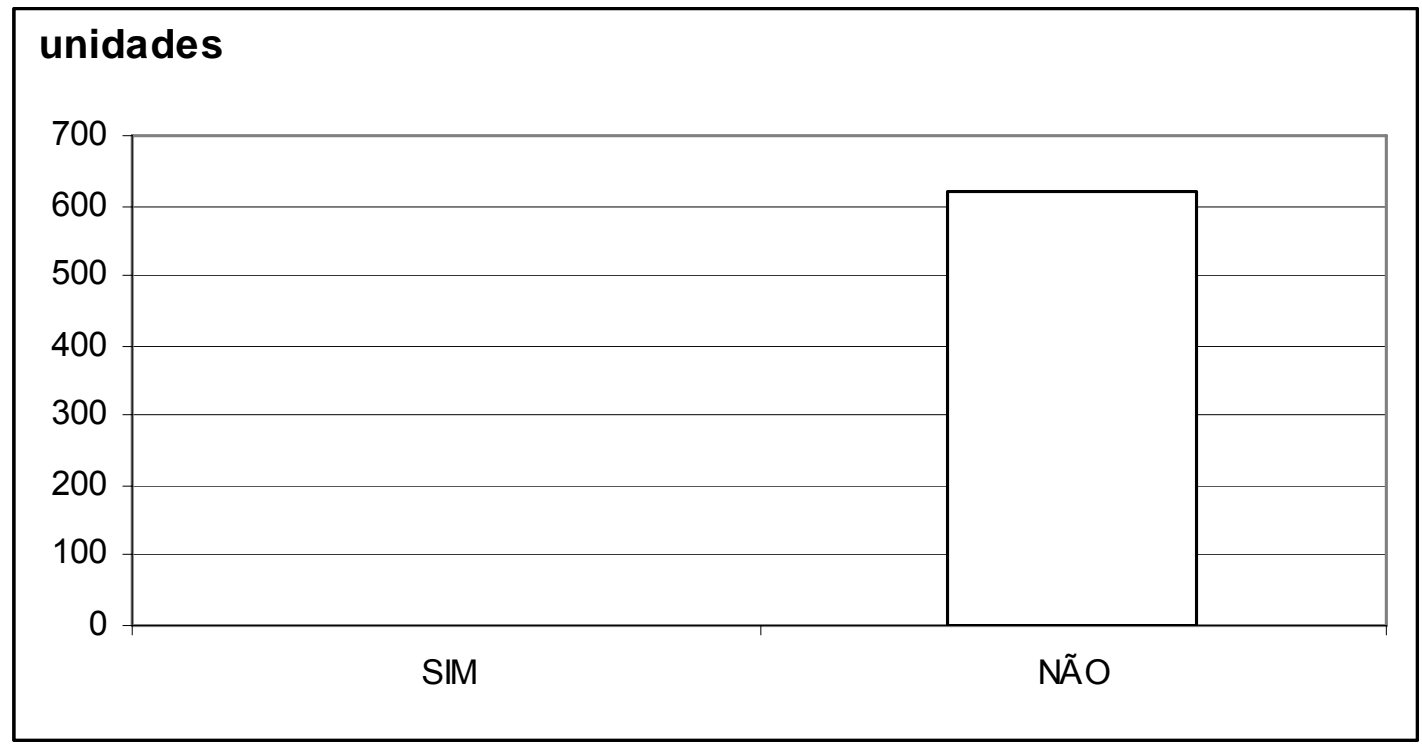

GRÁFICO 8: FREQUÊNCIA DE EXISTÊNCIA DE CHURRASQUEIRA NA AMOSTRA DE PERFIL SÓCIO-DEMOGRÁFICO BAIXO

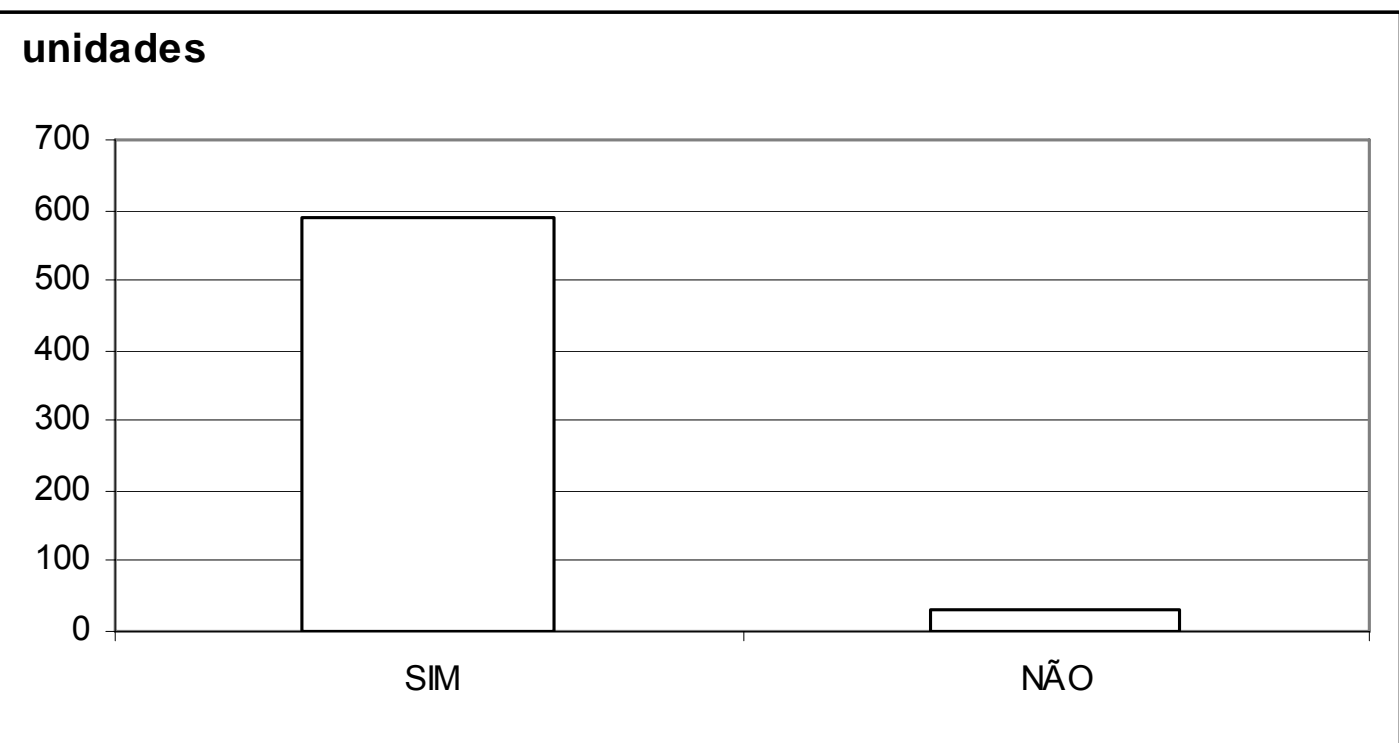


GRÁFICO 9: FREQUÊNCIA DE EXISTÊNCIA DE QUADRA NA AMOSTRA DE PERFIL SÓCIODEMOGRÁFICO BAIXO

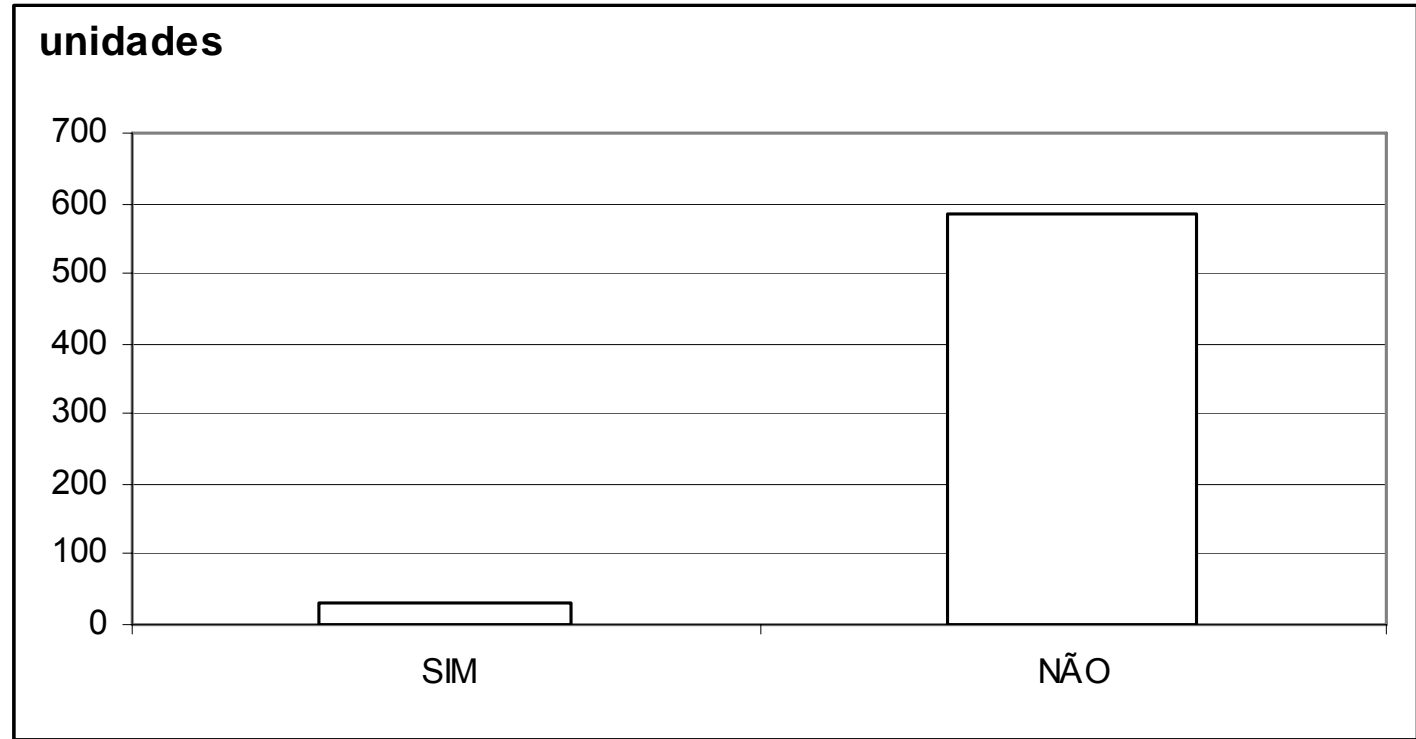

GRÁFICO 10: FREQUÊNCIA DE EXISTÊNCIA DE GUARITA NA AMOSTRA DE PERFIL SÓCIODEMOGRÁFICO BAIXO

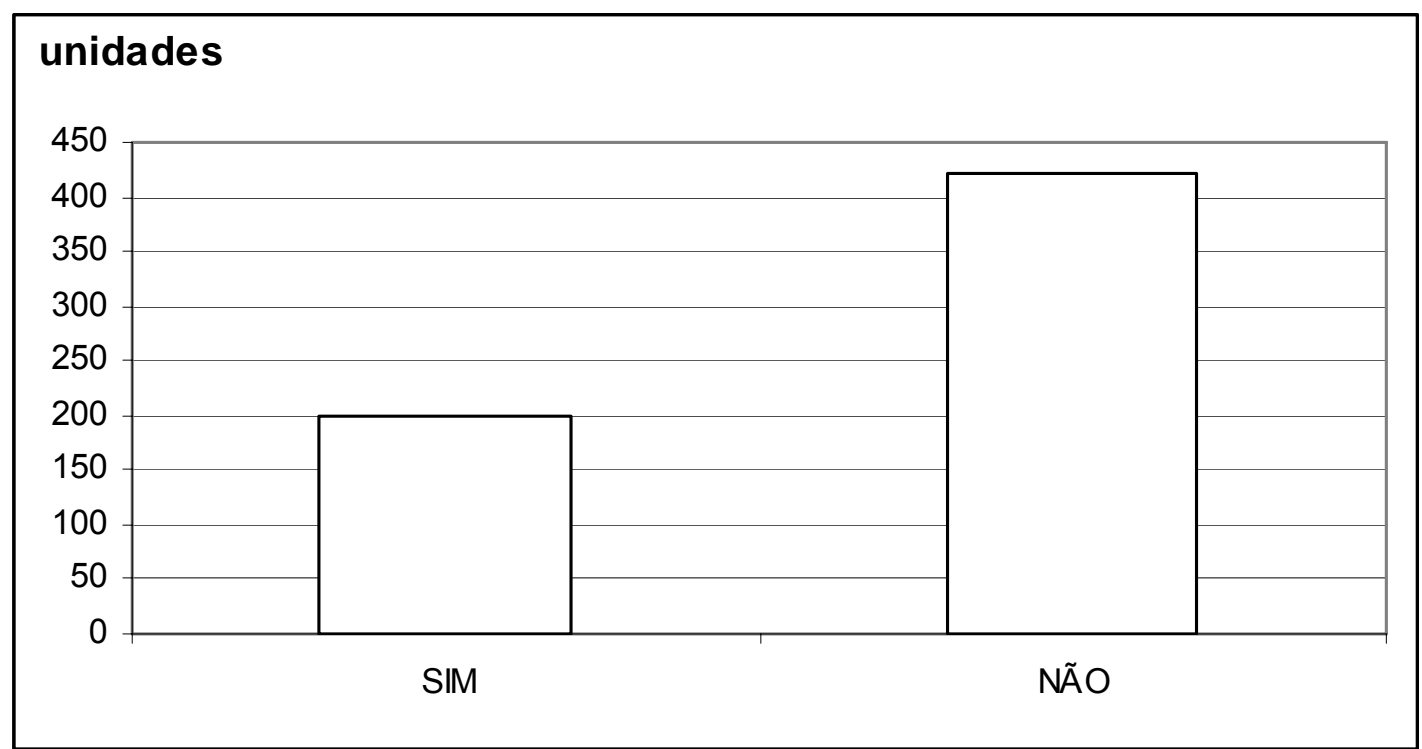


GRÁFICO 11: FREQUÊNCIA DE EXISTÊNCIA DE CFTV NA AMOSTRA DE PERFIL SÓCIODEMOGRÁFICO BAIXO

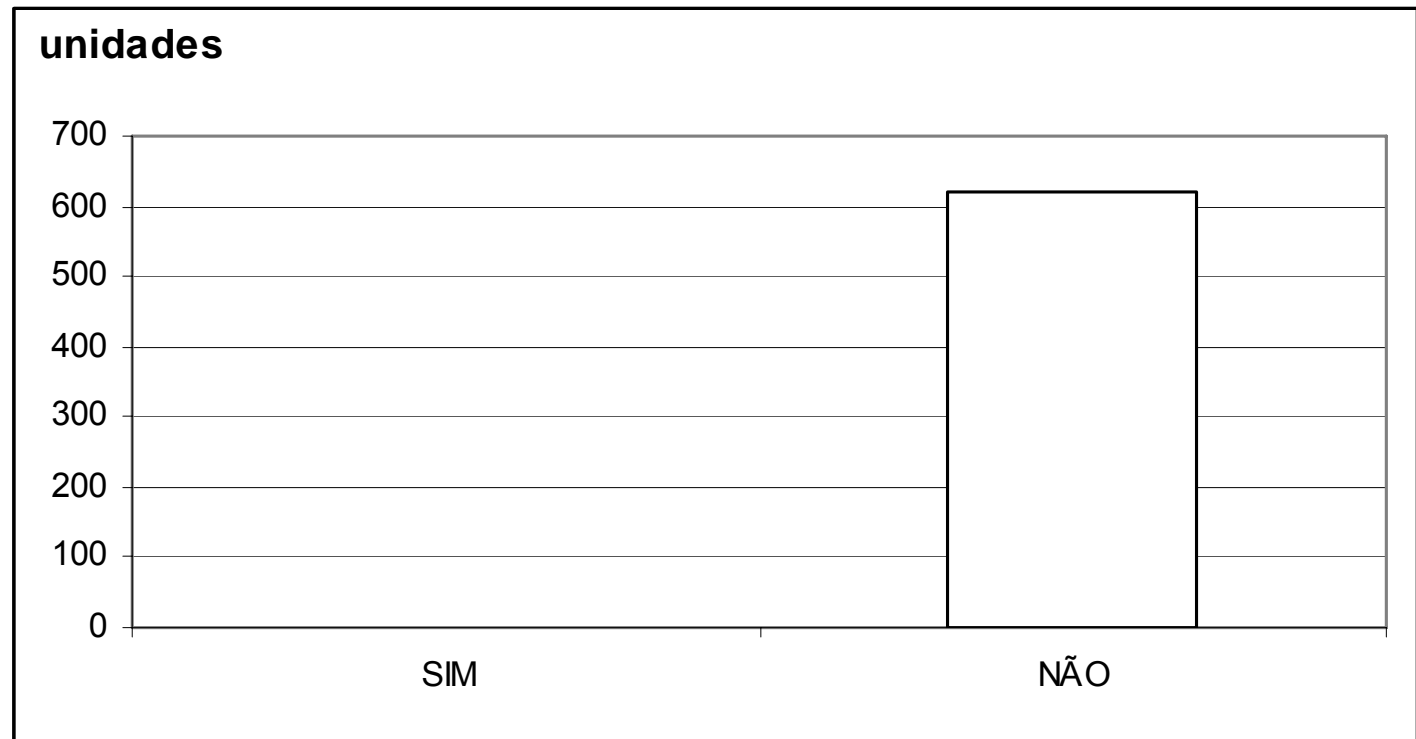

GRÁFICO 12: FREQUÊNCIA DE EXISTÊNCIA DE VARANDA NA AMOSTRA DE PERFIL SÓCIODEMOGRÁFICO BAIXO

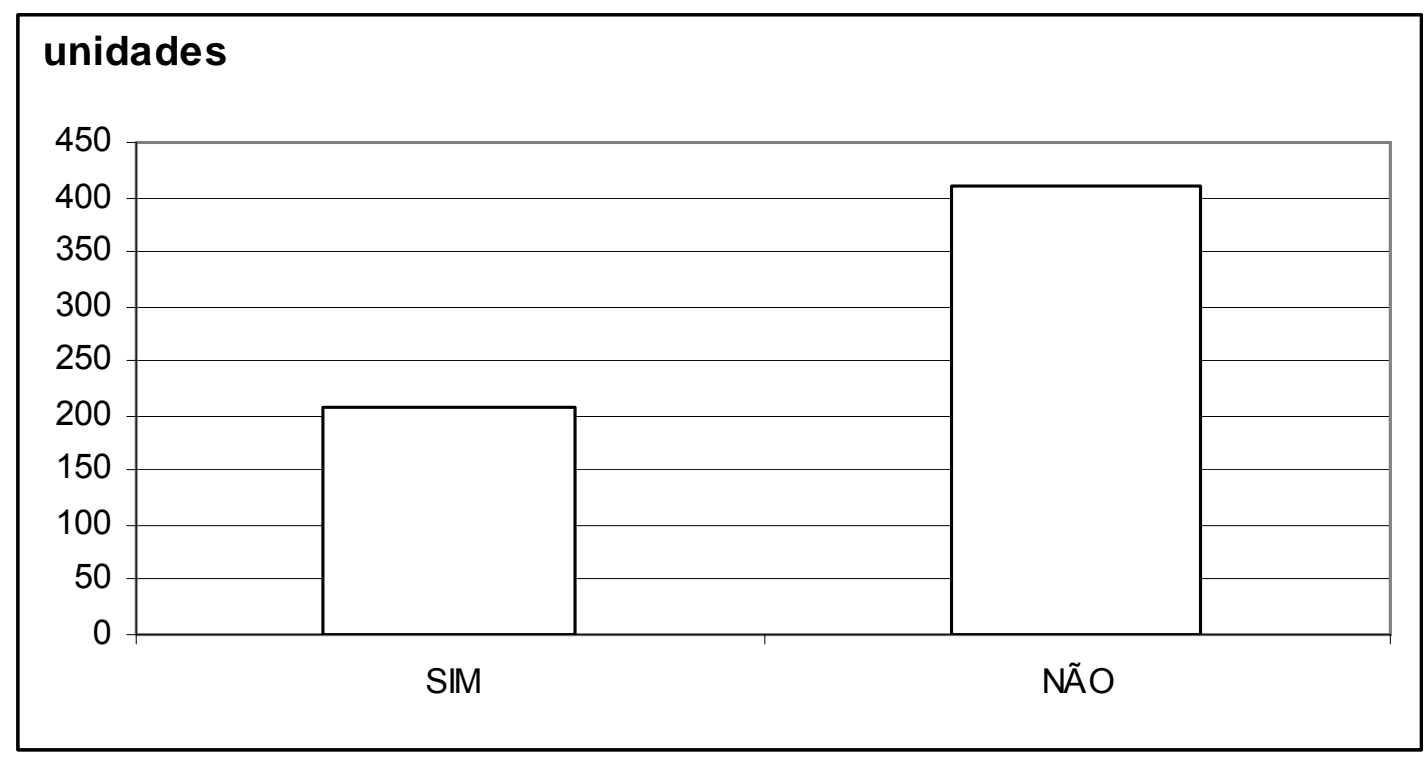


GRÁFICO 13: FREQUÊNCIA DE IMÓVEIS QUE SE ENCONTRAM NA METADE SUPERIOR DO EDIFÍCIO PARA A AMOSTRA DE PERFIL SÓCIO-DEMOGRÁFICO BAIXO

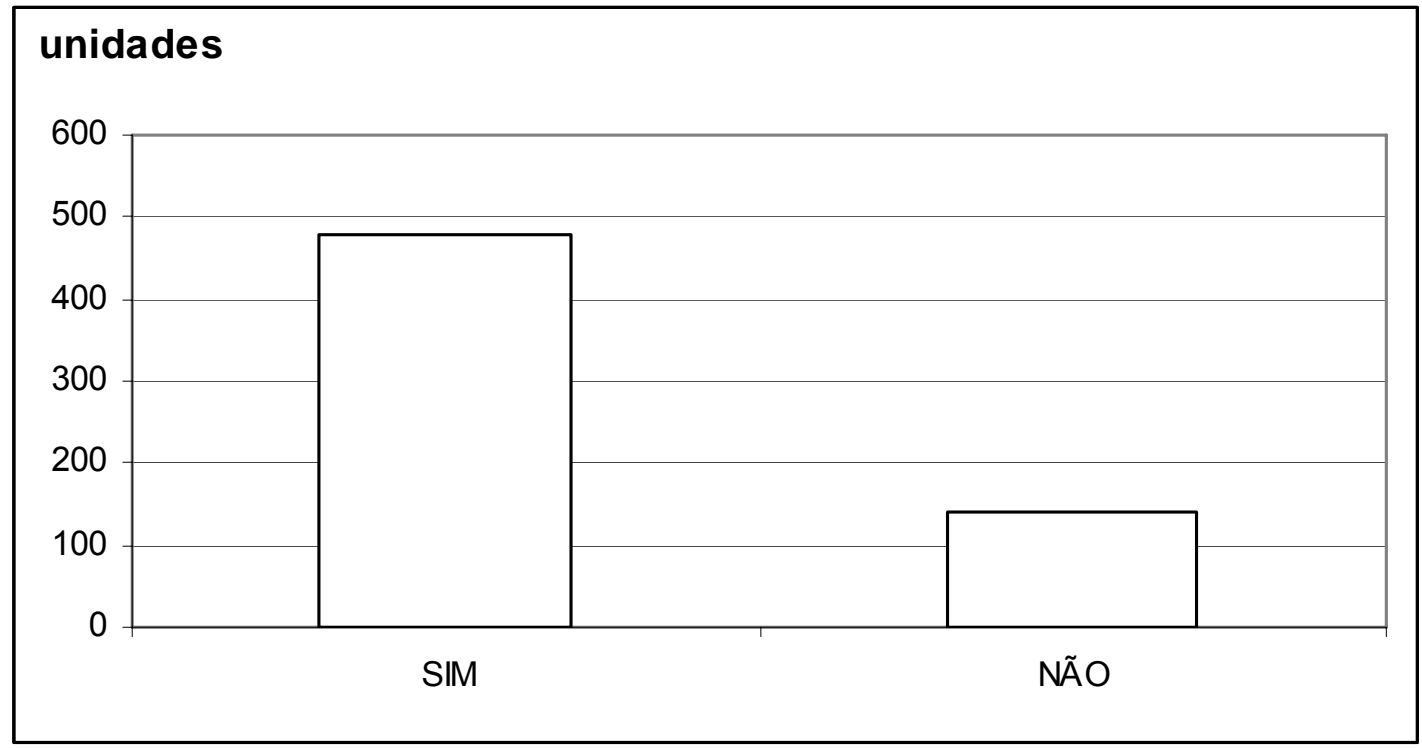

GRÁFICO 14: FREQUÊNCIA DE NÚMERO DE VAGAS NA GARAGEM PARA A AMOSTRA DE PERFIL SÓCIO-DEMOGRÁFICO BAIXO

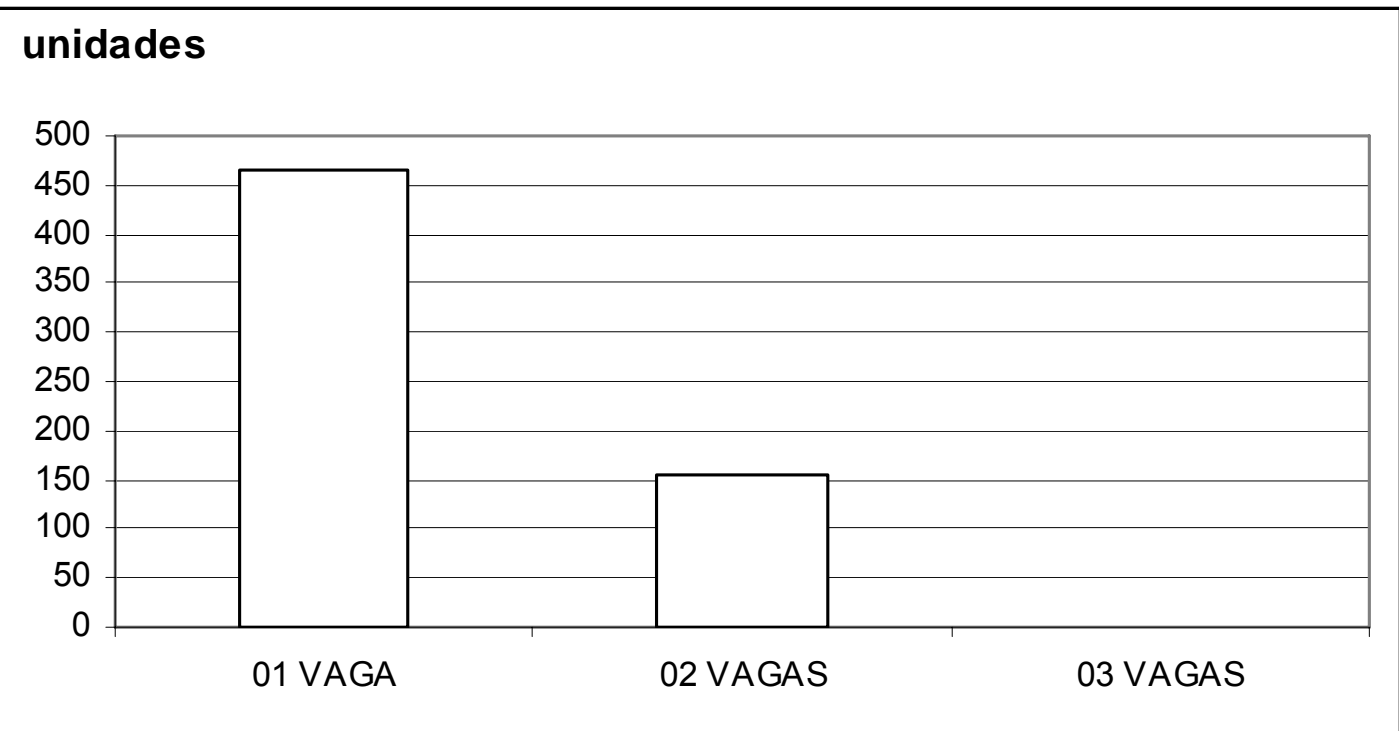


GRÁFICO 15: FREQUÊNCIA DE NÚMERO DE DORMITÓRIOS PARA A AMOSTRA DE PERFIL SÓCIODEMOGRÁFICO BAIXO

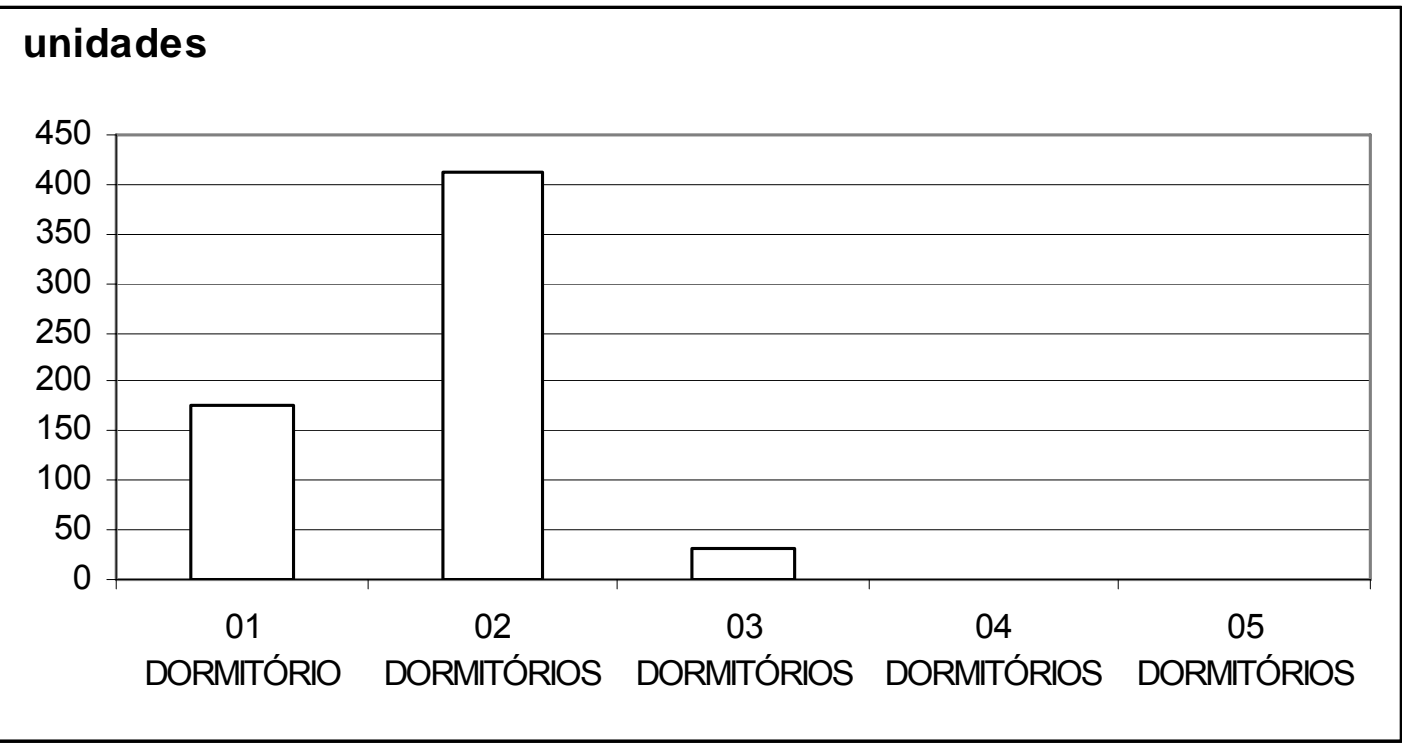

GRÁFICO 16: FREQUÊNCIA DE NÚMERO DE BANHEIROS PARA A AMOSTRA DE PERFIL SÓCIODEMOGRÁFICO BAIXO

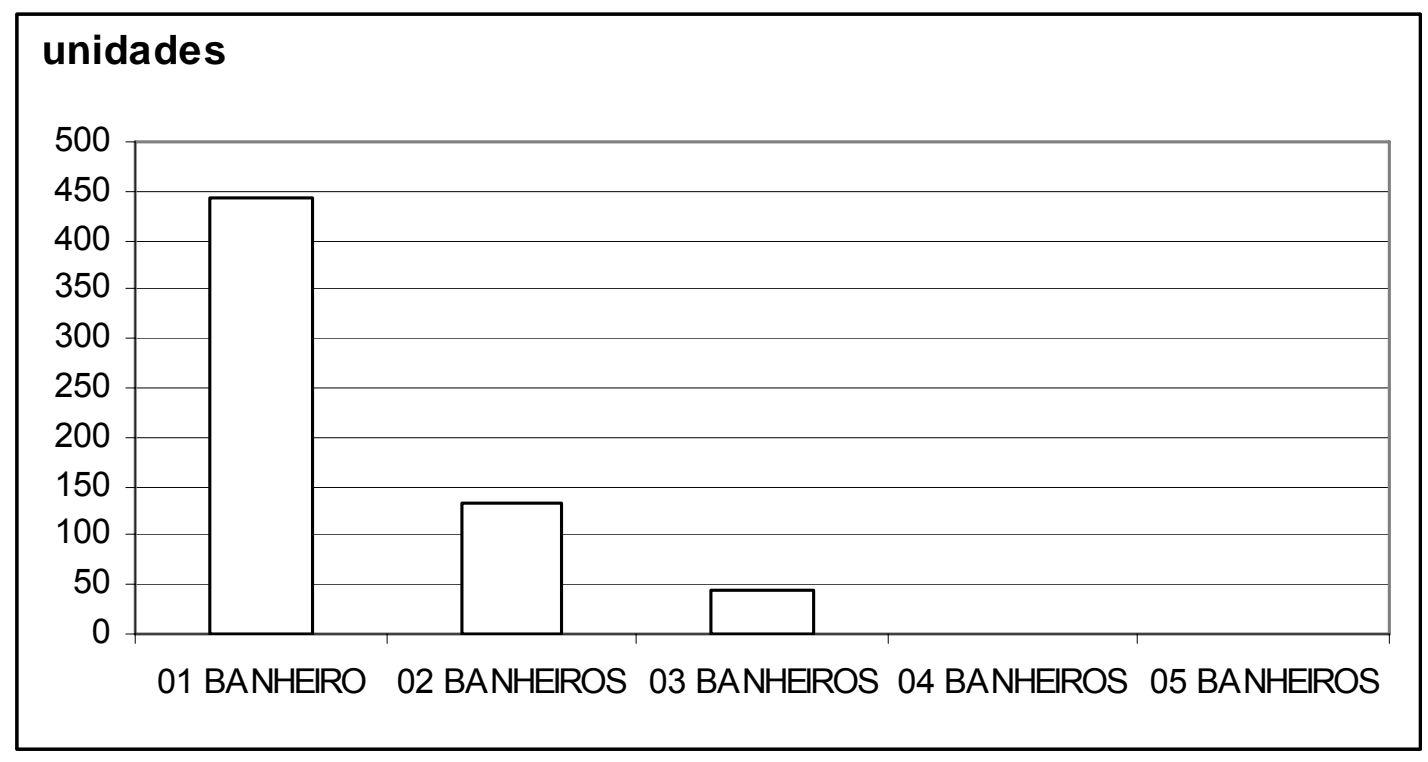


GRÁFICO 17: FREQUÊNCIA DE RENDA FAMILIAR NA AMOSTRA DE PERFIL SÓCIO-DEMOGRÁFICO BAIXO

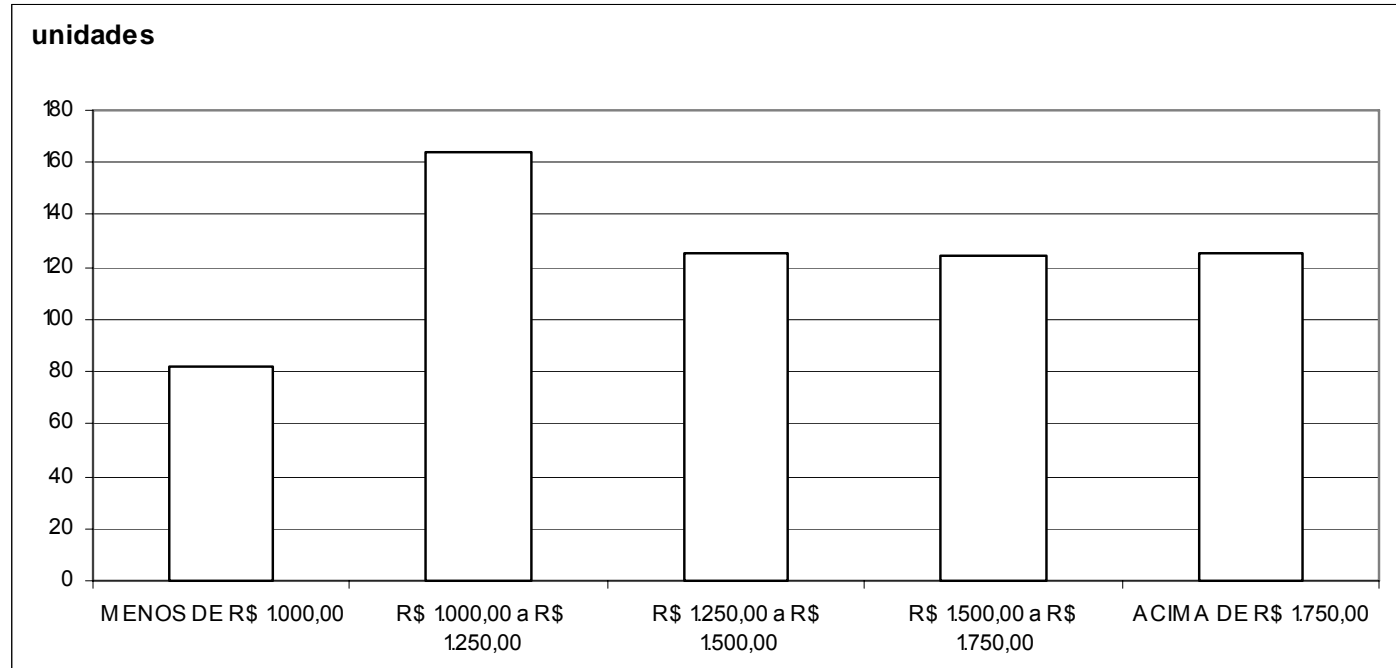

GRÁFICO 18: FREQUÊNCIA DE MEMBROS NA FAMÍLIA NA AMOSTRA DE PERFIL SÓCIODEMOGRÁFICO BAIXO

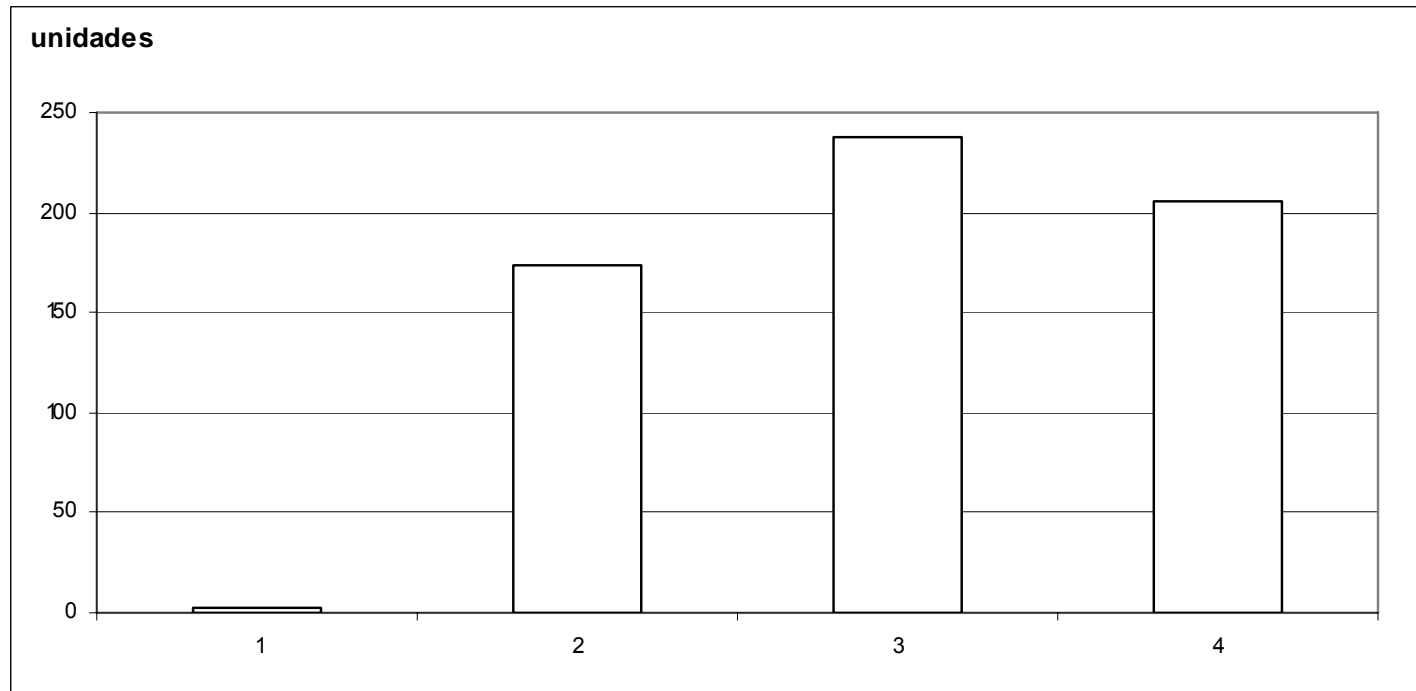


GRÁFICO 19: FREQUÊNCIA DE DENSIDADE DEMOGRÁFICA NA AMOSTRA DE PERFIL SÓCIODEMOGRÁFICO BAIXO

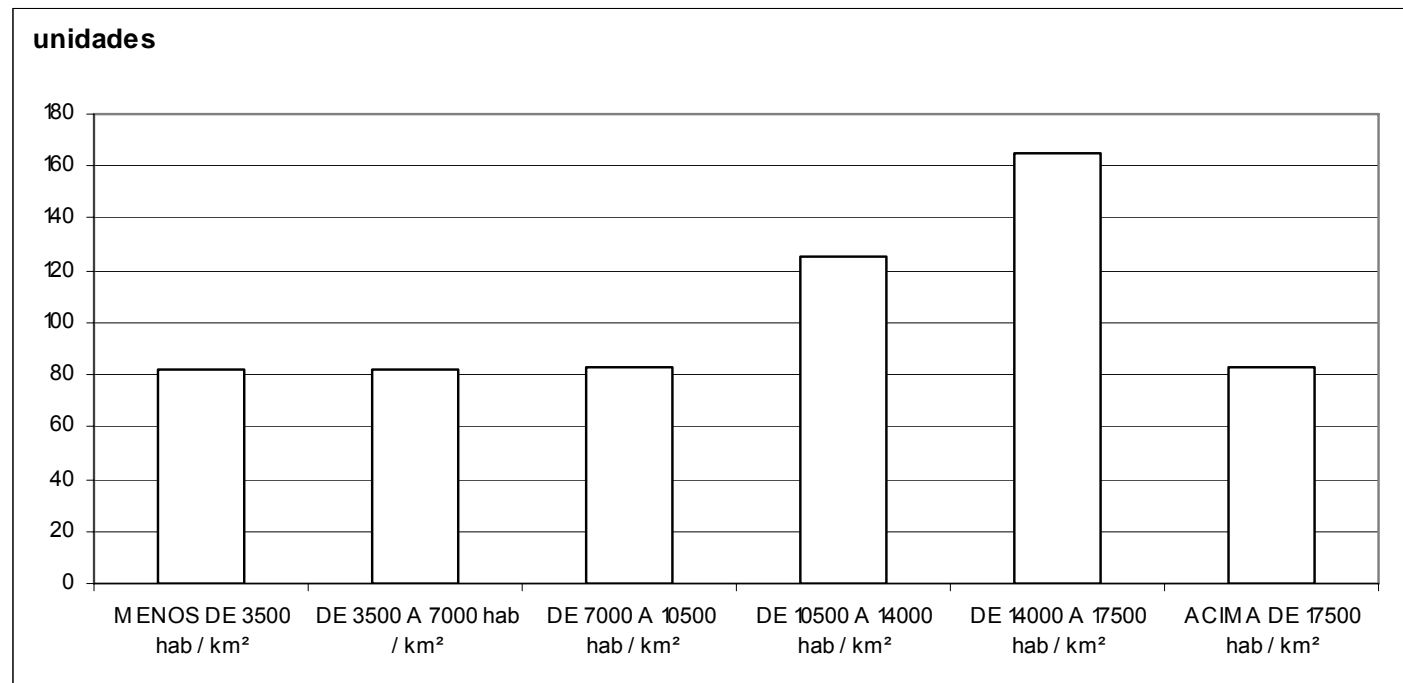

GRÁFICO 20: FREQUÊNCIA DE POPULAÇÃO NA AMOSTRA DE PERFIL SÓCIO-DEMOGRÁFICO BAIXO

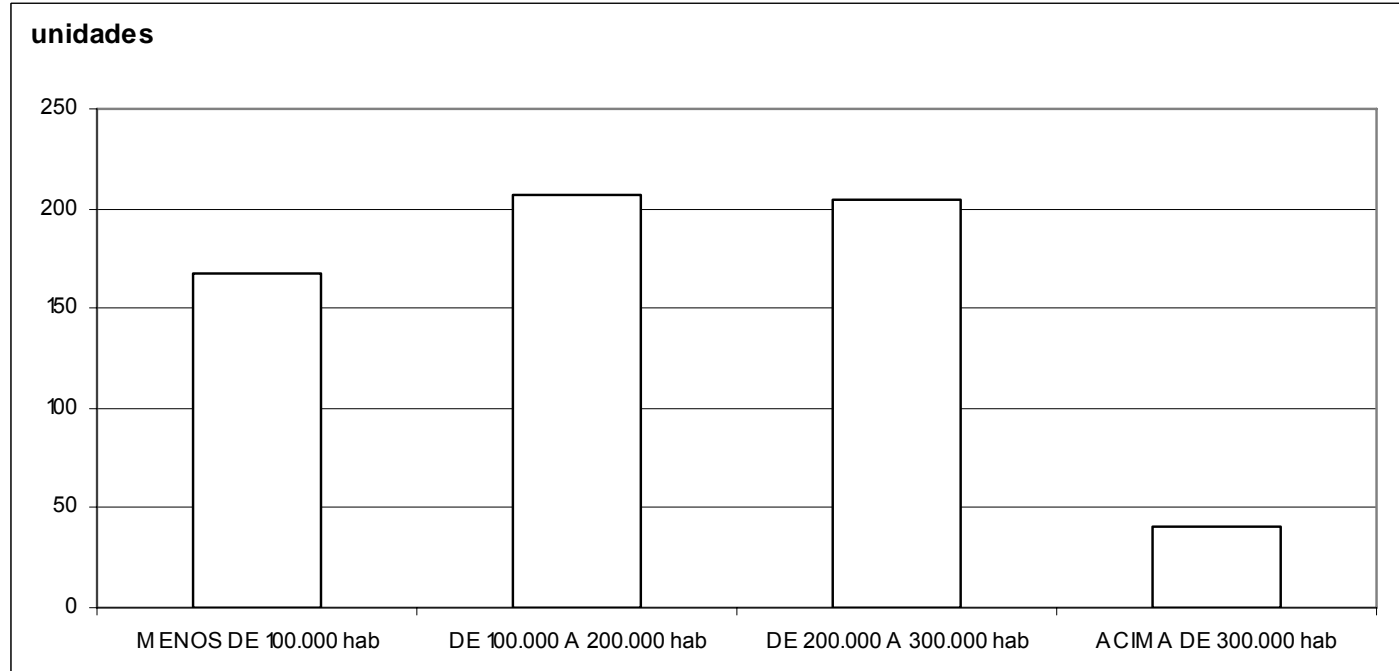


GRÁFICO 21: FREQUÊNCIA DE COLÉGIO PARTICULAR NA AMOSTRA DE PERFIL SÓCIODEMOGRÁFICO BAIXO

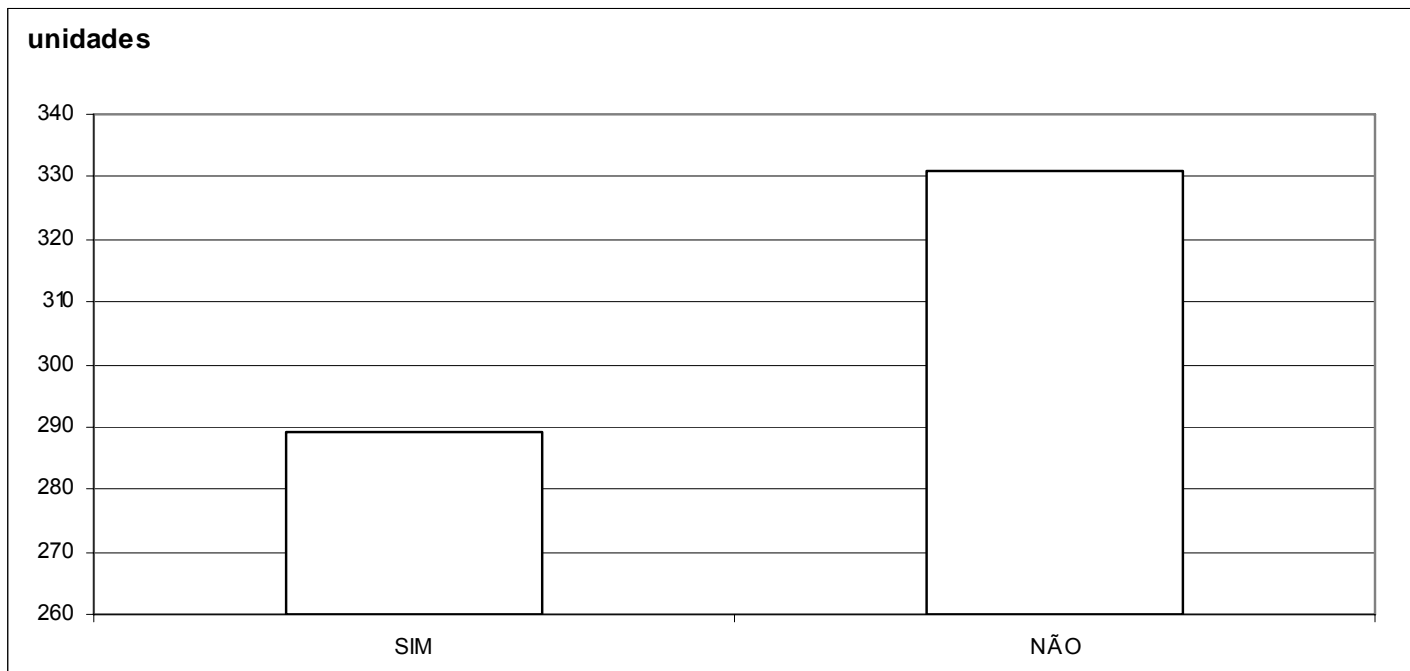

GRÁFICO 22: FREQUÊNCIA DE SHOPPING CENTER NA AMOSTRA DE PERFIL SÓCIODEMOGRÁFICO BAIXO

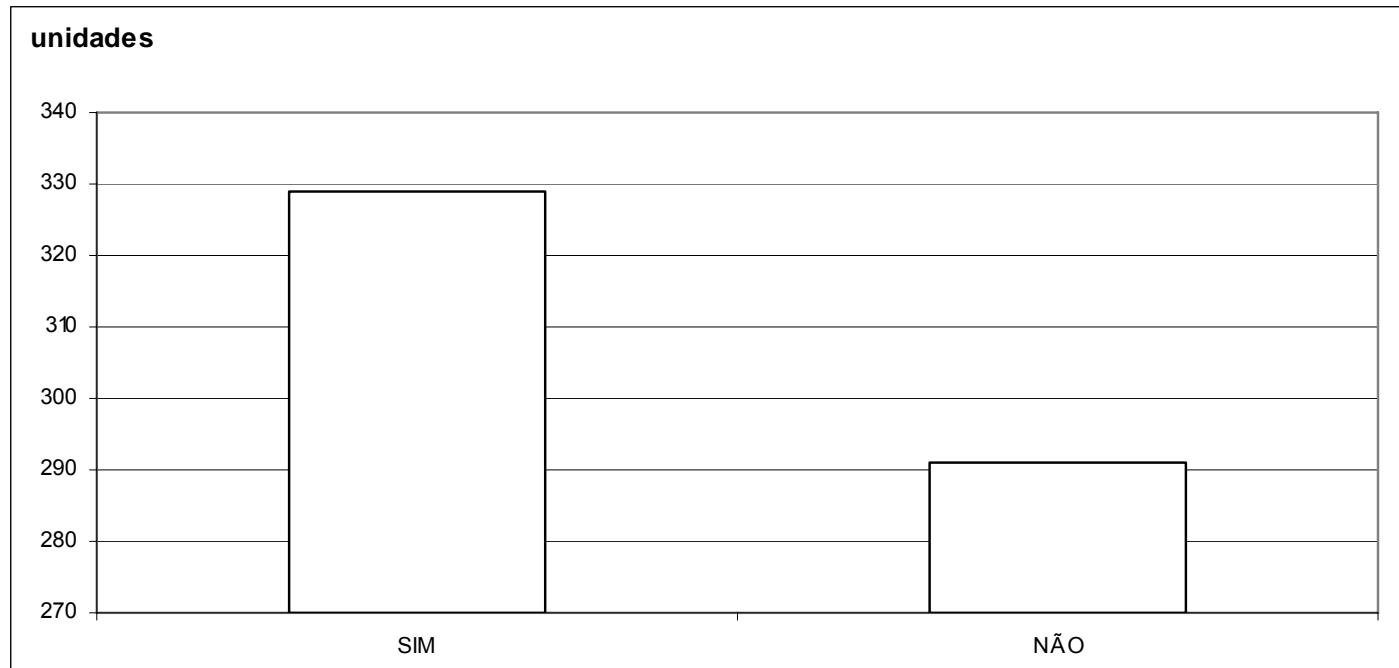


GRÁFICO 23: FREQUÊNCIA DE METRÔ NA AMOSTRA DE PERFIL SÓCIO-DEMOGRÁFICO BAIXO

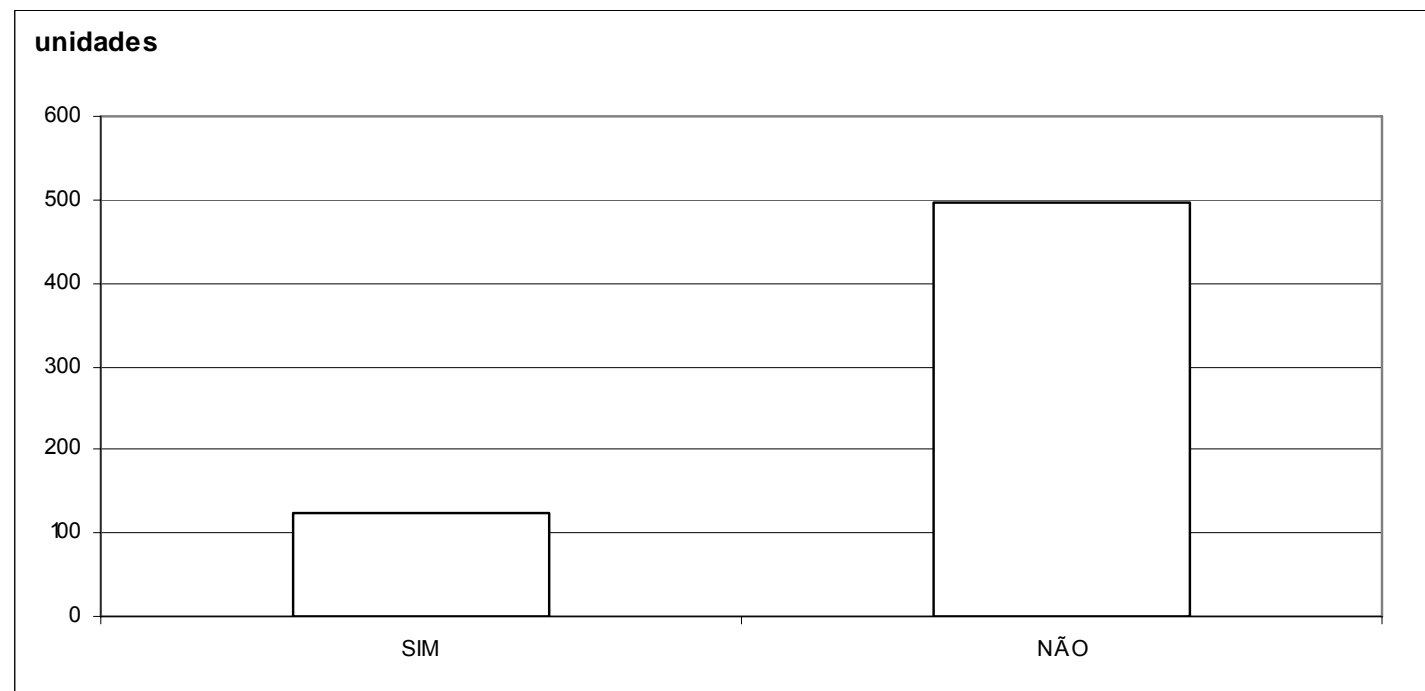

GRÁFICO 24: FREQUÊNCIA DE HOSPITAL PARTICULAR NA AMOSTRA DE PERFIL SÓCIODEMOGRÁFICO BAIXO

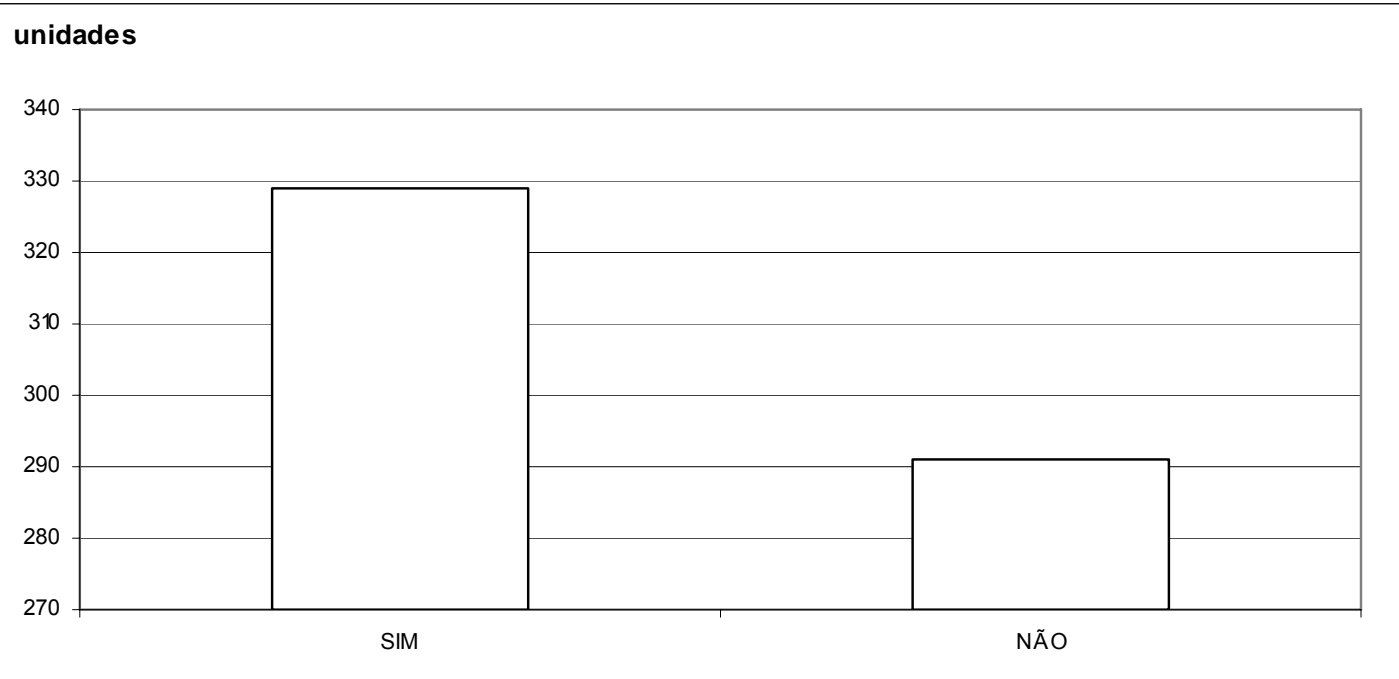


GRÁFICO 25: FREQUÊNCIA DE PARQUES E ÁREAS VERDES NA AMOSTRA DE PERFIL SÓCIODEMOGRÁFICO BAIXO

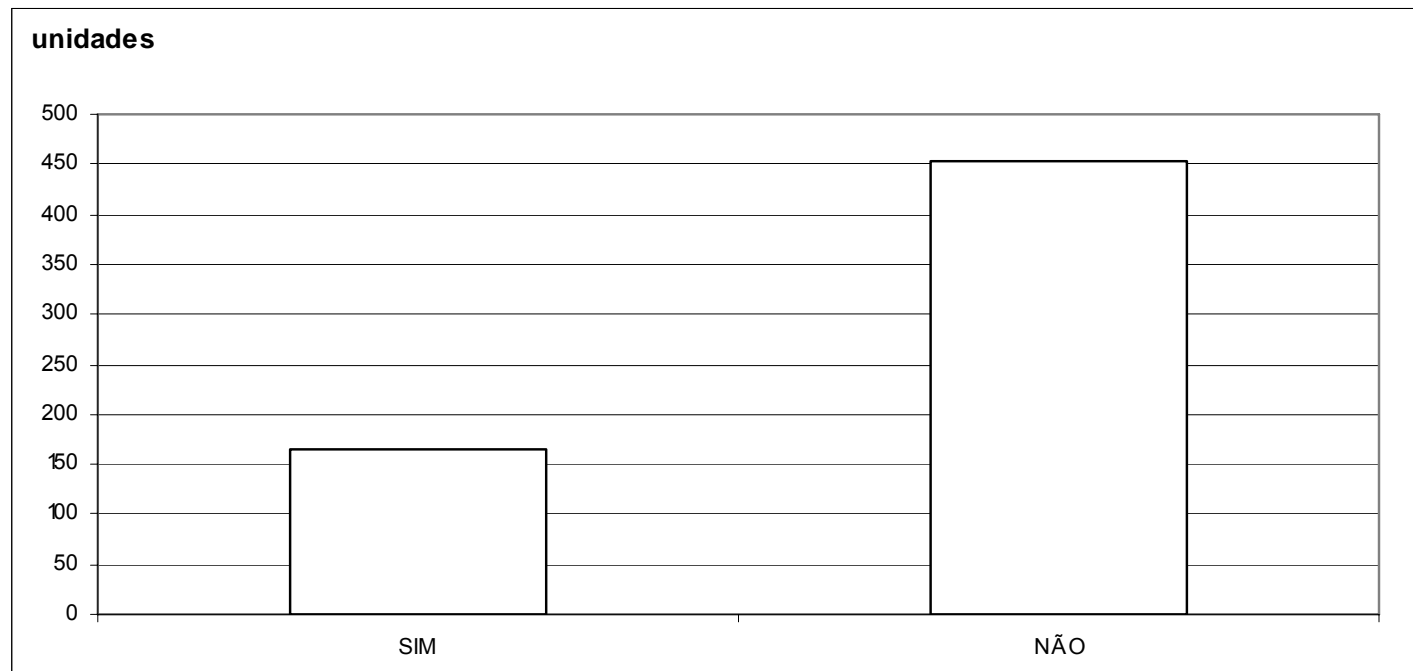

GRÁFICO 26: FREQUÊNCIA DE PONTOS DE INUNDAÇÃO NA AMOSTRA DE PERFIL SÓCIODEMOGRÁFICO BAIXO

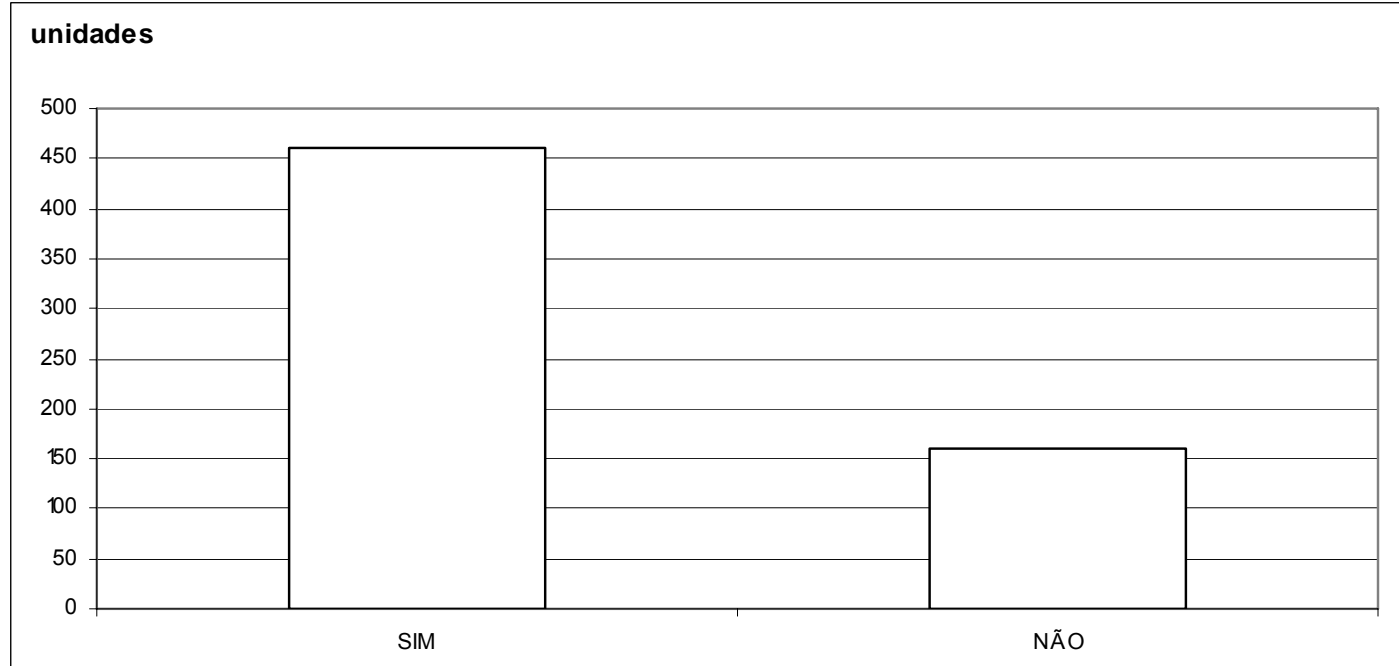


GRÁFICO 27: FREQUÊNCIA DE ATERROS E LIXÕES NA AMOSTRA DE PERFIL SÓCIODEMOGRÁFICO BAIXO

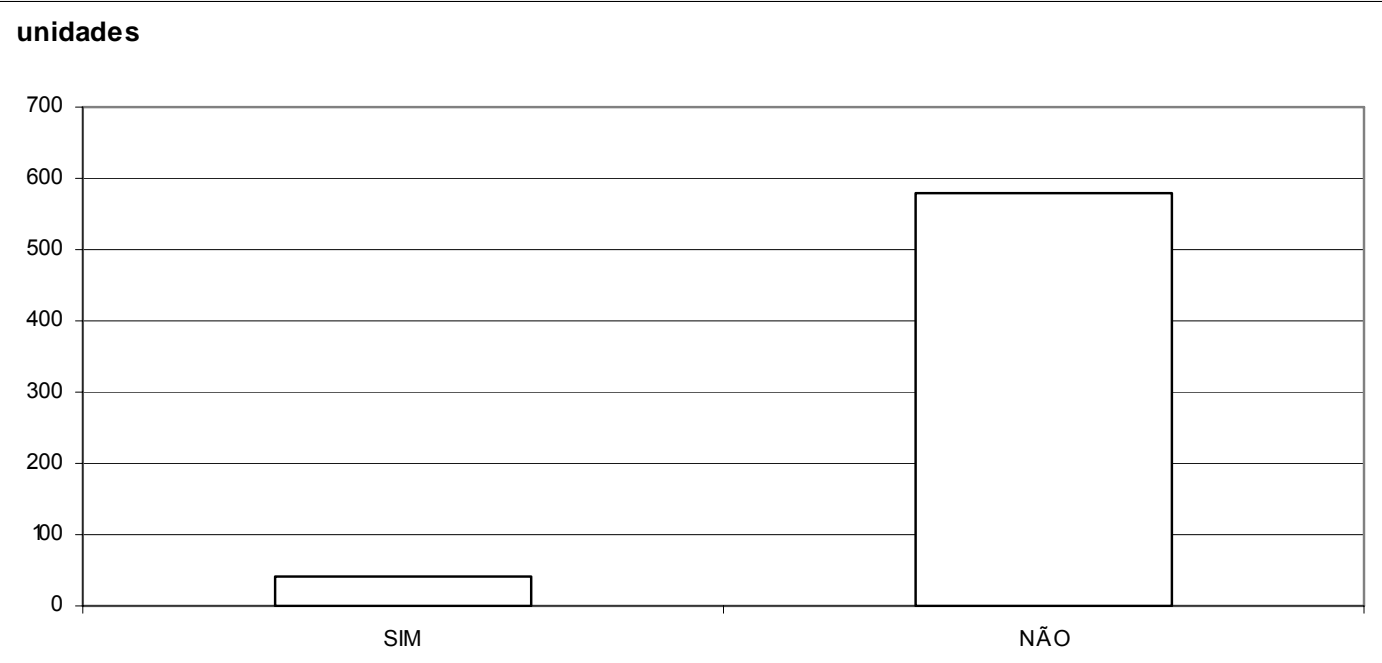




\section{I.2) Resultados do Primeiro Estágio de Rosen}

TABELA 9: VALORES DE R² AJUSTADOS RESULTANTES DO MÉTODO DE BOX-COX COM AS VARIAÇÕES DE $\theta$ E $\lambda$ PARA O PERFIL SÓCIO-DEMOGRÁFICO BAIXO

\begin{tabular}{|c|c|c|c|c|c|c|c|c|c|c|c|}
\hline \multirow{2}{*}{\multicolumn{2}{|c|}{ Box-Cox }} & \multicolumn{10}{|c|}{$\theta$} \\
\hline & & 0,0 & 0,1 & 0,2 & 0,3 & 0,4 & 0,5 & 0,6 & 0,7 & 0,8 & 0,9 \\
\hline \multirow{13}{*}{$\lambda$} & 0,0 & 0,9898 & 0,9881 & 0,9865 & 0,9855 & 0,9840 & 0,9822 & 0,9804 & 0,9789 & 0,9770 & 0,9758 \\
\hline & 0,1 & 0,9888 & 0,9861 & 0,9845 & 0,9835 & 0,9820 & 0,9802 & 0,9784 & 0,9769 & 0,9750 & 0,9738 \\
\hline & 0,2 & 0,9880 & 0,9831 & 0,9815 & 0,9805 & 0,9792 & 0,9772 & 0,9754 & 0,9739 & 0,9720 & 0,9708 \\
\hline & 0,3 & 0,9867 & 0,9791 & 0,9785 & 0,9765 & 0,9751 & 0,9730 & 0,9714 & 0,9699 & 0,9680 & 0,9668 \\
\hline & 0,4 & 0,9858 & 0,9741 & 0,9735 & 0,9713 & 0,9700 & 0,9680 & 0,9664 & 0,9651 & 0,9630 & 0,9618 \\
\hline & 0,5 & 0,9850 & 0,9681 & 0,9675 & 0,9653 & 0,9641 & 0,9622 & 0,9604 & 0,9591 & 0,9570 & 0,9558 \\
\hline & 0,6 & 0,9841 & 0,9611 & 0,9610 & 0,9582 & 0,9541 & 0,9552 & 0,9534 & 0,9521 & 0,9499 & 0,9487 \\
\hline & 0,7 & 0,9832 & 0,9531 & 0,9530 & 0,9502 & 0,9461 & 0,9472 & 0,9454 & 0,9440 & 0,9419 & 0,9407 \\
\hline & 0,8 & 0,9828 & 0,9441 & 0,9445 & 0,9411 & 0,9372 & 0,9380 & 0,9363 & 0,9350 & 0,9329 & 0,9313 \\
\hline & 0,9 & 0,9820 & 0,9341 & 0,9345 & 0,9311 & 0,9272 & 0,9280 & 0,9263 & 0,9250 & 0,9222 & 0,9213 \\
\hline & 1,0 & 0,9811 & 0,9231 & 0,9235 & 0,9200 & 0,9167 & 0,9160 & 0,9150 & 0,9140 & 0,9112 & 0,9103 \\
\hline & 2,0 & 0,9800 & 0,9111 & 0,9115 & 0,9080 & 0,9100 & 0,9031 & 0,9030 & 0,9020 & 0,8992 & 0,8983 \\
\hline & 3,0 & 0,9799 & 0,9109 & 0,9029 & 0,8950 & 0,8944 & 0,8929 & 0,8900 & 0,8890 & 0,8862 & 0,8853 \\
\hline
\end{tabular}

TABELA 10: RESULTADOS DA REGRESSÃO PARA A ESPECIFICAÇÃO LOGARÍTMICA - MÉTODO ENTER - PERFIL SÓCIO-DEMOGRÁFICO BAIXO

\begin{tabular}{c|c|c|c|c}
\hline Variável & $\begin{array}{c}\text { Coeficiente Não } \\
\text { Padronizado }\end{array}$ & $\begin{array}{c}\text { Coeficiente } \\
\text { Padronizado }\end{array}$ & Estatística t & $\begin{array}{c}\text { Nível de } \\
\text { Significância }\end{array}$ \\
\hline (Constante) & 10,5700 & & 677,904 & 0,000 \\
\hline LNAREA & 0,1290 & 0,213 & 32,812 & 0,000 \\
\hline SFES & 0,0421 & 0,118 & 8,717 & 0,000 \\
\hline SJOG & 0,0294 & 0,031 & 4,520 & 0,000 \\
\hline PISC & 0,0175 & 0,034 & 5,715 & 0,000 \\
\hline CHUR & 0,1540 & 0,198 & 25,675 & 0,000 \\
\hline QUAD & 0,0087 & 0,012 & 1,817 & 0,070 \\
\hline GUAR & 0,0857 & 0,240 & 11,179 & 0,000 \\
\hline VARD & 0,0148 & 0,042 & 3,191 & 0,001 \\
\hline ALTR & $-0,0071$ & $-0,018$ & $-3,727$ & 0,000 \\
\hline VAGA1 & 0,0461 & 0,119 & 11,721 & 0,000 \\
\hline DORM1 & 0,0570 & 0,154 & 8,269 & 0,000 \\
\hline DORM2 & 0,1150 & 0,155 & 14,289 & 0,000 \\
\hline BANH1 & 0,0216 & 0,053 & 6,043 & 0,000 \\
\hline BANH2 & 0,0655 & 0,101 & 16,164 & 0,000 \\
\hline
\end{tabular}

$\mathrm{R}^{2}$ ajustado: 0,9898

Estatística F: 4328,594

Prob. (Est. F): 0,000

Durbin-Watson: 1,842 


\section{I.3) Resultados do Segundo Estágio de Rosen}

TABELA 11: ESTIMAÇÃO DA EQUAÇÃO DE DEMANDA: SEGUNDO ESTÁGIO DE ROSEN - MÉTODO ENTER - PERFIL SÓCIO-DEMOGRÁFICO BAIXO

\begin{tabular}{|c|c|c|c|c|}
\hline Variável & $\begin{array}{c}\text { Coeficiente Não } \\
\text { Padronizado }\end{array}$ & $\begin{array}{l}\text { Coeficiente } \\
\text { Padronizado }\end{array}$ & Estatística t & $\begin{array}{c}\text { Nível de } \\
\text { Significância }\end{array}$ \\
\hline (Constante) & 662,850 & & 120,513 & 0,000 \\
\hline LNAREA & $-130,988$ & $-1,332$ & $-158,332$ & 0,000 \\
\hline SFES & 5,071 & 0,087 & 4,289 & 0,000 \\
\hline SJOG & 4,656 & 0,030 & 2,921 & 0,004 \\
\hline PISC & 1,576 & 0,019 & 2,302 & 0,022 \\
\hline CHUR & 18,971 & 0,150 & 13,187 & 0,000 \\
\hline QUAD & 4,603 & 0,038 & 3,974 & 0,000 \\
\hline GUAR & 8,611 & 0,148 & 4,780 & 0,000 \\
\hline VARD & 5,332 & 0,093 & 4,885 & 0,000 \\
\hline ALTR & $-0,113$ & $-0,002$ & $-0,238$ & 0,812 \\
\hline VAGA1 & 3,132 & 0,050 & 3,262 & 0,001 \\
\hline DORM1 & 10,872 & 0,180 & 6,878 & 0,000 \\
\hline DORM2 & 17,752 & 0,146 & 9,567 & 0,000 \\
\hline BANH1 & 4,035 & 0,061 & 4,552 & 0,000 \\
\hline BANH2 & 11,755 & 0,111 & 11,859 & 0,000 \\
\hline COLP & 2,218 & 0,041 & 4,367 & 0,000 \\
\hline SHOP & 0,475 & 0,009 & 0,955 & 0,340 \\
\hline METR & 2,733 & 0,040 & 3,654 & 0,000 \\
\hline HOSP & 0,892 & 0,016 & 1,499 & 0,134 \\
\hline PARQ & 0,319 & 0,005 & 0,841 & 0,401 \\
\hline INUN & $-1,027$ & $-0,017$ & $-1,992$ & 0,047 \\
\hline ATER & 0,008 & 0,000 & 0,011 & 0,991 \\
\hline LNRND & 2,531 & 0,031 & 3,914 & 0,000 \\
\hline LNMEMB & 1,749 & 0,018 & 2,401 & 0,017 \\
\hline
\end{tabular}

$\mathrm{R}^{2}$ ajustado: 0,9836

Estatística F: 1616,144

Prob. (Est. F): 0,000

Durbin-Watson: 1,954 
TABELA 12: ESTIMAÇÃO DA EQUAÇÃO DE OFERTA: SEGUNDO ESTÁGIO DE ROSEN - MÉTODO ENTER - PERFIL SÓCIO-DEMOGRÁFICO BAIXO

\begin{tabular}{|c|c|c|c|c|}
\hline Variável & $\begin{array}{c}\text { Coeficiente Não } \\
\text { Padronizado }\end{array}$ & $\begin{array}{c}\text { Coeficiente } \\
\text { Padronizado }\end{array}$ & Estatística t & $\begin{array}{c}\text { Nível de } \\
\text { Significância }\end{array}$ \\
\hline (Constante) & 640,278 & & 97,288 & 0,000 \\
\hline LNAREA & $-130,319$ & $-1,325$ & $-166,823$ & 0,000 \\
\hline SFES & 4,014 & 0,069 & 3,553 & 0,000 \\
\hline SJOG & 7,853 & 0,051 & 5,185 & 0,000 \\
\hline PISC & 3,620 & 0,044 & 5,352 & 0,000 \\
\hline CHUR & 19,456 & 0,153 & 14,438 & 0,000 \\
\hline QUAD & 0,999 & 0,008 & 0,862 & 0,389 \\
\hline GUAR & 13,695 & 0,235 & 7,698 & 0,000 \\
\hline VARD & 7,325 & 0,127 & 7,136 & 0,000 \\
\hline ALTR & $-0,837$ & $-0,013$ & $-1,859$ & 0,063 \\
\hline VAGA1 & 0,403 & 0,006 & 0,420 & 0,674 \\
\hline DORM1 & 7,031 & 0,117 & 4,687 & 0,000 \\
\hline DORM2 & 16,474 & 0,136 & 9,620 & 0,000 \\
\hline BANH1 & 3,593 & 0,054 & 4,286 & 0,000 \\
\hline BANH2 & 11,727 & 0,111 & 12,699 & 0,000 \\
\hline COLP & 1,086 & 0,020 & 2,123 & 0,034 \\
\hline SHOP & $-0,749$ & $-0,014$ & $-1,082$ & 0,280 \\
\hline METR & 0,606 & 0,009 & 0,685 & 0,494 \\
\hline HOSP & 1,577 & 0,029 & 2,882 & 0,004 \\
\hline PARQ & 0,099 & 0,002 & 0,278 & 0,781 \\
\hline INUN & $-0,720$ & $-0,012$ & $-1,511$ & 0,131 \\
\hline ATER & $-2,441$ & $-0,022$ & $-3,145$ & 0,002 \\
\hline LNDENS & 2,586 & 0,076 & 9,852 & 0,000 \\
\hline LNPOP & 1,663 & 0,037 & 3,772 & 0,000 \\
\hline
\end{tabular}

$R^{2}$ ajustado: 0,9850

Estatística F: 1812,580

Prob. (Est. F): 0,000

Durbin-Watson: 1,854 
TABELA 13: EQUAÇÕES DE DEMANDA E OFERTA - MÉTODO STEPWISE - PERFIL SÓCIODEMOGRÁFICO BAIXO

\begin{tabular}{|c|c|c|c|c|}
\hline Equação & \multicolumn{2}{|c|}{ Demanda } & \multicolumn{2}{|c|}{ Oferta } \\
\hline Variável & $\begin{array}{c}\text { Coeficiente Não } \\
\text { Padronizado }\end{array}$ & $\begin{array}{c}\text { Coeficiente } \\
\text { Padronizado* }\end{array}$ & $\begin{array}{c}\text { Coeficiente Não } \\
\text { Padronizado }\end{array}$ & $\begin{array}{c}\text { Coeficiente } \\
\text { Padronizado* }\end{array}$ \\
\hline (Constante) & 664,035 & & 637,299 & \\
\hline LNAREA & $-130,827$ & $-1,330$ & $-130,398$ & $-1,326$ \\
\hline SFES & 4,501 & 0,077 & 3,417 & 0,059 \\
\hline SJOG & 5,277 & 0,034 & 8,953 & 0,058 \\
\hline PISC & 1,867 & 0,023 & 4,532 & 0,055 \\
\hline CHUR & 19,192 & 0,151 & 19,226 & 0,152 \\
\hline QUAD & 4,990 & 0,041 & & \\
\hline GUAR & 9,708 & 0,166 & 14,416 & 0,247 \\
\hline VARD & 5,633 & 0,098 & 6,503 & 0,113 \\
\hline VAGA1 & 3,194 & 0,051 & & \\
\hline DORM1 & 9,671 & 0,160 & 6,945 & 0,115 \\
\hline DORM2 & 16,308 & 0,135 & 17,191 & 0,142 \\
\hline BANH1 & 4,283 & 0,064 & 4,699 & 0,071 \\
\hline BANH2 & 11,392 & 0,108 & 11,084 & 0,105 \\
\hline COLP & 2,485 & 0,046 & 1,511 & 0,028 \\
\hline METR & 2,138 & 0,031 & & \\
\hline INUN & $-1,423$ & $-0,023$ & & \\
\hline ATER & & & $-2,447$ & $-0,022$ \\
\hline LNRND & 2,665 & 0,032 & & \\
\hline LNDENS & & & 2,822 & 0,083 \\
\hline LNPOP & & & 1,722 & 0,038 \\
\hline & $\begin{array}{l}\mathrm{R}^{2} \text { ajustado: } 0,98 \\
\text { Estatística F: } 217 \\
\text { Prob. (Est. F): 0,0 } \\
\text { Durbin-Watson: } 1 \\
{ }^{*} \text { estatística t a } 5 \%\end{array}$ & 292 & $\begin{array}{l}\mathrm{R}^{2} \text { ajustado: 0,98 } \\
\text { Estatística F: } 272 \\
\text { Prob. (Est. F): 0,c } \\
\text { Durbin-Watson: } 1 \\
{ }^{*} \text { estatística t a } 5\end{array}$ & \\
\hline
\end{tabular}




\section{I.4) Resultados da Correlação Canônica}

TABELA 14: TESTES MULTIVARIADOS DE SIGNIFICÂNCIA PARA A EQUAÇÃO DE DEMANDA PERFIL SÓCIO-DEMOGRÁFICO BAIXO

\begin{tabular}{l|c|c|c|c}
\hline \multicolumn{1}{c|}{ Teste } & Valor & Aprox. F & Erro DF & Sig. F \\
\hline Pillais & 2,839 & 625,774 & 1806,00 & 0,000 \\
\hline Hottelings & 117,884 & 1383,798 & 1796,00 & 0,000 \\
\hline Wilks & 0,000 & 1012,898 & 1787,10 & 0,000 \\
\hline Roys & 0,985 & & & \\
\hline
\end{tabular}

TABELA 15: TESTES MULTIVARIADOS DE SIGNIFICÂNCIA PARA A EQUAÇÃO DE OFERTA - PERFIL SÓCIO-DEMOGRÁFICO BAIXO

\begin{tabular}{l|c|c|c|c}
\hline \multicolumn{1}{c|}{ Teste } & Valor & Aprox. F & Erro DF & Sig. F \\
\hline Pillais & 2,837 & 701,133 & 1812,00 & 0,000 \\
\hline Hottelings & 119,182 & 1590,859 & 1802,00 & 0,000 \\
\hline Wilks & 0,000 & 1140,048 & 1789,17 & 0,000 \\
\hline Roys & 0,986 & & & \\
\hline
\end{tabular}

TABELA 16: CORRELAÇÕES CANÔNICAS E AUTOVALORES PARA A EQUAÇÃO DE DEMANDA PERFIL SÓCIO-DEMOGRÁFICO BAIXO

\begin{tabular}{c|c|c|c}
\hline Raiz & Autovalor & Cor. Canônica & Cor. Quad. \\
\hline 1 & 66,165 & 0,993 & 0,985 \\
\hline 2 & 44,648 & 0,989 & 0,978 \\
\hline 3 & 7,072 & 0,936 & 0,876 \\
\hline
\end{tabular}

TABELA 17: CORRELAÇÕES CANÔNICAS E AUTOVALORES PARA A EQUAÇÃO DE OFERTA PERFIL SÓCIO-DEMOGRÁFICO BAIXO

\begin{tabular}{c|c|c|c}
\hline Raiz & Autovalor & Cor. Canônica & Cor. Quad. \\
\hline 1 & 62,060 & 0,993 & 0,987 \\
\hline 2 & 32,016 & 0,987 & 0,974 \\
\hline 3 & 5,924 & 0,936 & 0,876 \\
\hline
\end{tabular}


TABELA 18: TESTE UNIVARIADO DE SIGNIFICÂNCIA PARA AS FUNÇÕES CANÔNICAS DA EQUAÇÃO DE DEMANDA - PERFIL SÓCIO-DEMOGRÁFICO BAIXO

\begin{tabular}{c|c|c|c}
\hline Raiz & Wilks $L$. & Erro DF & Sig. F \\
\hline 1 to 3 & 0,000 & 1787,10 & 0,000 \\
\hline 2 to 3 & 0,002 & 1202,00 & 0,000 \\
\hline 3 to 3 & 0,123 & 602,00 & 0,000 \\
\hline
\end{tabular}

TABELA 19: TESTE UNIVARIADO DE SIGNIFICÂNCIA PARA AS FUNÇÕES CANÔNICAS DA EQUAÇÃO DE OFERTA - PERFIL SÓCIO-DEMOGRÁFICO BAIXO

\begin{tabular}{c|c|c|c}
\hline Raiz & Wilks L. & Erro DF & Sig. F \\
\hline 1 to 3 & 0,000 & 1789,17 & 0,000 \\
\hline 2 to 3 & 0,003 & 1206,00 & 0,000 \\
\hline 3 to 3 & 0,124 & 604,00 & 0,000 \\
\hline
\end{tabular}

TABELA 20: PESOS CANÔNICOS PADRONIZADOS PARA A PRIMEIRA FUNÇÃO CANÔNICA VARIÁVEIS DEPENDENTES - EQUAÇÃO DE DEMANDA - PERFIL SÓCIODEMOGRÁFICO BAIXO

\begin{tabular}{c|c}
\hline Variável & FUNÇÃO 1 \\
\hline DPDAREA & 0,876 \\
\hline $\mathrm{C}$ & $-0,190$ \\
\hline $\mathrm{V}$ & $-0,108$ \\
\hline
\end{tabular}

TABELA 21: PESOS CANÔNICOS PADRONIZADOS PARA A PRIMEIRA FUNÇÃO CANÔNICA VARIÁVEIS DEPENDENTES - EQUAÇÃO DE OFERTA - PERFIL SÓCIO-DEMOGRÁFICO BAIXO

\begin{tabular}{c|c}
\hline Variável & FUNÇÃO 1 \\
\hline DPDAREA & 0,890 \\
\hline C & $-0,160$ \\
\hline V & $-0,116$ \\
\hline
\end{tabular}


TABELA 22: PESOS CANÔNICOS PADRONIZADOS PARA A PRIMEIRA FUNÇÃO CANÔNICA VARIÁVEIS INDEPENDENTES - EQUAÇÃO DE DEMANDA - PERFIL SÓCIODEMOGRÁFICO BAIXO

\begin{tabular}{|c|c|}
\hline Variável & FUNÇÃO 1 \\
\hline LNAREA & $-1,178$ \\
\hline SFES & 0,194 \\
\hline SJOG & 0,033 \\
\hline PISC & 0,002 \\
\hline CHUR & 0,007 \\
\hline QUAD & 0,027 \\
\hline GUAR & $-0,068$ \\
\hline VARD & $-0,020$ \\
\hline VAGA1 & 0,031 \\
\hline DORM1 & 0,236 \\
\hline DORM2 & 0,148 \\
\hline BANH1 & $-0,054$ \\
\hline BANH2 & 0,053 \\
\hline COLP & 0,024 \\
\hline METR & 0,016 \\
\hline INUN & $-0,019$ \\
\hline LNRND & 0,042 \\
\hline
\end{tabular}

TABELA 23: PESOS CANÔNICOS PADRONIZADOS PARA A PRIMEIRA FUNÇÃO CANÔNICA VARIÁVEIS INDEPENDENTES - EQUAÇÃO DE OFERTA - PERFIL SÓCIODEMOGRÁFICO BAIXO

\begin{tabular}{c|c}
\hline Variável & FUNÇÃO 1 \\
\hline LNAREA & $-1,191$ \\
\hline SFES & 0,181 \\
\hline SJOG & 0,049 \\
\hline PISC & 0,029 \\
\hline CHUR & 0,018 \\
\hline GUAR & 0,05 \\
\hline VARD & $-0,009$ \\
\hline DORM1 & 0,201 \\
\hline DORM2 & 0,155 \\
\hline BANH1 & $-0,044$ \\
\hline BANH2 & 0,051 \\
\hline COLP & 0,016 \\
\hline ATER & $-0,014$ \\
\hline LNDENS & 0,074 \\
\hline LNPOP & 0,024 \\
\hline
\end{tabular}


TABELA 24: CORRELAÇÕES ENTRE AS VARIÁVEIS DEPENDENTES E AS VARIÁVEIS CANÔNICAS EQUAÇÃO DE DEMANDA - PERFIL SÓCIO-DEMOGRÁFICO BAIXO

\begin{tabular}{c|c}
\hline Variável & FUNÇÃO 1 \\
\hline DPDAREA & 0,959 \\
\hline $\mathrm{C}$ & $-0,577$ \\
\hline $\mathrm{V}$ & $-0,464$ \\
\hline
\end{tabular}

TABELA 25: CORRELAÇÕES ENTRE AS VARIÁVEIS DEPENDENTES E AS VARIÁVEIS CANÔNICAS EQUAÇÃO DE OFERTA - PERFIL SÓCIO-DEMOGRÁFICO BAIXO

\begin{tabular}{c|c}
\hline Variável & FUNÇÃO 1 \\
\hline DPDAREA & 0,965 \\
\hline $\mathrm{C}$ & $-0,558$ \\
\hline $\mathrm{V}$ & $-0,445$ \\
\hline
\end{tabular}


TABELA 26: CORRELAÇÕES ENTRE AS VARIÁVEIS INDEPENDENTES E AS VARIÁVEIS CANÔNICAS - EQUAÇÃO DE DEMANDA - PERFIL SÓCIO-DEMOGRÁFICO BAIXO

\begin{tabular}{c|c}
\hline Variável & FUNÇÃO 1 \\
\hline LNAREA & $-0,949$ \\
\hline SFES & $-0,347$ \\
\hline SJOG & 0,489 \\
\hline PISC & $-0,115$ \\
\hline CHUR & $-0,601$ \\
\hline QUAD & $-0,063$ \\
\hline GUAR & $-0,846$ \\
\hline VARD & $-0,789$ \\
\hline VAGA1 & $-0,864$ \\
\hline DORM1 & $-0,642$ \\
\hline DORM2 & $-0,058$ \\
\hline BANH1 & $-0,307$ \\
\hline BANH2 & $-0,072$ \\
\hline COLP & 0,004 \\
\hline METR & $-0,003$ \\
\hline INUN & $-0,158$ \\
\hline LNRND & $-0,128$ \\
\hline
\end{tabular}

TABELA 27: CORRELAÇÕES ENTRE AS VARIÁVEIS INDEPENDENTES E AS VARIÁVEIS CANÔNICAS - EQUAÇÃO DE OFERTA - PERFIL SÓCIO-DEMOGRÁFICO BAIXO

\begin{tabular}{c|c}
\hline Variável & FUNÇÃO 1 \\
\hline LNAREA & $-0,943$ \\
\hline SFES & $-0,333$ \\
\hline SJOG & 0,490 \\
\hline PISC & $-0,486$ \\
\hline CHUR & $-0,590$ \\
\hline GUAR & $-0,856$ \\
\hline VARD & $-0,799$ \\
\hline DORM1 & $-0,651$ \\
\hline DORM2 & $-0,392$ \\
\hline BANH1 & $-0,293$ \\
\hline BANH2 & $-0,063$ \\
\hline COLP & 0,004 \\
\hline ATER & $-0,077$ \\
\hline LNDENS & $-0,124$ \\
\hline LNPOP & 0,058 \\
\hline
\end{tabular}


TABELA 28: ÍNDICE DE REDUNDÂNCIA - PERFIL SÓCIO-DEMOGRÁFICO BAIXO

\begin{tabular}{c|c|c|c}
\hline \multirow{2}{*}{ DEMANDA } & $\begin{array}{c}\text { Média var. compart. } \\
\text { no próprio conjunto }\end{array}$ & $\begin{array}{c}\text { Correlação ao } \\
\text { quadrado }\end{array}$ & $\begin{array}{c}\text { Índice de } \\
\text { redundância }\end{array}$ \\
\cline { 2 - 4 } & 0,489 & 0,985 & 0,482 (Dep.) \\
\hline \multirow{2}{*}{ OFERTA } & 0,251 & 0,985 & 0,247 (Indep.) \\
\cline { 2 - 4 } & 0,480 & 0,987 & 0,474 (Dep.) \\
\hline
\end{tabular}




\section{J) PERFIL SÓCIO-DEMOGRÁFICO MÉDIO}

\section{J.1) Caracterização da Amostra}

GRÁFICO 28: FREQUÊNCIA DE PREÇOS NA AMOSTRA DE PERFIL SÓCIO-DEMOGRÁFICO MÉDIO

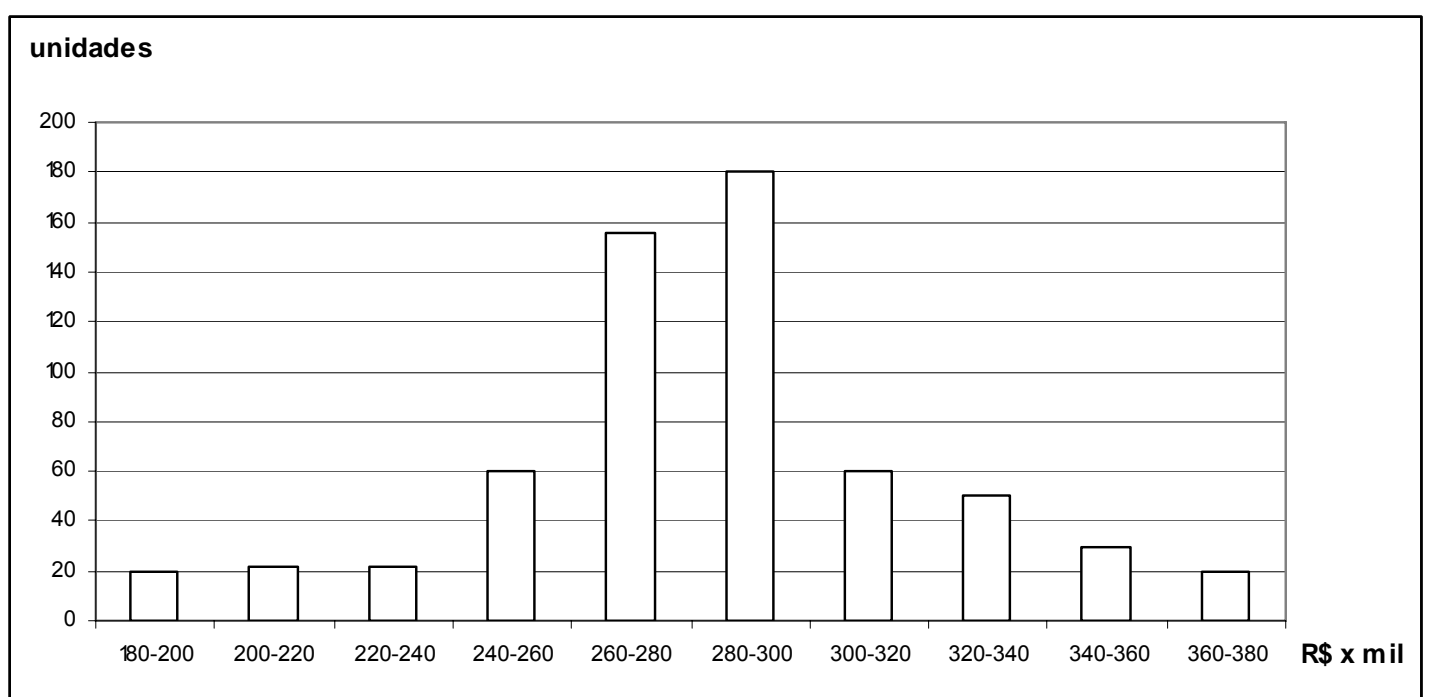

GRÁFICO 29: FREQUÊNCIA DE ÁREA TOTAL NA AMOSTRA DE PERFIL SÓCIO-DEMOGRÁFICO MÉDIO

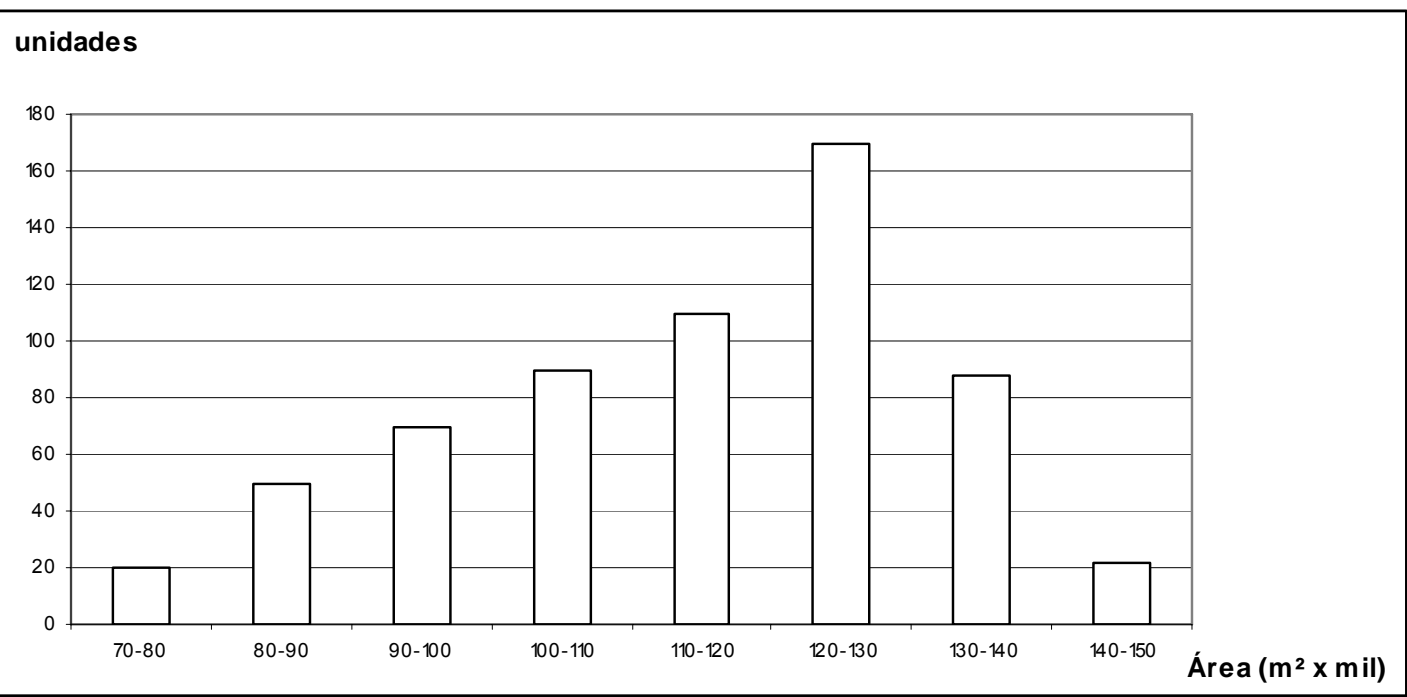


GRÁFICO 30: FREQUÊNCIA DE EXISTÊNCIA DE SALÃO DE FESTAS NA AMOSTRA DE PERFIL SÓCIO-DEMOGRÁFICO MÉDIO

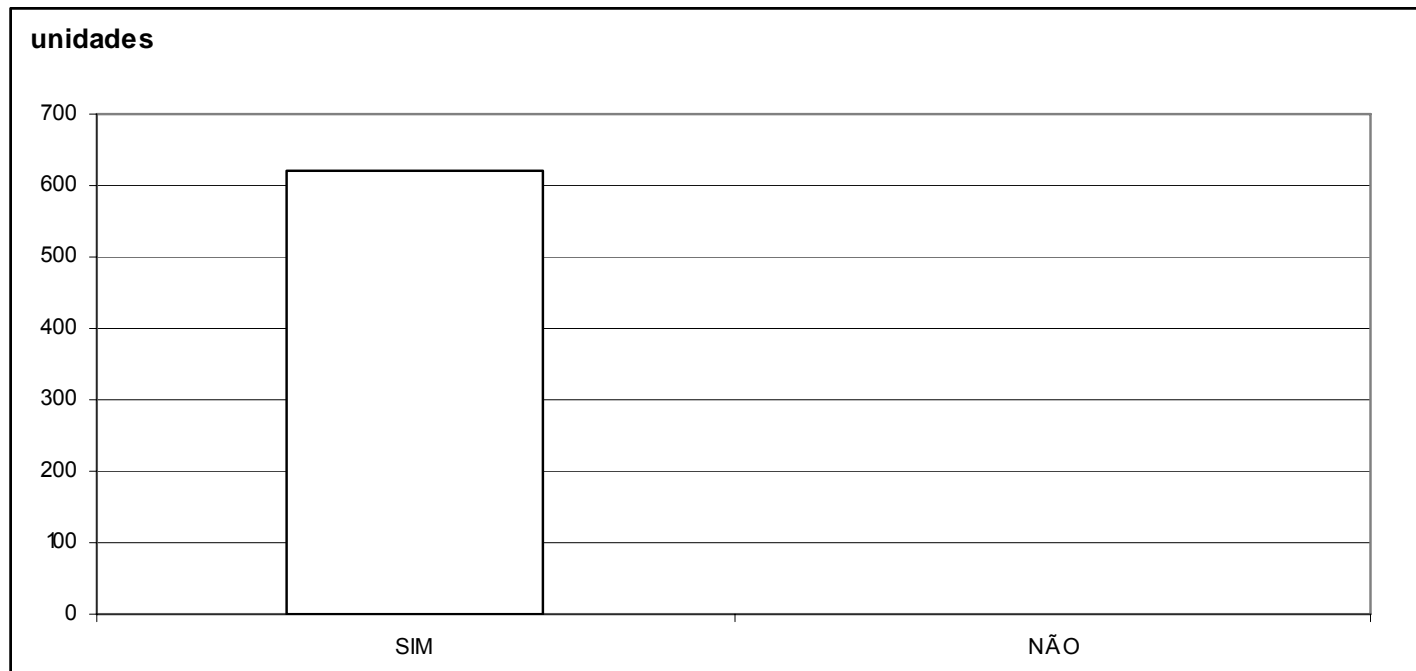

GRÁFICO 31: FREQUÊNCIA DE EXISTÊNCIA DE SALÃO DE JOGOS NA AMOSTRA DE PERFIL SÓCIO-DEMOGRÁFICO MÉDIO

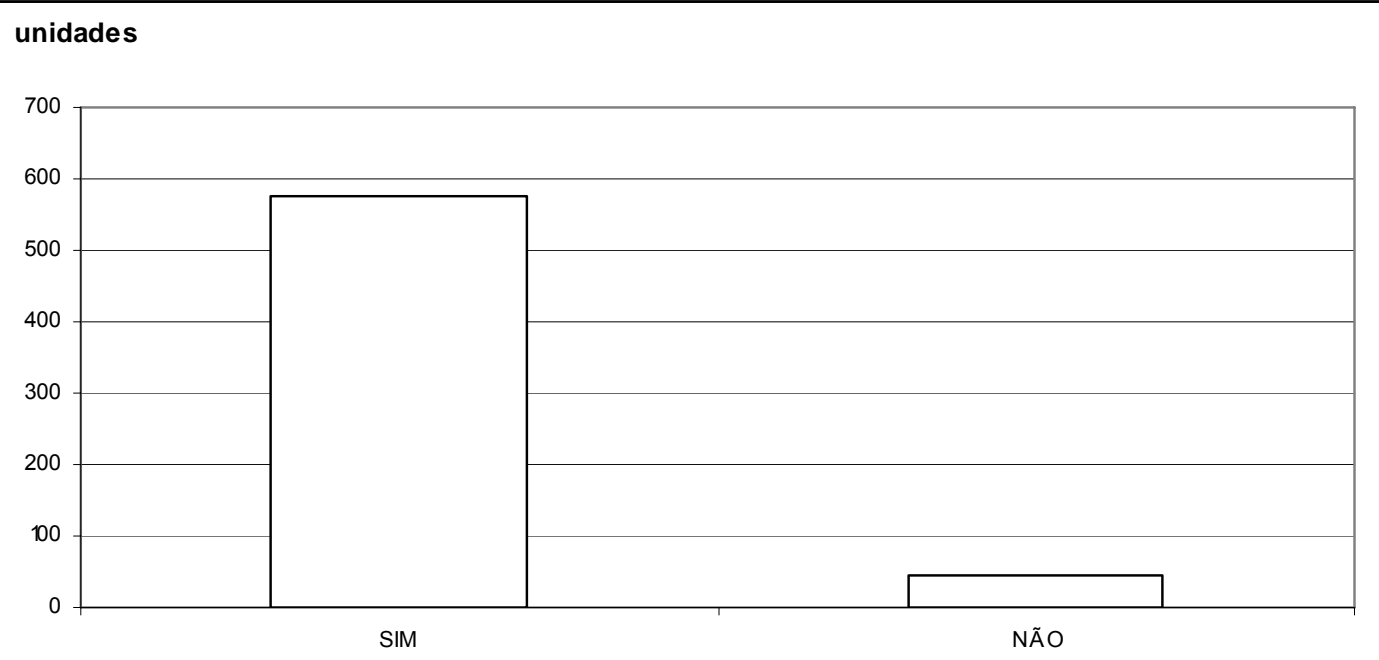


GRÁFICO 32: FREQUÊNCIA DE EXISTÊNCIA DE SALA DE GINÁSTICA NA AMOSTRA DE PERFIL SÓCIO-DEMOGRÁFICO MÉDIO

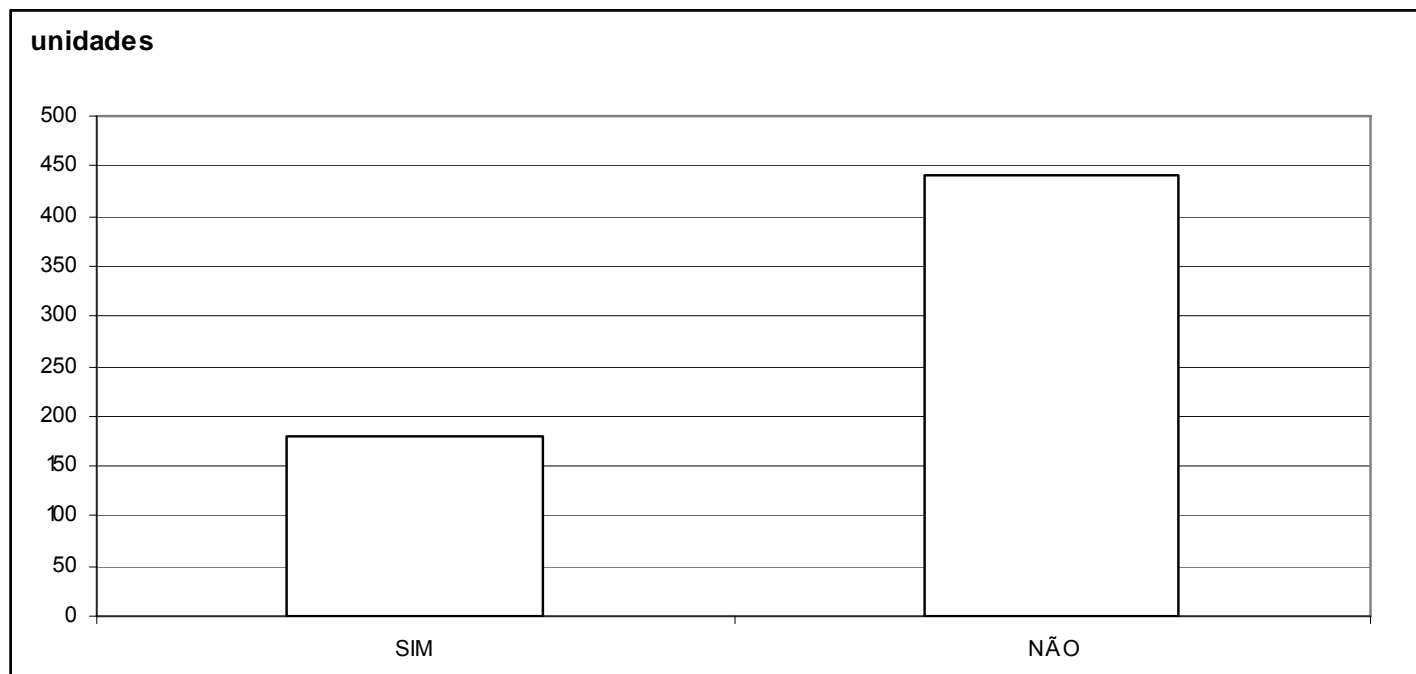

GRÁFICO 33: FREQUÊNCIA DE EXISTÊNCIA DE PISCINA NA AMOSTRA DE PERFIL SÓCIODEMOGRÁFICO MÉDIO

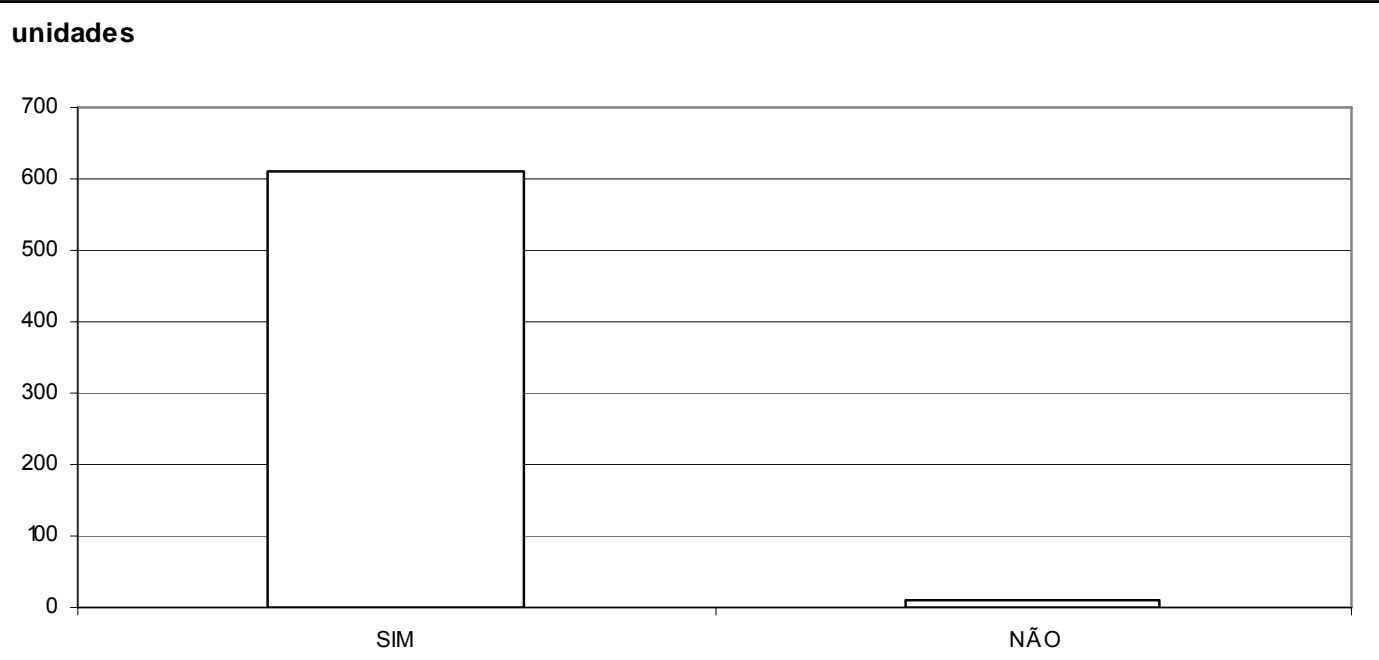


GRÁFICO 34: FREQUÊNCIA DE EXISTÊNCIA DE SAUNA NA AMOSTRA DE PERFIL SÓCIODEMOGRÁFICO MÉDIO

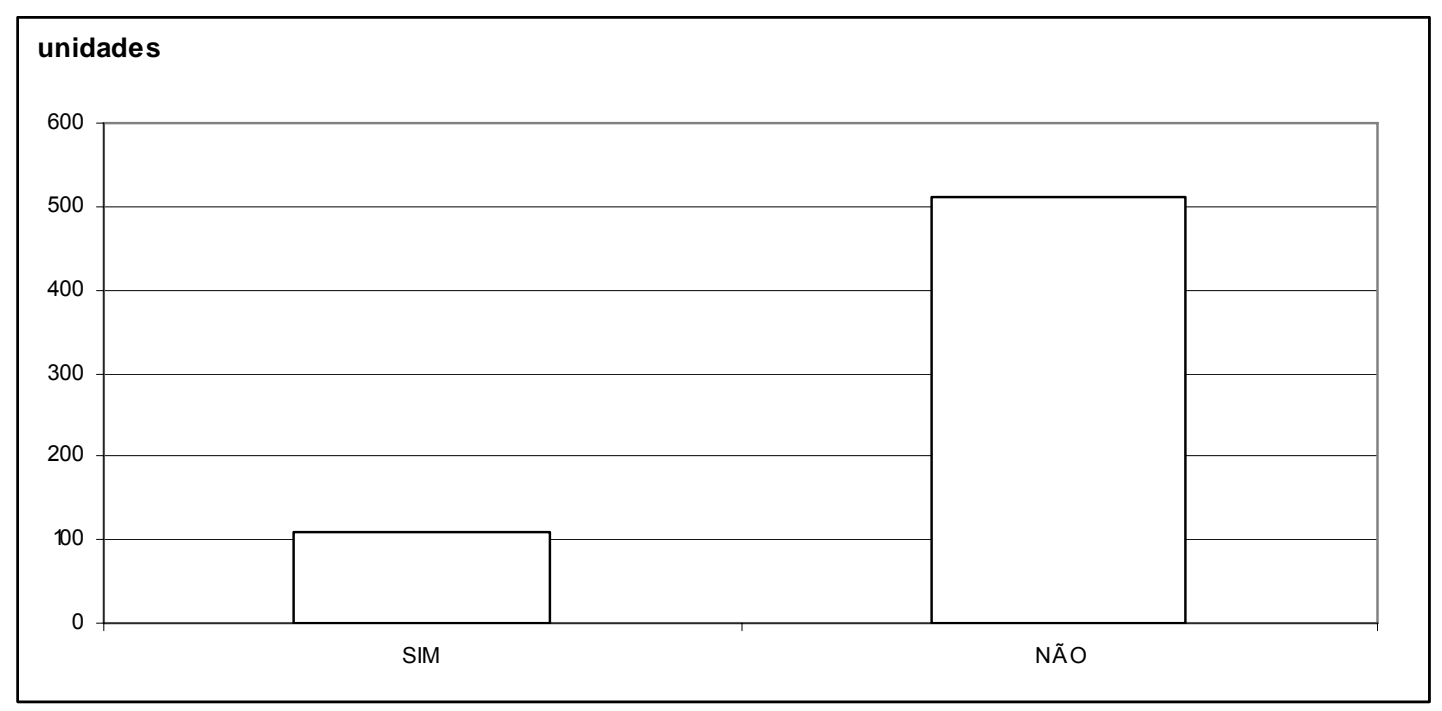

GRÁFICO 35: FREQUÊNCIA DE EXISTÊNCIA DE CHURRASQUEIRA NA AMOSTRA DE PERFIL SÓCIO-DEMOGRÁFICO MÉDIO

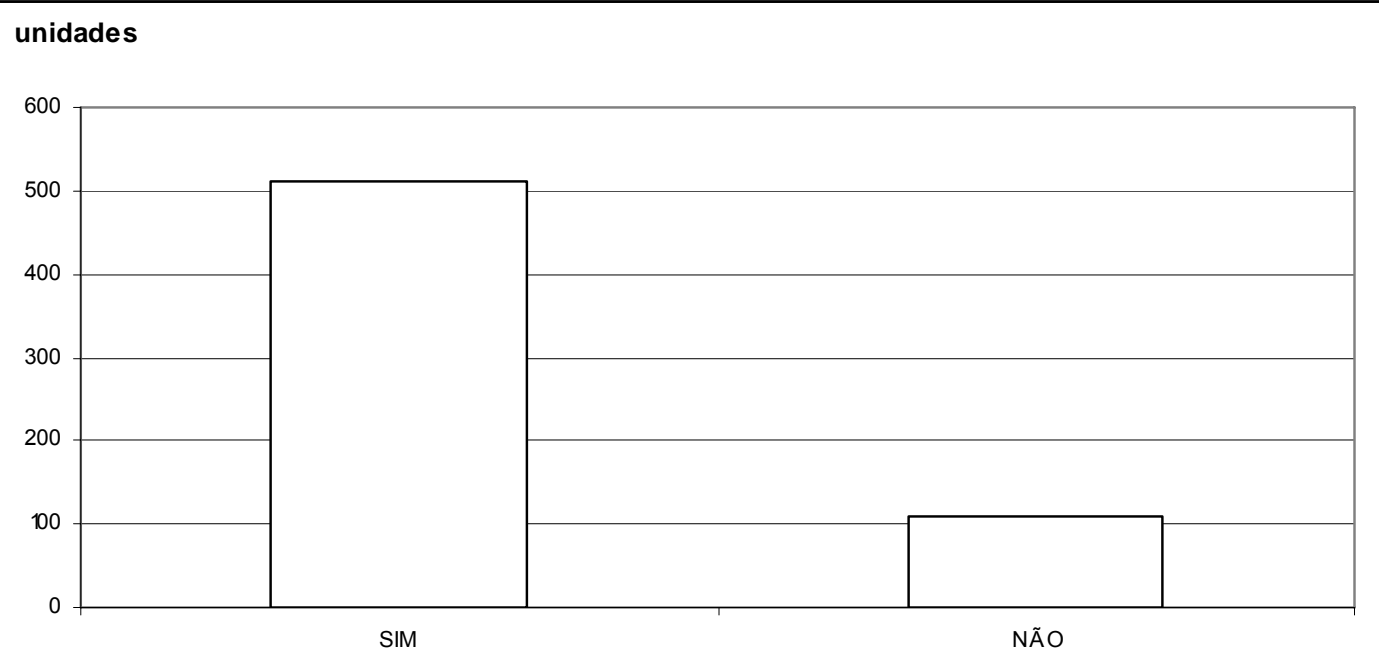


GRÁFICO 36: FREQUÊNCIA DE EXISTÊNCIA DE QUADRA NA AMOSTRA DE PERFIL SÓCIODEMOGRÁFICO MÉDIO

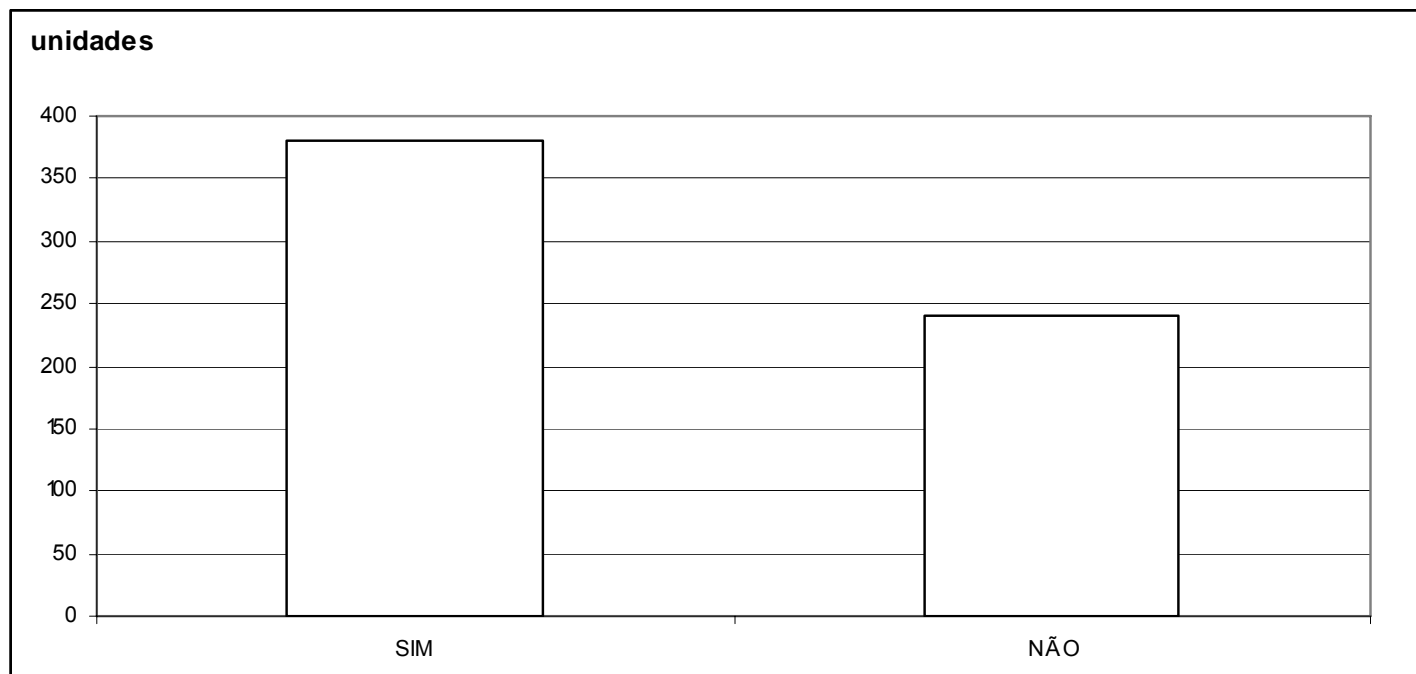

GRÁFICO 37: FREQUÊNCIA DE EXISTÊNCIA DE GUARITA NA AMOSTRA DE PERFIL SÓCIODEMOGRÁFICO MÉDIO

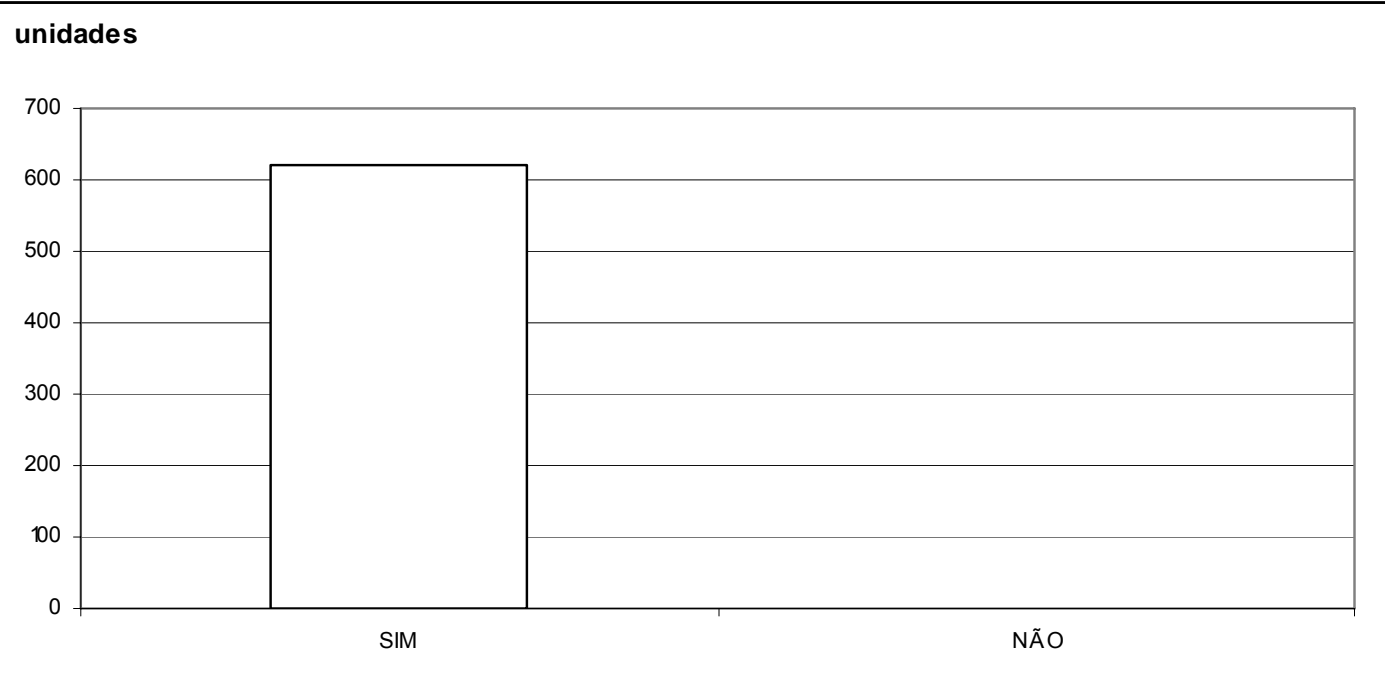


GRÁFICO 38: FREQUÊNCIA DE EXISTÊNCIA DE CFTV NA AMOSTRA DE PERFIL SÓCIODEMOGRÁFICO MÉDIO

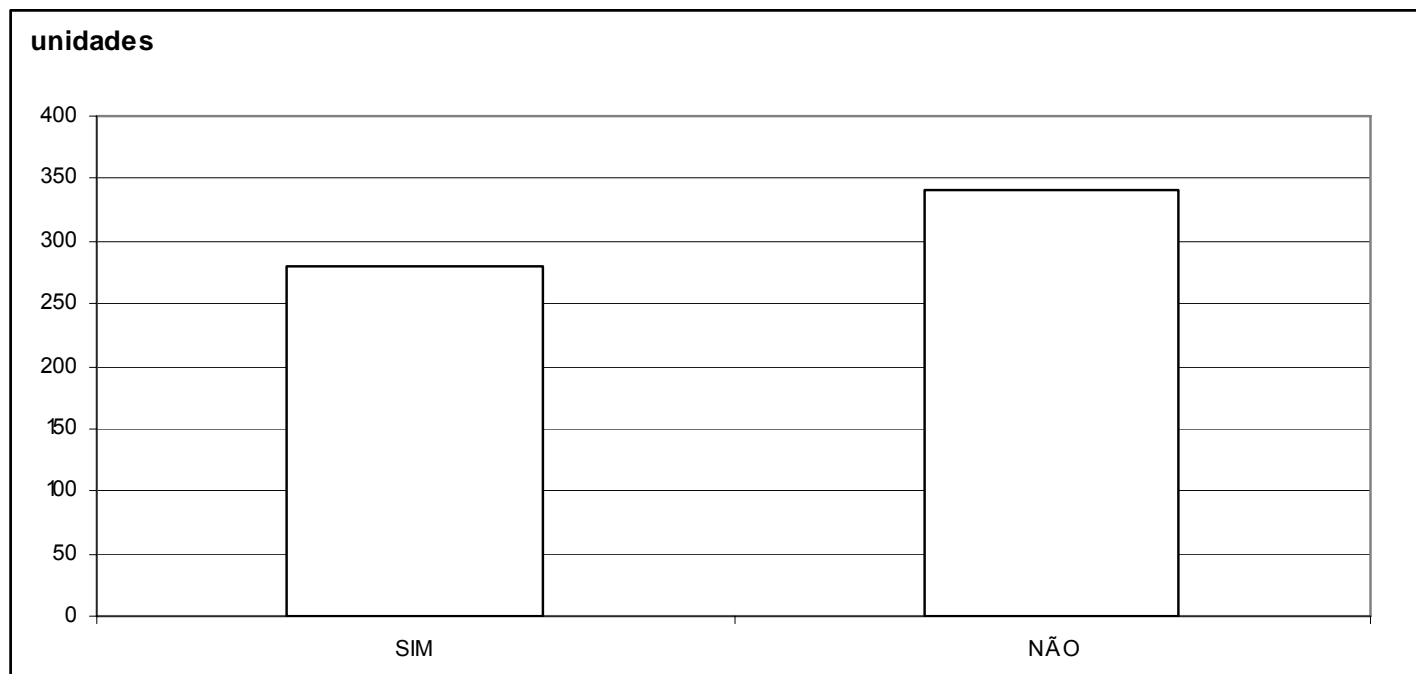

GRÁFICO 39: FREQUÊNCIA DE EXISTÊNCIA DE VARANDA NA AMOSTRA DE PERFIL SÓCIODEMOGRÁFICO MÉDIO

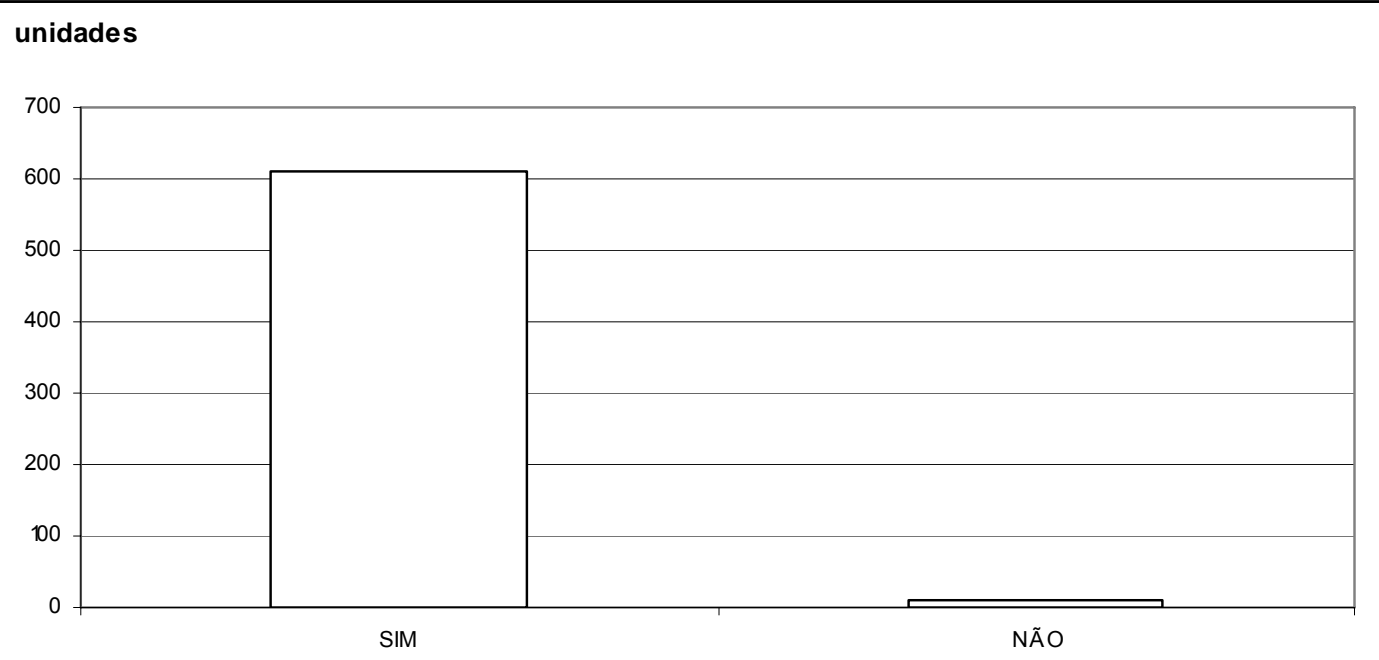


GRÁFICO 40: FREQUÊNCIA DE IMÓVEIS QUE SE ENCONTRAM NA METADE SUPERIOR DO EDIFÍCIO PARA A AMOSTRA DE PERFIL SÓCIO-DEMOGRÁFICO MÉDIO

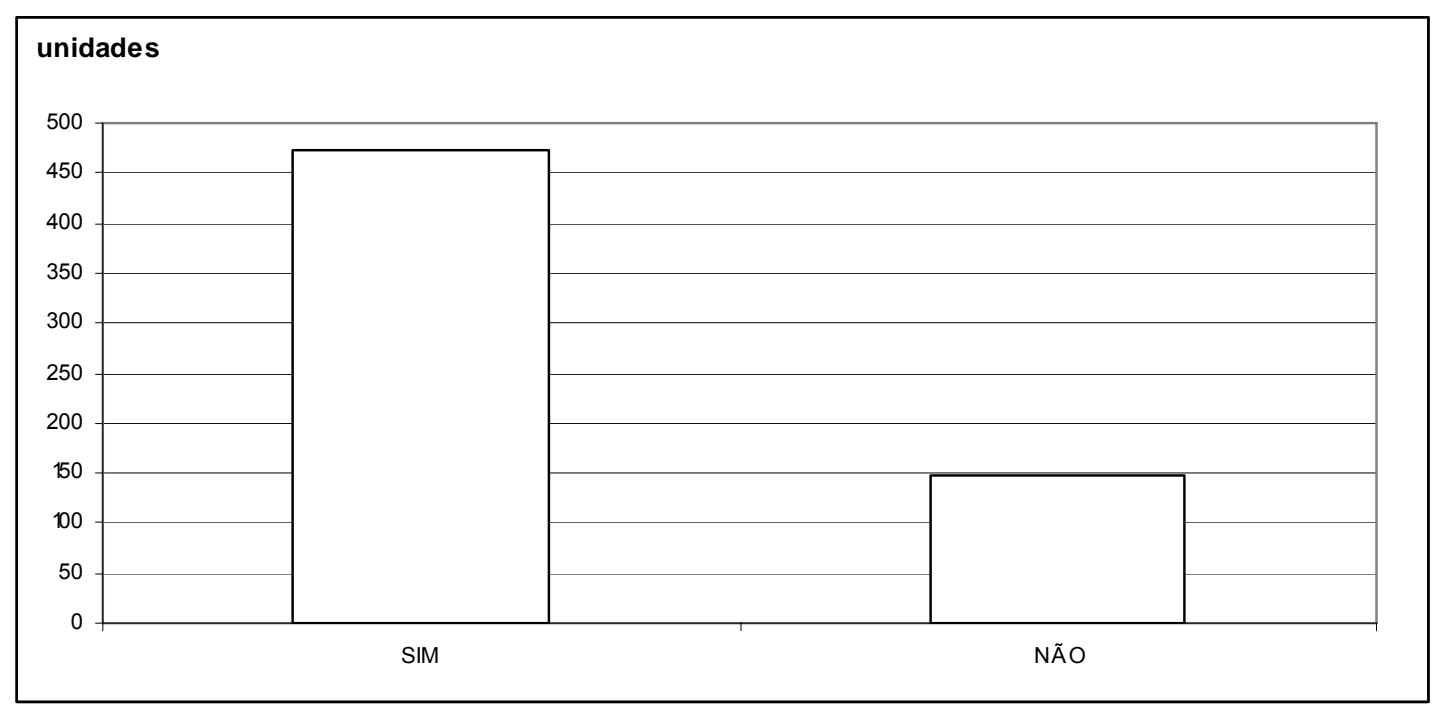

GRÁFICO 41: FREQUÊNCIA DE NÚMERO DE VAGAS NA GARAGEM PARA A AMOSTRA DE PERFIL SÓCIO-DEMOGRÁFICO MÉDIO

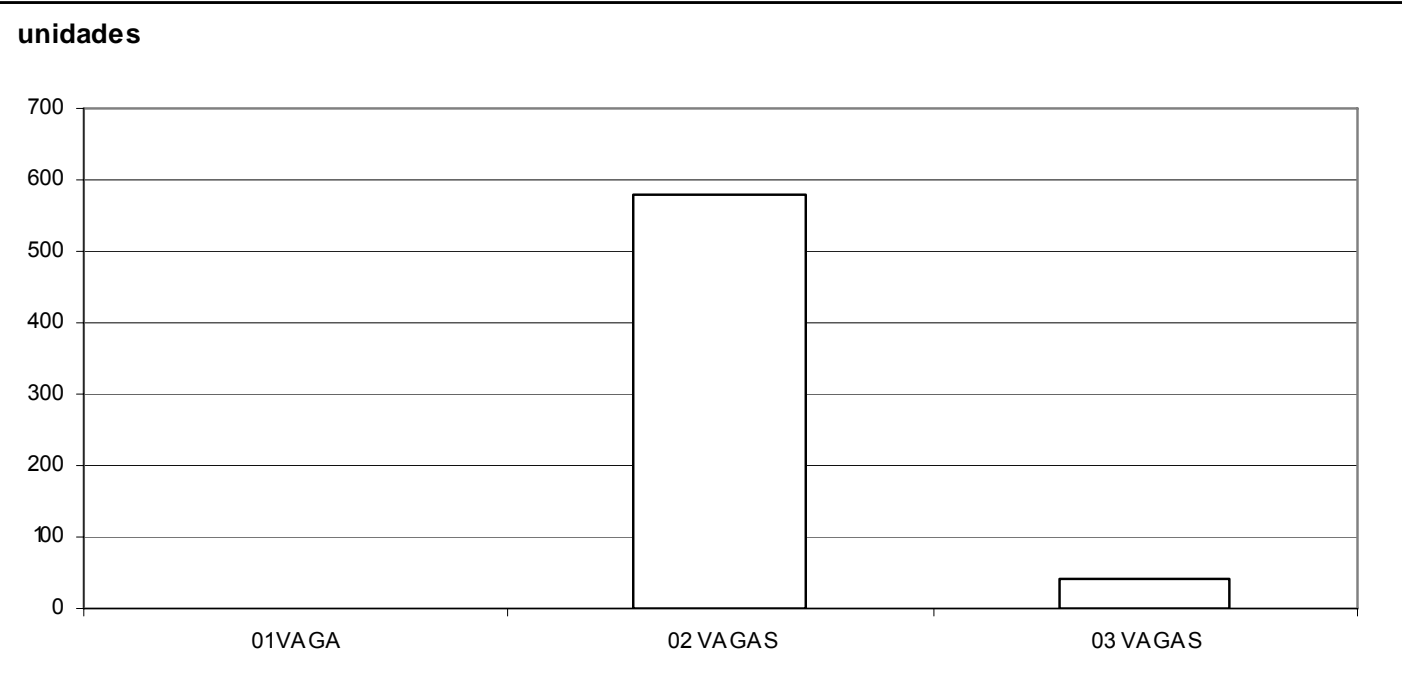


GRÁFICO 42: FREQUÊNCIA DE NÚMERO DE DORMITÓRIOS PARA A AMOSTRA DE PERFIL SÓCIODEMOGRÁFICO MÉDIO

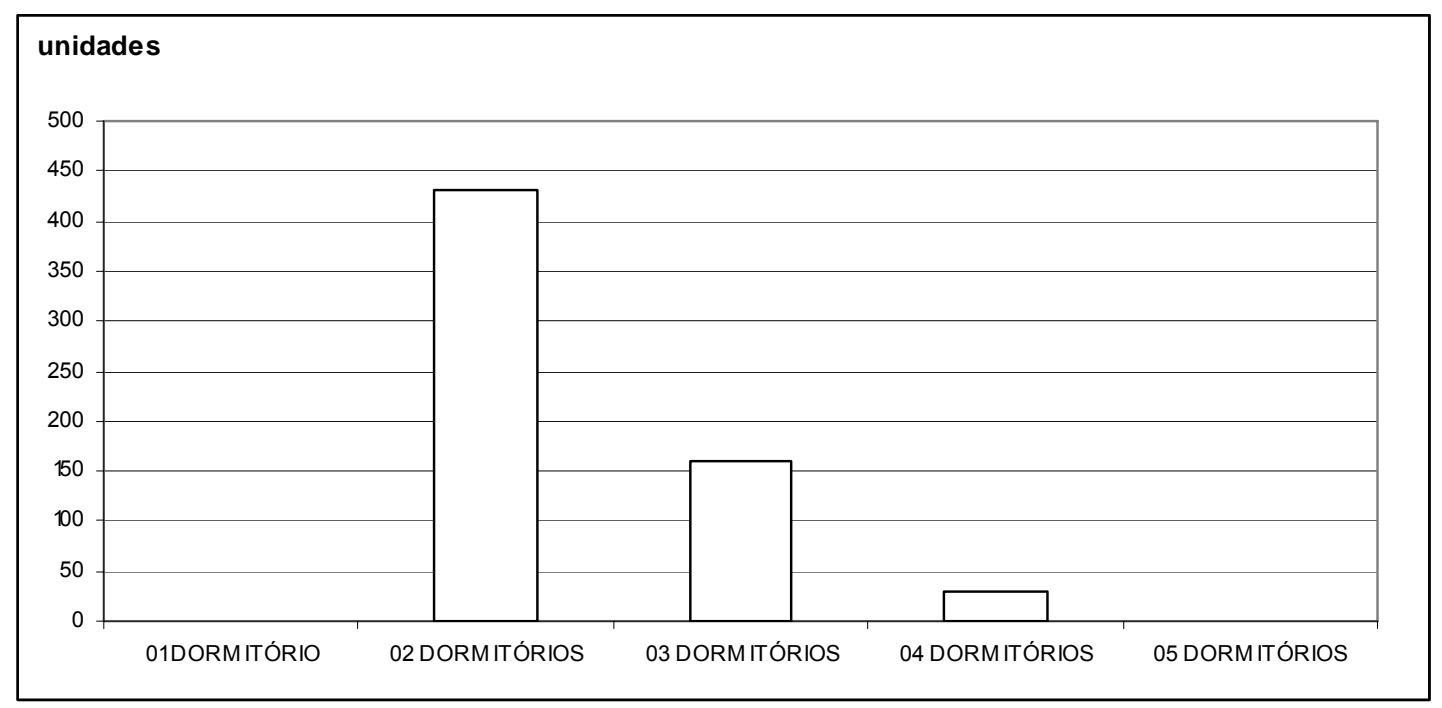

GRÁFICO 43: FREQUÊNCIA DE NÚMERO DE BANHEIROS PARA A AMOSTRA DE PERFIL SÓCIODEMOGRÁFICO MÉDIO

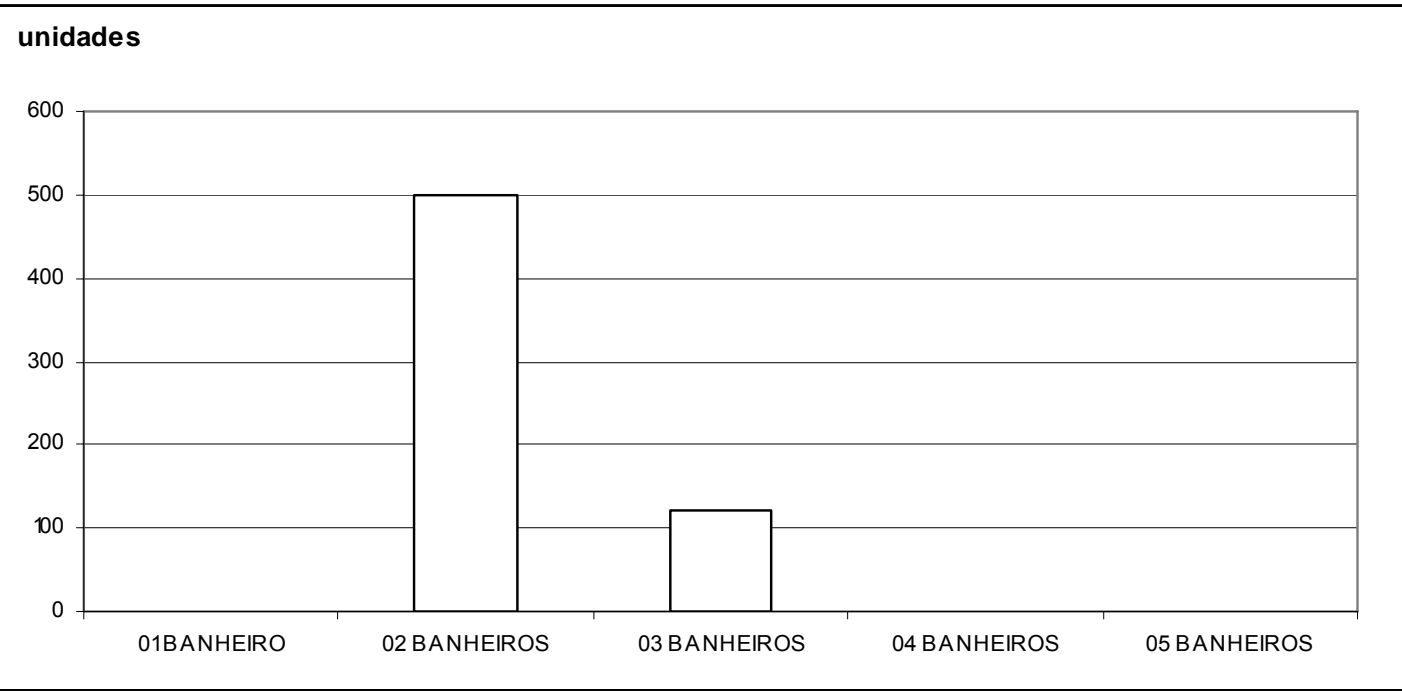


GRÁFICO 44: FREQUÊNCIA DE RENDA FAMILIAR NA AMOSTRA DE PERFIL SÓCIO-DEMOGRÁFICO MÉDIO

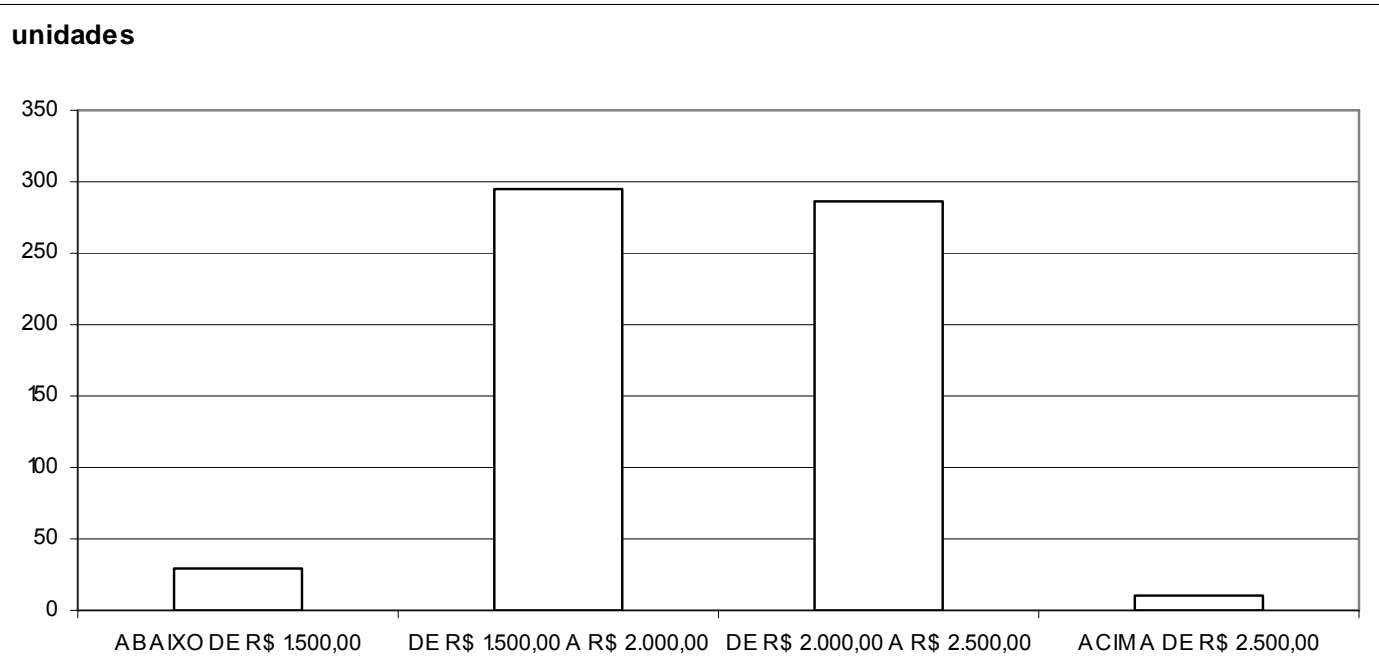

GRÁFICO 45: FREQUÊNCIA DE MEMBROS NA FAMÍLIA NA AMOSTRA DE PERFIL SÓCIODEMOGRÁFICO MÉDIO

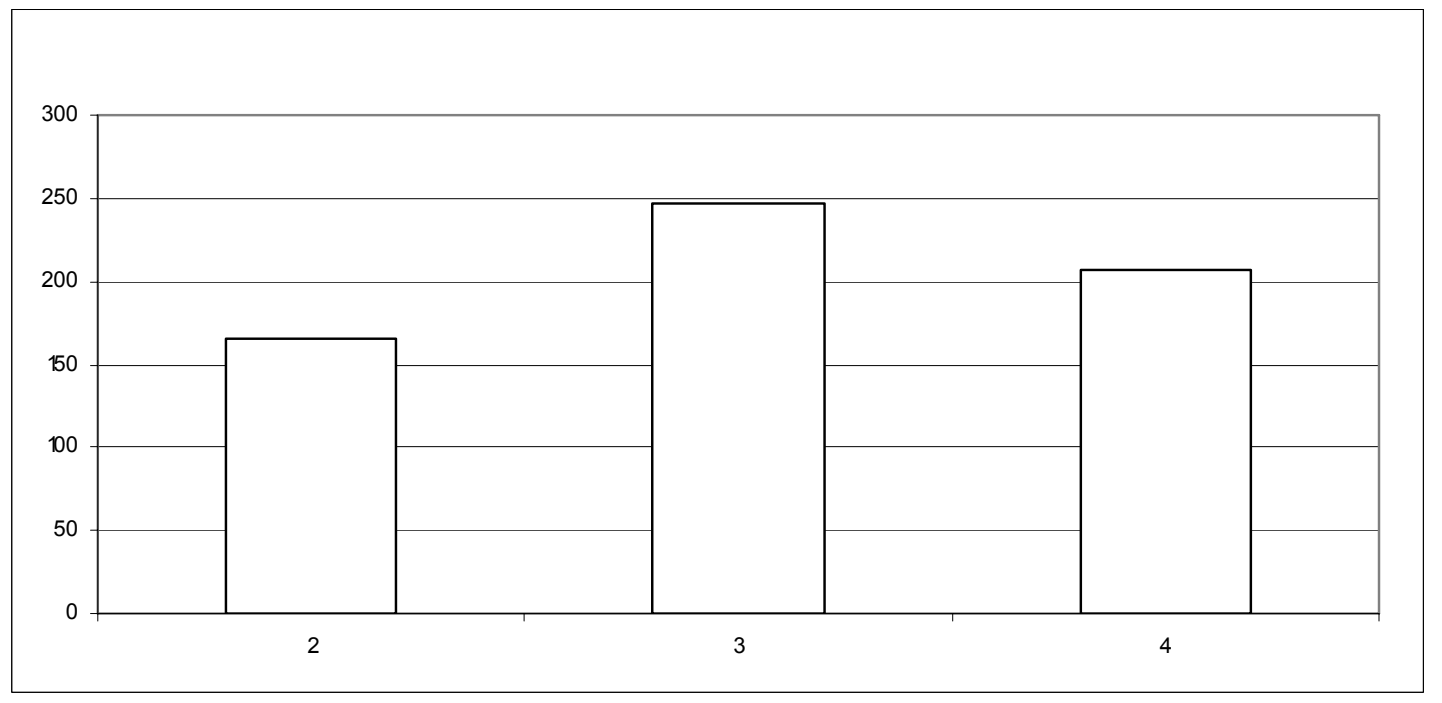


GRÁFICO 46: FREQUÊNCIA DE DENSIDADE DEMOGRÁFICA NA AMOSTRA DE PERFIL SÓCIODEMOGRÁFICO MÉDIO

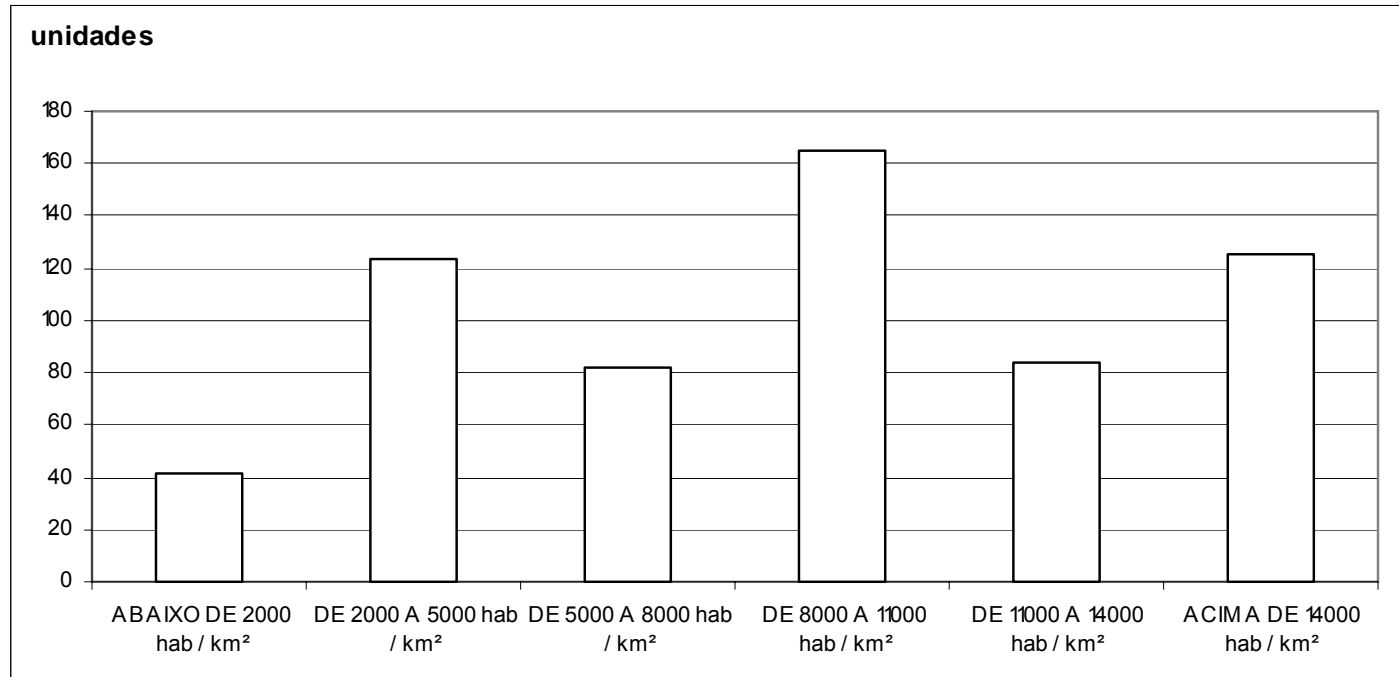

GRÁFICO 47: FREQUÊNCIA DE POPULAÇÃO NA AMOSTRA DE PERFIL SÓCIO-DEMOGRÁFICO MÉDIO

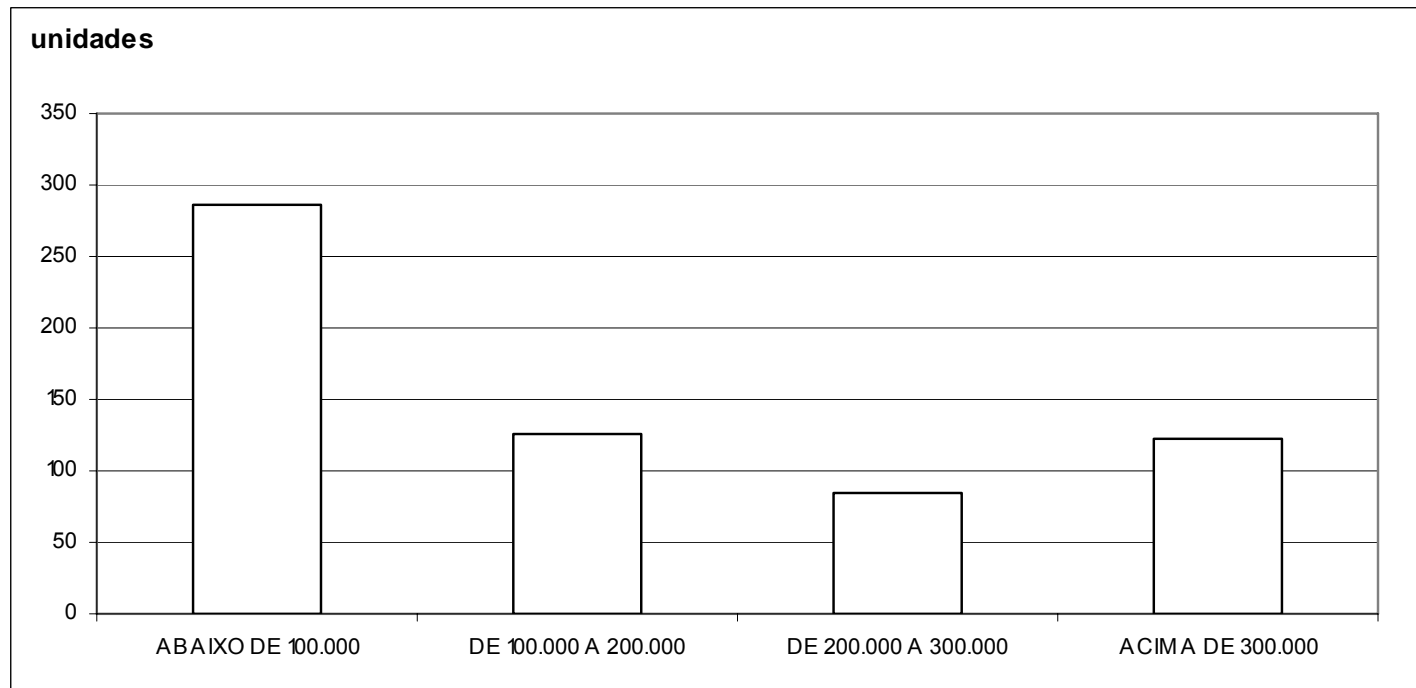


GRÁFICO 48: FREQUÊNCIA DE COLÉGIO PARTICULAR NA AMOSTRA DE PERFIL SÓCIODEMOGRÁFICO MÉDIO

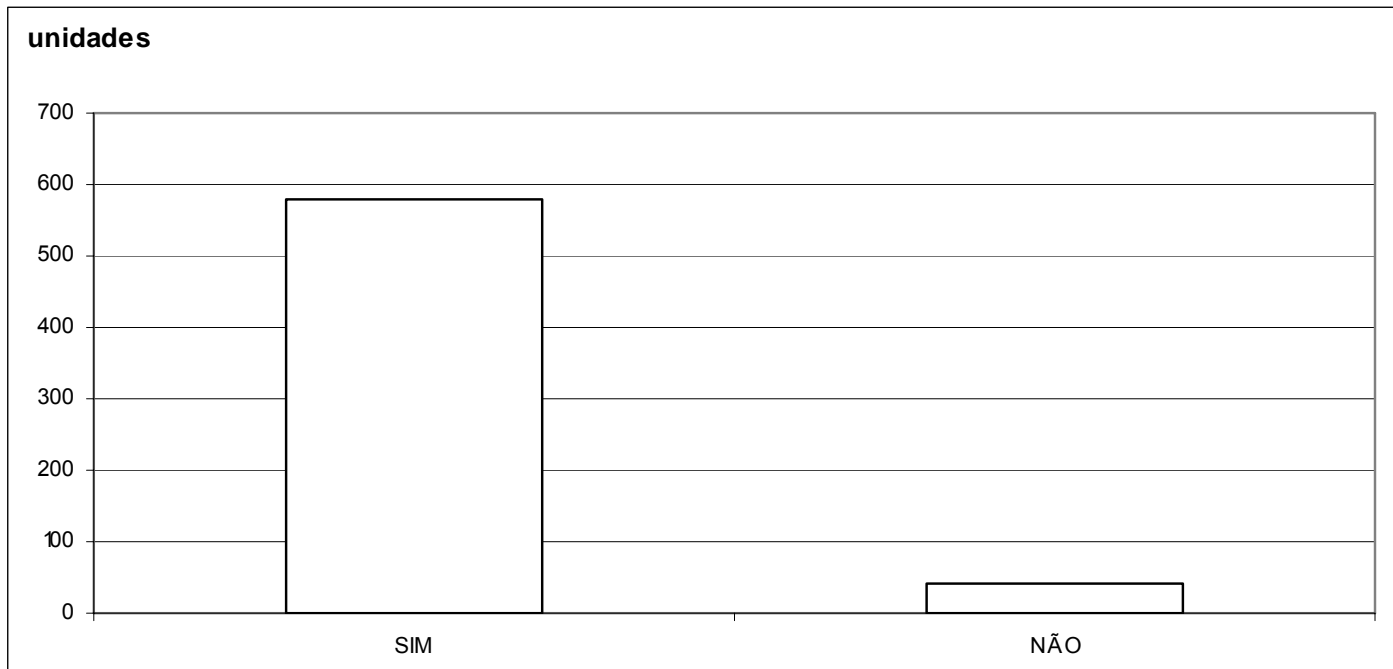

GRÁFICO 49: FREQUÊNCIA DE SHOPPING CENTER NA AMOSTRA DE PERFIL SÓCIODEMOGRÁFICO MÉDIO

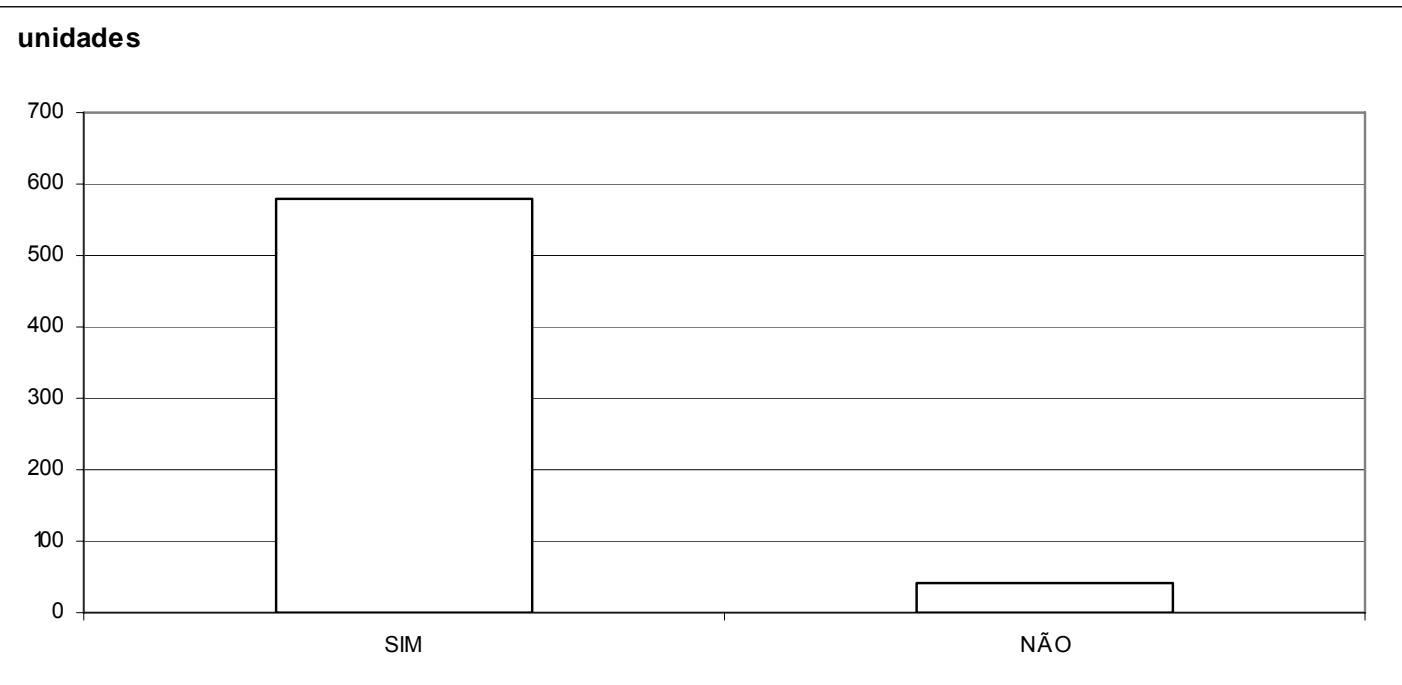


GRÁFICO 50: FREQUÊNCIA DE METRÔ NA AMOSTRA DE PERFIL SÓCIO-DEMOGRÁFICO MÉDIO

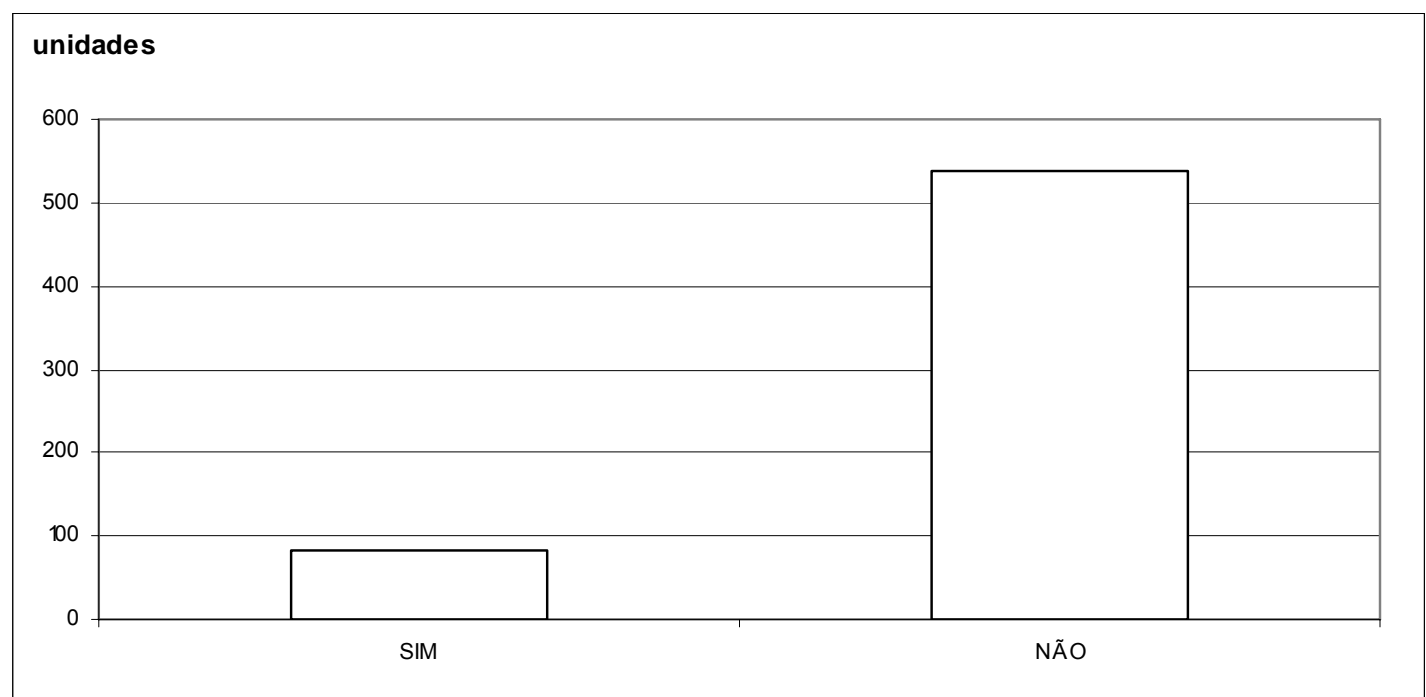

GRÁFICO 51: FREQUÊNCIA DE HOSPITAL PARTICULAR NA AMOSTRA DE PERFIL SÓCIODEMOGRÁFICO MÉDIO

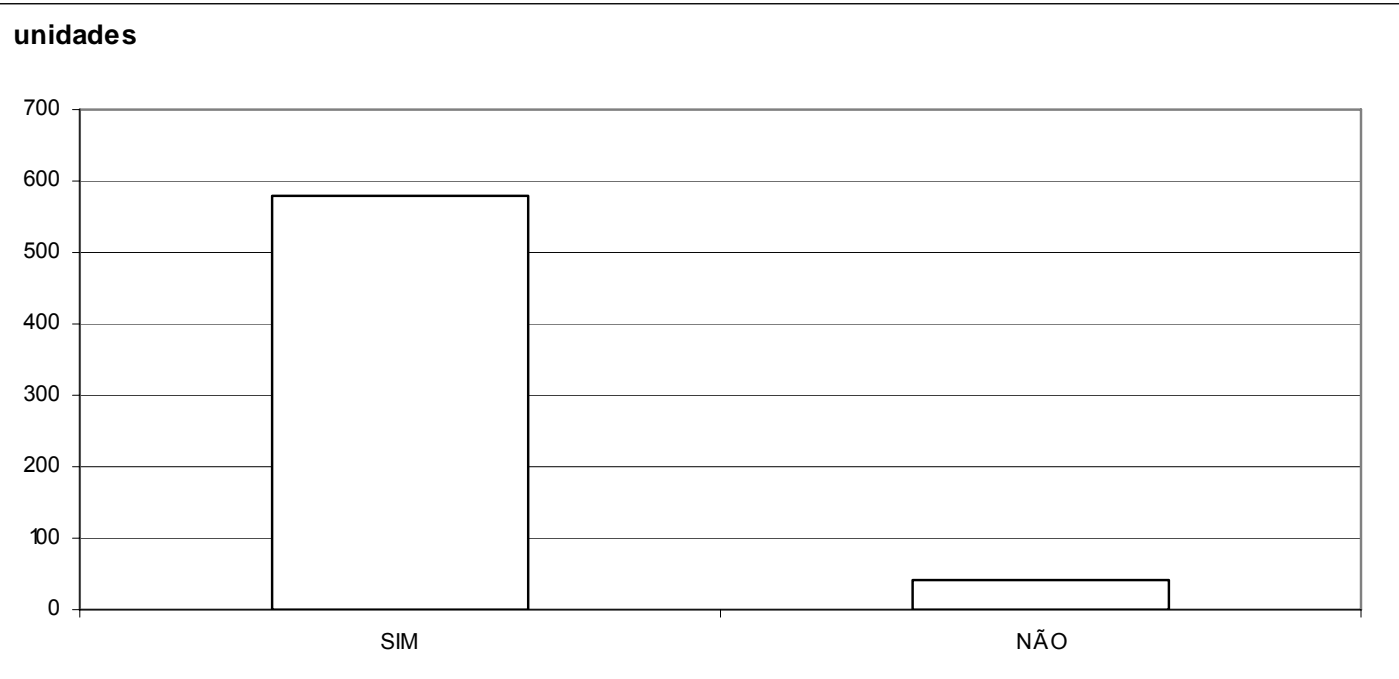


GRÁFICO 52: FREQUÊNCIA DE PARQUES E ÁREAS VERDES NA AMOSTRA DE PERFIL SÓCIODEMOGRÁFICO MÉDIO

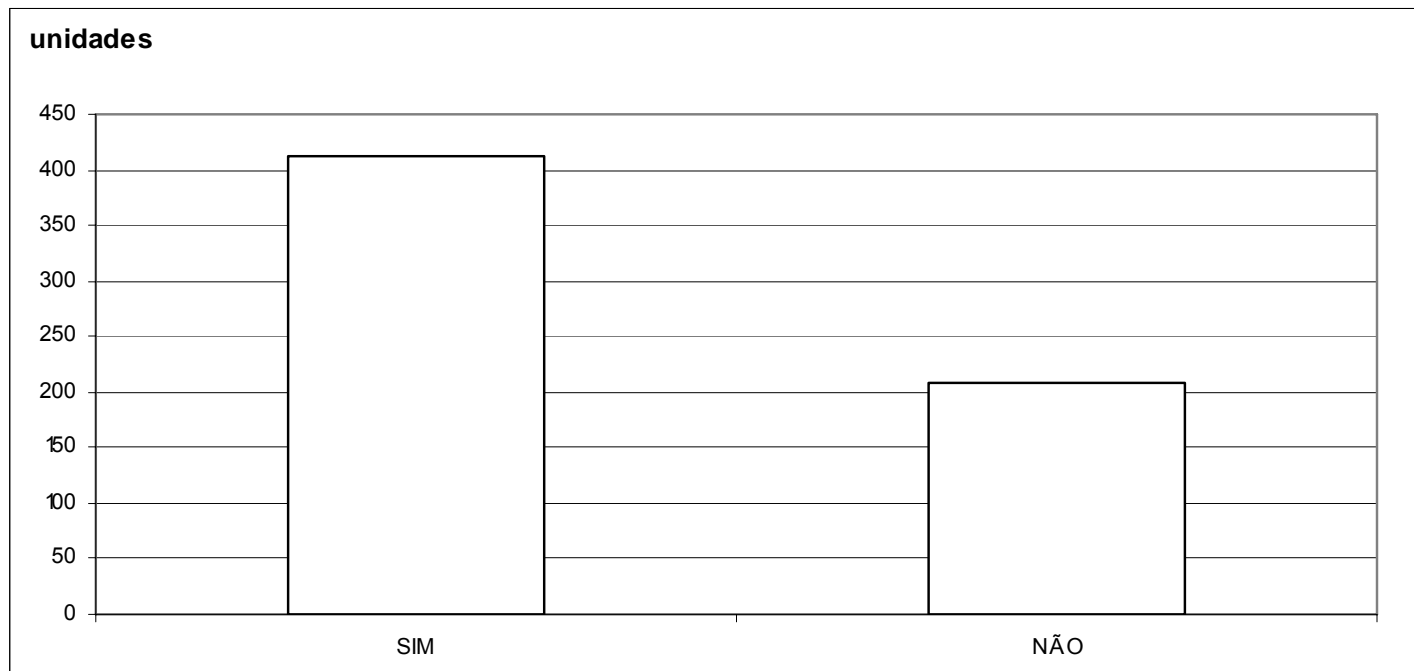

GRÁFICO 53: FREQUÊNCIA DE PONTOS DE INUNDAÇÃO NA AMOSTRA DE PERFIL SÓCIODEMOGRÁFICO MÉDIO

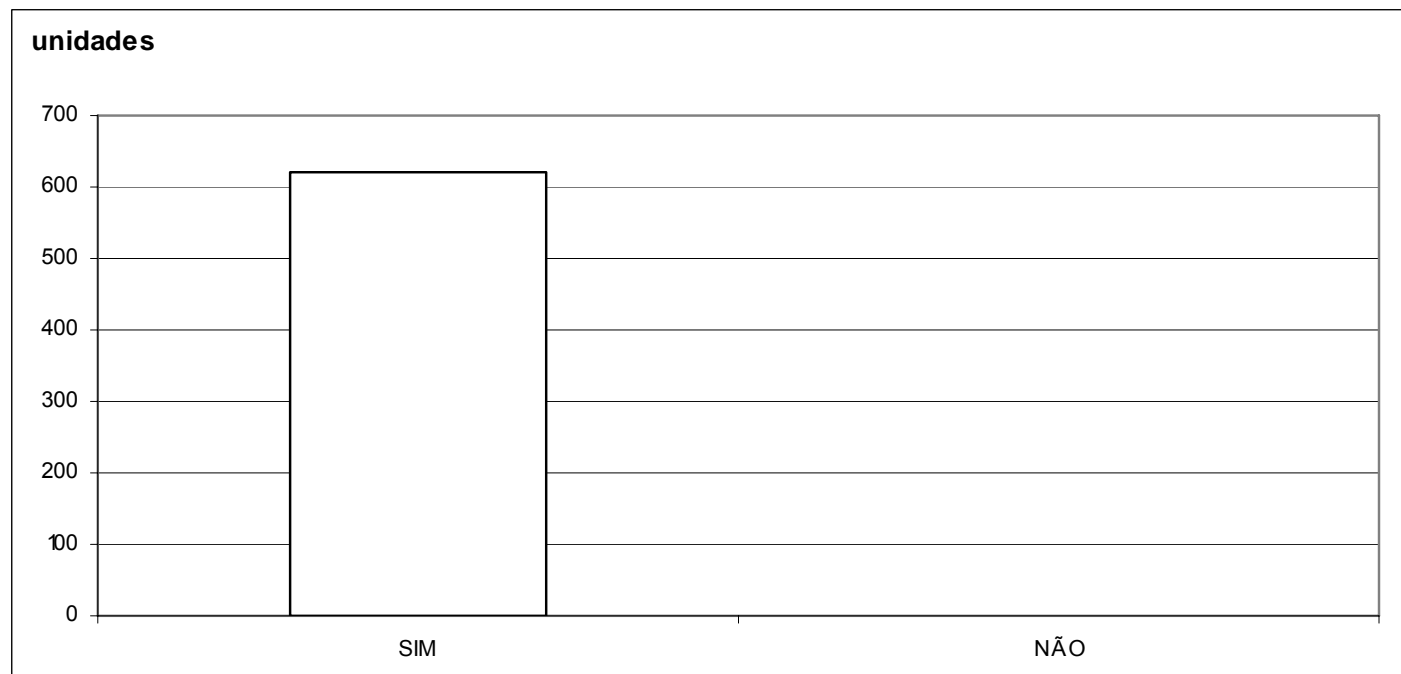


GRÁFICO 54: FREQUÊNCIA DE ATERROS E LIXÕES NA AMOSTRA DE PERFIL SÓCIODEMOGRÁFICO MÉDIO

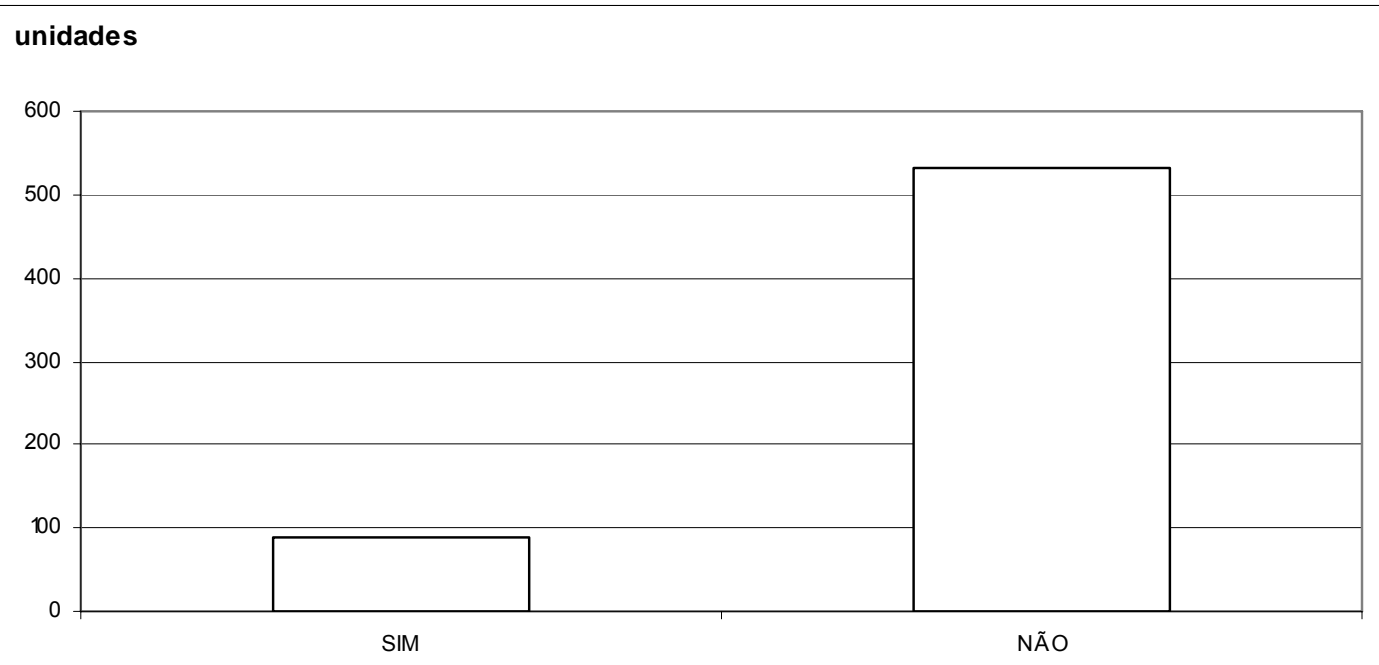




\section{J.2) Resultados do Primeiro Estágio de Rosen}

TABELA 29: VALORES DE R² AJUSTADOS RESULTANTES DO MÉTODO DE BOX-COX COM AS VARIAÇÕES DE $\theta$ E $\lambda$ PARA O PERFIL SÓCIO-DEMOGRÁFICO MÉDIO

\begin{tabular}{|c|c|c|c|c|c|c|c|c|c|c|c|}
\hline \multirow{2}{*}{\multicolumn{2}{|c|}{ Box-Cox }} & \multicolumn{10}{|c|}{0} \\
\hline & & 0,0 & 0,1 & 0,2 & 0,3 & 0,4 & 0,5 & 0,6 & 0,7 & 0,8 & 0,9 \\
\hline \multirow{13}{*}{$\lambda$} & 0,0 & 0,9808 & 0,9799 & 0,9783 & 0,9773 & 0,9758 & 0,9740 & 0,9722 & 0,9707 & 0,9688 & 0,9676 \\
\hline & 0,1 & 0,9806 & 0,9779 & 0,9763 & 0,9753 & 0,9738 & 0,9720 & 0,9702 & 0,9687 & 0,9669 & 0,9656 \\
\hline & 0,2 & 0,9798 & 0,9750 & 0,9733 & 0,9723 & 0,9710 & 0,9690 & 0,9672 & 0,9657 & 0,9638 & 0,9626 \\
\hline & 0,3 & 0,9785 & 0,9709 & 0,9703 & 0,9683 & 0,9669 & 0,9648 & 0,9632 & 0,9617 & 0,9598 & 0,9586 \\
\hline & 0,4 & 0,9776 & 0,9659 & 0,9653 & 0,9631 & 0,9618 & 0,9598 & 0,9582 & 0,9569 & 0,9548 & 0,9536 \\
\hline & 0,5 & 0,9768 & 0,9599 & 0,9594 & 0,9571 & 0,9559 & 0,9540 & 0,9522 & 0,9509 & 0,9488 & 0,9476 \\
\hline & 0,6 & 0,9751 & 0,9521 & 0,9520 & 0,9492 & 0,9451 & 0,9462 & 0,9439 & 0,9431 & 0,9409 & 0,9397 \\
\hline & 0,7 & 0,9750 & 0,9449 & 0,9448 & 0,9420 & 0,9379 & 0,9390 & 0,9372 & 0,9358 & 0,9337 & 0,9325 \\
\hline & 0,8 & 0,9746 & 0,9359 & 0,9363 & 0,9329 & 0,9290 & 0,9298 & 0,9281 & 0,9268 & 0,9247 & 0,9231 \\
\hline & 0,9 & 0,9738 & 0,9259 & 0,9263 & 0,9229 & 0,9190 & 0,9198 & 0,9180 & 0,9168 & 0,9140 & 0,9131 \\
\hline & 1,0 & 0,9730 & 0,9150 & 0,9154 & 0,9119 & 0,9086 & 0,9079 & 0,9069 & 0,9059 & 0,9031 & 0,9022 \\
\hline & 2,0 & 0,9718 & 0,9029 & 0,9034 & 0,8998 & 0,9018 & 0,8949 & 0,8948 & 0,8938 & 0,8910 & 0,8901 \\
\hline & 3,0 & 0,9717 & 0,9027 & 0,8947 & 0,8868 & 0,8862 & 0,8846 & 0,8818 & 0,8808 & 0,8780 & 0,8771 \\
\hline
\end{tabular}

TABELA 30: RESULTADOS DA REGRESSÃO PARA A ESPECIFICAÇÃO LOGARÍTMICA - MÉTODO ENTER - PERFIL SÓCIO-DEMOGRÁFICO MÉDIO

\begin{tabular}{c|c|c|c|c}
\hline Variável & $\begin{array}{c}\text { Coeficiente Não } \\
\text { Padronizado }\end{array}$ & $\begin{array}{c}\text { Coeficiente } \\
\text { Padronizado }\end{array}$ & Estatística t & $\begin{array}{c}\text { Nível de } \\
\text { Significância }\end{array}$ \\
\hline (Constante) & 9,6910 & & 110,405 & 0,000 \\
\hline LNAREA & 0,5500 & 0,562 & 26,564 & 0,000 \\
\hline SJOG & 0,0396 & 0,062 & 6,730 & 0,000 \\
\hline PISC & 0,0690 & 0,055 & 7,615 & 0,000 \\
\hline SAUN & 0,0162 & 0,038 & 2,092 & 0,037 \\
\hline QUAD & 0,0171 & 0,051 & 5,472 & 0,000 \\
\hline CFTV & 0,0115 & 0,035 & 3,387 & 0,001 \\
\hline VARD & 0,0518 & 0,041 & 5,830 & 0,000 \\
\hline ALTR & 0,0646 & 0,017 & 2,604 & 0,009 \\
\hline VAGA2 & 0,1210 & 0,157 & 11,267 & 0,000 \\
\hline DORM2 & 0,1040 & 0,276 & 17,588 & 0,000 \\
\hline DORM3 & 0,0508 & 0,076 & 6,563 & 0,000 \\
\hline BANH2 & 0,0224 & 0,054 & 3,014 & 0,003 \\
\hline RA & & & &
\end{tabular}

$\mathrm{R}^{2}$ ajustado: 0,9808

Estatística F: 2642,618

Prob. (Est. F): 0,000

Durbin-Watson: 1,542 


\section{J.3) Resultados do Segundo Estágio de Rosen}

TABELA 31: ESTIMAÇÃO DA EQUAÇÃO DE DEMANDA: SEGUNDO ESTÁGIO DE ROSEN - MÉTODO ENTER - PERFIL SÓCIO-DEMOGRÁFICO MÉDIO

\begin{tabular}{c|c|c|c|c}
\hline Variável & $\begin{array}{c}\text { Coeficiente Não } \\
\text { Padronizado }\end{array}$ & $\begin{array}{c}\text { Coeficiente } \\
\text { Padronizado }\end{array}$ & Estatística t & $\begin{array}{c}\text { Nível de } \\
\text { Significância }\end{array}$ \\
\hline (Constante) & 3817,683 & & 30,333 & 0,000 \\
\hline LNAREA & $-597,087$ & $-3,021$ & $-26,660$ & 0,000 \\
\hline SJOG & 41,393 & 0,319 & 6,743 & 0,000 \\
\hline PISC & 91,418 & 0,362 & 9,873 & 0,000 \\
\hline SAUN & 44,892 & 0,514 & 5,109 & 0,000 \\
\hline QUAD & 18,911 & 0,276 & 5,966 & 0,000 \\
\hline CFTV & 7,741 & 0,116 & 2,241 & 0,025 \\
\hline VARD & 68,631 & 0,272 & 7,296 & 0,000 \\
\hline ALTR & 4,206 & 0,054 & 1,594 & 0,111 \\
\hline VAGA2 & 132,502 & 0,853 & 12,085 & 0,000 \\
\hline DORM2 & 145,839 & 1,914 & 22,353 & 0,000 \\
\hline DORM3 & 104,737 & 0,772 & 11,584 & 0,000 \\
\hline BANH2 & 63,538 & 0,755 & 7,272 & 0,000 \\
\hline COLP & 34,089 & 0,254 & 7,351 & 0,000 \\
\hline SHOP & 39,019 & 0,291 & 8,361 & 0,000 \\
\hline METR & 8,247 & 0,084 & 2,501 & 0,013 \\
\hline HOSP & 31,357 & 0,234 & 6,135 & 0,000 \\
\hline PARQ & 9,346 & 0,132 & 3,233 & 0,001 \\
\hline ATER & $-11,823$ & $-0,124$ & $-3,444$ & 0,001 \\
\hline LNRND & $-3,403$ & $-0,014$ & $-0,420$ & 0,675 \\
\hline LNMEMB & 6,131 & 0,049 & 1,374 & 0,170 \\
\hline$R^{2}$ (ujusta & & &
\end{tabular}

$\mathrm{R}^{2}$ ajustado: 0,5665

Estatística F: 41,446

Prob. (Est. F): 0,000

Durbin-Watson: 1,913 
TABELA 32: ESTIMAÇÃO DA EQUAÇÃO DE OFERTA: SEGUNDO ESTÁGIO DE ROSEN - MÉTODO ENTER - PERFIL SÓCIO-DEMOGRÁFICO MÉDIO

\begin{tabular}{|c|c|c|c|c|}
\hline Variável & $\begin{array}{c}\text { Coeficiente Não } \\
\text { Padronizado }\end{array}$ & $\begin{array}{l}\text { Coeficiente } \\
\text { Padronizado }\end{array}$ & Estatística t & $\begin{array}{c}\text { Nível de } \\
\text { Significância }\end{array}$ \\
\hline (Constante) & 3782,144 & & 41,315 & 0,000 \\
\hline LNAREA & $-604,296$ & $-3,057$ & $-28,139$ & 0,000 \\
\hline SJOG & 42,545 & 0,328 & 7,231 & 0,000 \\
\hline PISC & 98,844 & 0,391 & 10,811 & 0,000 \\
\hline SAUN & 44,194 & 0,506 & 5,267 & 0,000 \\
\hline QUAD & 18,744 & 0,274 & 6,016 & 0,000 \\
\hline CFTV & 7,723 & 0,115 & 2,280 & 0,023 \\
\hline VARD & 74,261 & 0,294 & 8,309 & 0,000 \\
\hline ALTR & 4,903 & 0,063 & 1,955 & 0,051 \\
\hline VAGA2 & 139,403 & 0,897 & 12,685 & 0,000 \\
\hline DORM2 & 147,878 & 1,941 & 23,773 & 0,000 \\
\hline DORM3 & 105,276 & 0,776 & 12,149 & 0,000 \\
\hline BANH2 & 63,418 & 0,754 & 7,726 & 0,000 \\
\hline COLP & 29,807 & 0,222 & 6,551 & 0,000 \\
\hline SHOP & 70,328 & 0,524 & 7,153 & 0,000 \\
\hline METR & 37,531 & 0,381 & 3,166 & 0,002 \\
\hline HOSP & 33,365 & 0,249 & 6,867 & 0,000 \\
\hline PARQ & 10,543 & 0,149 & 3,629 & 0,000 \\
\hline ATER & $-13,334$ & $-0,140$ & $-3,954$ & 0,000 \\
\hline LNDENS & $-12,139$ & $-0,327$ & $-3,923$ & 0,000 \\
\hline LNPOP & 10,177 & 0,328 & 3,567 & 0,000 \\
\hline
\end{tabular}

$\mathrm{R}^{2}$ ajustado: 0,5760

Estatística F: 43,054

Prob. (Est. F): 0,000

Durbin-Watson: 1,935 
TABELA 33: EQUAÇÕES DE DEMANDA E OFERTA - MÉTODO STEPWISE - PERFIL SÓCIODEMOGRÁFICO MÉDIO

\begin{tabular}{|c|c|c|c|c|}
\hline Equação & \multicolumn{2}{|c|}{ Demanda } & \multicolumn{2}{|c|}{ Oferta } \\
\hline Variável & $\begin{array}{c}\text { Coeficiente Não } \\
\text { Padronizado }\end{array}$ & $\begin{array}{c}\text { Coeficiente } \\
\text { Padronizado* }\end{array}$ & $\begin{array}{c}\text { Coeficiente Não } \\
\text { Padronizado }\end{array}$ & $\begin{array}{c}\text { Coeficiente } \\
\text { Padronizado* }\end{array}$ \\
\hline (Constante) & 3872,665 & & 3777,383 & \\
\hline LNAREA & $-593,501$ & $-3,002$ & $-602,978$ & $-3,050$ \\
\hline SJOG & 39,415 & 0,304 & 41,256 & 0,318 \\
\hline PISC & 88,633 & 0,351 & 96,630 & 0,383 \\
\hline SAUN & 41,067 & 0,471 & 41,147 & 0,472 \\
\hline QUAD & 18,546 & 0,271 & 18,493 & 0,270 \\
\hline CFTV & 7,117 & 0,106 & 6,971 & 0,104 \\
\hline VARD & 67,713 & 0,268 & 72,184 & 0,286 \\
\hline VAGA2 & 130,407 & 0,839 & 138,025 & 0,888 \\
\hline DORM2 & 144,917 & 1,902 & 147,627 & 1,938 \\
\hline DORM3 & 104,118 & 0,767 & 105,599 & 0,778 \\
\hline BANH2 & 60,021 & 0,714 & 60,776 & 0,723 \\
\hline COLP & 34,236 & 0,255 & 30,188 & 0,225 \\
\hline SHOP & 40,421 & 0,301 & 72,961 & 0,544 \\
\hline METR & 7,897 & 0,080 & 40,117 & 0,408 \\
\hline HOSP & 31,886 & 0,238 & 33,450 & 0,249 \\
\hline PARQ & 8,983 & 0,127 & 10,179 & 0,144 \\
\hline ATER & $-11,156$ & $-0,117$ & $-12,234$ & $-0,128$ \\
\hline LNMEMB & 7,816 & 0,063 & & \\
\hline LNDENS & & & $-12,259$ & $-0,330$ \\
\hline \multirow[t]{2}{*}{ LNPOP } & & & 10,750 & 0,346 \\
\hline & \multicolumn{2}{|c|}{$\begin{array}{l}\mathrm{R}^{2} \text { ajustado: } 0,5660 \\
\text { Estatística F: } 45,784 \\
\text { Prob. (Est. F): } 0,000 \\
\text { Durbin-Watson: } 1,963 \\
\text { * estatística t a } 5 \%\end{array}$} & \multicolumn{2}{|c|}{$\begin{array}{l}\mathrm{R}^{2} \text { ajustado: } 0,5740 \\
\text { Estatística F: } 44,908 \\
\text { Prob. (Est. F): } 0,000 \\
\text { Durbin-Watson: } 1,982 \\
\text { * estatística t a } 5 \%\end{array}$} \\
\hline
\end{tabular}




\section{J.4) Resultados da Correlação Canônica}

TABELA 34: TESTES MULTIVARIADOS DE SIGNIFICÂNCIA PARA A EQUAÇÃO DE DEMANDA PERFIL SÓCIO-DEMOGRÁFICO MÉDIO

\begin{tabular}{l|c|c|c|c}
\hline \multicolumn{1}{c|}{ Teste } & Valor & Aprox. F & Erro DF & Sig. F \\
\hline Pillais & 2,006 & 67,436 & 1803,00 & 0,000 \\
\hline Hottelings & 8,265 & 91,482 & 1793,00 & 0,000 \\
\hline Wilks & 0,026 & 78,698 & 1785,60 & 0,000 \\
\hline Roys & 0,839 & & & \\
\hline
\end{tabular}

TABELA 35: TESTES MULTIVARIADOS DE SIGNIFICÂNCIA PARA A EQUAÇÃO DE OFERTA - PERFIL SÓCIO-DEMOGRÁFICO MÉDIO

\begin{tabular}{l|c|c|c|c}
\hline \multicolumn{1}{c|}{ Teste } & Valor & Aprox. F & Erro DF & Sig. F \\
\hline Pillais & 2,019 & 65,048 & 1800,00 & 0,000 \\
\hline Hottelings & 8,307 & 86,963 & 1790,00 & 0,000 \\
\hline Wilks & 0,025 & 75,233 & 1783,87 & 0,000 \\
\hline Roys & 0,839 & & & \\
\hline
\end{tabular}

TABELA 36: CORRELAÇÕES CANÔNICAS E AUTOVALORES PARA A EQUAÇÃO DE DEMANDA PERFIL SÓCIO-DEMOGRÁFICO MÉDIO

\begin{tabular}{c|c|c|c}
\hline Raiz & Autovalor & Cor. Canônica & Cor. Quad. \\
\hline 1 & 5,228 & 0,916 & 0,839 \\
\hline 2 & 2,063 & 0,821 & 0,673 \\
\hline 3 & 0,975 & 0,703 & 0,494 \\
\hline
\end{tabular}

TABELA 37: CORRELAÇÕES CANÔNICAS E AUTOVALORES PARA A EQUAÇÃO DE OFERTA PERFIL SÓCIO-DEMOGRÁFICO MÉDIO

\begin{tabular}{c|c|c|c}
\hline Raiz & Autovalor & Cor. Canônica & Cor. Quad. \\
\hline 1 & 5,236 & 0,916 & 0,840 \\
\hline 2 & 2,032 & 0,819 & 0,670 \\
\hline 3 & 1,040 & 0,714 & 0,510 \\
\hline
\end{tabular}


TABELA 38: TESTE UNIVARIADO DE SIGNIFICÂNCIA PARA AS FUNÇÕES CANÔNICAS DA EQUAÇÃO DE DEMANDA - PERFIL SÓCIO-DEMOGRÁFICO MÉDIO

\begin{tabular}{c|c|c|c}
\hline Raiz & Wilks $L$. & Erro DF & Sig. F \\
\hline 1 to 3 & 0,026 & 1785,60 & 0,000 \\
\hline 2 to 3 & 0,165 & 1200,00 & 0,000 \\
\hline 3 to 3 & 0,506 & 601,00 & 0,000 \\
\hline
\end{tabular}

TABELA 39: TESTE UNIVARIADO DE SIGNIFICÂNCIA PARA AS FUNÇÕES CANÔNICAS DA EQUAÇÃO DE OFERTA - PERFIL SÓCIO-DEMOGRÁFICO MÉDIO

\begin{tabular}{c|c|c|c}
\hline Raiz & Wilks L. & Erro DF & Sig. F \\
\hline 1 to 3 & 0,025 & 1783,87 & 0,000 \\
\hline 2 to 3 & 0,161 & 1198,00 & 0,000 \\
\hline 3 to 3 & 0,490 & 600,00 & 0,000 \\
\hline
\end{tabular}

TABELA 40: PESOS CANÔNICOS PADRONIZADOS PARA A PRIMEIRA FUNÇÃO CANÔNICA VARIÁVEIS DEPENDENTES - EQUAÇÃO DE DEMANDA - PERFIL SÓCIODEMOGRÁFICO MÉDIO

\begin{tabular}{c|c}
\hline Variável & FUNÇÃO 1 \\
\hline DPDAREA & 0,449 \\
\hline $\mathrm{C}$ & $-0,403$ \\
\hline $\mathrm{V}$ & $-0,508$ \\
\hline
\end{tabular}

TABELA 41: PESOS CANÔNICOS PADRONIZADOS PARA A PRIMEIRA FUNÇÃO CANÔNICA VARIÁVEIS DEPENDENTES - EQUAÇÃO DE OFERTA - PERFIL SÓCIO-DEMOGRÁFICO MÉDIO

\begin{tabular}{c|c}
\hline Variável & FUNÇÃO 1 \\
\hline DPDAREA & $-0,436$ \\
\hline $\mathrm{C}$ & 0,348 \\
\hline $\mathrm{V}$ & 0,568 \\
\hline
\end{tabular}


TABELA 42: PESOS CANÔNICOS PADRONIZADOS PARA A PRIMEIRA FUNÇÃO CANÔNICA VARIÁVEIS INDEPENDENTES - EQUAÇÃO DE DEMANDA - PERFIL SÓCIODEMOGRÁFICO MÉDIO

\begin{tabular}{|c|c|}
\hline Variável & FUNÇÃO 1 \\
\hline LNAREA & $-2,037$ \\
\hline SJOG & $-0,02$ \\
\hline PISC & 0,118 \\
\hline SAUN & 0,214 \\
\hline QUAD & 0,221 \\
\hline CFTV & 0,131 \\
\hline VARD & 0,072 \\
\hline VAGA2 & 0,332 \\
\hline DORM2 & 0,617 \\
\hline DORM3 & 0,286 \\
\hline BANH2 & 0,363 \\
\hline COLP & 0,141 \\
\hline SHOP & 0,065 \\
\hline METR & 0,028 \\
\hline HOSP & 0,068 \\
\hline PARQ & $-0,043$ \\
\hline ATER & 0,072 \\
\hline LNMEMB & 0,045 \\
\hline
\end{tabular}


TABELA 43: PESOS CANÔNICOS PADRONIZADOS PARA A PRIMEIRA FUNÇÃO CANÔNICA VARIÁVEIS INDEPENDENTES - EQUAÇÃO DE OFERTA - PERFIL SÓCIODEMOGRÁFICO MÉDIO

\begin{tabular}{|c|c|}
\hline Variável & FUNÇÃO 1 \\
\hline LNAREA & 1,977 \\
\hline SJOG & 0,008 \\
\hline PISC & $-0,116$ \\
\hline SAUN & $-0,216$ \\
\hline QUAD & $-0,219$ \\
\hline CFTV & $-0,139$ \\
\hline VARD & $-0,064$ \\
\hline VAGA2 & $-0,297$ \\
\hline DORM2 & $-0,559$ \\
\hline DORM3 & $-0,266$ \\
\hline BANH2 & $-0,345$ \\
\hline COLP & $-0,144$ \\
\hline SHOP & 0,047 \\
\hline METR & $-0,179$ \\
\hline HOSP & $-0,023$ \\
\hline PARQ & 0,062 \\
\hline ATER & $-0,093$ \\
\hline LNDENS & $-0,116$ \\
\hline LNPOP & 0,129 \\
\hline
\end{tabular}

TABELA 44: CORRELAÇÕES ENTRE AS VARIÁVEIS DEPENDENTES E AS VARIÁVEIS CANÔNICAS EQUAÇÃO DE DEMANDA - PERFIL SÓCIO-DEMOGRÁFICO MÉDIO

\begin{tabular}{c|c}
\hline Variável & FUNÇÃO 1 \\
\hline DPDAREA & 0,439 \\
\hline $\mathrm{C}$ & $-0,880$ \\
\hline $\mathrm{V}$ & $-0,883$ \\
\hline
\end{tabular}

TABELA 45: CORRELAÇÕES ENTRE AS VARIÁVEIS DEPENDENTES E AS VARIÁVEIS CANÔNICAS EQUAÇÃO DE OFERTA - PERFIL SÓCIO-DEMOGRÁFICO MÉDIO

\begin{tabular}{c|c}
\hline Variável & FUNÇÃO 1 \\
\hline DPDAREA & $-0,426$ \\
\hline $\mathrm{C}$ & 0,883 \\
\hline $\mathrm{V}$ & 0,892 \\
\hline
\end{tabular}


TABELA 46: CORRELAÇÕES ENTRE AS VARIÁVEIS INDEPENDENTES E AS VARIÁVEIS CANÔNICAS - EQUAÇÃO DE DEMANDA - PERFIL SÓCIO-DEMOGRÁFICO MÉDIO

\begin{tabular}{|c|c|}
\hline Variável & FUNÇÃO 1 \\
\hline LNAREA & $-0,928$ \\
\hline SJOG & $-0,452$ \\
\hline PISC & $-0,267$ \\
\hline SAUN & 0,412 \\
\hline QUAD & $-0,409$ \\
\hline CFTV & $-0,575$ \\
\hline VARD & $-0,281$ \\
\hline VAGA2 & $-0,334$ \\
\hline DORM2 & $-0,657$ \\
\hline DORM3 & $-0,381$ \\
\hline BANH2 & $-0,389$ \\
\hline COLP & $-0,033$ \\
\hline SHOP & 0,036 \\
\hline METR & 0,001 \\
\hline HOSP & 0,001 \\
\hline PARQ & 0,001 \\
\hline ATER & $-0,001$ \\
\hline LNMEMB & $-0,059$ \\
\hline
\end{tabular}


TABELA 47: CORRELAÇÕES ENTRE AS VARIÁVEIS INDEPENDENTES E AS VARIÁVEIS CANÔNICAS - EQUAÇÃO DE OFERTA - PERFIL SÓCIO-DEMOGRÁFICO MÉDIO

\begin{tabular}{|c|c|}
\hline Variável & FUNÇÃO 1 \\
\hline LNAREA & $-0,932$ \\
\hline SJOG & 0,442 \\
\hline PISC & 0,261 \\
\hline SAUN & $-0,407$ \\
\hline QUAD & 0,411 \\
\hline CFTV & 0,580 \\
\hline VARD & 0,274 \\
\hline VAGA2 & 0,338 \\
\hline DORM2 & 0,666 \\
\hline DORM3 & 0,386 \\
\hline BANH2 & 0,385 \\
\hline COLP & 0,031 \\
\hline SHOP & $-0,034$ \\
\hline METR & $-0,002$ \\
\hline HOSP & $-0,001$ \\
\hline PARQ & $-0,001$ \\
\hline ATER & 0,003 \\
\hline LNDENS & $-0,094$ \\
\hline LNPOP & $-0,098$ \\
\hline
\end{tabular}

TABELA 48: ÍNDICE DE REDUNDÂNCIA - PERFIL SÓCIO-DEMOGRÁFICO MÉDIO

\begin{tabular}{c|c|c|c}
\hline \multirow{2}{*}{ DEMANDA } & $\begin{array}{c}\text { Média var. compart. } \\
\text { No próprio conjunto }\end{array}$ & $\begin{array}{c}\text { Correlação ao } \\
\text { quadrado }\end{array}$ & $\begin{array}{c}\text { Índice de } \\
\text { redundância }\end{array}$ \\
\cline { 2 - 4 } & 0,582 & 0,839 & 0,488 (Dep.) \\
\hline \multirow{2}{*}{ OFERTA } & 0,152 & 0,839 & 0,128 (Indep.) \\
\cline { 2 - 4 } & 0,586 & 0,840 & 0,492 (Dep.) \\
\hline
\end{tabular}




\section{K) PERFIL SÓCIO-DEMOGRÁFICO ALTO}

\section{K.1) Caracterização da Amostra}

GRÁFICO 55: FREQUÊNCIA DE PREÇOS NA AMOSTRA DE PERFIL SÓCIO-DEMOGRÁFICO ALTO

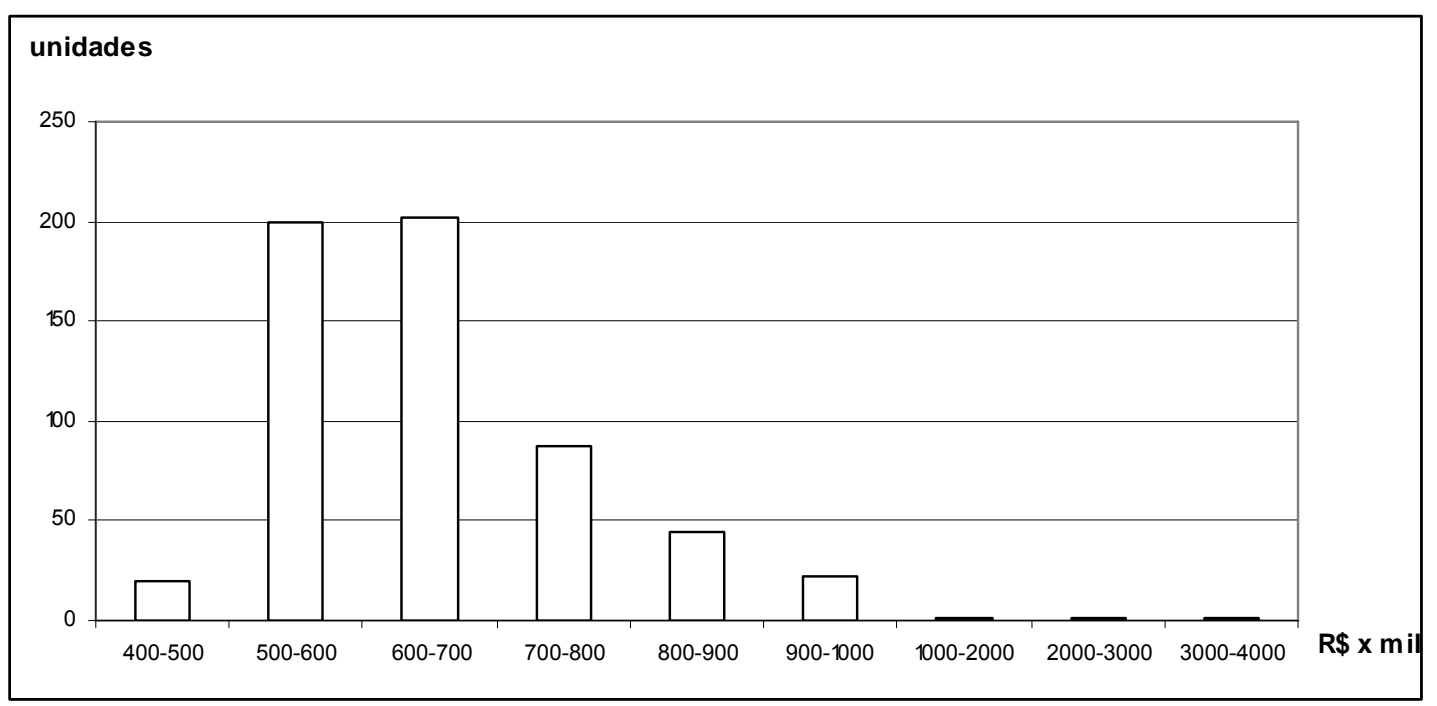

GRÁFICO 56: FREQUÊNCIA DE ÁREA TOTAL NA AMOSTRA DE PERFIL SÓCIO-DEMOGRÁFICO ALTO

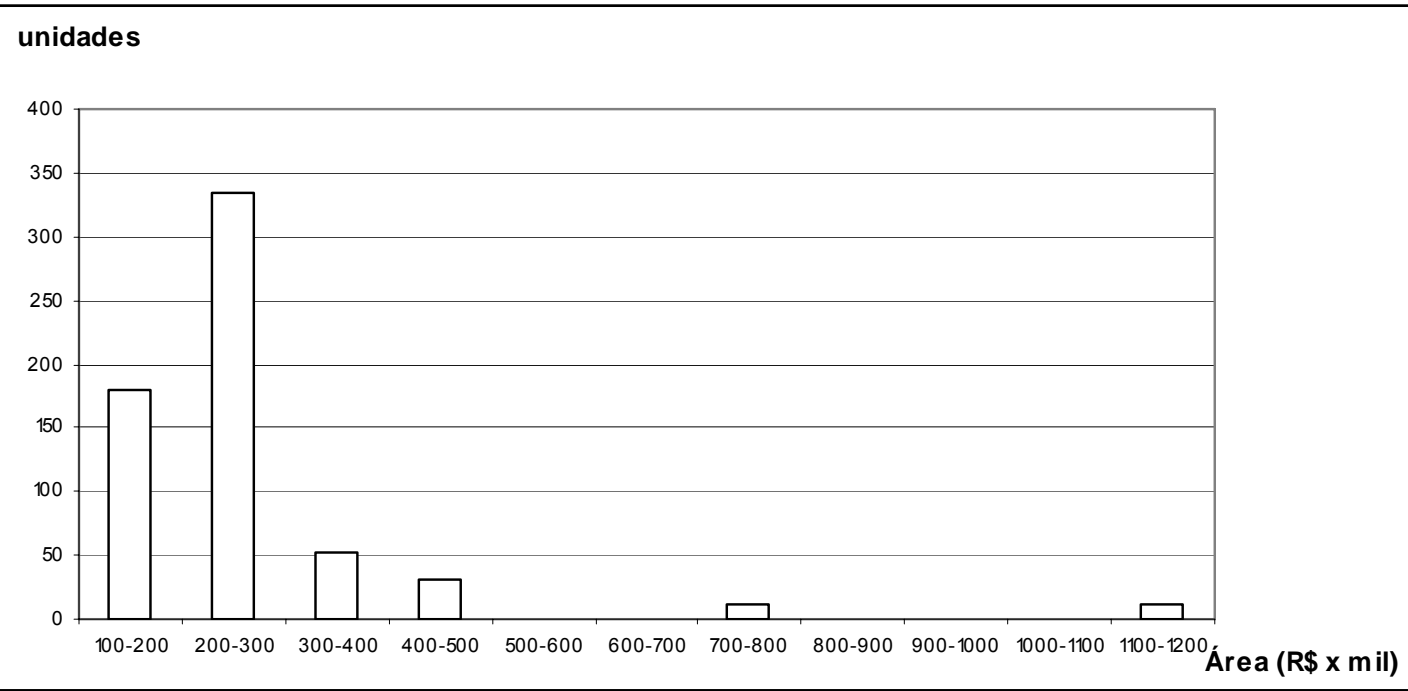


GRÁFICO 57: FREQUÊNCIA DE EXISTÊNCIA DE SALÃO DE FESTAS NA AMOSTRA DE PERFIL SÓCIO-DEMOGRÁFICO ALTO

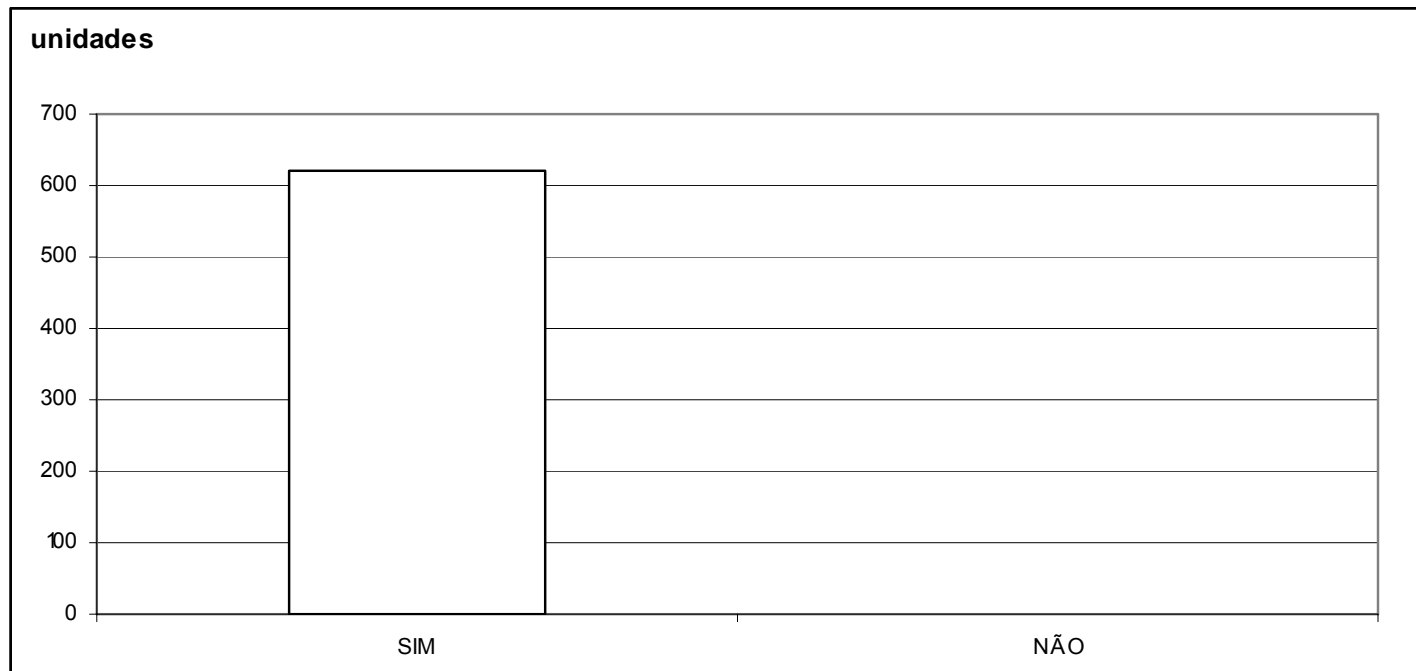

GRÁFICO 58: FREQUÊNCIA DE EXISTÊNCIA DE SALÃO DE JOGOS NA AMOSTRA DE PERFIL SÓCIO-DEMOGRÁFICO ALTO

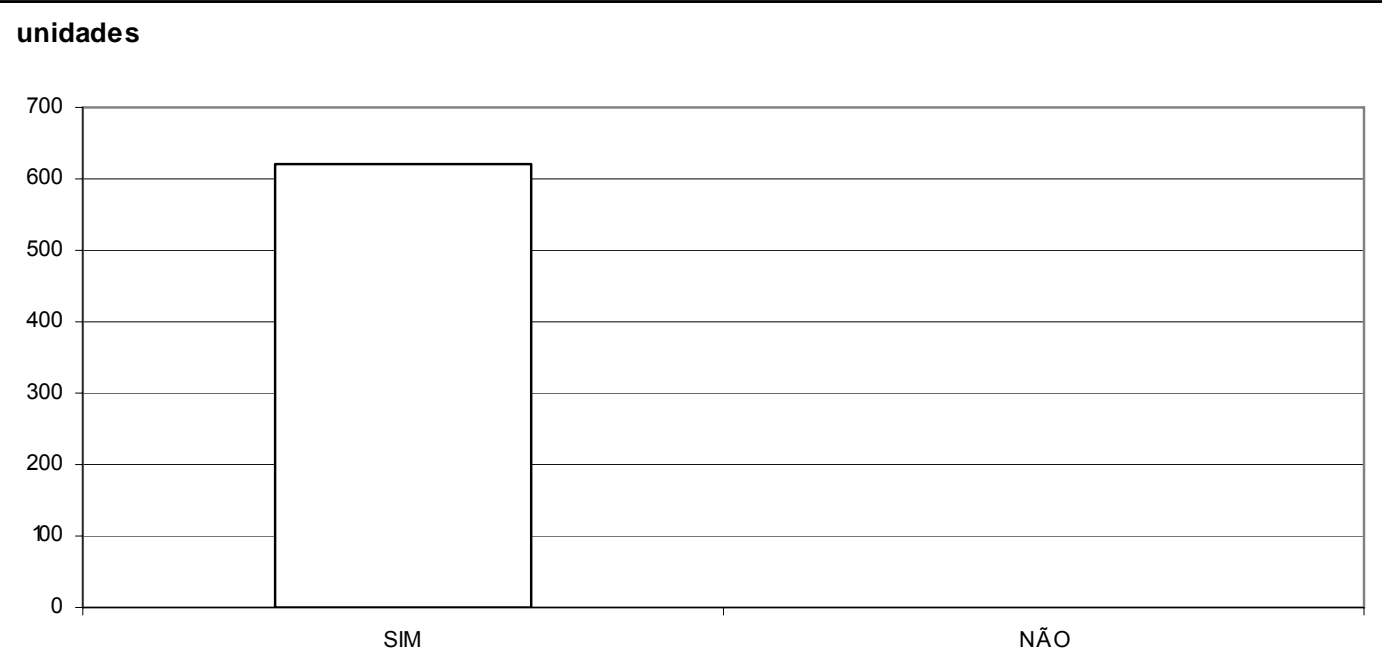


GRÁFICO 59: FREQUÊNCIA DE EXISTÊNCIA DE SALA DE GINÁSTICA NA AMOSTRA DE PERFIL SÓCIO-DEMOGRÁFICO ALTO

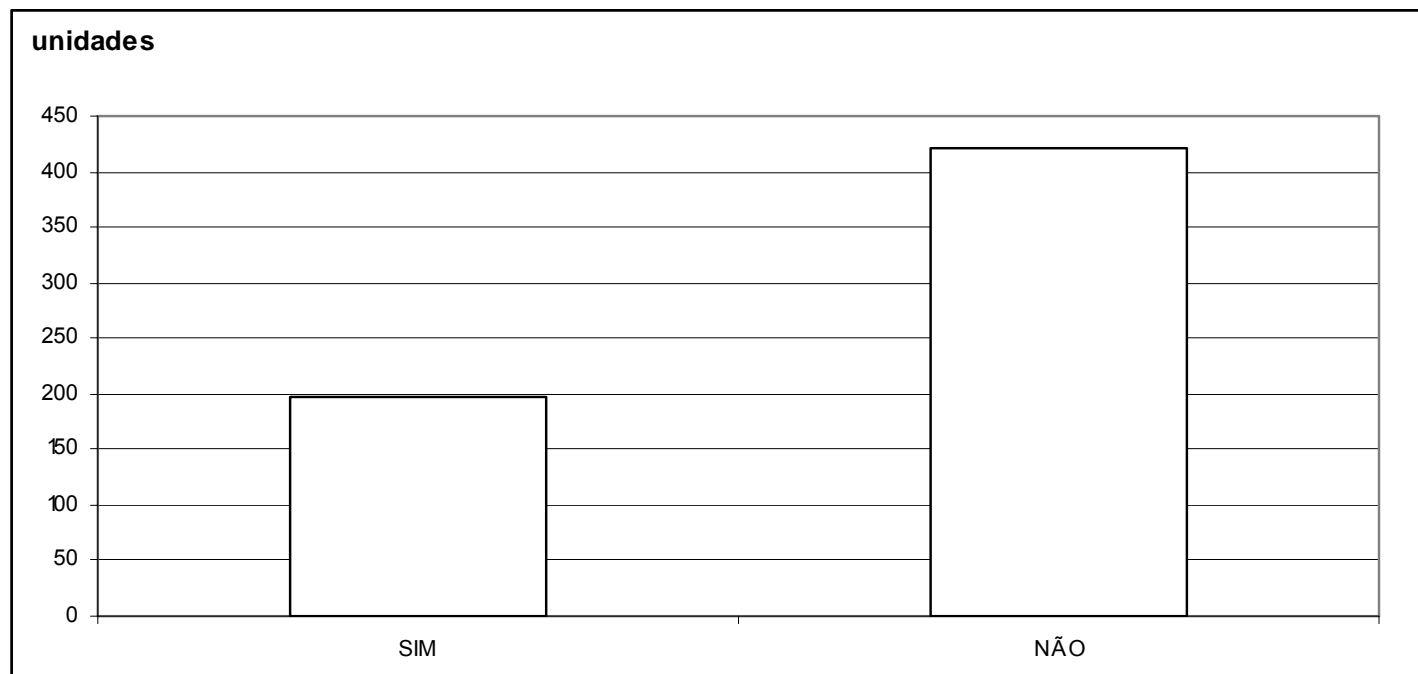

GRÁFICO 60: FREQUÊNCIA DE EXISTÊNCIA DE PISCINA NA AMOSTRA DE PERFIL SÓCIODEMOGRÁFICO ALTO

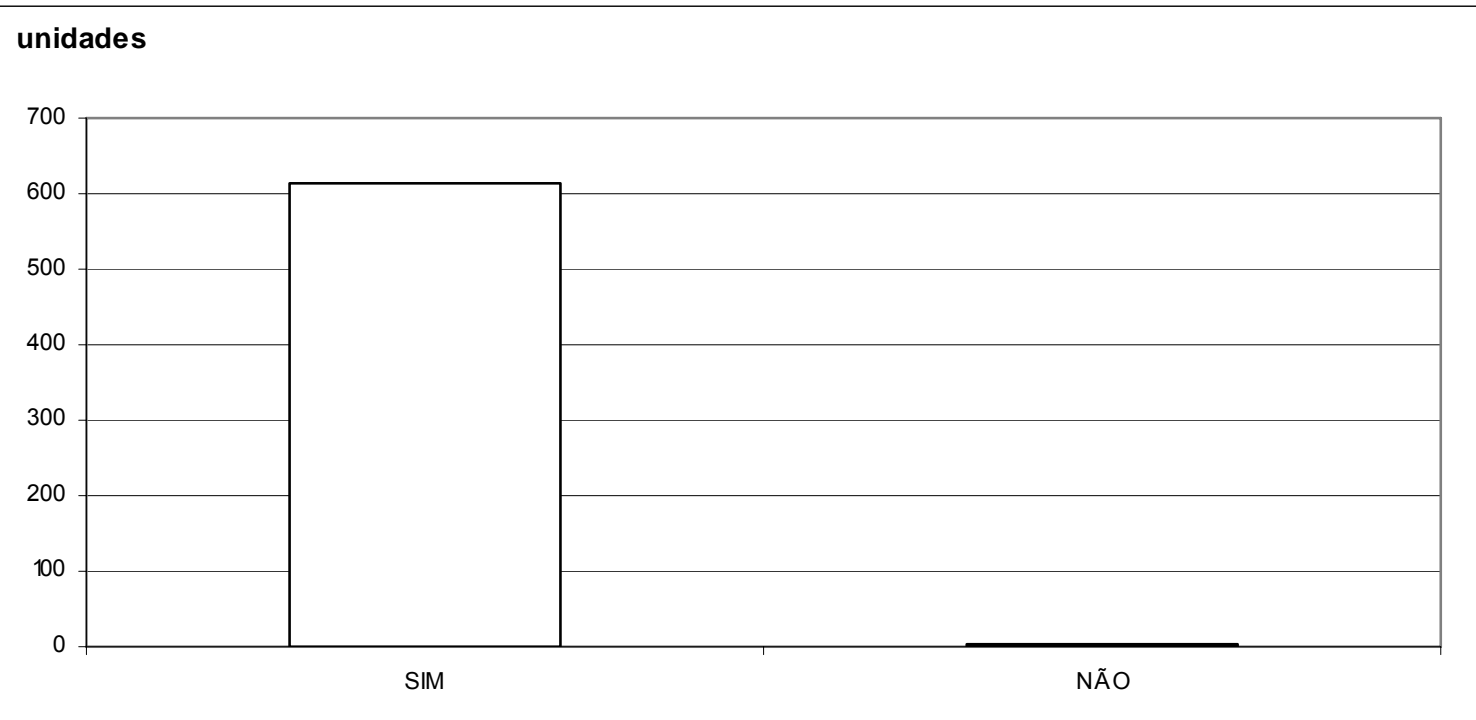


GRÁFICO 61: FREQUÊNCIA DE EXISTÊNCIA DE SAUNA NA AMOSTRA DE PERFIL SÓCIODEMOGRÁFICO ALTO

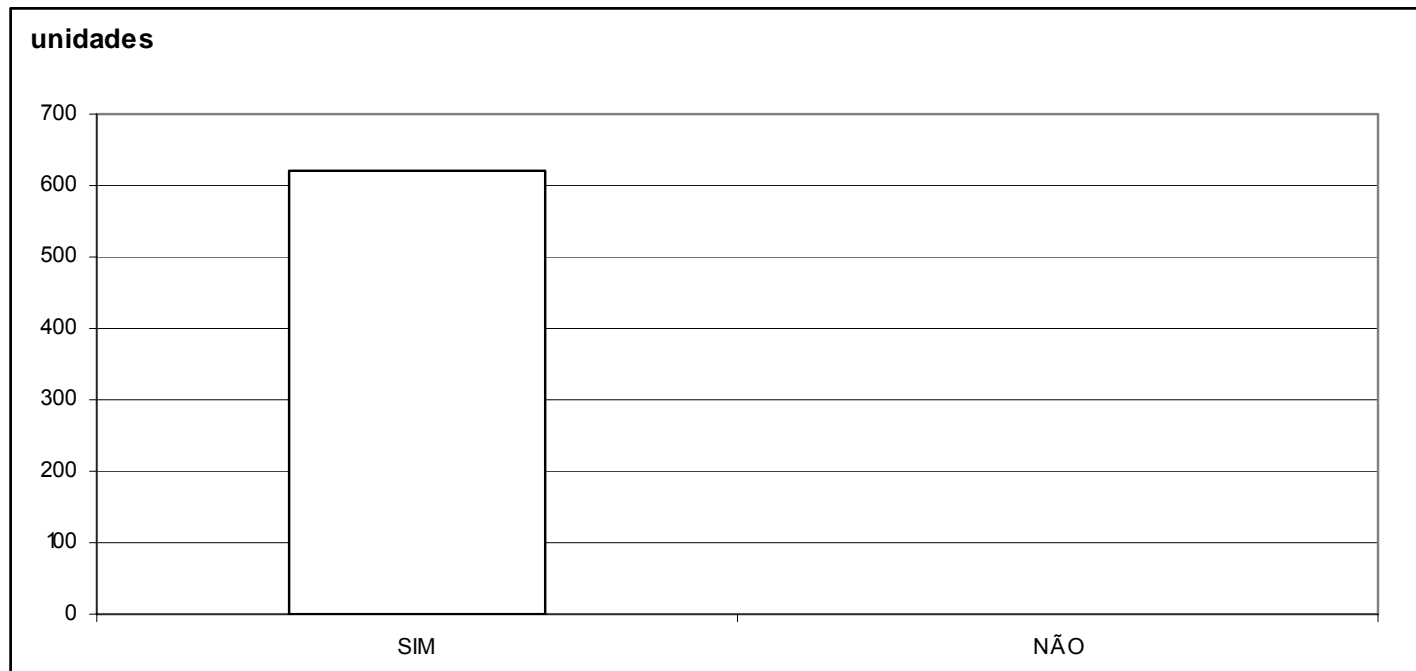

GRÁFICO 62: FREQUÊNCIA DE EXISTÊNCIA DE CHURRASQUEIRA NA AMOSTRA DE PERFIL SÓCIO-DEMOGRÁFICO ALTO

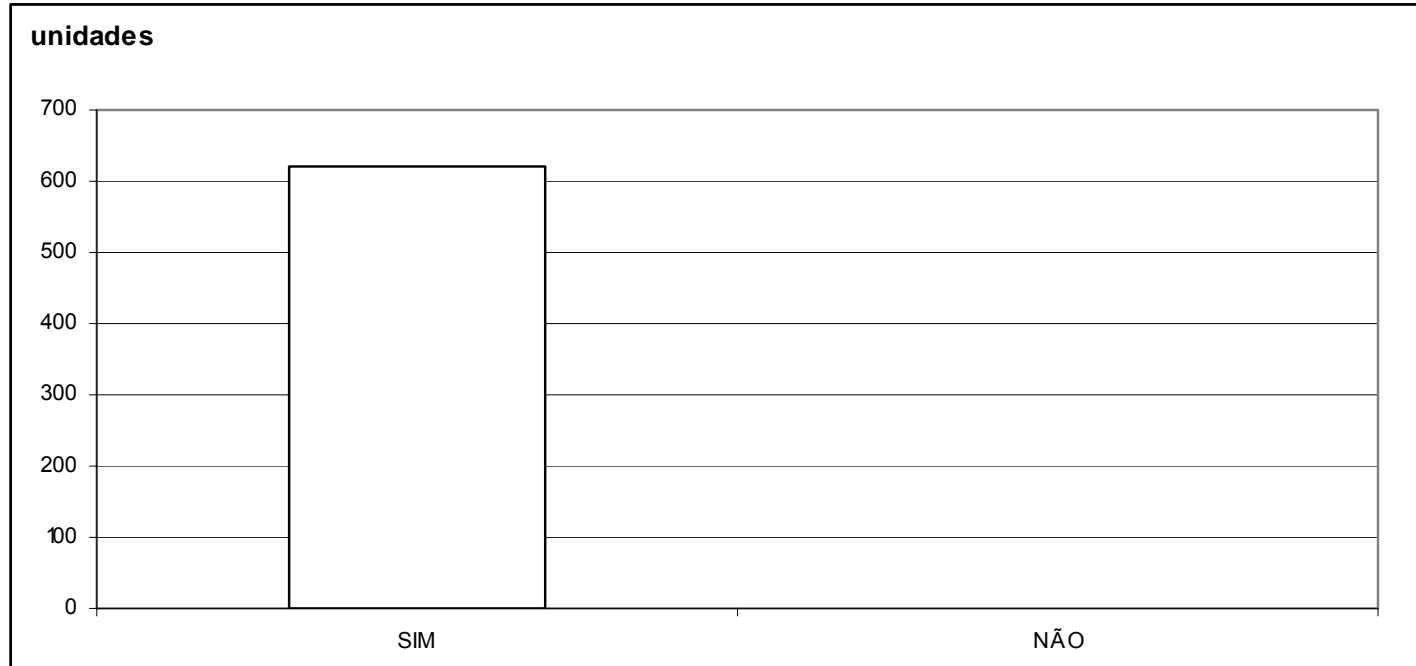


GRÁFICO 63: FREQUÊNCIA DE EXISTÊNCIA DE QUADRA NA AMOSTRA DE PERFIL SÓCIODEMOGRÁFICO ALTO

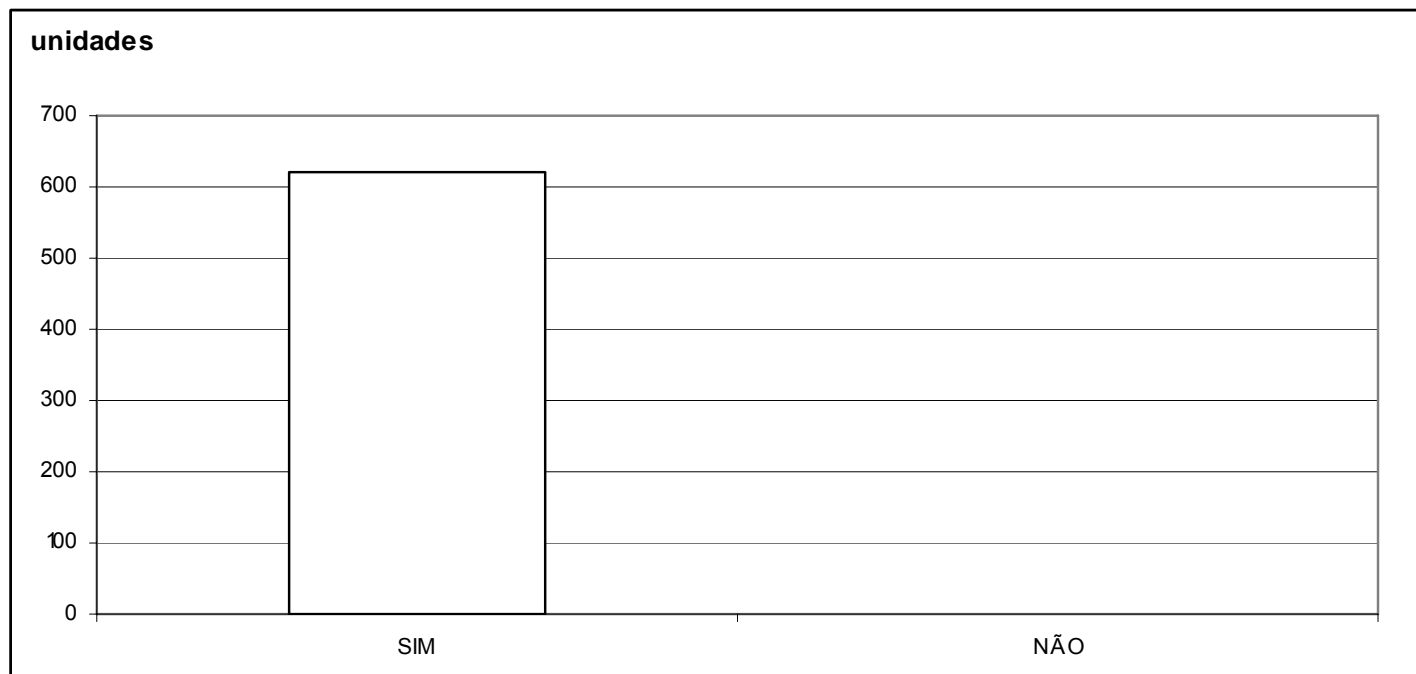

GRÁFICO 64: FREQUÊNCIA DE EXISTÊNCIA DE GUARITA NA AMOSTRA DE PERFIL SÓCIODEMOGRÁFICO ALTO

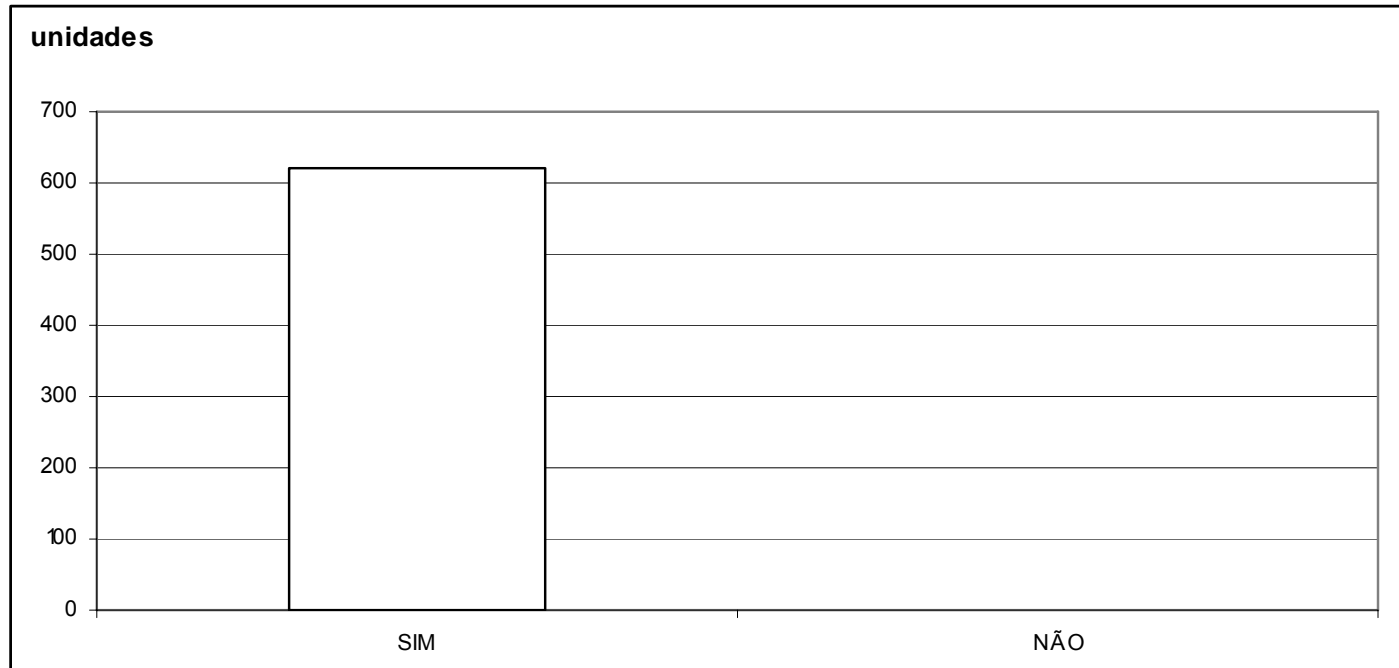


GRÁFICO 65: FREQUÊNCIA DE EXISTÊNCIA DE CFTV NA AMOSTRA DE PERFIL SÓCIODEMOGRÁFICO ALTO

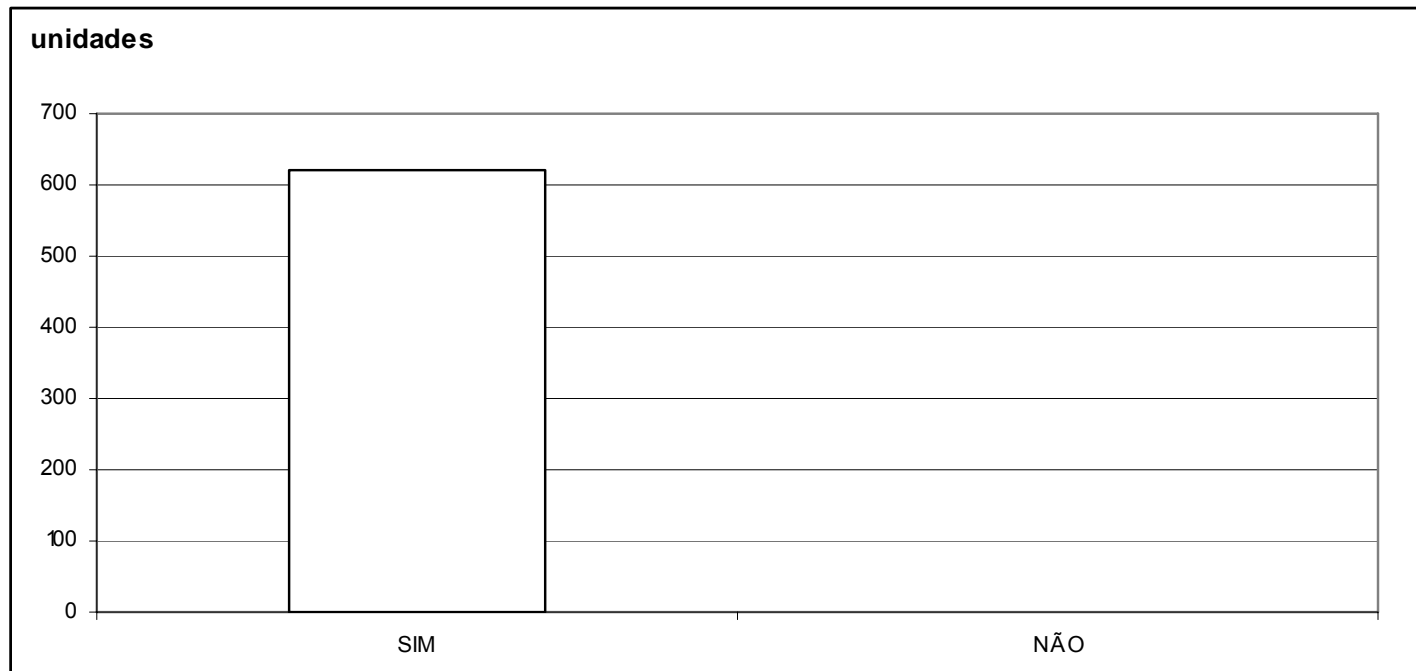

GRÁFICO 66: FREQUÊNCIA DE EXISTÊNCIA DE VARANDA NA AMOSTRA DE PERFIL SÓCIODEMOGRÁFICO ALTO

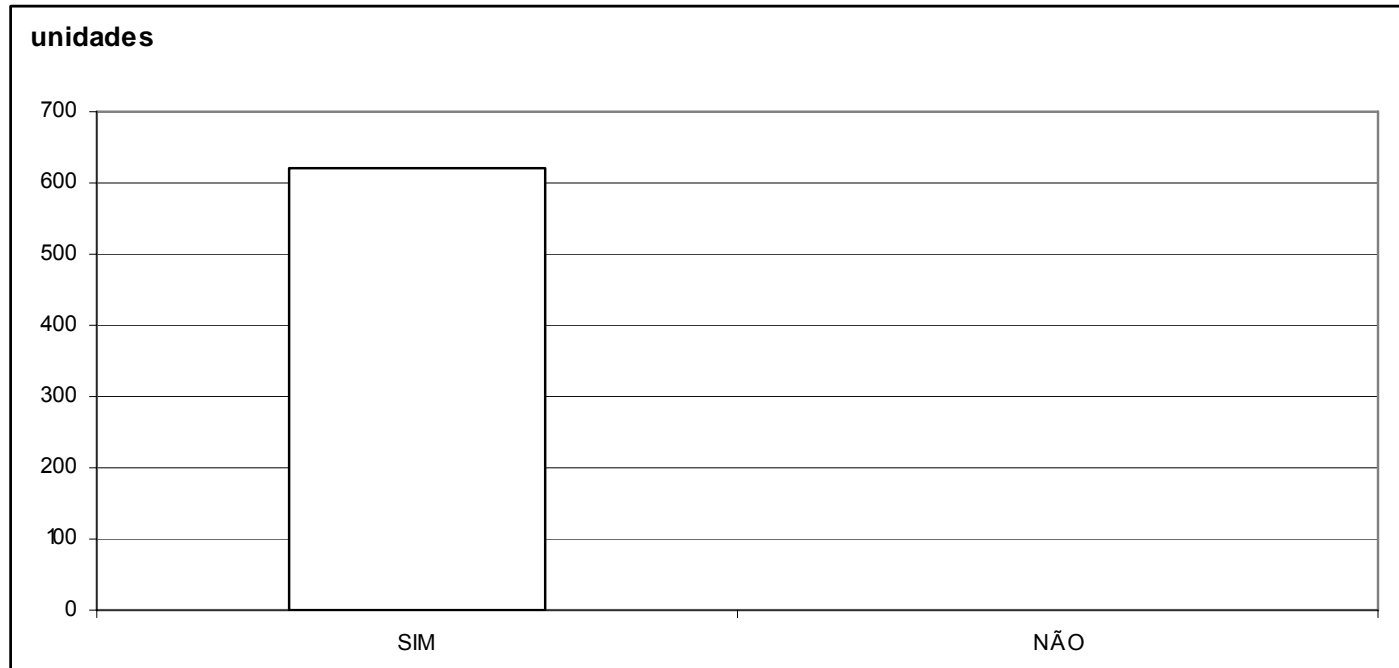


GRÁFICO 67: FREQUÊNCIA DE IMÓVEIS QUE SE ENCONTRAM NA METADE SUPERIOR DO EDIFÍCIO PARA A AMOSTRA DE PERFIL SÓCIO-DEMOGRÁFICO ALTO

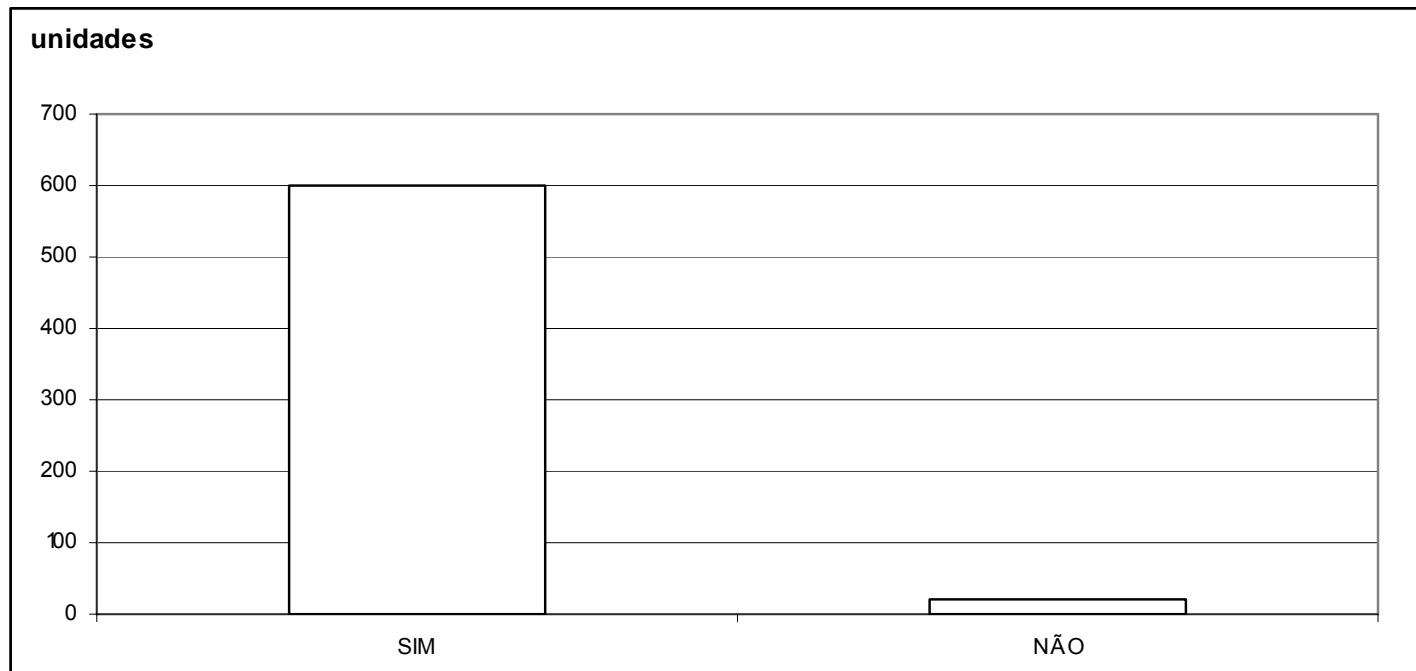

GRÁFICO 68: FREQUÊNCIA DE NÚMERO DE VAGAS NA GARAGEM PARA A AMOSTRA DE PERFIL SÓCIO-DEMOGRÁFICO ALTO

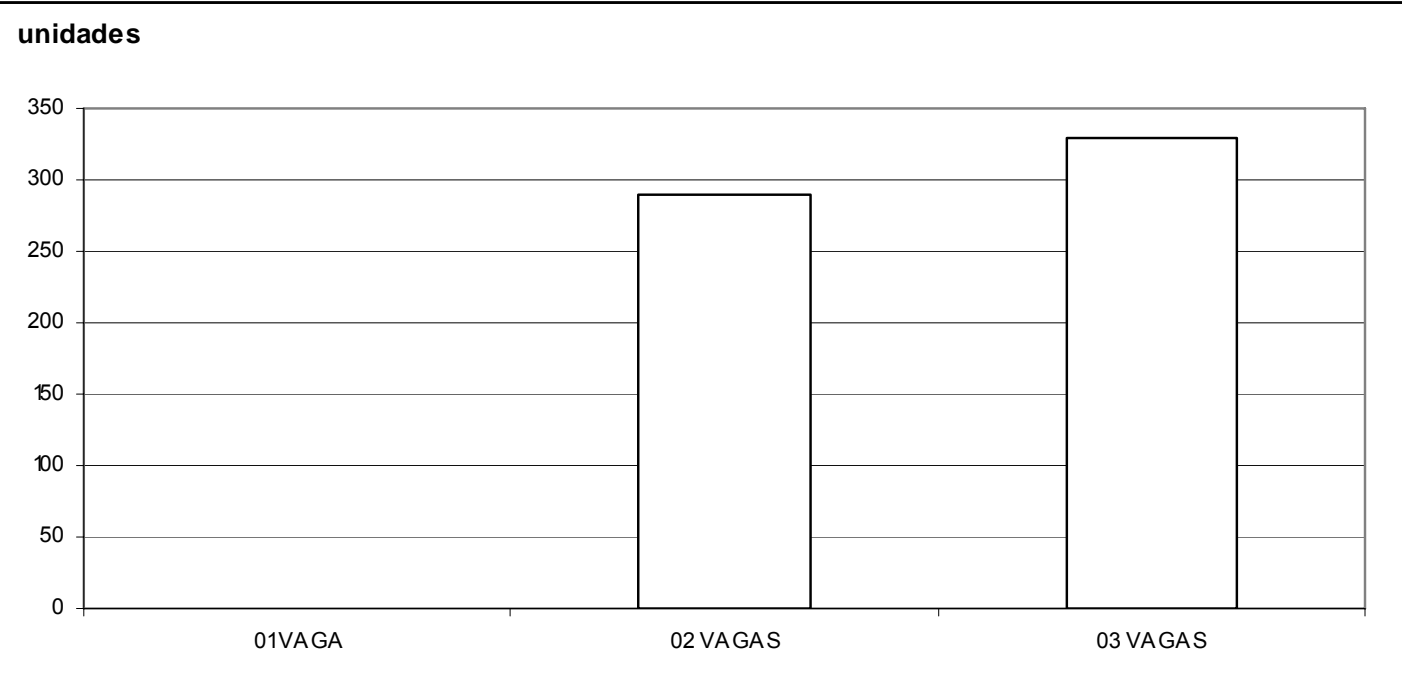


GRÁFICO 69: FREQUÊNCIA DE NÚMERO DE DORMITÓRIOS PARA A AMOSTRA DE PERFIL SÓCIODEMOGRÁFICO ALTO

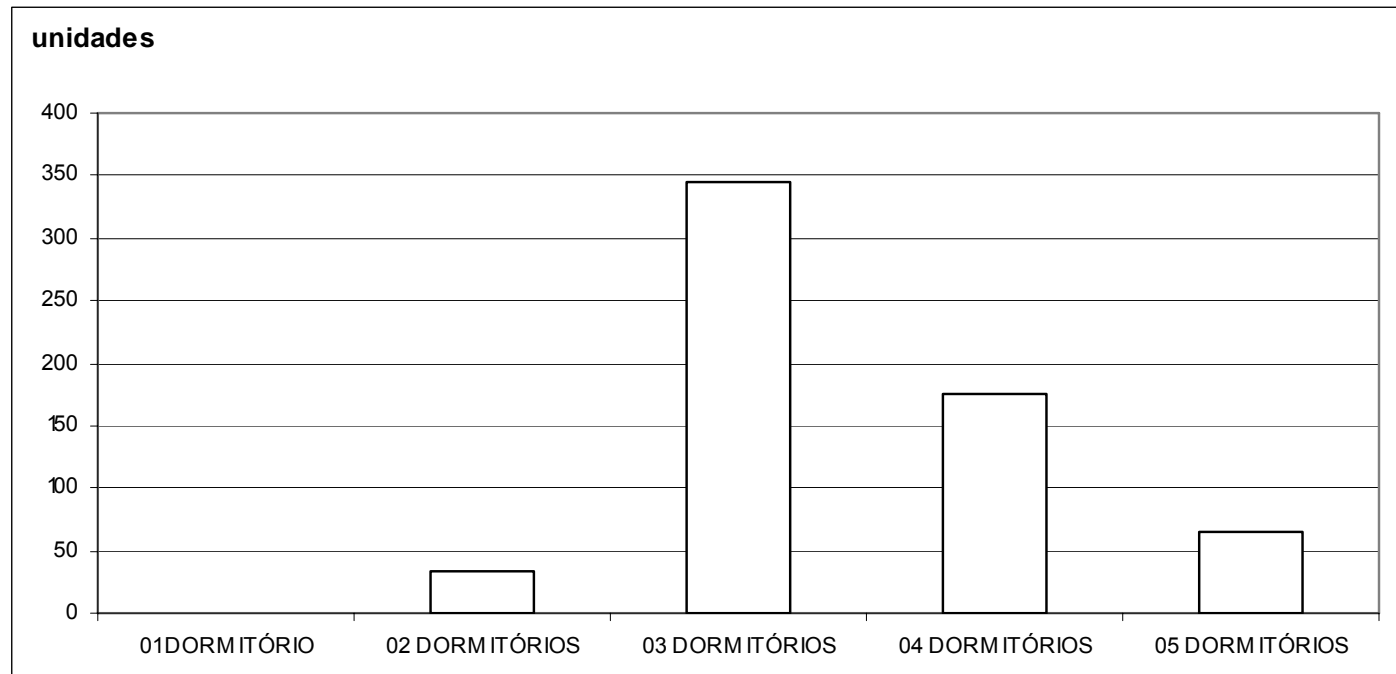

GRÁFICO 70: FREQUÊNCIA DE NÚMERO DE BANHEIROS PARA A AMOSTRA DE PERFIL SÓCIODEMOGRÁFICO ALTO

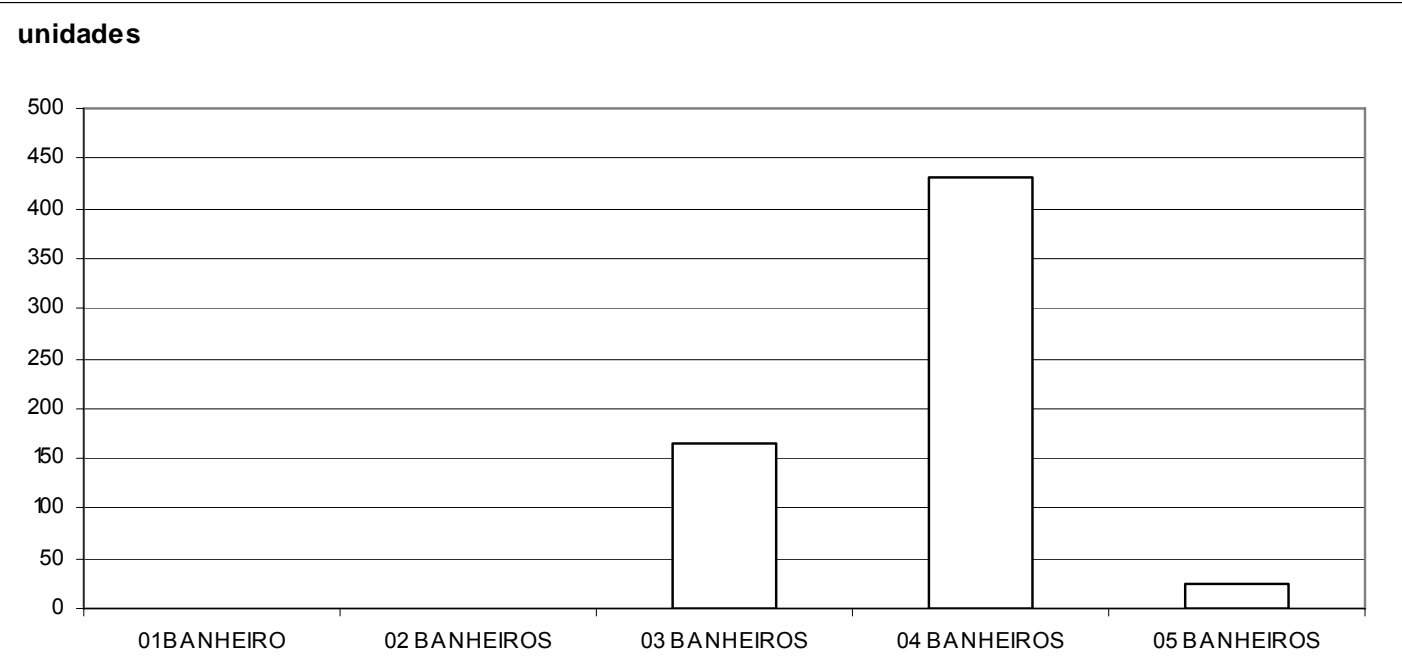


GRÁFICO 71: FREQUÊNCIA DE RENDA FAMILIAR NA AMOSTRA DE PERFIL SÓCIO-DEMOGRÁFICO ALTO

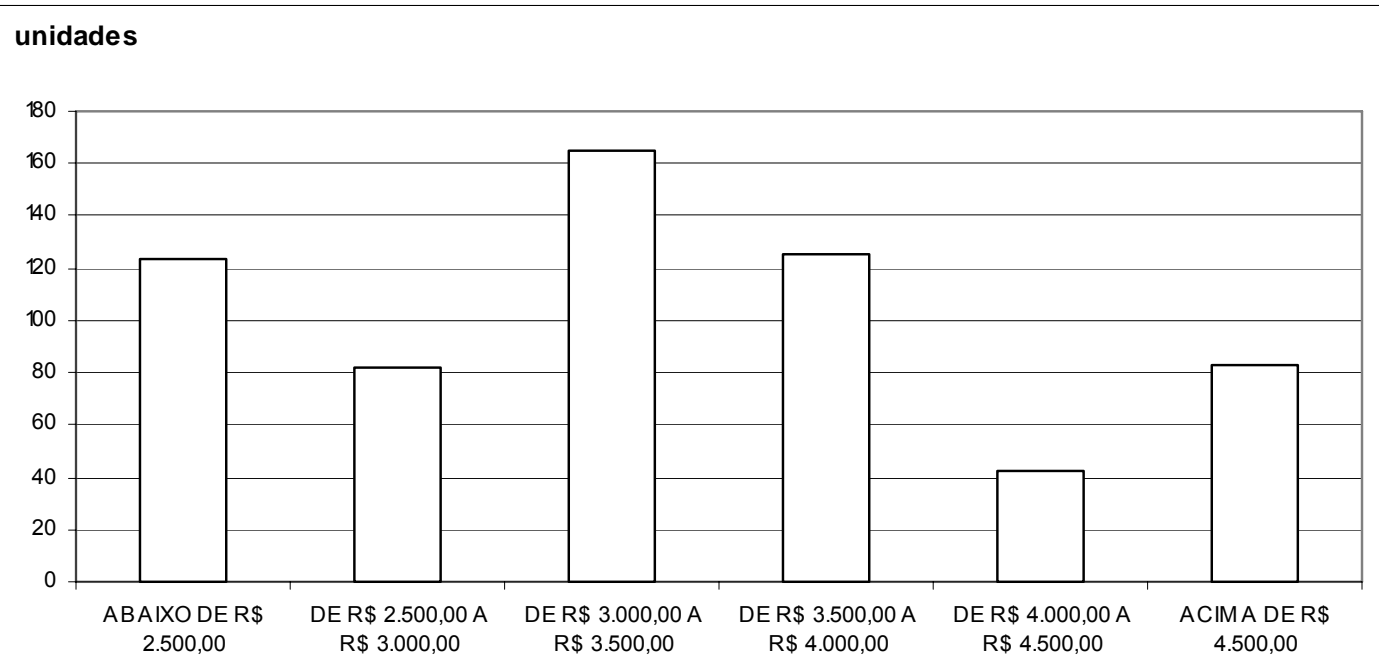

GRÁFICO 72: FREQUÊNCIA DE MEMBROS NA FAMÍLIA NA AMOSTRA DE PERFIL SÓCIODEMOGRÁFICO ALTO

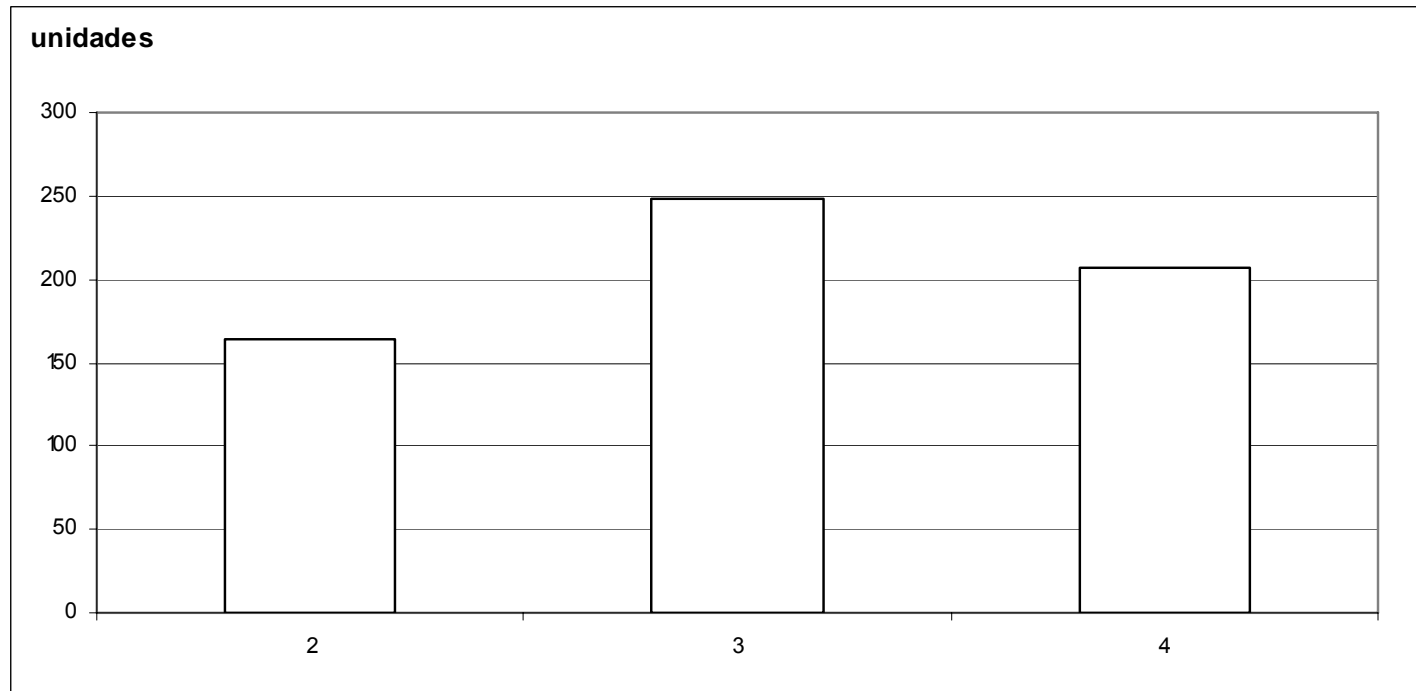


GRÁFICO 73: FREQUÊNCIA DE DENSIDADE DEMOGRÁFICA NA AMOSTRA DE PERFIL SÓCIODEMOGRÁFICO ALTO

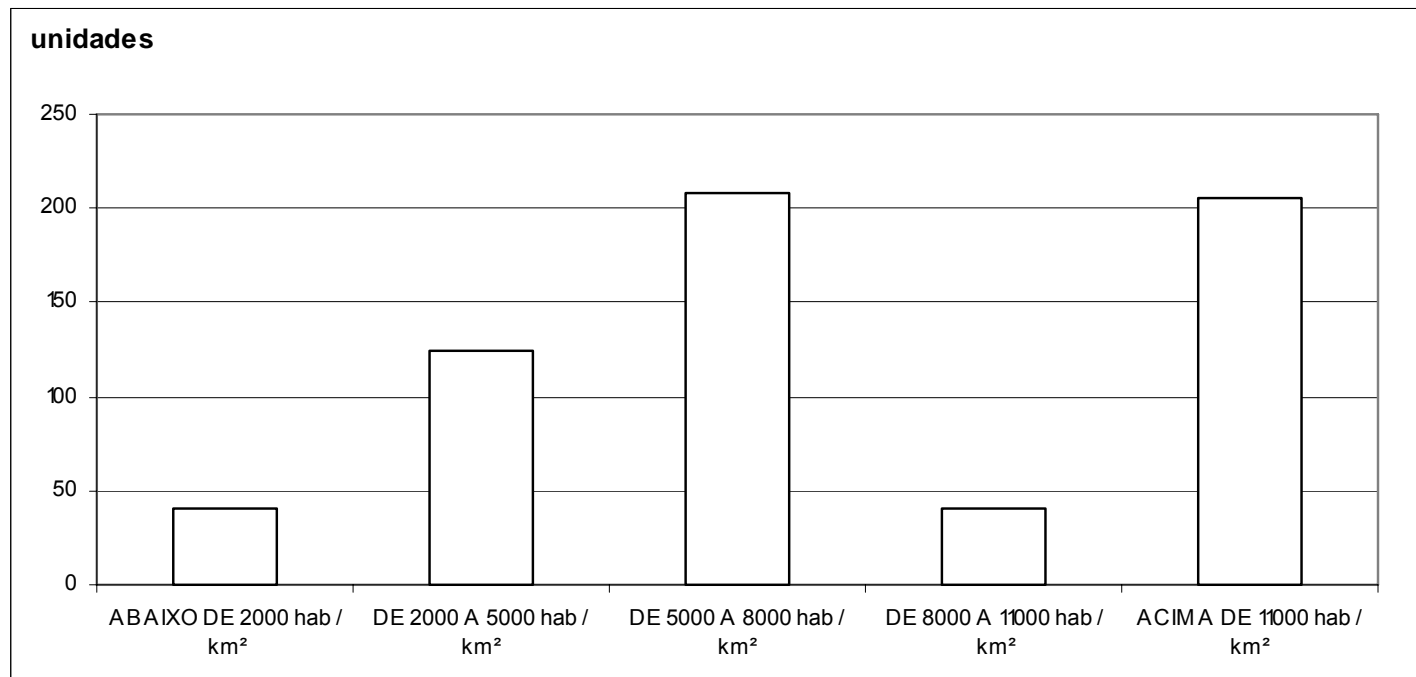

GRÁFICO 74: FREQUÊNCIA DE POPULAÇÃO NA AMOSTRA DE PERFIL SÓCIO-DEMOGRÁFICO ALTO

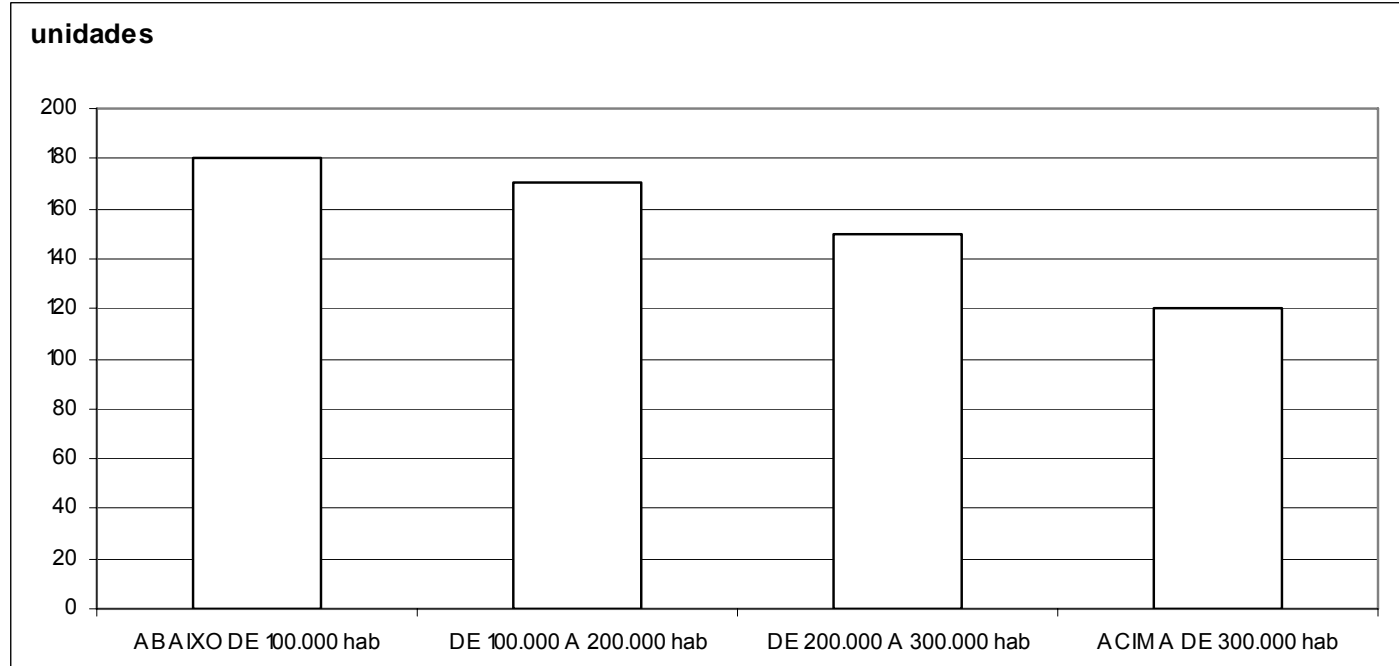


GRÁFICO 75: FREQUÊNCIA DE COLÉGIO PARTICULAR NA AMOSTRA DE PERFIL SÓCIODEMOGRÁFICO ALTO

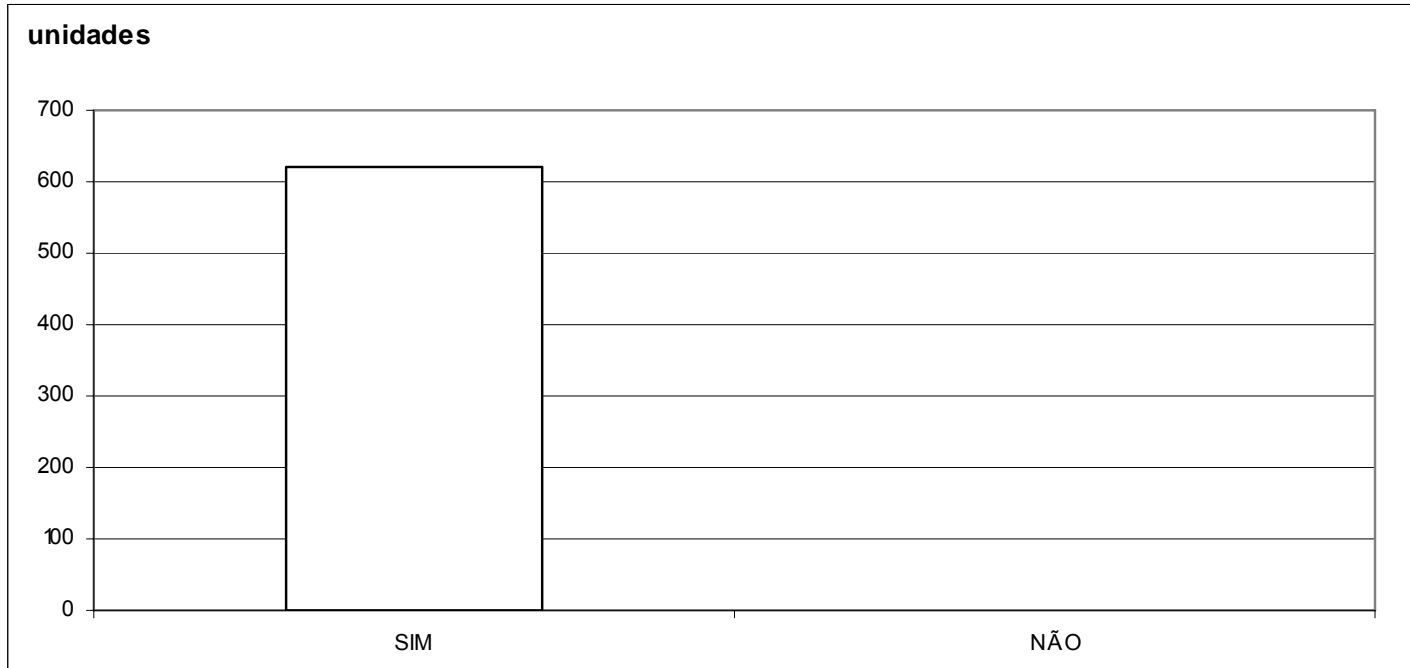

GRÁFICO 76: FREQUÊNCIA DE SHOPPING CENTER NA AMOSTRA DE PERFIL SÓCIODEMOGRÁFICO ALTO

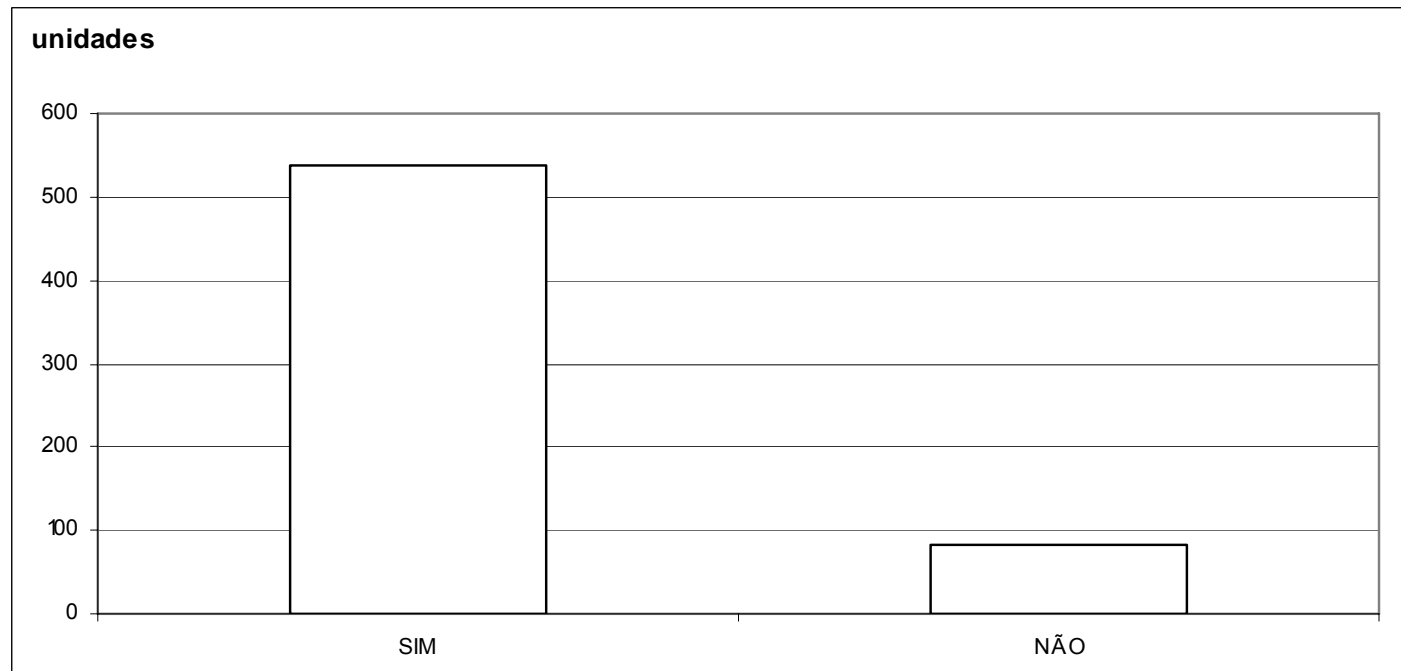


GRÁFICO 77: FREQUÊNCIA DE METRÔ NA AMOSTRA DE PERFIL SÓCIO-DEMOGRÁFICO ALTO

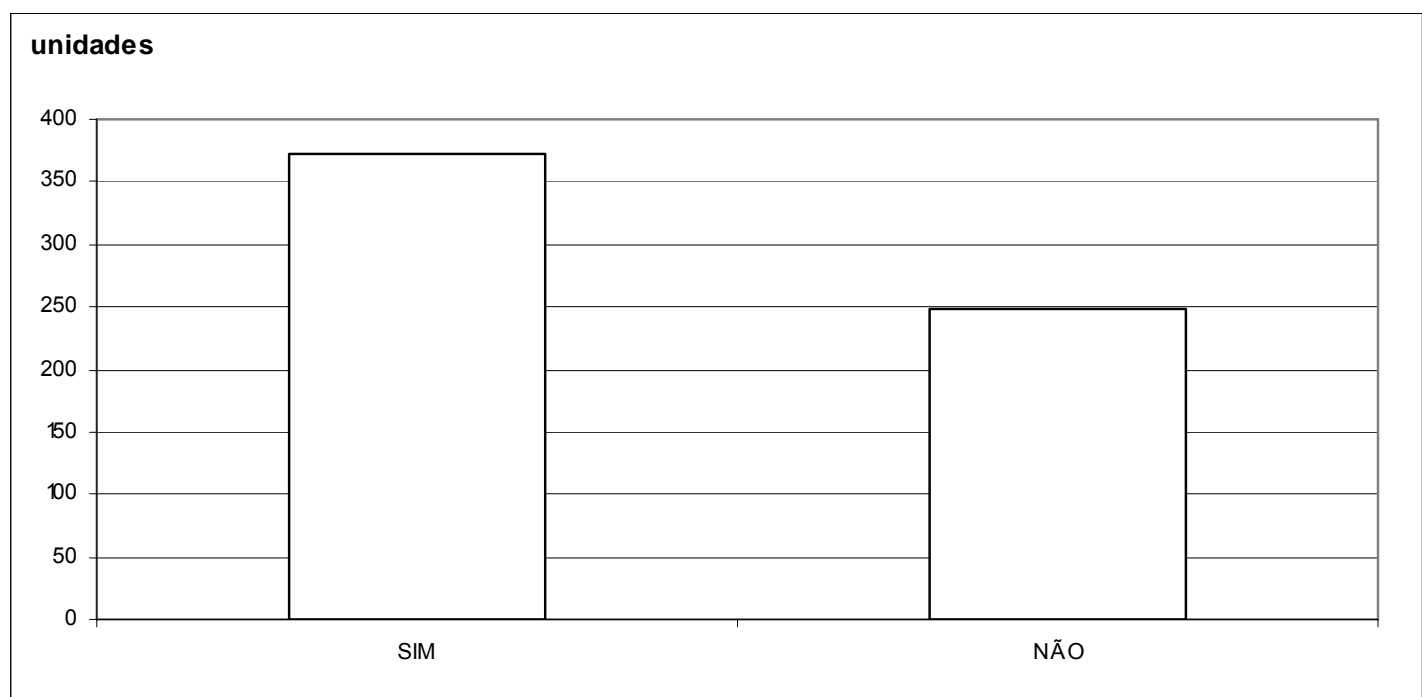

GRÁFICO 78: FREQUÊNCIA DE HOSPITAL PARTICULAR NA AMOSTRA DE PERFIL SÓCIODEMOGRÁFICO ALTO

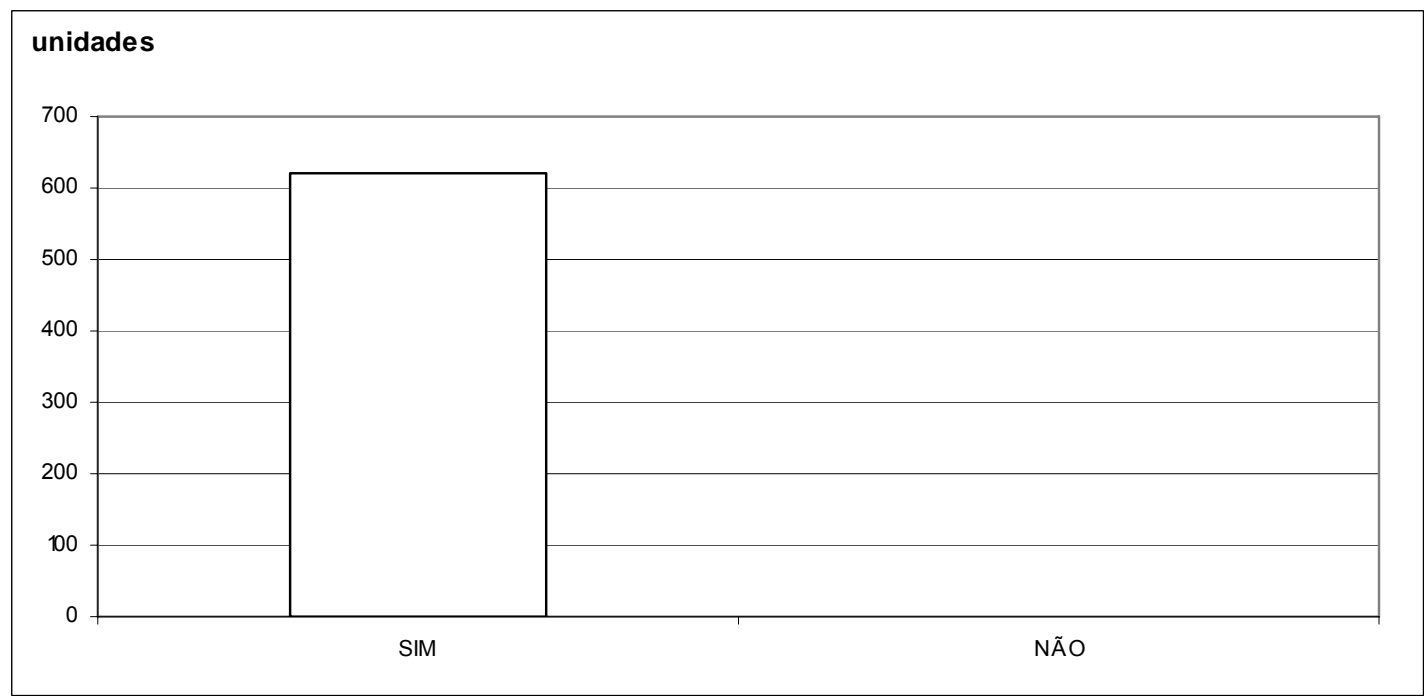


GRÁFICO 79: FREQUÊNCIA DE PARQUES E ÁREAS VERDES NA AMOSTRA DE PERFIL SÓCIODEMOGRÁFICO ALTO

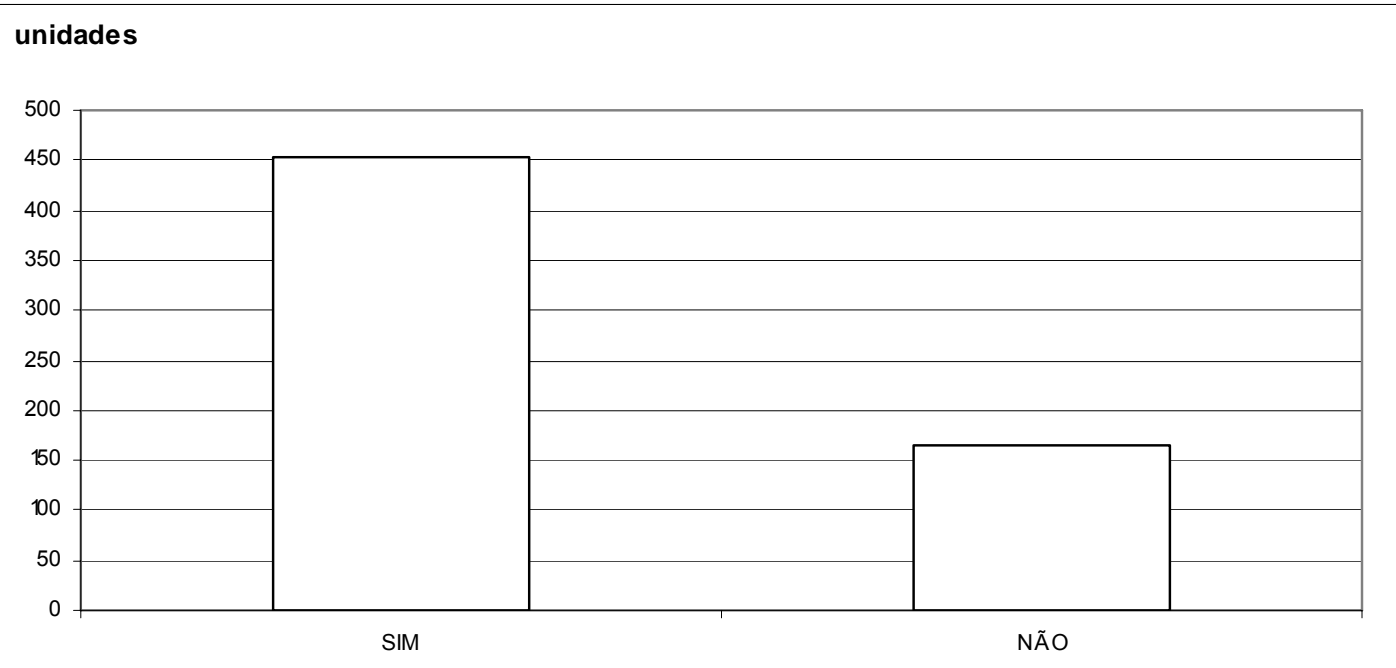

GRÁFICO 80: FREQUÊNCIA DE PONTOS DE INUNDAÇÃO NA AMOSTRA DE PERFIL SÓCIODEMOGRÁFICO ALTO

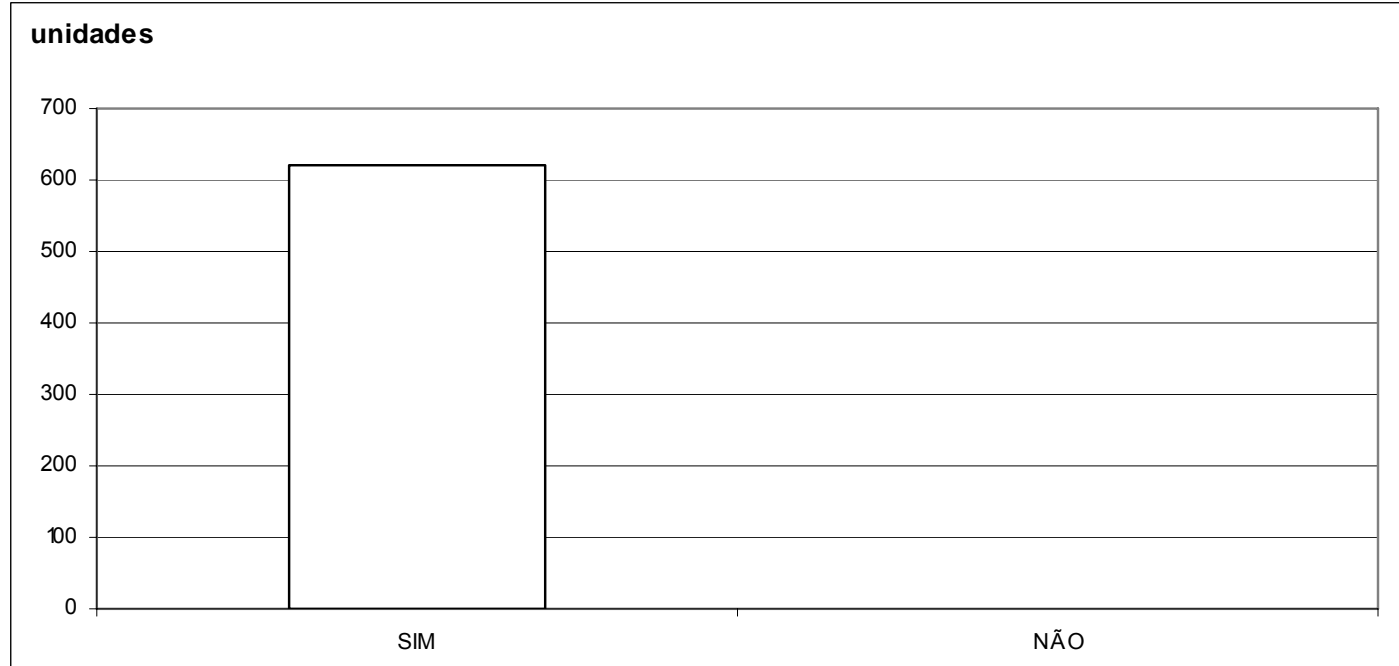


GRÁFICO 81: FREQUÊNCIA DE ATERROS E LIXÕES NA AMOSTRA DE PERFIL SÓCIODEMOGRÁFICO ALTO

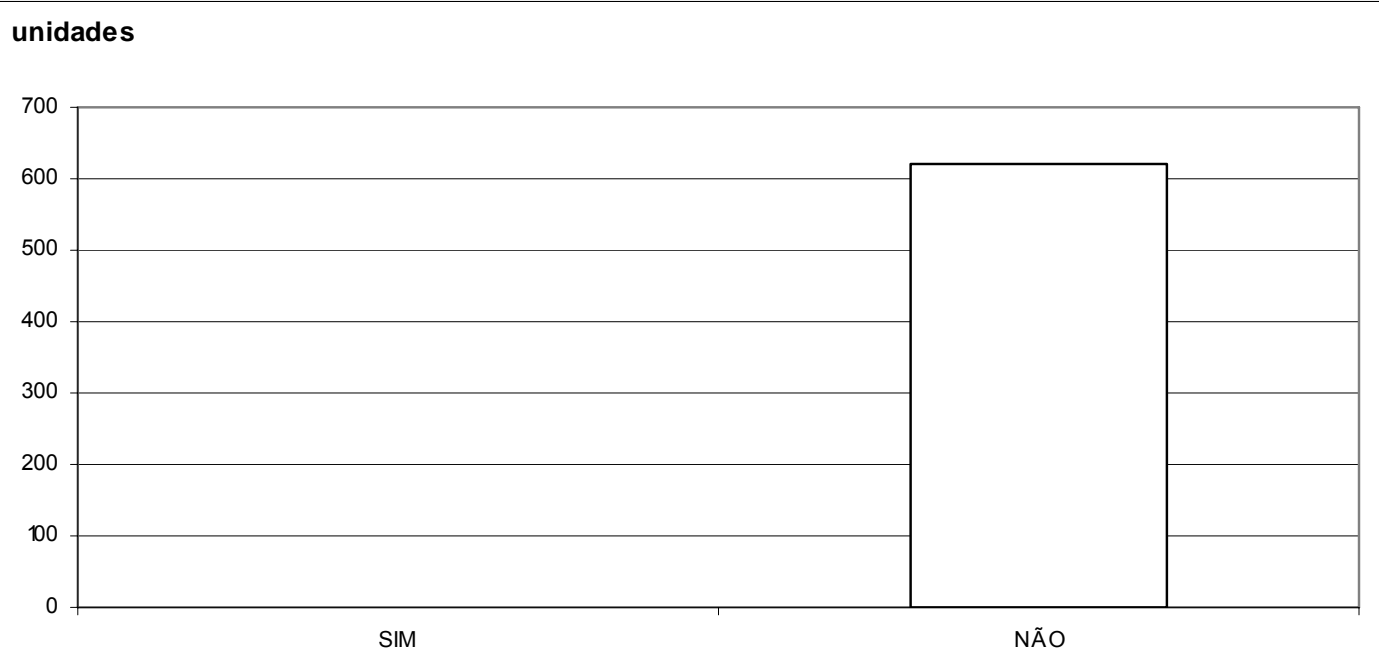




\section{K.2) Resultados do Primeiro Estágio de Rosen}

TABELA 49: VALORES DE R² AJUSTADOS RESULTANTES DO MÉTODO DE BOX-COX COM AS VARIAÇÕES DE $\theta$ E $\lambda$ PARA O PERFIL SÓCIO-DEMOGRÁFICO ALTO

\begin{tabular}{|c|c|c|c|c|c|c|c|c|c|c|c|}
\hline \multirow{2}{*}{\multicolumn{2}{|c|}{ Box-Cox }} & \multicolumn{10}{|c|}{$\theta$} \\
\hline & & 0,0 & 0,1 & 0,2 & 0,3 & 0,4 & 0,5 & 0,6 & 0,7 & 0,8 & 0,9 \\
\hline \multirow{13}{*}{$\lambda$} & 0,0 & 0,9844 & 0,9837 & 0,9821 & 0,9811 & 0,9796 & 0,9778 & 0,9759 & 0,9745 & 0,9725 & 0,9714 \\
\hline & 0,1 & 0,9843 & 0,9817 & 0,9801 & 0,9791 & 0,9775 & 0,9758 & 0,9739 & 0,9725 & 0,9706 & 0,9694 \\
\hline & 0,2 & 0,9836 & 0,9787 & 0,9771 & 0,9761 & 0,9748 & 0,9728 & 0,9709 & 0,9695 & 0,9676 & 0,9664 \\
\hline & 0,3 & 0,9821 & 0,9747 & 0,9741 & 0,9721 & 0,9707 & 0,9686 & 0,9669 & 0,9655 & 0,9635 & 0,9623 \\
\hline & 0,4 & 0,9814 & 0,9697 & 0,9690 & 0,9669 & 0,9656 & 0,9636 & 0,9620 & 0,9607 & 0,9586 & 0,9574 \\
\hline & 0,5 & 0,9805 & 0,9637 & 0,9631 & 0,9609 & 0,9597 & 0,9577 & 0,9560 & 0,9547 & 0,9526 & 0,9514 \\
\hline & 0,6 & 0,9788 & 0,9559 & 0,9558 & 0,9530 & 0,9489 & 0,9499 & 0,9477 & 0,9469 & 0,9447 & 0,9435 \\
\hline & 0,7 & 0,9788 & 0,9487 & 0,9486 & 0,9458 & 0,9417 & 0,9427 & 0,9410 & 0,9396 & 0,9375 & 0,9363 \\
\hline & 0,8 & 0,9784 & 0,9397 & 0,9400 & 0,9367 & 0,9328 & 0,9336 & 0,9319 & 0,9305 & 0,9284 & 0,9268 \\
\hline & 0,9 & 0,9776 & 0,9296 & 0,9300 & 0,9267 & 0,9227 & 0,9235 & 0,9217 & 0,9205 & 0,9178 & 0,9168 \\
\hline & 1,0 & 0,9767 & 0,9187 & 0,9192 & 0,9157 & 0,9123 & 0,9116 & 0,9107 & 0,9096 & 0,9069 & 0,9059 \\
\hline & 2,0 & 0,9756 & 0,9066 & 0,9071 & 0,9036 & 0,9055 & 0,8986 & 0,8985 & 0,8975 & 0,8947 & 0,8938 \\
\hline & 3,0 & 0,9753 & 0,9063 & 0,8984 & 0,8906 & 0,8898 & 0,8883 & 0,8856 & 0,8846 & 0,8817 & 0,8807 \\
\hline
\end{tabular}

TABELA 50: RESULTADOS DA REGRESSÃO PARA A ESPECIFICAÇÃO LOGARÍTMICA - MÉTODO ENTER - PERFIL SÓCIO-DEMOGRÁFICO ALTO

\begin{tabular}{c|c|c|c|c}
\hline Variável & $\begin{array}{c}\text { Coeficiente Não } \\
\text { Padronizado }\end{array}$ & $\begin{array}{c}\text { Coeficiente } \\
\text { Padronizado }\end{array}$ & Estatística t & $\begin{array}{c}\text { Nível de } \\
\text { Significância }\end{array}$ \\
\hline (Constante) & 11,0020 & & 105,227 & 0,000 \\
\hline LNAREA & 0,4060 & 0,417 & 19,662 & 0,000 \\
\hline SGIN & 0,00955 & 0,136 & 7,141 & 0,000 \\
\hline ALTR & 0,0637 & 0,034 & 3,995 & 0,000 \\
\hline VAGA2 & 0,0552 & 0,036 & 3,999 & 0,000 \\
\hline DORM3 & 0,0573 & 0,079 & 4,527 & 0,000 \\
\hline DORM4 & 0,2180 & 0,150 & 11,040 & 0,000 \\
\hline BANH2 & 0,0319 & 0,045 & 6,040 & 0,000 \\
\hline BANH3 & 0,1320 & 0,115 & 12,914 & 0,000 \\
\hline BANH4 & 0,6250 & 0,354 & 21,767 & 0,000 \\
\hline$R^{2}$
\end{tabular}

$\mathrm{R}^{2}$ ajustado: 0,9844

Estatística F: 4348,138

Prob. (Est. F): 0,000

Durbin-Watson: 2,019 


\section{K.3) Resultados do Segundo Estágio de Rosen}

TABELA 51: ESTIMAÇÃO DA EQUAÇÃO DE DEMANDA: SEGUNDO ESTÁGIO DE ROSEN - MÉTODO ENTER - PERFIL SÓCIO-DEMOGRÁFICO ALTO

\begin{tabular}{c|c|c|c|c}
\hline Variável & $\begin{array}{c}\text { Coeficiente Não } \\
\text { Padronizado }\end{array}$ & $\begin{array}{c}\text { Coeficiente } \\
\text { Padronizado }\end{array}$ & Estatística t & $\begin{array}{c}\text { Nível de } \\
\text { Significância }\end{array}$ \\
\hline (Constante) & 4013,881 & & 36,332 & 0,000 \\
\hline LNAREA & $-544,062$ & $-3,231$ & $-29,010$ & 0,000 \\
\hline SGIN & 77,210 & 0,637 & 6,125 & 0,000 \\
\hline ALTR & 49,189 & 0,154 & 3,326 & 0,001 \\
\hline VAGA2 & 52,817 & 0,201 & 4,152 & 0,000 \\
\hline DORM3 & 62,679 & 0,500 & 5,191 & 0,000 \\
\hline DORM4 & 221,786 & 0,881 & 11,629 & 0,000 \\
\hline BANH2 & 32,156 & 0,261 & 6,568 & 0,000 \\
\hline BANH3 & 125,229 & 0,630 & 13,097 & 0,000 \\
\hline BANH4 & 559,754 & 1,832 & 21,578 & 0,000 \\
\hline SHOP & 10,428 & 0,063 & 2,148 & 0,032 \\
\hline METR & 2,607 & 0,023 & 0,652 & 0,514 \\
\hline PARQ & 15,175 & 0,119 & 3,703 & 0,000 \\
\hline LNRND & $-9,567$ & $-0,041$ & $-1,247$ & 0,213 \\
\hline LNMEMB & 12,844 & 0,061 & 1,661 & 0,097 \\
\hline
\end{tabular}

$\mathrm{R}^{2}$ ajustado: 0,5773

Estatística F: 61,395

Prob. (Est. F): 0,000

Durbin-Watson: 2,106 
TABELA 52: ESTIMAÇÃO DA EQUAÇÃO DE OFERTA: SEGUNDO ESTÁGIO DE ROSEN - MÉTODO ENTER - PERFIL SÓCIO-DEMOGRÁFICO ALTO

\begin{tabular}{c|c|c|c|c}
\hline Variável & $\begin{array}{c}\text { Coeficiente Não } \\
\text { Padronizado }\end{array}$ & $\begin{array}{c}\text { Coeficiente } \\
\text { Padronizado }\end{array}$ & Estatística t & $\begin{array}{c}\text { Nível de } \\
\text { Significância }\end{array}$ \\
\hline (Constante) & 4074,173 & & 38,706 & 0,000 \\
\hline LNAREA & $-548,472$ & $-3,257$ & $-29,371$ & 0,000 \\
\hline SGIN & 81,355 & 0,671 & 6,419 & 0,000 \\
\hline ALTR & 43,506 & 0,136 & 2,881 & 0,004 \\
\hline VAGA2 & 47,529 & 0,180 & 3,638 & 0,000 \\
\hline DORM3 & 61,647 & 0,492 & 5,079 & 0,000 \\
\hline DORM4 & 223,777 & 0,889 & 11,857 & 0,000 \\
\hline BANH2 & 34,168 & 0,277 & 6,962 & 0,000 \\
\hline BANH3 & 120,853 & 0,608 & 12,848 & 0,000 \\
\hline BANH4 & 559,681 & 1,832 & 21,535 & 0,000 \\
\hline SHOP & 7,370 & 0,044 & 1,473 & 0,141 \\
\hline METR & $-2,725$ & $-0,024$ & $-0,651$ & 0,515 \\
\hline PARQ & 14,160 & 0,111 & 3,668 & 0,000 \\
\hline LNDENS & 0,631 & 0,007 & 0,194 & 0,846 \\
\hline LNPOP & $-8,181$ & $-0,101$ & $-3,347$ & 0,001 \\
\hline
\end{tabular}

$\mathrm{R}^{2}$ ajustado: 0,5831

Estatística F: 62,869

Prob. (Est. F): 0,000

Durbin-Watson: 2,107 
TABELA 53: EQUAÇÕES DE DEMANDA E OFERTA - MÉTODO STEPWISE - PERFIL SÓCIODEMOGRÁFICO ALTO

\begin{tabular}{|c|c|c|c|c|}
\hline Equação & \multicolumn{2}{|c|}{ Demanda } & \multicolumn{2}{|c|}{ Oferta } \\
\hline Variável & $\begin{array}{c}\text { Coeficiente Não } \\
\text { Padronizado }\end{array}$ & $\begin{array}{c}\text { Coeficiente } \\
\text { Padronizado* }\end{array}$ & $\begin{array}{c}\text { Coeficiente Não } \\
\text { Padronizado }\end{array}$ & $\begin{array}{c}\text { Coeficiente } \\
\text { Padronizado* }\end{array}$ \\
\hline (Constante) & 3946,468 & & 4079,385 & \\
\hline LNAREA & $-544,041$ & $-3,231$ & $-547,625$ & $-3,252$ \\
\hline SGIN & 79,049 & 0,652 & 81,412 & 0,672 \\
\hline$\overline{\text { ALTR }}$ & 48,350 & 0,151 & 45,455 & 0,142 \\
\hline VAGA2 & 53,053 & 0,201 & 46,558 & 0,177 \\
\hline DORM3 & 61,241 & 0,489 & 61,700 & 0,492 \\
\hline DORM4 & 219,410 & 0,872 & 221,361 & 0,879 \\
\hline BANH2 & 31,633 & 0,257 & 33,640 & 0,273 \\
\hline BANH3 & 123,170 & 0,620 & 118,925 & 0,598 \\
\hline BANH4 & 558,115 & 1,827 & 559,863 & 1,833 \\
\hline SHOP & 10,350 & 0,062 & & \\
\hline PARQ & 13,038 & 0,102 & 13,438 & 0,105 \\
\hline LNMEMB & 7,377 & 0,035 & & \\
\hline \multirow[t]{2}{*}{ LNPOP } & & & $-8,595$ & $-0,106$ \\
\hline & $\begin{array}{l}\mathrm{R}^{2} \text { ajustado: } 0,57 \\
\text { Estatística } \mathrm{F}: 71,5 \\
\text { Prob. (Est. F): 0,0 } \\
\text { Durbin-Watson: } 2 \\
{ }^{*} \text { estatística t a } 5 \%\end{array}$ & & $\begin{array}{l}R^{2} \text { ajustado: } 0,58 \\
\text { Estatística F: } 79,8 \\
\text { Prob. (Est. F): 0,0 } \\
\text { Durbin-Watson: } 2 \\
{ }^{*} \text { estatística t a } 5 \%\end{array}$ & \\
\hline
\end{tabular}




\section{K.4) Resultados da Correlação Canônica}

TABELA 54: TESTES MULTIVARIADOS DE SIGNIFICÂNCIA PARA A EQUAÇÃO DE DEMANDA PERFIL SÓCIO-DEMOGRÁFICO ALTO

\begin{tabular}{l|c|c|c|c}
\hline \multicolumn{1}{c|}{ Teste } & Valor & Aprox. F & Erro DF & Sig. F \\
\hline Pillais & 0,724 & 16,116 & 1821,00 & 0,000 \\
\hline Hottelings & 1,669 & 27,990 & 1811,00 & 0,000 \\
\hline Wilks & 0,347 & 21,331 & 1788,27 & 0,000 \\
\hline Roys & 0,606 & & & \\
\hline
\end{tabular}

TABELA 55: TESTES MULTIVARIADOS DE SIGNIFICÂNCIA PARA A EQUAÇÃO DE OFERTA - PERFIL SÓCIO-DEMOGRÁFICO ALTO

\begin{tabular}{l|c|c|c|c}
\hline \multicolumn{1}{c|}{ Teste } & Valor & Aprox. F & Erro DF & Sig. F \\
\hline Pillais & 0,730 & 17,798 & 1824,00 & 0,000 \\
\hline Hottelings & 1,708 & 31,298 & 1814,00 & 0,000 \\
\hline Wilks & 0,342 & 23,720 & 1786,09 & 0,000 \\
\hline Roys & 0,612 & & & \\
\hline
\end{tabular}

TABELA 56: CORRELAÇÕES CANÔNICAS E AUTOVALORES PARA A EQUAÇÃO DE DEMANDA PERFIL SÓCIO-DEMOGRÁFICO ALTO

\begin{tabular}{c|c|c|c}
\hline Raiz & Autovalor & Cor. Canônica & Cor. Quad. \\
\hline 1 & 1,542 & 0,779 & 0,607 \\
\hline 2 & 0,094 & 0,293 & 0,086 \\
\hline 3 & 0,033 & 0,180 & 0,032 \\
\hline
\end{tabular}

TABELA 57: CORRELAÇÕES CANÔNICAS E AUTOVALORES PARA A EQUAÇÃO DE OFERTA PERFIL SÓCIO-DEMOGRÁFICO ALTO

\begin{tabular}{c|c|c|c}
\hline Raiz & Autovalor & Cor. Canônica & Cor. Quad. \\
\hline 1 & 1,581 & 0,783 & 0,613 \\
\hline 2 & 0,094 & 0,294 & 0,086 \\
\hline 3 & 0,033 & 0,179 & 0,032 \\
\hline
\end{tabular}


TABELA 58: TESTE UNIVARIADO DE SIGNIFICÂNCIA PARA AS FUNÇÕES CANÔNICAS DA EQUAÇÃO DE DEMANDA - PERFIL SÓCIO-DEMOGRÁFICO ALTO

\begin{tabular}{c|c|c|c}
\hline Raiz & Wilks $\mathrm{L}$. & Erro DF & Sig. F \\
\hline 1 to 3 & 0,347 & 1788,27 & 0,000 \\
\hline 2 to 3 & 0,884 & 1212,00 & 0,000 \\
\hline 3 to 3 & 0,967 & 607,00 & 0,029 \\
\hline
\end{tabular}

TABELA 59: TESTE UNIVARIADO DE SIGNIFICÂNCIA PARA AS FUNÇÕES CANÔNICAS DA EQUAÇÃO DE OFERTA - PERFIL SÓCIO-DEMOGRÁFICO ALTO

\begin{tabular}{c|c|c|c}
\hline Raiz & Wilks L. & Erro DF & Sig. F \\
\hline 1 to 3 & 0,342 & 1786,09 & 0,000 \\
\hline 2 to 3 & 0,884 & 1214,00 & 0,000 \\
\hline 3 to 3 & 0,967 & 608,00 & 0,019 \\
\hline
\end{tabular}

TABELA 60: PESOS CANÔNICOS PADRONIZADOS PARA A PRIMEIRA FUNÇÃO CANÔNICA VARIÁVEIS DEPENDENTES - EQUAÇÃO DE DEMANDA - PERFIL SÓCIODEMOGRÁFICO ALTO

\begin{tabular}{c|c}
\hline Variável & FUNÇÃO 1 \\
\hline DPDAREA & $-1,013$ \\
\hline $\mathrm{C}$ & 0,068 \\
\hline $\mathrm{V}$ & $-0,187$ \\
\hline
\end{tabular}

TABELA 61: PESOS CANÔNICOS PADRONIZADOS PARA A PRIMEIRA FUNÇÃO CANÔNICA VARIÁVEIS DEPENDENTES - EQUAÇÃO DE OFERTA - PERFIL SÓCIO-DEMOGRÁFICO ALTO

\begin{tabular}{c|c}
\hline Variável & FUNÇÃO 1 \\
\hline DPDAREA & $-1,013$ \\
\hline C & 0,072 \\
\hline $\mathrm{V}$ & $-0,187$ \\
\hline
\end{tabular}


TABELA 62: PESOS CANÔNICOS PADRONIZADOS PARA A PRIMEIRA FUNÇÃO CANÔNICA VARIÁVEIS INDEPENDENTES - EQUAÇÃO DE DEMANDA - PERFIL SÓCIODEMOGRÁFICO ALTO

\begin{tabular}{c|c}
\hline Variável & FUNÇÃO 1 \\
\hline LNAREA & 4,223 \\
\hline SGIN & $-0,853$ \\
\hline ALTR & $-0,185$ \\
\hline VAGA2 & $-0,262$ \\
\hline DORM3 & $-0,639$ \\
\hline DORM4 & $-1,137$ \\
\hline BANH2 & $-0,335$ \\
\hline BANH3 & $-0,810$ \\
\hline BANH4 & $-2,433$ \\
\hline SHOP & $-0,079$ \\
\hline PARQ & $-0,130$ \\
\hline LNMEMB & $-0,040$ \\
\hline
\end{tabular}

TABELA 63: PESOS CANÔNICOS PADRONIZADOS PARA A PRIMEIRA FUNÇÃO CANÔNICA VARIÁVEIS INDEPENDENTES - EQUAÇÃO DE OFERTA - PERFIL SÓCIODEMOGRÁFICO ALTO

\begin{tabular}{c|c}
\hline Variável & FUNÇÃO 1 \\
\hline LNAREA & 4,231 \\
\hline SGIN & $-0,877$ \\
\hline ALTR & $-0,168$ \\
\hline VAGA2 & $-0,229$ \\
\hline DORM3 & $-0,639$ \\
\hline DORM4 & $-1,141$ \\
\hline BANH2 & $-0,354$ \\
\hline BANH3 & $-0,778$ \\
\hline BANH4 & $-2,427$ \\
\hline PARQ & $-0,134$ \\
\hline LNPOP & 0,139 \\
\hline
\end{tabular}


TABELA 64: CORRELAÇÕES ENTRE AS VARIÁVEIS DEPENDENTES E AS VARIÁVEIS CANÔNICAS EQUAÇÃO DE DEMANDA - PERFIL SÓCIO-DEMOGRÁFICO ALTO

\begin{tabular}{c|c}
\hline Variável & FUNÇÃO 1 \\
\hline DPDAREA & $-0,982$ \\
\hline C & 0,053 \\
\hline$V$ & $-0,011$ \\
\hline
\end{tabular}

TABELA 65: CORRELAÇÕES ENTRE AS VARIÁVEIS DEPENDENTES E AS VARIÁVEIS CANÔNICAS EQUAÇÃO DE OFERTA - PERFIL SÓCIO-DEMOGRÁFICO ALTO

\begin{tabular}{c|c}
\hline Variável & FUNÇÃO 1 \\
\hline DPDAREA & $-0,981$ \\
\hline $\mathrm{C}$ & 0,058 \\
\hline $\mathrm{V}$ & $-0,011$ \\
\hline
\end{tabular}

TABELA 66: CORRELAÇÕES ENTRE AS VARIÁVEIS INDEPENDENTES E AS VARIÁVEIS CANÔNICAS - EQUAÇÃO DE DEMANDA - PERFIL SÓCIO-DEMOGRÁFICO ALTO

\begin{tabular}{c|c}
\hline Variável & FUNÇÃO 1 \\
\hline LNAREA & $-0,843$ \\
\hline SGIN & $-0,247$ \\
\hline ALTR & $-0,596$ \\
\hline VAGA2 & $-0,689$ \\
\hline DORM3 & 0,093 \\
\hline DORM4 & $-0,466$ \\
\hline BANH2 & $-0,071$ \\
\hline BANH3 & 0,081 \\
\hline BANH4 & $-0,558$ \\
\hline SHOP & $-0,048$ \\
\hline PARQ & $-0,206$ \\
\hline LNMEMB & $-0,113$ \\
\hline
\end{tabular}


TABELA 67: CORRELAÇÕES ENTRE AS VARIÁVEIS INDEPENDENTES E AS VARIÁVEIS CANÔNICAS - EQUAÇÃO DE OFERTA - PERFIL SÓCIO-DEMOGRÁFICO ALTO

\begin{tabular}{c|c}
\hline Variável & FUNÇÃO 1 \\
\hline LNAREA & $-0,844$ \\
\hline SGIN & $-0,245$ \\
\hline ALTR & $-0,590$ \\
\hline VAGA2 & $-0,690$ \\
\hline DORM3 & 0,092 \\
\hline DORM4 & $-0,463$ \\
\hline BANH2 & $-0,072$ \\
\hline BANH3 & 0,080 \\
\hline BANH4 & $-0,554$ \\
\hline PARQ & $-0,206$ \\
\hline LNPOP & 0,213 \\
\hline
\end{tabular}

TABELA 68: ÍNDICE DE REDUNDÂNCIA - PERFIL SÓCIO-DEMOGRÁFICO ALTO

\begin{tabular}{c|c|c|c}
\hline \multirow{2}{*}{ DEMANDA } & $\begin{array}{c}\text { Média var. compart. } \\
\text { no próprio conjunto }\end{array}$ & $\begin{array}{c}\text { Correlação ao } \\
\text { quadrado }\end{array}$ & $\begin{array}{c}\text { Índice de } \\
\text { redundância }\end{array}$ \\
\cline { 2 - 4 } & 0,322 & 0,607 & 0,195 (Dep.) \\
\hline \multirow{2}{*}{ OFERTA } & 0,184 & 0,607 & 0,112 (Indep.) \\
\cline { 2 - 4 } & 0,322 & 0,613 & 0,197 (Dep.) \\
\hline
\end{tabular}




\section{L) COMPARAÇÃO ENTRE OS PERFIS SÓCIO-DEMOGRÁFICOS}

\section{L.1) Regressão Múltipla}

TABELA 69: COEFICIENTES PADRONIZADOS DAS EQUAÇÕES DE DEMANDA DE CADA PERFIL SÓCIO-DEMOGRÁFICO

\begin{tabular}{|c|c|c|c|}
\hline Variável & PERFIL BAIXO & PERFIL MÉDIO & PERFIL ALTO \\
\hline LNAREA & $-1,330$ & $-3,002$ & $-3,231$ \\
\hline SFES & 0,077 & & \\
\hline SJOG & 0,034 & 0,304 & \\
\hline SGIN & & & 0,652 \\
\hline PISC & 0,023 & 0,351 & \\
\hline SAUN & & 0,471 & \\
\hline CHUR & 0,151 & & \\
\hline QUAD & 0,041 & 0,271 & \\
\hline GUAR & 0,166 & & \\
\hline CFTV & & 0,106 & \\
\hline VARD & 0,098 & 0,268 & \\
\hline ALTR & & & 0,151 \\
\hline VAGA1 & 0,051 & & \\
\hline VAGA2 & & 0,839 & 0,201 \\
\hline DORM1 & 0,160 & & \\
\hline DORM2 & 0,135 & 1,902 & \\
\hline DORM3 & & 0,767 & 0,489 \\
\hline DORM4 & & & 0,872 \\
\hline BANH1 & 0,064 & & \\
\hline BANH2 & 0,108 & 0,714 & 0,257 \\
\hline BANH3 & & & 0,620 \\
\hline BANH4 & & & 1,827 \\
\hline COLP & 0,046 & 0,255 & \\
\hline SHOP & & 0,301 & 0,062 \\
\hline METR & 0,031 & 0,080 & \\
\hline HOSP & & 0,238 & \\
\hline PARQ & & 0,127 & 0,102 \\
\hline INUN & $-0,023$ & & \\
\hline ATER & & $-0,117$ & \\
\hline LNRND & 0,032 & & \\
\hline LNMEMB & & 0,063 & 0,035 \\
\hline
\end{tabular}


TABELA 70: COEFICIENTES PADRONIZADOS DAS EQUAÇÕES DE OFERTA DE CADA PERFIL SÓCIO-DEMOGRÁFICO

\begin{tabular}{|c|c|c|c|}
\hline Variável & PERFIL BAIXO & PERFIL MÉDIO & PERFIL ALTO \\
\hline LNAREA & $-1,326$ & $-3,050$ & $-3,252$ \\
\hline SFES & 0,059 & & \\
\hline SJOG & 0,058 & 0,318 & \\
\hline SGIN & & & 0,672 \\
\hline PISC & 0,055 & 0,383 & \\
\hline SAUN & & 0,472 & \\
\hline CHUR & 0,152 & & \\
\hline QUAD & & 0,270 & \\
\hline GUAR & 0,247 & & \\
\hline CFTV & & 0,104 & \\
\hline VARD & 0,113 & 0,286 & \\
\hline ALTR & & & 0,142 \\
\hline VAGA2 & & 0,888 & 0,177 \\
\hline DORM1 & 0,115 & & \\
\hline DORM2 & 0,142 & 1,938 & \\
\hline DORM3 & & 0,778 & 0,492 \\
\hline DORM4 & & & 0,879 \\
\hline BANH1 & 0,071 & & \\
\hline BANH2 & 0,105 & 0,723 & 0,273 \\
\hline BANH3 & & & 0,598 \\
\hline BANH4 & & & 1,833 \\
\hline COLP & 0,028 & 0,225 & \\
\hline SHOP & & 0,544 & \\
\hline METR & & 0,408 & \\
\hline HOSP & & 0,249 & \\
\hline PARQ & & 0,144 & 0,105 \\
\hline ATER & $-0,022$ & $-0,128$ & \\
\hline LNDENS & 0,083 & $-0,330$ & \\
\hline LNPOP & 0,038 & 0,346 & $-0,106$ \\
\hline
\end{tabular}


TABELA 71: RESULTADOS DOS TESTES CHOW

\begin{tabular}{|c|c|c|c|c|}
\hline EQUAÇÃO & $\begin{array}{c}\text { COMPARAÇÃO } \\
\text { ENTRE OS PERFIS } \\
\text { SÓCIO- } \\
\text { DEMOGRÁFICOS }\end{array}$ & F calculado & F crítico & Prob $>\mathrm{F}$ \\
\hline \multirow{6}{*}{ DEMANDA } & BAIXO & \multirow{2}{*}{3,444} & \multirow{2}{*}{1,893} & \multirow{2}{*}{0,000} \\
\hline & MÉDIO & & & \\
\hline & BAIXO & \multirow{2}{*}{2,519} & \multirow{2}{*}{1,869} & \multirow{2}{*}{0,000} \\
\hline & ALTO & & & \\
\hline & MÉDIO & \multirow{2}{*}{3,195} & \multirow{2}{*}{2,053} & \multirow{2}{*}{0,000} \\
\hline & ALTO & & & \\
\hline \multirow{6}{*}{ OFERTA } & BAIXO & \multirow{2}{*}{4,417} & \multirow{2}{*}{1,893} & \multirow{2}{*}{0,000} \\
\hline & MÉDIO & & & \\
\hline & BAIXO & \multirow{2}{*}{3,339} & \multirow{2}{*}{1,869} & \multirow{2}{*}{0,000} \\
\hline & ALTO & & & \\
\hline & MÉDIO & \multirow{2}{*}{4,474} & \multirow{2}{*}{2,053} & \multirow{2}{*}{0,000} \\
\hline & ALTO & & & \\
\hline
\end{tabular}




\section{L.2) Correlação Canônica}

TABELA 72: CORRELAÇÕES ENTRE AS VARIÁVEIS DEPENDENTES E AS VARIÁVEIS CANÔNICAS DE CADA PERFIL SÓCIO-DEMOGRÁFICO - EQUAÇÃO DE DEMANDA

\begin{tabular}{c|c|c|c}
\hline Variável & PERFIL BAIXO & PERFIL MÉDIO & PERFIL ALTO \\
\hline DPDAREA & 0,959 & 0,439 & $-0,982$ \\
\hline $\mathrm{C}$ & $-0,577$ & $-0,880$ & 0,053 \\
\hline $\mathrm{V}$ & $-0,464$ & $-0,883$ & $-0,011$ \\
\hline
\end{tabular}

TABELA 73: CORRELAÇÕES ENTRE AS VARIÁVEIS DEPENDENTES E AS VARIÁVEIS CANÔNICAS DE CADA PERFIL SÓCIO-DEMOGRÁFICO - EQUAÇÃO DE OFERTA

\begin{tabular}{c|c|c|c}
\hline Variável & PERFIL BAIXO & PERFIL MÉDIO & PERFIL ALTO \\
\hline DPDAREA & 0,965 & $-0,426$ & $-0,981$ \\
\hline $\mathrm{C}$ & $-0,558$ & 0,883 & 0,058 \\
\hline $\mathrm{V}$ & $-0,445$ & 0,892 & $-0,011$ \\
\hline
\end{tabular}


TABELA 74: CORRELAÇÕES ENTRE AS VARIÁVEIS INDEPENDENTES E AS VARIÁVEIS CANÔNICAS DE CADA PERFIL SÓCIO-DEMOGRÁFICO - EQUAÇÃO DE DEMANDA

\begin{tabular}{|c|c|c|c|}
\hline Variável & PERFIL BAIXO & PERFIL MÉDIO & PERFIL ALTO \\
\hline LNAREA & $-0,949$ & $-0,928$ & $-0,843$ \\
\hline SFES & $-0,347$ & & \\
\hline SJOG & 0,489 & $-0,452$ & \\
\hline SGIN & & & $-0,247$ \\
\hline PISC & $-0,115$ & $-0,267$ & \\
\hline SAUN & & 0,412 & \\
\hline CHUR & $-0,601$ & & \\
\hline QUAD & $-0,063$ & $-0,409$ & \\
\hline GUAR & $-0,846$ & & \\
\hline CFTV & & $-0,575$ & \\
\hline VARD & $-0,789$ & $-0,281$ & \\
\hline ALTR & & & $-0,596$ \\
\hline VAGA1 & $-0,864$ & & \\
\hline VAGA2 & & $-0,334$ & $-0,689$ \\
\hline DORM1 & $-0,642$ & & \\
\hline DORM2 & $-0,058$ & $-0,657$ & \\
\hline DORM3 & & $-0,381$ & 0,093 \\
\hline DORM4 & & & $-0,466$ \\
\hline BANH1 & $-0,307$ & & \\
\hline BANH2 & $-0,072$ & $-0,389$ & $-0,071$ \\
\hline BANH3 & & & 0,081 \\
\hline BANH4 & & & $-0,558$ \\
\hline COLP & 0,004 & $-0,033$ & \\
\hline SHOP & & 0,036 & $-0,048$ \\
\hline METR & $-0,003$ & 0,001 & \\
\hline HOSP & & 0,001 & \\
\hline PARQ & & 0,001 & $-0,206$ \\
\hline INUN & $-0,158$ & & \\
\hline ATER & & $-0,001$ & \\
\hline LNRND & $-0,128$ & & \\
\hline LNMEMB & & $-0,059$ & $-0,113$ \\
\hline
\end{tabular}


TABELA 75: CORRELAÇÕES ENTRE AS VARIÁVEIS INDEPENDENTES E AS VARIÁVEIS CANÔNICAS DE CADA PERFIL SÓCIO-DEMOGRÁFICO - EQUAÇÃO DE OFERTA

\begin{tabular}{|c|c|c|c|}
\hline Variável & PERFIL BAIXO & PERFIL MÉDIO & PERFIL ALTO \\
\hline LNAREA & $-0,943$ & $-0,932$ & $-0,844$ \\
\hline SFES & $-0,333$ & & \\
\hline SJOG & 0,490 & 0,442 & \\
\hline SGIN & & & $-0,245$ \\
\hline PISC & $-0,486$ & 0,261 & \\
\hline SAUN & & $-0,407$ & \\
\hline CHUR & $-0,590$ & & \\
\hline QUAD & & 0,411 & \\
\hline GUAR & $-0,856$ & & \\
\hline CFTV & & 0,580 & \\
\hline VARD & $-0,799$ & 0,274 & \\
\hline ALTR & & & $-0,590$ \\
\hline VAGA2 & & 0,338 & $-0,690$ \\
\hline DORM1 & $-0,651$ & & \\
\hline DORM2 & $-0,392$ & 0,666 & \\
\hline DORM3 & & 0,386 & 0,092 \\
\hline DORM4 & & & $-0,463$ \\
\hline BANH1 & $-0,293$ & & \\
\hline BANH2 & $-0,063$ & 0,385 & $-0,072$ \\
\hline BANH3 & & & 0,080 \\
\hline BANH4 & & & $-0,554$ \\
\hline COLP & 0,004 & 0,031 & \\
\hline SHOP & & $-0,034$ & \\
\hline METR & & $-0,002$ & \\
\hline HOSP & & $-0,001$ & \\
\hline PARQ & & $-0,001$ & $-0,206$ \\
\hline ATER & $-0,077$ & 0,003 & \\
\hline LNDENS & $-0,124$ & $-0,094$ & \\
\hline LNPOP & 0,058 & $-0,098$ & 0,213 \\
\hline
\end{tabular}

